Rafaela Eulberg

\title{
Neue Orte \\ für die Götter
}

Zu Lokalisierungsdynamiken

von tamilischer Hindu-Praxis

in der Schweiz

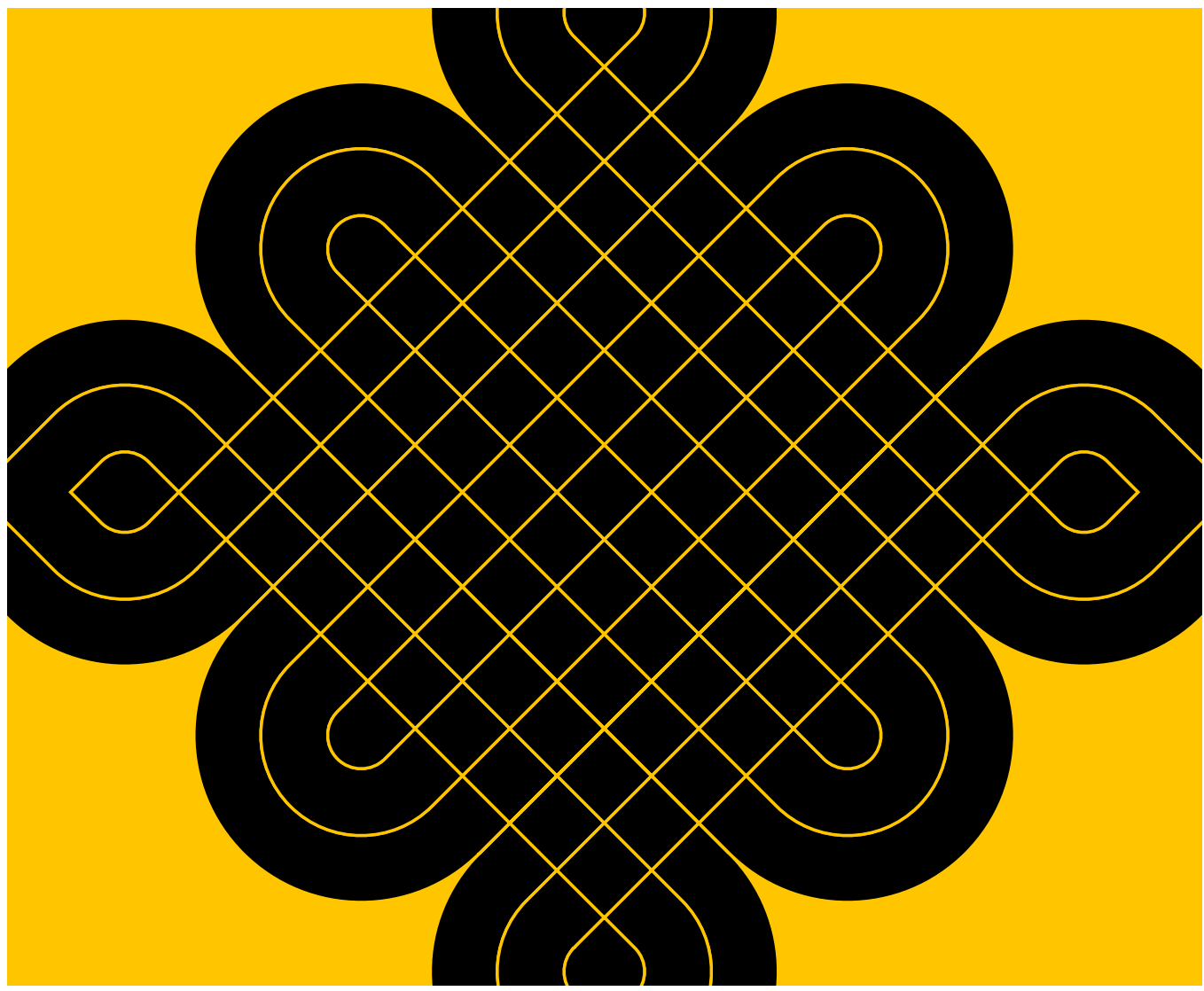


Neue Orte für die Götter

Zu Lokalisierungdynamiken von tamilischer Hindu-Praxis in der Schweiz

Rafaela Eulberg 


\section{CULTUREL}

Band 9

Die Reihe «CULTUREL» publiziert aktuelle Beiträge zur Erforschung von Religion und Religionen in Geschichte und Gegenwart, sowie zur Theorie und Methodologie der Religionswissenschaft. Im Rahmen eines kulturwissenschaftlichen Fachverständnisses, das sowohl historiographisch als auch gegenwartsanalytisch Neuland erschliessen will, bietet sie ein Forum für Forschungen zur Vielfalt religiöser Handlungs- und Ausdrucksformen in der Schweiz, in Europa und in globalen Kontexten.

\section{Herausgeberschaft}

Die Reihe wird im Namen der «Schweizerischen Gesellschaft für Religionswissenschaft» (SGR-SSSR) von Wissam Halawi, Jens Schlieter (Schriftleitung), Ricarda Stegmann, Christoph Uehlinger und Rafael Walthert herausgegeben. 
Rafaela Eulberg

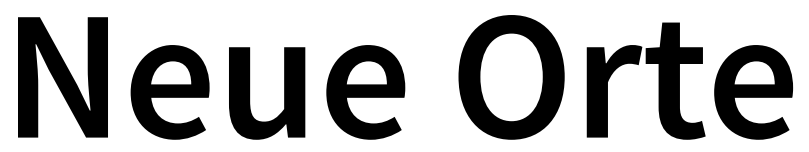

für die Götter

$\mathrm{Zu}$ Lokalisierungdynamiken von tamilischer Hindu-Praxis in der Schweiz 
Diese Publikation wurde vom Schweizerischen Nationalfonds zur Förderung der wissenschaftlichen Forschung unterstützt.

Die Dissertation «Neue Orte für die Götter. Zu Lokalisierungsdynamiken von Hindu-Praxis in der Schweiz im Kontext der sri-lankisch tamilischen Diaspora» wurde im Juni 2018 mit dem Fritz Stolz-Preis der Schweizerischen Gesellschaft für Religionswissenschaft (SGR/SSSR) ausgezeichnet.

Doktortitel im Jahr 2018 vergeben von der Kultur- und Sozialwissenschaftlichen Fakultät der Universität Luzern.

Erstgutachter Prof. Dr. Martin Baumann, Religionswissenschaftliches Seminar der Universität Luzern

Zweitgutachterin Prof. Dr. Edith Franke, Institut für Sozialanthropologie und Religionswissenschaft, Universität Marburg

CULTuREL, Band 9

Publiziert von

Seismo Verlag, Sozialwissenschaften und Gesellschaftsfragen AG, Zürich und Genf www.seismoverlag.ch | buch@seismoverlag.ch

Der Seismo Verlag wird vom Bundesamt für Kultur für die Jahre 2021-2024 unterstützt.

Text $\odot$ die Autorin 2022

ISBN (Print): 978-3-03777-242-3

ISBN (PDF): 978-3-03777-755-8

ISSN (Print): 2674-0982

ISSN (PDF): 2674-0990

DOI 10.33058/seismo.30755

Umschlag: Wessinger und Peng GmbH, Stuttgart und Zürich

Dieses Werk ist lizenziert unter einer Creative Commons Namensnennung - nicht kommerziell - keine Bearbeitungen (CC BY-NC-ND 4.0) International Lizenz 
Für Fennifer Maria Lawonn (1980-2010), mit der ich zusammen die tamilische Welt kennen lernte. 



\section{Inhalt}

$\begin{array}{ll}\text { Vorwort } & 13\end{array}$

$\begin{array}{ll}\text { Einleitung } & 15\end{array}$

\section{Kapitel I}

Perspektiven und Forschungsdesign 23

1 Analytische Perspektiven 24

1.1 Doing Ethnicity/Doing Gender: Anmerkungen zur Ver- 25 wendung dieser Kategorien

1.2 Hindu religioning in der Diaspora: eine aktionsorientierte 30 Perspektive

1.3 Die vier Analysekategorien der Studie: Diaspora, Inkorpora- 33 tion, Raum sowie Öffentlichkeit

2 Methodische Vorgehensweise 38

2.1 Die konkreten Forschungsbedingungen: Feldforschung 40 zwischen Kriegsberichterstattung und Minarettinitiative

2.2 Erfahrungen mit der Feldforschung als zentraler Methode 43 der Studie

3 Forschungsstand zu tamilischen Hindus in der Schweiz 49 und anderen Diaspora-Ländern

3.1 Literatur zu tamilischen Migrierten in der Schweiz 50

3.2 Tamilische Hindus in anderen Diaspora-Ländern 53 
Kapitel II

Die sri-lankisch tamilische Diaspora als Aspekt

der Lokalisierungsdynamiken von Hindu-Praxis

1 Die Lokalisierung in der transnationalen Sphäre:

Diaspora als Analysekategorie

1.1 Die sri-lankisch tamilische Diaspora: Einordnung in gängige $\quad 60$

Diaspora-Klassifikationen

1.2 Kritik an Diaspora-Klassifikationen: Verschleierung von

Ambivalenzen und Heterogenität

1.3 Neuere Konzepte: Diasporen als Herausforderer von Nationalstaaten

1.4 Diaspora als Selbstbezeichnung tamilischer Akteure

2 Das Wechselverhältnis von Religion und Diaspora

2.1 Die Diaspora einer Diaspora? Zum Begriff Hindu-Diaspora $\quad 75$

2.2 Interne Vielfalt: Tamilischer Hinduismus als fluides Feld 79

2.3 Überblick über die Verehrungsformen der Göttinnen und 83 Götter in Schweizer Tempeln

3 Rückbezüge zu einer imaginierten Nation und transnationale Vernetzungen

Kapitel III

Die Bedingungen des Residenzlandes als Aspekt

der Lokalisierungsdynamiken von Hindu-Praxis

1 Die Bedingungen der Aufnahmeländer: Inkorporation als Analysekategorie

2 Ethnische Nationalismen: Der Krieg in Sri Lanka (1983-2009) als zentraler Fluchtgrund

2.1 Problematiken der Konfliktwahrnehmung des sri-lankischen Bürgerkriegs

2.2 Die Vorgeschichte des Bürgerkrieges

2.3 Die Fluchtgeschichte Arumgams: «wenn ich ein oder zwei Tage spät warten/dann wäre ich sicher verhaftet worden»

3 Das Residenzland Schweiz: Die Etappen tamilischer Migration in die Schweiz

3.1 Die Anfangsjahre tamilischer Immigration in die Schweiz (1983-1992): «hier es gibt Möglichkeiten/wir können schon auf eigenen Füssen stehen» 
3.2 Der Nachzug tamilischer Frauen: Genderdifferenzen in der Immigration

3.3 Die öffentlichen Diskurse über die Migrantengruppe:

Der Imagewandel «der Tamilen»

3.4 Die Stadien der rechtlichen Inkorporation: der asylrechtliche Sonderfall Tamilen

3.5 Das Profil und die soziale Situation der Migrantengruppe zum Zeitpunkt der Studie

4 Die Etablierung tamilischer Hindu-Praktiken in der Schweiz - der Einfluss kontextueller Faktoren

4.1 Die Prägung durch die Herkunftsbedingungen (Einflussfaktor 1)

4.2 Die Flüchtlingspolitik des Aufnahmelandes als Inkorporationsbedingung (Einflussfaktor 2)

4.3 Integrationspolitik und Diskurse über Integration als Inkorporationsbedingung (Einflussfaktor 3)

4.4 Die Religionspolitik und Religionslandschaft des Residenzlandes (Einflussfaktor 4)

4.5 Reaktionen der Mehrheitsbevölkerung (Einflussfaktor 5)

5 Zusammenfassung: Der Einfluss der Inkorporations159 bedingungen auf tamilische Hindu-Praxis in der Schweiz

\section{Kapitel IV}

Soziale Räume des Vollzugs tamilischer Hindu-Praxis in der Schweiz

1 Orte des Religionshandelns: Raum als Analyse-

kategorie

2 Der pūcai-Platz im Schrank: Wohnungen als Räume der Ausübung von Hindu-Praxis

2.1 Lokalisierung und Materialität des pūcai-Platzes

2.2 Die häusliche pūcai: performative Hindu-Praxis im Wohnraum

2.3 Diasporische Veränderungen: vom Gott-Zimmer zum pūcai-Platz im Schrank

2.4 Weitere Aspekte häuslicher Hindu-Praxis: zwischen privatem pūcai-Platz und öffentlichen Tempeln 
3 Kontaktzonen: shared places als Räume der Ausübung von Hindu-Praxis

3.1 Kontaktzonen als Räume dynamischer Interaktion 186

3.2 «Am Anfang kamen alle Tamilen zu uns»: Die Krishna 187 Gemeinschaft Schweiz als Anlaufstelle für tamilische Hindus

3.3 Der Krishna-Tempel in Zürich: Gegenwärtige tamilische 200 Hindu-Praxis am Zürichberg

3.4 Weitere Kontaktzonen: Treffpunkte von Sathya Sai

Baba-Devotees und die Besuche von Amma

4 Tempelwerdung in der Diaspora: Angemietete Hallen als Räume der Ausübung von Hindu-Praxis

4.1 Von Asylunterkünften zu angemieteten Hallen: Aufbau und Entwicklungsphasen hindu-tamilischer Organisationsstrukturen in der Schweiz

4.2 Tamil Mandram und der Turkkai Amman Tempel in Luzern: Kompartmentalisierungsprozesse in den Anfängen der Migration

4.3 Doing Temple: Der Prozess der Tempelwerdung eines Gebäudes

4.4 Weitere Aspekte der Tempellandschaft in der Schweiz: die Etablierung von Reform-Tempeln

5 Das Jahresfest taipponkal als Beispiel für den Prozess der Tempelisierung

5.1 Eine Erinnerung an taipponkal in Sri Lanka

5.2 Taipponkkal in der Schweiz - diasporische Veränderungen

5.3 Die räumliche Dimension des Festes - Taipponkkal in Schweizer Tempeln

5.4 Der Prozess der Tempelisierung: Das Überkochen der Milch im Tempelraum

6 Transnationale Verbindungen: Orte ausserhalb der Schweiz

6.1 Religiöse Orte einer globalen tamilischen «Sakrallandkarte»

6.2 Wallfahrten nach Indien: Sabarimala und die Rückbindung der Pilgerreisen an Praktiken in der Schweiz

6.3 Weitere Aspekte der transnationalen Vernetzung von religiösen Orten: christliche Wallfahrtsorte

7 Zusammenfassung: Orte tamilischer Hindu-Praxis als sinnliche Wahrnehmungsräume 


\section{Kapitel V}

Tempelöffentlichkeiten tamilischer Hindu-Praxis

in der Schweiz

1 Religioning und öffentlicher Raum: Öffentlichkeit als Analysekategorie

2 Präsentationen von Sakralgebäuden als Aspekte von Tempelöffentlichkeiten

2.1 Öm-Zeichen und das Hissen von Flaggen:

Öffentliche Kennzeichnung der Gebäude als Hindu-Tempel

2.2 Tempeltortürme als öffentliche Präsentationsform von Hindu-Traditionen in der Diaspora

2.3 Tempel-Webpräsenzen: Präsentationen in virtuellen öffentlichen Räumen

3 Performative Aspekte von Tempelöffentlichkeiten

3.1 Tanzen mit dem kāvați-Bogen: Das jährliche Tempelfest als Kristallisationspunkt öffentlicher Präsentation

3.2 Sakrales Theater im Tempel: Aktualisierung von HinduMythologie

3.3 Öffentliche Präsenz an der Schnittstelle zwischen Religion und Politik: Performanzen für Frieden und Gerechtigkeit

4 Zusammenfassung: Tempelbauprojekte und politische Prozessionen als Aushandlungsprozesse auf dem Weg zu einer öffentlichen Hindu-Praxis 



\section{Vorwort}

Ich bin vielen Menschen dankbar, die mich über die Jahre bis zum Erscheinen dieses Buches begleitet, inspiriert, ermutigt und unterstützt haben: An erster Stelle danke ich den tamilischen Menschen, die sich mir vertrauensvoll geöffnet haben und mir Einblicke in ihr Leben gaben.

Von Herzen danke ich meinen Freundinnen Kathrin Rottländer (für ihren emotionalen, nie endenden Support und das Aufräumen des Literaturverzeichnisses) und Bärbel Buchholz (für das geduldige Korrektorat des langen Textes). Ein besonderer Dank gilt auch Lucia Stöckli, Adrian Hermann, Johannes Paetzold und meinen Wegbegleiter ${ }^{*} i n n e n$ an der Universität Luzern sowie im Pro*Doc-Programm «Interferenzen von Religion mit Politik und Wirtschaft im Spiegel ihrer Konstruktionsgeschichten» für ihre Unterstützung. Meinem Doktorvater, Martin Baumann, bin ich zu grossem Dank für seine kontinuierliche Unterstützung verpflichtet.

Ich danke allen, die gegen meine Zweifel argumentiert haben und mir Zuversicht gaben, dass dieses Buch real wird. Danke auch an meine Tochter Matea dafür, dass sie mich für dieses Buch zeitweise entbehren musste und bis hierher begleitet hat. Sie hat auch einen Entwurf für dieses Vorwort geschrieben und weil sie recht hat, möchte ich es nicht unzitiert lassen: «Natürlich sage ich auch einen Dank an alle, die dieses Buch lesen, ein ganz grosser Dank an euch. Ich hoffe, dass ihr das Buch toll und spannend findet.»

Das Buch stellt eine gekürzte Fassung der am 22.05.2017 unter dem Titel «Neue Orte für die Götter. Zu Lokalisierungsdynamiken von Hindu-Praxis in der Schweiz im Kontext der sri-lankisch tamilischen Diaspora» eingereichten Dissertation zur Erlangung der Doktorwürde der Kultur- und Sozialwissenschaftlichen Fakultät der Universität Luzern dar. 



\section{Einleitung}

Durch Migrationsbewegungen und Globalisierungsprozesse werden nicht nur ökonomisch relevante Güter, sondern auch kulturelle und religiöse Vorstellungen und Praktiken verbreitet und ausgetauscht. So haben Migrantinnen und Migranten aus Südasien Hindu-Traditionen in unterschiedlichste Regionen der Welt gebracht. Auch in der Schweiz haben sich auf diese Weise in den letzten Jahrzehnten vielfältige Formen von Hindu-Praxis in der Diaspora etabliert. Seit den 1980er Jahren kamen aus Sri Lanka geflüchtete tamilische Menschen in die Schweiz und zahlreiche weitere Diaspora-Länder, was zur Entstehung der sri-lankisch tamilischen Diaspora in ihrer momentanen Ausprägung geführt hat. Diese tamilischen Migrierenden ${ }^{1}$ brachten auch ihre religiösen Praktiken mit ins Exil. Die Mehrheit der religiösen Akteure dieser Diaspora kann dem Spektrum von Hindu-Traditionen zugeordnet werden. Der grösste Teil bezeichnet sich selbst mit dem tamilischen Terminus als Caivas (skr. Śaiva) ${ }^{2}$, verehrt also

1 In dieser Arbeit wird versucht, möglichst geschlechtergerechte Sprache wie geschlechtsneutrale Pluralkonstruktionen zu verwenden. Für einen besseren Lesefluss wird jedoch an den Stellen, an denen dies nicht möglich ist, im Plural die männliche Form benutzt, wobei immer alle Geschlechter mitgemeint sind.

2 In der folgenden Studie gebe ich tamilische Begriffe in der gängigen Transkription in lateinischen Buchstaben wieder. Ich habe versucht, für Fachtermini möglichst die emischen Begriffe zu verwenden, so wie sie von der Referenzgruppe gebraucht wurden. Im Falle im religiösen Feld gebräuchlicher Termini wurde tamilischen Selbstbezeichnungen in der Regel der Vorrang vor den Sanskrit-Bezeichnungen gegeben. In jenen Fällen, in denen von tamilischen Hindus Sanskrit-Wörter verwendet wurden, wurden die Sanskrit-Begriffe (Abkürzung skr.) benutzt; wenn in sakralen Räumen religiöse Begriffe in lateinischen Buchstaben (in deutscher oder englischer Sprache) vorgefunden wurden, wird dies an den entsprechenden Stellen benannt.

Der Religionshistoriker Peter Schalk verweist darauf, dass tamilische Hindu-Traditionen im Exil durch drei Schreibweisen (in Tamil, Sanskrit oder in der anglisierten Form) weitergegeben werden können (vgl. Schalk 2004a, 19f.). Ich schliesse mich Schalk an, der in seiner Darstellung tamilischer Caivas in Stockholm wie folgt verfährt: "My shifting use of terms is therefore not wrong-spelling, but reflects the use of Tamil devotees in Stockholm in shifting contexts" (Schalk 2004a, 20). Mit dieser Vorgehensweise versuche ich, möglichst nah an den Alltagswelten und Eigenperspektiven der untersuchten Gruppen zu bleiben, um in der wissenschaftlichen Analyse diese Lebenswelten auch auf sprachlicher Ebene zu rekonstruieren. Die unterschiedlichen 
den hinduistischen Gott Civan (skr. Śiva) als höchste Gottheit. ${ }^{3}$ Civan wird in der Regel gemeinsam mit seiner Familie, seiner Frau und seinen Söhnen Gaṇeśa und Murukan verehrt. ${ }^{4}$ Letzerer gilt vielen Akteuren als explizit tamilische Gottheit und betont die Tamilness der Verehrungspraxis. Die Göttin kann aber auch als unabhängige Repräsentationsform von cakti (oder catti; skr. śakti), der weiblich kosmischen Schaffenskraft, angesehen werden.

Tamilische Hindus in der Diaspora suchen neue Orte der Verehrung für diese Göttinnen und Götter und haben enorme Anstrengungen unternommen, um diese zu errichten, was diese Studie zeigt. Das Feld tamilischer Hindu-Praxis in der Schweiz ist ein schnell wandelbares und dynamisches Feld: Die Studie stellt Dynamiken der Lokalisierung von Hindu-Praxis in der Schweiz im Zeitraum von 2008 bis 2011 dar, wobei die Literaturverweise auch neuere Literatur nennen. ${ }^{5}$

sprachlichen Verwendungen und semantischen Verschiebungen werden als Hinweise auf diasporische Prozesse gewertet.

3 Die Studie folgt einem religionssoziologischen Ansatz und ist im Forschungsfeld Religion und Migration anzusiedeln. Für eine Einführung in die in der Arbeit thematisierten Göttinnen und Götter vgl. Kap. II 2.3.

4 Civañs Frau wird unter anderem als Pārvati oder Ammann bezeichnet. In jenen Tempeln im Untersuchungsfeld, die als Hauptgottheit eine Göttin haben, finden sich immer auch Statuen der genannten drei männlichen Götter, die als in einem Beziehungsverhältnis zueinanderstehend betrachtet werden.

5 Die Untersuchung ist im Rahmen des Nationalen Forschungsprogramms 58 (NFP 58) «Religionsgemeinschaften, Staat und Gesellschaft» entstanden, das als Reaktion auf die Veränderungsprozesse innerhalb der religiösen Landschaft in der Schweiz vom Schweizerischen Bundesrat ins Leben gerufen wurde (vgl. Haug 2007, 1).

Die vorliegende Dissertation ist aus einem Teilprojekt des NFP 58-Projekts «Zugewanderte Religion, öffentlicher Raum und Wandel von Geschlechterrollen tamilischer Hindus und vietnamesischer Buddhisten in der Schweiz» (geleitet von Prof. Dr. Martin Baumann, Universität Luzern) hervorgegangen. In dessen Rahmen wurden deskriptive Daten zur Geschichte, Etablierung und religiösen Institutionalisierung der beiden genannte Migrantengruppen erhoben und rekonstruiert. Zudem wurden religiöse Vergemeinschaftungsdynamiken und Strategien gesellschaftlicher Positionierung sowie migrationsbedingten Veränderungen von Geschlechterrollen innerhalb der religiösen Praxis analysiert.

Das Projekt erarbeitete anwendungsbezogene Kenntnisse zu Strategien der gesellschaftlichen Positionierung dieser religiösen Minderheiten (vgl. Baumann/Eulberg/Weigelt 2011). Zentrale Anliegen waren dabei, die gesellschaftlichen Kontroversen um den Platz religiöser Minderheiten im Nationalstaat Schweiz zu versachlichen und die religiöse Pluralisierung durch Migrationsbewegungen im Hinblick auf Neuaushandlungen öffentlicher Räume in der Schweiz zu untersuchen. Die hier vorgelegte Studie verortet sich zentral innerhalb dieses Teilprojekts und der hier skizzierten Themenbereiche, auch wenn im Folgenden nur bestimmte Aspekte dieser Fragestellungen ausführlich behandelt werden können. 
Im letzten Jahrzehnt wurden tamilische Immigrantinnen und Immigranten und ihr religiöses Leben von der Schweizer Mehrheitsgesellschaft verstärkt wahrgenommen: Dies belegen so unterschiedliche Beispiele wie der Erfolg des Romans Der Koch des bekannten Schweizer Autors Martin Suter $(2010)^{6}$ oder die Einweihung des ersten tamilischen Hindu-Tempels in südasiatischem Stil in der Nähe von Olten im Jahr 2013 (vgl. Baumann/TungerZanetti 2014).

Die hier vorgelegte religionswissenschaftliche Studie untersucht diese Prozesse der Etablierung einer religiösen Minderheit in der Residenzgesellschaft. Sie legt dabei einen besonderen Fokus auf die sozialen Räume zur Durchführung der Praktiken und die Präsentationen sri-lankisch tamilischer Hindus in öffentlichen Sphären.

Die Studie behandelt Lokalisierungsdynamiken von Hindu-Praktiken, welche von Handelnden ausgeführt werden, die ihre Herkunft in den tamilischen Gebieten Sri Lankas verorten ${ }^{7}$ und die nun im nationalen Kontext der Schweiz und unter ihren Bedingungen der Inkorporation (vgl. Kap. III) leben. Meist setzt sich jener von der ersten Generation der tamilischen Migrantinnen und Migranten ${ }^{8}$ als $~ «$ Heimat» ${ }^{9}$ bezeichnete soziale Raum aus den verlassenen Orten auf der Insel im Indischen Ozean zusammen, die politisch als Republik Sri Lanka organisiert ist. Obwohl die meisten tamilischen Migrierenden ihre Zugehörigkeit zur Gruppe der Tamilen in den Vordergrund stellen und ihr (aktueller oder ehemaliger) Status als Bürger Sri Lankas eher eine formelle Zuschreibung ist oder war, hatte die staatliche Politik ihres Herkunftslandes entscheidende Auswirkungen auf die Aus-

6 Die Hauptfigur des Buches, Maravan Vilasam, ist ein tamilischer Immigrant, der als Koch tätig ist. Wie die Mehrheit der tamilischen Immigranten in der Schweiz ist er Hindu; der Roman thematisiert am Rande auch seine religiöse Praxis. Ausserdem geht der Roman auf die Auswirkungen des Bürgerkriegs in Sri Lanka auf tamilische Migranten in der Schweiz ein.

7 Meist handelt es sich dabei um Migranten der ersten Generation, die offiziell Staatsangehörige Sri Lankas oder aber im Residenzland eingebürgert sind. Aber auch Angehörige der zweiten Generation können ihre Identität zentral in Südasien verorten.

8 Die Bezeichnung Migrantin/Migrant verweist darauf, dass diese Akteure ihre Herkunftsregion verlassen und sich (noch) nicht langfristig an einem neuen Ort niedergelassen haben. Die Bezeichnung Immigranten verweist darauf, dass sich die Menschen bewusst an einem neuen Ort beheimatet haben. Um der Tatsache Rechnung zu tragen, dass in den Anfangsjahren der Migration geflüchtete Tamilen von der Schweiz aus weiter in andere Diaspora-Länder wie Grossbritannien oder Kanada immigriert sind, wird für die erste Generation mehrheitlich der Begriff Migrantinnen/Migranten verwendet. Diese Unterscheidung wird im Bewusstsein dessen getroffen, dass eine genaue Trennung zwischen den Kategorien nicht möglich ist und die Übergänge fliessend sind.

9 Zum Begriff der Heimat und seinen Implikationen vgl. beispielsweise Gebhard 2007. 
gestaltung ihres Lebens. Infolge von repressiven Massnahmen des sri-lankischen Staates gegenüber der tamilischen Minderheit entschlossen sich viele Tamilen, das Land zu verlassen und als «Flüchtlinge» in unterschiedlichsten Aufnahmeländern zu leben. Eines davon ist der Nationalstaat Schweiz, dessen eigene Inkorporationsbedingungen bei der Ankunft tamilischer Migrierende wiederum entscheidenden Einfluss auf deren Lebensgestaltung und die Lokalisierungsdynamiken tamilisch-hinduistischer Praxis hatten.

\section{Entstehungszeitraum der Studie: Der Bürgerkrieg in Sri Lanka}

Die vorliegende Untersuchung ist in einer für die tamilische Bevölkerung Sri Lankas historisch entscheidenden Periode entstanden. Anders als im Fall Christopher McDowells (1996), der seine Studie über tamilische Migranten aus Sri Lanka in der Schweiz - "A Tamil Asylum Diaspora. Sri Lankan Migration, Settlement and Politics in Switzerland" - zu einer Zeit verfasste, als eine friedliche Lösung des Konflikts nicht ausgeschlossen schien $^{10}$, wurde die vorliegende Studie in einer Zeit begonnen, als der Konflikt in Sri Lanka erneut eskalierte. ${ }^{11}$ Anfang 2008 wurde in Sri Lanka nach sechs Jahren wieder der Kriegszustand ausgerufen. ${ }^{12}$ Auch das historische Datum der offiziellen Beendigung des Bürgerkriegs nach fast dreissig Jahren, nach dem militärischen Sieg der sri-lankischen Regierung über die Liberation Tigers of Tamil Eelam (LTTE) im Mai 2009, und die daraus resultierenden Umbrüche im Land, in den tamilischen Gebieten und auch in der Diaspora, fielen in die Entstehungszeit der Studie. Die aktuellen Ereignisse in Sri Lanka hatten auch Auswirkungen auf die in der Diaspora lebenden Tamilen und zum Teil auch auf ihre religiöse Praxis. Somit haben die politischen Geschehnisse in Sri Lanka auch den Entstehungsprozess der vorliegenden Untersuchung beeinflusst.

10 "At the time of completing this work (early 1995) it appeared that under a new government, Sri Lanka was entering a period of relative calm in which democratic principles were to be re-established" (McDowell 1996, 3).

11 Die Eskalation setzte ein, als am 2. November 2007 der politische Anführer der Liberation Tigers of Tamil Eelam (LTTE) Suppayya Paramu Thamilselvan (1967-2007) und weitere ranghohe Mitglieder der LTTE bei einem Luftschlag der sri-lankischen Armee getötet wurden. Dies führte zu einem Rückschlag für den Friedensprozess im Land (zum Bürgerkrieg in Sri Lanka und zur LTTE siehe Abschnitt III 2).

122009 wurde das Waffenstillstandsabkommen von der Regierung Sri Lankas aufgekündigt. Der Präsident Sri Lankas Mahinda Rajapaksa kündigte daraufhin den "final war" gegen die LTTE noch im selben Jahr an. 


\section{Lokalisierungsdynamiken tamilischer Hindu-Praxis}

Gegenstand der Studie ist es, spezifische Dynamiken des Beheimatungsprozesses tamilischer Hindu-Praxis in der Schweiz nachzuzeichnen. Dabei sollen sowohl konkrete Orte, an denen solche Praxis geschieht, als auch öffentliche Performanzen tamilischer Hindus in den Blick genommen werden. Der Begriff der Lokalisierungsdynamik betont die Prozesshaftigkeit des Geschehens und hebt lokale Auswirkungen globaler Prozesse hervor.

Des Weiteren zeigt die Studie den Einfluss verschiedener Inkorporationsbedingungen auf die Etablierung wie auch die Vernetzungen der Lokalisierungsdynamiken im Kontext der sri-lankisch tamilischen Diaspora auf. Tamilischen Praktiken in unterschiedlichsten sozialen Räumen in der Schweiz, aber auch in anderen Aufnahmeländern - ist gemein, dass sie sich durch vielfältige Bezüge zum südasiatischen Kontext auszeichnen. Dabei haben die politischen Entwicklungen in Sri Lanka Auswirkungen auf das Leben tamilischer Migranten in der Diaspora. Durch Migrationsbewegungen sind transnationale soziale Räume jenseits nationalstaatlicher Grenzen entstanden (vgl. Pries 1997).$^{13}$ Den Kontext der Studie bildet neben dem nationalstaatlichen Gefüge der Schweiz die transnationale sri-lankisch tamilische Diaspora, die aufgrund des Bürgerkrieges in Sri Lanka entstanden ist. Die Studie zeigt dabei am Schweizer Beispiel auf, dass tamilische Hindu-Praxis zum einen in eben einem solchen transnationalen sozialen Raum anzusiedeln ist, zum anderen jedoch durch nationalstaatliche Bedingungen konkret beeinflusst wird. Solche Einflussfaktoren sind einerseits aus Bedingungen des Herkunftslandes, aus dem die Menschen geflohen sind, abzuleiten, andererseits aus den Inkorporationsbedingungen des neuen Staates, in dem sie leben. Hindu-Praxis tamilischer Migranten findet folglich in einem Raum statt, der von den Bedingungen in der Republik Sri Lanka, dem neuen nationalen Kontext der Schweiz wie auch von den Bezügen zu anderen Orten innerhalb der sri-lankisch tamilischen Diaspora beeinflusst ist. Die nationalstaatlichen Pole Sri Lanka und Schweiz erzeugen also ein Spannungsfeld, in dem sich die Akteurinnen und Akteure bewegen.

13 Mit dem Begriff transnationale soziale Räume sind keine statischen, geographisch fixierten Orte gemeint, sondern bewegliche symbolische Sphären. «[Transnationale soziale Räume sind] neue 〈soziale Verflechtungszusammenhänge `, die geographisch-räumlich diffus bzw. multilokal sind und gleichzeitig einen nicht nur transitorischen sozialen Raum konstituieren, der sowohl eine wichtige Referenzstruktur sozialer Positionen und Positionierungen ist, als auch die alltagsweltliche Lebenspraxis, (erwerbs-) biographische Projekte und Identitäten der Menschen bestimmt und zugleich über den Sozialzusammenhang von Nationalgesellschaften hinausweist» (Pries 1997, 34). 
Sobald sich religiöse Praxis von Migranten etabliert, wird diese des Weiteren in der öffentlichen Sphäre der Mehrheitsgesellschaft sichtbar und positioniert sich in dieser. Religiöse Praxis findet nicht nur hinter verschlossenen Türen statt, sondern ist in aller Regel auch auf das Handeln im öffentlichen Raum ausgerichtet. Der Wunsch nach öffentlich als Sakralbauten sichtbaren religiösen Stätten und die konkrete Realisierung eines repräsentativen Tempelbaus sind dabei zentrale Prozesse.

\section{Leitende Forschungsfragen und Ziel der Studie}

Analyseperspektiven der Untersuchung stellen die Kategorien Diaspora, Inkorporation, Raum und öffentliche Sphäre dar. Folgende Vorannahmen bilden den Ausgangspunkte der Studie: Religiöse Praxis ist immer im Wandel begriffen, niemals statisch und reagiert auf die kontextuellen Bedingungen des Religionshandelns. Die Dynamiken der religiösen Praxis von DiasporaAkteuren haben immer auch mit den spezifischen Umgebungsbedingungen der Diaspora zu tun. Lokalisierungsdynamiken und die öffentliche Präsenz geben Aufschluss über Spezifika der Immigrantengruppe wie auch des nationalen Kontextes.

Die Untersuchung stellt folgende übergeordnete Forschungsfrage in den Mittelpunkt: Wie stellen sich die Lokalisierungsdynamiken von HinduPraxis dar, die von sri-lankisch tamilischen Akteuren in der Schweiz ausgeführt werden?

Aus dieser leitenden Perspektivierung lassen sich folgende Fragen ableiten: Wie sieht das Wechselverhältnis zwischen den Bestrebungen zur Etablierung von Hindu-Praxis und den Spezifika der sri-lankisch tamilischen Diaspora auf der einen und nationalstaatlicher Inkorporation in der Schweiz auf der anderen Seite aus? Zentraler Fokus innerhalb der Untersuchung der Lokalisierungsdynamiken ist die Untersuchung der sozialen Räume des Vollzugs von Hindu-Praxis tamilischer Immigranten in der Schweiz. Welche unterschiedlichen Formen der Orte des Religionshandelns sind auszumachen? Welche Institutionalisierungsprozesse entstehen und welche konkreten Orte religiöser Vergemeinschaftung haben sich etabliert? Wie präsentiert sich das religiöse Handeln tamilischer Hindus in der Schweizer Öffentlichkeit zwischen den Polen von Transnationalismus und nationalstaatlicher Inkorporation?

Ziel der Studie ist es, einen umfassenden Einblick in die Praktiken tamilischer Hindus im nationalstaatlichen Kontext der Schweiz zu geben und besonders die Aspekte der Lokalisierung und des öffentlichen Sichtbarwerdens dieser Immigrantengruppe zu analysieren. Eine solche Untersuchung kann das Wechselverhältnis von Religion und Migration in spezifischen nationalen Kontexten aufzeigen. Daraus kann abgeleitet werden, wie Min- 
derheitenreligionen in einem neuen Kontext Legitimationsstrategien für ihre öffentliche Präsenz entwickeln und wie die nationalstaatlichen Reaktionen abhängig von den wahrgenommenen Spezifika verschiedener religiöser Gruppen unterschiedlich ausfallen können.

Die Untersuchung ist als eine auf empirischer Forschung basierende religionswissenschaftliche Studie konzipiert und innerhalb des Theoriefelds der Diaspora- und der transnationalen Migrationsstudien anzusiedeln.

Die Studie leistet damit einen Beitrag zu den sich im Zeitalter der Globalisierung immer stärker etablierenden Diaspora-Studien. Innerhalb dieser will sie - als religionswissenschaftliche Studie - den Faktor Religion und hier im Besonderen das religiöse Handeln von Diaspora-Akteuren als Forschungsgegenstand ins Zentrum stellen.

\section{Aufbau der Studie}

Die vorliegende Studie ist in fünf Kapitel unterteilt und endet mit einem abschliessenden Fazit. Sie beginnt in Kapitel I mit der Darstellung der analytischen Perspektive und dem methodischen Design der Arbeit. Vier Analysekategorien (Diaspora, Inkorporation, Raum und Offentlichkeit) bilden den theoretischen Rahmen. Die ethnographische Methode der Untersuchung nutzt die Instrumente qualitativer empirischer Forschung und bezieht sich in erster Linie auf teilnehmende Beobachtungen und das Führen von Interviews.

Die sri-lankisch tamilische Diaspora bildet den Rahmen für das religiöse Handeln tamilischer Migranten in der Schweiz, was in Kapitel II dargestellt wird. Rückbezüge zu einer imaginierten Nation und transnationale Vernetzungen sind hier wichtige Faktoren. Zunächst wird eine Begriffsbestimmung von Diaspora vorgenommen und daran anschliessend wird das Wechselverhältnis der Begriffe Religion und Diaspora im Kontext der Studie bestimmt.

Kapitel III fokussiert auf die Inkorporationsbedingungen des Residenzlandes Schweiz und zeichnet zunächst den zentralen Fluchtgrund für viele Migranten, den Bürgerkrieg in Sri Lanka, nach. Der schweizerische Kontext hat konkrete Auswirkungen auf die Etablierung tamilischer Hindu-Praxis in diesem Nationalstaat und wird systematisiert dargestellt.

Konkrete Räume des Vollzuges von Hindu-Praxis in der Schweiz und ihre Dynamiken bilden den inhaltlichen Schwerpunkt der Studie und werden in Kapitel IV unter verschiedenen Aspekten behandelt. Zunächst wird der soziale Raum der Wohnung als Austragungsort von Hindu-Praxis vorgestellt. Anschliessend werden shared spaces - soziale Räume, die tamilische Hindus mit anderen Gruppen teilen - sowohl als erste Anlaufstellen für tamilische Migranten in den Anfangsjahren der Migration als auch als 
gegenwärtige Kontaktzonen dynamischer Interaktion beschrieben. Daran anschliessend wird die Etablierung eigener sri-lankisch tamilischer Tempelräume thematisiert, die sich durch die Umwidmung angemieteter Hallen zu religiösen Wahrnehmungsräumen und eine Verlagerung von häuslichen Praktiken in den Tempel als Vergemeinschaftungsort auszeichnet. Bezugsorte für in der Schweiz lebende tamilische Hindus sind darüber hinaus auch religiöse Orte ausserhalb der Schweiz wie Wallfahrtsorte in Südindien, da sich die Akteure in der transnationalen tamilischen Sphäre bewegen.

Kapitel $V$ thematisiert den Weg der hindu-tamilischen Minderheit in unterschiedliche öffentliche Sphären. Die Studie geht dabei von einer Pluralität dieser Sphären aus, was konkret anhand von verschiedenen Tempelöffentlichkeiten gezeigt wird. Tamilische Hindu-Tempel präsentieren sich auf unterschiedliche Art sowohl in tamilischen öffentlichen Sphären als auch in den Öffentlichkeiten der Schweizer Mehrheitsbevölkerung. Öffentliche performative Praktiken, besonders während der jährlichen Tempelfeste als Kristallisationspunkte öffentlicher Repräsentation von Hindu-Praxis, aber auch Performanzen für Frieden und Gerechtigkeit im Kontext des Bürgerkrieges in Sri Lanka, werden dargestellt. Auch die Spannungsfelder, in welchen diese öffentlichen Präsentationen stehen, werden dabei angeschnitten.

Die vier Hauptkapitel zu Hindu-Praxis im Kontext der tamilischen Diaspora enden mit einer Zusammenfassung, welche die wichtigsten Punkte abschliessend und im Hinblick auf analytische Aspekte bündelt. Die Studie schliesst mit dem resümierenden Fazit, welches unter dem Stichwort Beheimaten durch diasporische ${ }^{14}$ Innovationen diese Analysepunkte systematisiert und als Ausgangspunkt für weitere Forschungen zusammenstellt.

14 In Anlehnung an das englische Adjektiv diasporic soll im Folgenden der Begriff diasporisch analog zum Substantiv Diaspora gebraucht werden (vgl. Baumann 2003a, 67). 


\title{
Kapitel I \\ Perspektiven und Forschungsdesign
}

\author{
Research is a relationship. Ethnographer, \\ informants, and to a less direct extent, readers, are \\ engaged in an open-ended dialogue. It is through \\ this circulation of ideas - not through the author's \\ act of inscribing words on the page - that \\ knowledge is produced. \\ (Gunn 2009, 46)
}

In diesem ersten Kapitel der Untersuchung soll zunächst die analytische Perspektive vorgestellt werden, die ich im Folgenden einnehme. Nach generellen Anmerkungen zur Verwendung der sich durch die ganze Studie ziehenden Kategorien Ethnie und Gender (I 1.1) liegt ein aktionsorientierter Fokus auf Hindu-Praxis (I 1.2). Leitend hierfür sind die theoretischen Grundannahmen des Hindu religioning (nach dem von Malory Nye kreierten Verb religioning, vgl. Nye 2000b). Daran anschliessend werden die vier Kategorien der Analyse - Diaspora, Inkorporation, Raum und Öffentlichkeit - vorgestellt (I 1.3). Diese theoretischen Grundbegriffe bilden den Rahmen zur Analyse der untersuchten Praktiken.

Auf die zentralen Forschungsfragen der Studie wurde das methodische Vorgehen abgestimmt: Neben der Analyse von Sekundärliteratur und Primärquellen waren qualitative Forschung mit Schwerpunkt auf ethnographischer Feldforschung, ergänzt durch das Führen verschiedener Formen von Interviews, die zentralen Elemente, um die Daten zur Analyse zu erheben (I 2.2). Besondere Beachtung kommt in dieser Darstellung den konkreten Forschungsbedingungen im Zeitraum der Feldarbeit zu, die Einfluss auf die methodische Vorgehensweise hatten (I 2.1). Die Berichte über die Kriegsereignisse in Sri Lanka und die Debatten um die öffentliche Sichtbarkeit von Minderheitenreligionen in der Schweiz, die einen ihrer Höhepunkte in der Abstimmung über die sogenannten Minarettinitiative 2009 hatte, sind hier zu nennen. 
Das Kapitel schliesst mit einem Überblick über den Forschungsstand zur Referenzgruppe und stellt die Literaturlage zu tamilischen Migranten in der Schweiz und zu tamilischen Hindus in anderen Diaspora-Ländern vor (I 3).

\section{Analytische Perspektiven}

Ausgehend von eigenen empirischen Studien $\mathrm{zu}$ in den USA lebenden römisch-katholischen Immigranten aus Kuba versucht Thomas A. Tweed in seinem Buch Crossing and Dwelling: A Theory of Religion eine allgemeine Religionstheorie aufzustellen, die auch den Dynamiken des religiösen Lebens von Migrantinnen und Migranten im transnationalen Raum gerecht wird: "I was looking for a theory of religion that made sense of the religious life of transnational migrants and addressed three themes - movement, relation, and position" (Tweed 2006, 5). Das Anliegen der vorliegenden Studie über hindu-tamilische Diaspora-Akteure in der Schweiz ist zwar nicht primär die religionswissenschaftliche Theoriebildung, jedoch stellte sich auch hier die Frage nach Forschungsperspektivierung und -design, welche dem religiösen Leben von transnational vernetzten Immigrantinnen und Immigranten gerecht werden. Die von Tweed plausibel in den Mittelpunkt gerückten Themenfelder «Bewegungen», «Beziehungsverhältnisse» und «Positionierungsstrategien» spielen daher auch im Kontext der vorliegenden Studie eine zentrale Rolle.

Nach grundlegenden Anmerkungen zur Verwendung der Kategorien Ethnie und Gender in der Studie (1.1) wird im Folgenden die Fokussetzung der Studie erläutert. Nach der Darstellung des aktionsorientierten Ansatzes der Studie (1.2) wird die Perspektive dargestellt, welche im Forschungsfeld eingenommen wurde und die vier Analysekategorien der Studie vorgestellt (1.3). Diese zentralen Arbeitsbegriffe, welche den analytischen Rahmen der Studie bilden, werden im Folgenden umrissen und die Studie so auch innerhalb des (religions-)wissenschaftlichen Diskurses verortet. Allerdings werden die Begriffe an dieser Stelle nicht - vom eigentlichen Inhalt der Untersuchung losgelöst - nacheinander behandelt, sondern hier zunächst nur vorgestellt und dann im Verlauf der Studie in den einzelnen Kapiteln in ihrer theoretischen Rahmung und am konkreten Beispiel genauer expliziert. 


\subsection{Doing Ethnicity/Doing Gender: Anmerkungen zur Verwendung dieser Kategorien}

Da diese Studie bereits im Titel und in der Bestimmung ihres «Feldes» auf ethnische Kategorisierungen zurückgreift, soll vorab das zugrundeliegende Vorverständnis der Kategorie Ethnie thematisiert werden. In den letzten Jahrzehnten wurde berechtigte Kritik am Ethnizitätsbegriff und damit unmittelbar verknüpften, mitunter rassistischen oder marginalisierenden Implikationen geübt. Martin Sökefeld weist darauf hin, dass eine «Vergegenständlichung» von Einwanderern - die Reduktion von Menschen mit Migrationshintergrund zu Forschungsobjekten - in Wissenschaft und Politik Parallelen aufweist (vgl. Sökefeld 2004, 9). Damit kritisiert er implizit eine Wissenschaftstradition, welche Othering - die Konstruktion einer distinkten Gruppe als «die Anderen» - betreibt.

Das Verständnis der Kategorien Ethnie wie auch Gender, welches dieser Studie zugrunde liegt, basiert auf einem sozialkonstruktivistischen Paradigma. Ethnische Differenzen - wie auch Geschlechtsunterschiede - werden als Resultate sozialer Konstruktionsleistungen von Akteuren der Alltagswelt wie auch von wissenschaftlichen Akteuren angesehen (vgl. Tyrell 2008). Die Zuschreibung als Ethnie wird oft von der Dominanzgesellschaft getroffen, die damit die Grenze zu anderen Gruppen zieht, welche als die «Anderen» beschrieben werden: « L'ethnicité, c'est la culture des autres, qui sont en fait des dominés » (Juteau 1999, 165).$^{15}$ Ethnische Zuschreibungen sind immer als Verhältnisbestimmungen zu anderen Gruppen zu verstehen und damit relational. Zentral für das Verständnis von Ethnizität in dieser Arbeit ist die Studie Ethnic Groups and Boundaries des norwegischen Sozial-Anthropologen Fredrik Barth (1969), welcher die soziale Organisation kultureller Differenz herausgestellt und den Terminus Ethnie eingehend problematisiert hat. Ethnische Identitäten werden seinem Verständnis nach «gemacht», in erster Linie durch ihre Grenzen bestimmt und durch den relationalen Prozess der Inklusion und Exklusion aufrechterhalten. Die Grenzen zwischen den Gruppen werden durch soziale Interaktion innerhalb und ausserhalb der Gruppe verhandelt. Der dynamische Charakter von ethnischen Identitätszuschreibungen enthält immer Selbst- wie auch Fremdzuschreibungen. Joane Nagel stellt heraus, dass ethnische Identitätskonstruktionen sowohl von der Gruppe selbst als auch durch die Mehr-

15 Danielle Juteau $(1999,18)$ weist darüber hinaus auf die Gefahr hin, dass der Begriff Ethnie die als solche definierte Gruppe aus der Gruppe der «Menschheit» ausschliesst: « Chez les majoritaires, elle s'appelle humanité, tandis que chez les minoritaires, elle se nomme ethnicité ». 
heitsgesellschaft hergestellt werden: "Ethnicity is the product of actions undertaken by ethnic groups as they shape and reshape their self-definition and culture; however, ethnicity is also constructed by external social, economic, and political processes and actors as they shape and reshape ethnic categories and definitions" (Nagel 1994, 2). Ich verstehe im Folgenden ethnische Identitäten als Ergebnisse sozialer Interaktion, die sich narrativ konstruieren und diskursiv entfalten.

Øivind Fuglerud (2001) folgt in seinem Artikel Time and Space in the Sri Lanka-Tamil Diaspora der These, dass im konkreten Kontext der tamilischen Diaspora sich eine ethnisch-nationale Identität des «Tamilisch-Seins» erst in den letzten Jahrzehnten herausgebildet habe. Dabei bezieht er sich auf Bryan Pfaffenberger (1994), der aufzeigt, dass das Label «Tamile» im Sri Lanka der 1970er Jahre in erster Linie eine Kasten-Bezeichnung war. In Interviews mit Arbeitern, die als sogenannte «Unberührbare» galten, stellte Paffenberger fest, dass diese die Mitglieder der landbesitzenden Kaste als «Tamilen» bezeichneten. Erst später entwickelt sich dann ein Verständnis von «Tamilen» als eigener Ethnie und Nation ${ }^{16}$ : "The effort to construct nation from caste in less than thirty years may explain some of the internal tensions that have been part of this project" (Fuglerud 2001, 210). Das Beispiel zeigt die Fluidität der Begrifflichkeiten und Klassifikationen und macht deutlich, dass ethnische Zuschreibungen historisch und kontextuell wandel- und verhandelbar ist. Die Bezeichnung sri-lankische Tamilen korreliert mit der offiziellen Klassifizierung dieser Gruppe in den Fragebögen zur Volkszählung in Sri Lanka. In der Volkszählung von 2001 wurde nach der Zugehörigkeit zu einer «ethnischen Gruppe» gefragt, wobei als Auswahl an zweiter und dritter Stelle 'Sri Lanka Tamil' und 'Indian Tamil' genannt wurden. ${ }^{17}$ Diese Unterscheidung zeigt an, dass diese Termini fest im nationalen Diskurs verankert sind. Obwohl viele Tamilen die Bezeichnung Sri Lanka als Ausdruck singhalesischer Dominanz ablehnen und anstelle dessen den

16 Mit der Selbstbezeichnung tamilische Nation rekurrieren die Akteure auf das Recht, sich auf international geltendes Völkerrecht berufen zu können. Ethnien können sich nur auf Minderheitenschutz berufen; Nationen haben nach Art. 1 und 55 der Charta der UNO dagegen auch das Recht auf staatliche Selbstbestimmung - selbst dann, wenn sie - wie die Tamilen in Sri Lanka - Teil eines anderen Staates sind.

17 Der Fragebogen der Volkszählung (Population and Housing Schedule - Form F3) konnte auf der Webpräsenz des sri-lankischen Department of Census and Statistics eingesehen werden (vgl. http://nada.statistics.gov.lk/index.php/catalog/955/download/4329; 09.01.2021).

Mit den indischen Tamilen Sri Lankas ("Hill Country Tamils") ist jene tamilische Bevölkerung gemeint, die im 19. und 20. Jahrhundert aus Südindien als Plantagenarbeiter nach Sri Lanka kam. 
tamilischen Begriff für die Insel ĭlam verwenden ${ }^{18}$, wird dieser Terminus in der vorliegenden Studie unter der folgenden Prämisse verwendet: Mit der Bezeichnung Sri Lanka-Tamilen oder sri-lankische Tamilen will ich nicht einfach der staatlichen Definitionsmacht folgen, sondern deutlich machen, dass viele Mitglieder der Untersuchungsgruppe Staatsangehörige eines Nationalstaates mit dem Namen Sri Lanka waren oder sind, und dessen nationalstaatlichen Mechanismen unterworfen waren.

Die Studie zeigt das Spannungsfeld auf, in welchem tamilische Akteure konkret handeln. Nationalstaatliche Grenzen, Gesetze und Diskurse üben Einfluss auf die Praktiken und Strategien tamilischer Hindus aus. Mit einer Fokussierung auf die nationalstaatlichen Grenzen der Schweiz will die Arbeit jedoch nicht dem sogenannten «methodologischen Nationalismus» (Wimmer/Glick Schiller 2002) ${ }^{19}$ Vorschub leisten, sondern die Wirkmacht dieser historisch gewachsenen und damit konstruierten Grenzen aufzeigen. Ebenso stellt sich die Problematik, dass viele Fachbegriffe, die auf das sogenannte «Heimatland» der Migrantinnen und Migranten verweisen, diese einseitig in der sogenannten «Heimat» verorten. Gerd Baumann $(1999,158)$ konstatiert in Bezug auf die Verwendung des Begriffs "back home": "To my knowledge, there is, as yet, no social science term that avoids the othering implications of "back home".

Die Kategorie Gender, das Sprechen von «tamilischen Frauen und Männern», stellt eine weitere in der Studie verwendete Ordnungskategorie dar. Im Folgenden wird dieser Analysekategorie das innerhalb der Gender Studies $^{20}$ etablierte Konzept des doing gender zugrunde gelegt, welches Geschlecht als Produkt performativer Handlungen versteht und die Dynamik und Prozesshaftigkeit von sozialer Wirklichkeit in den Mittelpunkt stellt: "Gender is not a set of traits, nor a variable, nor a role, but the product of social doings of some sort" (West/Zimmerman 1987, 129). Dabei enthält das Konzept Kritik an strukturellem Essentialismus und radikalem Biologismus. West und Zimmerman unterscheiden etwa zwischen biologischem

18 Auch der Religionswissenschaftler Peter Schalk verwendet in seinen Schriften den Terminus Ilamtamile (vgl. Schalk 2006a).

19 Andreas Wimmer und Nina Glick Schiller (2002, 302) definieren den Terminus «methodologischer Nationalismus» wie folgt: "We are designating as methodological nationalism the assumption that the nation/state/society is the natural social form of the modern world".

20 Gender Studies versuchen dezidiert zu zeigen, dass und wie Geschlechterdifferenzen genau hergestellt werden und welche Bedeutung diese als soziale Konstrukte und Strukturkategorien - auch in der wissenschaftlichen Forschung - haben (vgl. z. B. von Braun/Stephan 2006). Oft ist jedoch in den vorliegenden Analysen zu Gender-Fragen eine gewisse Religions-Blindheit festzustellen; das heisst, dass die Kategorie Religion nicht als eine relevante Kategorie mit in die Analysen einbezogen wird (vgl. King 2008). 
Geschlecht (sex), Geschlechterkategorien (sex categories) und dem sozialen Geschlecht (gender). Mit sex sind durch die Gesellschaft vorgegebene biologische Merkmale gemeint, welche alle Mitglieder der Gesellschaft klassifizieren. Die Bezeichnung sex categories rekurriert auf die soziale $\mathrm{Zu}-$ ordnung zu einem der beiden «Geschlechter» im alltäglichen Leben durch Inszenierungspraktiken. In der Interaktionssituation werden Akteure der Kategorie «Mann» oder «Frau» zugeordnet, was nicht unbedingt dem biologischen Geschlecht entsprechen muss. Gender wird als Merkmal sozialer Situationen verstanden: es ist abgeleitet aus der Mitgliedschaft in einer der beiden sex categories. Besonders Judith Butler macht den Aspekt der Performativität im Akt des doing gender stark (vgl. Butler 1991).

Im Folgenden verwende ich Gender als analytische Kategorie, die das von Gesellschaften (und somit auch von «Religion») produzierte Wissen der Geschlechterdifferenz untersucht. Geschlecht wird als eine gesellschaftliche Strukturkategorie, Geschlechterbeziehungen als Repräsentationen religiöser und kultureller Regelsysteme verstanden. Gender-spezifische Fragestellungen sind - insbesondere in der deutschsprachigen - Religionswissenschaft erst in den letzten Jahrzehnten behandelt worden. Es erfolgte ein Paradigmenwechsel weg von einer androzentrischen Betrachtungsweise religiöser Traditionen - welche den homo religiosus implizit immer als vir religiosus auffasste - hin zu einer geschlechtergerechten Untersuchung religiöser Phänomene, welche die Kategorie «Geschlecht» mit in die Analysen einfliessen lässt (vgl. Juschka 1999; Höpflinger/Jeffers/PezzoliOlgiati 2008; Maske/Günther 2019).

Pierrette Hondagneu-Sotelo (2005) hat für den Themenkomplex Gender und Migration drei Phasen wissenschaftlichen Interesses rekonstruiert, die analog zu den Etappen der Integration der Kategorie Gender in die Religionswissenschaft gesehen werden können. Während seit den 1980er Jahren eine Abkehr von einer androzentrisch ausgerichteten Forschung, verstanden als erste Phase, hin zur Frauenforschung mit feministischen Ansätzen stattfand ${ }^{21}$, lag der Fokus in den 1990er Jahren dann auf Gender und Religion bzw. Gender und Migration (Phase 2). Nach diesem erneuten Paradigmenwechsel ("making the gender-critical turn"), in welchem Gender als kulturwissenschaftliche Analysekategorie verstanden wird, wird Gender gegenwärtig als ein grundlegendes Analyseelement religiöser Pra-

21 Pierrette Hondagneu-Sotelo $(2005,4)$ beschreibt diese Phase als "remedying the exclusion of women in research (Women Studies)". Innerhalb der Religionswissenschaft setzte ein erster Paradigmenwechsel durch den Einfluss der kritisch-feministischen Theorie ein, aus dem die Feministische Religionswissenschaft entstand. 1977 fordert Rita Gross, von einer androzentrischen zu einer androgynen Methodologie überzugehen (Gross 1977). 
xis bzw. innerhalb von Migration angesehen. "Gender patterns are deeply embedded in cultural discourses and social institutions, including religious worlds, making them difficult to recognize and separate out from other elements. The critical gender awareness necessary for the work does not come 'naturally'; rather, it requires what has been termed 'a gender-critical turn' that affects a radically new way of seeing, thinking, and working [...]" (Calef 2009, 2). Susan Calef verweist darauf, dass ein kritischer Blick auf Gender-Themen durch diesen Paradigmenwechsel erst entsteht, da GenderThemen mit vielfältigen kulturellen Phänomenen verflochten sind.

Die vorliegende Studie ist nicht so konzipiert, dass die Kategorie Gender als Analysekategorie in einem separaten Kapitel thematisiert wird ${ }^{22}$; vielmehr wird diese in allen Bereichen der Arbeit mitberücksichtigt. Ursula King schreibt zu einer solchen Vorgehensweise:

Critical gender studies in religion have conclusively demonstrated that there are no gender-neutral phenomena. Everything is subtly, and often invisibly, patterned by a gender dynamic operating in language, thought, experience, and institutions. (King 2005, 3299 f.).

Sowohl in der «Feldarbeit» als auch in der Analyse ist der Blick auf Genderaspekte gerichtet. So werden beispielsweise geschlechtsspezifische Regulierungen in der religiösen Praxis und ihre Grenzverschiebungen thematisiert, wie sie etwa durch Reformbewegungen vorgenommen wurden.

Zusammenfassend bedeutet das dargelegte Verständnis der Kategorien Gender und Ethnie für diese Studie unter anderem, dass weder herausgearbeitet werden soll, was «authentische» ${ }^{23}$ tamilische Praxis oder der Kern des kulturellen und religiösen Lebens «der Tamilen» sei, noch zu welchen Praktiken Frauen oder Männern qua ihres Geschlechtes einen besseren Zugang hätten. Vielmehr beschreibe ich Präsentationsformen von in der Schweiz lebenden Menschen, welche sich als zur Gruppe der Tamilen zugehörig verstehen und gemäss ihrer Selbstaussage «Hinduismus» praktizieren. Im Folgenden beziehe ich mich in der Verwendung von Fachbegriffe, die sich auf die Kategorien Gender und Ethnie beziehen, auf die Selbstbe-

22 Hier soll somit nicht einem Ansatz gefolgt werden, welcher Frauen (oder auch Männer) als «externalisierte Forschungsobjekte» ansieht, wie dies beispielsweise Friedrich Heiler in seinem Werk Die Frau in den Religionen der Menschheit (veröffentlicht 1977) getan hat.

23 Bei der Beschreibung von religiöser Praxis von Migrantinnen und Migranten wird oftmals konstatiert, dass jene Praktiken nicht «korrekt» durchgeführt würden, da sie von der «richtigen» Ausführung der Praktiken im Herkunftsland abweichen. Steven Vertovec $(2000,1)$ stellt mit Bezug auf Hindu-Praktiken ausserhalb von Indien fest: "It is often inherent in popular views of diaspora that the homeland is 'authentic' and that the diaspora represents but a deviation from the 'true' or presumed normative form". 
zeichnungen der Personen. Dabei werden keine essentialistischen Aussagen zu den Konzepten gemacht: Die/derjenige wird im Folgenden als Tamilin und Tamile bezeichnet, die/der sich als solche/solcher versteht. ${ }^{24}$ Diejenige Person wird als weiblich/männlich beschrieben, welche sich als Frau bzw. Mann versteht.

\subsection{Hindu religioning in der Diaspora: eine aktions- orientierte Perspektive}

Im Zentrum der vorliegenden Studie stehen Lokalisierungsdynamiken und Performanzen als Formen der öffentlichen Präsenz tamilischer Hindus im Nationalstaat Schweiz. Methodologisch folgt die Arbeit einer aktionsorientierten Ausrichtung; folglich wird Religion in erster Linie als eine Praxisform verstanden (vgl. Bowen [1998] 2008). Damit folge ich der innerhalb der Kulturwissenschaften - zu denen die Religionswissenschaft im Rahmen dieser Arbeit gezählt wird (vgl. Gladigow/Auffahrt/Rüpke 2005; von Brück 2007) - vorgenommenen Praxiswende (practice turn, vgl. Schatzki/KnorrCetina/von Savigny 2001), welche das Handeln von Akteuren als zentralen Aspekt kultureller Systeme versteht (vgl. Hörning/Reuter 2004, 10). Die Perspektive der Studie ist auf das doing religion und dessen räumliche Gebundenheit gerichtet, auf das Handeln von Akteuren, die sich selbst als Praktizierende von Hindu-Traditionen verstehen. Durch Handlungsprozesse werden soziale wie auch als religiös bezeichnete Phänomene interaktiv hergestellt. Malory Nye hat das Verb religioning für Religionshandeln synonym zum Begriff doing religion in den wissenschaftlichen Diskurs eingeführt und umgeht damit eine essentialistische Auslegung des Religionsbegriffs:

Religioning is not a thing, with an essence, to be defined and explained. Religioning is a form of practice, like other cultural practices, that is done and performed by actors with their own agency [...], who have their own particular ways and experiences of making the religiosities manifest. (Nye 2000b, 467)

24 Hier folge ich Peter Schalk nicht, der in seinen neueren Publikationen als entscheidendes Kennzeichen der Gruppe die Sprache bestimmt und den Begriff «Tamilsprechende» bzw. "tamil speaking people" verwendet (vgl. Schalk 2004b, 2007a). Gegen die Auswahl der Sprache als zentrales Kriterium spricht im Kontext dieser Arbeit zum einen die Tatsache, dass viele Muslime Sri Lankas tamilisch sprechen, sich aber nicht als Tamilen bezeichnen, und zum anderen der Blick auf die zweite Generation in der Diaspora. Einige dieser Akteure verstehen sich als Tamilen, beherrschen Tamilisch jedoch nur noch rudimentär. 
Nicht die konzeptionellen Hintergründe des Religionshandelns - wie die dahinterliegenden Welterklärungsmodelle, Gottesbilder oder anthropologische Konzepte - analysiere ich an erster Stelle. Vielmehr nehme ich einen kontextualisierten Zugriff auf religiöse Praxis vor, der auf die räumliche Dimension des Handelns fokussiert. Das Praxisverständnis der Studie fusst auf Pierre Bourdieus Entwurf einer Theorie der Praxis (Bourdieu 1979). Ein praxistheoretischer Ansatz überwindet eine Einteilung in induktive und deduktive Herangehensweise. Mit Bourdieu gehe ich davon aus, dass das Handeln sozialer Akteure nicht allein durch rationale Konzepte oder Intentionalität erklärt werden kann, sondern dass die «Anforderungen der Praxis» entscheidenden Einfluss auf diese haben (vgl. Ebrecht/Hillebrandt 2002, 8). Im Folgenden gehe ich von einem weiten Praxis-Begriff aus, der sowohl Handlungen (im Sinne des englischen Nomens action) als auch das Sprechen über Hindu-Praxis und -Traditionen beinhaltet. Hindu-Praxis meint hier also sowohl die Handlungen der Akteure als auch das Sprechen über diese Handlungen der in ihrem Selbstverständnis zu Hindu-Traditionen gehörigen Personen.

Ein solch aktionsorientiertes Verständnis basiert auf sozialkonstruktivistischen Axiomen und geht davon aus, dass Wirklichkeit sozial konstruiert ist: «Die gesellschaftliche Wirklichkeit ist keine <objektive Tatsache», sondern eine 〈interaktive Sache des Tuns〉» (Hörning/Reuter 2004, 10). Die als objektiv wahrgenommene Wirklichkeit wird als Produkt sozialer Handlungen verstanden, welche intersubjektiv nachvollziehbar ist. Konstruktivistische Ansätze enthalten sich einer Aussage über das «Wesen» von Religion:

The use of the term "construction" just highlights the need to clarify the discursive and social processes that lead to variation in religious meaning, whether or not one asserts a realist core to the religious phenomena under study. (Engler 2005, 29)

Innerhalb des aktionsorientierten Ansatzes ist der Begriff der Agency zentral. ${ }^{25}$ Der Fokus dieser Untersuchung liegt in erster Linie auf Agency als Gestaltungsmacht (performative agency; vgl. Engler 2005, 20). Um diese Handlungskompetenz der Immigranten in ihrem «Tun» zu beschreiben, wird in der Studie der Begriff des Akteurs verwendet. Jedoch meint die Verwendung des Terminus - auch im Hinblick auf die oftmals Einschrän-

25 In der Definition des Begriffes schliesst diese Studie an Krüger/Nijhawan/Stavrianopoulou (2005) an: «Agency kann als 〈transformative Handlungsmacht〉 oder 〈Handlungskompetenz〉 ins Deutsche übersetzt werden, wenngleich damit eine wichtige Dimension des englischen Begriffs ausgespart bleibt: die der korporativen Handlungsinstanz» (Krüger/Nijhawan/Stavrianopoulou 2005, 4). 
kungen nach sich ziehenden Umgebungsbedingungen - keine uneingeschränkte Handlungsmacht. Dem Konzept der agency wird daher das Konzept der patiency zur Seite gestellt (vgl. Schnepel 2005); neben der Handlungsmacht von Akteuren soll auch auf ihre Fähigkeit, Handlungsohnmacht auszuhalten, verwiesen werden. Dies erscheint gerade im Kontext der Migrationsforschung wichtig, um den Lebenswirklichkeiten der Akteure gerecht zu werden. Die Aspekte des Erduldens, Erleidens und Wartens sollen mitberücksichtigt werden, jene Momente, in denen sich Akteure «ohnmächtig» fühlen und eine Einschränkung ihrer Handlungsmacht erleben (vgl. Lauser/Weissköppel 2008, 24). Im Laufe der vorliegenden Studie wird gezeigt, dass besonders in den Anfangsjahren der Migration, als die rechtliche Situation vieler tamilischer Migranten unklar war, die patiency der Akteure in hohem Masse gefordert war (vgl. Kap. III 3.4).

Eine aktionsorientierte Ausrichtung richtet den Blick neben alltäglichen Praktiken des doing auch auf wissenschaftliche Praktiken des doing. Mit ersterem werden Prozesse kulturellen und religiösen Handelns von Akteuren beschrieben. «Hinduismus» wird durch die konkrete Praxis religiöser Akteure «gemacht» (doing hinduism) wie etwa durch das Anzünden von Räucherstäbchen am häuslichen pūcai-Platz oder durch das Ziehen des Prozessionswagens während des Tempelfestes.

Das Zweite rekurriert auf die Tatsache, dass Wissenschaft selbst schon kulturelles Handeln ist. Es sind Akteure, die Wissenschaft gemacht haben und machen. «Praxistheoretische Ansätze betonen also nicht nur das «Inder-Welt-Sein> kultureller Akteure. Sie reflektieren auch ihr eigenes praktisches Verhältnis des Verhaftet- und Eingebundenseins, jene praktische Logik der Theorie, die Aussagen über kulturelle Akteure trifft» (Hörning/ Reuter 2001, 13). «Religion» wird auch durch Forscherinnen und Forscher der Religionswissenschaft konstruiert, wie Steven Engler $(2005,39)$ betont: “The unsurprising 'discovery' that 'religion' is a construct simply invites us to clarify how it is constructed and to continue to participate, reflexively and self-consciously, in its ongoing construction". So wurde und wird «Hinduismus», auch in dieser Studie, durch den Akt wissenschaftlichen Schreibens «gemacht», was - in Anlehnung an Nyes Anmerkung zu writing of religion - als writing Hinduism bezeichnet werden kann (vgl. Nye 2000a, 10).

Ich bin mir derjenigen Prozesse innerhalb dieser Studie bewusst, die zur Konstruktion von «Hinduismus» beitragen und damit auch dem Aspekt, dass mein Schreiben gesellschaftliche Relevanz hat. Es ist festzuhalten, dass diese Untersuchung auf einer Beschreibungsebene das thematisiert, was als Hindu-Praxis präsentiert wird. Die Verwendung der Begriffe Präsentation und Repräsentation zeigt an, dass dabei nicht eine Essenz von etwas, «was dahinter liegt», dargestellt werden soll. Daraus folgt auch, dass in der Stu- 
die keine Unterscheidung getroffen wird, ob eine Praxis beispielsweise Ausdruck von «Kultur» und damit nicht zwingend «religiös» oder beispielsweise nur politische Praxis und damit ebenfalls keine religiöse Handlung sei. Dies bedeutet jedoch nicht, dass die genannten Termini keine Relevanz im Kontext dieser Studie haben; als virulente und wirkmächtige Abgrenzungsbegriffe «im Feld» spielen sie eine wichtige Rolle und beschreiben spezifische Dynamiken und Charakteristika innerhalb des Untersuchungsfeldes.

\subsection{Die vier Analysekategorien der Studie: Diaspora, Inkorporation, Raum sowie Öffentlichkeit}

Im Folgenden werden die Analysekategorien, die den Blickwinkel der Studie vorgeben, kurz vorgestellt - in den jeweiligen Kapiteln werden sie dann detaillierter skizziert und auf den Untersuchungsgegenstand angewendet.

\section{A. Hindu-Praxis in der Diaspora}

Im Zentrum der vorliegenden Studie stehen Lokalisierungsdynamiken von Hindu-Praxis in der Diaspora. Diaspora stellt eine zentrale wissenschaftliche Kategorie der Studie dar, welche sowohl auf Rückbezüge der DiasporaAkteure zu einem postulierten Herkunftsland wie auch auf transnationale Verbindungen verweist (zum Diaspora-Begriff vgl. Mayer 2005; Knott/ McLoughlin 2010; vgl. Kap. II 1.). Martin Baumann führt den Begriff als «Allgemeinbegriff» in die Religionswissenschaft ein (vgl. Baumann 2003a, 279).

Hindu-Praxis in der Diaspora ist durch Religionstransfer entstanden. So werden beispielsweise verschiedene hinduistische Rituale durch tamilische Migrantinnen und Migranten, die sich dauerhaft in der Diaspora niederlassen, von Sri Lanka in die Schweiz mitgebracht und unterliegen dort dynamischen Modifikationen. Ritualtheorien und Untersuchungen zu sogenanntem Ritualtransfer als eine Erscheinungsform von Ritualdynamik haben Aspekte dieser Phänomene in den Blick genommen (vgl. Langer et al. 2006). Die vorliegende Untersuchung geht von einem weiteren Begriff von Hindu-Praxis aus und fokussiert nicht nur auf den eng gesteckten Begriff des Rituals. ${ }^{26}$

26 In den im religiösen Kontext des Untersuchungsfeldes zentralen Sprachen, dem Tamilischen und dem Sanskrit, gibt es kein eindeutiges Äquivalent zum Fachbegriff Ritual: Im Sanskrit, der zentralen Sprache der religiösen Texte von Hindu-Traditionen, finden sich Begriffe, welche dem Begriff zwar nahekommen, aber ihm nicht klar entsprechen, wie etwa die Termini, welche von der Wurzel $k r$ - für «machen, tun» abgeleitet sind, beispielsweise karma und kriya (vgl. 
Transfer von religiöser Praxis bedeutet das Übertragen der Praktiken von einem sozialen Umfeld in ein anderes durch diasporische Akteure (vgl. Neubert 2006, 3). ${ }^{27}$ In dieser Studie wird jedoch nicht der Transfer selbst, sondern die diasporische Praxis nach einem erfolgten Transfer thematisiert. Es geht nicht primär um einen direkten Vergleich der Praxis in altem und neuem sozialem Umfeld. Fokus ist vielmehr die Praxis nach dem Transfer. Dieser zeichnet sich durch dynamische und kreative Prozesse in der Umsetzung religiöser Praktiken aus. Die Prozesse der Etablierung von religiösen Praktiken an bestimmten Orten in der Diaspora bedeuten immer auch Veränderungen - innerhalb der religiösen Praxis im Vergleich zum ursprünglichen sozialen Umfeld. Ein dauerhafter Transfer kann nur gelingen, wenn sich die religiöse Praxis wandelt und dem neuen sozialen Umfeld anpasst. Anschaulich und detailliert wird dies in dieser Studie unter anderem am Beispiel des Jahresfestes taipponkkal gezeigt (vgl. Kap. IV 5.)

Adaptionsprozesse, die erst die Kontinuität in der religiösen Praxis in der Diaspora ermöglichen, sind jedoch kein dem Diaspora-Kontext vorbehaltenes Phänomen. Es wird keine dichotome Gegenüberstellung von «statischer» religiöser Praxis im Herkunftsland im Gegensatz zu sich verändernder religiöser Praxis im Residenzland postuliert. Paul Gilroy (1993) spricht in diesem Zusammenhang von «changing same» (2003, 101), um Kontinuität wie auch den stetigen Wandel von Praktiken zu umschreiben. Sandhya Shuklar weist auf die Gefahr hin, dass kulturelle Modifikationen ausschliesslich mit Diaspora-Phänomenen erklärt werden:

Things stay the same and they change in South Asia as well as other diasporas. To faithfully maintain the duality of that fundamental truism, though, is to resist the reduction of any cultural moment to national or homeland difference. (Shukla 2001, 552)

Religiöse Handlungen unterliegen immer und überall komplexen Dynamiken und haben per se dynamischen Charakter - in Sri Lanka, in der Schweiz wie auch in anderen Diaspora-Ländern. So hat sich beispielsweise die religiöse Praxis in den tamilischen Gebieten Sri Lankas in den letzten Jahr-

Michaels 2006, 86). Diese verweisen auf die Bedeutung des Handelns für diese Traditionen. In der tamilischen Sprache entstammen viele Begriffe, welche dem Begriff Ritual nahekommen, dem Sanskrit wie kiriyai für «Handlung, Ritus» (vgl. Schalk 2006b, 91).

27 Allerdings muss trotz der Dynamik von religiöser Praxis und Ritualkomplexen ein zentrales statisches Element in Ritualen erhalten bleiben, welches die Identität eines spezifischen Religionshandelns stiftet (vgl. Neubert 2006, 10). Findet sich dieses nicht, kann nicht mehr von diasporischer Praxis gesprochen werden. Entweder hat sich die religiöse Praxis vollkommen im neuen Kontext assimiliert, oder aber es ist eine neue Form religiöser Praxis entstanden, die jedoch nicht mehr als diasporisch bezeichnet werden kann. 
zehnten aufgrund der sozio-politischen Verhältnisse entscheidend verändert. Christina Natali zeigt dies beispielsweise für Bestattungspraktiken auf (vgl. Natali 2008).

Die Untersuchung hat nicht zum Ziel, die religiöse Praxis tamilischer Hindus in der Schweiz mit der Praxis in Sri Lanka zu vergleichen. Es sollen keine normativen Wertungen vorgenommen werden, welche Praktiken sich als weniger «echt» und damit weniger «richtig» im Gegensatz zu «echter» Hindu-Praxis ausweisen. Ein direkter Vergleich mit Indien als «dem Massstab für authentische Hindu-Praxis» ist für die Untersuchung der Transformationsprozesse von Diaspora-Gruppen und von Dynamiken kultureller Reproduktion irreführend. Steven Vertovec, der in seinem Buch Hindu Diaspora. Comparative Patterns (2000) methodologische Ansätze zur Untersuchung von Hindu-Traditionen in der Diaspora vorstellt, weist auf die Unzulänglichkeit einer solchen Betrachtungsweise hin und fordert sinnvollerweise zu einem Perspektivwechsel auf:

Dhooleka Sarhadi Raj $(1997,25)$ is not alone in urging researchers to resist understanding diasporic South Asians by going to South Asia. We need to stop looking to India as the ideal culture, the fountainhead, or yardstick. There is indeed a need for a shift in perspective and method. This should entail a change from constantly measuring socio-cultural transformation among diaspora communities against some presumed archetype (usually associated with a homeland), to analysing and accounting for the dynamics of cultural reproduction, innovation and change in situ. (Vertovec 2000,2)

\section{B. Kontextuelle Faktoren: Diasporische Dynamiken als Resultate von (Herkunfts- und) Inkorporationsbedingungen im Residenzland}

Beim Fokus auf Lokalisierungsdynamiken wird der Blick immer auch auf die Umgebungsbedingungen des Handelns sozialer Akteure gelenkt. Dabei untersuche ich im Folgenden die Wechselwirkung mit gesellschaftlichen, politischen, wirtschaftlichen und anderen Prozessen. Gemäss dem aktionsorientierten Ansatz betrachte ich Religion, im Sinne von religiöser Praxis, immer als untrennbar von sozialer Praxis. Soziale Verhältnisse nehmen Einfluss auf religiöse Praxis und umgekehrt kann Religion die gesellschaftlichen Gegebenheiten beeinflussen. Der Rahmen, in dem religioning stattfindet, hat entscheidenden Einfluss auf religiöses Handeln. Das vorgestellte agency-Konzept schliesst auch die Umgebungsbedingungen (Art und Weise, Zeitpunkt und Ort der konkreten religiösen Praxis) ein. Verschiedenste Faktoren spielen dabei eine Rolle: «Gestaltungsmächtige Agency steht in einem komplexen Geflecht von ökonomischen, politischen, sozialen und religiösen Aspekten» (Krüger/Nijhawan/Stavrianopoulou 2005, 22). Die Ausgestaltung 
von Hindu-Praxis beeinflussen neben den Umgebungsbedingungen noch weitere unterschiedliche Aspekte wie beispielsweise die Handlungsmacht der einzelnen Akteure oder der traditionell vorgegebene Ablauf der Praxis.

Folgerichtig thematisiert diese Studie auch die soziale Situation der religiösen Akteure, die Umgebungsbedingungen und, da es um religiöse Praxis in der Diaspora geht, die Bedingungen der Inkorporation dieser in fremd-kulturelle Umgebung. Der Begriff der Inkorporation stellt somit eine wichtige Analysekategorie der Arbeit dar, welche in Kapitel III mit Blick auf die Untersuchungsgruppe in der Schweiz genauer vorgestellt wird. Unter gesellschaftlicher Inkorporation von Immigranten werden Verflechtungen in unterschiedlichen Bereichen des gesellschaftlichen Lebens und auf verschiedenen Ebenen verstanden, wobei auch eine transnationale Perspektive Berücksichtigung findet (vgl. Pries 2005, 2007).

Den Kontext dieser Untersuchung stellen jedoch nicht nur die Bedingungen des Residenzlandes dar. Der transnationale soziale Raum, in dem sich tamilische Immigranten bewegen, ist auch von den Ereignissen im Herkunftsland und den Gründen der Migration beeinflusst. Es ist eine Leitthese dieser Studie, dass der Konflikt in Sri Lanka ein entscheidender Faktor war, welcher Hindu-Praxis von tamilischen Migranten im Untersuchungszeitraum beeinflusste (vgl. Jacobsen 2009, 182).

\section{Soziale Räume des Religionshandelns und ihre Lokalisierungsdynamiken}

Die Studie fokussiert, neben der Verknüpfung der religiösen Praxis mit dem historisch-politischen Kontext, im Besonderen auf Lokalisierung und ihre Dynamiken als ein Aspekt der Rahmung für religiöses Handeln. Neben der wissenschaftlichen Analysekategorie der Diaspora, welche transnationale Vernetzungen besonders berücksichtigt, soll die konkrete lokale Gebundenheit von Hindu-Praxis daher über die Kategorie Raum in den Blick genommen werden (vgl. Kapitel IV). Eine Analyse der Ausgestaltung von sozialen Räumen des religiösen Vollzuges wird herangezogen, um sowohl Spezifika der religiösen Gruppe wie auch Dynamiken, die aus den Inkorporationsbedingungen resultieren, und Interaktionen der Hindu-Akteure mit dem schweizerischen Umfeld aufzuzeigen.

Neben Kulturvereinen von Immigrantinnen und Immigranten und von diesen geführten Geschäften, in denen Elemente «materieller Kultur» zum Kauf angeboten werden, sind spezifische religiöse Orte in vielen Fällen von hoher Wichtigkeit für das Leben von zugewanderten Minderheiten (vgl. Baumann/Tunger-Zanetti 2008; Peach/Gale 2003). Jacobsen $(2009,182)$ verweist darauf, dass ein Charakteristikum der sri-lankisch tamilischen Diaspora gerade die Etablierung von Tempelräumen wie auch öffentliche Performanzen während der Tempelfeste sind. 
Tempeln als sozialen Räumen kommt daher in dieser Studie eine grosse Rolle zu. Unter anderem wird der Prozess einer diasporisch bedingten Tempelisierung, der Verschiebung von religiösen Handlungen vom privaten Bereich in den Tempelraum, dargestellt (vgl. Kap. IV 5). Das place-making von Immigranten im Residenzland verweist auch auf Diskurse um öffentlichen und privaten Raum und die dabei zugrundeliegenden Öffentlichkeitskonzepte.

\section{D. Öffentlichkeiten von Hindu-Praxis}

Religiöses Handeln an konkreten Orten wird erst durch Kommunikation in eine Öffentlichkeit als religiöser Ausdruck erkennbar. Indem ich auf die öffentliche Dimension von religiösem Handeln und den Orten religiöser Praxis fokussiere, werden Positionierungsstrategien und Inkorporationsdynamiken von Immigrantengruppen im nationalstaatlichen Gefüge ersichtlich. Diese Studie untersucht soziale Räume auch als öffentliche Ausdrucksformen tamilischer Hindus innerhalb des Nationalstaates Schweiz.

Anstatt eine universelle öffentliche Sphäre zu postulieren, geht die vorliegende Studie von der Prämisse einer Pluralität von öffentlichen Sphären aus, welche sowohl im Rahmen von Nationalstaaten angesiedelt sind als auch über nationalstaatliche Grenzen hinweg gebildet werden. Diese Netzwerke multipler Öffentlichkeiten entstehen durch Aushandlungsprozesse zwischen den einzelnen Sphären.

In brief, there is no more the public opinion, at the singular, but many, which are more provisional, inconstant and volatile than in the past. The many public opinions create sub-societies at variable durability, for the same reason that there is no more the people at the singular, but different people [...], with different shared cultures, living together under the same rule and law. (Allievi 2004, 186)

Durch Wandlungsprozesse in der Moderne sind die verschiedenen öffentlichen Sphären fluide und wandelbar.

Gerade im Kontext der Untersuchung religiöser Praxis von Akteuren einer transnationalen Diaspora im Zeitalter der Globalisierung kann nicht mehr von der Öffentlichkeit im Singular gesprochen werden. Pnina Werbner $(2002,253)$ weist in ihrer Arbeit zu Muslimen in Manchester auf unterschiedliche öffentliche Sphären hin, in denen diasporische Gruppen handeln: "[Diasporic movements can] both sustain autonomous spaces of public debate and attempt to influence wider public political realms and centres of power."

Martin Baumann (2009c) hat herausgestellt, dass öffentlicher Raum innerhalb der gegenwärtigen Situation des Nationalstaates Schweiz nicht 
«neutral», sondern ein umkämpftes Terrain ist. Wechselwirkungen mit Inkorporationsbedingungen werden besonders in Untersuchungen zur öffentlichen Präsentation von Immigrantenreligionen deutlich.

Die Studie unterscheidet im Folgenden schematisch zwischen Schweizer nationalen Öffentlichkeiten (die öffentlichen Sphären der Schweizer Mehrheitsbevölkerung) und - in Anlehnung an Appadurais (1996) Konzept der diasporic public spheres - diasporischen tamilischen Öffentlichkeiten, die in die transnationale sri-lankisch tamilische Diaspora eingebunden sind. Als ein Beispiel für ein Ereignis, welches hauptsächlich in tamilischen öffentlichen Sphären bekannt ist, sei der māvīrar nāl, der sogenannte Great Heroes' Day genannt, an welchem Ende November an verschiedenen Orten der globalen tamilischen Diaspora - und auch in der Schweizer Stadt Freiburg der getöteten Kämpferinnen und Kämpfer der Tamil Tiger gedacht wird (vgl. Schalk 2003a). "The Great Heroes' Day is a political event, a day arranged by the LTTE to secure support from the Tamils, not to display LTTE or Tamil culture to a multicultural audience" (Jacobsen 2008a, 202).

Beide Sphären - die der Mehrheitsbevölkerung und die der Diaspora wiederum können ausdifferenziert werden und interferieren und beeinflussen sich gegenseitig. Tamilische Hindu-Praxis findet in unterschiedlichen diskursiven Arenen statt: Sie kann nur der tamilischen Offentlichkeit innerhalb der Schweiz bekannt sein oder sich auch bewusst in der Schweizer Mehrheitsöffentlichkeit präsentieren.

\title{
2 Methodische Vorgehensweise
}

\author{
Ethnographic research and writing is a dynamic, \\ meaning-making process, just as is ritual activity. \\ Just as humans create meaning in and through \\ their devotional activities and ritual encounters, \\ people who write and read academic treatments of \\ these activities create meaning in and through their \\ textual encounters. \\ (Gunn 2009, 47)
}

An die vorgestellte analytische Perspektive der Studie und die formulierten Forschungsfragen wurde auch die methodische Vorgehensweise angepasst, die im Folgenden dargestellt wird. Diese basiert auf Literaturanalysen zu den Inkorporationbedingungen von Hindu-Praxis in der Schweiz und auf 
ethnographischen Methoden. Nachdem die Ethnologie in den 1980er Jahren noch die Hoheit über ethnographische Arbeiten besass, gab es in den letzten Jahren einen Aufschwung an auf Ethnographie basierten Arbeiten innerhalb der Religionswissenschaft. ${ }^{28}$ Den Ausgangspunkt der vorliegenden ethnographiebasierten religionswissenschaftlichen Arbeit stellten konkrete Orte von Hindu-Praxis in der Schweiz dar. Dabei wird Robert Orsis Überlegungen zu "lived religion" gefolgt:

Workplaces, homes, and streets - as well as churches, temples, shrines, class meetings, and other more immediately recognizable sites of religious activity - are the places where humans make something of the worlds they have found themselves thrown into, and in turn, it is through these subtle, intimate, quotidian actions on the world that meanings are made, known and verified. "Religion" is best approached (...) by meeting men and women at this daily task, in all the spaces of their experience. (Orsi 1997, 7)

Ein Zugang zum Phänomen Religion wird möglich, indem man Orte aufsucht, an welchen Menschen agieren, den verschiedenen Orten des Religionshandelns.

Den Feldzugang ermöglichte hierbei der Besuch von konkreten Orten wie tamilischen Lebensmittelläden, Tempeln und kulturellen Veranstaltungen. Tempelräumen als soziale Räume tamil-hinduistischer Religiosität kommt, wie gezeigt werden wird, in der Diaspora eine bedeutende Rolle zu. Als monetäre und spirituelle Investitionen sind sie als Schritte zur gesellschaftlichen Eingliederung der Tamilen in fremd-kultureller Umgebung zu verstehen. Die Tempel ermöglichen auch in der Diaspora den Zugang zu den Göttinnen und Göttern. Gemäss dem gewählten aktionsorientierten Ansatz der Studie kreisen die empirischen Erhebungen um die konkreten als religiös bezeichneten Praktiken und Kommunikationsvorgänge an diesen Orten.

Im Folgenden werden zunächst die konkreten Forschungsbedingungen benannt und aufgezeigt, in welchem zeitlichen und örtlichen wie auch gesellschaftspolitischen Kontext die Studie entstanden ist. Daran anschliessend werden die angewandten Methoden der qualitativen Forschung und die Formen der Datenerhebung vorgestellt. Ethnographische Feldforschung stellt die zentrale Methode der Forschung dar. Mit Feld als sozio-räumlichem Begriff ist hier das Wirkungsfeld sri-lankisch tamilischer Hindus

28 Fragen der Anbindung von Ethnographie an religionswissenschaftliche Theorien bzw. innerhalb der Religionswissenschaft verwendeter Theorie widmete sich die religionswissenschaftliche Zeitschrift Method and Theory in the Study of Religion in Ausgabe 13/1 (2001) wie auch 21/1-2 (2009). Vgl. ausserdem das Handbuch von Stausberg/Engler (2011), in dem unterschiedliche Forschungsmethoden für die Religionswissenschaft vorgestellt werden. 
gemeint, die in die Schweiz migrierten, was nicht bedeutet, dass sie diese religiösen Handlungen nur innerhalb der Schweiz tätigen. «Ein Feld hat keine fixe Grenze, die überschritten werden kann, um es ungehindert und komplett überblicken zu können. Vielmehr konstruieren die Forschenden das Feld, zu dem sie Zugang suchen, erst im Forschungsprozess, da es sich angesichts der faktischen Vernetzung nur scheinbar um eine isolierte, eigenständige soziale Einheit handelt» (Franke/Maske 2011, 106).

\subsection{Die konkreten Forschungsbedingungen: Feldforschung zwischen Kriegsberichterstattung und Minarett- initiative}

Die Feldforschung zu dieser Studie wurde in den Jahren 2007 bis 2010 - und in eingeschränktem Masse im Hinblick auf das Tempelbauprojekt in Trimbach bis 2013 - im Rahmen des handlungsorientiert angelegten Projektes «Zugewanderte Religion, öffentlicher Raum und Wandel von Geschlechterrollen» des Nationalen Forschungsprogrammes 58 des Schweizer Nationalfonds unter der Leitung von Professor Dr. Martin Baumann durchgeführt. ${ }^{29}$ Der Forschungsprozess führte zu einer Spezifizierung der Forschungsfragen der vorliegenden Studie.

Ausgangspunkt der Feldforschung war teilnehmende Beobachtung an Orten des religiösen Handelns von tamilischen Hindus in der Schweiz. Ich habe vierzehn als Tempel bezeichnete Orte in der Schweiz besucht, an welchen tamilische Hindus religiöse Praxis vollziehen. ${ }^{30}$ An sieben dieser Tempel habe ich mehrfach und zu unterschiedlichen Anlässen Beobachtungen durchgeführt, wie etwa während der wöchentlichen pūcai (skr. pūjja), der Jahresfeste, des jährlichen Tempelfests mit Prozession, der interreligiösen Begegnungen in den Tempeln und sogenannten Friedensgebete aufgrund der kriegerischen Auseinandersetzungen in Sri Lanka. ${ }^{31}$ Darüber hinaus

29 An dieser Stelle möchte ich mich bei allen Informantinnen und Informanten bedanken, die mit mir in Dialog getreten sind, sowie allen Forschenden und mir nahestehenden Menschen, mit denen ich das von mir im ethnographischen Prozess Erlebte reflektiert habe.

30 Im Laufe meiner Forschung wurde ich über 23 als Tempel deklarierte Orte in der Schweiz in Kenntnis gesetzt. Adresse und Bezeichnung der Orte wie auch das genaue Datum meines Besuches werden an den Stellen erwähnt, an welchen in der Arbeit von Handlungen oder Gegebenheiten an diesen Orten berichtet wird.

31 Dabei handelt es sich um den Śrī Civacuppiramaṇiyar Tempel in Adliswil, den Viṣnu Turkkai Ammañ Tempel in Adliswil und nach seinem Umzug 2010 in Dürnten, den Civañkōvil in Glattbrugg, den Sri Man̄ōnmaṇi Ampāl Ālayam in Trimbach, sowohl im Ortskern Trimbachs in einer angemieteten Lagerhalle in der Bleichstrasse als auch den Tempelbetrieb im noch unferti- 
habe ich die Tamilen-Wallfahrt am Wallfahrtsort Einsiedeln in der Zentralschweiz als Kontaktzone zwischen römisch-katholischen Akteuren und Hindus besucht. Ausserdem waren Anlässe reform-hinduistischer Gruppen Gegenstand der Untersuchung, an welchen Tamilen teilnehmen, wie das Singen von bhajans (tam. pacanai) zu Ehren Sathya Sai Babas in der Sankt Karl Kirche in Luzern und die Besuche von Mātā Amritanandamaȳ Devi, verkürzt genannt Amma, in Winterthur (vgl. Kap. IV 3.4. zu den Treffpunkten der Sathya Sai Baba Devotees und den Besuchen von Amma). Weitere Veranstaltungen, an denen tamilische Hindu-Akteure beteiligt waren, wie interreligiöse Gebete, habe ich ebenfalls besucht.

Ergänzt wurden die Beobachtungen durch Teilnahme an tamilischen Anlässen, die nicht explizit als religiös bezeichnet werden, wie Versammlungen tamilischer NGOs oder des māvīrar nāl, des sogenannten Great Heroes' Day in Freiburg, an welchem jährlich den getöteten Soldaten der LTTE gedacht wird. ${ }^{32}$ Zum Feld gehören auch tamilische Geschäfte, die wichtige Elemente der materiellen Kultur zum Vollzug von Hindu-Praxis anbieten.

Neben den öffentlichen Orten und Anlässen habe ich über persönliche Kontakte Akteure zu Hause besucht, die mir dankenswerterweise Einblicke in ihre private religiöse Praxis gaben. So konnte ich dabei sein, als im familiären Kreis pūcais und religiöse Handlungen aus Anlass von wichtigen Festen durchgeführt wurden.

Jeder empirisch Forschende steht dem Problem gegenüber, dass ihm oder ihr das Forschungsfeld «davon läuft», das heisst, dass die vorgefundene und erhobene «Realität» sich noch während der Auswertung der Daten verändert und andere Parameter zugrunde liegen. Das in dieser Studie untersuchte Feld zeichnet sich in besonderem Masse dadurch aus, dass es stetigen Wandlungsprozessen unterworfen ist. Viele Orte tamilischer Hindu-Praktiken in der Schweiz waren/sind noch keine fest etablierten Lokalitäten; vielmehr sind sie provisorische Einrichtungen, die meist in angemieteten Räumen oder an variablen öffentlichen Orten lokalisiert sind, über welche oftmals Aushandlungsprozesse mit den lokalen Behörden anstanden oder anstehen. Diese Prozesse führen dazu, dass Orte wie auch Formen der Praktiken ein dynamisches, sich schnell wandelndes Feld darstellen. Daher sind die folgenden Ausführungen als Momentaufnahmen zu

gen Rohbau ab 2010 und den fertig gestellten Neubau des Tempels am Ortsrand ab 2013, den Hindu Tempel Basel, sowohl an seinem Standort in Muttenz 2008 als auch am Standort im Dreispitz 2009, den Śrī Turkkai Amman Tempel an meinem damaligen Wohnort Luzern und den Krishna Tempel der ISKCON in Zürich.

32 Diese Veranstaltung wurde im Untersuchungszeitraum (2007 bis 2011) durchgängig am 27. November jeden Jahres im Forum Fribourg durchgeführt. 
verstehen und nicht per se generalisierbar. ${ }^{33}$ So kann sich die Lage wie auch die Ausgestaltung eines Tempels oder auch seine Präsentation im virtuellen Raum sehr schnell, beispielsweise durch einen Umzug, ändern. ${ }^{34}$

Jeder/jede Forschende beginnt die Feldarbeit von ihrem/seinem eigenen sozialen Standort aus. Diese subjektiven Parameter beeinflussen den Forschungsprozess in unterschiedlicher Weise. ${ }^{35}$ Tweed weist daraufhin, dass der/die Forschende nur einen subjektiven Ausschnitt des Feldes wahrnimmt und analysieren kann:

I can see from where I am. As I have noted, I can't see everything. Culturally mediated objects enter and leave my sensorial and conceptual horizon. The horizon shifts as I do. And my position (including my gender, class, and race) obscures some things as it illumines others. (Tweed 2006, 18)

Die Forscherin als durch ihre kulturelle Kontextgebundenheit im Feld Fremde steht innerhalb der Feldforschung sozialen Hierarchieverhältnissen gegenüber, die selbstreflexiv mitbedacht werden sollten.

In den Untersuchungszeitraum der Studie fiel das offizielle Ende des Bürgerkrieges auf Sri Lanka durch den Sieg der sri-lankischen Armee über die LTTE. Die Konfrontation mit harten Realitäten machten auch mich emotional betroffen - besonders in den Tagen des Endes des Konfliktes im Mai 2009, als schätzungsweise 1000 (!) Menschen pro Tag im Zuge der Gefechte starben. ${ }^{36}$ Die ethisch angemessene Herangehensweise an die Arbeit beinhaltet, dass Interviewte und Beobachtete nicht als blosse «Datenlieferanten» angesehen werden und auch Mit-Leiden zugelassen wurde, wenn

33 Die Beschreibungen beispielsweise von Tempeleinrichtungen oder der Gestaltung der Aussenperspektive beziehen sich immer auf das angegebene Datum der Beobachtung. Diese Platzierung der materiellen Kultur verändert sich mitunter sehr schnell. Nichtsdestotrotz ist die Beschreibung solcher situativen Gegebenheiten aufschlussreich, um Ausgestaltungen und Dynamiken von Hindu-Praxis in der Diaspora zu analysieren.

34 Während des Untersuchungszeitraums zogen drei der Tempel um, an welchen mehrfach teilnehmende Beobachtungen durchgeführt wurden. Dabei handelt es sich um den Hindu-Tempel in Basel, den Sri Mañōnmaṇi Ampāl Ālayam in Trimbach und den Viṣnu Turkkai Ammañ Tempel, der von Adliswil nach Dürnten umzog.

35 Mein sozialer Standort und sich mein daraus erarbeiteter «Standpunkt» (vgl. zur Standpunkttheorie u.a. Harding 1994; Haraway 1995) war davon geprägt, dass ich die Forschung als Anfang/Mitte dreissigjährige, kinderlose Frau durchgeführt habe, welche römisch-katholisch sozialisiert wurde und aus Deutschland stammt. Der letzte Aspekt weist mich also auch als Ausländerin im Schweizer Kontext aus. Obgleich ich als Arbeitsmigrantin einen anderen Migrationshintergrund hatte als die tamilischen Akteure, mit denen ich in Kontakt stand, stellten Themen, welche den gemeinsamen Status als mit Ausländerausweis im Land Lebende betrafen, verbindende Aspekte von Lebenswirklichkeit dar.

36 Vgl. die Schätzungen des Untergeneralsekretärs für humanitäre Angelegenheiten der Vereinten Nationen John Holmes; zitiert nach Fuglerud 2011, 71. 
Informanten vom kürzlichen Tod ihrer Angehörigen oder der Ungewissheit über das Wohlergehen ihrer Familien in Sri Lanka berichteten.

Im Zuge dieser Diskurse im Feld stand der Umgang mit politischen Gerüchten (auch zur Person der Forschenden) und der Umgang mit Vereinnahmungsversuchen bestimmter Gruppen für ihre Interessen wie explizite oder implizite Forderungen nach politischer Positionierung der Forschenden oder etwa nach der «Aufdeckung politischer Machenschaften in den Tempeln». Die Abgrenzung zu unterschiedlichsten Interessensgruppen und die Wahrung politischer Neutralität im Feld stellten einen herausfordernden Teil der Feldarbeit dar.

Einfluss auf den Forschungsprozess und die Diskurse im Feld hatte auch die sogenannte Minarettinitiative. Im Jahr 2007 hatten Mitglieder der Schweizerischen Volkspartei (SVP) und der Eidgenössisch-Demokratischen Union (EDU) eine eidgenössische Volksinitiative lanciert, durch die das Verbot des Baus von Minaretten in die Verfassung aufgenommen werden sollte. Der Initiative war eine Politisierung von religiösen Differenzen durch die SVP vorangegangen, welche bei den Schweizer Nationalratswahlen 2003, 2007 wie auch 2011 die stärkste Partei war. Nachdem die Initiative am 29. November 2009 vom Stimmvolk angenommen worden war, wurde Artikel 72 der Bundesverfassung zu «Kirche und Staat» um einen dritten Absatz erweitert: «Der Bau von Minaretten ist verboten.»

In dieser Zeit waren auch tamilische Tempelbauprojekte mit Tempeltürmen in Planung, die durch die Diskurse um die Politik der «islamischen Türme» beeinflusst wurden. Die tamilischen Akteure empfanden es teilweise als risikoreich, in einer Zeit, in der die Minarettdebatte in vollem Gang war, die Planung von über zehn Meter hohen religiösen Türmen in der Mehrheitsöffentlichkeit publik zu machen.

\subsection{Erfahrungen mit der Feldforschung als zentraler Methode der Studie}

Qualitative Forschung ${ }^{37}$ beruft sich nicht auf ein normatives, sondern auf ein interpretatives Paradigma; die besonderen Eigenschaften und Merkmale eines Feldes sollen erfasst werden. Für die hier vorgelegte Untersuchung erwies sich eine qualitative, explorative Herangehensweise als besonders geeignet.

37 Qualitative Forschungsmethoden haben für gender-sensible Forschung vielfältige Vorteile, da sie ein hochflexibles Instrument der Datenerfassung darstellen (vgl. Krüger 1999). 
Zentrales Instrument der qualitativen Forschung dieser Studie stellten die teilnehmende Beobachtung, dabei geführte ero-epische Gespräche (Girtler 2001, 147 ff.) und das Führen von Interviews dar.

Ziel der ethnographischen Feldarbeit war unter anderem, marginalisierte Orte und Praktiken sichtbar zu machen. Ein erster Schritt war das Sammeln von religionstopographischen Informationen, um Kenntnis über wichtige Orte zu erhalten. Ergänzend wurden während der Feldforschung Primärquellen gesammelt. Ephemera - Materialen, die nur für eine kurzzeitige Nutzung gedacht sind - wie Poster, Flyer, Eintrittskarten und Prospekte, wurden ebenfalls als Datengrundlage herangezogen. Ausserdem wurden Texte auf tamilischen Webpräsenzen eingesehen, auf die ich während des Forschungsprozesses «im Feld» aufmerksam wurde. Da dem Aspekt der materiellen Kultur grosse Bedeutung im Feld zukommt, wurden auch nonverbale Quellen einbezogen und ausgewertet (vgl. Laack 2007, 129 f.).

Durch das Führen von unstrukturierten und halb-standardisierten Experteninterviews ${ }^{38}$ sowie narrativ-biographischen Interviews ${ }^{39}$ konnten wichtige Informationen aus dem Feld erhoben werden (vgl. Flick/von Kardorff/Steinke 2000; Girtler 2001). ${ }^{40}$ Die Namen der Interviewten wurden anonymisiert, um die Personen nach der öffentlichen Zugänglichkeit meiner Daten im Zuge der Veröffentlichung zu schützen. ${ }^{41}$

Zentrales Forschungsinstrument der vorliegenden Studie war die Methode der teilnehmenden Beobachtung (vgl. Girtler 2001). Wichtige Forschungshandlung war dabei das Aufsuchen ${ }^{42}$ derjenigen Orte, an denen

38 Ich gehe mit Gläser/Laudel von einem weiten Experten-Begriff aus. Mit Experten sind Menschen gemeint, die ein spezielles Wissen über soziale Sachverhalte besitzen. Über Priester, Repräsentanten, Funktionsträger der Tempelvereine und Akteure im interreligiösen Dialog hinaus sind dies auch engagierte Tempelbesucher. Ein Experteninterview ist die Methode, dieses Wissen zu erschliessen (vgl. Gläser/Laudel 2004, 10).

39 Themenzentrierte unstrukturierte Interviews wurden mit einer offenen Einstiegsfrage zum religiösen Lebenslauf eröffnet. Diese Frage lautete: «Vielleicht kannst du einfach mal anfangen zu erzählen von deinem religiösen Lebenslauf, angefangen in der Kindheit bis heute. Wie du deine Religion gelebt hast oder was sie für dich bedeutet.» Die Geschichten, die generiert wurden, ergaben Einblicke in die religiösen, durch die Migration geprägten Lebensgeschichten.

40 Hier sei auf die Problematik des «Aufzeichnens» von Interviews verwiesen, was für einige Informanten eine angespannte Situation erzeugen kann. Gerade bei Migrantengruppen, die sich unsicher fühlen, sich in der deutschen Sprache verständlich zu artikulieren, kann dies zu Hemmungen im Erzählen führen. Auf der anderen Seite bietet das Transkribieren und Zitieren von Interviews die Chance, dass die Akteure in ihren eigenen Worten zu Wort kommen.

41 An der Stelle der ersten Erwähnung eines Interviews wird Datum und Ort der Interviewführung genannt und allgemeine Angaben zur Person der/des Interviewten gegeben.

42 Dabei handelte es sich vielfach um den Akt des Auf-Suchens im eigentlichen Sinn. Da viele als Tempel bezeichnete Orte in abgelegenen Gegenden angesiedelt waren, welche nur 
tamilische Hindu-Praxis in der Schweiz ausgeübt wird, sowie die Teilnahme an zentralen Festen und Ritualen.

«In der Beobachtung und Beschreibung gegenwärtiger religiöser Phänomene liegt eine der zentralen Aufgaben religionswissenschaftlicher Forschung, um religiöse Rituale, Verhaltensweisen und Glaubensäusserungen in ihrer gelebten Ausprägung und Vielfalt zu erfassen» (Franke/Maske 2011, 110).

Unter teilnehmender Beobachtung wird «das systematische Erfassen, Festhalten und Deuten sinnlich wahrnehmbaren Verhaltens zum Zeitpunkt seines Geschehens» verstanden (Atteslander 2003, 79). Blickwinkel der Beobachtung sind die Forschungsfragen der jeweiligen Untersuchung mit dem Zweck der Beschreibung und schriftlichen Sichtbarmachung der religiösen Handlungen. «Keine andere Form der Datenerhebung erlaubt den Forschenden einen ähnlich tiefen Einblick in die Alltagsereignisse einer sozialen Gemeinschaft, in die vielfältigen Wertvorstellungen und Interessen der Erforschten sowie in ihren jeweiligen sozialen Kontext» (Franke/Maske 2011, 101). Gerade bei der Untersuchung von gegenwartskulturellen religiösen Phänomenen, die bisher wenig Beachtung gefunden haben, wie es beim religiösen Leben vieler Migrantengruppen der Fall ist, ist das Instrument der teilnehmenden Beobachtung zentral.

Als Variante der Methode wurde grösstenteils die teilnehmende, unstrukturierte und offene Beobachtung gewählt: Durch die Teilnahme an Festen und Ritualen konnte auch die sinnliche Ebene der Handlungen erlebt und potenziell rekonstruiert werden. Die nicht-sprachlichen Ebenen, Aspekte der Visualität und Materialität konnten durch die teilnehmende Beobachtung erhoben werden und ermöglichen so einen umfassenderen Einblick ins Feld. Oftmals beinhaltete der Prozess der teilnehmenden Beobachtung in erster Linie das reine Mitmachen und Beobachten ohne Nachfragen bei Anwesenden nach dem Sinn oder Hintergrund des Beobachteten. Wie Ron Geaves in seinen Untersuchungen feststellt, ist für die Anwesenden oftmals das Ausführen der Handlungen der zentrale Aspekt:

The search for meaning by the fieldworker can be a forlorn pursuit as often participants simply have nothing further to say about a particular religious activity. I was often met with a shrug of the shoulders or the response, "it has always been done that way". (Geaves 2007, 12) (3 $^{4}$

schwer mit öffentlichen Verkehrsmitteln zu erreichen sind, mussten diese zunächst von der Forscherin «entdeckt» werden. Somit war der erste Schritt der teilnehmenden Beobachtung das Sich-Aufmachen zum Ort der Handlungen, die dann beobachtet werden.

43 Auch Schalk (2003b, 379) berichtet davon, dass das religiöse Hintergrundwissen zu Themen wie Soteriologie und Religionsgeschichte unter tamilischen Hindus im Stockholmer Tempel 
Im Laufe meiner Feldforschung habe ich während meiner Beobachtung in unterschiedlichem Grad an den Aktivitäten im Tempel teilgenommen. In manchen Situationen wählte ich aufgrund einer Unkenntnis der Ritualabläufe oder zum Zweck des genaueren Beobachtens nicht-teilnehmende Beobachtung.

Gerade im Kontext einer marginalisierten Migrantengruppe und der angesichts des Konfliktes in Sri Lanka vorhandenen Verunsicherung über die Motivation und politischen Verstrickungen mancher Akteure im Feld, ist es aus forschungsethischer Sicht angebracht, sich im Feldforschungsprozess als Forschende erkennen zu geben und das Ziel der Beobachtungen, nämlich das Verfassen einer wissenschaftlichen Studie, offen zu legen. Auch erlaubte der offene Zugang zu fotografieren und das gewonnene Bildmaterial in der Studie zu nutzen. An manchen Anlässen war es aus Gründen der Praktikabilität nicht möglich, «offen» zu beobachten, da es aufgrund der Grösse der Anlässe nicht realisierbar war, alle Anwesenden über meinen Status aufzuklären.

Der Vorteil einer unstrukturierten Form der Beobachtung besteht darin, dass man ohne einen vorgegebenen Analysekontext in das Feld eintritt (vgl. Greschat 1988, 62 ff.). So konnten die für die Fragestellung der Studie relevanten Aspekte im Feld erst «gefunden» werden. Es hat sich beispielsweise erst im Forschungsprozess gezeigt, dass die Fastenregeln zur Verehrung des Gottes Aiyappan und die damit verbundene Wallfahrt als ein gegendertes Ritual (vgl. Osella/Osella 2003), ein Ritualkomplex, welcher nur für Männer zugelassen ist, eine zunehmend wichtige Rolle innerhalb der Praxis tamilischer Hindus in der Schweiz spielen (vgl. Abschnitt IV 6.2).

Feldforschung selbst besteht immer schon aus dem Akt des sich von einem Ort zum anderen Ort Bewegens und stellt einen Prozess, eine Reise, dar. Die Dimension der Lokalisierung ist dem Feldforschungsprozess immer schon inhärent:

Fieldwork reveals that a self-conscious shifting of social and geographical location can be an extraordinary valuable methodology for understanding social and cultural life, both through the discovery of phenomena that would otherwise remain invisible and through the acquisition of new perspectives on things we thought we already understood. (Gupta/Ferguson 2008, 97)

Zu Beginn der Feldforschung stellte sich die Frage des Feldzugangs. Dieser erfolgte über die Orte der religiösen Praxis, in erster Linie die Tempel-

relativ gering ist: "Caivacittanta soteriology is not studied explicitly in Stockholm by Tamil Caivas, and probably only very few are able to give a summary of it and delimit it from other soteriological schools." 
räume. Bis auf die Tempelfeste war es in der Regel so, dass ich die einzige Nicht-Tamilin bzw. Nicht-Südasiatin war, was bereits durch meine Hautfarbe wie auch durch meine Kleidung ${ }^{44}$ sichtbar wurde. Der Schritt des Überschreitens der Schwelle des Tempels war immer auch der Übergang in eine mir durch meine Sozialisation nicht vertraute Sphäre. Akhil Gupta und James Ferguson $(2008,90)$ beschreiben «Feldarbeit» in diesem Sinne auch als "a spatial journey into Otherness". Der Übergang von einer schweizerisch geprägten Sphäre in eine tamilische Öffentlichkeit war meist eine Kontrasterfahrung, die es im Vorfeld zu reflektieren galt. ${ }^{45}$ So schreibt Gert Selle (1993, 61): «Mit dem Zögern beim Betreten eines fremden Raumes beginnt die Orientierungsarbeit; was dabei erspürt oder gesehen wird, ist nicht nur das Spürbare und Sichtbare.» Intensive teilnehmende Beobachtung ist somit eine Tätigkeit, welche den/die Forschende/n auf unterschiedlichen Ebenen herausfordert. Diese Herausforderungen galt es im Forschungsprozesses zu integrieren.

Meine Präsenz hatte auch Auswirkungen auf den Raum und die Handlungen in diesem. Der Tempel war als zentrale Kontaktzone der Feldforschung ein Ort der Interaktion zwischen mir als Forscherin und tamilischen Akteurinnen und Akteuren. Es kam vor, dass die zumeist männlichen Verantwortlichen im Tempel eine jüngere Tamilin beauftragt haben, mir den Tempel und die Handlungen, die in diesem passieren, zu erklären. Ich habe mich während der Rituale in den Bereich der Frauen begeben und auch aus Respekt vor der Gruppe versucht, die geschlechtsspezifischen Vorschriften, welche für den Tempelbesuch vorgesehen sind, zu beachten. ${ }^{46}$

44 Der Aspekt der Kleidung der Forschenden beeinflusste auch den empirischen Forschungsprozess. Da ich während der teilnehmenden Beobachtung nach westlichen modischen Standards gekleidet war, war die Kleidung auch immer ein Unterscheidungsmerkmal zwischen Forscherin und den Hindu-Akteuren. Gleichzeitig habe ich meinen Kleidungsstil den Normen für einen Tempelbesuch angepasst und darauf geachtet, dass die Kleidung dem Anlass angemessen war.

45 Auch Edith Franke und Verena Maske $(2011,124)$ sowie Martin Baumann $(1998,22$ f.) beschreiben das Unbehagen, das es zu überwinden gilt, wenn der/die Forschende sich als Frem$\mathrm{de} / \mathrm{r}$ in eine unbekannte Situation begibt.

46 Eine zentrale geschlechtsspezifische Vorschrift für den Besuch von Hindu-Tempeln ist das Verbot des Besuches der Tempel während der Menstruation. Im Handzettel der Gruppe Saivanerikoodam, welcher beim Tag der offenen Tür am 10.06.2008 im Katirvēlāyuta Cuvāmi Tempel in St. Margrethen verteilt wurde, war zu lesen: «Um besonderes Verständnis wird dafür gebeten, dass Frauen während ihrer Periode aus religiösen Gründen den Tempel nicht betreten dürfen.» Ausnahme bildete der Reform-Tempel Melmaruvathur Adiparasakthi Amma Tempel der Aum Sakthi-Bewegung (vgl. Kap. IV 4.4), den Frauen auch während ihrer Menstruation betreten dürfen und an den Ritualen teilnehmen können. 
Während ich mich in der «Frauenecke» aufhielt, kam es meist zu kurzen Gesprächen. Zahlreiche informelle Gespräche gaben einen Einblick in die religiöse Lebenswelt der Migrantinnen, sofern es Sprachbarrieren zuliessen. Da viele Tamilen in einer Gruppe, meist mit Familienangehörigen, und selten alleine in den Tempel gehen, habe ich es so wahrgenommen, dass ich als Nicht-Tamilin, welche in keinem sichtbaren Beziehungszusammenhang alleine die Tempelrituale und -feste besucht, besonders aus dem Rahmen fiel, was oft den Feldzugang erschwerte. Als ich mit einem Kollegen und dessen zweijähriger Tochter ein Tempelfest aufsuchte, war der Zugang signifikant leichter. Man sprach mich häufiger an, interagierte mit dem Kind und bezog mich mehr ein. Die Aussenwahrnehmung, dass man in einer Gruppe, als «Familie», das Tempelfest besucht, war vertrauensfördernd und führte dazu, dass ich, meinem Empfinden nach, offener empfangen wurde.

Felddaten zu erheben, stellt immer einen gemeinsamen und längerfristig angelegten Prozess dar. Dabei wurde versucht, einen Zwischenweg zwischen aktiver Teilnahme und aussenstehender, distanzierter Beobachtung zu gehen (vgl. Franke/Maske 2011, 125).

Zumeist besteht Feldforschung aus zwei unterschiedlichen, sich jedoch beeinflussenden Formen des Schreibens: Zum einen die Niederschrift der Feldnotizen, welche direkt nach oder während der Feldarbeit angefertigt werden, und zum anderen das wissenschaftliche Schreiben nach der Auswertung der Notizen. Unmittelbar nach der Feldforschung habe ich das Beobachtete in einem Gedächtnisprotokoll verschriftlicht. In einem «Schreiben ohne Hemmungen» (Franke/Maske 2011, 113) wurde versucht all das Beobachtete, so genau wie möglich, in Worten festzuhalten. ${ }^{47}$

47 Die Auswertung der Feldnotizen erfolgte durch verschiedene Kodiertechniken (vgl. Franke/Maske 2011, 115) und basiert auf dem Ansatz der grounded theory («gegenstandsverankerte Theoriebildung», vgl. Corbin/Strauss 1990). Diese systematische Auswertung von Daten hat die Generierung einer realitätsnahen Theorie und neuer wissenschaftlicher Ansätze zum Ziel. Grounded theory bezeichnet dabei eine Reihe von sich ergänzenden Verfahren, die darauf abzielen, Hypothesen in einem zirkulären und rückkoppelnden Prozess aufzustellen, um den empirischen Gegebenheiten gerecht zu werden. Nach einer ersten Auswertung wurden Thesen aufgestellt, die auf die weiteren Beobachtungen, die dann strukturiert vorgenommen wurden, rückwirkten. Edith Franke und Verena Maske $(2011,115)$ konstatieren abschliessend in ihren Überlegungen zum Umgang mit den in der Feldforschung erhobenen Daten: «Insgesamt besteht eine relative Regellosigkeit in der konkreten Auswertungsarbeit, die sich deshalb dem Vorwurf des Impressionistischen ausgesetzt sieht. Es besteht ausserdem kein Konsens darüber, wie Daten, die mittels verschiedener methodischer Herangehensweisen erhoben wurden, aufeinander bezogen werden sollten.» 
Im Folgenden wird ein Überblick über den Forschungsstand zu tamilischen Hindus gegeben und über die Literatur, die den Analysen zu dieser Arbeit zugrunde liegt.

\section{Forschungsstand zu tamilischen Hindus in der Schweiz und anderen Diaspora-Ländern}

Die Analyse des religiösen Lebens sri-lankisch-stämmiger Hindus in der Diaspora ist bisher ein unterrepräsentiertes Feld innerhalb der Untersuchungen $\mathrm{zu}$ «Hinduismus» ausserhalb Südasiens. Publikationen, die sich ausschliesslich diesem Thema widmen, bilden die Ausnahme ${ }^{48}$; dazu gehören die Monographie Ritualizing on the Boundaries: Continuity and Innovation in the Tamil Diaspora von Fred W. Clothey (2006) ${ }^{49}$ und der Sammelband Tempel und Tamilen in zweiter Heimat. Hindus aus Sri Lanka im deutschsprachigen und skandinavischen Raum (Baumann/Luchesi/Wilke 2003). Auch in Grossbritannien als ehemaliger Kolonialmacht Sri Lankas wurden bisher wenige Forschungsarbeiten verfasst, welche Aspekte dieser Gruppe von Hindu-Immigranten thematisieren. So schreibt Ron Geaves, der 2007 mit Saivism in the Diaspora eine umfassende Studie zur Verehrung Civans ausserhalb Südasiens vorgelegt hat:

The vast majority of Tamil and Punjabi (both Hindu and Sikh) migrants have rural origins but the impact of this on the development of British Hinduism remains largely understudied and unknown. (Geaves 2007, 82)

Im britischen Kontext stellen die Forschungen von Demelza Jones (2016) und der Anthropologin Ann R. David eine Ausnahme dar. Letztere untersucht auf der Basis von performativitätstheoretischen Ansätzen sri-lankisch tamilische Hindu-Praxis in Grossbritannien (David 2008, 2009, 2010). Auch zu hindu-tamilischem Leben in Kanada, dem Land, in dem die meisten Exil-Tamilen aus Sri Lanka leben, liegen bisher wenige Studien vor, welche das religiöse Leben der Immigrantengruppe untersuchen. ${ }^{50}$

48 Im Folgenden wird die Literaturgrundlage zur Migrantengruppe und dann zur Referenzgruppe der tamilischen Hindus in anderen Diaspora-Ländern zusammengestellt. Literaturangaben zu den Analysekategorien werden dann erwähnt, wenn diese im Laufe der Arbeit thematisiert werden.

49 Die Studie thematisiert jedoch nicht ausschliesslich religiöse Praktiken von Tamilen aus Sri Lanka, sondern auch aus Indien.

50 Zur Literatur zur tamilischen Migrantengruppe in Kanada vgl. unter anderem Amarasingam 2008, Zulfika 2013. 


\subsection{Literatur zu tamilischen Migrierten in der Schweiz}

Eine Folge der Eskalation des Bürgerkrieges in Sri Lanka war die Emigration vieler Tamilinnen und Tamilen in unterschiedlichste Länder. ${ }^{51}$ Als in den 1980er Jahren auch in der Schweiz die Zahl tamilischer Asylsuchender anstieg, entstanden die ersten soziologisch oder sozial-anthropologisch ausgerichteten Studien zu tamilischen Migrierten in der Schweiz. 1984 initiierten die Schweizer Hilfswerke Brot für Brüder, Caritas Schweiz, Fastenopfer, das Hilfswerk der evangelischen Kirchen Schweiz (HEKS), Helvetas und Swissaid gemeinsam die Projektgruppe «Tamilen» und gaben am Seminar für Ethnologie der Universität Bern eine Untersuchung zu den tamilischen Neuankömmlingen in Auftrag - damit entstand die erste wissenschaftliche Untersuchung zu tamilischem Leben in der Schweiz (vgl. Wicker et al. 1984) sowie die Publikation Auf der Suche nach der Zukunft: Tamilische Flüchtlinge aus Sri Lanka - Analyse und Handlungsvorschläge (Projektgruppe «Tamilen» 1984).

Die bislang umfangreichste empirische Studie zur tamilischen Flüchtlingssituation in der Schweiz wurde vom politischen Anthropologen Christopher McDowell im Rahmen seiner 1995 eingereichten Dissertation an der Universität Zürich verfasst. 1996 erschien diese Monographie, welche die Hintergründe der Emigration und die rechtlichen Inkorporationsbedingungen, wie die nationalstaatliche Asylpolitik, von tamilischen Asylsuchenden in der Schweiz zwischen 1983 und 1991 untersuchte, unter dem Titel $A$ Tamil Asylum Diaspora - Sri Lankan Migration, Settlement and Politics in Switzerland (McDowell 1996). Es folgten Publikationen zur Migrationssituation tamilischer Geflüchteter und zu ihrem Verhältnis zum Herkunftsland und ihrer potenziellen Rückkehrbereitschaft (Meier-Mesquita 1992, 1993). Martin Stürzinger, der Mitarbeiter und Beauftragter für den Friedensprozess der Schweizer Botschaft in Colombo war, übernahm 2002 eine Auftragsforschung für das Berghof Forschungszentrum für konstruktive Konfliktbearbeitung in Berlin, in welcher er die sri-lankische Diaspora in der Schweiz und die Etablierung von eigenen Institutionen sri-lankischer Flüchtlinge behandelt. In dieser Schrift thematisiert er auch das politisch brisante Thema des Einflusses der LTTE auf tamilische Migrierte in der Schweiz (Stürzinger 2002). Stürzinger verfasste auch verschiedene öffent-

51 Es liegt umfassende Literatur zur Entstehung des Konflikts in Sri Lanka und zum Hintergrund der Migrationsbewegungen von Tamilen in unterschiedlichste Länder vor. Auf Literatur zum sri-lankischen Konflikt und die Problematik dieser Bürgerkriegsgeschichtsschreibung geht Abschnitt III 2 ein. 
lich zugängliche Gutachten zur Situation tamilischer Flüchtlinge (z.B. für die Schweizer Flüchtlingshilfe im Jahr 2000; vgl. Stürzinger 2000).

Wichtige Sekundärliteratur für die vorliegende Dissertation sind die Publikationen des Nationalfonds-Forschungsprojektes Social Change among Sri Lankan Tamil Refugees in Switzerland, welches von 2001 bis 2003 am Institut für Ethnologie der Universität Bern durchgeführt wurde. Die Forschungsprojekte thematisierten soziale Netzwerke, Werteorientierung, Umgang mit Krankheit, die Situation jugendlicher Migrierter und die Reaktionen von Tamilinnen und Tamilen auf die Kultur der Schweizer Mehrheitsbevölkerung. Die Ergebnisse der Studien zeigen insbesondere die Heterogenität in verschiedenen Bereichen innerhalb der untersuchten Gruppe auf. Auch die soziale Schichtung, welche unter anderem ihre Ursache in Kastenvorstellungen hat, wurde thematisiert (Lüthi 2004, 2005). Die Projektmitarbeiterin Johanna Vögeli $(2003,2004,2005)$ untersuchte in ihren Beiträgen eingehend Geschlechterbeziehungen innerhalb der tamilischen Diaspora.

Der von Brigitte Luchesi, Annette Wilke und Martin Baumann herausgegebene Band Tempel und Tamilen in zweiter Heimat (Baumann/Luchesi/ Wilke 2003) beinhaltet auch drei Artikel, welche detailliert die Situation von tamilischen Hindus in der Schweiz darstellen: Christoph Peter Baumann (2003) gibt einen Überblick zu tamilischen Hindus und Tempeln in der Schweiz und beschreibt die Geschichte des Vināyakar-Tempels in Basel. Damaris Lüthi (2003) fokussiert auf religiöse Praktiken von tamilischen Flüchtlingen in Bern. Dabei untersuchte sie sowohl die Praktiken hinduistischer als auch christlicher tamilischer Migrierter. Besondere Beachtung finden Praktiken im privaten Wohnbereich wie auch wichtige Übergangsrituale. Wichtig in Hinblick auf migrationsbedingte Dynamiken von Geschlechterrollen ist der Beitrag von Johanna Vögeli (2003).

Damaris Lüthi (2007) und Martin Baumann (2009b, 2010) haben in den Folgejahren weitere Artikel zum religiösen Leben tamilischer Migrierter im Schweizer Kontext veröffentlicht. Im Rahmen eines von Knut A. Jacobsen und Selva J. Raj (2008) herausgegebenen Sammelbandes zur «südasiatischen christlichen Diaspora» thematisiert Lüthi religiöses Leben christlicher Tamilen in Bern (2008). Martin Baumann hat ausgehend von der Theorie des civic social capital Institutionalisierungsprozesse von tamilischen Hindus in der Schweiz analysiert (Baumann 2010a). Kap. IV 5 der vorliegenden Studie nimmt Baumanns Ausführungen zum Prozess der templeisation (2009b) zur Grundlage. Auf Basis der Analysen von Vasudha Narayanan (2006), Professorin für Religionswissenschaft an der University of Florida, beinhaltet die These die Verschiebung von religiöser Autorität und Authentizität fort von den Frauen zu Hause hin zum männlichen Ritualspezialisten 
und der Lokalität des Tempels. Der wissenschaftliche Neologismus templeisation bringt damit die wachsende Bedeutung von Hindu-Tempeln in der Diaspora zum Ausdruck.

Aktuelle Veröffentlichungen zu hindu-tamilischem Leben in der Schweiz sind unter anderem die Publikationen von Katharina Limacher (z. B. Limacher/Rückamp 2016), die Dissertation von Monika Müller Migration und Religion. Junge hinduistische und muslimische Männer in der Schweiz (2013) und meine Publikationen (Eulberg 2013, 2014, 2019).

2007 erschien eine erste offizielle Studie zur Situation der sri-lankischen Diaspora in der Schweiz, welche vom Schweizer Bundesamt für Migration (BFM) in Auftrag gegeben wurde. Die Autorinnen Joëlle Moret, Denise Efionayi und Fabienne Stants stellen darin umfassende Informationen zum sozialen Leben in der Schweiz lebender Tamilen und Singhalesen zusammen. ${ }^{52}$ Statistisches Informationsmaterial findet sich in den Angaben des Bundesamtes für Statistik und den «Ausländer- und Asylstatistiken», herausgegeben vom Bundesamt für Migration BFM. 2004 gab Claude Bovay (in Zusammenarbeit mit Raphaël Broquet) im Auftrag des Schweizerischen Bundesamts für Statistik Daten zur Religionslandschaft in der Schweiz auf der Grundlage der Eidgenössischen Volkszählung des Jahres 2000 heraus. Diese Veröffentlichung liefert im Folgenden die Grundlage zu den Zahlenangaben zur Hindu-Bevölkerung in der Schweiz. ${ }^{53}$

Neben diesen gedruckten Veröffentlichungen finden sich Informationssammlungen zu hindu-tamilischem Leben im Internet. Veröffentlichungen auf den Webpräsenzen des Vereins INFOREL (www.inforel.ch) oder Religionen Schweiz (www.religionenschweiz.ch) des Religionswissenschaftlichen Seminars der Universität Luzern liefern öffentlich zugängliche Berichte zu unterschiedlichen religiösen Gruppen.

Neben der wissenschaftlichen Literatur zur Referenzgruppe wurden Beiträge in Massenmedien herangezogen, um an verschiedenen Diskursen zu tamilischer Hindu-Praxis zu partizipieren. Schweizer Medienbericht-

52 Kurz nach Erscheinen des Buches kritisierten Vertreter des Swiss Tamil Forums in einem informellen Gespräch mir gegenüber, dass darin homogenisierend von sri-lankischen Staatsbürgern ausgegangen und keine Unterscheidung zwischen tamilischer und singhalesischer Diaspora gemacht werde. Da sie einen eigenen Staat anstreben und den sri-lankischen Staat als ihnen feindlich gegenübergestellt ansehen, wehren sie sich gegen die Subsumierung unter sri-lankische Diaspora. Diese Kritik wurde nach Angaben des Forums vor Vertretern des Bundesamtes vorgetragen.

53 Es ist zu beachten, dass in der korrespondierenden Datenerhebung der Studie nur nach der Mitgliedschaft in einer hinduistischen Vereinigung gefragt wurde. Viele meiner Informanten bezeichnen sich zwar als Hindus und besuchen regelmässig die Tempel, aber sind keine Mitglieder in einer organisierten Vereinigung. 
erstattungen über tamilische Feste oder Tempelbauprojekte spiegeln einen Blick der Mehrheitsbevölkerung auf das religiöse Leben dieser Immigrantengruppe wider. Daneben präsentieren eigene Berichterstattungen tamilischer Organisationen eine gruppeninterne Perspektive, die innertamilische Diskurse darstellen, nicht aber als repräsentative Meinung aller Exil-Tamilen gelten können.

Zur Situation tamilischer Migrierter in der Schweiz liegen auch visuelle Dokumentationen vor. Vera Markus hat in ihrem Bildband In der Heimat ihrer Kinder eindrückliche Schwarzweissfotografien aus dem alltäglichen Leben tamilischer Migrantinnen und Migranten in der Schweiz veröffentlicht (Markus 2005). Aus dem Bereich des Dokumentarfilms sei beispielsweise der Film Sind wir wirklich schuldig? Kleinklasse aus dem Jahr 2005 (herausgegeben von Thema Visual Media Switzerland) genannt, der aus der Perspektive eines tamilischen Mädchens anschaulich die Schwierigkeiten aufzeigt, denen eine tamilische Migrantenfamilie in der Schweiz ausgesetzt ist. ${ }^{54}$

\subsection{Tamilische Hindus in anderen Diaspora-Ländern}

Neben der Literaturlage zu tamilischen Migrierten in der Schweiz wurden auch Studien zu tamilischen Hindus in anderen Diaspora-Ländern herangezogen. Das religiöse Leben tamilischer Hindus im Exil wurde in den letzten Jahren zunehmend von Forschenden in anderen Diaspora-Ländern untersucht. Diese Ergebnisse wurden für die vorliegende Studie herangezogen, um zum einen Charakteristika und spezifische Merkmale tamilischen Lebens unter den Bedingungen des Nationalstaates Schweiz herauszuarbeiten und zum anderen Gemeinsamkeiten tamilisch-hinduistischen Lebens innerhalb einer transnationalen Diaspora aufzuzeigen.

Aus religionswissenschaftlicher Perspektive wurden die tamilische Minderheit und ihr religiöses Leben in Tempel und Tamilen in zweiter Heimat (Baumann/Luchesi/Wilke 2003) umfassend thematisiert. Der Sammelband untersuchte tamilische Hindu-Traditionen unter den Bedingungen von Migration in Deutschland, Skandinavien und der Schweiz. Darin behandelte Luchesi besonders die Wege aus der Unsichtbarkeit (Luchesi 2003a) als Formen der öffentlichen Präsentation. Sie geht auch auf die Tempelausgestaltung und Einweihungsrituale für den ersten bisher im südasia-

54 Ausserdem ist der Dokumentarfilm «Wanakam» von Thomas Isler (Zürich, 2004) zu nennen, der die prekäre Situation tamilischer Migrierter ohne sicheren Aufenthaltsstatus zeigt. 
tischen Stil fertig gestellten Tempel in Kontinentaleuropa, den Śrì Kāmākși Ampāl Ālayam im westfälischen Hamm-Uentrop, ein (Luchesi 2003b). Dessen Etablierungsprozess und seine Bedeutung im religiösen Feld sind zentrale Themen des Sammelbandes. Für die vorliegende Studie waren diese Analysen sehr instruktiv, da in der Schweiz, in Trimbach bei Olten, zur Zeit der Feldforschung ein ähnliches Tempelbauprojekt durchgeführt wurde (vgl. Baumann/Tunger-Zanetti 2014).

Darüber hinaus ist der Hammer Tempel ein wichtiger Referenzort für tamilische Hindus in Europa und wird auch von in der Schweiz lebenden Migrierten besucht. Geschichte und Ritualpraxis des Tempels, seine Organisation und die Rolle des Hauptpriesters als Initiator des Tempelbaus wird im Sammelbandbeitrag von Martin Baumann (2003d) dargestellt. Die hindutamilische Tempellandschaft in Deutschland wurde u.a. von Back (2007) und Luchesi (2004b) beschrieben.

Besonders aus den skandinavischen Ländern liegen verhältnismässig viele Studien zur Religiosität von tamilischen Migrantinnen und Migranten vor. Für Norwegen sind besonders die Forschungen von Øivind Fuglerud $(1999,2001,2011)$ und Knut Axel Jacobsen $(2003,2004,2006,2008,2009) \mathrm{zu}$ nennen. ${ }^{55}$ Marianne Fibiger $(2003,2011,2012)$ nimmt in ihren Studien die Situation tamilischer Hindus in Dänemark in den Blick. Der tamilische Tempel im schwedischen Stockholm wird von Peter Schalk (2003b, 2004a) detailliert beschrieben. Vom selben Autor sind die Untersuchungen zum māvirrar nāl der LTTE (Schalk 2003b) und seine Publikationen zur Ideologie der LTTE (Schalk 2007b) zu nennen. Neben diesen Publikationen sei auf die Veröffentlichungen sri-lankisch tamilischstämmiger Autoren wie den in Grossbritannien lebenden Dhananjayan Sriskandarajah (2004) und R. Cheran (2003) aus Kanada hingewiesen, welche kenntnisreich die tamilische Diaspora thematisieren. ${ }^{56}$

55 Norwegen hat einen besonderen Stellenwert innerhalb der europäischen Diaspora der Tamilen. Der norwegische Staat unterhielt während des Bürgerkriegs intensive diplomatische Beziehungen zu Sri Lanka und war früh in der Entwicklungshilfe für Sri Lanka und dann im Friedensprozess engagiert. Die ersten tamilischen Migranten, die nach Norwegen kamen, waren christliche Arbeitsmigranten. Daher ist der Prozentsatz christlicher Tamilen innerhalb der norwegischen Diaspora besonders gross (vgl. Jacobsen 2003). Die Residenzländer Schweiz und Norwegen verbindet eine Besonderheit innerhalb der tamilischen Diaspora in Europa: Sie waren im Untersuchungszeitraum die einzigen europäischen Diaspora-Länder, in denen die LTTE nicht als Terrororganisation verboten war.

56 Einen Überblick über aktuelle Studien zu Tamilen in Europa ist auf der Homepage des Tamils in Europe Research Network zu finden (https://tamilresearchnetworkeurope.wordpress. com). 
Im Rückblick auf den hier dargestellten Forschungsstand lässt sich konstatieren, dass eine explizit religionswissenschaftlich ausgerichtete Studie, welche einen vertieften Einblick in tamilische Hindu-Traditionen in der Schweiz liefert und dynamische Prozesse innerhalb der religiösen Praxis der Diaspora-Akteure untersucht, bisher fehlt. Einen Versuch, diese Lücke zu schliessen, wird die vorliegende Arbeit im Folgenden machen. 



\title{
Kapitel II \\ Die sri-lankisch tamilische Diaspora als Aspekt der Lokalisierungsdynamiken von Hindu-Praxis
}

\author{
The Sri Lankan Tamil diaspora is a complex social \\ formation that has been shaped by premigratory \\ experiences, the process of migration and dispersal, \\ the process of adjustment to host societies, the \\ growth of Tamil nationalism, and the hegemony \\ of the LTTE as the dominant Tamil political force.
}

(Sriskandarajah 2004, 500)

\begin{abstract}
Migrationsprozesse und die Bedingungen der Ansiedlung im Residenzland sind Faktoren, welche Unterschiede in der Eingliederung verschiedener Immigrantengruppen in unterschiedlichen nationalen Kontexten bewirken können. Dabei stellen zunächst die Gründe und die Art der Immigration wichtige Weichen (Vertovec 2000, 21). Ob eine Migration als freiwillig oder gezwungen beschrieben wird, ob sie zeitlich begrenzt oder auf unbestimmte Zeit angelegt ist, kann Unterschiede in den Strategien religiöser Akteure in der Diaspora bewirken und die Prozesse der Transmission religiöser Traditionen ins neue Umfeld beeinflussen.

Die sri-lankisch tamilische Diaspora in der Schweiz ist der Rahmen dieser religionswissenschaftlichen Untersuchung zu tamilischen HinduTraditionen. Die religiösen Akteure der Untersuchungsgruppe sind mehrheitlich als Asylsuchende aus Sri Lanka in die Schweiz gekommen und somit auch Akteure der sri-lankisch tamilischen Diaspora. Die Dynamiken von Hindu-Praktiken tamilischer Migrantinnen und Migranten, die Prozesse ihrer Lokalisierung in der Schweiz und die öffentlichen Ausdrucksformen dieser Praktiken können nicht getrennt vom sozialen Lebensumfeld tamilischer Migrierter betrachtet werden.
\end{abstract}


Die vorliegende Studie ist im Bereich der Diaspora-Studien anzusiedeln: Diaspora wird dabei als eine wissenschaftliche Analysekategorie verstanden. Daher wird die Darstellung des Profils der sri-lankisch tamilischen Diaspora in der Schweiz, als eine Kontextbedingung der untersuchten Hindu-Praktiken, im Folgenden in theoretische Vorannahmen zum Begriff der Diaspora eingebunden.

\section{Die Lokalisierung in der transnationalen Sphäre: Diaspora als Analysekategorie}

Der Studie liegt der Begriff der Diaspora als zentrale wissenschaftliche Analysekategorie zugrunde (vgl. Baumann 2000a, 325 ff.; Wahlbeck 2002). Im Folgenden soll ein kurzer Überblick über die Genese des Begriffs gegeben, die Übertragbarkeit des Begriffs auf die tamilischen Migrantengruppen in der Schweiz verdeutlicht und das eigene Verständnis des Terminus Diaspora offengelegt werden.

Eine Vielzahl von Studien zum Diaspora-Begriff sind in den letzten Jahren erschienen (vgl. z. B. Sahoo/Maharaj 2007). ${ }^{57}$ Dessen Definitionen divergieren zum Teil sehr. Mehrfach ist auf die Gefahr der Verwässerung und Redundanz des Begriffes als wissenschaftliches Modewort hingewiesen worden. Innerhalb des «Diaspora-Booms» wurde Diaspora in einer sehr breiten und populären Verwendung des Konzepts zu einem Synonym für verschiedenste Formen von Migrantengruppen: ${ }^{58}$ "The word diaspora is used today to describe any community that has emigrated whose numbers make it visible in the host community" (Marienstras 1989, 125). Es wird dieser religionswissenschaftlichen Untersuchung eine Arbeitsdefinition von Diaspora zugrunde gelegt, auf welche die Analyse des Materials aufgebaut wird und welche Anknüpfungspunkte für transkulturelle Vergleiche bietet.

Der Begriff der Diaspora ist der jüdischen Religionsgeschichte entlehnt und erfuhr seit seiner Entstehung verschiedene Neuinterpretationen in unterschiedlichen Kontexten: Der griechische Begriff diaspora ( $\delta \iota \alpha \sigma \mathrm{o} \rho \alpha$ )

57 An dieser Stelle kann kein Gesamtüberblick über die vorliegenden Diaspora-Studien gegeben werden. Es sind nur für diese Studie unmittelbar relevante Werke genannt.

58 Cohen bringt seine Kritik an einem inflationären Gebrauch des Begriffes wie folgt zum Ausdruck: "Diaspora is one of the buzz words of the post modern age; it has the virtue of sounding exotic while rolling sibilantly off the English tongue; it whispers the promise of hidden depths of meaning yet assimilates them to shape of a wave breaking gently on native shores" (Cohen 1998, 3). 
kann mit «Zerstreuung/Verstreuung» übersetzt werden (vgl. van Unnik 1993; Baumann 2000a; 2007a). Abgeleitet ist er vom negativ konnotierten Verb diaspeírein (griechisch für «ausstreuen, sich zerstreuen, getrennt werden»), aus dem sich später das Substantiv diaspora entwickelte. Die älteste bekannte Verwendung des Wortes findet sich in der griechischen Übersetzung des Alten Testamentes (Deuteronomium 28, $64 \mathrm{ff}$.) und bezeichnet jüdisches Leben in fremdreligiöser Umwelt, ausserhalb von Eretz Israel. Dabei beschreibt der Neologismus diaspora ein dreifaches Begriffsfeld: eine von Gott als Strafe erwirkte Zerstreuung, die Mahnung zu Reue und Busse und die soteriologische Aussicht auf Rückkehr ins Heimatland bei erneuter Befolgung der Gebote JHWHs. Willem Cornells van Unnik konstatiert

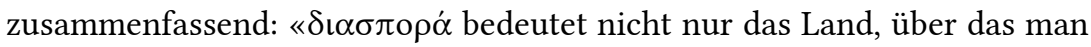
zerstreut ist, sondern auch die Tat des Zerstreuens sowie die Leute, die zerstreut sind» (van Unnik 1993, 149). ${ }^{59}$

Bereits in der christlichen Eschatologie wurde der Diaspora-Begriff dem jüdischen Kontext enthoben und einer Re-Interpretation unterzogen: In diesem Kontext wurde Diaspora als Leben in der diesseitigen Welt im Gegensatz zur wahren Heimat im Himmelreich verstanden (vgl. Baumann 2006a, 6). Mit der Ausbreitung des Christentums verlor diese Interpretation jedoch wieder an Popularität. Nach der Reformation tauchte der DiasporaBegriff erneut auf und meinte das Leben in einer von einer anderen Konfession dominierten Gegend (vgl. Baumann 2003a, $60 \mathrm{ff}$.). Bis in die 1960er Jahre blieb der Diaspora-Begriff ausschliesslich auf jüdisch-christliche Kontexte beschränkt. Durch die African Studies ${ }^{60}$ und kulturwissenschaftliche Ansätze erfuhr er eine Begriffserweiterung, welche sich auf unterschiedlichste - kulturelle und religiöse - Kontexte bezog. Herauszustellen gilt, dass die semantische Erweiterung des Diaspora-Begriffs diesen nun nicht mehr zwangsläufig religiös konnotiert.

Vielfach wurde in der Analyse verschiedener Diaspora-Situationen die jüdische Diaspora als Prototyp des Phänomens angesehen. In Entsprechung zu Cliffords Begriffsbestimmung basiert diese Studie auf der Annahme, dass das Beispiel der jüdischen Diaspora kein definitorischer Prototyp, sondern lediglich ein «nicht-normativer Ausgangspunkt» zur Bestimmung von Diaspora ist (vgl. Clifford 1994, 306). Im Folgenden wird die Genese des Begriffs, begonnen bei der Neuinterpretation in den frühen 1990er Jahren

59 Dieses dreifache Begriffsfeld findet sich auch im modernen Diaspora-Begriff wieder. Auch hier meint Diaspora sowohl die Migrantengruppe, das Residenzland wie auch den Akt des Zerstreuens.

601966 schlug George Shepperson in seinem Artikel "The African Abroad or the African Diaspora” den Begriff African Diaspora vor (vgl. Baumann 2000a, 336). 
bis zu sogenannten postmodernen Definitionen, anhand der sri-lankisch tamilischen Diaspora nachgezeichnet und damit zugleich das Profil derselben skizziert.

\subsection{Die sri-lankisch tamilische Diaspora: Einordnung in gängige Diaspora-Klassifikationen}

Ein zentraler Terminus in dieser Studie ist der Begriff der tamilischen Diaspora, welcher sich in der wissenschaftlichen Literatur bereits etabliert hat (z. B. McDowell 1996; Fuglerud 1999, 2001; Sriskandarajah 2004; Wayland 2004; Clothey 2006; Somalingam 2017) und im Folgenden nicht als religiös konnotiert verstanden wird. Auf das Themenfeld Diaspora und Religion wird in Kap. II 2 - zusammen mit Anmerkungen zum Terminus Hindu-Diaspora - eingegangen.

Mit dem Begriff tamilische Diaspora ist im Folgenden immer die sri-lankisch tamilische Diaspora gemeint, die in erster Linie aufgrund des sri-lankischen Bürgerkrieges seit 1983 entstanden ist. Nicht eingeschlossen sind dabei die tamilischen Migrierten aus Indien, die meist aufgrund wirtschaftlicher Faktoren im Ausland leben. Die Mehrheit der sri-lankisch tamilischen Migrantinnen und Migranten sind aufgrund von ethnischen Spannungen und als diskriminierend erlebten Handlungen der sri-lankischen Regierung aus Sri Lanka geflüchtet (vgl. Sriskandarajah 2004; vgl. Kap. III 2). ${ }^{61}$ Vielfach wird die tamilische Diaspora - wie beispielsweise auch die armenische oder kurdische Diaspora - als klassische Diaspora bezeichnet, da die Entstehungsgeschichte der tamilischen Diaspora Parallelen zur jüdischen Erfahrung aufweist. Zentraler Unterschied zur ursprünglichen jüdischen Bedeutung ist jedoch, dass die Begriffsbestimmung von Diaspora im Fall der Bezeichnung «tamilische Diaspora» nicht religiös konnotiert ist.

Tamilische Ausprägungen von Diaspora, die indische wie die sri-lankische, können unter dem Oberbegriff der südasiatischen Diaspora subsu-

61 Allerdings begann die Geschichte der sri-lankisch tamilischen Diaspora nicht erst mit dem Bürgerkrieg auf Sri Lanka. Als 1833 im British Commonwealth die Sklaverei abgeschafft wurde und ein hoher Bedarf an Arbeitskräften herrschte, kamen Vertragsarbeiter vom indischen Subkontinent als Wirtschaftsflüchtlinge - zusammen mit ihren Familien - in andere Länder wie u. a. Malaysia (vgl. Apputhurai 2013). Auch eine grosse Anzahl von Arbeitern aus Tamil Nadu wurden nach Sri Lanka entsandt. Die Entstehung der sri-lankisch tamilischen Diaspora kann in drei Phasen eingeteilt werden: Migrationsbewegungen zur Zeit der britischen Kolonisation (1796-1948), nach der Unabhängigkeit Sri Lankas und nach den Pogromen von 1983 bis in die Gegenwart. Die Zeit vor 1983 zeichnete sich besonders durch Wirtschaftsmigration aus. 
miert werden. ${ }^{62}$ Der Terminus Südasien wird dabei als deskriptive Kategorie verstanden, welche die geopolitische Region der Länder des indischen Subkontinents beschreibt. ${ }^{63}$

Eine der frühsten detaillierten Begriffsbestimmungen einer Neuinterpretation des Diaspora-Begriffs findet sich im ersten Heft der Zeitschrift Diaspora von 1991. William Safran stellt in seinem Artikel fünf Merkmale für die Diaspora-Definition auf (vgl. Safran 1991, 83f.). Im Anschluss daran hat auch Robin Cohen einen besonderen Kriterien-Katalog mit neun Merkmalen für Diaspora-Gemeinschaften formuliert (vgl. Cohen 1997). ${ }^{64}$

An diesen Kategorisierungen wurde berechtigte Kritik geübt, da sie nur einen Teil der heute als Diaspora beschriebenen Gruppierungen abdecken (z.B. Mayer 2005, 9 ff.). Eine kurze Skizzierung des Profils der tamilischen Diaspora orientiert sich im Folgenden am Kriterienkatalog Safrans (1991, 83f.). Anhand dieser Konkretisierung der Definitionspunkte wird die notwendige Kritik an diesen Konzepten am konkreten Beispiel deutlich gemacht und durch andere Diaspora-Konzepte ergänzt.

\section{A. Gezwungene Migration in fremde Regionen}

Als erstes Kriterium nennt Safran die unfreiwillige Zerstreuung von einem Heimatland in zwei oder mehr fremde Regionen. Im Laufe der verschiedenen Phasen des sogenannten Eelam War ${ }^{65}$ (vgl. Kap. III 2) kamen Tamilen seit 1983 als Asylsuchende in verschiedene Diaspora-Länder, die über alle Kontinente verteilt sind. 2001 bestand die tamilische Diaspora aus circa 700'000 Mitgliedern. Dies bedeutet, dass die Zahl der im Ausland lebenden Tamilen ungefähr ein Drittel der tamilischen Bevölkerung Sri Lankas vor Ausbruch des Bürgerkriegs umfasst (vgl. Cheran 2003, 9; Fuglerud 2001,

62 Untersuchungen zur südasiatischen Diaspora liegen beispielsweise von Vertovec (1991), Jacobsen (2004) und Ballard (2007) vor. Überlegungen zum konstruierten Begriff Südasien im Kontext von Diaspora-Analysen vgl. Shukla 2001.

63 Eine der ersten Studien, die sich mit südasiatischen communities in der Migration auseinandersetzte, war die Arbeit Religions of Immigrants from India and Pakistan (Williams 1988).

64 Cohen hat ausserdem eine Typologie verschiedener Diasporen erstellt. Nach dieser Typologie wäre die sri-lankisch tamilische Diaspora in der Schweiz als victim/refugee diaspora, ähnlich der jüdischen und armenischen Diaspora, zu klassifizieren (vgl. Cohen 1997, 29). Nach Cohen wären die vor 1983 entstandenen tamilischen Migrantengemeinschaften als labour, trade und imperial diasporas zu bezeichnen. Die von Cohen vorgenommene Differenzierung verschleiert jedoch den ambivalenten und fliessenden Charakter von Diasporen.

65 Mit diesem Terminus wird ausgedrückt, dass es sich um einen separatistischen Konflikt handelt. Die militärischen Auseinandersetzungen kreisten um Eelam, einen unabhängigen tamilischen Staat, für den die LTTE kämpfte und den die Regierung Sri Lankas verhindern wollte, um am sri-lankischen Unitary State festzuhalten. 
197) ${ }^{66}$ Cohen ergänzt als Kennzeichen einer Diaspora, dass die Zerstreuung oft traumatisch für die Vertriebenen ist (vgl. Cohen 1997, 26). Auch dies kann im Hinblick auf die tamilischen Gruppierungen festgestellt werden (vgl. z. B. Meinhold-Bergmann 2006).

\section{B. Kollektive Erinnerung an das Heimatland}

Safran fasst unter dieses zweite Charakteristikum von Diaspora die Etablierung von Mythen und die Rekonstruktion der Ausdehnung, Geschichte und Errungenschaften des Herkunftslandes. Tamilische Migrantinnen und Migranten berufen sich auf eine Heimatregion im Norden und Osten Sri Lankas. Diese wird (meist von politischen Kreisen) mit Tamil Eelam bezeichnet, wobei Eelam $^{67}$ (tam. ìlam) der alte tamilische Begriff für die gesamte Insel Sri Lanka ist. Der Erhalt der tamilischen Kultur und der Diskurs über ihre Errungenschaften werden u. a. in tamilischen Kulturvereinen gepflegt. Die Idealisierung der mutmasslichen angestammten Heimat führt zu einem kollektiven Bekenntnis zu ihrer Aufrechterhaltung oder Wiederherstellung. Cohen führt den Nachsatz «even to its creation» (Cohen 1997, 26) an und thematisiert damit die Bestrebungen von Diaspora-Gruppierungen, autonome Nationalstaaten zu gründen.

Die im Untersuchungszeitraum dominante tamilische politische Gruppierung, die LTTE (Liberation Tigers of Tamil Eelam), kämpfte während des Bürgerkrieges dafür, im Norden und Osten des Landes einen souveränen und international anerkannten tamilischen Staat zu errichten. ${ }^{68}$ Bis 2009 waren Teile des Ostens und Nordens teilautonom und unter Kontrolle der LTTE. Auch nach der offiziellen Beendigung des Bürgerkriegs wurde hauptsächlich von Diaspora-Akteuren ${ }^{69}$ die Errichtung eines eigenen, von den Vereinten Nationen anerkannten tamilischen Staates gefordert. ${ }^{70}$ Ann

66 Nach Cheran lebte 2003 einer von vier sri-lankischen Tamilen in der Diaspora (vgl. Che$\operatorname{ran} 2003,9)$.

67 Weitere Schreibweisen sind Eezham, Ezham, Iizham, Izham oder Ilam.

68 Während der ersten Friedensgespräche zum Konflikt in Sri Lanka in der bhutanesischen Hauptstadt Thimpu stellte die sri-lankisch tamilische Delegation 1985 vier zentrale Forderungen. An zweiter Stelle der sogenannten Thimpu Deklaration hiess es: "Recognition of the existence of an identified homeland for Tamils in Sri Lanka”.

69 Vimalarajah/Cheran konstatieren, dass der Wunsch nach einem eigenen Staat hauptsächlich von den Tamilen in der Diaspora, nicht jenen in Sri Lanka selbst ausgehe, was zu Dissonanzen zwischen tamilischen politischen Akteuren im Herkunftsland und der Diaspora führe (Vimalarajah/Cheran 2010, i).

70 Mitte 2009/2010 fand in vielen Diaspora-Ländern, so auch in der Schweiz, ein Referendum über einen eigenständigen tamilischen Staat statt. In diesem stimmten die meisten Tamilen für einen eigenen tamilischen Staat im Norden der Insel (vgl. Vimalarajah/Cheran 2010). 


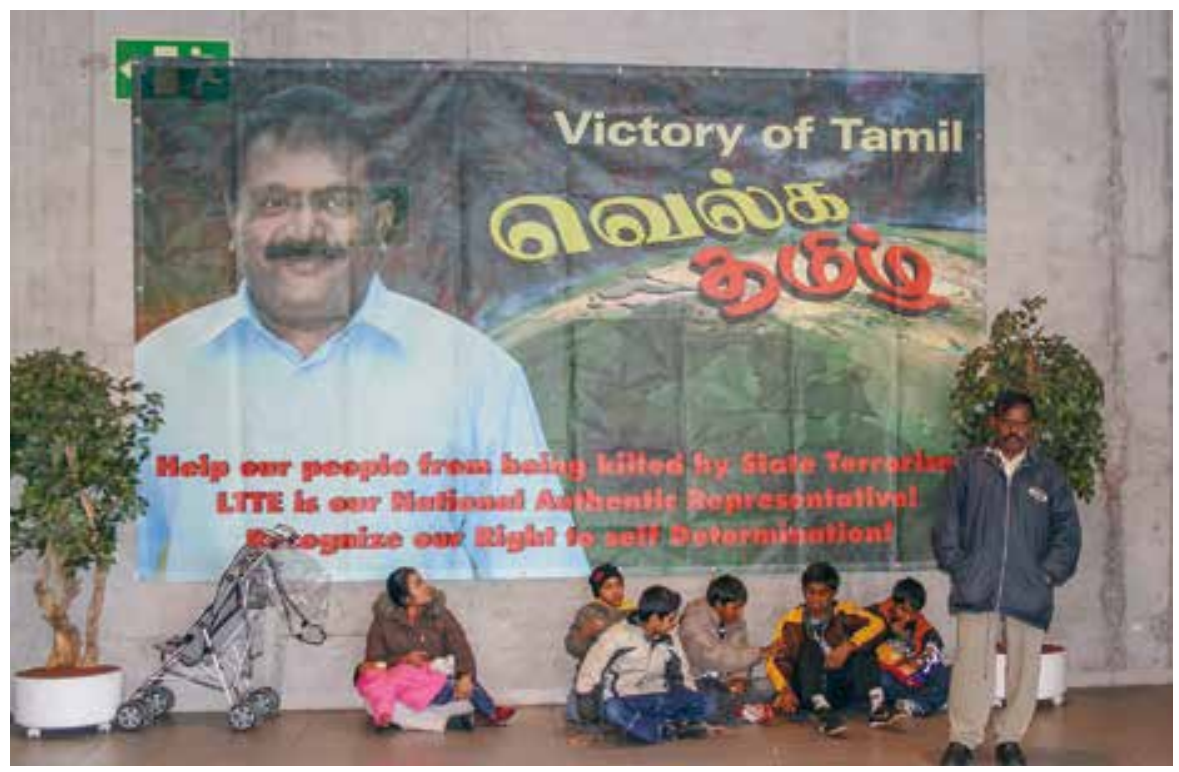

Abb. II 1: Poster im Eingangsbereich des Forum Fribourg während des māvīrar nāl, des sogenannten Great Heroes’ Day am 27.11.2007.

R. David konstatiert: "It is interesting to consider here the concept of cultural and religious place-making for the Tamils in terms of Tamil Eelam. Not only is there evidence of place-making in the diaspora, but for many Tamils the establishment of their own state in Sri Lanka absorbs much of their emotional, political and financial capital" (David 2008, 91).

\section{Mangelnde Akzeptanz der Migrierten in der Residenzgesellschaft}

Die Wahrnehmung der Migrierten, sie seien im Residenzland nicht voll akzeptiert, ist für Safran des Weiteren konstitutiv für eine Diaspora. Auch tamilische Immigrantinnen und Immigranten in der Schweiz artikulierten mangelnde Akzeptanz von Seiten der Mehrheitsgesellschaft. Der 2001 gegründete tamilische Verein Katamaran - Verein zur Integration der tamilisch sprechenden Gemeinschaft in der Schweiz beschrieb die Situation der tamilischen Immigrantengruppe trotz eines vollzogenen Image-Wandels auf seiner Webpräsenz 2009 wie folgt: «Dieser Umschwung der öffentlichen Meinung hat der tamilischen Bevölkerung in der Schweiz abgesehen von einer Abnahme gewalttätiger rassistischer Attacken durch Rechtsextreme bisher nicht viel genützt. Sicher waren ihre Integrationschancen in den frostigen 80er Jahren schlecht. Doch auch heute, wo sie hoch in der Gunst von Arbeitgebern, Sozialarbeiterinnen, Flüchtlingsbetreuern und 
sogar des Stammtisches stehen, haben sich diese nur scheinbar verbessert. $\gg^{71}$ Ein in der Schweizer Diaspora lebender tamilischer Hindu-Priester beschreibt diskriminierende Erfahrungen als Migrant: «Wir haben auch viele schlechte Erfahrungen gemacht/hier und auch meine Kollegen in Deutschland. Weil viele glauben/ Tamilen seien nicht intelligente Leute / sie hätten keine Ahnung oder so». ${ }^{72}$ Auf die soziale Situation der tamilischen Migranten in der Schweiz geht Kapitel III 3.5 ein.

\section{Rückkehrwunsch}

Die Entwicklung einer Rückkehrbewegung, welche breite Zustimmung innerhalb der Gruppe hat, ist nach Safran ein weiteres Kennzeichen einer Diaspora. Für Cohen ist der Rückkehrgedanke innerhalb der Diaspora-Definition nicht entscheidend (vgl. Cohen 1997). Tamilische Diaspora-Akteure propagierten durch ihre politischen Meinungsführer eine zukünftige Rückkehr in einen eigenen tamilischen Staat nach Ende des Bürgerkriegs. Auch nachdem die Hoffnung auf einen eigenen Staat 2009 erst einmal aufgegeben werden musste, bleibt bei einigen Tamilinnen und Tamilen der ersten Migrantengeneration der Wunsch bestehen, «irgendwann einmal» («wenn sich die politische Lage stabilisiert hat» oder «wenn wir pensioniert sind» usw.) nach Sri Lanka zurückzukehren.

\section{E. Aktivitäten zur Unterstützung des Heimatlandes und Gruppensolidarität}

Als fünften Punkt nennt Safran die Herkunftsregion unterstützende Aktivitäten, welche durch «communal consciousness» und Gruppensolidarität ermöglicht werden. Diese können finanzieller Art sein, sie können durch politische Proteste und Aufklärungsarbeit umgesetzt werden oder durch die Initiierung und Unterstützung von NGOs. Auch viele Schweizer Tempelvereine unterstützen Hilfsprojekte in Sri Lanka und engagierten sich besonders in durch den Tsunami 2004 und den Bürgerkrieg betroffenen Gebieten in Sri Lanka. ${ }^{73}$

Akteure der tamilischen Diaspora finanzierten zu einem grossen Teil den Kampf der LTTE gegen die sri-lankische Regierung. Darüber hinaus leistet sie enorme monetäre Unterstützung für die zivile Bevölkerung in

71 www.verein-katamaran.org/Verein Katamaran.htm; 05.01.2009.Aktuell ist der Verein unter www.verein-katamaran.ch zu finden.

72 Interview 1; 19.12.2007. Das Interview wurde in der Wohnung des Priesters in der Zentralschweiz durchgeführt.

73 Vgl. zum Beispiel das Engagement der zur ISKCON gehörenden Swiss Tamil Krishna Society in Sri Lanka dargestellt in Kap. IV 3.3. 
den tamilischen Gebieten (vgl. Cheran 2003, 10). ${ }^{74}$ Diese Unterstützung wird von einem starken ethnischen Gruppenbewusstsein getragen.

The Sri Lankans' political awareness and cultural ties to their homeland are major factors in their diasporic situation, in the sense of a displaced people whose political and financial support is devoted to rebuilding and supporting their homeland and whose sense of a global, diasporic family is a powerful articulation of Tamil Sri Lankan nationalism. (David 2008, 91)

Neue Medien spielen für die Unterstützung des Heimatlandes eine tragende Rolle (vgl. Tsagarousianou 2004). In Anlehnung an den von Radhika Gajjala geprägten Begriff der digital diasporas (vgl. Gajjala 2006) kann auch von einer digital tamil diaspora gesprochen werden (vgl. Tsagarousianou 2004, 52). Die Funktion des Internets als verbindendes Medium drückt sich beispielsweise im Slogan der bis zu ihrer Schliessung stark frequentierten Webpräsenz Tamilnation ${ }^{75}$ aus: "Vannakam, Welcome. www.tamilnation. org - 6000 webpages, a growing togetherness" ${ }^{76}$ Die tamilische Togetherness ist grundlegende Voraussetzung für tamilische Diaspora-Politik (vgl. Sheffer 2003). Der diasporische Nationalismus, der in transnationalen Netzwerken aufrechterhalten wird, findet seinen Ausdruck auch in der Solidarität mit Tamilen in anderen Diaspora-Ländern.

\subsection{Kritik an Diaspora-Klassifikationen: Verschleierung von Ambivalenzen und Heterogenität}

An den Klassifizierungen Safrans und Cohens als umfassenden generalisierenden Diaspora-Definitionen ist zu kritisieren, dass sie Ambivalenzen diasporischer Akteure und Differenzen zwischen den Exil-Erfahrungen verschleiern und die Vielfalt der Diaspora-Gruppierungen nicht abbilden. Der Diaspora-Begriff birgt die Gefahr, zur Essentialisierung ethnischer Identitäten beizutragen und kann eine Neuauflage des Paradigmas statischer ethnischer Gruppenzuschreibungen darstellen. Yasemin N. Soysal geht davon aus, dass Diaspora eine Naturalisierung von Zugehörigkeiten beinhaltet, da dieses Konzept auf der Vorstellung fixierter, wenn auch ver-

74 Nach Cheran schätzt die sri-lankische Regierung die Zahlungen der tamilischen Diaspora an die LTTE auf rund 80 Millionen Dollar jährlich, was von tamilischen Politikern jedoch bestritten wird (vgl. Cheran 2003, 10).

75 Diese Internetseite wurde am 25.01.2010 geschlossen und ist seitdem nicht mehr zugänglich. Eine Analyse zum Inhalt von tamilnation.org vgl. Whitaker 2004.

76 Zitat auf der Startseite von www.tamilnation.org (27.11.2008). 
lassener Orte basiert (Soysal 2000). Floya Anthias kritisiert, dass DiasporaKonzepte die Herkunftsorte in der Beschreibung von Migrantenidentitäten als zentral setzen und man von primordialen Zugehörigkeiten ausgeht. Zwar werden transnationale Prozesse berücksichtigt, jedoch werden die Gruppengemeinsamkeiten über den verlassenen «Heimatort» definiert (Anthias 1998).

Auch die Autoren Vimalarajah und Cheran thematisieren in ihrer Analyse von Dynamiken innerhalb der sri-lankisch tamilischen Diaspora die Problematik der Verwendung des Begriffs Diaspora:

We also acknowledge the difficulty of using the singular term Tamil Diaspora that does not lend itself to the diversity and multiple locations and assumes homogeneity within the community in terms of issues such as political affiliations, intergenerational relations, migration history and gender dynamics. (Vimalarajah/Cheran 2010, 9)

Die Definitionen von Safran/Cohen beschreiben einseitig den politisch dominanten tamilischen Diskurs, nämlich das von der LTTE als Meinungsführerin in der politischen Sphäre vertretene Diaspora-Verständnis. McDowell macht in seiner Studie zu tamilischen Migrierten in der Schweiz deutlich: "The Liberation Tigers of Tamil Eelam (LTTE), for example, appeal to overseas Tamils by continuously stressing a "victim diaspora"' (McDowell 1996, 12). Eine in dieser Weise homogenisierende Auslegung des Konzepts bestätigt die dominante Position der LTTE bis 2009. Es ist festzustellen, dass als Reaktion auf den wissenschaftlichen Diskurs eine zunehmende Anzahl von Migrantengruppierungen den Begriff Diaspora in ihrer Aussendarstellung verwendet und er als sprachliches Instrument für das Handeln von politischen Akteuren dient (vgl. Cohen 1997; Baumann 2000a; Vertovec 2004 und vgl. Kapitel II 1.2). Daher ist zwischen einer wissenschaftlichen und einer politischen Begriffsverwendung zu unterscheiden, deren Grenzen jedoch fliessend sind. Als politischer Begriff wird Diaspora unterschiedlich verwendet. Er kann zur Festschreibung von essentialistisch verstandenen nationalen Identitäten verwendet werden oder eben zur Überwindung dieser. Im letzt genannten Fall wird ihm ein visionäres Potential zugeschrieben.

Diasporen sind, nach Gordon, immer «disparate diasporas» (Gordon 1998). Sie werden in dynamischen Prozessen kontinuierlich neu ausgehandelt und rekonstruiert.

I suggest that diasporas should be seen not as given communities, a logical, albeit deterritorialized, extension of an ethnic or national group, but as imagined communities, continuously reconstructed and reinvented. (Tsagarousianou 2004, 52) 
Nicht abgebildet wird in den engen Kategorisierungen die Heterogenität der diasporischen Formationen. In der Schweiz kann nicht von einer in sich geschlossenen tamilischen Diaspora-Gemeinschaft gesprochen werden. Interne Unterscheidungen, die oft auch bewusste Abgrenzungen nach sich ziehen, werden beispielsweise zwischen der regionalen Herkunft der Tamilen aus Sri Lanka (aus den Ostgebieten um Batticaloa oder aus dem Norden um die Halbinsel Jaffna), nach Kaste, politischer Ausrichtung, Positionierung zur LTTE (als Mitglieder, Sympathisierende, Tolerieriende oder aber Gegner), weltanschaulicher (beispielsweise sozialistisch, nationalistisch oder religiös ausgerichtet) und religiöser Orientierung (christliche, muslimische, hinduistische Zugehörigkeit) vorgenommen. Innerhalb der Gruppe der tamilischen Hindus muss dann weiter unterschieden werden, welcher Traditionslinie gefolgt wird. Auch können die von Safran skizzierten Charakteristika nur auf die erste Generation der tamilischen Diaspora, welche sich durch ethno-linguistische Bindungen auszeichnet, als im Gros passend angesehen werden. Nicht generalisierbar sind diese Darstellungen auf die im Residenzland geborenen Generationen.

Ein zentraler Kritikpunkt an den Kriterien Safrans ist besonders der Aspekt, dass dem Diaspora-Begriff immer ein mehr oder weniger konkretes Bestreben nach Rückkehr in die Heimat inhärent sei (vgl. Clifford 1994; Cohen 1997; Mayer 2005, 10). Dies ist im Hinblick auf die tamilische Diaspora in der Schweiz nur auf einen Teil der ersten Generation zutreffend, obwohl die politischen Meinungsführer dies als eines ihrer Hauptziele proklamieren. Cheran sieht in seiner Analyse der tamilischen Diaspora den Aspekt der Rückkehr als nicht konstitutiv an (vgl. Cheran 2003, 10).

Dass das Verhältnis der tamilischen Migrantinnen und Migranten zum Heimatland divergieren kann, soll zusammenfassend anhand der Analysen des norwegischen Anthropologen Øivind Fuglerud veranschaulicht werden. Fuglerud unterscheidet zwei idealtypische Positionen der tamilischen Exilanten im Verhältnis zum Herkunftsland und zum Exil: In seiner Untersuchung der tamilischen Diaspora in Norwegen macht er zwei Verständnisse aus, die sich durch ihre dahinterliegenden Konzepte von Zeit und Ort unterscheiden. Das erste diasporische Bewusstsein versteht Exil als eine Möglichkeit, die tamilische Kultur trotz des Krieges zu bewahren - unabhängig vom Umgebungsort. Das verlassene Heimatland steht nicht im Fokus, sondern vielmehr die Rekonstruktion tamilischen Lebens an den unterschiedlichsten Orten. Hier ist auch die Vorstellung enthalten, dass die Hindu-Gottheiten «mit den Menschen gehen» und diese unabhängig vom Ort verehrt werden können (vgl. Fuglerud 2001, 211). Dies nennt Fuglerud das traditionelle Modell. Der zweite Diskurs - von ihm revolutionäres Modell genannt - verknüpft Exil immer direkt mit dem Krieg im Herkunfts- 
land. Das Heimatland ist zentraler Referenzpunkt; die sozialen Veränderungen, welche von den Diaspora-Akteuren im Heimatland erwirkt werden, stehen im Mittelpunkt (vgl. Fuglerud 2001, 196). ${ }^{77}$

Diese idealtypische Gegenüberstellung unterstreicht die Heterogenität der tamilischen Diaspora und betont in ihr unterschiedliche Formen des diasporischen Bewusstseins.

\subsection{Neuere Konzepte: Diasporen als Herausforderer von Nationalstaaten}

Entgegen den eng gesteckten Merkmalskatalogen Safranscher Prägung wird in neueren Theorien Diaspora als ein komplexes Konzept mit unterschiedlichen Bedeutungen und Verwendungsweisen benutzt. Postmodern ausgerichtete Diaspora-Konzepte wenden sich gegen einen territorialisierten Kulturbegriff, welcher Kultur als an eine in einem bestimmten Territorium lebende Gruppe gebunden ansieht. Diaspora-Kulturen werden als travelling cultures (vgl. Clifford 1997) mit mobilen, grenzüberschreitenden Beziehungen verstanden, deren Akteure sich durch multiple Loyalitäten auszeichnen. ${ }^{78}$ Neuere Diaspora-Konzepte stellen dadurch grundsätzlich die Idee der kulturellen Homogenität von Nationalstaaten in Frage. Einige Autoren sehen Diaspora-Gruppierungen als subversiv agierende Gruppen gegen die Homogenität der Nation an. Nach Cohen werden Diasporen demnach von Opfern zu Herausforderern von Nationalstaaten. Cheran zeigt anhand der kanadischen Volkszählung von 2001 für die tamilische Diaspora in Kanada sehr anschaulich, dass trotz Kampagnen von tamilischen Organisationen sich weitaus weniger Menschen als von diesen angestrebt als «tamilisch» klassifiziert haben (vgl. Cheran 2003, 12f.). Dies kann als Zei-

77 Auch McDowell stellt in seiner Analyse der tamilischen Diaspora in der Schweiz zwei Extremformen des tamilischen Diaspora-Verständnisses fest: Auf der einen Seite steht das politische Diaspora-Verständnis der LTTE, in welchem der Aspekt der Verfolgung und die Anbindung an das Herkunftsland im Mittelpunkt stehen (analog zum revolutionären Modell von Fuglerud). Als Gegenpol skizziert McDowell das Diaspora-Bewusstsein der tamilischen Bevölkerungsgruppe der Pungudutheevans, welche dem Fuglerudschen traditionellen Modell folgen (vgl. McDowell 2004, 543).

78 Cheran führt in der Analyse der tamilischen Diaspora den Begriff der diaspora circulation ein (vgl. Cheran 2003). Er spricht u. a. von homeland tourism, womit er die Reisen von tamilischen Migranten nach Sri Lanka meint. Schätzungsweise 25000 bis 35000 Tamilen reisten nach dem Waffenstillstand von 2002 jährlich nach Sri Lanka. Diese Angaben wurden von Cheran nach Auskünften von tamilischen travel agencies aus Kanada, Frankreich, Deutschland und Belgien zusammengetragen (vgl. Cheran 2003, 13). 
chen für durch diasporische Prozesse entstandene multiple tamilische Identitäten gedeutet werden.

Trotz der berechtigten Kritik an Safran/Cohen folgt diese Studie jedoch nicht den so genannten postmodern views of Diaspora (Cohen 1997, $129 \mathrm{ff}$.), welche den Aspekt des Anti-Essentialismus, der Diversität und Hybridität an die zentrale Stelle in der Begriffsdefinition setzen. Das subversive Potential von Diasporen zur Überwindung von (gedanklichen oder nationalen) Grenzen und als Gruppen kosmopolitischer anti-nationalistischer Akteure überzubetonen, wird den Gegebenheiten innerhalb der tamilischen Diaspora während des Untersuchungszeitraums nicht gerecht (vgl. Mayer 2005, 13). Die tamilische Diaspora dient nicht als ein Beispiel für «eine potentielle Subversion von Nationalität/Nationalismus» (vgl. Clifford 1997, 9), da eine dominante Meinung innerhalb des tamilischen Diaspora-Diskurses auf Inanspruchnahme des Nationenbegriffs beruht.

Sri Lankan Tamils have not adopted the cosmopolitan, multicultural framework espoused by many Western host societies in relation to their homeland. Rather (...) these diasporas cling to traditional loyalties associated with nation and ethnicity, and draw on premigratory frameworks. (Sriskandarajah 2004, 499)

In diesem Sinn kann die tamilische Diaspora eher den new ethno-national diasporas zugerechnet werden (vgl. Sheffer 2007), welche sich durch ein trans-nationales Bewusstsein ${ }^{79}$ und nicht-staatlich organisierte, transstaatliche politische Organisationsformen auszeichnen. ${ }^{80}$ Charakteristisch für die tamilische Diaspora im Untersuchungszeitraum war ein long-distance nationalism (vgl. Fuglerud 1999; Sriskandarajah 2004, 496 f.). Der Begriff Diaspora beinhaltet im Folgenden also immer die Bezugnahme auf die Begriffe des Heimatlandes und der Nation.

Die Studie stützt sich des Weiteren auf die von Steven Vertovec herausgearbeiteten zentralen Bedeutungen des Diaspora-Begriffs: Diaspora als Typ von Bewusstsein, als Modus kultureller Produktion und als soziale Form (vgl. Vertovec 1999). Diaspora als Bewusstseinsform konstatiert ein double consciousness (Gilroy 1993) der Diaspora-Akteure. Das diasporische Bewusstsein bildet eine Brücke zwischen lokalen und «heimatlichen» Identitätskonzepten. "Diaspora consciousness is entirely a product of cultures

79 Mit dem Begriff des transnationalen nationalen Bewusstseins wird das Selbstverständnis ausgedrückt, dass das Bewusstsein, einer Nation anzugehören, innerhalb eines transnationalen Kontextes aufrechterhalten wird.

80 Sheffer führt in seinem Aufsatz jedoch die tamilische Diaspora und ihre politischen Bezüge nicht explizit auf (Sheffer 2007). 
and histories in collision and dialogue" (Clifford 1994, 319). Inhärent ist dem diasporischen Bewusstsein eine kollektive Erinnerung an «Heimat». Vertovec spricht dezidiert auch von einem religious diaspora consciousness, was Anschlüsse für explizit religionswissenschaftliche Fragestellungen ermöglicht (vgl. Vertovec 1999).

Diaspora als Modus kultureller Produktion verweist auf die kreativen Freiräume, die Diasporen als hybride Kulturen bieten können. Besonders der zweiten Generation dienen diese kulturellen Expressionen als Ausdrucksformen ihres diasporischen Bewusstseins. Hier seien exemplarisch die Kunstformen und die durch diese ausgelösten Kontroversen der international renommierten britisch-tamilischen Künstlerin M.I.A. genannt, die in ihrer musikalischen und bildnerischen Kunst immer wieder ihre «hybride» Identität und den Konflikt auf Sri Lanka aufnimmt (vgl. Perera 2013). Die Kontroversen um ihre Kunst zeigen anschaulich unterschiedlichste Facetten der tamilischen Diaspora. ${ }^{81}$

Diaspora als soziale Form bezeichnet besondere soziale Bindungen, ambivalente politische Orientierungen der Diaspora-Akteure und für die Gruppe charakteristische ökonomische Strategien, welche durch die Diaspora entstanden sind. Der Begriff verweist auf die von Hettlage postulierte triadische Struktur von Diasporen (vgl. Hettlage 1991). Es lassen sich mindestens drei Pole von Diaspora ausmachen, zwischen deren Wechselwirkungen sich Diaspora-Situationen konstituieren: das Herkunftsland, die Residenzgesellschaften und die Diaspora-Gruppe (vgl. Vertovec 1999, 278).

Die erste Verbindungslinie in diesem Modell stellt die Verbindung der Diaspora-Gruppe zum Herkunftsland dar. Diasporen, die aufgrund von kriegerischen Konflikten im Heimatland entstanden sind, zeichnen sich vielfach durch eine Deterritorialisierung des Konflikts aus: Der Konflikt und die politischen Auseinandersetzungen werden in die Diaspora-Länder ausgeweitet. Durch die gestiegene Mobilität und die modernen Kommunikationsmittel ist das politische Gewicht der Diaspora-Gruppen auf innerstaatliche Konflikte im Herkunftsland gewachsen (vgl. Demmers 2002).

81 M.I.A. ist der Künstlername von Mathangi «Maya» Arulpragasam. Ihre Eltern sind srilankische Tamilen, welche aufgrund der ethnischen Konflikte nach Grossbritannien flohen. Die Künstlerin wurde in London geboren und zog mit ihrer Familie im Alter von sechs Monaten zurück nach Sri Lanka. Mayas Vater Arul Pragasam (nach dem ihre erste CD Arular benannt ist) trat dort der politischen Organisation Eelam Revolutionary Organisation of Students (EROS) bei. Ihre Mutter kehrte mit der zehnjährigen Maya und deren Schwester wieder nach London zurück, wo sie in einem Flüchtlingsheim lebten. Nach ihrem Schulabschlusss studierte sie am Londoner Saint Martins College of Art Kunst und Film. Die Webpage Tamilnation skizzierte detailliert die Biographie M. I.A.s, ihren künstlerischen Werdegang und die Verbindungslinien zum Konflikt in Sri Lanka (www.tamilnation.org/diaspora/unitedkingdom/mia.htm; 23.11.2009). 
"Diaspora can actively be involved in violent conflicts at the end of the world through electronic means, and influence these conflicts by sending money, arms, and opinions" (Demmers 2002, 89). Das bedeutet, dass Diasporen das Potential haben, Konflikte zu beeinflussen, welches konfliktverstärkend oder konfliktschlichtend eingesetzt werden kann. Der Einfluss der tamilischen Diaspora in der Schweiz auf den Konflikt in Sri Lanka wird in den Medien der Mehrheitsgesellschaft thematisiert und ist Gegenstand wissenschaftlicher Abhandlungen (z.B. Arnold 2007).

Die zweite Verbindungslinie im Modell ist das Verhältnis der DiasporaGruppe zum Residenzland. Eine unsichere Zukunft im Residenzland, das in einigen Fällen nicht frei gewählt wurde, verstärkt die Tatsache, dass die Bindung zum Heimatland aufrechterhalten bleibt. Hinzuzufügen ist, dass auch das Verhältnis des Residenzlandes zum Heimatland Einfluss auf die Diaspora ausübt.

Innerhalb des Modells stellen die Beziehungen der Diaspora-Akteure in den verschiedensten Ländern den dritten Pol dar. Kritiker bemängeln an diesem Modell, dass der Vielfalt der Vernetzungen von Diaspora-Akteuren nicht Rechnung getragen wird. Das Verhältnis der Diaspora-Gruppierungen in den verschiedenen Ländern untereinander lässt sich alternativ auch mit dem Terminus Transnationalismus beschreiben. ${ }^{82}$ Seit den 1960er Jahren wurde dieser Begriff in den Kulturwissenschaften für jene Phänomene verwendet, die sich nationalen Zuordnungen entziehen (vgl. Mayer 2005, $16 \mathrm{ff}$.). Der sogenannte transnational turn hat zu einer paradigmatischen Wende innerhalb der Migrationsstudien geführt (vgl. Faist 2007; McLoughlin 2007). In den letzten Jahren sind zahlreiche Studien zum Thema Transnationalismus erschienen (z. B. Hannerz 2003; Ballard 2007; Khagram/Levitt 2008; Vertovec 2009). Die tamilische Diaspora ist als sehr aktive transnationale Gruppierung zu charakterisieren. Es entstand ein transnational social space, in dem die Diaspora-Akteure als «drittem» Raum agieren (vgl. Pries 2001).

Das in dieser Studie beschriebene und analysierte Handeln der religiösen Akteure wird auch als ein in einem transnationalen Raum situiertes Religionshandeln verstanden. Es ist gekennzeichnet durch vielfältige Verbindungen über nationalstaatliche Grenzen hinweg - wie familiäre Netzwerke oder im religiösen Bereich die sogenannten "travelling priests", religiöse Spezialisten, die in unterschiedlichsten Diaspora-Ländern in verschiedenen Tempeln zu wichtigen Anlässen eingesetzt werden.

82 Der Begriff Transnationalismus wurde 1916 vom US-Amerikaner Randolph Bourne durch seinen Aufsatz Trans-national America geprägt. 


\subsection{Diaspora als Selbstbezeichnung tamilischer Akteure}

Der Diaspora-Begriff ist, wie bereits erwähnt, nicht nur eine Bezeichnung, die in wissenschaftlichen Analysen im Hinblick auf die Verstreuung von Migrierten Verwendung findet. Es ist festzustellen, dass als Reaktion auf die wissenschaftlichen Diskurse eine zunehmende Anzahl von Migrantengruppierungen den Begriff Diaspora zur Selbstbeschreibung verwendet (vgl. Vertovec 2004).

Der Diaspora-Diskurs wird eingesetzt, um kollektive Selbstzuschreibungen zu formulieren und Gruppenidentitäten zu definieren. "One reason for the term's appeal to a range of groups lies in its relevance to addressing, in a summary fashion, a core dilemma faced by any dispersed or transplanted people: how to survive as a group" (Vertovec 2004, 277). Er ist im gegenwärtigen gesellschaftlichen Diskurs vieler Migrationsländer ein anerkanntes Instrument, um Gruppenforderungen in der Kommunikation mit der Residenzgesellschaft angemessen zu formulieren. Die Selbstbezeichnung als Diaspora und die damit gemeinte inhaltliche Bedeutung drückt auch immer ein spezifisches Selbstverständnis der Gruppierung aus. Cohen stellt fest, dass jene Migrantengruppen, die den Begriff Diaspora verwenden, diesen mit einer eigenen Bedeutung aufgeladen haben und ihn als Instrument im politischen Diskurs verwenden (vgl. Cohen 1999).

Gemäss dem Alltagsverständnis impliziert der Begriff, dass es sich bei einer Diaspora-Gruppe um Vertriebene handelt, die Leiden und Ungerechtigkeit über sich ergehen lassen mussten. Viele Aktivisten gehen selbst von einem klassischen Diaspora-Verständnis aus, welches negative Erfahrungen wie Unterdrückung, Verfolgung und den Wunsch nach Heimkehr als zentral setzt. Meist schliesst die explizite Verwendung des Diaspora-Begriffs von Migrantenvereinigungen einen Appell mit ein, um auf die Anliegen der Migrantengruppe aufmerksam zu machen.

Innerhalb tamilischer Migrantengruppen sind es meist politisch aktive Gruppierungen, die den Begriff «Diaspora» verwenden, um auf ihre Anliegen als diskriminierte Ethnie in Sri Lanka zu verweisen und damit politische Forderungen zu verbinden. Vimalarajah und Cheran verweisen darauf, dass im Kontext des Konflikts in Sri Lanka der Diaspora-Begriff für unterschiedliche Zwecke eingesetzt werden kann:

Conceptually the term diaspora has also led to a vibrant debate within the Tamil Diaspora itself. There is a growing anxiety within the Tamil Diaspora that the term has been re-introduced into the current political discourses concerning Sri Lanka to divide the global Tamils from the Tamils on the island in 
a sinister move to weaken the political project of the Tamils and de-politicize their cause to a mere humanitarian and development concern. (Vimalarajah/ Cheran 2010, 8)

In der Schweiz nannte sich 2009 eine Dachorganisation von Tamilen «Tamilen Forum Schweiz. Confederation of Tamil Diaspora Organizations in Switzerland» (TFS). ${ }^{83}$ Der Appell, den diese tamilische Gruppierung an die Residenzgesellschaft richtet, zielt auf die Anerkennung des Rechts der Tamilinnen und Tamilen auf Selbstbestimmung. Ein Slogan der Dachvereinigung Tamilen Forum Schweiz lautete 2009: «Lasst die Tamilen leben!»

\title{
2 Das Wechselverhältnis von Religion und Diaspora
}

\author{
Religions can provide additional cement to bind \\ a diasporic consciousness, but they do not \\ constitute diasporas in and of themselves [...].
}

(Cohen 1997, 189)

Obwohl der Begriff Diaspora - wie in den vorangegangenen Abschnitten gezeigt wurde - ursprünglich einem religiösen Kontext entstammt, ist er nach modernen Diaspora-Konzepten kein Begriff, der per se religiös konnotiert ist. Vertovec konstatiert 2004, dass die Sphäre «Religion» im wachsenden Feld der Diaspora-Studien eine untergeordnete Rolle spielt (vgl. Vertovec 2004). Sozial- und Politikwissenschaften haben den Begriff der Diaspora innerhalb ihrer Fächer etabliert, in der Religionswissenschaft bestanden jedoch lange Vorbehalte, diesen aus der jüdischen Religionsgeschichte stammenden Begriff zu generalisieren. Erst später hat auch die Religionswissenschaft den Begriff in seiner erweiterten, vom jüdischen Kontext abgekoppelten Bedeutung aufgenommen (z. B. Baumann 1997). Auch die wechselseitigen Beziehungen zwischen transnationalen Kontexten und religiösen Dynamiken wurden lange Zeit sowohl von Seiten der Sozialwissenschaften als auch von der Religionswissenschaft vernachlässigt. Zwar etablierte sich die Transnationalismus-Forschung, jedoch

83 Der Verein Tamilenforum Schweiz existierte von 2009 bis 2014 und verstand sich als ein Dachverband von tamilischen Gruppierungen in der Schweiz. 
wurden dabei in der Vergangenheit meist Bezüge zu religiösen Dynamiken ausser Acht gelassen. (Ausnahmen stellen neuere Forschungen dar (z. B. Baumann 2002; Vertovec 2004; McLoughlin 2007). Lauser/Weissköppel (2008) verweisen darauf, dass Religion in einigen gegenwärtigen Studien sogar als Paradebeispiel für Kontinuität im Migrationskontext dient: «Interessanterweise spielt Religion im transnationalen Forschungsparadigma zunehmend eine exemplarische Rolle, weil insbesondere an DiasporaGruppen gezeigt werden konnte und kann, welche Kontinuität (nicht nur) religiöse Herkunftsidentitäten entfalten können (...)» (Lauser/Weissköppel 2008, 7).

Diaspora-Situationen bewirken in unterschiedlichsten Bereichen und so auch im Feld der religiösen Praxis und des religiösen Selbstverständnisses der Akteure eine Neuorganisation, was in dieser Studie gezeigt wird. Religiöse Partizipation kann sich verändern - sei es aufgrund von individuellen Entscheidungen der Migranten, gruppendynamischen Prozessen und/oder aufgrund äusserer Gegebenheiten im Migrationsland. Raymond Williams stellt in seiner Studie, die sich als eine der ersten mit südasiatischen communities in der Migration auseinandersetzte, allgemein fest: "Migration [...] forces reformulation of the religious identity" (Williams 1988, 12). Vertovec spricht dezidiert von einem religious diaspora consciousness (vgl. Vertovec 1999, 283). Dies beinhaltet auch ein Hinterfragen von althergebrachten religiösen Vorstellungen und die Entwicklung von Legitimierungsstrategien, um sich im neuen Kontext zu positionieren.

Im wissenschaftlichen und gesellschaftspolitischen Kontext wurde die Debatte geführt, ob die Diaspora-Situation die Intensität der religiösen Praxis der Migrantinnen und Migranten steigert. Welche Folgerungen aus der Analyse des Wechselverhältnisses zwischen diasporischer und religiöser Identität gezogen werden können, hängt von dem zugrundeliegenden Religionsverständnis, der Situation im Diaspora-Land und der Diaspora-Gruppe selbst ab. Soziale und kulturelle Faktoren des Herkunftslandes vor der Migration wie auch die Bedingungen im Residenzland nehmen entscheidenden Einfluss auf die Entwicklung religiöser Praxis in neuer Umgebung. Fragwürdig erscheint es, Einzelfallstudien auf ein verallgemeinerndes Verständnis von Religion und Diaspora zu übertragen. «Religion» wird nicht automatisch durch die Diaspora-Situation gefördert und verliert auch nicht per se durch diese an Bedeutung. Vielfach wird jedoch einseitig auf das Erstarken von religiöser Praxis und Lebenshaltung in der Diaspora verwiesen. So beispielsweise Williams (1988):

Immigrants are religious - by all counts more religious than they were before they left home - because religion is one of the important identity markers that 
helps them preserve individual self-awareness and cohesion in a group. (Williams 1988,11$)^{84}$

Hinnells verwendet den Terminus «diaspora religion»(Hinnells 1997). Diese definiert er als "the religion of any people who have a sense of living away from the land of the religion, or away from the old country" (Hinnells 1997, 686). Dieser unscharfen Definition von «diaspora religion» folge ich hier nicht. Vielmehr verstehe ich «Religion» als einen möglichen Identitätsmarker - neben weiteren - einer Diaspora. Wie Cohen konstatiert, gehe ich davon aus, dass Religion ein zusätzliches Bindeelement zur Festigung eines diasporischen Bewusstseins sein kann (vgl. Cohen 1997, 189).

\subsection{Die Diaspora einer Diaspora? Zum Begriff Hindu- Diaspora}

Im Folgenden wird das Themenfeld «Religion und Diaspora» im Hinblick auf Hindu-Traditionen ausserhalb Südasiens dargestellt. Religiöse global flows sind keine Phänomene der Neuzeit. ${ }^{85}$ Religionswissenschaftliche Untersuchungen von Hindu-Traditionen ausserhalb des indischen Subkontinents - jenseits der kala pani, der «Schwarzen Wasser» - sind eine vergleichsweise neue Entwicklung innerhalb der Hinduismus-Forschung. Oftmals wurden dabei die Praktiken und Vergemeinschaftungsformen von «Westlern», welche zum «Hinduismus konvertierten», als Forschungsthema untersucht. ${ }^{86}$ Immigranten, welche Hindu-Traditionen in den Westen brachten, trugen jedoch entscheidend zur Verbreitung von Hindu-Prak-

84 Williams verweist jedoch weiter darauf, dass eine Verstärkung des religiösen Lebens nur auf jene Migrierten zutrifft, die bereits im Herkunftsland religiös waren. Das religiöse Leben intensiviere sich, so Williams, durch die Migrationssituation. Jene Migrierten, die jedoch vor der Auswanderung keine religiöse Bindung hatten, nähmen diese auch in der Diaspora nicht auf. Vielfach wird in diesem Fall der Verlust von sozialer Kontrolle in der Migration dazu genutzt, die Freiheit in Anspruch zu nehmen, religiöse Anlässe nicht (oder nicht so häufig) zu besuchen (vgl. Williams 1988, 3, 38).

85 Hindu-Traditionen ausserhalb des «heiligen» Indien finden sich bereits im 5. und 6. Jahrhundert nach der Zeitenwende, als Brahmanen hinduistische Traditionen nach Kambodscha, Vietnam und Indonesien transferierten. Es folgte eine Migrationsbewegung hinduistischer Akteure, welche eng an die Kolonisierung des indischen Subkontinents gekoppelt war. Nach der Aufhebung der Sklaverei im British Raj 1833 wurden Tamilen aus Indien als Vertragsarbeiter zusammen mit ihren Familien - nach Sri Lanka, Malaysia und Singapur entsandt.

86 Frank J. Korom schreibt dazu überspitzt: "The Maharishi's flirtation with the Beatles, for instance, received much more attention than was paid to actual ethnic communities of Indians living abroad during the psychedelic era" (Korom 2010, 19). 
tiken auf allen Kontinenten bei. ${ }^{87}$ Die meisten Forschenden, die sich mit diesem Phänomen und den konkreten Praktiken von hinduistischen Migranten in der Diaspora beschäftigten, haben Prozesse innerhalb der indischen Diaspora untersucht (z. B. Williams 1988; Vertovec 2000), da Migrantinnen und Migranten aus der Republik Indien weltweit die grösste Gruppe der diasporischen Hindus ausmachen. Hindu-Traditionen, die von migrierten Menschen aus Sri Lanka praktiziert werden, wurden bis dato seltener in den Blick genommen (vgl. Kap. I 3).

Im wissenschaftlichen Diskurs wurde die Debatte geführt, ob es sinnvoll ist, von Hindu-Diaspora zu sprechen und diese von einer generellen indischen oder tamilischen Diaspora zu separieren. ${ }^{88}$ Der Begriff HinduDiaspora orientiert sich zunächst am traditionellen Begriff einer religiösen Diaspora. Der Begriff der Hindu-Diaspora geht von einer spezifischen Hindu-Weltsicht und einem Rückbezug auf Indien als sakralem Heimatland aus. Vertovec hat in seinem Buch Hindu Diaspora detailliert aufgezeigt, warum seiner Meinung dieser Begriff tragfähig ist (Vertovec 2000).

(...) it is possible to talk of a "Hindu-Diaspora" especially because, no matter where in the world they live, most Hindus tend to sacralize India and therefore have a special kind of relationship to a spiritual homeland. (Vertovec 2004, 281)

Seine Analysen beziehen sich jedoch hauptsächlich auf indische Migranten oder twice migrants (vgl. Vertovec 2000, 15). In Hindu Diaspora erwähnt er nicht die grosse Anzahl an sri-lankisch-stämmigen Hindus, die ausserhalb Südasiens leben: "Not all Indians are Hindus of course, but practically all Hindus are Indians (Nepalese and Balinese Hindus being obvious exceptions)" (Vertovec 2000, 3).

Vertovec geht davon aus, dass Hindus erst in der Diaspora «ethnisiert» wurden. Nimmt man jedoch die Gruppe der sri-lankischen Tamilen in den Blick, fand eine «Ethnisierung» bereits durch die historische Entwicklung in Sri Lanka und die politischen Diskurse im Herkunftsland statt (vgl. Kap. III 2). Darüber hinaus lassen sich weitere Unterschiede zu indischen Hindu-

87 Migrierte Hindus können in drei Hauptgruppen unterteilt werden: jene, die als sogenannten Arbeitsverpflichtete und Zwangsarbeitende den indischen Subkontinent verliessen, 2. Wirtschaftsmigranten und Exilanten, die zu Ausbildungszwecken ins Ausland gingen, und 3. solche, die aufgrund von religiösen oder ethnischen Konflikten aus ihrer Heimat fliehen mussten (vgl. Nugteren 2009, $71 \mathrm{f}$.).

88 Eingewendet werden kann beispielsweise, dass Hindus die Migrationsprozesse, die Bedingungen der Inkorporation und die Erfahrung von Diskriminierung mit anderen religiösen Gruppen Südasiens teilen. 
Migranten ausmachen: Die indische Diaspora versteht das von ihr verlassene Heimatland als «heilig». Die neue Heimat muss daher erst sakralisiert werden. Im Falle der tamilischen Diaspora ist jedoch nicht per se von einem religiösen Verständnis der Heimat in Sri Lanka wie auch nicht von einem Verständnis von Indien als Herkunftsland auszugehen. Zwar beziehen sich tamilische Migranten aus Sri Lanka teilweise auch auf Indien als «religiöses Mutterland». Indien wird jedoch nur von den indischen Tamilen, den sog. Hill Country Tamils, die ab dem 19. Jahrhundert als Arbeiter auf die Insel kamen, auch als «zweites» Heimatland angesehen. Aufgrund der jüngsten Geschichte finden sich tiefgreifende Ressentiments vieler sri-lankischer Tamilen gegenüber der Politik des Staates Indien. ${ }^{89}$

Vertovec schreibt, dass so gut wie alle Hindus, die ausserhalb Südasiens leben, Indien als heiligen Ort ansehen:

Yet for many commited Hindus, the tie to India goes beyond ethnic (and its often conflated racial/cultural) origins. For many, if not most, such Hindus India is a sacred space abounding with sacred places, from local shrines venerated by castes and clans to sites described in central religious texts like the Mahabarata, where the most widely recognized gods and legendary humans are believed to have undertaken some of their most significant deeds. It is mother India - Bharat Mata, conceived by many as goddess herself. (Vertovec 2000, 3)

Bezogen auf die Situation tamilischer Hindus finden sich zwar Rückbezüge auf Indien (wie auf die Himalaya-Region in den Geschichten um den Gott (ivan), jedoch beziehen diese sich zu einem grossen Teil auf die tamilischen - oder weiter gefasst - drawidischen Gebiete Indiens. In Kapitel IV 6.2 wird gezeigt, dass Orte in den Bundesstaaten Tamil Nadu und Andrah Pradesh als wichtige Orte des Rückbezugs tamilischer Hindus in der Diaspora dienen, zu denen auch Wallfahrten unternommen werden. Orte aus-

89 Dieses öffentliche Bild steht in Zusammenhang mit dem Eingreifen Indiens in den srilankischen Bürgerkrieg durch die Entsendung der Indian Peace Keeping Forces (vgl. Kap. III 2; Bose 1994; Bullion 1995). Durch den Indo-Sri Lanka Peace Accord (Juli 1987) wurden 1989 zur Implementierung seiner Vereinbarungen indische Soldaten nach Sri Lanka gesandt. Diese Indian Peace Keeping Forces waren mit UNO-Mandat und unter Zustimmung der sri-lankischen Regierung bis im Jahr 1990 in den tamilischen Gebieten der Insel stationiert. Ihr Auftrag war die Entwaffnung der LTTE und die Sicherung der nördlichen Provinzen. Bei Ankunft der IPKFs wurden diese von einem Grossteil der Tamilen - ausser der LTTE - als «Helfer in der Not» angesehen. Diese Wahrnehmung änderte sich jedoch schnell und die indischen Soldaten verloren an Ansehen (vgl. McDowell 1996, 181). Ihnen werden Massaker an Zivilisten und Vergewaltigungen von Frauen vorgeworfen. Die Abkürzung IPKF wurde daraufhin in Innocent People Killing Force umgedeutet. 
serhalb der drawidischen Gebiete fungieren seltener als religiöse Referenzpunkte. ${ }^{90}$ Auch Ritualspezialisten werden aus Indien in die Schweiz eingeladen, jedoch meist solche, welche Tamilisch sprechen.

Eine Ausnahme bilden die tamilischen Hindus, welche sich VaișnavaTraditionen zugehörig fühlen, da für diese die heiligen Orte der KrishnaVerehrung und damit nicht-drawidische Gebiete von grosser Bedeutung sind. Jedoch beziehen sich diese Akteure, ebenso wie die anderen tamilischen Akteure, unabhängig von ihrer religiösen Ausrichtung, auf die tamilischen Gebiete in Sri Lanka als ihre Heimatregion.

Radhika Sekar bringt mit Bezug auf die historischen Entwicklungen in Südasien die Überlegung in die wissenschaftliche Diskussion ein, dass bereits das Leben der Hindus in Sri Lanka als Hindu-Diaspora bezeichnet werden kann. "If India is considered the punya bhumi, then the Hindu settlement in Sri Lanka can be considered a diaspora" (Sekar 2001, 230). Somit wäre die heutige sri-lankisch tamilische Diaspora die Diaspora einer Hindu-Diaspora. Diese Auffassung würde jedoch dem Selbstverständnis jener sri-lankischen Tamilen widersprechen, welche sich als ursprüngliche Bewohner der Insel ansehen. ${ }^{91}$ Die Postulierung einer «Diaspora einer Diaspora» würde Sri Lanka des Weiteren aus indischen Sakrallandschaft ausgliedern. Es kann aber auch argumentiert werden, dass die Insel im Indischen Ozean Teil der sacred geography Indiens ist, da sie in Hindu-Schriften, beispielsweise im hinduistischen Epos Rāmāyaṇa, vorkommt.

Da eine Verwendung des Begriffs Hindu-Diaspora zahlreiche Schwierigkeiten nach sich zieht, wird in dieser Studie ausschliesslich der in diesem Kontext tragfähigere Begriff der tamilischen Diaspora herangezogen. «Religion» wird dabei als ein ergänzendes Element zur Festigung eines diasporischen Bewusstseins angesehen (vgl. Cohen 1997, 189). ${ }^{92}$

90 Akteure der reform-hinduistischen Gruppe Saivanerikoodam berichteten u. a. von ihren Reisen nach Nordindien.

91 "However, the early migrants into the island are now regarded by their communities as indigenous [...]" (Geaves 2007, 88). Vergleiche dazu auch die Anmerkungen in Abschnitt II 1.1 zur Etablierung von das Heimatland betreffenden Mythen als Kennzeichen einer Diaspora.

92 Obwohl also der Begriff Hindu-Diaspora nicht auf das Untersuchungsfeld angewendet wird, werden jedoch Anleihen an Studien zur indischen «Hindu-Diaspora» genommen. 


\title{
2.2 Interne Vielfalt: Tamilischer Hinduismus als fluides Feld
}

\author{
[... to be a Hindu is neither an unchanging, \\ primordinal identity nor an infinitely flexible one \\ which one can adopt or shed at will, depending on \\ circumstances. It is an identity acquired through \\ social practice and, as such, constantly negotiated \\ in changing contexts.
}

(van der Veer/Vertovec 1991, 14)

Diese Studie thematisiert religiöse Praktiken jener Akteure der sri-lankisch tamilischen Diaspora, welche sich selbst als «Hindus» oder mit einem äquivalenten emischen Begriff wie Caiva oder Vaiṣnava klassifizieren. Eine Analyse diasporischer Hindu-Praktiken wirft unweigerlich die Frage auf, was sich hinter dem Begriff Hindu verbirgt. Peter van der Veer und Steven Vertovec $(1991,14)$ verweisen darauf, dass Hindu-Identitäten kontext- und zeitabhängige Produkte von Aushandlungsprozessen sind - diasporische tamilische Hindu-Identitäten im Kontext des Nationalstaates Schweiz stellen spezielle Ausformungen dieser Identitätskonfigurationen dar. Der Begriff tamilischer Hinduismus kann dabei als ein Diskursprodukt betrachtet werden, welches aus der Konstruktion einer einheitlichen tamilischen Identität wie auch aus dem Postulat von Hinduismus als «Religion» entstanden ist. ${ }^{93}$

Frykenberg beschrieb Hinduismus treffend als ein «mosaic of discontinuities» (Frykenberg 1989, 41). Verschiedene Autoren haben aufgezeigt, dass das Bild des «Hinduismus» als eine in sich geschlossene «Religion» eine historisch konstruierte Fremdbezeichnung darstellt (Frykenberg 1989, 1993; Fitzgerald 2005; Pennington 2005). ${ }^{94}$ Viele Elemente, die als allgemein

93 Der von Clothey verwendete Begriff Tamil religions erscheint wenig hilfreich, da er einen einheitlichen tamilischen Kern unterschiedlicher religiöser Praxis impliziert. "The term Tamil religions denotes the religious traditions and practices of Tamil-speaking people" (Clothey 2005, 8973).

94 Innerhalb des wissenschaftlichen Diskurses nimmt von Stietencron eine Extremposition zur Frage der Konstruiertheit «des Hinduismus» ein: «Eine Zeitlang glaubte man auch, dass es ihn [den Hinduismus] wirklich gebe. Heute weiss man, ohne dies zugeben zu wollen, dass der Hinduismus nichts ist als eine von der europäischen Wissenschaft gezüchtete Orchidee. Sie ist viel zu schön, um sie auszureissen, aber sie ist eine Retortenpflanze: In der Natur gibt es sie nicht» (von Stietencron 1984, 213 f.). 
gültig für «den Hinduismus» in wissenschaftlichen Systematisierungen angesehen werden - wie die Veden, das Kastensystem und eine Reinkarnationsvorstellung - werden beispielsweise nicht in allen «Hindu»-Traditionen anerkannt (vgl. Malinar, 21) ${ }^{95}$ Dieser «Erfindung» liegen nach Beyer die Imaginationen von Orientalisten und Kategorisierungen der Kolonialmächte zugrunde.

Der Begriff Hindu war im ersten Jahrhundert nach unserer Zeit zunächst eine persische regionale Bezeichnung für die Bewohner des indischen Subkontinents, welche die in Südasien lebenden Muslime einschloss. Erst mit der britischen Kolonisierung entwickelte sich eine religiöse Bedeutung von «Hindu» (vgl. Vertovec 2000, 8ff). Die Briten entwarfen «den Hinduismus» in erster Linie als das Andere des Islams.

British perceptions of Indian society as an aggregation of religious communities gave impetus to representations of identity in idioms emphasizing differences, not commonalities, between those who among other things happened to be Muslim, Hindu or Sikh. (Jalal 2002, 43f.)

Der sich im 19. Jahrhundert etablierende Terminus Hinduismus wurde also ursprünglich als Fremdbezeichnung konstruiert, welche die als religiös eingeordneten Praktiken des indischen Subkontinents zu anderen Traditionen abgrenzte.

Die Bezeichnung Hindu existiert seit der britischen Kolonialherrschaft auch im offiziellen Religionsdiskurs Sri Lankas. Die Kolonialherren nahmen eine Klassifizierung der Bevölkerung des damaligen Ceylon vor; dabei verbanden sie in ihrer Kategorisierung die Verwendung der Sprache Sinhala mit der Ausübung von buddhistischer Praxis, während sie die tamilische Sprache mit Hindu-Traditionen verknüpften (vgl. Younger/Ramanathapillai 2009, 321) ${ }^{96}$ Hinduism ist die offizielle Bezeichnung in staatlichen Erlässen und seit 1871 eine der Kategorien in den Fragebögen der alle zehn

95 Auch Frykenberg weist dezidiert auf den konstruierten Charakter «des Hinduismus» hin: "Yet, all of the elements in that loose and undefined complex of ideologies and institutions, which have been brought together under this name, together with all of the aggregate collage of what has been 'organized' and 'syndicated' under its banner, did not just gradually (or naturally) evolve. Nor did Hinduism simply spring, full-blown, into being. Rather, it was constructed, piece by piece" (Frykenberg 1993, 523).

96 Die Autoren verweisen auch auf die weiterführenden Konsequenzen dieser Schematisierung, welche schlussendlich eine entscheidende Grundlage für die Bürgerkriegsdiskurse lieferten. "When the colonial interpretation also added the confusing issue of 'race' to its classification and suggested that Hindus are of a different racial stock than Buddhists, the classification scheme had become bizarre" (Younger/Ramanathapillai 2009, 321). 
Jahre durchgeführten Volkszählungen. ${ }^{97}$ Durch diese formelle staatliche Zuschreibung positionieren sich die Personen, welche in den Formularen der Volkszählung Hindu ankreuzen, als zur im Weltreligionen-Paradigma postulierte drittgrössten «Religion der Welt» gehörig und gliedern sich in die Gruppe von einer Billion Menschen weltweit ein, die als Hindus bezeichnet werden.

Der konstruierte Begriff «Hinduismus» wurde dann im 19. Jahrhundert im Rahmen der Hindu-Reformbewegung als Selbstbezeichnung aufgenommen. «Reform-Hindus» postulierten eine einheitliche «Weltreligion» in Südasien - angelehnt an das Paradigma der jüdisch-christlichen Religionstraditionen - und nahmen eine Rekonstruktion einer hinduistischen Traditionsgeschichte vor (vgl. Beyer 2006, 190). Als Selbstbezeichnung wurde der Begriff dabei auch zu politischen Zwecken genutzt.

Die Hindu-Praktiken von sri-lankischen Tamilen sind nicht erst seit der Entstehung einer transnationalen Diaspora globalen Einflüssen unterworfen. Bereits vor dem Wirken der Briten wirkten christliche Missionare während der portugiesischen Kolonialzeit in den von Tamilen bevölkerten Küstenregionen der Insel, während beispielsweise die religiösen Praktiken der Menschen in den singhalesischen Gebieten im Landesinneren relativ wenig von portugiesischen Akteuren beeinflusst wurden. In diese Zeit fiel auch die Zerstörung wichtiger Hindu-Tempel. Die niederländische Kolonialherrschaft im 17. Jahrhundert prägte die Hindu-Praktiken in den tamilischen Gebieten in der Form, dass von der Entstehung eines «Hinduismus protestantischer Ausrichtung» gesprochen werden kann (vgl. Younger/Ramanathapillai 2009, 328). Religiöse Transformations- und Austauschprozesse fanden in Sri Lanka also bereits in den letzten Jahrhunderten statt.

Als Beispiel eines sri-lankisch tamilischen Hindus, welcher in jener Zeit eine Erneuerung des Caivam anstrebte, sei Ārumuka Nāvalar (1822-1879), geboren als Ārumuka Pillai, aus Jaffna (tam. yālppāṇam) genannt (vgl. Hudson 1992). Sein Engagement war von den Aktivitäten protestantischer Missionare geprägt, bei denen er als Tamil-Übersetzer angestellt war und bei der Übertragung der Bibel ins Tamilische mithalf. Als Reaktion auf christliche Angriffe auf die Tradition des Caivam rief er 1848 eine eigene religiöse Bewegung ins Leben. Seine Neukonzeption des Caivam war von der Theo-

97 Hindu war eine der Kategorien unter der Rubrik Religionszugehörigkeit, welche in den Volkszählungen Ceylons bzw. Sri Lankas gewählt werden konnte. Der Fragebogen zur Volkszählung Sri Lankas (Census of Population and Housing des Departement of Census and Statistics) aus dem Jahr 2001 fragte unter P 8 nach Religion. Dabei konnten folgende Optionen gewählt werden: 1. Buddhist, 2. Hindu, 3. Islam, 4. Roman Catholic, 5. Other Christian, 6. Other (vgl. http://nada.statistics.gov.lk/index.php/catalog/955/related_materials; 11.01.2021). 
logie und Organisation der christlichen Missionen beeinflusst, was sich unter anderem darin zeigte, dass er in Tempeln predigte und den Freitag zum «Sabbat» der Hindus erklärte (vgl. Younger/Ramanathapillai 2009, 329 ff.). Er zog Parallelen zwischen den Caivam-Tempelritualen und jenen im jüdischen Tempel, wie sie das Alte Testament beschreibt, um die Praktiken des Caivam im Diskurs mit den christlichen Kolonisatoren zu legitimieren (vgl. Sugirtharajah 2008, 551). Nāvalar gab eine Zeitschrift heraus und argumentierte darin, wie auch in seinem Hauptwerk Śaiva-tūṣaṇapariharam aus dem Jahr 1854 - was etwa mit «Das absolute Ende des Missbrauchs des Caivam» übersetzt werden kann -, gegen die Theologie der christlichen Missionare.

Am Beispiel Ārumuka Nāvalars und seiner Innovationen zeigt sich, dass die Tradition des Caivam bzw. des tamilischen Hinduismus von religiösen (wie auch wissenschaftlichen) Akteuren immer wieder neu konstruiert und aktualisiert wird. Bereits vor der Entstehung der globalen tamilischen Diaspora hat der Einfluss der Kolonialherrschaften in Sri Lanka zu tiefgreifenden Veränderungen der religiösen Praxis geführt. Die Auswirkungen der Reformen Ārumuka Nāvalars reichen bis in die gegenwärtige Praxis tamilischer Hindus in der Diaspora. Es ist beispielsweise in der Schweiz festzustellen, dass der Freitag der wichtigste Tag zum Besuch eines Tempels ist. Diese Betonung des Freitags als zentraler Tag des Tempelbesuchs, analog zum christlichen Sonntag, geht auf Nāvalar zurück. Auch das Singen von die Gottheit verehrenden Liedern, tamilisch pacanai (skr. bhajas) genannt, von Frauen und Kindern vor der pücai, was in den vielen Tempeln in der Schweiz praktiziert wird, wurde von ihm institutionalisiert. Er unterrichtete als Erster auch Frauen und Kinder in den tamilischen Hymnen der Nāyanar ${ }^{98}$. Bis zu diesem Zeitpunkt war dies Männern einer speziellen Kaste vorbehalten.

Beyer zeigt auf, dass eine Kontinuität der Selbstkonzeption des Hinduismus unter Hindus über die Jahrhunderte und geographischen Regionen hinweg existiert. Dies gilt auch für die Diaspora-Situation (Beyer 2006, 188 ff.). Geaves weist darauf hin, dass der Begriff Hindu im Kontext tamilischer Traditionen jedoch nicht unumstritten ist, da er oftmals mit nordindischen, indoarischen Traditionslinien assoziiert wird. Vielfach beziehen sich tamilische Hindus auf spezifisch «tamilische» Gottheiten wie Murukan, die unter anderem als Sinnbilder für den drawidischen Widerstand gegen

98 Unter dem Begriff Nāyanar versteht man 63 im Saiva Siddhanta verehrte Dichter, die im 6. bis 8. Jahrhundert in Tamil Nadu lebten. 
Sanskritisierungstendenzen gelten. ${ }^{99}$ Auf der anderen Seite betont Geaves, dass der Begriff «Hindu» in der Diaspora-Situation ein zentrales Strategieinstrument ist, um sich in die religiöse Landschaft des neuen Kontextes einzuordnen (vgl. Geaves 2007, 9).

\section{3 Überblick über die Verehrungsformen der Göttinnen und Götter in Schweizer Tempeln}

Auch im Schweizer Kontext wird in der Aussendarstellung meist der Begriff Hindu oder seltener der englische Terminus Saivite Hindu verwendet. Die Mehrheit der «tamilischen Hindus» klassifizieren sich intern selbst noch einmal konkreter als Caivas und verehren den Gott Civan (skr. Siva) als ihren Hauptgott. Caivam kann in verschiedene Strömungen unterteilt werden (vgl. Schalk 2004a, 80 ff.); diese Differenzierungen spielen jedoch in der alltäglichen Praxis und den Diskursen der Praktizierenden in der Schweiz eine untergeordnete Rolle. ${ }^{100}$ An dieser Stelle kann kein umfassender indologischer Überblick über Lehre und Praxis des Caivam und auch keine detaillierte ikonographische Analyse der Göttinnen und Götter gegeben werden. Vielmehr wird auf entsprechende Literatur verwiesen; die Verehrungsformen werden anhand der im Untersuchungsfeld vorgefundenen Darstellungen vorgestellt. Dazu zählen in erster Linie als soziale Räume der Verehrung der pücai-Platz im privaten Bereich und der Tempel.

Die Tempelpraxis tamilischer Tempel in der Schweiz ist geprägt von der Schule des Caivacittāntam (skr. Śaiva Siddhānta; vgl. Schalk 2004a, $88 \mathrm{ff}$.). Den philosophischen Hintergrund dieser religiösen Tradition können jedoch die wenigsten Akteure benennen; implizit wird diese Praxis jedoch von den Akteuren angewendet. Die religiösen Textgrundlagen der CaivamTradition sind die Schriften Civa Ākamam (skr. Śiva Āgama), aus welchen die Glaubenslehren abgeleitet werden. Tempelverehrung stellt eine zentrale Form der religiösen Praxis dar, was sich auch in der Diaspora-Situation zeigt. Gemeinsam ist den Caivas Sri Lankas ein Rückbezug auf die Cankam (skr. sangha)-Literatur, welche aus tamilischen Gedichten besteht, die in akam (Liebesgedichte) und puram (Heldengedichte) eingeteilt werden.

99 Geaves erzählt die Anekdote, dass er einen Tamilen in Mauritius fragte, ob ein religiöses Bauwerk, ein «Hindu-Tempel» sei, woraufhin der Mann verneint und antwortet, dass es sich um einen «tamilischen Tempel» handele (vgl. Geaves 2007, 9).

100 Es sind zum Beispiel Unterschiede zum kashmirischen Shivaismus auszumachen und auch Differenzen zwischen südindischem und sri-lankischem Caivam sind zu finden (vgl. Bastin 2002, 13). 
Die Bezeichnung Caivam bezieht sich auf eine religiöse Tradition und Praxis, welche auf die Verehrung des Gottes Civan, seiner Ehefrau und seiner Kinder zentriert ist. Im Folgenden werden diese «transzendenten Akteure» innerhalb der tamilischen Diaspora und ein Teil ihrer Darstellungsformen in Schweizer Tempeln kurz vorgestellt. ${ }^{101}$

Geaves weist auf die unterschiedlichen Erscheinungsformen und Deutungen der Gestalt Civans hin: "This [Civan] is not a god to be treated as a single entity but rather a multi-faceted construct who could be used as a metaphor for 'Hinduism' itself" (Geaves 2007, 34). Meist wird er als männliche Gottheit dargestellt, welcher grosse Macht zugeschrieben wird. Die Geschichten, die um seine Figur kreisen, zeichnen ihn als eine ambivalente Gestalt: Zum einen wird er als Asket verehrt, zum anderen wird ihm grosse sexuelle Energie zugeschrieben (vgl. Doninger O'Flaherty 1973; Geaves 2007, $15 \mathrm{ff}$.).

Civan wird auf dem ganzen indischen Subkontinent von Hindus verehrt. Obwohl Civan in den meisten Schweizer Tempeln zu finden ist, war der Civankōvil in Glattbrugg (Kanton Zürich) im Untersuchungszeitraum der einzige traditionelle Tempel in der Schweiz, welcher Civan als Hauptgott gewidmet war. ${ }^{102}$ An zentraler Stelle wird Civan auch in den Räumlichkeiten der Hindu-Reformgruppe Saivanerikoodam in Bern verehrt. Die Ikonographie Civans in den Schweizer Tempeln ist vielfältig. Vielfach wird Civan in nicht-menschlicher Form in Gestalt des phallusförmigen ilinkam (skr. linga) verehrt. Im Glattbrugger Tempel beispielsweise stand 2008 ein civan ilinkam aus Stein auf einem goldenen Podest, welches Civans Reittier (tam. vākanam; skr. vāhana), den Stier nanti (skr. nandī) zeigt. Hinter dem civan ilinkam ragt eine Schlange aus Gold nach oben, welche mit ihrem Kopf den Stein abschirmt.

In der Form des Dreizacks wurde Civan beispielsweise im Śrī Kalyāna Murukan Tempel in Bern verehrt - dort war beim Besuch am 13.10.2007 rechts hinter dem Eingang ein Schrein mit einem goldenen Dreizack zu finden. Die Tempel in der Schweiz wie auch die pūcai-Plätze tamilischer Hindus in der Schweiz zeigen Civan aber auch in anthropomorpher Form. So wird er im Tempel in Luzern als candraśekhara dargestellt und trägt

101 Da es sich nicht um eine indologische Arbeit handelt, werden die Gottheiten nicht in all ihren Aspekten analysiert. Vielmehr basiert die Darstellung auf den Präsentationen der Gottheiten in den Tempeln in der Schweiz und auf unter Tamilen in der Schweiz verbreiteten Narrativen über diese Gottheiten. Eine Priorisierung von Gottheiten wird nach den Gegebenheiten des Feldes vorgenommen.

102 Der Tempel nennt sich offiziell Arulmigu Sivan Kovil - Saiva Thamil Sangam. Seine Kontaktdaten lauten: Industriestr. 34, 8152 Glattbrugg. 
einen Halbmond in seinem Haar. Der tanzende Civan (civan națarāya; skr. Śiva națarāja), ist eine weitere verbreitete Form der Darstellung dieser Gottheit in Schweizer Tempeln.

Civan kommt innerhalb der tamilischen Diaspora des Weiteren eine grosse Bedeutung als Vater des elefantenköpfigen Ganeśas und vor allem Murukans zu. Als Vaterfigur wird er jährlich in der Aufführung zum Mangofest in verschiedenen Schweizer Tempeln in den Mittelpunkt gestellt (vgl. Kap. V 3.3).

Sein Sohn Murukan ${ }^{103}$, dessen Name vom tamilischen Wort muruku für Jugendlichkeit abgeleitet ist, ist eine häufig dargestellte Figur in Schweizer Tempeln. Murukak kațavul valipātu, die Verehrung des Gottes Murukann, ist für Tamilinnen und Tamilen in der Schweiz zentraler Ausdruck ihrer religiösen Praxis. Der Gott gilt vielen Praktizierenden als explizit tamilische Gottheit (vgl. Geaves 2007, 49).

This accompanying pride in the Dravidian cultural heritage is at least one of the reasons why he is so fondly worshiped today, for many Tamilians recognize that Murukan has been identified with the Tamil cultural heritage for centuries and is thus the legitimate recipient of Tamil worship. (Clothey 1972, 81)

Ron Geaves weist dezidiert darauf hin, dass Murukan als Identifikationsfigur der tamilischen «kulturellen Renaissance» und des tamilischen Nationalismus genutzt wird (vgl. Geaves 2007, 35). Geaves betont auch die Verbindung von Murukan-Verehrung mit den aktuellen politischen Ereignissen in den tamilischen Gebieten Sri Lankas. Er verweist auf die Analysen Amirthalingam Selliahs, der eine direkte Verbindung zieht zwischen der marginalisierenden Politik gegenüber den Tamilen in Sri Lanka und der Herausbildung einer tamilischen Identitätspolitik, welche unter anderem Murukan als tamilisches Symbol einbezieht (vgl. Geaves 2007, 51).

Any analysis of Murugan in Sri Lanka has to take into account that his worship predominates in war-torn regions of the island where people caught up in the conflict and feeling helpless turn to a god whose unique double role as god of War and Love provides a unique combination for the fullfillment of their needs. (Geaves 2007, 57)

In der Schweiz befindet sich ein dem Gott Murukan geweihter Tempel beispielsweise in Aarau (Kanton Aargau) und in Bern. ${ }^{104}$ Auch Murukan wird

103 Für einen Überblick zur Verehrungsgeschichte von Murukan vgl. Clothey 1972, $80 \mathrm{ff}$.

104 In Bern heisst er Śrī Kalyāna Murukañ Tempel; kalyāna kann mit «glücksverheissend» übersetzt werden. 


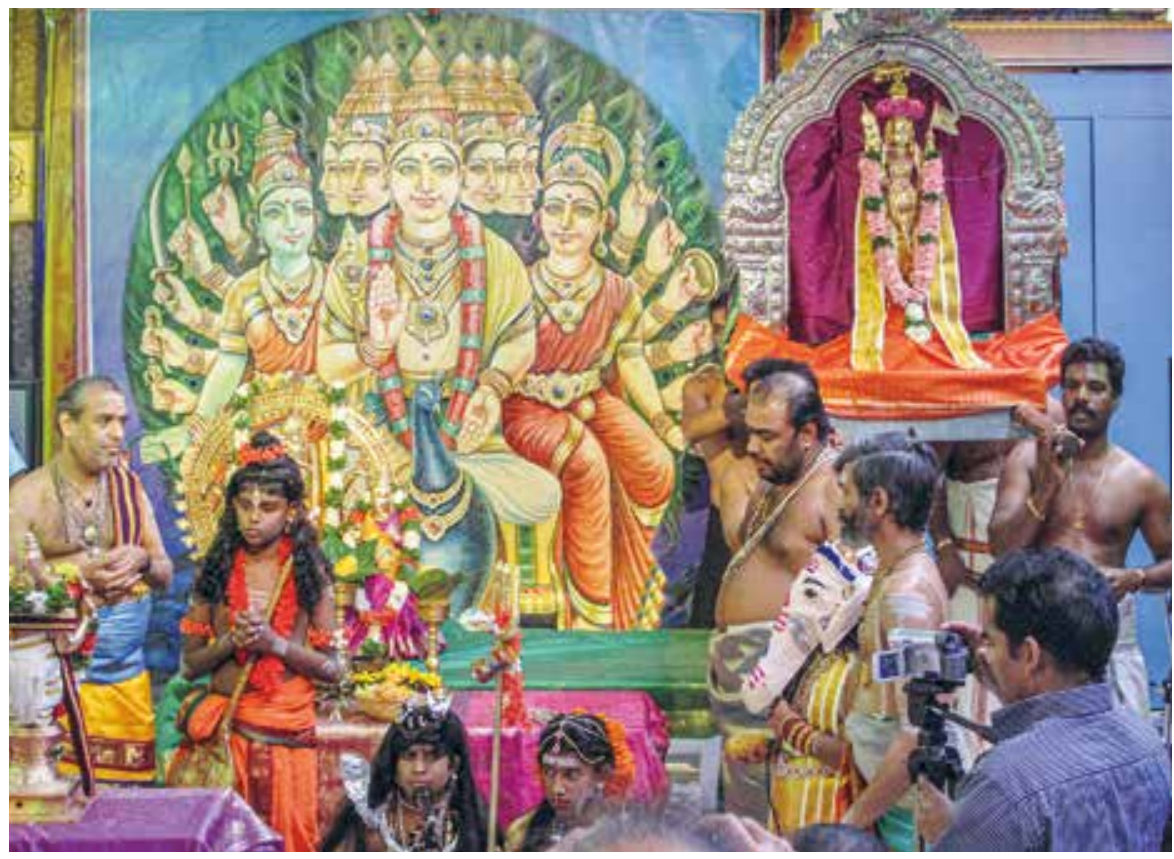

Abb. II 2: Darstellung des sechsköpfigen Murukañs auf seinem Reittier, dem Pfau, in Begleitung seiner Frauen Teyvānai und Valli i (Tempelfest des Śrì Civacuppiramaṇiyar Tempels in Adliswil/Kanton Zürich, 18.08.2010). ${ }^{105}$

in verschiedenen Formen und unter verschiedenen Namen verehrt ${ }^{106}$; häufige Bezeichnungen im tamilischen Spektrum sind Kärttikēyan, Kumaran, oder Kantan (skr. Skanda). Die unterschiedlichen Bezeichnungen der Murukan-Tempel in der Schweiz stellen unterschiedliche Aspekte seiner Mythologie in den Vordergrund. Häufig wird er mit sechs Köpfen reitend auf dem Pfau dargestellt und/oder in Begleitung seiner Frauen Teyvānai und Valli. Die Hauptgottheit des Śrī Civacuppiramaniyar Tempels in Adlis-

105 Das Bild wurde während der theatralen Performanz der Kinder zum Anlass des Mangofestes (vgl. Kap. V 3.2) aufgenommen. Murukan wird hier nicht nur auf dem gemalten Tuch dargestellt. Auch die dreidimensionale Statue vorne links und vor allem die von Männern getragene Figur verkörpern Murukan. Nicht zu sehen auf dem Foto ist das Kind, welches die Rolle Murukañs im Theaterstück übernahm.

106 "The scheme of gathering various deities under the rubric of a particular greater deity is endemic to Hinduism" (Rodrigues 2009, 547). Murukan werden 108 Namen zugeschrieben, die auf unterschiedliche Eigenschaften oder Elemente seiner Lebensgeschichte verweisen. Entsprechende Darstellungen finden sich auch in den Tempeln in der Schweiz. 
wil und des tamilischen Hindu-Tempels im Kanton Tessin ist cuppiramaniyar. Dieser Begriff, der mit «gut zu den Brahmanen» übersetzt werden kann, stellt Murukan ikonographisch als jungen Mann dar. Im Katirvèlāyuta Cuvāmi Tempel in St. Margrethen wird Murukan in der nicht-menschlichen Form seiner Waffe, der Lanze (tam. vēl), verehrt; so bedeutet der Name des Tempels «Herr der strahlenden Lanze».

Ganeśa, Murukañs älterem Bruder, waren die meisten der hindu-tamilischen Tempel in der Schweiz gewidmet. Mit den Ritualen vor Ganeśas Schrein, der auch Vināyakar, Gaṇapati oder Pilllaiyār genannt wird, beginnt jede Tempel-pūcai. "If we want to start any action, if we start without performing puja to Vināyakar, there will be some hindrance", so der Tempelpriester des Tempels im deutschen Hamm, Paskaran (zitiert und übersetzt nach Schalk 2004a, 143). Auch Ganeśa wird in den Tempeln unter verschiedenen Namen und in verschiedenen Formen verehrt. Tempel, welche seinen explizit tamilischen Namen Pillaiya ${ }^{107}$ tragen, finden sich in der französischsprachigen Schweiz in Vernier (Kanton Genf) und Prilly (Kanton Waadt). Pillaiyār wird auch in Burgdorf (Kanton Bern) in einem Tempel verehrt. Als Vināyakar gilt er als der Beseitiger von Hindernissen. ${ }^{108}$ "He is a friendly god, considerate and reliable, a redeemer for all who suffer. He makes it possible to endure life in İlam and in Sweden [in the diaspora, R.E.] and to endure suffering in silence" (Schalk 2004a, 140). Tempel, die diesen Namen tragen, finden sich in Bärau bei Langnau (Kanton Bern) und in Steffisburg (Kanton Bern).$^{109}$ Der Tempel in Baar (Kanton Zug), welcher im Industriegebiet gelegen ist, trägt den Name Śrī Siddhivināyaka. Dieser kann nach Konrad Meisig mit «der Tempel des Herrn, der die Hindernisse zur Vollendung beseitigt» oder «des Herrn, der zur Vollendung führt» (Meisig 2001) übersetzt werden. In Graubünden findet sich ein Navashakti Vināyakar Tempel, welcher die Verehrung von cakti (skr. śakti) und Ganeśa im Namen vereint; die Hauptgottheit des Tempels ist Ganeśa (vgl. BrunEnderlin 2000, 4).

Die Civan-Familie schliesst auch weibliche Gottheiten ein, welche in diesem Kontext oft als Civans Frau identifiziert werden. Die Göttinnen, welche in den Tempeln verehrt werden, können als lokale Dorfgottheiten, Gefährtinnen eines männlichen Gottes oder unabhängige Formen der Göt-

107 Dieser Begriff bezieht sich auf die Darstellung des Gottes als Kind. Pillai bedeutet im Tamilischen Kind.

108 Peter Schalk hat 2004 seine Bedeutung für die Praktizierenden innerhalb der tamilischen Diaspora in Schweden in seinem Buch " God as a Remover of Obstacles" dargelegt (Schalk 2004a).

109 Der vollständige Name des Tempels lautet Śrī Varacitti Vināyakar Tempel. 


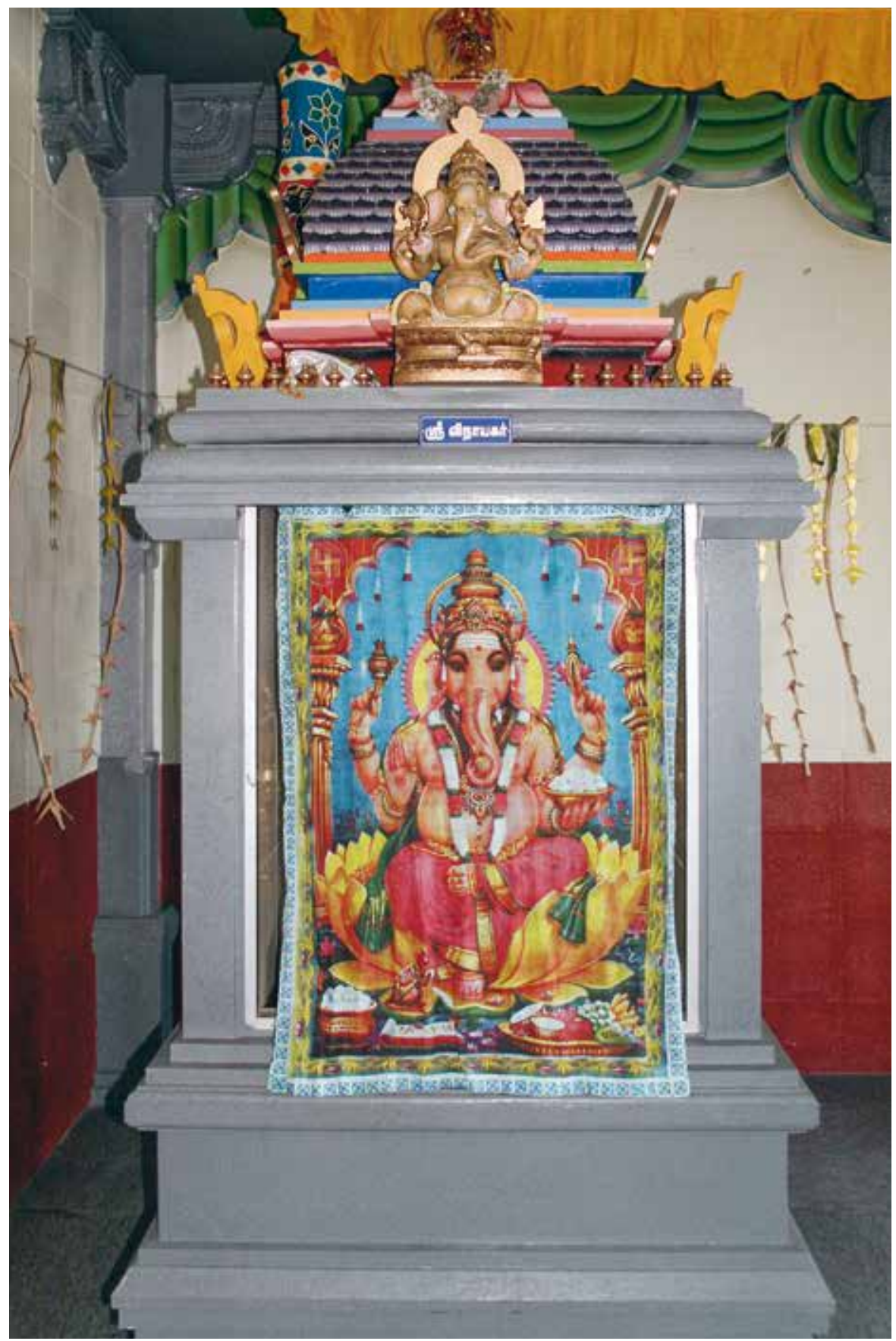

Abb. II 3: Schrein für Gaṇeśa im Katirvēlāyuta Cuvāmi Tempel in St. Margrethen

(11.06.2008). 
tin gedeutet werden. "Although contemporary Hindu apologists tend to argue that all the myriad forms of the supramundane feminine are manifestations of the one Mother-goddess, there are innumerable variations" (Geaves 2007, 17). Man̄ōnmaṇi Ampāl oder Ammañ werden von den Gläubigen als Repräsentation von cakti und als Gefährtin von Civan angesehen. Der erste in der Schweiz nach südasiatischem Vorbild gebaute Hindu-Tempel hat Manōnmaṇi als Hauptgottheit (vgl. Baumann/Tunger-Zanetti 2014). Als Verkörperung von cakti wird sie als eigenständige Gottheit angesehen. Informanten im Feld bezeichneten sie gleichzeitig auch als Ehefrau Civans bzw. Civan als ihren Gefährten. Civan, Murukan und Ganeśa werden im Tempel auch mit einem jeweils eigenen Schrein verehrt.

Im Untersuchungszeitraum waren zwei Tempel in der Schweiz Turkkai Amman gewidmet; einmal ein Tempel in Root bei Luzern und einer in Grenchen (Kanton Solothurn). Turkkai (skr. durgā) wird besonders an Dienstagen und Samstagen verehrt, um Schutz vor den aus der Astrologie zugeschriebenen Energien (skr. gráha; tam. kōtl)) der Planeten Mars bzw. Saturn zu erbitten. ${ }^{110}$ Turkkai wird als eine Gottheit angesehen, welche die negativen Einflüsse dieser Himmelskörper kontrollieren kann (vgl. Rodrigues 2009, 544). Navarāttiri (skr. Navarātri), das Fest der neun Nächte, ist jenes Fest, in welchem Turkkai am umfangreichsten verehrt wird.

Im Vergleich zu traditionellen Ausformungen tamilischer Hindu-Religiosität spielt die Verehrung von Turkkai in der rezenten Diaspora eine überproportional grosse Rolle (Shanmugalingam 2002). Innerhalb der orthodoxen Caiva-Tradition dominieren männliche Gottheiten. Diese Veränderungen sind jedoch nicht nur vor dem Hintergrund der Diaspora-Situation zu sehen: Auch in Sri Lanka ist in den letzten drei Jahrzehnten ein zahlenmässiger Anstieg an Turkkai-Tempeln zu verzeichnen. Die Etablierung eigener Tempel mit der Hauptgottheit Turkkai, die im Allerheiligsten verehrt wird, ist eine relativ neue Entwicklung innerhalb der tamilischen Gebiete in Sri Lanka. Nach dem Civa Ākamam war Turkkai nicht als Hauptgottheit eines Tempels vorgesehen. "There where no separate temples for the Goddess Durga [Turkkai, R.E.] prior to mid 1970s. This situation has changed dramatically in Jaffna and from here it has spread to many parts of the country" (Shanmugalingam 2002, 93). ${ }^{111}$ Mit dem Anstieg an Vereh-

110 In allen Tempeln der Schweiz ist auch ein Schrein für die Navagraha (tam. navakkirakam), die neun Planeten, inklusive der mythischen Himmelsgestirne Rahu und Kethu, errichtet.

111 Weiter heisst es: "Even in areas where a separate Durga temple is not available, small shrine rooms have been constructed for this popular goddess and her image is propitiated in these shrines. This has become necessary to cater to the needs of the increasing number of devotees of all age groups from all parts of the country" (Shanmugalingam 2002, 93). 


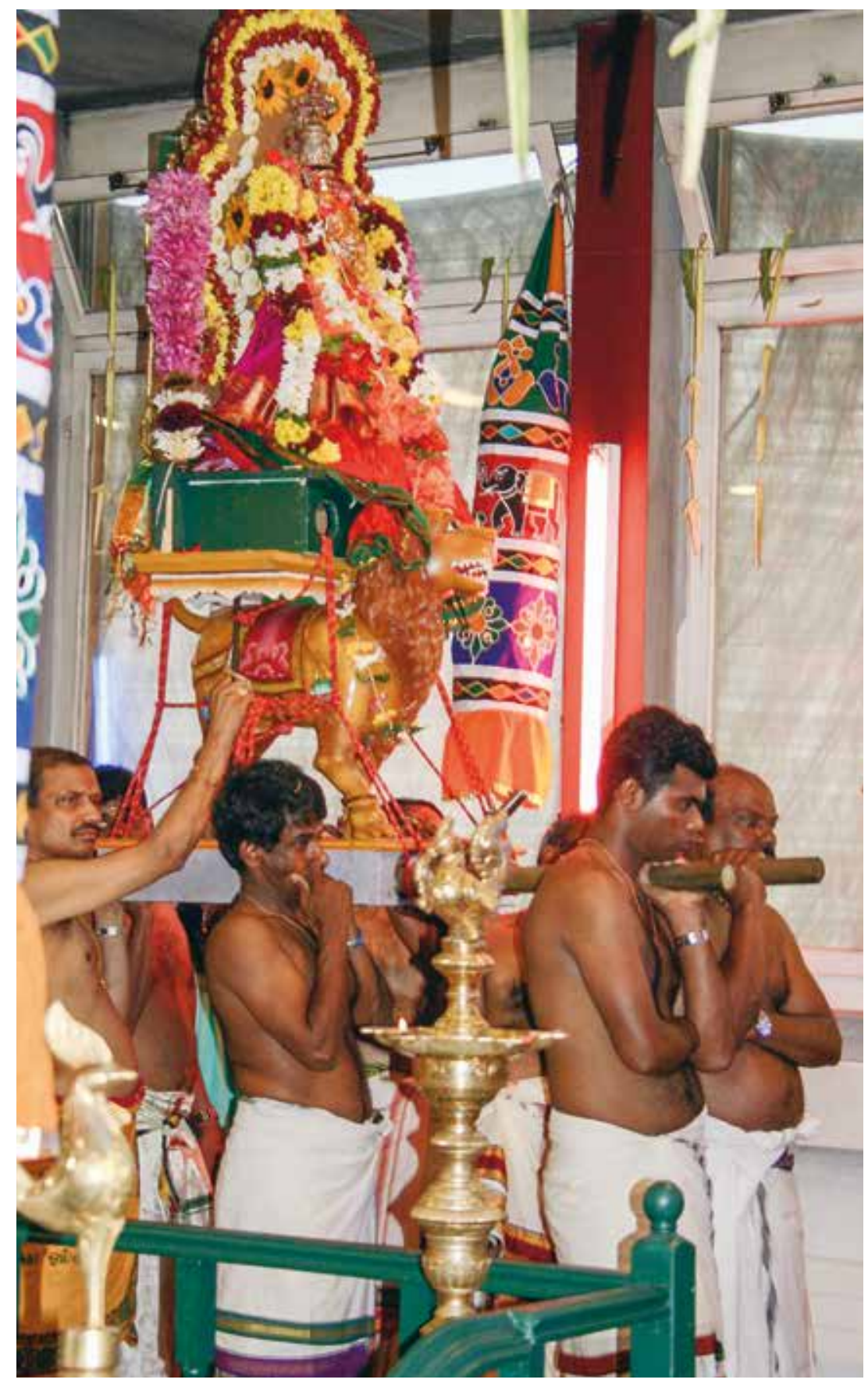

Abb. II 4: Turkkai auf ihrem Reittier, dem Löwen, während der Prozession im Inneren des Turkkai Ammañ Tempels Luzern im Rahmen des Tempelfestes (11.08.2008). 
rungsorten für Turkkai geht auch ein Bedeutungswandel dieser Gottheit für die Hindus einher. Shanmugalingam zeigt in seiner Studie $A$ new face of Durga 2002 zur rezenten Verehrung Turkkais auf der Jaffna-Halbinsel anschaulich auf, dass die Popularität dieser Göttin Resultat der ethnischen Spannungen und des darauffolgenden militärischen Konflikts in Sri Lanka ist. Dies unterstreicht eine Leitthese der vorliegenden Studie, nämlich, dass der Konflikt in Sri Lanka Auswirkungen auf das religiöse Leben tamilischer Hindus im Land und auch in der Diaspora hatte. Den Deutungswandel der Göttin Turkkai sieht der Autor der Studie als Produkt des gesellschaftlichen, psychologischen und symbolischen Wandels in Jaffna an. ${ }^{112}$ Er zeigt auf, wie Turkkai von einer unpopulären Gottheit, die nur drei Tage im Jahr (zum Fest Navarāttiri) als Kriegsgöttin verehrt wurde, zu einer zentralen Gottheit in der tamilischen Gesellschaft Sri Lankas wurde. Frauen haben durch die Turkkai-Verehrung Anteil an rituellen Vollzügen bekommen. So wurde ihnen als rituelle Neuerung erlaubt, den Tempelwagen têr während des jährlichen Tempelfestes zu ziehen, was ursprünglich Männern vorbehalten war (Shanmugalingam 2002, 194f.). Auch wurde zum ersten Mal eine Frau Präsidentin eines Tempelkommitees in einem Turkkai-Tempel, welcher der orthodoxen Shaiva-Tradition angehört.

Seit den 1970er Jahren lässt sich die Tendenz feststellen, dass auch in traditionellen Tempeln ein Turkkai-Schrein aufgestellt wird. Von Jaffna hat sich die Turkkai-Verehrung in die Hauptstadt Colombo ausgeweitet. Die Exilanten haben diese Form der Verehrung Turkkais in die Diaspora-Länder getragen (vgl. Shanmugalingam 2002, 3). Der Autor stellt heraus, dass die steigende Verehrung Turkkais mit einem Wandel der zugeschriebenen Rolle der Göttin einhergeht. Er konstatiert, dass sie sich von einer furchterregenden Kriegsgöttin zu einer gütigen und wohlwollenden Gottheit gewandelt hat. Familieninteressen wie die Bitte um Nachwuchs und eine gute Ehe und Anliegen, welche den Krieg betreffen, sind Gründe, warum Turkkai in den tamilischen Gebieten Sri Lankas verehrt wird (vgl. Shanmugalingam 2002, $41 \mathrm{ff}$.): Frauen verehren Turkkai und bringen ihr Opfer dar, um einer traditionellen Rolle als Ehefrau und Mutter gerecht zu werden. Damit stabili-

112 Seine Untersuchung bezieht sich auf den Ausgangspunkt der Bewegung, den Turkkai Ammañ Tempel in Tellippalai, Jaffna. Seit 1977 steigt die Zahl weiblicher Besucher drastisch, wodurch das Tempel-Einkommen grösser wird. Dies machte die räumliche Erweiterung des Tempels möglich, was wiederum zu einer kontinuierlichen Steigerung der Popularität des Tempels führte. Tellippalai selbst ist der Heimatort des Autors der Studie. Der Turkkai-Tempel hatte einen grossen Einfluss in den tamilischen Gebieten und es finden sich zahlreiche Ableger-Tempel (satellite temples). Im Mai 1992 wurde der Tempel in Jaffna im Zuge des Bürgerkrieges von der sri-lankischen Armee bombardiert. In einem Gespräch erzählte mir eine Tamilin, dass der Tempel sehr berühmt sei, weil dort Turkkai als kleine, schwarze Göttin verehrt werde. 


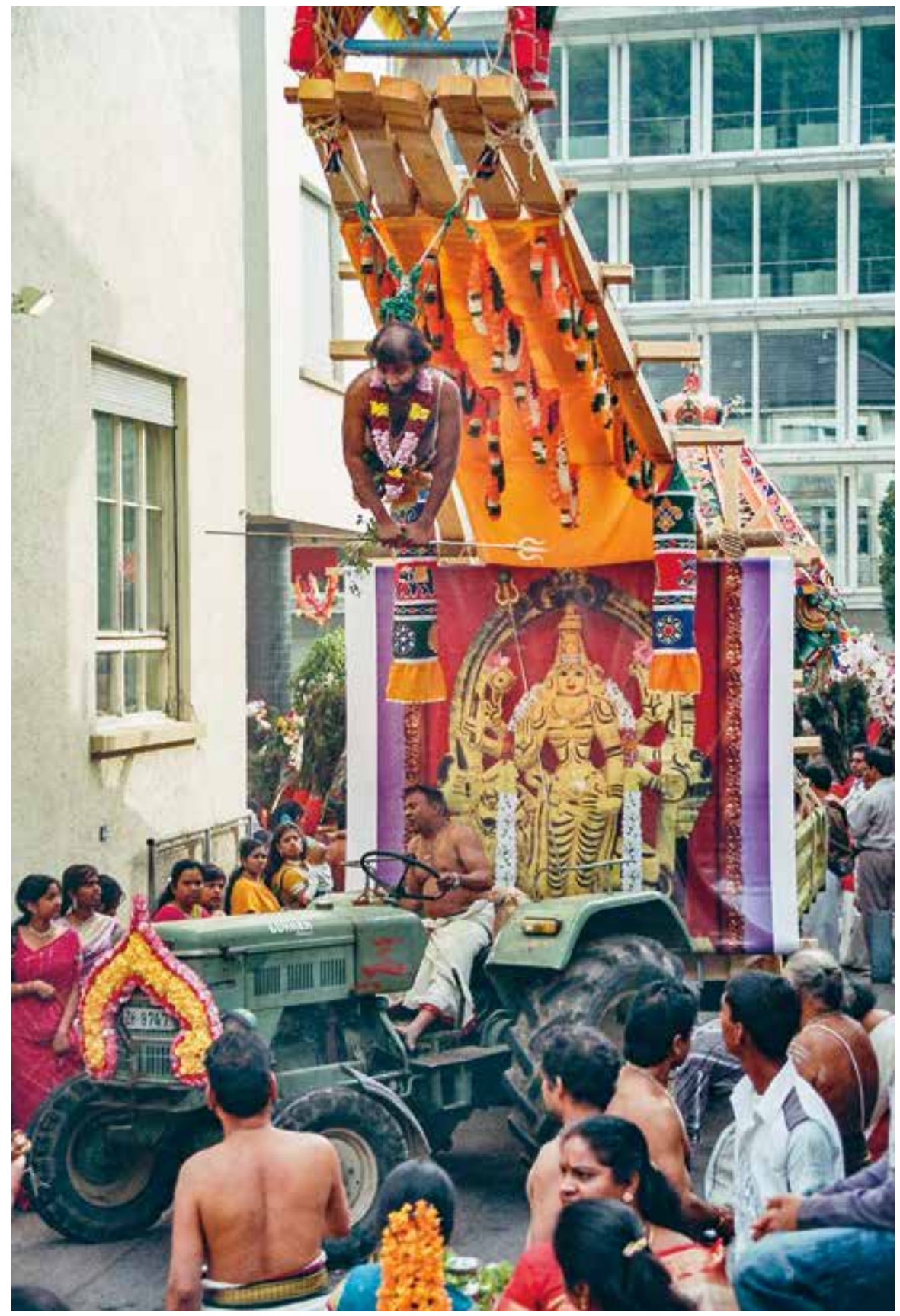

Abb. II 5: Die Darstellung Viṣnu Turkkai Amman̄s, befestigt an der Konstruktion für den hängenden kāvați (vgl. Kap. V 3.1), während des Tempelfestes des Viṣnu Turkkai Ammañ Tempels in Adliswil (15.09.2007). 
siert, wie Shanmugalingam zeigt, diese Form der Turkkai-Verehrung herrschende konservative Geschlechterbilder.

Shanmugalingam stellt heraus, dass eine besondere Form von Turkkai, nämlich Turkkai Vișnu, besondere Popularität in der Diaspora erlangt hat.

Temples have been set up in Canada, France, Denmark, Switzerland and Germany. The goddess in these temples is that of Vishnu Durga who is believed to protect them, bless them with jobs, husbands, and a happy marriage life.

(Shanmugalingam 2002, 169)

In der Schweiz findet sich in Dürnten, Kanton Zürich (nach seinem Wegzug aus Adliswil), ein Viṣnu Turkkai Ammañ Tempel.

Neben der Verehrung zentraler Göttinnen-Figuren und den Mitgliedern der Civan-Familie finden sich in den Schweizer Tempeln auch Figuren (mürttis) weiterer Hindu-Gottheiten. Auf die Figur Aiyappans, welcher in einigen Schweizer Tempeln ein Schrein eingerichtet ist und welche die Caivam und Viṣnu-Traditionslinie miteinander verbindet, wird in Kap. IV 6.2 näher eingegangen.

Viṣnu (auch Nārāyaṇa genannt) wird in den tamilischen Gebieten meist als Perumā lverehrt. Im Tempel in Trimbach und im Śrí Civacuppiramaniyar Tempel in Adliswil wird Krishna, die Inkarnation Vișnus, als Kind in einer Statue als cantānakōpālan (skr. santāna-Gopāla) dargestellt. Der Kopf der kosmischen Schlange sesha wölbt sich wie ein schützendes Dach über ihn. Informanten erklärten mir, dass sich besonders kinderlose Paare an ihn wenden, um ein Kind zu bekommen.

Eine Minderheit der in der Schweiz lebenden Hindus ist in der VaișnavaTradition verwurzelt. Als Vaiṣnavas sind sie hauptsächlich in der Swiss Tamil Krishna Society (STKS) organisiert, einer Gruppe, welche mit der International Society for Krishna Consciousness (ISKCON) verbunden ist (vgl. Kap. IV 3.2 f.). ${ }^{113}$

Im hindu-tamilischen Milieu findet sich ein breites Bewusstsein für inner-hinduistischen Pluralismus. Der hier präsentierte Überblick über die Gottheiten stellt daher nur eine schematische Darstellung wichtiger transzendenter Akteure dar, denen im rituellen Vollzug Agency zugeschrieben wird. Innerhalb des Spektrums spielen regionale Unterschiede eine grosse Rolle, was zu einer internen Vielfalt auch unter Caivas führt. Eine Informantin, welche aus den Ostgebieten Sri Lankas stammt, verweist beispiels-

113 Die tamilische Transkription des Sanskrit-Begriffs krșna lautet kiruṣna. Es findet sich jedoch auch ein originär tamilischer Name für Krishna: kaṇnann, welcher Krishna in kindlicher Gestalt beschreibt. kaṇnann ist vom tamilischen Begriff kaṇ für «Auge» abgeleitet und meint soviel wie «der mit den Augen». 


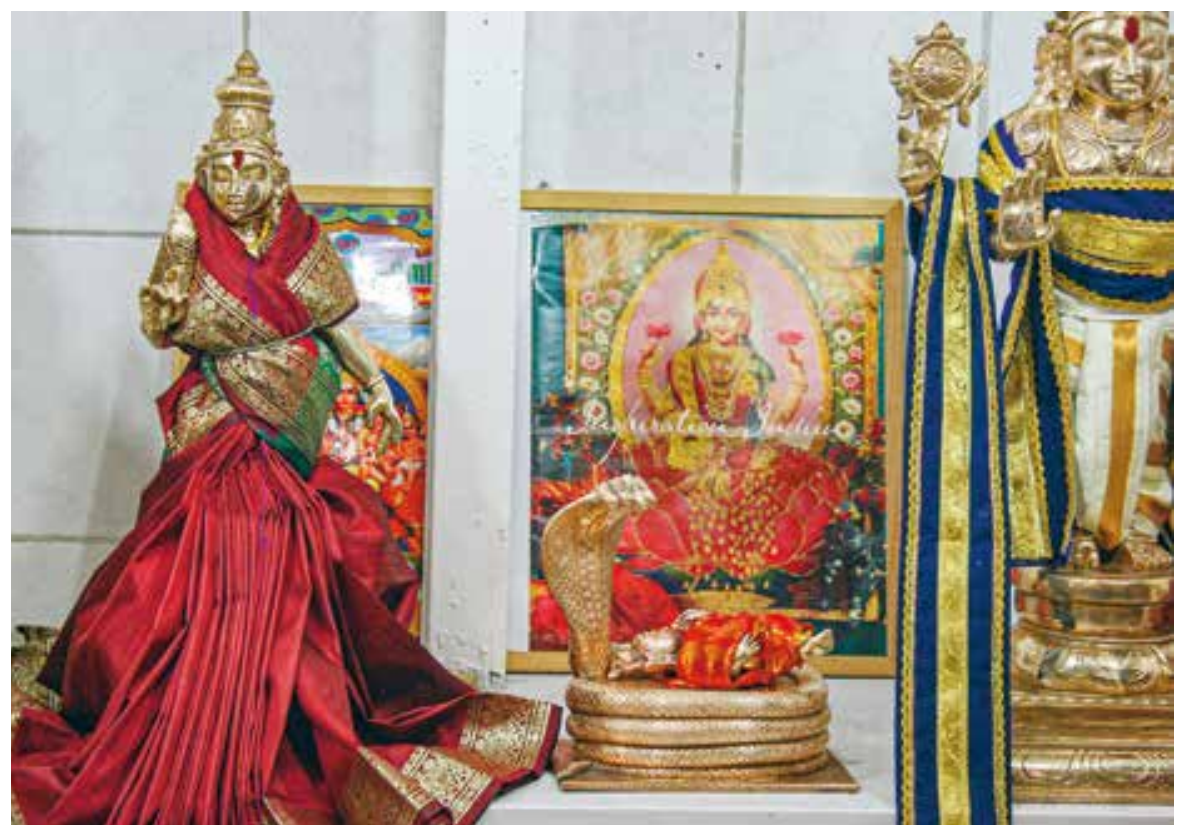

Abb. II 6: Krishna als cantānakōpālan unter der Schlange sesha im Śrī Civacuppiramaṇiyar Tempel in Adliswil. Hinter ihm ist ein Bild Lakhșmīs angebracht, die Gefährtin Viṣnus; rechts neben ihm ist eine Figur Nārāyaṇas aufgestellt (31.01.2009).

weise auf die internen Unterschiede der religiösen Praxis unter Tamilen in Sri Lanka.

Obwohl die meisten tamilischen Hindus Civan als den höchsten Gott ansehen, erkennen sie andere Strömungen «des Hinduismus» an. Exemplarisch dafür sei das religiöse Selbstverständnis und die Hindu-Praxis der Akteurin Lakhi ${ }^{114}$ skizziert. Lakhi, 20 Jahre, bezeichnet sich selbst als Hindu und gehört der zweiten Generation der tamilischen Diaspora in der Schweiz an. Sie versteht Hinduismus als einen Oberbegriff über viele «Religionen»: «Vielleicht weisst du das schon, dass es im Hinduismus mehrere Religionen gibt.» Sie ist mit unterschiedlichen dieser von ihr als «Religionen» bezeichneten Ausrichtungen vertraut. Ihre religiösen Präferenzen beschreibt sie mit der Nennung ihrer Lieblingsgottheiten. Sie bezeichnet Krishna, also eine zentrale Gestalt aus dem Spektrum der Vaishnavas, als ihre Lieblings-

114 Das Interview mit Lakhi wurde am 12.01.2009 geführt. Lakhi kam mit zwei Jahren nach Europa, lebt mit ihrer Familie in Zürich und macht eine kaufmännische Ausbildung. 
gottheit, weist aber auch Shiva entscheidende Bedeutung zu: «Mein Lieblingsgott ist Krishna / zugleich auch Shiva». ${ }^{115}$

Lakhi besucht mit ihrer Familie verschiedene religiöse Stätten: CaivamTempel in der Schweiz, den ISKCON-Tempel in Zürich (vgl. Kap. IV 3.2/3.3) und Versammlungsorte von Sathya Sai Baba-Verehrern (vgl. Kap. IV 3.4). Sie tanzte bharatanatyam (tam. paratanātțiyama) und praktizierte damit eine religiöse Ausdrucksform, die der Caivam-Tradition angehört (vgl. David 2009). Emotional fühlt sie sich der Vaishanava-Tradition am nächsten. Thre religiöse Praxis richtet sie also auf mehrere religiöse Bezugspunkte, Krishna wie auch Civan.

Also ich glaube jetzt/mein Lieblingsgott ist Krishna/also Vishnu. Dann habe ich noch Shiva. Ich habe Bharatanatyam gelernt/also eine Tanzart aus Indien. Shiva ist dort der Hauptgott/das heisst/ich habe ihn auch geehrt/so gesagt/wenn man tanzt, muss man ihn ehren und tanzen.

Das Phänomen des hindu-religious overlap kommt auch in der Ausgestaltung der Hindu-Tempel in der Schweizer Diaspora zum Ausdruck. Im Śrì Civacuppiramaniyar Tempel in Adliswil wurde ein neuer Schrein installiert, welcher der Verehrung Viṣnus gewidmet ist. Ein Tempelmitglied erklärt dies mit der Diaspora-Situation: «Wir können hier nicht für jeden Gott einen Tempel bauen/deshalb ist das zusammen.» ${ }^{116}$

\section{Hindu-Sein als Teil eines gemeinsam geteilten tamilischen Erbes}

Der Begriff der Diaspora eröffnet auch die Frage nach dem Beziehungsverhältnis zwischen als religiös und kulturell etikettierter Identität. Die Begriffe «Religion» wie auch «Kultur» ${ }^{117}$ sind Ergebnisse historisch gewachsener diskursiver Prozesse. " $[A]$ large part of cultural practice across the globe is manifest through forms and discourses that appear to fit into the broad parameters of what western scholars have come to call 'religion"' (Nye 2000a, 6). An dieser Stelle kann die Debatte über die Verhältnisbestimmung und Problematik der Begriffe «Kultur» und «Religion» nicht umfassend geführt werden. Wie unter Kapitel I 1. dargelegt, fokussiert diese Studie auf Hindu-Praxis und umgeht mit diesem Begriff eine Dichotomisierung in als religiös kategorisierte auf der einen und als kulturell zugeschriebene Praxis auf der anderen Seite.

115 Interview 2; 12.01.2009.

116 Mitglied des Tempelvorstands des Śrī Civacuppiramaṇiyar Tempels in Adliswil am 01.02.2009.

117 Zum Begriff der Kultur vgl. Moebius 2010, 14 ff.; Müller-Funk 2002. 
Das «religiöse Selbstverständnis» der Akteure bewegt sich zwischen folgenden äussersten Polen: Es finden sich Akteure, welche sich mit dem Begriff Hindu bezeichnen, aber von sich selbst angeben, nicht sehr religiös zu sein. Ihr Verständnis von Hindu-Sein basiert auf der Annahme, dass diese Identitätszuschreibung Teil einer heritage identity sei, sie diese Zugehörigkeit von ihren Eltern geerbt haben. Der andere äussere Pol stellen jene Akteure dar, welche als zentrales Merkmal ihrer Identitätskonfiguration eine intensive religiöse Praxis angeben und ihr Verständnis als Hindu-Sein aussschliesslich dem System »Religion» zuordnen und es von ethnischer Zugehörigkeit abkoppeln.

Die Selbstbezeichnung als Hindu bzw. Caiva ist für viele der Migrierten der ersten Generation ein Teil einer geteilten ethnischen Identität - eine Variable einer Identitätskonstruktion, die als Teil eines gemeinsamen tamilischen Erbes angesehen wird. So kann eine Gruppe von religiösen Akteuren ausgemacht werden, welche ihre religiöse Zugehörigkeit als Teil einer unabänderlichen Herkunft ansehen. Sie geht in der Regel auf keine individuelle Wahl der Akteure zurück.

Das Selbstverständnis des Akteurs Murari sei exemplarisch für diese Positionierung dargestellt. Für ihn stellt es eine unabänderliche Tatsache dar, dass er Hindu ist. Er ist es durch seine Geburt und sieht dies als Konstante für sein weiteres Leben an: «Ich bin ein geborene Hindu. Das ist so. Das ist fertig / Punkt.» ${ }^{118}$ Er schliesst für sich einen Wechsel der Religionszugehörigkeit aus: «Ich bin Hindu. Das ist klar für mich. Es ist klar. Ich sage nicht: <Nein/so nicht.> Ich bin so einfach gebürtige Hindu.» ${ }^{119}$ Jedoch betont er, dass dieses Selbstverständnis nicht mit einer regelmässigen religiösen Praxis korreliert. Sein Hindu-Sein wird nicht durch das Fernbleiben von religiösen Orten oder Nicht-Praxis gefährdet; unabhängig davon ist und bleibt er Hindu:

Ich bin ein Hindu. Gebürtige Hindu. Ich lebe so. Das ist so. Dann ich sage auch nicht: <Ich bin ein Hindu. Ich wollte immer jede Freitag jetzt in Tempel.> Das will ich auch nicht. Ich bin ein Tempel/äh/ich bin ein Hindu. Okay. Ist fertig.

Mit dem im Plural formulierten Überbegriff Hindu-Traditionen soll im Folgenden die Heterogenität der Praktiken und Verständnisse angezeigt werden. Der Begriff der Tradition anstelle der Verwendung des Terminus Hindu-Religionen wurde gewählt, um keine binäre Schematisierung in religiöse und nicht-religiöse Phänomene vorzunehmen. Der Begriff

118 Die folgenden Zitatausschnitte entstammen dem Interview mit dem in Luzern lebenden Tamilen Murari am 04.12.2008 in dessen Wohnung. Interview 4; 04.12.2008.

119 Interview 4; 04.12.2008. 
Hinduismus wird in den Fällen aufgegriffen, wo von den verantwortlichen religiösen Akteuren ein "homogeneous Hinduism" (Jacobsen 2009, xxxvii) als eine «gegenwärtige globale Religion» zum Ausdruck gebracht werden soll.

\section{Rückbezüge zu einer imaginierten Nation und transnationale Vernetzungen}

Der Diaspora-Begriff als Darstellungsform sozialer Phänomene im Zeitalter der Globalisierung liefert eine Beschreibungskategorie für soziale Formationen, welche sich auf der einen Seite nationalstaatlichen Zuordnungen entziehen, auf der anderen Seite jedoch durch nationalstaatliche Denkmodelle entscheidend mitgeprägt wurden (vgl. Mayer 2005, 8). Dieses Faktum prädestiniert den Diaspora-Begriff als Analysekategorie für die vorliegende Studie.

Diaspora ist als dynamischer Prozess der Gruppenbildung von Migrierten zu verstehen, wobei Gruppenidentitäten als konstruierte Einheiten, als die Prozesse und Produkte sozialen Handelns verstanden werden. Diaspora-Identitäten entstehen durch konstruierte Gemeinschaftsvorstellungen und sind somit immer, wie Nationen auch, vorgestellte Gemeinschaften (vgl. Anderson 1983). Die Bildungen von Diaspora-Gemeinschaften sind auch immer Prozesse kultureller Inszenierungspraktiken. Dabei können die Gemeinschaftsvorstellungen von verschiedenen Akteuren unterschiedlich stark vertreten werden. Die äusseren Pole einer Diaspora sind auf der einen Seite politisch engagierte «Diaspora-Aktivisten» und auf der anderen Seite die «schweigende Mehrheit». Wenn Migrierte einen Gemeinschaftsdiskurs teilen, dann kann von einer Diaspora gesprochen werden. An dieser Stelle kann, angelehnt an einen aktionszentrierten Ansatz, von doing diasporaProzessen gesprochen werden: Konstitutiv für ein spezifisches diasporisches Gruppenbewusstsein ist das Bewusstsein der Fragmentierung und ein gemeinsamer Bezugspunkt, ein imaginiertes, von der Gruppe in der Vergangenheit verlassenes Zentrum («die Heimat»; "the homeland”). Die Konstruiertheit des Bezugspunkts ist hervorzuheben.

Das in diesem Kapitel herausgearbeitete Diaspora-Verständnis stützt sich auf die von Clifford, Baumann und Vertovec entworfenen Arbeitsdefinitionen von Diaspora, welche einen Mittelweg zwischen homogenisierenden und postmodernen Diaspora-Auffassungen darstellen. Der DiasporaBegriff wird weiter gefasst, als ihn William Safran 1991 bestimmt hat, und schliesst auch jene Gruppierungen ein, welchen kein Rückkehrwunsch als 
identitätsstiftendes Merkmal inhärent ist (vgl. u. a. Clifford 1997). Baumann versucht den Diaspora-Begriff aus den gängigen Real- und Nominaldefinitionen zu bestimmen und eine Arbeitsdefinition zu etablieren, welche Vergleiche ermöglicht. Er legt folgende generalisierende und relativ offene Arbeitsdefinition von Diaspora vor: Diaspora bezeichnet eine migrierte Gruppe, welche in einem oder mehreren Aufnahmeländern lebt, sich jedoch identifikatorisch auf «ein fiktives oder real existierendes, geographisch entferntes Land bzw. Territorium und dessen kulturell-religiöse Traditionen» rückbezieht (vgl. Baumann 2000a, 327; 2003a, 68). «Fehlt eine Rückanbindung, die sich in symbolisch-inhaltlichen und materiellen Bezügen ausdrücken kann, soll eine Situation nicht als diasporisch bezeichnet werden» (Baumann 2007, 15).

Zusammenfassend bleibt festzuhalten, dass der Begriff der Diaspora als eine Analysekategorie zugrunde gelegt wird, wobei dieser in Bezug auf die Untersuchungsgruppe als nicht religiös konnotiert verstanden wird. Diaspora beschreibt eine soziale Formation, dessen Akteure ein Gruppenbewusstsein teilen, welches von der Erfahrung der Zerstreuung geprägt ist. Dieses verweist immer auch auf ein imaginiertes Heimatland, welches verlassen wurde. Diaspora-Akteure agieren in einem transnationalen Raum, über nationalstaatliche Grenzen hinweg, sind jedoch durch Nationengrenzen geprägt. Darauf folgt, dass die Praxis von Hindu-Traditionen durch tamilische Migrierte in einem transnationalen Raum stattfindet, nationalstaatliche Denkmodelle jedoch im Handeln der Diaspora-Akteure relevante Kategorien sind. Die tamilische Sprache, Rückbezüge zu tamilischen Regionen in Sri Lanka und Bezüge zum Bürgerkrieg sind auch im religiösen Feld der tamilischen Hindus in der Schweiz wirkmächtig (vgl. das Fazit dieser Studie).

Das tamilische Hindu-Spektrum zeichnet sich durch interne Vielfalt aus, obwohl in den Schweizer Tempeln bis auf die Orte von Reformgruppierungen meist die selben Göttinnen und Götter verehrt werden. Jedoch sind die Positionierungsstrategien tamilischer Akteure heterogen. Die HinduPraxis kann als eine individuelle Entscheidung an den verschiedensten Orten der Diaspora ohne verstärkte Anbindung an die Herkunftsregionen durchgeführt werden oder aber als Teil der heritage identity mit dezidiertem Rückbezug auf die verlassene Heimat vollzogen werden. 


\title{
Kapitel III \\ Die Bedingungen des Residenzlandes als Aspekt der Lokalisierungsdynamiken von Hindu-Praxis
}

\author{
Es gibt keine Heimat, die nicht zur Fremde werden \\ könnte, und umgekehrt ${ }^{120}$ \\ (Ilja Trojanow, Der entfesselte Globus, 2008, 8)
}

Nach der Einordnung des Begriffs der sri-lankisch tamilischen Diaspora innerhalb der gegenwärtigen Diaspora-Diskurse wird im Folgenden ein Überblick über die tamilische Diaspora in der Schweiz gegeben. Die Darstellung erfolgt auf der Basis der Analysekategorie Inkorporation, deren theoretische Implikationen vorab skizziert werden (III 1).

Tamilinnen und Tamilen flüchteten seit den 1980er Jahren aus ihrer in der Republik Sri Lanka gelegenen Heimat. Diese wurde ihnen durch eine Politik der Marginalisierung von Minderheiten und der Verfestigung ethnischer Nationalismen «zur Fremde». Der Bürgerkrieg und seine Vorgeschichte als zentraler Fluchtgrund werden im Folgenden als Hintergrund der tamilischen Immigration in die Schweiz dargestellt (III 2.). Daran anschliessend folgt die Darstellung der Phasen der tamilischen Immigration ins Residenzland Schweiz und der Bedingungen der dortigen Inkorporation zugewanderter Minderheiten. Ausgangspunkt der Darstellung ist die Annahme, dass die Inkorporationsbedingungen zentralen Einfluss darauf haben, wie und ob «die Fremde» Migrierten zur «Heimat» werden kann. Abschnitt III 3. stellt aus einer historischen Perspektive die Etappen der tamilischen Einwanderung in die Schweiz dar.

Die Inkorporationsbedingungen stellen gleichzeitig wichtige Rahmenbedingungen für die religiöse Beheimatung zugewanderter Religionen dar.

120 Zitat aus dem Buch von Ilja Trojanow Der entfesselte Globus $(2008,8)$. 
Der Einfluss der kontextuellen Faktoren auf die Etablierung tamilischer Hindu-Praktiken in der Schweiz wird gebündelt in fünf Einflussfaktoren dargestellt (III 4).

\section{Die Bedingungen der Aufnahmeländer: Inkorporation als Analysekategorie}

Die Verwendung des Begriffs Inkorporation in dieser Studie stützt sich auf die Ausführungen des Migrationssoziologen Ludger Pries (Goebel/Pries 2003; Pries 2003; 2005, 2007). Ich verwende den Begriff der Inkorporation im Sinne Pries' im Folgenden für die Beschreibung der Eingliederung der transnational vernetzten Immigrantengruppe der sri-lankisch tamilischen Diaspora. Pries versteht unter der gesellschaftlichen Inkorporation von Migrierenden einen ergebnisoffenen sozialen Prozess der «ökonomischen, kulturellen, politischen und sozialen Verflechtung von Migranten auf der lokalen, regionalen, nationalen und transnationalen Ebene, also sowohl in der (bzw. den) Herkunftsregion(en) und der (bzw. den) Ankunftsregion(en)» (Pries 2007, 114).

Inkorporation als multi-dimensionaler Prozess kann gemäss Pries also nach gesellschaftlich relevanten oder sozialräumlichen Kriterien geordnet werden. Gesellschaftliche Inkorporation besteht aus einer ökonomischen, politischen, sozialen und kulturellen Ebene (vgl. Pries 2005, 1). In der sozialräumlichen Differenzierung ist in den Ausführungen von Pries die Einbeziehung der transnationalen Perspektive zentral, wobei die lokale, nationale, regionale Ebene und die transnationale Perspektive interferieren. «So wie die Migrierenden zu einer Vielfalt verschiedener gesellschaftlicher Bezugsgruppen gehören mögen, so kann ihre Inkorporation gleichzeitig in verschiedenen geographischen Räumen stattfinden» (Pries 2005, 21).

Die Darstellung von Inkorporationsdynamiken erfolgt ergebnisoffen; Pries geht nicht von einem Stufenmodell der gesellschaftlichen Eingliederung aus, an dessen Ende eine «gelungene Integration» steht. Vielmehr versucht das Konzept der gesellschaftlichen Inkorporation ein wertneutrales Werkzeug zur Beschreibung der Eingliederung von Migrierten zu liefern, ohne mit den normativ besetzten und politisch vorbelasteten Termini Integration oder Assimilation zu operieren (vgl. Glorius 2007, 45; Sökefeld 2004). ${ }^{121}$ Diese Studie operiert auf analytischer Ebene nicht mit diesen Begriffen.

121 Rainer Bauböck skizziert eingehend die Problematik des Begriffes Integration und zeigt auf, warum er ihn trotz Kritik für einen geeigneten wissenschaftlichen Terminus hält 
Der Terminus Assimilation, der aus dem Lateinischen mit Angleichung übersetzt werden kann, hat sich teilweise «zu einem Kampfbegriff in der politischen Debatte der Einwanderungsländer in der westlichen Hemisphäre entwickelt» (Aumüller 2009). Auch der Terminus Integration kann durch die einseitige Betonung der Eingliederungsanforderungen an die Migrierten innerhalb vieler Integrationskonzepte schnell zu einem Kampfbegriff innerhalb eines «Leitkultur-Diskurses» werden. Sogenannte «Integrationspolitik» wie auch mehrheitsgesellschaftliche Integrations-Diskurse, die mit diesem Begriff operieren, werden im Folgenden als Elemente der Inkorporationsbedingungen betrachtet. Diese Diskurse gehen vielfach davon aus, dass sich Migrierte der Residenzgesellschaft unterzuordnen hätten; Integration wird hier also als Anpassung an die mehrheitsgesellschaftlichen Machtstrukturen verstanden (vgl. Bauböck 2001, 27).

In der Analyse dieser Studie wird der Begriff der Inkorporation verwendet, um multiple Bedingungen für die Eingliederung von Immigranten zu beschreiben. Dabei konzentriert sich die Analyse von Inkorporationsprozessen nicht nur auf die Eingliederung, sondern auch auf Ausschlussprozesse (vgl. Beyeler/Suter Reich 2008, 234f.). Sie nimmt die Gesamtheit der Bedingungen in den Blick, welche die agency von Diaspora-Gruppen begünstigen oder einschränken.

Yasemin Soysal verwendet den Begriff der Inkorporationsregime, den sie in ihrem 1994 erschienenen Buch Limits of Citizenship. Migrants and Postnational Membership in Europe einführt.

In using the term incorporation regime, I refer to the patterns of policy discourse and organization around which a system of incorporation is constructed. All states develop a set of legal rules, discursive practices, and organizational structures that define the status of foreigners vis-à-vis the host state, and the forms and boundaries of their participation in host policy institutions.

(Soysal 1994, 32)

In der Schweiz kann nicht nur von einem «Inkorporationsregime» gesprochen werden. Aufgrund des dezentralen dreistufigen Systems in der Schweiz - bestehend aus Bund, Kanton, Gemeinde - ist eine «Vielzahl lokaler Ausprägungen» von Inkorporationsregimen auszumachen (vgl. Beyeler/ Suter Reich 2009, 142). Diskursive Muster der Residenzgesellschaft und die institutionellen Rahmenbedingungen des Residenzlandes haben auch zentrale Auswirkungen auf die Handlungsstrategien von Immigrantinnen und Immigranten, die versuchen, die von ihnen mitgebrachten religiösen Traditionen im neuen Kontext zu etablieren (vgl. Beyeler/Suter Reich 2008, 2009).

(vgl. Bauböck 2001). 
Die Inkorporation von Migrierten ist auch immer eine Bedingung der Inkorporation von Immigranten religionen. Eine Darstellung der inkorporativen Bedingungen ist daher unerlässlich, um Voraussetzungen und Dynamiken der Etablierung von tamilischen Hindu-Traditionen in der Schweiz zu verstehen.

Aspekte der Schweizer Inkorporationsbedingungen werden im Folgenden in einem historischen Überblick über tamilische Immigration in die Schweiz gezeigt. Auswirkungen auf die tamilische Hindu-Praxis werden dabei angeschnitten. Systematisiert aufgelistet werden die Auswirkungen der inkorporativen Bedingungen auf die Praxis tamilischer Hindus in Kapitel III 4.

\section{Ethnische Nationalismen: Der Krieg in Sri Lanka (1983-2009) als zentraler Fluchtgrund}

Bevor die Bedingungen des Residenzlandes für die Etablierung tamilischer Hindu-Praxis dargestellt werden, skizziere ich im Folgenden zusammenfassend den zentralen Grund für die Flucht tamilischer Hindus und die Hintergründe des Konfliktes in Sri Lanka.

Im Zeitraum der Untersuchung lebten circa 800000 sri-lankisch-stämmige Tamilen ausserhalb Sri Lankas - circa 42000 davon in der Schweiz. ${ }^{122}$ Nicht Colombo oder die Stadt Jaffna in Sri Lanka ist gegenwärtig die Stadt, in welcher die meisten sri-lankischen Tamilen leben - die kanadische Metropole Toronto ist der Ort mit den meisten sri-lankisch tamilischen Einwohnern. ${ }^{123}$ Diese Situation geht hauptsächlich auf den Bürgerkrieg in Sri Lanka zurück, der zwischen den Konfliktparteien der Regierung des Staates Sri Lanka mit ihren militärischen Einheiten und der militanten tamilischen Separatistenbewegung LTTE geführt wurde. ${ }^{124}$ Der Krieg begann offiziell

122 Zum demographischen Profil und den statistischen Angaben zur Untersuchungsgruppe vgl. Kapitel III 3.5. Die im Folgenden genannten statistischen Zahlen sind den Angaben des Bundesamtes für Statistik und den «Ausländer- und Asylstatistiken», herausgegeben vom Bundesamt für Migration (BFM), entnommen (BFM 2007; 2010; 2012).

123 Für das Jahr 2008 nennt Jacobsen 800000 Tamilinnen und Tamilen, welche in dieser kanadischen Metropole lebten (vgl. Jacobsen 2009, 182).

124 An dieser Stelle kann nicht detailliert auf die Komplexität des Konfliktes, die Etappen der Vorgeschichte und den genauen historischen Ablauf des Bürgerkrieges eingegangen werden. Die Darstellung fokussiert im Folgenden auf für diese Arbeit relevante Aspekte und erhebt keinen Anspruch auf Vollständigkeit. Zu den Hintergründen und dem Verlauf des Konfliktes vgl. unter anderem Bandarage 2009; Flück 2005; Fricke 2002; Manogaran/Pfaffenberger 1994; Nubin 
am 23. Juli 1983 mit einem Anschlag der LTTE auf Regierungssoldaten und darauffolgenden Pogromen an Tamilinnen und Tamilen und wurde von der sri-lankischen Regierung am 19. Mai 2009 mit dem Sieg über die LTTE als beendet erklärt.

Diskurse um den Krieg und seine Auswirkungen spielen im alltäglichen Leben der Migrierten eine zentrale Rolle. Innerhalb der Feldforschung wurde deutlich, dass diese auch Auswirkungen auf ihr religiöses Leben haben. Gespräche über den Konflikt wurden beispielsweise in den Räumlichkeiten der Tempel als sozialen Treffpunkten geführt. Auch das Image einzelner Tempel selbst wird von Tamilen in der Schweiz teilweise mit einer politischen Positionierung im Konflikt verbunden. So finden sich innerhalb der tamilischen Diaspora in der Schweiz Stimmen, die einige Tempelvereine als LTTE-Unterstützerorganisationen benennen (vgl. Kap. IV 4). ${ }^{125}$ Interferenzen zwischen politischen und religiösen Diskursen zeigen sich in der Organisation von so genannten «Friedensgebeten» in Hindu-Tempeln in der Schweiz, mit welchen die Hoffnung nach einem friedlichen Ende des Bürgerkrieges zum Ausdruck gebracht wurde (vgl. Kap. V 3.3).

Zentrale Push-Faktoren für tamilische Migration waren die ethnische Polarisierung im Land und der darauffolgende Bürgerkrieg, ${ }^{126}$ die aus den Transformationsprozessen nach der Unabhängigkeit des Landes entstanden. Auf die singhalesische nationale Dominanzpolitik folgte die Formierung militanter ethno-nationalistischer tamilischer Gruppen. Dies führte zu einem gesellschaftlichen Klima der Angst und zum Verlust von bürgerlichen Freiheiten. Im Vergleich zu Geflüchteten aus anderen kriegerischen Konflikten mit ähnlichen Push-Faktoren entschlossen sich überproportional viele Tamilen aus Sri Lanka zur Migration innerhalb des eigenen Landes (vgl. McDowell 1996, 269). Diese Besonderheit der sri-lankisch tamilischen Migration hat mehrere Gründe, die McDowell in seiner Studie A Tamil Asy-

2002; Rösel 1997; Spencer 1990; Winslow/Woost 2004. Die sozialen, ökonomischen und politischen Gründe, die seit der Unabhängigkeit Sri Lankas zur Migration von Tamilinnen und Tamilen führten, hat detailliert unter anderem McDowell analysiert (1996).

125 In der Veröffentlichung des Bundesamtes für Migration zur sri-lankischen Diaspora in der Schweiz heisst es: «Die politische Organisation LTTE unterstützt mehr oder weniger offen einen Teil dieser Aktivitäten wie auch einige Tempel und rechtfertigt dies mit der Notwendigkeit, die tamilische Kultur und Identität zu bewahren, wobei dieser Diskurs eng mit einer nationalistischen Ideologie verwoben ist» (Moret et al. 2007, 89) und «2002 übte die LTTE grossen Einfluss in vielen dieser Tempel aus und nichts lässt darauf schliessen, dass sich daran bis heute etwas geändert hätte» (Moret et al. 2007, 97).

126 Das 2005 aus dem Bundesamt für Flüchtlinge (BFF) und dem Bundesamt für Zuwanderung, Integration und Auswanderung (IMES) entstandene Bundesamt für Migration thematisiert in seiner Studie Die srilankische Diaspora den Krieg als zentralen Grund der tamilischen Einwanderung in die Schweiz (Moret et al. 2007). 
lum Diaspora. Sri Lankan Migration, Settlement and Politics in Switzerland systematisiert (vgl. McDowell 1996, 270 ff.). Die Untersuchung zeigt auch auf, dass eine strikte Unterscheidung zwischen Push- und Pull-Faktoren als alleinige Gründe für Migrationsbewegungen den Gegebenheiten nicht gerecht wird (vgl. Baumann 2009a, 341). Die Entscheidungsmacht der einzelnen Akteure der Migration ist des Weiteren ein wichtiger Aspekt für oder gegen Migration. ${ }^{127}$ Der einschneidende Schritt, das Land als Flüchtling zu verlassen, wurde von tamilischer Seite durch mehrere Faktoren begünstigt: Zum einen kann die relativ offene Einreise- und Aufnahmepolitik europäischer Staaten in den 1980er Jahren gegenüber Asylsuchenden als Pull-Faktor genannt werden, zum anderen gab es unter sri-lankischen Tamilen aus der Mittelklasse bereits während der britischen Kolonialzeit eine Tradition der interkontinentalen Migration. Sri-lankische Tamilen waren in der Verwaltung des Commonwealth auf verschiedenen Kontinenten beschäftigt. Diese Arbeit galt als prestigeträchtig. "Making it overseas' became the pinnacle of achievement, surpassing even the higher grades of civil service in Ceylon" (McDowell 1996, 91). Arbeitsmigration wurde als Mittel des sozialen Aufstiegs angesehen. "[...] a spirit of migration, mostly by middle-class Tamils, became built in to Tamil cultural aspirations, aspirations which were realised through institutionalised asylum migration [...]" (McDowell 1996, 69). Die Migrationstradition unter der tamilischen Bevölkerung Sri Lankas vor 1983 erfuhr durch den Bürgerkrieg eine Transformation. Migrierenden aus der Zeit nach 1983 dienten die bereits existierenden tamilischen communities in Nord-Amerika, Grossbritannien, Singapur und Malaysia mitunter als Brückenköpfe. Jene Migrierende, die sich nach 1983 in Grossbritannien niederliessen, fanden beispielsweise in London eine bereits etablierte sri-lankisch tamilische «Kulturszene» (vgl. McDowell 1996, 92). Soziale Netzwerke und Familienzusammenhalt waren eine wichtige soziale Ressource, welche Migrationsbestrebungen erleichterte. In den 1980er Jahren kam es darüber hinaus zur Institutionalisierung und Professionalisierung der tamilischen Migration mit dem Ziel des Asylantrags in einem europäischen Land (vgl. McDowell 1996, 270 ff.). Geflüchtete Menschen, die in die Schweiz kamen, konnten nicht auf solche gewachsenen Strukturen, die auf bereits im Land etablierte Tamilen (oder im religiösen Bereich auf Institutionen südasiatischer Hindus) zurückgehen, zurückgreifen.

127 Anthony H. Richmond hat ein analytisches Modell von reaktiver versus proaktiver Migration entworfen, was im Gegensatz zum Push/Pull-Modell grössere Betonung auf die agency der Migrierten legt. Reaktive Immigranten sind beispielsweise Geflüchtete, die das Land aufgrund einer existentiellen Bedrohungslage verlassen (vgl. Baumann 2009a, 341). 
Im Folgenden sollen die zentralen Push-Faktoren der Migration von srilankischen Tamilen in die Schweiz - die Marginalisierung der tamilischen Minderheit nach 1948 und der Bürgerkrieg in Sri Lanka - zusammenfassend dargestellt werden. Dabei werde ich zunächst kurz auf die Problematik einer wissenschaftlich exakten Darstellung des Konflikts und die soziale Wirkmacht der Geschichtsschreibung des Bürgerkriegs hinweisen. In den Analysen des Krieges in Sri Lanka dominiert ein Diskurs, der eine dualistische Gegenüberstellung der Ethnien Tamilen und Singhalesen vornimmt und ethnische Differenzen zwischen diesen Gruppen als Konfliktursachen ausmacht. Die Politikwissenschaftlerin Asoka Bandarage kritisiert diese monokausale Konfliktanalyse (vgl. Bandarage 2008, 2009). Statt die beiden Ethnien als homogene Kategorien und zentrale Konfliktparteien zu sehen, plädiert sie für einen multipolaren Ansatz. ${ }^{128}$ Sie benennt als zusätzliche Faktoren des Konflikts intra-ethnische Auseinandersetzungen und sozioökonomische Faktoren und versteht den Krieg - u.a. durch die von ihm ausgelösten Migrationsbewegungen und den Einfluss der tamilischen Diaspora - als ein transnationales Phänomen.

\subsection{Problematiken der Konfliktwahrnehmung des sri-lankischen Bürgerkriegs}

Dass Geschichtsschreibung in vielen Kriegen instrumentalisiert und als Legitimationsstrategie genutzt wurde und wird, zeigen Analysen verschiedenster Konflikte. Propaganda greift in vielen Fällen auf Geschichtsschreibung zurück und benutzt sie als Steinbruch für ihre argumentativen Strategien. Auch im Konflikt in Sri Lanka nutzen verschiedene Interessengruppen in ihrer Argumentation selektiv historische Ereignisse und Belege, um die eine oder andere Seite einseitig als Opfer bzw. Täter zu etikettieren. Dies macht es schwierig, den Konflikt so weit wie möglich neutral darzustellen. Interessengeleitete Geschichtsvermittlung kann durch verschiedenste Strategien, wie Hervorheben oder Weglassen bestimmter Daten und Ereignisse, geschehen. ${ }^{129}$

128 Aber auch andere Autoren verweisen auf die komplexen Faktoren, die zum Ausbruch des Krieges führten. Oskar Flück betrachtet beispielsweise die naturräumlichen und humangeographischen Faktoren und die Rolle der muslimischen Minderheit als wichtige Aspekte des Konfliktes (vgl. Flück 2005, 54f.). Auch McDowell konstatiert, dass die Gründe des Krieges nicht monokausal zu erklären sind (vgl. McDowell 1996, 71).

129 Aus zahlreichen Beispielen sei an dieser Stelle stellvertretend das Folgende herausgegriffen: Nach McDowell wurden bereits im Sri Lanka der 1980er Jahre Dokumentationen von den Konfliktparteien genutzt, um die jeweils eigene Position zu legitimieren. So veröffentlichte 
Eine wichtige Rolle innerhalb der Geschichtsvermittlung spielen auch die dabei verwendeten Begriffe. Im Kontext des Konflikts in Sri Lanka findet beispielsweise eine Debatte um die Verwendung des Begriffs Bürgerkrieg $^{130}$ und um den Namen des Landes ${ }^{131}$ statt. Im Online-Text Eezham Thamizh and Tamil Eelam: Understanding the terminologies of identity heisst es auf der Webseite TamilNet: "The term Sri Lanka, associated with the constitution also was seen as a symbol of oppression by the Tamil community of the island" ${ }^{\prime 32}$. Im Folgenden verwende ich den Begriff Bürgerkrieg, wie auch den Begriff Sri Lanka, als nicht-normative Beschreibungsbegriffe der aktuellen Gegebenheiten. Sri Lanka wird dabei als offizieller Name des völkerrechtlich anerkannten Staates verstanden, der sich gegenwärtig als Einheitsstaat konstituiert und innerhalb dessen der Konflikt von den Bürgern des Staates ausgetragen wurde.

Dass die Darstellung und Analyse des Konfliktes ein umkämpftes Feld ist, das auch soziale Wirkmacht hat, zeigt sich auch innerhalb der tamilischen Diaspora in der Schweiz. Hier sei im Besonderen auf zwei Bereiche verwiesen. Zum einen hatte und hat eine Einschätzung der Situation der Tamilen in Sri Lanka konkrete und nachhaltige Auswirkungen auf die Asylpolitik gegenüber tamilischen Flüchtlingen und einzelnen Asylentscheiden. Asylanerkennung, Aufenthaltsstatus, Wegweisung und Rückführungsprogramme für tamilische Flüchtlinge hingen in der Schweiz in den 1980er und 90er Jahren auch von der Einschätzung der Gefahrenlage für Mitglieder der tamilischen Minderheit in Sri Lanka ab. ${ }^{133}$

beispielsweise die sri-lankische Regierung 1983 das Papier Sri Lanka - The Truth About Discrimination against the Tamils (Ministry of State, Overseas Information Service No.7). Basierend auf demselben Material publizierten aber auch tamilische Forschungseinrichtungen Berichte wie das Theepam Institute im Januar 1987 das Dokument State Sector Employment and Tamils in Sri Lanka, welche zu entgegengesetzten Schlussfolgerungen kamen (vgl. McDowell 1996, 80).

130 Dabei geht es um die Debatte, ob es sich um einen Konflikt zwischen zwei Ethnien innerhalb eines Einheitsstaates handle oder um den Kampf zweier Nationen, denen jeweils ein eigener Staat zustehe.

131 Die Begriffe Ceylon wie auch Sri Lanka sind politisch aufgeladene Begriffe: Ceylon ist ein kolonial geprägter Name, der von den Holländern und Briten verwendet wurde. Sri Lanka bedeutet «ehrenwerte Insel» und verweist nach Bandarage bereits auf den Anspruch, «Land der Singhalesen» zu sein (vgl. Bandarage 2009, 64). Von einigen tamilischen Akteuren wird die respektvolle Anrede Sri aus politischen Gründen nicht verwendet, und sie sprechen nur von Lanka. Tamilische Akteure verwenden darüber hinaus auch den tamilischen Begriff für die Insel īlam (oder die davon abgeleiteten Varianten Ealam oder Eelam), um die Perspektive der tamilischen Minderheit einzunehmen.

132 www.tamilnet.com/art.html?catid=13\&artid=27012; 25.10.2010.

133 Ein Beispiel: Der Bundesrat entschied 1984, dass eine Abschiebung von Tamilen nach Sri Lanka vertretbar sei, obwohl eine Delegation des eidgenössischen Bundesamtes für Polizei- 
Es finden sich auch Beispiele für einen Zusammenhang zwischen staatlicher Unterstützung der Immigranten-Gruppe und der Art des Aufenthaltsstatus der Einwanderer, die auf der Einschätzung der Lage in Sri Lanka basierten: Das Hilfswerk Caritas führte seit Anfang der 1990er Jahre speziell auf tamilische Flüchtlinge zugeschnittene Angebote durch, wie die «ethnospezifischen Kurs- und Informationsangebote für tamilische Frauen» der Caritas Luzern im Jahr 1994. ${ }^{134}$ Innerhalb der Unterstützungsangebote wurden auch kulturelle und religiöse Bedürfnisse der Migrierten berücksichtigt. Das hatte Auswirkungen auf die Etablierung tamilischer Hindu-Traditionen in der Schweiz. In den Anfangsjahren des tamilischen Vereins Tamil Mandram, der als Treffpunkt für Tamilen im Kanton Luzern gegründet wurde, wurden im Rahmen der Vereinstätigkeit religiöse Anlässe durchgeführt; auch richtete die Caritas einen kleinen Tempelraum in Luzern ein (vgl. Kap. IV 4.2). Die finanziellen Unterstützungsbeiträge hingen in diesem Fall mit dem rechtlichen Status der tamilischen Migrierten zusammen. So hatte die Caritas in ihrem Finanzplan für den Aufbau des Vereins 1992 Gelder des Bundesamts für Flüchtlinge vorgesehen. Diese wurden ihr aufgrund des rechtlichen Status des Zielpublikums jedoch nicht zugesprochen.

Des Weiteren ist auch die öffentliche Meinung gegenüber Tamilinnen und Tamilen in der Schweiz teilweise von der Vermittlung der Geschichte der tamilischen Minderheit in Sri Lanka und der Fluchtursachen abhängig. Der Bürgerkrieg in Sri Lanka war in der Schweiz kein in den Medien breit präsentes Thema. Es kam nur in seltenen Fällen zu einer öffentlichen Diskussion des Fluchthintergrundes der tamilischen Geflüchteten. Das gesellschaftliche politische Klima gegenüber Tamilen schwankte zwischen humanitärer Bereitschaft, verfolgten Minderheiten zu helfen, und einer Abwehrhaltung, die vor allem daraus resultierte, dass Tamilen per se als «Sympathisanten von Terroristen» angesehen wurden. Hier spielt der Diskurs über die LTTE im Bürgerkrieg eine wichtige Rolle. Die Einschätzung dieser Gruppe schwankte zwischen den Polen der wertschätzenden Anerkennung der Tamil Tiger als Freiheitskämpfer und der negativen Beurteilung als gefährliche Terroristen. Letztere Haltung drückt sich auf politischer Ebene durch die Forderung des Verbotes der LTTE durch den

\footnotetext{
wesen nach Sri Lanka reiste und feststellte, dass «für junge Tamilen jederzeit das Risiko bestehe, verhaftet zu werden» (Stürzinger 2002, 4). Es regte sich zivilgesellschaftlicher Protest gegen die Massnahmen, woraufhin der Entscheid noch im selben Jahr zurückgenommen wurde (vgl. Stürzinger 2002, 4).

134 Grobkonzept Tamilinnen-Projekt; 21.November 1994; Caritas Luzern (Staatsarchiv Luzern, Signatur: A 1480/111).
} 
Schweizer Staat aus. Ihr Image hatte damit auch Einfluss auf das öffentliche Bild tamilischer Migrierter in der Schweiz.

Auf den mehrheitsöffentlichen Diskurs über tamilische Immigrantinnen und Immigranten bauten die politischen Appelle von Tamilen der ersten und zweiten Generation an die Schweizer Mehrheitsbevölkerung auf, in denen sie auf die Situation der tamilischen Bevölkerung in Sri Lanka aufmerksam machten. In diesem Kontext wurde besonders gegen Ende des Krieges eine historische Darstellung des Konflikts in der Öffentlichkeitsarbeit eingesetzt. Innerhalb der Diskurse um das Schicksal der Tamilen in Sri Lanka wurden historische Vergleiche herangezogen - es wurde von einem Genozid ähnlich jenem an den Jüdinnen und Juden durch die Nationalsozialisten und von einem «zweiten Gaza» gesprochen. ${ }^{135}$ Damit sollte für Solidarität mit der tamilischen Bevölkerung Sri Lankas und den tamilischen Immigrantinnen und Immigranten geworben werden.

Als Beispiel sei die Informations-Karte des Tamilenforum Schweiz genannt, welche Anfang 2009 an die Schweizer Mehrheitsbevölkerung verteilt wurde - so beispielsweise anlässlich einer tamilischen Demonstration in Bern vor dem Bundeshaus am 30.03.2009. Zentraler Slogan auf der Vorderseite der Karte war: «Im Nordosten von Sri Lanka treibt die Regierung hunderttausende tamilische Zivilisten in den sicheren Tod während die Welt gebannt auf das Börsengeschehen schaut!» Die Rückseite der Karte bot einen kurzen Überblick über die Geschichte der Tamilen und Singhalesen in Sri Lanka von der Frühzeit bis in die Gegenwart. Unter der Frageformel «Wussten Sie, dass ...» wurden einzelne Phasen der Geschichte Sri Lankas aufgelistet. Zur Situation 2008 findet sich folgende Zusammenfassung: «Wussten Sie, dass ... die singhalesische Regierung mehrere Abkommen mit den Tamilen brach, und so auch das 2002 ausgehandelte Waffenstillstandsabkommen im Jahr 2008 einseitig und gegen den Willen der Tamilen kündigte?» Die Liste endet mit dem Resümee, dass im Moment im Land ein Genozid an den Tamilen geschehe («Das, was die Regierung von Sri Lanka in Vanni tut, einen Namen hat? Nämlich: Genozid - Völkermord!»).

135 Vgl. den Artikel von Peter Blunschi, Tamilen protestieren gegen zweites Gaza, in: 20 Min, 03.02.2009 (vgl. www.20min.ch/news/schweiz/story/Tamilen-protestieren-gegen-zweites-Gaza--20248663; 10.10.2010). 


\subsection{Die Vorgeschichte des Bürgerkrieges}

Die folgende zusammenfassende Darstellung über den Bürgerkrieg in Sri Lanka als zentrale Fluchtursache wird mit Fokus auf die tamilische Bevölkerungsgruppe vorgenommen. Durch diese Perspektivierung soll jedoch die Gruppe der Tamilen während des Bürgerkrieges nicht pauschal als eine homogene Gruppe «der Opfer» dargestellt werden.

Die ethnischen Spannungen in Sri Lanka sind vor allem ein Phänomen der Neuzeit, welches mit der britischen Kolonisation (1796/1818-1948) begann (vgl. Bandarage 2009). Dem Bürgerkrieg war ein schwelender und von den britischen Kolonisatoren indirekt geschürter Konflikt im damaligen Ceylon vorausgegangen. Ethnische Spannungen innerhalb des Vielvölkerstaates $^{136}$ wurden zur Zeit der britischen Kolonialherrschaft durch die Besetzung einflussreicher Positionen in der Verwaltung mit Tamilen angeheizt und traten nach Abzug der Briten offen zu Tage. Die Zeit von 1948 bis zum Beginn des Bürgerkrieges 1983 war von inter- wie auch intra-ethnischen Unruhen geprägt. ${ }^{137}$

Nach der Unabhängigkeit des Landes 1948 reagierte die singhalesische Mehrheit - im Zuge des Demokratisierungsprozesses des Landes, der Aufarbeitung der kolonialen Machtstrukturen und der Umverteilung der Macht - auf ihre indirekte Benachteiligung gegenüber der tamilischen Bevölkerung durch die britischen Kolonisatoren. ${ }^{138}$ Aus tamilischer Perspektive wurden die Entscheidungen der mehrheitlich singhalesischen Regierungspartei, der Sri Lankan Freedom Party (SLFP), in erster Linie als

136 Die letzte Volkszählung vor Kriegsausbruch 1981 gab an, dass $72 \%$ der Bevölkerung Sri Lankas Singhalesen waren, 12,7\% sri-lankische Tamilen, 5,5\% indische Tamilen, 7\% zur tamilisch sprechenden muslimischen Bevölkerung zählten (sogenannte Moors) und die restlichen 0,6\% sich aus den Gruppen der Burgern, Malayen und Veddhas zusammensetzten (vgl. DeVotta 2004: 22). Der Fragebogen zur Volkszählung in Sri Lanka aus den Jahren 2001 und 2012 teilt die Bevölkerung in folgende ethnische Gruppen ein: An erster Stelle werden Sinhalesen genannt, danach folgt die Nennung Sri Lanka Tamil und Indian Tamil, an vierter Stelle die Gruppe der Sri Lanka Moor, 5. Burgher, 6. Malay, 7. Sri Lanka Chetty, 8. Bharatha und 9. Other (vgl. http://www. statistics.gov.lk/PopHouSat/CPH2011/index.php; 05.01.2015).

137 In den Jahren vor Ausbruch des Krieges waren beispielsweise inner-singhalesische Konflikte Thema der Innenpolitik des Landes. Extremistische Parteien der Singhalesen wurden in den 1950er Jahren verboten und der damalige Regierungschef Bandaranaike wurde 1959 von einem singhalesisch-buddhistischen Mönch ermordet. 1971 wurde von der Regierung eine Revolte der singhalesischen «Volksbefreiungsfront» Janata Vimukti Peramuna (JVP) niedergeschlagen. Mehrere Tausend Anhänger der JVP wurden ermordet oder in sogenannte Umerziehungslager gebracht (vgl. de Silva 1981).

138 Hier spielten auch ökonomische Faktoren eine Rolle. Die 1950er Jahre waren in Ceylon von schlechten ökonomischen und sozialen Bedingungen geprägt (vgl. McDowell 1996, 72). 
Massnahmen zur Diskriminierung und Marginalisierung der Minderheiten des Landes angesehen. Anti-tamilische Politik wurde auf unterschiedlichen Ebenen wahrgenommen. Den indisch-tamilischen Arbeitern, die von den Briten ins Land geholt wurden, wurde 1948 die Staatsbürgerschaft und damit das Wahlrecht entzogen (Ceylon Citizenship Act). Noch 1963 waren $8 \%$ der Menschen der Insel ohne Pass - das war die Hälfte der tamilischen Bevölkerung (vgl. Flück 2005, 58). Ängste der Minderheiten wurden auch durch die Umsiedlungen von Singhalesen in traditionell tamilische und muslimische Gebiete im Norden und Osten des Landes geschürt (vgl. McDowell 1996, 74). In den 1950er Jahren bildeten sich politisch orientierte buddhistische Gruppen in Ceylon, die einen religiösen Dominanzanspruch erhoben. ${ }^{139}$

Tamilische Akteure begannen sich politisch zu organisieren und gegen die verschiedenen gesetzlichen Massnahmen der singhalesisch dominierten Regierung nach $1948 \mathrm{zu}$ protestieren. Im Fokus stand dabei die Bildungsund Sprachpolitik der Regierung. Der Official Language Act (inoffiziell auch Sinhala Only Act genannt) unter Präsident S. W.R.D. Bandaranaike, der die Sprache der Mehrheit, Sinhala, 1956 zur einzigen offiziellen Sprache des Landes erklärte, richtete sich zum einen gegen die ehemalige Kolonialmacht und ihre sprachliche Dominanz, zum anderen drückte er den kulturellen Dominanzanspruch der Singhalesen in der Bildung einer einheitlichen sri-lankischen Nation aus. Tamilische Intellektuelle sahen dieses Gesetz als ein Symbol der Minderheitenunterdrückung durch die singhalesische Mehrheit an. "Tamil leaders claimed that Sinhala language legislation would bring in an era of 'apartheid' with Sinhalese as the 'masters and rulers' and Tamils would be forced to 'accept subject status under them" (Bandarage 2009, 45). Im Bereich Bildungspolitik hatte das 1970 festgelegte Zulassungssystem zu Universitäten zur Folge, dass es der tamilischen Minderheit erschwert wurde, umfassende universitäre Bildung zu erhalten. Als sich 1972 das Land in Sri Lanka umbenannte und eine neue Verfassung als sozialistisch-demokratische Republik und «Einheitsstaat» erhielt, wurde auch der Artikel zum Schutz von Minderheitenrechten gestrichen. Durch eine Vorzugsstellung des Buddhismus in der Verfassung wurde ein religiöser Nationalismus verfestigt.

Diese Massnahmen des Staates zogen den Widerstand der tamilischen Bevölkerung nach sich. 1971 kam es zu einem Jugendaufstand von Tamilen mit mehreren Tausend Toten. 1971 reiste auch der erste tamilische Asylsu-

139 Zum singhalesischen Nationalismus und der Beteiligung buddhistischer Akteure vgl. u. a. Bartholomeusz 2002, DeVotta 2007, Deegalle 2006, Tambiah 1992. 
chende in die Schweiz ein (vgl. Moret et al. 2007, 37). ${ }^{140} \mathrm{Im}$ Jahr darauf gründeten sich die Tamil New Tigers (TNT), aus denen 1976 die LTTE entstand. ${ }^{141}$ Ein wichtiges im kollektiven Gedächtnis vieler Tamilen verankertes Ereignis, welches von einigen tamilischen Flüchtlingen während der Feldforschung dieser Studie als Schlüsselereignis geschildert wurde, war die Zerstörung der Öffentlichen Bibliothek in Jaffna 1981. Die dreitägigen Ausschreitungen von singhalesischer Seite, die von den staatlichen Sicherheitseinheiten gesteuert wurden, führten zu einer Radikalisierung der tamilischen Jugend, die in diesem Akt den Willen zur Zerstörung des tamilischen kulturellen Erbes sahen (vgl. Knuth 2006, 80 ff.).

Verschiedene tamilische Widerstandsgruppen formierten sich, die alle auf der Basis eines gemeinsamen Zieles, der Errichtung eines unabhängigen Tamil Eelam, agierten (vgl. McDowell 1996, 87). Legitimiert wurde dieses Ziel mit einer als rassistisch angesehenen Regierungspolitik und einer diskriminierenden Gesetzgebung im Land (vgl. McDowell 1996, 87). Die Mehrheit der Widerstandsorganisationen war geprägt von marxistisch-leninistischen Weltanschauungen und propagierte einen progressiven Patriotismus. Auch auf tamilischer Seite kam es zu inner-ethnischen Konflikten: Aufgrund von Rivalitäten zwischen den tamilischen Rebellenorganisationen gründeten sich unterschiedliche Widerstandsgruppen, die meist aus Abspaltungen von der LTTE entstanden. Die 1980er Jahre waren von der Opposition zwischen LTTE und PLOTE (The People's Liberation Organisation of Tamil Eelam) geprägt. Spannungen zwischen den beiden Gruppen, die mindestens bis 2007 auch in der Schweiz Sektionen hatten (vgl. Stürzinger 2002, 16; Moret et al. 2007, 118), reichen auch in die Diaspora hinein. ${ }^{142}$

In den Spannungen unter den tamilischen Widerstandsgruppen spielten regionale und Kasten-Differenzen eine Rolle. ${ }^{143}$ McDowell nennt die Dominanz der Jaffna-Tamilen im Widerstandskampf "the Jaffnaness of Rebellion"

140 Insgesamt gab es sechs Personen aus Sri Lanka, die in den 1970er Jahren Asyl in der Schweiz suchten (vgl. Stürzinger 2002, 4).

141 Zur Entstehungsgeschichte und Ideologie der LTTE vgl. u.a. Hellmann-Rajanayagam 1994.

142 Im Bericht «Innere Sicherheit der Schweiz 2007» heisst es beispielsweise: «In der Schweiz kam es während der 1.Mai-Feier in Zürich zu einem Raufhandel zwischen Anhängern der rivalisierenden Liberation Tigers of Tamil Eelam (LTTE) und der People's Liberation Organization of Tamil Eelam (PLOTE)» (Bundesamt für Polizei 2008, 11).

143 In der LTTE dominierten beispielsweise Akteure aus der Karaiyar-Kaste (Fischerkaste), der auch ihr Führer Vēluppillại Pirapāharan angehörte. Akteure aus höheren Kasten wie die Vellalla unterstützten vielfach die PLOTE; Menschen aus sogenannten tieferen Kasten die EPRLF, die Eelam People Revolutionary Liberation Front (vgl. Lüthi 2005, 22). 
(vgl. McDowell 1996, 87). Besonders zwischen Tamilen aus den Ostgebieten und jenen aus Jaffna kam es zu Spannungen (vgl. McDowell 1996, 90). Diese hier angedeutete Heterogenität sri-lankischer Tamilen spiegelte sich auch in der tamilischen Diaspora in der Schweiz wider und hatte teilweise Auswirkungen auf Ausdifferenzierungsprozesse im religiösen Leben der tamilischen Akteure. In der Schweiz sind kastenbezogene, politische und regionale Differenzen unter Tamilen zu beobachten.

Zusammenfassend kann von einer Singhalisierung der Gesellschaft Sri Lankas im Zuge der Dekolonisierung gesprochen werden (vgl. Rösel 1996, 1997). Von singhalesischer wie tamilischer Seite fand eine Ideologisierung der eigenen Geschichtsschreibung statt; ethnische Grenzen verfestigten sich, bis es 1983 zum Ausbruch des Bürgerkrieges kam.

\subsection{Die Fluchtgeschichte Arumgams: «wenn ich ein oder zwei Tage spät warten / dann wäre ich sicher verhaftet worden»}

Der Bürgerkrieg in Sri Lanka kann in verschiedene Etappen eingeteilt werden, die als Eelam-Kriege bezeichnet werden (vgl. Rösel 1996). Der 1. EelamKrieg begann unter Präsident Junius Richard Jayawardene (Amtszeit 19781989) und dauerte vom sogenannten Schwarzen fuli 1983 bis 1987. Im Juli 1983 töteten LTTE-Mitglieder 13 Regierungssoldaten in Jaffna. Daraufhin kam es zu schweren Pogromen an der tamilischen Bevölkerung ${ }^{144}$ und zu internen Fluchtbewegungen von Tamilinnen und Tamilen, die versuchten, in den Norden des Landes oder ins südindische Tamil Nadu zu gelangen (vgl. Flück 2005, 64f.). Einige Tamilen flohen auch nach Übersee - 1983 kamen 845 tamilische Asylsuchende in die Schweiz. Eelam Krieg I endete mit der Übersendung von indischen Truppen, die als Indian Peace Keeping Forces die Situation in Sri Lanka beruhigen sollten. ${ }^{145}$ In dieser Periode des Krieges bis 1987 kam es zu ersten grossen Migrationsbewegungen von tamilischen Geflüchteten in die Schweiz.

144 Dieses Ereignis markiert für viele tamilische Menschen eine Zäsur, der auch in der Diaspora jährlich gedacht wird. In der Schweiz fanden im Untersuchungszeitraum Gedenkveranstaltungen zu diesem Anlass statt.

145 Nach dem Abzug der Indian Peace Keeping Forces war die Haltung der tamilischen Bevölkerung zum Nachbarstaat Indien mehrheitlich negativ geprägt. 1991 ermordete eine LTTESelbstmordattentäterin den indischen Premierminister Rajiv Ghandi, was zu einem Verbot der LTTE in Indien führte. Zum Verhältnis Sri Lankas zu Indien vgl. Bose 1994; Bullion 1995. 
Exemplarisch für die Geflüchteten aus Sri Lanka, die zur Zeit des 1. Eelam-Krieges - teilweise über Umwege - in die Schweiz kamen, sei hier die Fluchtgeschichte des Tamilen Arumugam skizziert, der 1985 im Alter von 25 Jahren in die Schweiz kam. ${ }^{146}$ Er migrierte nicht im Familienverband, sondern nahm den Fluchtweg mit anderen jungen Männern aus dem Bekanntenkreis auf sich. Zwischen 1983 und 1991 waren 74Prozent der tamilischen Asylsuchenden in der Schweiz männlich; ihr Durchschnittsalter betrug 26 Jahre (vgl. McDowell 1996, 119). Dies ist auf geschlechtsspezifische Gründe der Migration zurückzuführen, da sich vor allem junge tamilische Männer von der sri-lankischen Regierung bedroht fühlten und/oder eine Rekrutierung durch tamilische Guerillagruppen fürchteten. ${ }^{147}$

Arumugam verliess seine Heimat nicht freiwillig; er sah sich gezwungen zu emigrieren, da er sich in seiner Heimat nicht mehr sicher fühlte und ihm eine Verhaftung durch den Staat drohte:

Das ist nicht Zufall [, dass ich in der Schweiz bin], weil/von Sri Lanka ich muss weg. Ich habe schon eine sehr gefährliche Situation gehabt und wenn ich ein oder zwei Tag spät warten, dann wäre ich sicher verhaftet worden.

Nicht nur Arumugam war durch staatliche Sanktionen bedroht, auch Familienangehörigen und Bekannten drohte die Verhaftung wegen politischem Engagement in tamilischen Organisationen und sozialem Einsatz für die grosse Anzahl an intern vertriebenen Tamilinnen und Tamilen im Land.

Damals mein Kolleg und Kollegin/mein Onkel verhaftet worden und Familie so, weil wir haben schon von der Familie her/wir haben schon/eine politische Bewegung mitgemacht. Und ich war auch dann nach der Uni/diesem ersten Jahr war/dann habe ich auch da mitgemacht. Und diese Zeit war 1983 und diese erste, grösste Bürgerkrieg von Sri Lanka/der wir haben schon geholfen den Tamilen von Süden nach Osten oder in den Norden zu kommen.

Die gewalttätigen Übergriffe im Jahr 1983, bei denen circa 3000 Tamilen ums Leben kamen, leiteten den «ersten Bürgerkrieg» ein, durch welchen sich die tamilische Bevölkerung anti-tamilischen Ausschreitungen und der Willkür des Staatsapparats ausgeliefert sah. Es kam zur Vertreibung von

146 Das narrative Interview mit Arumugam wurde am 09.10.2008 in seiner Wohnung in Luzern geführt, aufgenommen und transkribiert. Die folgenden Zitate entstammen diesem Interview. Zum Zeitpunlkt des Interviews war Arumugam 48 Jahre alt und arbeitete als Krankenpfleger.

147 Gemeinsam war den tamilischen Asylsuchenden in der Schweiz, dass sie Sri Lanka aufgrund einer Bedrohungslage verliessen. Die Gefährdungslage und die Fluchtwege der einzelnen Asylsuchenden konnten unterschiedlich sein; durch die Schilderung des folgenden Einzelfalls soll nicht der Eindruck erweckt werden, dass sie einheitlich wären. 
Tamilen aus dem singhalesisch dominierten Süden des Landes und der Hauptstadt Colombo. Sechzig Prozent der Tamilen Colombos verliessen die Stadt und flohen in den Osten oder Norden des Landes (vgl. McDowell 2004, 537).

Arumugam stand unter Beobachtung und sah sich in einer akuten Gefährdungslage. Es drohte die Verhaftung bzw. das «Verschwinden»: ${ }^{148}$

Und dann damals auch die singhalesische Militär/Polizist und so/diese Leute haben schon/die Leute/wer macht mit/oder die Aktivität/wer macht mit/ haben sie schon irgendwo in einem Augen immer so/haben sie einen nach dem anderen verhaftet worden und dann einen nach dem anderen verschwunden worden und so.

Arumugam fühlte sich nicht nur von der Regierungsseite bedroht. Er berichtet, dass auch die sich formierenden tamilischen Widerstandsgruppen junge Tamilen gegen deren Willen rekrutierten. ${ }^{149}$ Die angespannte Lage versetzte seine Familie in begründete Sorge um Arumugam, da man eine weitere Eskalation des Konfliktes befürchtete, was auch eintrat:

Dann von meiner Familie her Mutter/Vater/Mutter/ haben sie gesagt: $<$ Nein. Das ist so.> Und dann gleich Zeit kommt von diese [3] der Gruppe/ der RebellGruppe/ einer nach dem anderen die Gruppe gegründet/und gross und gross und gross. Sie nehmen einfach die Leute/die junge Leute. Und meine Familie/ sie haben gemeint: $<\mathrm{ja} /$ das kommt/irgendwann ist zu gross/irgendwann explodiert.>

In jener Zeit wurden die tamilischen Rebellen-Gruppen gestärkt und junge tamilische Männer für den Guerilla-Kampf rekrutiert. Für Arumugam war eine militärische Beteiligung im Kampf von Tamilen gegen die singhalesische Regierung trotz seines politischen Engagements gegen deren Politik keine Option. Er und seine Familie sahen keine andere Möglichkeit als die Flucht. Ein konkretes Land wurde dabei nicht ins Auge gefasst; zentral war, ausser Landes - «irgendwo» - in Sicherheit zu sein.

Dann ich persönlich wollte auch nicht unbedingt mit den Waffen mitmachen/will ich auch nicht. Dann wir haben gemeint, das ist schwer. Ist nicht für uns. Irgendwann wir müssen weg. Und ich bin der erste Sohn gesiehen/der grösste und dann meine Familie hat gesagt: <Nein. Muss weg. Irgendwo/irgendwo muss weg.>

148 Zur Kriegsstrategie des sogenannten Verschwindenlassens und den Folgen für die Angehörigen vgl. Preitler 2006.

149 Auf unfreiwillige Rekrutierung durch tamilische Widerstandsgruppen verweist auch Martin Baumann (Baumann 2003c, 43). 
Zwischen 1983 und 1986 war die Hälfte der männlichen Migrierenden, die in die Schweiz einreisten, der jeweils älteste Sohn der Familie (tam. aṇnann), welchem innerhalb der traditionellen tamilischen Familie ein besonderer Status zukommt (vgl. McDowell 1996, 121).

Voraussetzung für die Migration waren finanzielle und soziale Ressourcen. Die Kosten der Flucht wurden meistens von den Familien übernommen (vgl. McDowell 1996, 122, 271). Eine wichtige Voraussetzung für eine gelingende Flucht war auch die Unterstützung durch bereits in Europa lebende Tamilen. Arumugam wählte die Region Europa als Fluchtdestination, da schon ein Bekannter als Asylsuchender in Europa lebte. Die Flucht unternahm er in einer Gruppe tamilischer Männer:

Dann wir haben schon einen Kolleg/alte Schulkolleg, der war schon zwei, drei Monate vor uns ist in Europa. Und der hat uns/mich/uns geschrieben. Wenn Schwierigkeit haben/irgendwann dann kommt hier. Dann habe ich gemeint: Gut/gehe ich schon dann.

Nach dem Scheitern der indischen «Friedenstruppen» und nach Friedensgesprächen zwischen der Regierung und der LTTE eskalierte die Situation bald erneut, und ab Juni 1990 kam es zum sogenannten 2. Eelam-Krieg, der im Januar 1995 endete. Die längste Periode des Bürgerkrieges war die Zeit des 3. Eelam-Krieges (April 1995 bis Februar 2002). Nachdem Norwegen einen Waffenstillstand ausgehandelt hatte, trafen sich im Februar 2002 Vertreter der Konfliktparteien zu Friedensverhandlungen in Oslo, während derer sich beide Parteien auf eine föderalistische Lösung einigten. Die Regierung Sri Lankas hob ein Verbot der LTTE auf und beauftragte eine Expertengruppe aus Skandinavien, die Situation zu beobachten (Sri Lanka Monitoring Mission). Nach 2002 stabilisierte sich die Lage in Sri Lanka, bis es im August 2006 wieder zum Kriegsausbruch kam. Im Februar 2006 nahmen die Konfliktparteien und norwegische Vermittler in der Schweiz Verhandlungen auf, um die Lage in Sri Lanka zu stabilisieren und die Waffenruhe von $2002 \mathrm{zu}$ festigen, welche jedoch scheiterten. Die letzte Phase des Bürgerkrieges fiel zu einem grossen Teil in die Entstehungszeit dieser Studie. Im Januar 2008 kündigte die sri-lankische Regierung die militärische Vernichtung der Tamil Tigers an; damit brachen sie das Waffenstillstandsabkommen von 2002 (vgl. Goodhand/Korf 2010). Als Reaktion darauf stieg die Zahl der Asylgesuche in der Schweiz wieder an. ${ }^{150}$

150 Nachdem 2007636 Menschen aus Sri Lanka einen Asylantrag gestellt hatten, stieg im Jahr 2008 und dann noch einmal mehr im Jahr 2009 die Zahl der Gesuche von sri-lankischen Bürgern um Asyl in der Schweiz. 
Der Krieg in Sri Lanka forderte nach Schätzungen der Nichtregierungsorganisation Human Rights Watch 2010 zwischen 80000 und 100000 Todesopfer und Zehntausende weitere intern Vertriebene. ${ }^{151}$ Jede Station des Krieges führte darüber hinaus zu steigenden Zahlen Geflüchteter.

\section{Das Residenzland Schweiz: Die Etappen tamilischer Migration in die Schweiz}

Tamilische Migrierende flohen in unterschiedliche Zielländer und fanden in diesen nationalen Kontexten unterschiedliche Inkorporationsbedingungen vor. ${ }^{152}$ Die folgenden Abschnitte fokussieren auf den Nationalstaat Schweiz als eines der Residenzländer tamilischer Diaspora-Akteure und im Besonderen auf den vom Staat vorgegebenen Rahmen der Eingliederung der tamilischen Geflüchteten.

\subsection{Die Anfangsjahre tamilischer Immigration in die Schweiz (1983-1992): «hier es gibt Möglichkeiten / wir können schon auf eigenen Füssen stehen»}

Die Einreisebestimmungen und die Aufnahmebedingungen der Staaten sind eine zentrale nationale Inkorporationsbedingung. Die Immigration von Tamilinnen und Tamilen aus Sri Lanka war und ist keine vom Schweizer Staat gesteuerte Einwanderung - im Gegensatz zur Flüchtlingspolitik der Schweiz im Fall anderer Flüchtlingsgruppen aus Asien wie beispielsweise den tibetischen Geflüchteten im Jahr 1963 und den sogenannten "Boat People" aus Südostasien Ende der 1970er Jahre, die als Kontingentflüchtlinge im Rahmen einer humanitären Hilfsaktion in die Schweiz kamen (vgl. Spescha et al. 2010, 42 f.). Breit angelegte staatlich unterstützte Hilfsangebote von Nichtregierungsorganisationen, wie diese bei den sogenannten Indochina-Flüchtlingen gewährt wurden (vgl. Caritas Schweiz 1984), fehlten bei den tamilischen Asylsuchenden aus Sri Lanka. Ihre Asylanträge unterliegen einer Einzelfallprüfung, und der Schweizer Staat

151 Vgl. den World Report 2010 - Sri Lanka von Human Rights Watch unter www.hrw.org/ world-report/2010/country-chapters/sri-lanka (01.10.2015).

152 Prioritär migrierten Tamilinnen und Tamilen in englischsprachige Länder, da in diesen die Sprachbarrieren weniger hoch waren und aufgrund der Kolonialgeschichte bereits ein Beziehungsgeflecht vorhanden war (vgl. David 2008, 2). 
sieht kein kollektives staatliches Unterstützungsangebot für bestimmte Gruppen von Asylsuchenden vor. Dies hatte auch Auswirkungen auf die gesellschaftliche Eingliederung der sri-lankischen Geflüchteten in der Schweiz. Während in der «Indochina-Aktion» 1978 bis 1982 spezielle «Aufnahmeangebote» konzipiert wurden und den 7500 Geflüchteten aus Thailand, Kambodscha, Laos und Vietnam Betreuergruppen aus Freiwilligen zur Seite gestellt wurden (vgl. Caritas Schweiz 1984), konnten tamilische Hindus sich nicht auf solche breit angelegte zivilgesellschaftliche Hilfe stützen. ${ }^{153}$

Ein weiterer Unterschied zwischen tamilischen Geflüchteten und Kontingentflüchtlingen, der Einfluss auf die Inkorporation in der Schweiz hatte, war die Aufnahme der südostasiatischen Geflüchteten in Familienverbänden. Hintergrund war, dass der Schweizer Staat sozial stabile Strukturen innerhalb der Immigrantengruppe schaffen wollte. Auch der Nachzug von Familienangehörigen sollte diesem Ziel dienen. Tamilische Migrierende reisten im Gegensatz dazu individuell und anfangs nicht als Familien in die Schweiz. Die mehrheitlich männlichen Geflüchteten, die geflohen waren und in der Schweiz dezentral angesiedelt wurden, lebten in den Anfangsjahren meist in instabilen sozialen Strukturen.

Auch im Bereich der Ausgangsbedingungen zur Einrichtung religiöser Institutionen sind Unterschiede festzustellen. Betreuergruppen regten an, mit staatlicher Unterstützung buddhistische Pagoden einzurichten (vgl. Caritas Schweiz 1984, 38 f.). Tamilische Hindus mussten mehr Eigeninitiative einbringen, um eigene religiöse Orte in der Schweiz zu etablieren.

Die Mehrheit der Tamilinnen und Tamilen, welche seit den frühen 1980er Jahren in die Schweiz migrierten, reiste auf verschiedenen Wegen und unterschiedlich organisiert «illegal», das heisst ohne Einreiseerlaubnis oder gültiges Visum, als Asylsuchende in die Schweiz ein. Wie die Mehrheit der Tamilen, die damals als Asylsuchende in die Schweiz einreisten, kam auch Arumugam über Deutschland in die Schweiz (vgl. McDowell 1996, 140 ff.) Ihn führte seine Flucht über die Hauptstadt Colombo mit dem Flugzeug nach Ost-Berlin.

Und dann ich auch schon mit dem/noch zwei Kollegen zusammen/schnell ist in Colombo. Niemand weiss dann schon ausser unsere Familie. Damals es ist nicht so grosse Problem. Dann wir waren schon/direkt nach Berlin/Ost-Berlin. Dann auch wir kein Visum brauchen wir/ dann Ost-Berlin.

153 Vereinzelt gründeten sich NGOs wie die Freiplatzaktion, Beratungsstelle für Menschen aus Sri Lanka in Basel, die seit Mitte der 1980er Jahre im Bereich der Asylberatung tamilischer Migrierter tätig ist (vgl. http://freiplatzaktion-basel.ch; 01.11.2010). 
Die meisten Tamilen landeten in Ost-Berlin, da bis 1985 die Einreise visumsfrei war (vgl. McDowell 1996, 223; Baumann 2003c, 45f.). ${ }^{154}$ Arumugam reiste weiter in die Schweiz:

Und diese Kolleg war/ist im Deutschland irgendwo/ist in München oder so irgendwo. Aber wir haben auch ein andere Kolleg gehabt. Er war Polizist gesiehn in Sri Lanka. Er hat auch jede Menge Probleme gehabt und so. Und er war in der Schwyz / der Schweiz. Und wir haben schon Kontakt mit diese Kollegen. Und er hat gesagt: Es wäre besser do / hier kommen/als Deutschland. ${ }^{155}$

McDowell benennt das bessere Angebot an Sozialhilfeeinrichtungen und ökonomische Faktoren als Gründe, warum viele tamilische Asylsuchende weiter in die Schweiz reisten. "Switzerland was seen, in a sense, as an extension of Germany, but providing richer opportunities and greater security through social assistance provisions" (McDowell 1996, 140). Da das Saisonnierstatut 1991 abgeschafft wurde, mangelte es der Schweiz an ungelernten Arbeitskräften (vgl. McDowell 1996, $140 \mathrm{ff}$.). Es können also humanitäre, ökonomische und politische Gründe festgestellt werden, welche die Aufnahme tamilischer Geflüchteter in der Schweiz zur damaligen Zeit begünstigten.

Ein Grund für Arumugam, in die Schweiz zu reisen, waren darüber hinaus persönliche Verbindungen. Weiter begründet er seine Entscheidung mit dem Aspekt der agency. In der Schweiz sah er bessere Bedingungen, um ein selbstbestimmtes Leben zu führen und die Möglichkeit zu haben, eigenmächtig zu handeln («selbstständig Arbeit suchen und arbeiten/ selbststän$\operatorname{dig} /$ studieren / arbeiten»).

Warum [sind Sie weiter in die Schweiz gereist]? Er [der Kollege] war auch nicht so lange hier [in der Schweiz]. Irgendwie/vielleicht sechs Monate/neun Monate. Hat er gesagt: <Hier es gibt Möglichkeit/wir können schon eigene Füsse stehen/etwas machen oder so.> Ich erinnere mich. In Deutschland ist/irgendwie Flüchtlingslager/Camp und so. Und do/hier/ist selbstständig Arbeit suchen und arbeiten/selbstständig/studieren/arbeiten/so etwas.

Arumugam kontrastiert das Inkorporationsregime Deutschlands mit dem der Schweiz. Die negativ konnotierten Begriffe «Flüchtlingslager/Camp» werden den Aufnahmebedingungen in Deutschland zugeordnet. Arumugam konstatiert aber auch Schattenseiten des Lebens als Migrant in der Schweiz: «Aber es hat auch schwierige Leute hier/überall hat schwierige Leute.»

154 Die visumsfreie Einreise über Ost-Berlin wurde laut Baumann als «Schlupfloch» bezeichnet. McDowell spricht vom Berlin Gap (vgl. McDowell 1996, 223). Nach 1985 sank die Anzahl der Asylsuchenden in der Bundesrepublik (vgl. Baumann 2003c, 45 f.).

155 Interview 3; 9.10.2008. 
Die Einreise in die Schweiz erfolgte irregulär: «Und dann habe ich gemeint: <Ja. Ist gut/ja.> Dann mit dem Schlepper von Ost-Berlin in die Schweiz/wir sind da gekommen. Und dann sind wir da/aber ganz wenige Leute hier/ überall ganz wenig.» ${ }^{156}$

Nach der Ankunft in der Schweiz beantragte Arumugam Asyl:

Damals war es/nicht wie jetzt so überall/nur drei Orte/jetzt/aber damals wenn du kommst, gehst du zu einem Polizei-Posten/sagst du oder fragst du Asyl. Dann sie kommen: < so / so / so >. Wir haben so gemacht.

Die Mehrheit der tamilischen Geflüchteten, die in die Schweiz einreiste, galt als «Asylsuchende» nach dem 1981 in Kraft getretenen Asylgesetz (AsylG) (vgl. BFM 2007, 34), deren Antrag auf Asyl einer Einzelfallprüfung im Rahmen eines Asylverfahrens unterliegt.

Arumugam wurde von staatlicher Seite eine Kollektiv-Unterkunft organisiert. Aus eigener Initiative suchte er eine Arbeit, die er im Niedriglohnsektor fand:

Und sie haben unsere / ein Hotel gesucht und wir waren schon im Hotel. Dann waren wir eine Woche da. Dann haben sie schon einen Lager/Lagerplätze / es ist nicht Lager / Asylbewerberunterkunft. Und bin ich dort drei Monate/ innerhalb drei Monate habe ich schon eine Arbeit gefunden/in einem Maschinenfabrik.

Die Kantone und ausführend die Gemeinden waren für die Unterbringung der Asylsuchenden und Unterstützung bei der Arbeitssuche zuständig (vgl. McDowell 1996, 240). Die Asylsuchenden wurden auf die verschiedenen Kantone in der Schweiz verteilt; die Unterbringung sollte dezentral erfolgen. Der Verteilungsschlüssel auf die Kantone wurde nach der Bevölkerung des Kantons prozentual ermittelt. Asylsuchende gelten als «fürsorgeabhängig» vom Schweizer Staat. Dieser sichert ihnen Verpflegung, Unterkunft, Unfall-/Krankenversicherung und in der Regel Taschengeld zu (vgl. Mehr 2001, 31). Arumugan spricht hier die drei Phasen der Betreuung von Asylsuchenden in den 1980er Jahren an, die «Erstaufnahmephase, Zentrenphase und Nachzentrenphase» genannt wurden (vgl. Schill 1991, 21). «Während der Erstaufnahmephase leben die AsylbewerberInnen für 4-6 Wochen in Billighotels oder in speziell vom Kanton gemieteten Unterkünften» (Schill 1991, 21). Danach wurden die Geflüchteten in Zentren für Asylbewerber im Kanton gebracht. «Während der ersten 3 Monate ihres Aufenthaltes im Kanton Luzern dürfen die AsylbewerberInnen keine Arbeit annehmen» (Schill 1991, 21).

156 Zum Phänomen der irregulären Migration in die Schweiz und der Zuhilfenahme von sog. Schleusern beim Migrationsweg vgl. D’Amato/Gerber/Kamm 2005. 
Tamilische Asylsuchende begannen bereits in den Asylunterkünften provisorische Orte für Hindu-Praxis einzurichten und stellten Bilder von Hindu-Göttinnen und Göttern auf, die zu pūcai-Plätzen wurden (vgl. Kap. IV 4.1).

In der Nachzentrenphase wurden die Geflohenen dann von einer Beratungsstelle für Asylsuchende betreut. Die Arbeit, die Arumugam findet, ist charakteristisch für tamilische Asylsuchende in den Anfangsjahren der Migration. Susan Schill schreibt in ihrer Studie aus dem Jahr 1991 über Tamilinnen im Kanton Luzern: «Die Männer arbeiten alle in Hilfsjobs, in Restaurants als Küchen- und Officehilfe oder Hausbursche, in Fabriken als Hilfsarbeiter und im Kantonsspital in der Putzequipe» (Schill 1991, 21).

Das geregelte Einkommen durch ein Arbeitsverhältnis bedeutete, dass Arumugam in eine eigene kleine Wohnung ziehen konnte, was von den zuständigen Asylbehörden organisiert wurde. Zentral war für ihn, nach den anfänglichen Monaten der (Fürsorge-)Abhängigkeit von den Schweizer Behörden seine persönliche Autonomie wiederzuerlangen und auch die Sprache des Residenzlandes zu erlernen. Dieses Engagement war mit einer hohen zeitlichen Belastung verbunden:

Dann bin ich selbstständig. Dann gleichzeitig habe ich studiert. Erstens ich habe eine Sprachschule besucht/Abendschule/am Tag arbeiten und so. Die Asylunterkunft sie haben schon eine Wohnung/sie suchen schon Wohnung für uns/wenn wir eine Arbeit gefunden haben. Oder sie suchen auch eine Arbeit für uns. Sie haben schon/mir eine Wohnung gesucht/eine Ein-Zimmer-Wohnung. Dann bin ich/nur drei Monate bin ich irgendwie so abhängig gewesen. Dann bin ich/sogar Schule und Arbeit/alles habe ich schon selber.

Arumugam arbeitete vier Jahre in der Fabrik und besucht kontinuierlich Sprachkurse, bevor er seinen Arbeitsort wechselte. 1989 reiste seine Frau nach.

Dann habe ich schon noch/danach/vier Jahre. Dann habe ich auch am gleichen Ort Arbeit gewechselt. (...) ich habe schon immer den Deutsch-Kurs besucht. Dann habe ich schon Arbeit/bei der Caritas. 89 kam meine Frau/in Sri Lanka haben uns kennen gelernt. (...) Dann habe ich Visum und alles gemacht.

Dass in den Anfangsjahren der Migration hauptsächlich tamilische Männer ohne Familienanbindung einreisten, hatte spezifische psycho-soziale Auswirkungen. Die Situation vieler tamilischer Migrierter war von Isolation und Einsamkeit geprägt. Dies lag an den sozialen Bedingungen als Geflüchtete in einer fremden Umgebung und am Fehlen stabiler sozialer Strukturen. Die meisten Asylsuchenden lebten in Sri Lanka als Grossfami- 
lien zusammen; in der Schweiz mussten sie zunächst ganz ohne Familienanbindung und dann in Kleinfamilien leben (vgl. Bär 2003, 31). Einige Geflüchtete litten aufgrund ihrer Situation an psychischen Problemen, und es kam zu einem Anstieg an depressiven Erkrankungen (vgl. McDowell 1996, 240). Auch brachten tamilische Bürgerkriegsgeflüchtete häufig ein in ihrem Heimatland erlittenes Trauma mit ins Diasporaland, was sich nicht selten in posttraumatischen Belastungsstörungen äusserte (vgl. MeinholdBergmann 2006, 24 ff.). Ein ehrenamtlicher Betreuer tamilischer Asylsuchender berichtete im Jahr 1987: «Wir erleben täglich, wie Tamilen wegen ihrer schwierigen Lage depressiv werden oder Zuflucht zum Alkohol nehmen, um ihr Leid zu vergessen. Nicht wenige haben schon einen Selbstmordversuch gemacht» (idea magazin 1987, 6).

Ein weiterer Aspekt, der Einfluss auf die Lebenswelt der Migrierten hatte, war das Fehlen von hinduismus-bezogenen Institutionen, in denen die Akteure ihre gewohnten Praktiken durchführen und sich mit ihren Bitten und Sorgen an die Gottheiten wenden konnten. McDowell spricht von «spiritual desolation» tamilischer Migrierter in den Anfangsjahren der Migration (McDowell 1996, 244; vgl. Kap. IV 4).

\subsection{Der Nachzug tamilischer Frauen: Genderdifferenzen in der Immigration}

In den frühen 1990er Jahren reisten viele tamilische Frauen als Ehefrauen und Verlobte ihren Männern in die Schweiz nach, was charakteristisch für die tamilische Migration in diesen Jahren war. Im Jahr 1992 stieg die Zahl von Tamilinnen beträchtlich an, die Asyl in der Schweiz suchten. In den Jahren 1993 bis 1999 stellten mehr tamilische Frauen als Männer einen Asylantrag (vgl. Bär 2003, 11).

Mit dem Nachzug von Tamilinnen änderte sich das Profil der tamilischen Diaspora in der Schweiz. Familienstrukturen etablierten sich und Hindu-Praxis konnte in grösserem Umfang ausgeführt werden. Neben Frauen, die ihren Männern oder Verlobten ins Exil folgten, kamen auch ledige Tamilinnen als Asylsuchende in die Schweiz. Als sich die Kämpfe in Sri Lanka ausweiteten und immer mehr tamilische Männer ins Exil flohen, wurden auch Frauen von tamilischen Rebellengruppen rekrutiert.

By the early 1990s the asylum migrant population included for the first time

Tamil women, who, like the men before them, were fleeing persecution and avoiding forced conscription or further involvement in the fighting. (McDowell 2004, 539) 
Posttraumatische Belastungsstörungen tamilischer Frauen unterschieden sich teilweise von denen männlicher Migranten. Physische sexualisierte Gewalt und Vergewaltigungen waren nicht nur im Sri-Lanka-Konflikt eine gezielte Kriegsstrategie, die auf die Frauen der gegnerischen Partei gerichtet war. Zuzana Hrdličková macht deutlich, dass Gewalt gegenüber tamilischen Frauen während der Eelam-Kriege diese auch sozial deklassierte:

More than a quarter of a century of war has brought not only many casualties and displacement but also a lot of sexual violence against Tamil women, making them karpalippu - those whose chastity has been destroyed. We do not have an exact number but it seems that thousands of women have been raped and subsequently abandoned by their families and/or husbands. (Hrdličková 2008, 466)

Frauen als Nachreisende waren in besonderem Masse an ihre Lebenspartner gebunden. Laut einer empirischen Studie aus dem Jahr $1991 \mathrm{zu}$ tamilischen Ehefrauen im Kanton Luzern hatten die nachreisenden Tamilinnen wenig Kenntnisse und Informationen über das Leben in der Schweiz (vgl. Schill 1991). «Keine der Frauen wusste weder kulturell, politisch, noch sonstwie Bescheid über die Schweiz. Die meisten glaubten, dass in der Schweiz Englisch gesprochen würde» (Schill 1991, 27). Besonders die Frauen, die nicht arbeiteten, litten unter Isolation. Schill stellt die Situation der Frauen anhand eines Inteviewauszugs wie folgt dar:

In Sri Lanka sind wir nie alleine, immer sind wir zusammen mit der Familie und den Verwandten. Alles wird zusammen gemacht. Hier sind wir stets alleine. Wir gehen kurz aus zum Einkaufen und danach sind wir den ganzen Tag alleine in der Wohnung, bis am Abend der Mann von der Arbeit heimkommt. (Schill 1991, 29)

Der Prozess der Migration bewirkt Veränderungen in sozialen Strukturen einer Gruppe, was auch dynamische Verschiebungen von Geschlechterkonstellationen beinhalten kann.

Rollenverschiebungen innerhalb des sozialen Gefüges der Familien konnten im konkreten Fall durch die Erwerbsarbeit beider Eheleute ausgelöst werden. Barbara Bär fasst die Aussagen tamilischer Frauen in ihrer Studie wie folgt zusammen:

Die Frauen der jüngeren Generation hätten in ihrer Heimat zwar eine Erwerbstätigkeit ausgeübt, dies sei aber freiwillig gewesen. In der Schweiz hätten die tamilischen Frauen keine Wahl und müssten erwerbstätig sein. (Bär 2002, 31; vgl. auch Vögeli 2005, 328 ff.)

An dieser Stelle kann nicht detailliert auf die komplexe Dynamik des Themenfelds «Gender und Diaspora» eingegangen werden. In den Analysen 
werden oftmals zwei gegenläufige Tendenzen festgestellt: Festgelegte Geschlechterrollen aus dem Heimatkontext können durch die Migrationssituation aufgebrochen werden oder können sich in der Diaspora-Situation noch verstärken. ${ }^{157}$ Beide Entwicklungen waren innerhalb der tamilischen Diaspora in der Schweiz festzustellen.

\subsection{Die öffentlichen Diskurse über die Migrantengruppe: Der Imagewandel «der Tamilen»}

Neben den Bedingungen der Einreise und Aufnahme von Migrierenden im Residenzland ist auch der öffentliche Diskurs gegenüber Einwanderern im Allgemeinen und der Immigrantengruppe im Speziellen ein Element der Inkorporationsbedingungen. Diskurse über «die Fremden» und ihre sozialen Bedingungen - von Fremdenfeindlichkeit über Nicht-Beachtung bis hin zu Fremdenfreundlichkeit (vgl. Kleinert 2004) - haben Einfluss auf Positionierungsstrategien von Migrantengruppen.

Das Image «der Tamilen» hatte auch Einfluss auf ihre Niederlassung in der Schweiz und die Etablierung eigener religiöser Strukturen. Tamilischen Geflüchteten haftete in den 1980er Jahren in der Mehrheitsöffentlichkeit ein tendenziell negatives Image an. Eine fremdenfeindliche Stimmung wurde von einer «Medienkampagne ohnegleichen» (Moret et al. 2007, 39) gegen Tamilen begleitet: «Sie wurden mit Drogenhandel in Verbindung gebracht, galten als Sozialbetrüger, da sie aufgrund des Arbeitsverbotes, dem sie zu Beginn ihres Aufenthaltes unterlagen, von Sozialhilfe abhängig waren, und wurden so zur Zielscheibe zahlreicher verbaler und sogar physischer Übergriffe» (Moret et al. 2007, 39).

Es kam auch zu rassistischen Übergriffen auf tamilische Geflüchtete. Am 21.Januar 1987 wurde beispielsweise ein tamilischer Asylsuchender, der im Durchgangszentrum Brugg-Lauffohr lebte, in Aarau bei einem fremdenfeindlich motivierten Angriff schwer verletzt. ${ }^{158}$ Martin Stürzinger beschreibt das xenophob aufgeladene gesellschaftliche Klima gegenüber tamilischen Einwanderern wie folgt:

157 Vielfach wurde in der Literatur der Aspekt der Dominanz von Männern in Netzwerken der Diaspora hervorgehoben (vgl. Werbner 2007, 653). Jedoch finden sich auch von Frauen aufgebaute transnationale Organisationen, die erheblichen Einfluss in unterschiedlichen Diasporen haben.

158 Vgl. die Nachrichtenspalte auf Seite 5 im Reformierten Forum mit dem Titel «Aarauer schlugen Tamilen nieder» vom 05.02.1987. 
Tamilenwitze machten die Runde, Berner Gewerbeschüler nannten ihre Grümpelturniermannschaft «Tamilen-Killer», vielerorts schlugen Skinheads Tamilen zusammen. Vor allem in Bern, wo weitaus am meisten Asylgesuche von Tamilen gestellt worden waren, kam es im Anschluss an Flüchtlingsveranstaltungen immer wieder zu Schlägereien. (Stürzinger 2002, 23)

Mitte der 1990er Jahre jedoch änderte sich das gesellschaftliche Klima gegenüber «den Tamilen». Jörg Stolz hat im Rahmen seiner Dissertation in einer quantitativen Befragung 1994/95 in Zürich zu fremdenfeindlichen Ressentiments innerhalb der Schweizer Bevölkerung einen so genannten «Tamilen-Effekt» festgestellt (vgl. Stolz 2000, 133). «Tamilen» werden sympathischer als alle anderen nicht-europäischen Gruppen wahrgenommen. Das Sympathie-Profil weist Ähnlichkeiten mit dem «der Deutschen» auf. Mehr als die Hälfte der Befragten empfand die tamilischen Migrantengruppe als «eher sympathisch» bzw. «sehr sympathisch»- circa 21 Prozent geben an, dass sie diese Gruppe als «sehr sympathisch» erleben (vgl. Stolz 2000, 132)..$^{159}$

Das Bundesamt für Migration führt den Umschwung der öffentlichen Meinung auf eine gelungene ökonomische Integration «und den höflichen-zurückhaltenden Charakter dieser Menschen» zurück (Moret et al. 2007, 39). Diese Einschätzung ist umstritten; vielmehr spielten auch die demographische Zusammensetzung der Immigranten-Gruppe eine wichtige Rolle bei der Fremdwahrnehmung. Der Imagewandel hing unter anderem mit dem Nachzug von Frauen und Kinder zusammen, nachdem in den Anfangsjahren der Migration mehrheitlich tamilische Männer in der Schweiz als Asylsuchende lebten und das öffentliche Bild der Migrantengruppe prägten. In der öffentlichen Meinung interferierten Gender-Stereotypisierungen mit Stereotypen über «die Fremden». Das Bild des «fremden schwarzen Mannes» wurde vom Bild der «fleissigen, unauffälligen tamilischen Familie» abgelöst.

McDowell nennt dazu in seiner Studie anschauliche Beispiele, die fremdenfeindliche Dynamiken in den Anfangsjahren der Migration förderten. Er berichtet beispielsweise aus dem Leben des Asylsuchenden Vasanthakumar, der 1990 in die Schweiz kam, und kurz darauf abgeschoben wurde. Seine Lebenssituation in einer Asylunterkunft im Kanton Appenzell Ausserrhoden war von Einsamkeit geprägt, da er in kein soziales Netz eingebunden war und tamilische Bekannte in der Schweiz zu weit weg lebten.

159 Stolz führt nur eine kurze Erklärung für diesen Effekt an. Er gibt als Gründe zum einen die «gute Presse der tamilischen Gruppe» an wie auch die sehr guten Erfahrungen, «die man im Gastgewerbe mit tamilischen Angestellten gemacht» habe (vgl. Stolz 2000, 133). 
Boredom, frustration, loneliness and a spiritual desolation pervaded Vasanthakumar's time in Appenzell. The few occasions he ventured from his room were to buy whisky and cigarettes from the local shop. He understood no German and had little reason to communicate with others in the village, who, he felt, watched his every move. One summer's day he went further than the shop, and, perhaps in need of company, stood by the school gates as children came out for lunch. Mothers pushing prams looked with horror at the crouching figure of a young Tamil man smiling at little girls through the iron railings, and reeking of whisky. (McDowell 1996, $244 \mathrm{f}$.)

Vasanthakumar wurde von Frauen des Dorfes des Versuchs der sexuellen Belästigung beschuldigt. Aufgrund dieser Beschwerde und sozialer Auffälligkeiten wurde er zu einem Gespräch nach Bern gebeten. Sein Asylantrag wurde abgelehnt und er wurde schlussendlich angewiesen, das Land zu verlassen (vgl. McDowell 1996, 245.). McDowell weist darauf hin, dass dieses Beispiel Prozesse der «Fremdenangst» aufzeige, die Aufschlüsse über die soziale Konstruktion des «Fremden» und des «Eigenen» geben könnten.

The decision to report Vasanthakumar's behaviour was rooted in a genuine fear on the part of the women of the village that he presented a danger. The presence of foreigners, particularly dark-skinned foreigners, in isolated Swiss communities, and the response of locals towards them raises many interesting questions about 'us and them' issues in Switzerland. (McDowell 1996, $244 \mathrm{f}$.)

Diese Fremdwahrnehmung von tamilischen Migranten änderte sich teilweise, als sich innerhalb der tamilischen Einwanderergruppe Familienstrukturen etabliert hatten. Oftmals ist der mehrheitsgesellschaftliche Diskurs über tamilische Geschlechterverhältnisse vom Bild der unterdrückten tamilischen Ehefrau geprägt. Presseberichte rekurrieren immer wieder auf tamilische Zwangsehen und Unterdrückung von jungen tamilischen Frauen in der Schweiz. ${ }^{160}$ Tamilische Frauen gelten durch ihren Status als Migrantinnen und als Mitglieder einer als stark patriarchal strukturiert wahrgenommenen Kultur als doppelt diskriminiert. Vögeli stellt in ihren Untersuchungen dar, dass dieses Bild nicht den Machtverhältnissen innerhalb der tamilischen Gruppen entspreche (vgl. Vögeli 2005, 324). ${ }^{161}$

160 Die Wochenzeitung «Die Zeit» berichtete 2010 beispielsweise in einem Artikel über «tamilische Zwangsehen» in der Schweiz (Matthias Daum, «Liebe ist Kopfsache», in: Die Zeit, 05.08.2010, Nr. 32, S. 10).

161 Darauf verweist auch der Titel ihres Textes «Stärker als ihr denkt», der eine einseitige Wahrnehmung der tamilischen Frauen durch die Residenzgesellschaft impliziert (Vögeli 2005). 


\subsection{Die Stadien der rechtlichen Inkorporation: der asyl- rechtliche Sonderfall Tamilen}

Martin Stürzinger, ehemaliger Länderexperte Sri Lanka der Schweizer Flüchtlingshilfe, der in Mapping der srilankischen Diaspora in der Schweiz (2002) die Asylpolitik der Schweiz gegenüber tamilischen Geflüchteten eingehend schilderte, bemerkt, dass «die srilankische und natürlich insbesondere die tamilische Diaspora in der Schweiz [...] die Schweizer Asylpraxis $[\ldots]$ wie keine andere singuläre Gruppe [geprägt hat]» (Stürzinger 2002, 3). ${ }^{162}$ Dies lag vor allem daran, dass eine verhältnismässig grosse Anzahl an tamilischen Migrantinnen und Migranten in der Schweiz Asyl suchte und es zu einer Polarisierung innerhalb der Asylpolitik des Landes kam. Tamilische Asylsuchende wurden zu einem kontroversen Thema im öffentlichen Diskurs. Stephan Parak, Mitarbeiter des Bundesamtes für Migration, konstatiert, dass die «Tamilenfrage» zu einem «Prüfstein für die schweizerische Asylpolitik schlechthin» geworden sei (Parak 2005, 83). Die Ankunft der ersten grösseren Gruppe tamilischer Geflüchteter aus Sri Lanka, die in der Schweiz Schutz suchten, fiel in die Zeit, als der Schweizer Staat gerade sein erstes Asylgesetz implementiert hatte, welches 1979 verabschiedet worden war und 1981 in Kraft trat. ${ }^{163}$ Darin wurde die Einzelfallprüfung eingeführt; tamilische Migrantinnen und Migranten der frühen 1980er Jahren waren somit die ersten, die in die rechtliche Kategorie «Asylsuchende» fielen.

Im Folgenden sollen die Ebenen der rechtlichen (vor allem in Bezug auf den Aufenthaltsstatus der Geflüchteten), der administrativen und der politischen Inkorporation (in erster Linie die Strategien der Behörden und die Integrationspolitik der Schweiz) in den Blick genommen werden. Diese Strategien hatten alle Einfluss auf die öffentliche Meinung gegenüber den tamilischen Asylsuchenden. Die Etablierung tamilischer Hindu-Praxis in der Schweiz wurde von diesen Faktoren mitbestimmt.

162 Auf die Details der Asylpolitik der Schweiz gegenüber tamilischen Geflüchteten kann im Folgenden nicht im Einzelnen eingegangen werden. Für die Jahre 1983 bis 1991 hat diese McDowell ausführlich analysiert (McDowell 1996).

163 Als das Gesetz 1981 in Kraft trat, reichten vier sri-lankische Bürger ein Asylgesuch ein (vgl. Stürzinger 2002, 4). Das Asylgesetz der Schweiz erlebte in den folgenden Jahren verschiedene Revisionen (1984, 1988, 1990, 1995, 1998) und wurde dabei verschärft. Die erste Revision des Gesetzes erfolgte laut Stürzinger «nicht zuletzt in Anbetracht der zunehmenden Gesuche von Asylbewerbern aus Sri Lanka» (Stürzinger 2002, 4). 


\section{Der unsichere Status als Asylsuchende und «vorläufig Aufgenommene»}

Als Asylsuchende erhielten die tamilischen Geflüchteten den Status N, bis sie einen Entscheid über das Asylgesuch bekamen - auch als abgewiesene Asylsuchende behielten sie diesen Status bis zur Abschiebung, der es ihnen nicht erlaubte, Familiennachzug zu organisieren oder ihren Wohnort in einen anderen Kanton zu verlegen. Der Asylentscheid zog sich teilweise über Jahre hin, da die Behörden mit der grossen Anzahl an Gesuchen überlastet waren.

Tamilische Migrantinnen und Migranten wurden in den Anfängen der Einwanderung in die Schweiz meist als Sonderfall im juristischen Sinne behandelt. Sie wurden mehrheitlich nicht als de-jure-Flüchtlinge ${ }^{164}$ anerkannt, ihren Asylgesuchen wurde - wie im Falle der meisten Bürgerkriegsgeflüchteten - nicht stattgegeben. Weniger als vier Prozent der tamilischen Asylsuchenden erhielt politisches Asyl (vgl. Moret et al. 2007, 32) ${ }^{165}$ Jedoch wurden die nicht anerkannten Geflüchteten meist auch nicht abgeschoben. Sie galten als de-facto-Flüchtlinge, die mit einer vorläufigen Aufenthaltsbewilligung («Aufenthaltsbewilligung F») geduldet, aber nicht asylberechtigt waren. Diese Ersatzmassnahme wurde angewandt, da eine Abschiebung aufgrund der Lage im Herkunftsland als unzumutbar angesehen wurde. Aus humanitären Gründen sollte ihnen vorläufig Schutz gewährt werden. McDowell nennt sie «neue Asylsuchende» (vgl. McDowell 1996, 9).

Einige, denen Asyl in der Schweiz verwehrt wurde, verliessen das Land oder hielten sich als illegalisierte Sans Papiers weiterhin in der Schweiz auf. Der rechtliche Status vieler vorläufig Aufgenommener wurde mit kollektiven Regulierungen in einen sicheren Aufenthalt umgewandelt. Die unklare rechtliche Situation zuvor, in der die meisten Geflüchteten einen juristischen Zwischenstatus innehatten, hatte auch Auswirkungen auf ihr gesellschaftliches Leben. Neben dem Anspruch auf Sozialhilfe hatte ein F-Ausweis, der immer nur für ein Jahr ausgestellt wird, auch Einschränkungen zur Folge. Der Wohnkanton durfte nicht gewechselt und das Land nicht verlassen werden. Erwerbstätigkeit musste von der kantonalen Fremdenpolizei bewilligt werden. In einigen Kantonen besteht für Personen mit F- oder N-Bewilligung eine Einschränkung der Arbeits-

164 Nach Artikel3 Absatz 1 des Asylgesetzes gelten als de-jure-Flüchtlinge «Personen, die in ihrem Heimatstaat oder im Land, in dem sie zuletzt wohnten, wegen ihrer Rasse, Religion, Nationalität, Zugehörigkeit zu einer bestimmten sozialen Gruppe oder wegen ihrer politischen Anschauungen ernsthaften Nachteilen ausgesetzt sind oder begründete Furcht haben, solchen Nachteilen ausgesetzt zu werden».

165 Im Jahr 2002 beispielsweise waren 29272 sri-lankische Bürger in der Schweiz gemeldet. 1'171 erhielten in diesem Jahr Asyl, was circa vier Prozent entspricht. 
erlaubnis auf gewisse Branchen, die eher im Niedriglohnsektor angesiedelt sind. 1990 wurde ein Verbot erlassen, welches Asylsuchenden verwehrte, in den ersten drei Monaten des Lebens in der Schweiz zu arbeiten, um die Schweiz «unattraktiv» für arbeitssuchende Ausländer zu machen (vgl. Mehr 2001, 31).

Die Situation der «N- und F-Ausländer» war unsicher, da immer die Möglichkeit bestand, dass sie nach einer Aufhebung des vorläufigen Status innerhalb einer kurzen Frist gezwungen sein würden, die Schweiz zu verlassen. Es bestanden wenige Möglichkeiten, sich längerfristig im Residenzland Schweiz zu beheimaten. Lathan Suntharalingam berichtet über seine unsichere Lebenssituation mit N-Ausweis am Tag der Flüchtlinge 2007 in Cham:

Ich weiss aus eigener Erfahrung, was es heisst, mit «Status N», also mit einem abgelehnten Asylgesuch leben zu müssen. Dies bedeutet, jederzeit in die Heimat zurückgeführt, also ausgeschafft werden zu können. Ich frage Sie alle, liebe Zuhörerinnen und Zuhörer, liebe Freundinnen und Freunde, ich frage Sie alle: Wie soll ein Mensch, den ständig solche Unsicherheiten quälen, wie soll ein solcher Mensch in diesem Land sein Leben organisieren, seine Zukunft planen, die hiesige Sprache lernen können? ${ }^{166}$

\section{Zwischen humanitärer Tradition und Angst vor «Überfremdung»}

Die Politik der Schweizer Behörden gegenüber tamilischen Geflüchteten war bereits in den Anfängen der Migrationsbewegungen ambivalent: Die in der humanitären Tradition der Schweiz (vgl. Spescha et al. 2010, $31 \mathrm{ff}$.) stehende Aufnahme von Kriegsgeflüchteten stand Ängsten vor einem zu grossen Ausländeranteil in der Schweiz gegenüber. ${ }^{167}$

Stürzinger berichtet davon, dass schon im Frühling 1983, als erst wenige Asylsuchende aus Sri Lanka in der Schweiz registriert waren, von Seiten der Behörden ein Bedrohungsszenario gezeichnet wurde: «Eine <eigentliche Flut> von Flüchtlingen aus Sri Lanka habe eingesetzt, und allesamt

166 www.lathan.ch/index.php?id=7\#c117; 10.10.2010.

167 Das erste Volksbegehren Gegen die Überfremdung der Schweiz des Komitees «Nationale Aktion gegen die Überfremdung der Schweiz» wurde 1965 eingereicht und 1968 zurückgezogen. Es folgten weitere sogenannte Überfremdungsinitativen: 1970 wurde die Schwarzenbach-Initative («Eidgenössiche Volksinitative Überfremdung») mit 54 Prozent abgelehnt. Auch die Initiative Gegen die Überfremdung und Überbevölkerung der Schweiz, in der verschiedene Massnahmen zur Regulierung der Einwanderung in der Schweiz gefordert wurden, verfehlte 1974 knapp die Mehrheit. 1977 wurde über die 4. Überfremdungsinitative und die Volksinitative für die Beschränkung der Einbürgerung abgestimmt, die ebenfalls vom Stimmvolk abgelehnt wurden (vgl. D’Amato 2001, 212). 
seien sie von Schlepperorganisationen illegal in die Schweiz eingeschleust worden» (Stürzinger 2002, 3). ${ }^{168}$

Die Schweizer Behörden verfolgten unterschiedliche Handlungsstrategien. Dabei wurde die patiency vieler Migrierender aus Sri Lanka in hohem Masse gefordert, da der rechtliche Status vieler Geflüchteter durch Wartezeiten auf den Asylentscheid lange Zeit ungeklärt war (zum Begriff patiency vgl. Schnepel 2005; Kap. I 1.2). Dies hatte wiederum Einschränkungen der Agency der tamilischen Geflüchteten zur Folge, da es keine Möglichkeit gab, in einen anderen Kanton zu ziehen, und Familiennachzug schwierig zu organisieren war.

Aufgrund der Ereignisse in Sri Lanka stieg die Zahl der tamilischen Asylsuchenden in den 1980er Jahren stetig an. In der Schweiz lebte von 1983 bis 1991 etwa ein Fünftel der tamilischen Geflüchteten, die nach Europa kamen. Die Schweizer Behörden waren auf eine so grosse Anzahl Geflüchteter nicht eingestellt (vgl. McDowell 1996, 9). Martin Stürzinger legt dar, dass es bereits in den 1980er Jahren Vorbehalte nicht nur in der öffentlichen Meinung der Schweiz gegenüber Geflüchteten aus Sri Lanka gab, sondern auch auf administrativer Ebene. Es wurden gezielt Massnahmen ergriffen, um die Einreise weiterer Asylsuchender aus Sri Lanka einzudämmen:

Um mögliche Asylbewerber abzuschrecken, versandte das BAP [Bundesamt für Polizeiwesen] vorerst nur die negativen Bescheide. Die Fälle, in denen sich positive Entscheide abzeichneten, wurden unter Verschluss gehalten. (Stürzinger 2002, 4)

Bereits in den 1980er Jahren fanden politische Debatten darüber statt, ob die Zwangsmassnahme der Abschiebung nach Sri Lanka angesichts der Situation der tamilischen Minderheit humanitär vertretbar sei. Lange Zeit waren die Meinungen in der Schweizer Politik darüber geteilt. Stürzinger spricht für diesen Zeitraum von einer «widersprüchlichen Politik» der Schweiz gegenüber den tamilischen Asylsuchenden.

Das Ziel war klar: Mit dem Damoklesschwert einer ständig drohenden Rückschaffung sollte die Schweiz als Asylland unattraktiv gemacht werden. Gleichzeitig wurden in der Boulevardpresse Asylbewerber immer wieder mit Kriminellen gleichgesetzt. (Stürzinger 2002, 5)

168 Auch die vom Eidgenössischen fustiz- und Polizeidepartement über das Amt für Migration in Auftrag gegebene Studie Die srilankische Diaspora in der Schweiz stellt für die Anfangsjahre der Migration tamilischer Geflüchteter in die Schweiz fest: «Die Schweizer Behörden standen faktisch vor einem grossen Dilemma: sie konnten diese Personen aufgrund der Lage in Sri Lanka einerseits nur schwer zurückschicken, aber andererseits fürchteten sie, die Schweiz in den Augen potenzieller Neuankömmlinge zu attraktiv zu machen» (Moret et al. 2007, 34). 
1985 wurde aufgrund der steigenden Zahl an Geflüchteten in der Schweiz das Amt des Delegierten für das Flüchtlingswesen (DFW) im Eidgenössischen Justiz- und Polizeidepartement (EJPD) geschaffen. Verschiedenste Hilfsorganisationen und Einzelpersonen wie auch auf internationaler Ebene Amnesty International protestierten gegen mögliche Rückführungen von Tamilinnen und Tamilen nach Sri Lanka. ${ }^{169}$ Dies führte zu einer Polarisierung der Schweizer Gesellschaft (vgl. Parak 2005, 85 f.). «Bei vielen Schweizern entstand der Eindruck, Tamilen würden einzig wegen Protesten nicht ausgeschafft. Doch selbst die Schweizer Botschaft in Colombo erklärte, die Lage habe sich verschärft» (Stürzinger 2002, 5).

In den Jahren der ersten tamilischen Asylgesuche (1983-1987) wurden diese zu einem öffentlichen Thema, welches politisch hoch brisant war. 1986/1987 dehnte sich beispielsweise der Streit um die Abschiebung von dreissig in Bern lebenden Tamilen zu einem nationalen innenpolitischen Konflikt aus (vgl. Parak 2005, 86f.).

1987 entschied der Delegierte des Flüchtlingswesens, auf zwangsweise Abschiebungen zu verzichten. Bis 1991 wurden nur straffällig gewordene Tamilen nach Sri Lanka abgeschoben. Höhepunkt der Asylgesuche von Menschen aus Sri Lanka war das Jahr 1991, als 7501 sri-lankische Staatsbürger Asyl in der Schweiz beantragten. Von 1986 bis 2009 stellten insgesamt 40123 Personen aus Sri Lanka in der Schweiz einen solchen Antrag.

\section{Organisierte Rückführungen nach Sri Lanka}

Das Jahr 1994 markierte eine Zäsur der Schweizer Politik gegenüber tamilischen Migrantinnen und Migranten aus Sri Lanka. Als erstes europäisches Land verabschiedete die Schweiz in Kooperation mit dem United Nations High Commissioner for Refugees (UNHCR) ein «Rückkehrabkommen» mit der sri-lankischen Regierung. Es sollte abgewiesenen Asylsuchenden, die ihr Gesuch nach dem 30.Juni 1990 eingereicht hatten, die Möglichkeit geben, «in Sicherheit und Würde» nach Sri Lanka zurückzukehren. Nachdem andere Massnahmen nicht gewirkt hatten, war das Abkommen nach McDowell in erster Linie als Abschreckungsmassnahme für potenziell in die Schweiz reisende Migrierende initiiert worden, um die Anzahl weiterer Einreisen in die Schweiz zu verringern.

169 Diese Entwicklungen innerhalb der Schweizer Zivilgesellschaft wurden auch in der Bundesrepublik Deutschland rezipiert. So berichtete das deutsche Nachrichtenmagazin Der Spiegel darüber unter dem Titel «Mit allen Mitteln. Helvetisches Wunder: Für das Asylrecht dunkelhäutiger Tamilen rebellieren Bürger gegen ihren Staat» (Der Spiegel 06/1987; 02.02.1987). 
The main objective of the return scheme was to limit the potential of high immigration in the future. To those observing the negotiations leading up to the signing of the Agreement it was apparent that the scheme was designed more to act as a deterrent to further asylum seeking from Sri Lanka (and elsewhere), than to reduce the numbers of asylum seekers already in the country. (McDowell 1999, 129f.)

Nichtregierungsorganisationen kritisierten das Abkommen als gegen die humanitäre Tradition der Schweiz gerichtet. Auch tamilische Geflüchtete in der Schweiz protestierten gegen die Massnahmen. Das Rückführungsabkommen führte zur Anordnung der Abschiebung vieler abgelehnter tamilischer Asylsuchender, jedoch wurde diese in vielen Fällen aufgrund der politischen Lage in Sri Lanka auf unbestimmten Zeitpunkt verschoben.

Das Rücknahmeabkommen wurde aufgrund von anhaltender Gewalt in Sri Lanka bereits am 03. November 1995 ausgesetzt. Die tamilischen Migrierten, deren Ausreisefristen bereits abgelaufen waren, aber aufgrund der politischen Lage in Sri Lanka nicht abgeschoben werden konnten, standen vor dem Dilemma, dass ihnen nun aufgrund des ungeklärten Rechtsstatus eine Erwerbstätigkeit in der Schweiz nicht erlaubt war. ${ }^{170}$

\section{Stabilisierung der rechtlichen Situation durch kollektive Regularisierungen}

Im Rahmen des Abkommens wurde 1994 die Gruppe von sri-lankischen Bürgern rechtlich regularisiert, welche vor dem 30.Juni 1990 in die Schweiz eingereist waren. Ungefähr 9‘000 sri-lankische Bürger wurden vorläufig aufgenommen und erhielten den Ausweis F. Drei Mal hat die Schweiz eine kollektive Regularisierung vorgenommen, die einen rechtlich prekären Status von tamilischen Asylsuchenden aufhob und «ihnen die Möglichkeit zur Integration» gab (Moret et al. 2007, 37f.). 1990 erhielten circa 4400 Menschen, die vor 1986 eingereist waren, den Aufenthaltsstatus B; die erwähnte Massnahme von 1994 im Rahmen des Rückführungsprogrammes nach Sri Lanka war die einzige Regularisierung, welche nur sri-lankische Staatsbürger betraf. Die umfassendste kollektive Anerkennung von tamilischen Migrantinnen und Migranten geschah durch die Humanitäre Aktion im Jahr 2000 (HUMAK), als das EJPD beschloss, Geflüchtete mit hängigem Verfahren, die vor dem 31. Dezember 1992 in der Schweiz ein Asylgesuch einge-

170 Die Schweizer Kantone reagierten unterschiedlich auf diese Sachlage. Das Bundesamt für Flüchtlinge erliess am 24. November 1995 die Empfehlung an die Kantone, die Arbeitsverhältnisse ausnahmsweise zu verlängern. 
reicht hatten, vorläufig aufzunehmen. Der Schweizer Bundesrat reagierte mit dieser auf die unsichere und prekäre Situation von rund 16000 - mehrheitlich sri-lankischen - Geflüchteten, die auf einen amtlichen Bescheid zu ihrem Asylgesuch warteten.

Trotz der angespannten politischen Lage in Sri Lanka trat am 01. November 2000 ergänzend das «Rückkehrhilfeprogramm Sri Lanka» in Kraft. Durch dieses sollten den in der Schweiz abgewiesenen Asylsuchenden nach ihrer Abschiebung sowie freiwillig Zurückkehrenden vor Ort Hilfsangebote gemacht werden. «Mit dem durch die Erhöhung der Zahl der kontrollierten Ausreisen verbundenen Signal sollte als längerfristiges Ziel ein Trendbruch eingeleitet, das heisst mehr Ausreisen als Einreisen erreicht werden» (Projektteam Sri Lanka 2005, 2). Der Schlussbericht der Leitungsgruppe bewertet das Programm als gelungen. ${ }^{171}$ Auf kantonaler Ebene wurden «Rückkehrberatungsstellen» (RKB) eingerichtet; finanzielle Rückkehrhilfen wurden nach Vorlage von Projektvorschlägen genehmigt, welche vom International Organization for Migration (IOM) Büro in Colombo ausbezahlt wurden. Das Programm endete im März 2004.

Im zivilgesellschaftlichen Bereich kam es zu Protesten gegen die Rückführung von Tamilinnen und Tamilen nach Sri Lanka. So reichte die Freiplatzaktion Region Basel 2001 die Petition «Keine Rückkehr nach Sri Lanka ohne Sicherheit und Würde!» an die Staatspolitische Kommission ein. Darin wurden auch die Rückkehrhilfeprogramme des Bundesamtes für Flüchtlinge kritisiert. ${ }^{172}$

In den Jahren, als es Rückkehrabkommen zwischen der Schweizer und der sri-lankischen Regierung gab, tauchten - laut Stürzinger - circa 8000 tamilische Geflüchtete aus Angst vor einer Abschiebung nach Sri Lanka unter. ${ }^{173}$

171 Von 2001 bis 2004 reisten 179 Personen im Rahmen dieses Programms nach Sri Lanka aus; 244 meldeten sich für das Programm an, reisten dann aber doch nicht aus, und 64 erschienen nicht am Flughafen.

172 Das Eidgenössische Justiz- und Polizeidepartement gab zu dieser eingereichten Petition am 29.08.2001 eine Stellungnahme ab, in welcher sie keine Situation allgemeiner Gewalt in Sri Lanka und kein erhöhtes Risiko für Rückkehrende aus der Schweiz attestierte und Abschiebungen für zumutbar erklärte. Auf diese Stellungnahme hin entschied die Staatspolizeiliche Kommission, dass kein gesetzgeberischer Handlungsbedarf bestehe. www.parlament.ch/afs/data/d/ bericht/2001/d_bericht_s_k24_0_20012022_0_20020130.htm; 01.11.2010.

173 Vgl. den Artikel von Martin Stürzinger, Zwischen Heimweh und neuer Integration. Tamilen in der Schweiz und der prekäre Friedensprozess in Sri Lanka, in: Neue Zürcher Zeitung, 24.05.2003, online einsehbar unter: www.nzz.ch/article8T1EQ-1.256850 (10.01.2015). 


\subsection{Das Profil und die soziale Situation der Migranten- gruppe zum Zeitpunkt der Studie}

Das Profil der tamilischen Migrantinnen und Migranten in der Schweiz änderte sich im Laufe der Jahre. Unterschiede in Alter, Geschlecht, ökonomischem und kulturellem Hintergrund, der Herkunftsregion und der Bürgerkriegserfahrung der einreisenden Tamilen führten dazu, dass die tamilische Diaspora in der Schweiz divers und heterogen ist, was bereits in den vorangegangenen Kapiteln angesprochen wurde.

Die soziodemographische Zusammensetzung der Gruppe im Untersuchungszeitraum wird im Folgenden anhand statistisch erhobener Daten und mit Blick auf die zweite Generation der Migrantengruppe vorgestellt. Im ersten Teil stehen die Grösse der Gruppe, ihr rechtlicher Status, auch in Bezug auf Staatsbürgerschaft und Einbürgerung, ihr ökonomischer Status und Bildungsstand und ihr Alter, Geschlecht und Zivilstand im Blick.

Der zweite Abschnitt fokussiert auf die sogenannte zweite Generation und die besonderen Anforderungen und Chancen von tamilischen Schweizern bzw. Schweizer Tamilen, ihren Platz in der Mitte der Schweizer Gesellschaft zu finden. Dabei werden im Besonderen die Herausforderungen, welche die Zugehörigkeit zur Gruppe der «tamilischen Hindus» beinhaltet, in den Blick genommen.

\section{Das Profil der Gruppe: statistisch erhobene Zahlen im Untersuchungs- zeitraum}

Zum soziodemographischen Profil der tamilischen Immigranten-Gruppe in der Schweiz liegen für den Zeitraum der Studie keine umfangreichen empirischen Untersuchungen und Analysen vor, weshalb dieses im Folgenden anhand statistischer Daten konkretisiert wird. ${ }^{174}$

Diese Zahlen geben Auskünfte über Grösse und Dynamiken der Gruppe im Zeitraum der Untersuchung. Durch die Erhebungen im Intervall von drei Jahren können Rückschlüsse auf Prozesse und Veränderungen innerhalb der Gruppe gezogen werden. Die genaue Zahl der sri-lankisch-tamilischen Personen in der Schweiz ist schwer zu ermitteln, da die statistischen

174 Den Ausführungen liegen Angaben des Bundesamtes für Statistik sowie die «Ausländer- und Asylstatistiken», herausgegeben vom Bundesamt für Migration (BFM), aus den Jahren 2006, 2009 und 2012 zugrunde. Dabei beziehe ich mich auf gemäss dem Zentralen Ausländerregister ZAR und der automatisierten Personenregistratur AUPER erhobene Zahlen von Ende Dezember 2006 sowie von Ende Dezember $2009 \mathrm{zu}$ «Bestand und Bewegungen» und zu «Retrospektiven Ergebnissen» (BFM 2007; 2010) sowie den Statistikbericht von 2012 (BFM 2012). 
Zahlen immer nur Angaben über die Gesamtzahl der sri-lankischen Bürger wiedergeben. Das BFM geht davon aus, dass 90 bis 95 Prozent davon Tamilinnen und Tamilen sind (vgl. Moret et al. 2007, 30).

Ende 2009 und auch 2012 stellten sri-lankische Bürger laut BFM die vierzehntgrösste Gruppe der «ständigen ausländischen Wohnbevölkerung» in der Schweiz dar. ${ }^{175}$ Damit waren sie die grösste asiatische und auch die grösste aussereuropäische Ausländergruppe in der Schweiz (vgl. BFM 2010a, 23)..$^{176}$

Von 2006 bis 2012 nahm die Zahl der «ständigen ausländischen Wohnbevölkerung» aus Sri Lanka stetig ab. Dies liegt in der hohen Zahl an Einbürgerungen begründet. Vergleicht man jedoch die Zahl der sri-lankisch stämmigen Menschen in der Schweiz - damit sind solche mit sri-lankischem Pass und solche, welche zum Zeitpunkt ihrer Geburt einen sri-lankischen Pass hatten und diesen dann gegen einen Schweizer Pass eintauschten, gemeint - stieg die Zahl der Gruppe. Zwischen den Jahren 2007 und 2012 ist ein Wachstum von 6420 Personen festzustellen. ${ }^{177}$ Ende 2012 lebten mindestens 51366 Personen sri-lankischer Herkunft in der Schweiz. Diese Zahl umfasst 29156 Personen mit Staatsangehörigkeit Sri Lanka ${ }^{178}$ und 22210 eingebürgerte Menschen mit Herkunftsland Sri Lanka. Dazu ist noch die unbekannte Zahl an illegalisierten Personen und in der Schweiz geborene Kinder bereits eingebürgerter ehemaliger sri-lankischer Bürger zu nennen, die nicht in den Statistiken auftauchen. Es ist davon auszugehen, dass 2012 circa 46000 Tamilen in der Schweiz lebten.

Beginn der vorliegenden Untersuchung stellt das Jahr 2007 dar: In diesem Jahr lebten 44949 Personen (inklusive eingebürgerter Personen), die

1752009 umfasste die Gesamtzahl der sri-lankischen Wohnbevölkerung in der Schweiz 30746 Personen, im Jahr 201223907 Menschen. Diese Angaben beinhalten nicht nur Aufenthalter und Niedergelassene, sondern auch Kurzaufenthalter, internationale Funktionäre und Diplomaten, Asylsuchende und vorläufig Aufgenommene.

176 Nicht zu Asien bzw. Aussereuropa gezählt werden die in der Schweiz lebenden türkischen Staatsangehörigen, die 2009 4,2\% der ausländischen Bevölkerung stellten und auch 2012 zahlreicher waren als sri-lankische Bürger. An zweiter Stelle der asiatischen Immigrantinnen und Immigranten stehen die thailändischen Staatsangehörigen (2006 0,5\%; vgl. BFM 2007, 23).

177 Zwischen 1990 und 2009 waren sri-lankische Bürger die Gruppe in der Schweiz, welche das grösste Wachstum in Prozenten zu verzeichnen hatte (3576,5\%), was einem Zuwachs von 26967 Personen entsprach (vgl. BFM 2010, 25). Ähnlich sieht die Entwicklung zwischen den Jahren 1987 und 2006 aus (Veränderung von 3657,7\%), was einem Zuwachs von $29^{`} 911$ Personen entspricht (vgl. BFM 2007, 25).

178 Diese Zahl umfasste 23907 Personen aus Sri Lanka, die zur ständigen ausländischen Wohnbevölkerung zählten, 1195 anerkannte Flüchtlinge aus Sri Lanka, 3560 Personen aus Sri Lanka, die als Asylsuchende registriert waren, und 494 Personen aus Sri Lanka, welche Asylgesuche in der Schweiz gestellt hatten. 
zur sri-lankischen Diaspora zu rechnen sind, in der Schweiz; circa 42000 davon waren Akteure der tamilischen Diaspora. Die grösste Anzahl an srilankischen Staatsbürgern in der Schweiz wurde im Jahr 2000 erfasst. ${ }^{179}$

Die Gruppe der tamilischen Immigrantinnen und Immigranten in der Schweiz zeichnet sich durch ihr relativ junges Alter aus. 2009 waren $44 \%$ der sri-lankischen Staatsbürger zwischen 10 und 20 Jahren in der Schweiz und $41 \%$ zwischen 0 bis 10 Jahren. Nur $15 \%$ waren 20 Jahre und länger in der Schweiz. Sri-lankische Bürger haben im Vergleich zu anderen grossen Einwandergruppen eine auffallend grosse Zahl an Aufenthaltern und eine niedrige Zahl an Niedergelassenen (vgl. BFM 2007a, 27; 2010a, 28f.). 2009 hatten nur 29\% eine Niederlassungsbewilligung (vgl. BFM 2010a, 26). Die grösste Zahl der anerkannten Geflüchteten wohnte im Kanton Zürich, es folgt der Kanton Bern und der Kanton Aargau. In der französischsprachigen Schweiz leben die meisten sri-lankischen Bürger im Kanton Waadt.

Im Jahr 2009 standen mit 1415 Anträgen Asylgesuche aus Sri Lanka an dritter Stelle der Gesuche und mit 9,8\% an dritter Stelle der Anzahl der Personen, die sich im Asylprozess befanden (3964 Personen; BFM 2010a, 45). 915 Personen wurde 2009 in der Schweiz Asyl gewährt, was die höchste Zahl seit 2002 war. Dies stand im Zusammenhang mit den militärischen Gefechten in Sri Lanka.

Hauptgrund für die anhaltend hohe Zahl von Asylgesuchen ist die Schlussoffensive der Regierung gegen die LTTE im Frühjahr 2009, welche zu einem erhöhten Abwanderungsdruck führte. Auch nach dem Ende der bewaffneten Kämpfe blieb das Migrationspotenzial vorläufig hoch (BFM 2010, 42).

Mehr als 10000 Personen, die in der Schweiz lebten und in den Statistiken als sri-lankische Bürger geführt wurden, waren in der Schweiz geboren. Das war mehr als ein Drittel der in der Schweiz wohnhaften sri-lankischen Bürger (2009: 36,2\%) und weit mehr als der Durchschnitt von 23 Prozent innerhalb der ständigen ausländischen Wohnbevölkerung (vgl. BFM 2007a, 28f.).

Die Zugehörigkeit zur sri-lankischen Diaspora ist nicht an die sri-lankische Staatsbürgerschaft gekoppelt. Seit dem Jahr 2000 liessen sich immer mehr Tamilinnen und Tamilen einbürgern, was eine Abkehr vom Nationalstaat Sri Lanka bedeutet. Ende 2012 hatten circa 43Prozent der Personen mit sril-lankischer Herkunft einen Schweizer Pass. ${ }^{180}$

179 Das sind 35790 Personen; vgl. BFS Statistik zu «Wohnbevölkerung nach detaillierter Staatsangehörigkeit».

180 Das Einbürgerungskonzept der Schweiz basiert auf dem ius sanguinis (vgl. Cattacin/ Kaya 2001, 207). Im Jahr 2006 waren Bürger aus Sri Lanka die fünftgrösste Gruppe der Eingebür- 
Die Mehrheit der sri-lankischen Bürger war verheiratet. Die Volkszählung von 2000 zeigte, dass Tamilinnen und Tamilen überproportional häufig im Familienverbund zusammen mit Kindern lebten. Die Anzahl binationaler Ehen mit Schweizern betrug $20065 \%$ und $20093 \%$; dabei waren mehr sri-lankische Frauen mit Schweizer Männern verheiratet als umgekehrt.

Sri-lankische Männer und Frauen, die in der Schweiz leben, weichen im Bildungsstand kaum voneinander ab. Es kann also nicht von einem genderspezifischen Gefälle bei der Bildung gesprochen werden. Die Studie des Bundesamts für Migration weist darauf hin, dass die meisten tamilischen Eltern eine gute Ausbildung für ihre Söhne wie auch ihre Töchter wünschen (vgl. Moret et al. 2007, 52).

Laut Bundesamt für Migration (BMF) haben sri-lankische Familien aufgrund des soziodemographischen Profils ein erhöhtes Armutsrisiko und sind vielfach zur Gruppe der working poor zu zählen (vgl. Moret et al. 2007, 63). Jedoch ist die Beschäftigungsquote von sri-lankischen Männern relativ hoch. «Srilankische Migranten, insbesondere die Männer, sind verglichen mit der übrigen ausländischen Bevölkerung gut in den Arbeitsmarkt integriert, in ihrer Mehrheit (70\%) allerdings als wenig oder nicht-qualifizierte Arbeitskräfte, vor allem im Hotel- und Gastgewerbe, wo ihre Arbeit ganz besonders geschätzt wird» (Moret et al. 2007, 63).

Im wirtschaftlichen Sektor war ein Geschlechtergefälle festzustellen: Viele Frauen waren nicht beschäftigt, während ein hoher Prozentsatz an Männern eine Arbeitsstelle hat. Des Weiteren ist im ökonomischen Sektor der Unterschied zwischen der ersten und zweiten Generation sehr gross. Während in Bezug auf die erste Generation von Unterschichtung gesprochen werden kann, ist bei der zweiten Generation soziale Aufwärtsmobilität festzustellen. Für die Zukunft kann eine Homogenisierung in Bezug auf den ökonomischen Lebensstandard mit der Schweizer Mehrheitsbevölkerung angenommen werden.

\section{Die zweite Generation: Tamilische Schweizer / Schweizer Tamilen}

Der Begriff der zweiten bzw. dritten Generation ist im wissenschaftlichen Diskurs nicht unumstritten (vgl. Juhasz/Mey 2003). Monika Müller beschreibt die Jugendlichen der zweiten Generation als «Grenzgänger» (Müller 2013, $265 \mathrm{ff}$.). Tamilen der nachfolgenden Generationen können ihre Zugehörigkeit zu einer nicht-christlichen Religion und ihre Hautfarbe wie

gerten (6,2\%; 2935 Personen; BFM 2007, 39). Von 1974 bis einschliesslich 2007 bekamen 13285 Personen aus Sri Lanka einen Schweizer Pass. Im Jahr 2009 waren Bürger aus Sri Lanka die siebtgrösste Gruppe der Eingebürgerten (4,8\%; 2157 Personen; vgl. BFM 2010, 39). 
auch ihre fehlende Schweizer Staatsbürgerschaft als soziales Ausschlusskriterium erleben.

Bei Akteuren der zweiten Generation kann die Zugehörigkeit zu einer in der Schweiz «fremden» Religionstradition wie den Hindu-Traditionen Dissonanz auslösen. Charakteristisch für viele Mitglieder der zweiten Generation ist die Ausbildung einer hybriden Identität, das Leben zwischen den Welten und Kulturen. Die Tamilinnen und Tamilen der zweiten Generation können sich sowohl als Schweizer als auch als Tamilen oder keiner der beiden Gruppen zugehörig fühlen. Diese Uneindeutigkeit der Identitätskonfigurationen können kreative Freiräume bieten. Exemplarisch seien Auszüge aus dem Interview mit der 20-jährigen Lakhi, sri-lankische Tamilin der zweiten Generation, genannt, die sich weder als Tamilin noch als Schweizerin identifiziert. Sie beschreibt ihre empfundene Nicht-Zugehörigkeit zu einer klar umgrenzten kulturellen Gruppe wie folgt: ${ }^{181}$

Ich denke jeden Tag nicht nach, woher ich komme. Ich fühle mich/jetzt/persönlich gesagt/ich fühle mich leer/ich fühle mich nicht als Tamile/ich fühle mich nicht als Inder/ich fühle mich nicht als Schweizer/ich fühle mich einfach als Mensch. Ich lebe hier/das ist es. Wenn mich jemand fragt: <Woher kommst du? > sage ich: <Joa/Indien/Zürich/ich weiss nicht. $>^{182}$

Sie entzieht sich der Logik einer klaren kulturellen und nationalen Identitätszuschreibung und einem Labelling von aussen:

Ich bin ein bisschen komisch, weil ich nicht weiss, wohin ich gehöre. Ich bin einfach hier. Und sage: Ich verstehe alle Länder/verstehe alle Kulturen. Ja, das ist es. Ich will einfach nur Mensch.

Laut Müller 2013 lassen sich verschiedene Strategien von Tamilen der zweiten Generation im Umgang mit den Kategorisierungen der Schweizer Mehrheitsgesellschaft feststellen: Strategien der Neutralisierung, in welchen die Ausschlussmechanismen als nicht relevant dargestellt werden, Strategien der Abgrenzung und des Rückzuges. Eine Gruppe der nachfolgenden Generationen erlebt sich als Aussenseiter sowohl in der Schweiz als auch im Herkunftsland der Eltern bzw. Grosseltern. Auch wenn «Tamilen» die Schweizer Staatsbürgerschaft besitzen, fühlen sie sich nicht zugehörig zur Gruppe der Alteingesessenen (vgl. Müller 2013, $227 \mathrm{ff}$.).

Hindu-Traditionen werden primär als nicht zum Schweizer Kontext passend wahrgenommen. Den Akteuren ist bewusst, dass Hindu-Traditio-

181 Das Interview mit Lakhi wurde am 12.01.2009 in einem Café in Zürich geführt. Die folgenden Gesprächs-Zitate stammen aus dem Interview mit ihr.

182 Interview $2 ; 12.01 .2009$. 
nen eine Neuerung innerhalb der religiösen Landschaft der Schweiz darstellen. Die religiösen Traditionen werden als durch die Eltern, die als Träger einer «Schweiz-fremden Kultur» angesehen werden, weitergegebenes kulturelles Erbe betrachtet. Viele Akteure der zweiten Generation thematisieren, dass ihre religiöse Praxis kein Resultat einer individuellen Entscheidung ist, sondern aus ihrem kulturellen Hintergrund und ihrer Familientradition zu erklären ist.

Lakhi, welche seit achtzehn Jahren in der Schweiz lebt, nimmt eine ambivalente Haltung gegenüber der religiösen Tradition ein, in der sie aufgewachsen ist und die sie praktiziert.

Also / es ist ein ganz/wie soll man sagen/für mich es ist ganz komisch/wenn man in der Schweiz lebt und eine andere Religion hat/die gar nicht hier existiert. Ich habe die Religion nur kennen gelernt, weil meine Eltern mir das von Kindheit an erklärt haben, wie es funktioniert und mich immer in die Tempels mitgenommen haben. Sonst wäre ich nie auf diese Religion/also/selber darauf gekommen. Und ich muss sagen/ich bin nicht streng gläubig. Ja/ich glaube schon an die Religion/aber für mich sind alle Religionen gleich.

Die Akteurin grenzt ihre religiöse Praxis, die sie als nicht zur Schweiz dazugehörig ansieht, von ihrer religiösen Überzeugung ab. Ihre religiöse Praxis wird als Erbe ihrer Eltern durchgeführt, von welcher sie sich innerlich abgrenzt.

Eine verbreitete Haltung vieler Tamilen der zweiten Generation ist es, Hindu-Traditionen als Teil der kulturellen Herkunft ihrer Familie zu akzeptieren und zu praktizieren. In ihrem religiösen Selbstbild trennen sie jedoch diese religiöse Praxis von ihrem persönlichen Religionsverständnis und ihrer individuellen religiösen Überzeugung ab. Lakhi vertritt ein universalistisches Religionsverständnis: Ihre religiöse Überzeugung fusst nicht auf einer einzigen religiösen Tradition, der religiösen Tradition ihrer Eltern, sondern versteht sich als humanistische Ethik jenseits der religiösen Trennlinien. Die Akteurin praktiziert äusserlich die in ihrer Familie gepflegten Hindu-Traditionen, bekennt sich jedoch innerlich nicht ausschliesslich zu einer Hindu-Tradition. Daher versteht sie sich nach ihren Massstäben als «nicht sehr religiös». Ihr ist es wichtig zu betonen, dass sie sich nicht selbst für die Religion, die sie lebt, entschieden hat, sondern sie diese als Familienerbe, als eine Form von kulturellem Erbe (vgl. Michael 2007, 43 ff.) praktiziert:

Daher/also/ich weiss schon viel über den Hinduismus/wie es funktioniert/ wie man sich muss verhalten / aber ich bin jetzt grad sehr religiös / würde ich nicht sagen. Also/wie schon gesagt/also/es hat mich nicht/[3] weisst $\mathrm{du} / \mathrm{also}$ überzeugt/also/ich meine jetzt/Religion ist für mich, wenn ein 
Mensch und ein anderer Mensch sich verstehen und/ja/gut auskommen. Sie müssen sich nicht sagen / ich bin Hindu/du bist Christ/ und jetzt/ wir müssen uns jetzt arrangieren. ${ }^{183}$

Das Religionsverständnis der Akteurin fusst auf einer bestimmten Ethik; sie lehnt eine Etikettierung und Einteilung in verschiedene religiöse Traditionen ab, obwohl sie mit dem System der Hindu-Traditionen vertraut ist.

Die zweite und dritte Generation tamilischer Schweizer ist durch ihre Schulsozialisation fest in der Schweizer Gesellschaft verankert; viele sind zugleich stark an tamilischen Traditionen orientiert. Durch die Dominanz der LTTE im öffentlichen Raum wurde der Rückbezug auf tamilische Kulturwerte gefördert. Ganesh/McDowell sprechen in diesem Zusammenhang von 〈culturalisation of politics〉 (Ganesh/McDowell 2014, 146).

Im Laufe der Jahre hat sich ein eigener Ausdruck tamilisch-schweizerischer Jugendkultur etabliert: Ausdruck ist beispielsweise die Wahl der Miss Tamil Switzerland seit 2013, bei der es zu Kontroversen innerhalb der tamilischen Diaspora kam. In kontroversen Debatten um diesen Anlass wurde ein sogenannter generational gap deutlich (vgl. Haefli 2013). Die Festigung einer schweizerisch-tamilischen Identität wird von eigenen tamilischen Fussballmannschaften in der Schweiz gefördert. In vielen Schweizer Kantonen gibt es tamilische Fussballvereine, wie zum Beispiel den SC Royal Bern, der bereits 1990 in Bern gegründet wurde. ${ }^{184}$

Das politische Engagement der zweiten Generation ist sowohl auf die Herkunftsregion ihrer Eltern wie auch die Schweiz als neue Heimat gerichtet. Als Ausdruck politischen Engagements der zweiten Generation innerhalb der Schweizer Politlandschaft ist die Wahl des heutigen SP-Politikers Rupan Sivaganesan 2006 in den Kantonsrat von Zug zu nennen und das politische Engagement des SP-Politikers Lathan Suntharalingam im Kanton Luzern. Tamilen der zweiten Generation sind auch in transnationalen tamilischen Kontexten politisch aktiv. Im März 2010 waren zwei Drittel der Gewählten des Swiss Council of Eelam Tamils junge Schweizer Tamilen. ${ }^{185}$ Das Swiss Council of Eelam Tamils hat sich nach dem Ende des Bürgerkrieges gegründet und arbeitete mit dem Transnational Government of Tamil

183 Interview 2; 12.01.2009.

184 Weitere tamilische Fussballvereine für Jungen/Männer gab bzw. gibt es in den Kantonen Aargau und Basel, weitere zwei Clubs im Kanton Bern (FC Tamil Little Stars und FC United Fire), in den Kantonen Luzern, Neuenburg, St. Gallen, Tessin, Waadt, Zug und drei im Kanton Zürich. In den Kantonen Bern, Luzern, Waadt und Zug gibt es auch Fussballmannschaften für Mädchen; vgl. www.scroyal.ch (01.03.2015).

185 Vgl. http://www.tamilelection.ch (01.03.2015). 
Eelam zusammen. ${ }^{186}$ Nach dem offiziellen Ende der LTTE wurden neue Organisationen gegründet, welche für einen separaten tamilischen Staat eintreten und zur Festigung einer globalen tamilischen Einheit beitragen wollen (vgl. Brun/van Hear 2012; Hess/Korf 2014). ${ }^{187}$

Zusammenfassend lässt sich sagen, dass sich das Profil der Akteure der zweiten Generation im Vergleich zur Generation der Erstankommenden wie auch die Herausforderungen, welchen sich die beiden Gruppen gegenübersehen, unterscheiden. Das schlägt sich in den unterschiedlichen Positionierungsstrategien religiöser Akteure der Gruppen nieder. Gemeinsam war erster wie zweiter Generation ein bleibender Rückbezug auf die Ereignisse in den Herkunftsregionen.

\title{
4 Die Etablierung tamilischer Hindu-Praktiken in der Schweiz - der Einfluss kontextueller Faktoren
}

\author{
Hindu socio-religious phenomena and the identities \\ of Hindu people from place to place outside India are \\ often highly unlike each other, having travelled along \\ diverse historical trajectories conditioned by a wide \\ range of locally contextual factors. (Vertovec 2000, 1)
}

Die sri-lankisch tamilische Diaspora, deren Entstehung und Profil in den vorangegangenen Kapiteln dargestellt wurde, bildet den historischen und sozio-politischen Rahmen für die Ausübung von Hindu-Praktiken durch tamilische Migrantinnen und Migranten in der Schweiz. Lokale Hindu-Praxis in der Schweiz, die durch Akteure der tamilischen Diaspora gestaltet wird, ist immer auch Teil der Praxis einer globalen tamilischen Diaspora. Sie findet jedoch auch an einem konkreten Ort mit unterschiedlichen kontextuellen Bedingungen statt.

De-Lokalisierung durch die Flucht tamilischer Hindu-Akteure auf unterschiedliche Kontinente geht also mit Re-Lokalisierung, der konkreten

186 Jedem Diaspora-Land war gemäss der Grösse der tamilischen Bevölkerung eine bestimmte Anzahl an Delegierten innerhalb des Transnational Government of Tamil Eelam zugeordnet. Die Schweiz war mit 10 Delegierten vertreten.

187 Vgl. http://tgte.org (01.03.2015). 
Ausübung der religiösen Praktiken in einem bestimmten neuen Kontext, einher. Dieser «globalisierte Lokalismus» ${ }^{188}$ hat in den unterschiedlichen Residenzländern unterschiedliche Ausprägungen, die in unterschiedlichen kontextuellen Faktoren begründet liegen. So können beispielsweise das Profil und die religiöse Praxis von sri-lankischen Migrantinnen und Migranten in Nachbarstaaten aufgrund länderspezifischer Faktoren stark divergieren. Grosse Unterschiede sind zum Beispiel zwischen der Schweiz und ihrem Nachbarland Italien festzustellen. Diese Differenz hat ihren Ursprung in den spezifischen Ausprägungen der Migrationspolitik der Länder wie auch in arbeitsmarktpolitischen Faktoren. ${ }^{189}$

Steven Vertovec hat in The Hindu Diaspora verschiedene Faktoren benannt, welche Einfluss auf die unterschiedliche Ausgestaltung von HinduPraxis in der Diaspora haben (vgl. Vertovec 2000, 21 ff.). "In order to account for meanings, actions, and 'contextual parameters' among Hindu people in a variety of geographical and historical locations, a broad range of factors must be accounted for in a systematic way" (Vertovec 2000, 21). Angelehnt an seine Systematisierung und im Anschluss an die Darstellung der Etappen tamilischer Einwanderung in den vorangegangenen Abschnitten gehe ich im Folgenden spezifisch auf die Bedingungen der Etablierung tamilischer Hindu-Praktiken im Residenzland Schweiz ein.

$\mathrm{Zu}$ den verschiedenen kontextuellen Faktoren, die auf die Ausprägung des religiösen Lebens von Migrierenden einwirken, gehören immer auch die Herkunftsbedingungen - also die kontextuellen Faktoren, welche die Immigrantengruppe im Herkunftsland prägte (Faktor 1) ${ }^{190}$ Politische und soziale Komponenten der Herkunftsbedingungen wurden bereits dargestellt; im Folgenden werden für den Untersuchungskontext zentrale

188 Der Begriff bezieht sich auf den von Santos geprägten Terminus globalized localism (Santos 1995), welcher auch in Studien zur Hindu-Diaspora aufgenommen wurde (vgl. Waghorne 2004, 171).

189 In Italien stellen nicht tamilische Hindus, sondern singhalesische Christinnen und Christen die Mehrheit der sri-lankischen Staatsangehörigen (vgl. Henayaka-Lochbihler/Lambusta 2004). Seit den 1970er Jahren kamen hauptsächlich singhalesische katholische Frauen aus Sri Lanka als Arbeitsmigrantinnen nach Italien. 1996 wurden durch das Dini Dekret Familienzusammenführungen für sri-lankische Geflüchtete erleichtert und Familienangehörige der bereits im Land lebenden Sri Lanker zogen nach (vgl. Henayaka-Lochbihler/Lambusta 2004). Tamilische Bürgerkriegsgeflüchtete aus Sri Lanka sind in Italien eine Minderheit innerhalb der sri-lankischen Staatsangehörigen.

190 Vertovec (2000) benennt den Aspekt der Prägung durch die staatliche Religionspolitik und die historisch gewachsene Religionslandschaft im Herkunftsland nicht explizit. Im Kontext dieser Untersuchung verdient dieser Punkt jedoch Erwähnung, da er Einfluss auf die Positionierungsstrategien der Migrantinnen und Migranten im religiösen Feld des neuen Kontextes zu haben scheint. 
Aspekte des religiösen Feldes Sri Lankas angeschnitten, welche Einfluss auf tamilisch-hinduistisches Leben in der Schweiz hatten. Des Weiteren wirkten sich die bereits skizzierten Bedingungen im Aufnahmeland Schweiz auf die konkrete Ausgestaltung der Hindu-Praktiken aus. Diese werden im Folgenden systematisiert zusammengestellt.

Die rechtliche Inkorporation der Migrantengruppe als Einflussfaktor der Ausgestaltung des religiösen Lebens der Tamilen werde ich als zweiten Einflussfaktor thematisieren (Faktor 2). Daran anschliessend möchte ich zeigen, dass die Schweizer Integrationspolitik und herrschende Diskurse über Integration als Inkorporationsbedingung Einfluss hatten (Faktor 3). Auswirkungen auf das religiöse Leben tamilischer Geflüchteter hatten auch die historisch gewachsene Religionslandschaft des neuen Kontextes und Aspekte der von ihr geprägten Religionspolitik (Faktor 4). Wie in der Darstellung der allgemeinen Bedingungen der Eingliederung beschrieben, zeigt sich, dass auch die Reaktion der Mehrheitsbevölkerung auf Immigrantenreligionen und Hindu-Praktiken im Speziellen einen wichtigen Eingliederungsaspekt darstellt (Faktor 5), welcher sich in Bezug auf die verschiedenen Generationen von tamilischen Hindus unterschiedlich auswirkte.

\subsection{Die Prägung durch die Herkunftsbedingungen (Einflussfaktor 1)}

Kontextuelle Faktoren, welche die Immigrantengruppe im Herkunftsland prägten, sind grundlegende Einflussfaktoren der Etablierung religiös-kultureller Praktiken der Geflüchteten in neuem Kontext. Migrierende sind immer schon von der Religionslandschaft und -politik ihres Herkunftslandes und den Bedingungen für die Ausgestaltung des religiösen Lebens in diesem geprägt. Die Mehrheit der Bevölkerung Sri Lankas (circa 70 Prozent) gehört dem Theravada-Buddhismus an. Um die 15 Prozent der Bevölkerung klassifizieren sich selbst als Hindu. ${ }^{191}$ Bürger, welche Hindu-Traditionen praktizieren - die Mehrheit davon versteht sich als Caivas - waren im nationalen Kontext Sri Lankas schon immer eine religiöse Minderheit und

191 Gemäss der letzten Volkszählung in Sri Lanka im Jahr 2012 bezeichnen sich 70,2 Prozent der Bevölkerung als Buddhisten, 12,6 Prozent als Hindus. Im Gegensatz zur vorangegangenen Volkszählung im Jahr 2001 wurden auch in den tamilisch dominierten Distrikten Zählungen durchgeführt. Im Distrikt Jaffna, Kilinochchi, Mullaitivu, Varvuniya und Batticaloa gab die Mehrheit der Befragten 2012 an, Hindu zu sein (vgl. Departement of Census and Statistics Sri Lanka; online einsehbar unter: http://www.statistics.gov.lk/PopHouSat/CPH2011/index.php?file Name=pop43\&gp=Activities\&tpl=3; 02.01.2021). 
standen in Austauschbeziehungen mit anderen religiösen Strömungen. ${ }^{192}$ "It [Saivism] flourished in a multicultural setting and it had votaries among diverse ethnic groups" (Pathmanathan 2008, 828). Daher ist das Bewusstsein für religiöse Pluralität nicht erst eine Folge des Migrationsprozesses. Bereits in Sri Lanka war der Umgang mit den verschiedenen religiösen Traditionen ein Thema des Religionsdiskurses. Sowohl von staatlicher Seite als auch innerhalb politischer Diskussionen innerhalb tamilischer Gruppen wird der Umgang mit Religionspluralität verhandelt. Auch eine Beeinflussung tamilischer Hindus durch christliche Akteure setzte nicht erst im Migrationskontext ein. Die koloniale Vergangenheit Sri Lankas ging mit einer nachhaltigen christlichen Einflussnahme auf buddhistische wie auch hinduistische Praktiken einher. Einflussreiche reform-hinduistische Akteure aus Sri Lanka, wie Ārumuka Nāvalar, waren von christlichen Organisationsstrukturen und Denkmustern beeinflusst (vgl. Kap. II 2.2).

Die Vielfalt der Religionslandschaft Sri Lankas spiegelt sich in der Zusammensetzung der religiösen Zugehörigkeit tamilischer Migrantinnen und Migranten, die in die Schweiz kamen, wider. Religiöse Zugehörigkeit interferiert in Sri Lanka in manchen Fällen mit ethnischer Zugehörigkeit, in anderen Fällen ist religiöse Zugehörigkeit ethnienüberspannend. «Hindu sein» geht mehrheitlich mit «tamilisch sein» einher. Die Zugehörigkeit zu christlichen Gruppen hingegen korreliert nicht mehrheitlich mit ethnischer Zugehörigkeit. Unter den sri-lankischen Christen finden sich sowohl Tamilen als auch Singhalesen; öffentlich postulierte Gruppengrenzen werden jedoch meist entlang der Linie «Singhalese» oder «Tamile» gezogen. Im Gegensatz dazu definieren sich die Muslime Sri Lankas, die im staatlichen Diskurs als Moors bezeichnet werden, primär über ihre religiöse Zugehörigkeit und werden als distinkte Bevölkerungsgruppe wahrgenommen. Auch die Wechselwirkung religiöser Organisationen mit politischen Interessengruppen ist uneinheitlich. Während sich die LTTE beispielsweise explizit als religionsneutrale Organisation versteht ${ }^{193}$, definieren sich singhalesische Organisationen teilweise als Interessenvertreter einer ethnischen Gruppe wie auch als buddhistische Organisationen (vgl. u.a. Deegalle 2006, DeVotta 2007, Tambiah 1992).

192 In den östlichen Provinzen Sri Lankas leben Hindus beispielsweise seit dem Mittelalter in direkter Nachbarschaft mit Muslimen zusammen (vgl. Pathmanathan 2008, 828).

193 Dies wurde vor allem von Peter Schalk (vgl. z. B. Schalk 2003a) aufgezeigt. Kontroversen, ob die LTTE im wissenschaftlichen Kontext als säkulare Organisation bezeichnet werden kann, zeichnet Fuglerud 2011 nach. Die Verflechtungen der öffentlichen Präsentation der LTTE mit Caivam-Symbolik sind jedoch unbestritten. 
Some Sinhala nationalists explicitly use Buddhism to spearhead their claims, but others do not, while the Tamil separatist discourse steers clear of religion altogether. Therefore, the religious field in Sri Lanka is not characterized by clearly de-lineated boundaries enclosing "pure" spaces, but is a highly contested and hybrid zone, fraught with internal boundaries and enmeshed with politics. (Goodhand/Klem/Korf 2009, 680 f.)

Wie auch die Mehrheit der tamilischen Bevölkerung Sri Lankas sich selbst als Hindu bezeichnet, ist auch das Gros der tamilischen Exilanten in der Schweiz Anhänger hinduistischer Traditionen. Das Gros der tamilischen Hindus der ersten Generation vertritt, wie im Herkunftsland auch, keinen spiritualisierten, universalisierten «Hinduismus», sondern praktiziert Hindu-Traditionen, die eng an die Zuordnung zu einer ethnischen Gruppe gebunden sind.

Christinnen und Christen unterschiedlicher Denominationen stellen in der Schweiz wie in Sri Lanka die zweitgrösste Religionsgruppe der tamilischen Bevölkerung. Die organisierte Zugehörigkeit der circa 10 bis 15 Prozent der tamilischen Christen in der Schweiz ist vielfältig. Ein Grossteil der aus Sri Lanka angekommenen christlichen Geflüchteten waren Mitglieder der römisch-katholischen Kirche.

Wie auch in Sri Lanka verstehen sich tamilisch sprechende Muslime, die in der Schweiz als Migrantinnen und Migranten leben, in erster Linie als Muslime und grenzen sich damit von der Gruppe der «Tamilen» ab. ${ }^{194} \mathrm{Im}$ Vergleich zu den tamilischen Geflüchteten, die sich als Christen oder Hindus bezeichnen, ist die Anzahl an sri-lankisch tamilischen Muslimen in der Schweiz weitaus geringer. ${ }^{195}$ Ungefähr 350 Familien zählen nach eigenen Angaben 2011 zu den sri-lankischen Muslimen, die in der Schweiz leben. ${ }^{196}$ Der Prozess der Institutionalisierung dieser Gruppe führte zur Gründung der Sri Lankan Muslim Association (SLMA) in der Schweiz, welche 2008 in Bern die Moschee Masjid-ul-Qghair in einem angemieteten Raum eröffnete. Die SLMA versteht sich in erster Linie als Teil der muslimischen Diaspora und ist mit anderen muslimischen Organisationen in der Schweiz verbunden. So ist sie Mitglied von Umma, dem islamischen Kantonalverband Bern.

194 Auch bei meinem Besuch der Masjid-ul-Qghair der Sri Lankan Muslim Association in Bern am Tag der offenen Moschee am 07.11.2009 betonten die Anwesenden immer wieder, dass sie sich selbst in erster Linie als Muslime aus Sri Lanka verstehen. Auf die Frage, ob er Tamile oder Singhalese sei, antwortete ein Verantwortlicher, dass er Muslim sei.

195 Nur 0,1 Prozent der Angehörigen von islamischen Gruppierungen in der Schweiz wurde in Sri Lanka geboren (vgl. Bovay 2004, 33).

196 Diese Zahlen wurden 2011 auf der nicht mehr aktiven Webpräsenz der Vereinigung angegeben (vgl. www.slma-suisse.org; 01.07.2011). 
Die Gründung der Vereinigung war jedoch auch eine Reaktion auf die besondere Situation in Sri Lanka, um die muslimische Bevölkerung in Sri Lanka zu unterstützen.

The purpose to form a strong organization became a priority after the recent tragedies in Sri Lanka, where we faced the lack of coordination amongst us to organize emergency assistance to our brothers and sisters in Sri Lanka. (www. slma-suisse.org; 01.07.2011)

Verbindungen zu tamilischen Hindus bestehen nur vereinzelt auf individueller Basis.

Zusammenfassend kann festgestellt werden, dass tamilische Geflüchtete sich bereits vor ihrer Ankunft im europäischen Kontext in einem vielfältigen und ausdifferenzierten religiösen Feld bewegten, in welchem Hindus auf nationaler Ebene eine Minderheit darstellen. Der Umgang mit religiöser Pluralität im nationalen Kontext wie auch innerhalb der ethnischen Gruppe fand folglich schon in Sri Lanka statt. Innerhalb der Gruppe der Tamilen stellen Hindus jedoch im Herkunftsland wie auch im Residenzland Schweiz die Mehrheit.

\subsection{Die Flüchtlingspolitik des Aufnahmelandes als Inkorporationsbedingung (Einflussfaktor 2)}

Zentrale Einflussbedingungen auf die Etablierung tamilischer Hindu-Praxis in der Schweiz sind die bereits dargestellten unterschiedlichen Ebenen der Inkorporation im Residenzland Schweiz (vgl. Kap. III 3). Diese beeinflussten die Etablierung von Hindu-Traditionen in der Schweiz nachhaltig.

Vertovec nennt unter dem Aspekt der Infrastruktur der Aufnahmegesellschaft als Einflussfaktor der Eingliederung von Hindus im neuen Kontext den Punkt "nature of governmental policies towards migrant/refugee groups” (Vertovec 2000, 21). Dieser Aspekt spielt im Hinblick auf die Situation von Hindus aus Sri Lanka, die als Geflüchtete in die Schweiz kamen, eine grosse Rolle. Seit dem Zweiten Weltkrieg ist die Migrationspolitik der Schweiz, wie in vielen anderen europäischen Ländern, im Wandel. Eine Politik der «offenen Tür» von 1948 bis 1968, basierend auf der humanitären Tradition der Schweiz, wurde von einer restriktiveren Politik gegenüber einwandernden Menschen abgelöst (vgl. Piguet 2006).

Wie gezeigt wurde, war die Ankunft tamilischer Asylsuchender seit den 1980er Jahren von einer widersprüchlichen Schweizer Politik geprägt (vgl. Kap. III 3). Unklarheit bestand auf Seiten der Behörden über die tatsächliche Gefahrenlage für Tamilen in Sri Lanka, was auch in den Besonderheiten des 
Bürgerkriegs in Sri Lanka begründet liegt. Daraus resultierte eine wechselhafte Asylpolitik gegenüber den Geflüchteten. Seit Beginn ihrer Ankunft führte der Schweizer Staat einzelne Massnahmen ein, die von Asylgesuchen abschrecken sollten (vgl. Kap. III 3.4). Besonders die rechtliche Unsicherheit und die Gefahr einer Abschiebung konstituierten eine belastende und prekäre Situation für die tamilischen Einwanderer.

Laut der Volkszählung von 2000 hatten von den in der Schweiz lebenden Hindus, deren Mehrheit Tamilen sind, ein Drittel der Gruppe einen unsicheren Aufenthaltsstatus: 24,1 Prozent verfügte über einen vorläufigen Aufnahmestatus (Ausweis F), 13 Prozent waren Asylsuchende (Ausweis N). Die Mehrheit (44,5 Prozent) besass Aufenthaltsbewilligung B (vgl. Bovay 2004, 119). Somit besassen 81,6 Prozent nur einen befristeten Aufenthaltsstatus.

Diese Hintergründe hatten Auswirkungen auf einzelne Positionierungsstrategien tamilischer Akteure in der Etablierung ihrer Hindu-Traditionen in der Schweiz und deren Dynamiken. Die unsichere Situation der Tamilinnen und Tamilen bewirkte, dass sich viele Geflüchtete - auch in der Ausgestaltung ihres religiösen Lebens - nur provisorisch in der Schweiz einrichteten. Ihre Kapazitäten, um beispielsweise Tempel zu bauen oder offensiv als organisierte Hindu-Gruppen in die Öffentlichkeit der Mehrheitsgesellschaft zu treten, waren gering. Die anfänglich defensive Haltung in der Praxis des religiösen Lebens tamilischer Hindus liegt auch in der Unsicherheit gegenüber den Behörden und der öffentlichen Meinung begründet. Aktivisten der Freiplatzaktion Zürich beschreiben in Die vorläufige Aufnahme: Zwischen humanitärer Grosszügigkeit und gesellschaftlicher Benachteiligung die unsichere Situation der Geflüchteten mit dem Status F wie folgt:

Es ist daher leicht nachvollziehbar, dass die betroffenen Personen diesen Aufenthaltsstatus - auch wenn sie über das ihnen gewährte Bleiberecht erleichtert sind - als prekär, weil provisorisch und nicht auf längere Zeit voraussehbar, wahrnehmen. Wie lässt sich die eigene Zukunft (insbesondere diejenige der Kinder) planen und etwas aufbauen, wenn die grundlegende Sicherheit fehlt, dauerhaft in der Schweiz bleiben zu können? ${ }^{197}$

Erst seit dem Jahr 2000 hat eine Stabilisierung der sozialen und rechtlichen Situation tamilischer Geflüchteter in der Schweiz stattgefunden, was zu Veränderungen in den Positionierungsstrategien und damit den Organisationsstrukturen führte, wie Martin Stürzinger konstatierte: «Und seit das Damoklesschwert einer ständig drohenden Rückschaffung zumindest für einen Teil von ihnen verschwunden ist, beginnt sich die kleine Gemein-

197 Dieses Zitat war am 1.9.2010 unter www.freiplatzaktion.ch/?p=171 einsehbar. 
schaft zu organisieren» (Stürzinger 2002, 12). Dieser Wandel förderte auch den organisierten Aufbau religiöser Infrastruktur, da den Akteuren nun weit mehr Ressourcen zur Verfügung standen, um in die Errichtung von Verehrungsorten für die Hindu-Göttinnen und Götter zu investieren. Wie auch andere Migrationskontexte gezeigt haben, kann erst eine sichere rechtliche Lage von Geflüchteten zu einer längerfristigen Beheimatung auch auf religiöser Ebene - beispielsweise durch den Bau von religiösen Orten - im neuen Kontext führen.

\subsection{Integrationspolitik und Diskurse über Integration als Inkorporationsbedingung (Einflussfaktor 3)}

«Integration» im weitesten Sinn wird in der Schweiz als staatliches Anliegen verstanden, und der Schweizer Staat versteht sich als einer der Träger von «Integrationsbemühungen». Innerhalb der Vielschichtigkeit der Migranteninkorporation in der Schweiz spielen die so genannte Integrationspolitik und die öffentlichen Diskurse über «Integration» eine zentrale Rolle. Der Integrationsdiskurs und die Integrationspolitik haben Einfluss auf Handlungsstrategien und die Positionierung der Immigrantinnen und Immigranten in der öffentlichen Sphäre der Residenzgesellschaft.

«Integration» wird als das Hauptziel der Flüchtlings- bzw. der Migrationspolitik der Schweiz definiert. «Die volle Integration anerkannter Flüchtlinge ist rasch möglichst zu realisieren» heisst es in einem Überblick über den Asyl- und Flüchtlingsbereich, herausgegeben vom Bundesamt für Flüchtlinge (vgl. Mehr 2001, 22). Auch Soysal weist in ihrer Studie auf den zentralen Stellenwert des Integrationskonzeptes in der Schweizer Politik hin: "The key term of the Swiss policy on migration is integration', rather than 'emancipation' or 'mutual coexistence" (Soysal 1994, 53). Integrationspolitik hat auch deshalb einen wichtigen Stellenwert in der Schweiz, da die Eidgenossenschaft zwar eine der höchsten Einwanderungszahlen in Europa hat, sich jedoch von ihrem nationalen Selbstverständnis her nicht als Einwanderungsland versteht (vgl. D’Amato 2010, 131).

Spescha et al. weisen in ihrem Handbuch zum Migrationsrecht darauf hin, dass der Begriff der Integration im Schweizer Ausländergesetz zwar explizit aufgeführt, jedoch darin nicht klar definiert wird (vgl. Spescha et al., 2010, 235 ff.). Soysal, die verschiedene Inkorporationsregime in unterschiedlichen europäischen Ländern verglichen hat, stellt fest, dass in der Schweiz «Integration» als ein individueller Prozess des Einzelnen angesehen wird (vgl. Soysal 1994). Von ihnen werde erwartet, dass sie sich selbstständig in der Gemeinde, in der sie leben, «integrieren» (vgl. Soysal 1994, 53f.). 
Schweizer Integrationspolitik begann mit der Erarbeitung so genannter Integrationskonzepte in den 1990er Jahren, welche zunächst in den grössten Schweizer Städten angewandt wurden. Verschiedene Städte verabschiedeten Leitbilder zur Integrationspolitik und benannten darin unterschiedliche Bereiche, in welchen «Integrationsarbeit» betrieben werden sollte. Die Sprachpolitik als Teil der Integrationspolitik sieht vor, dass Geflüchtete, die Bezüge vom Staat erhalten, verpflichtet sind, eine der Landessprachen der Schweiz zu lernen. Im Gegensatz zum britischen Kontext, wo Sprachbarrieren für tamilische Einwanderer meist keine Rolle spielten (vgl. Geaves 2007, 90), war das Erlernen der deutschen, französischen oder italienischen Sprache eine grosse Hürde für die erste Generation. Staatliche Integrationspolitik erstreckt sich aber auch auf die Bereiche Bildungspolitik, Erwerbsleben und die Wohnsituation.

Im Rahmen der Integrationspolitik kann der Schweizer Staat öffentliche Gelder für «Integrationsprojekte» sprechen. Art. 53 des «Ausländergesetzes» $(A u G)^{198}$ «Förderung der Integration» verpflichtet die «Organe der Integrationsförderung» Bund, Kantone und Gemeinden, «günstige Rahmenbedingungen für die Chancengleichheit und die Teilhabe der ausländischen Bevölkerung am öffentlichen Leben» zu schaffen (AuG Art. 53, Abs.2). Auch die Einrichtung von Integrationsabteilungen oder -büros auf Gemeinde- und Kantonsebene ist Bestandteil der Integrationspolitik (vgl. D’Amato 2010, 139 ff.). Aber auch die restriktive Praxis zur Erlangung des Schweizer Bürgerrechts kann zur Integrationspolitik gezählt werden. Der öffentliche Diskurs über Integration, der mit Debatten um die Stellung von Migrantengruppen in der Gesellschaft verbunden ist, steht in einem sich gegenseitig beeinflussenden Verhältnis zur offiziellen Integrationspolitik.

Als Reaktion auf die offizielle Integrationspolitik der Schweiz nehmen auch Immigranten-Organisationen in ihrer öffentlichen Präsentation den Aspekt einer gelungenen Integration auf. Soysal stellt heraus, dass im Gegensatz zu anderen Residenzländern wie Schweden oder den Niederlanden in der Schweiz der Aspekt der «erfolgreichen Integration» auch in den Immigranten-Gruppierungen selbst besonders betont wird. "In Switzerland, most migrant organizations are small-scale operations sharing a goal that is generally stated as 'furthering the integration of migrants" (Soysal 1994, 100).

Dies trifft für tamilische Organisationen und auch für tamilische HinduVereine zu. So führte der Verein zur Förderung der tamilischen Kultur in der Schweiz in Trimbach, welcher auch Initiator des ersten traditionellen Hindu-

198 Bundesgesetz über die Ausländerinnen und Ausländer vom 16. Dezember 2005 (SR 142.20). 
Tempelbaus in der Schweiz war, 2010 an zweiter Stelle seines Vereinszwecks die «Integrationsförderung von erwachsenen und jugendlichen Tamilen in der Schweiz» auf. ${ }^{199}$

\subsection{Die Religionspolitik und Religionslandschaft des Residenzlandes (Einflussfaktor 4)}

Durch die Religionspolitik des Residenzlandes und dem damit zur Verfügung stehenden Freiraum in der religiösen Ausgestaltung werden entscheidende Weichen für die Form der Re-Etablierung religiöser Praxis von Immigrantinnen und Immigranten im neuen Kontext gestellt. Die Religionspolitik und die historisch gewachsene religiöse Landschaft des Landes sind weitere Aspekte des lokalen Rahmens der Etablierung tamilischer Hindu-Praktiken.

Die Schweiz hat eine lange Tradition, divergierende sprachliche, ethnische, aber auch religiöse Bevölkerungsgruppen einzugliedern und interne Spannungen zu bewältigen.

Der Schweizer Staat versteht sich als Willensnation; das heisst, dass gesellschaftliche Kohäsion durch die Anstrengungen jedes einzelnen Bürgers - trotz unterschiedlicher Ebenen der Diversität wie Sprache und Religion - unternommen werden (Dahinden 2008). "For most Swiss citizens it is obvious that 'the Swiss' are far from being a homogenous group with an overarching collective identity; in fact they are pluralistic and diverse on different levels" (Dahinden 2008, 4). Auch der Staat versteht sich dabei als aktiver Träger der «Integration» unterschiedlicher Religionen in einen einheitlichen gesellschaftlichen Kontext. Walter Kälin unterscheidet drei Sphären, in denen integrative Anstrengungen zur Stabilisierung gesellschaftlicher Kohäsion unternommen werden: die staatliche, öffentliche und private Sphäre. Innerhalb der öffentlichen Sphäre agiert der Staat als Schiedsrichter; Träger von Integrationsbemühungen ist jedes Individuum. In der privaten Sphäre gewährt der Staat nach Kälin dem Individuum weit-

199 Handelsregister des Kantons Solothurn, No 190, 30.09.2010, 128. Jahrgang (Tagesregister-Nr. 4633 vom 24.09.2010). Des Weiteren heisst es in der Beschreibung des Vereinszwecks des Verein zur Förderung der tamilischen Kultur in der Schweiz in der Vereinsliste der Gemeinde Trimbach: «Der gemeinnützige Verein zur Förderung der tamilischen Kultur in der Schweiz hat sich gebildet, um den tamilischen Flüchtlingen in der Region Mittelland die Integration in der Schweiz zu erleichtern und die Remigrationsfähigkeit in ihre Heimat zu erhalten» (http://www. trimbach.ch/de/freizeitundkultur/freizeit/vereinsliste/welcome.php?action=showverein\&verein _id=10103; 03.01.2021). 
gehende Autonomie, wenn dieses sich an die Grundrechte des Staates hält (vgl. Kälin 2000).

Gemäss Schweizer Verfassung ist die Schweiz ein religionsneutraler Staat, der sich in Religionsfragen unparteiisch zu verhalten hat und Schutz vor direkter wie indirekter Diskriminierung gewährleistet. Damit steht der Wohnbevölkerung der Schweiz also ein erhebliches Mass an gesetzlich festgeschrieben Freiräumen zur Religionsausübung zur Verfügung, was tamilischen Hindus in ihrem Streben, Verehrungsorte für ihre Gottheiten zu errichten, zugutekommt.

1847 wurde die Religionsfreiheit in die Konstitution des Schweizer Bundesstaates aufgenommen. Ganz bewusst wird der Begriff «Religion» von juristischer Seite offengehalten (vgl. Winzeler 2008, 21). Die Glaubensund Gewissensfreiheit ist ein in der Schweizer Verfassung verankertes Grundrecht, welches Freiräume bieten soll, in denen eine Entfaltung ohne Beeinträchtigung durch Dritte oder den Staat möglich ist (vgl. Winzeler 2008, 19f.). Die GGF wird im Schweizer Gesetz durch Art. 15 der Bundesverfassung gewährleistet. Sie gehört zu den in der Verfassung verankerten Grundrechten, die jedoch eingeschränkt werden können, wenn religiöse Gemeinschaften durch ihr Handeln dem «ordre public» widersprechen (vgl. Winzeler 2008, 23).

Charakteristikum der Religionspolitik der Schweiz ist, dass der Bund den 26 Kantonen der Schweiz garantiert, ihr Verhältnis zu den Religionsgemeinschaften weitgehend autonom zu ordnen. Die Regelung des Verhältnisses zwischen Staat und Religion in konkreten Sachfragen ist kantonale Angelegenheit, was im ersten Absatz des Artikels 72 «Kirche und Staat» der Bundesverfassung festgelegt ist. ${ }^{200}$ Absatz 2 verweist darauf, dass Bund und Kantone jedoch auch gemeinsam Massnahmen «zur Wahrung des öffentlichen Friedens zwischen den Angehörigen der verschiedenen Religionsgemeinschaften» treffen können.

Aus der Dezentralisierung des Verhältnisses zwischen Staat und Religion ergibt sich eine heterogene Ordnung des Verhältnisses der religiösen Gemeinschaften zu den politischen Organen, die in der unterschiedlichen Geschichte der einzelnen Kantone begründet liegen. ${ }^{201}$ Tamilische Akteure sind also seit ihrer Ankunft in der Schweiz mit einer komplexen Rechts-

200 In diesem Artikel der Bundesverfassung wird jedoch der christlich konnotierte Terminus «Kirche» verwendet: «Für die Regelung des Verhältnisses zwischen Kirche und Staat sind die Kantone zuständig.» Gemeint sind jedoch unterschiedliche Organisationsformen religiöser Gruppierungen.

201 Zur Geschichte der Religionspolitik in der Schweiz vgl. unter anderem Pfaff-Czarnecka 2009, Baumann/Stolz 2007a. 
landschaft konfrontiert, gemäss deren Vorschriften sie ihr religiöses Leben zu organisieren hatten. Religiöse Gemeinschaften unterliegen in den unterschiedlichen Kantonen unterschiedlichen Vorschriften. Zwei Kantone (Genf und Neuchâtel) zeichnen sich durch die Trennung zwischen Staat und Religion aus und sind laizistisch ohne Landeskirchen und öffentlichrechtlich anerkannte Religionsgemeinschaften organisiert. Diese beiden «Trennungskantone» kennen nur privatrechtliche Formen der Vergemeinschaftung von Religionsgemeinschaften.

In der Schweiz finden sich drei Formen der juristischen Anerkennung von Religionsgemeinschaften (vgl. Cattacin et al. 2003). An erster Stelle steht die privat-rechtliche Anerkennung als Verein gemäss Art. 60-79 ZGB oder als Stiftung (Art. 80-89 ZGB; vgl. Winzeler 2008, 43). Die privatrechtliche Organisation ist eine Möglichkeit zur öffentlichen Organisation einer Gruppe, welche mit wenigen Pflichten verbunden ist. So besteht beispielsweise keine Pflicht, sich in ein Vereinsregister eintragen zu lassen oder den Verein demokratisch zu organisieren. Mit dieser Form der Institutionalisierung sind jedoch auch keine Privilegien verbunden (vgl. Cattacin et al. 2003, 12). Die privatrechtliche Organisation, die in allen Kantonen möglich ist, wurde von tamilischen Akteuren als einzige ihnen zur Verfügung stehende Organisationsform in Anspruch genommen. Tamilische Geflüchtete gründeten Kulturvereine, politische Vereine und auch «Tempelvereine».

Eine weitere Möglichkeit ist die öffentlich-rechtliche Anerkennung einer religiösen Gruppe. Einzige nicht-christliche Religionsgruppe, welche im Untersuchungszeitraum in fünf Kantonen als öffentlich-rechtliche Religionsgemeinschaft anerkannt war, ist die Israelitische Gemeinde (vgl. Lore$\tan 2007,163)$. Die jüdische Minderheit ist seit dem Mittelalter Teil der Religionslandschaft der Schweiz. Die Hindernisse der öffentlich-rechtlichen Anerkennung von nicht-christlichen Religionsgemeinschaften variieren von Kanton zu Kanton (Cattacin et al. 2003). Bisher haben nur die muslimischen Organisationen versucht, auf rechtlichem Weg als Körperschaften des öffentlichen Rechts anerkannt zu werden. Interessenvertreter tamilischer Hindus haben zwar öffentlich ihren Wunsch nach öffentlich-rechtlicher Anerkennung kundgetan, aber im Untersuchungszeitraum keine formell juristischen Schritte für eine Anerkennung unternommen. ${ }^{202}$ Einige

202 Die öffentlich-rechtliche Anerkennung bringt nicht nur auf der symbolischen Ebene Prestige, sondern bietet auch zahlreiche Privilegien wie das Recht, eine theologische Fakultät an Universitäten aufzubauen, Seelsorgedienste in Krankenhäusern und Gefängnissen anzubieten, Religionsunterricht an staatlichen Schulen zu geben, Steuern bei den Mitgliedern zu erheben und Steuerbefreiungen zu erlangen (vgl. Pfaff-Czarnecka 2009, 232 f). Laut einer Agenturmeldung von 23.09.2009 erwägten Luzerner Hindus innerhalb der kantonalen Vorgaben eine öffentlich-rechtli- 
Kantone, wie Basel-Stadt, Zürich, Freiburg und Aargau, kennen darüber hinaus die Möglichkeit einer «kleinen» Anerkennung, die den Religionsgemeinschaften ein begrenztes Mass an Privilegien gibt (vgl. Winzeler 2009, 124). Der Jurist Christoph Winzeler sieht darin einen Weg, «die fremden, für die Schweiz neuen Religionen zu akkomodieren» (Winzeler 2009, 124). Diese Option wurde jedoch während des Untersuchungszeitraums nicht auf die Organisation tamilischer Hindus angewandt.

Die dritte Form der juristischen Anerkennung von Religionsgemeinschaften ist die Organisation als Landeskirche. Die beiden christlichen Kirchen mit der grössten Mitgliederanzahl in der Schweiz, die römisch-katholische und die evangelisch-reformierte Kirche, nehmen eine Sonderstellung innerhalb der Schweiz ein, da sie bis auf die Trennungskantone den Status einer Landeskirche haben (vgl. Loretan 2007, 163). ${ }^{203}$

Neben migrationspolitischen Bedingungen haben auch die spezifischen Ausprägungen der religiösen Landschaft der Schweiz, als Ergebnis der Geschichte des Landes, Auswirkung auf die Positionierungsstrategien von tamilischen Hindus. Die Schweiz als christlich geprägtes Land, deren Mehrheit der Bürger Mitglied in einer christlichen Kirche ist, beginnt erst in den letzten Jahrzehnten, durch Migrationsbewegungen zu einem religionspluralen Land zu werden.

1970 war die Schweiz eines der europäischen Länder mit dem grössten Bevölkerungsanteil an Mitgliedern in christlichen Kirchen (vgl. Baumann/ Tunger-Zanetti 2011, 154). ${ }^{204}$ Die religiöse Landschaft der Schweiz wurde historisch durch religiöse Spannungen zwischen Katholiken und Reformierten bestimmt. Seit der Reformation ist die Religionsgeschichte der Schweiz durch eine Aufteilung der Kantone nach Konfessionen geprägt (vgl. Baumann/Stolz 2007b, 43). Auch gegenwärtig dominiert in einigen Kantonen eine der Grosskirchen immer noch die religiöse Landschaft. ${ }^{205}$

che Anerkennung: «Man könne sich in der tamilisch-hinduistischen Gemeinde durchaus vorstellen, gemäss den Möglichkeiten der neuen Luzerner Kantonsverfassung die öffentlich-rechtliche Anerkennung anzustreben, sagte ihr Priester Sasitharan Ramakrishnasarma» (www.livenet.ch/ news/schweiz/145268-anerkennung_auch_fuer_orthodoxe_und_hindus.html; 01.12.2010).

203 In einigen Kantonen ist zusätzlich zu diesen Kirchen auch noch die Christkatholische Kirche öffentlich-rechtlich anerkannt.

204 Die Volkszählung von 1970 gab an, dass 97,8 Prozent der Schweizer Bevölkerung Mitglied in einer christlichen Kirche waren, wobei eine überwiegende Mehrheit davon der römischkatholischen Kirche und den reformierten Kirchen angehörte.

205 Die Kantone Freiburg, Tessin und Wallis sind beispielsweise von der römisch-katholischen Kirche geprägt, während in den Kantonen Schaffhausen und Bern die Mehrzahl der Bürger Mitglied in der reformierten Kirche ist. 
Daneben finden sich die sogenannten paritätischen Kantone, in denen beide Religionsgruppen ungefähr den gleichen Prozentsatz ausmachen.

Seit den 1970er Jahren wandelte sich die religiöse Landschaft der Schweiz, was sich besonders im sinkenden Prozentsatz der Mitglieder christlicher Kirchen zeigt. Vor allem Säkularisierungs- und Zuwanderungsprozesse waren Gründe für diese Wandlungsprozesse (vgl. Baumann/Tunger-Zanetti 2011, 155 f.; Bovay 2004, 17 ff.). Insgesamt ist festzustellen, dass die Zahl der Mitglieder in religiösen Gemeinschaften schrumpft (vgl. Baumann/Stolz 2007b, 60). Die grösste Verschiebung der letzten dreissig Jahre findet im Bereich der Kategorie «ohne Religionszugehörigkeit» statt: Während im Jahr 1970 1,1 Prozent angaben, keiner Religionsgemeinschaft anzugehören, waren es im Jahr 2000 11,1 Prozent.

Nicht-christliche Religionen wuchsen von 1970 bis 2000 von 0,7 auf 5,3 Prozent, wobei die muslimische Gruppe den grössten Zuwachs verzeichnete. Es ist festzustellen, dass die nicht-christliche Bevölkerung der Schweiz hauptsächlich in Städten lebt. Dies korreliert mit den Angaben zur ausländischen Wohnbevölkerung in der Schweiz. In Städten haben Migrantinnen und Migranten oft bessere Chancen auf dem Arbeitsmarkt, und auch die gesellschaftliche Eingliederung fällt oft leichter (vgl. Baumann/Stolz 2007b, 45).

Nicht-christliche Immigrantinnen und Immigranten haben somit durch das Praktizieren ihrer jeweiligen religiösen Tradition zur Erweiterung der Religionsvielfalt in der Schweiz beigetragen (vgl. Baumann/Stolz 2007a). Innerhalb der Religionslandschaft stellen hinduistische Migrantinnen und Migranten eine marginale Grösse dar, deren Etablierung keine lange Tradition im Land hat - im Unterschied zu beispielsweise jenen europäischen Ländern, welche als Kolonialmächte eine längere Geschichte des Austausches mit diesen in Asien gewachsenen religiösen Praktiken haben. Hindus machten 2000 nur 0,38 Prozent der Schweizer Wohnbevölkerung aus und sind erst in den letzten Jahrzehnten im Land öffentlich präsent geworden. Baumann/Tunger-Zanetti sprechen in Bezug auf die religiöse Landschaft von einer «kleinen religiösen Pluralität» (Baumann/Tunger-Zanetti 2011, 156). Die breite Masse der Schweizer Bürger nimmt ihr Land bisher nicht als einen religionspluralen Staat wahr. «Bislang wird diese [die religiöse Pluralität] in der Öffentlichkeit vielfach nur wenig wahrgenommen und ist in ihrer internen Heterogenität [...] kaum bekannt» (Baumann/TungerZanetti 2011, 156). Gründe dafür sind, neben religionsrechtlichen Aspekten wie die fehlende öffentliche Anerkennung der Gruppen als Religionsgemeinschaften, das weitgehende Fehlen von öffentlich sichtbaren architektonischen Ausdrucksformen der Gruppen (Baumann/Tunger-Zanetti 2011, 156). Diese Form der öffentlichen Re-Lokalisierung wird in der Schweiz von 
tamilischen Hindus jedoch auf unterschiedlichen Ebenen in Angriff genommen, wie diese Studie zeigt (vgl. Kap. V).

Die Religionsgeschichte der Schweiz, welche die Religionslandschaft prägte, wirkte sich auch in anderer Form als sozialer Inkorporationsfaktor auf tamilische Hindu-Migrantinnen und Migranten aus. In der Schweiz konzipierten Hilfswerke mit christlichem Hintergrund - wie beispielsweise die Caritas als Organisation der römisch-katholischen Kirche und das Hilfswerk der Evangelischen Kirchen der Schweiz (HEKS) oder der Christliche Friedensdienst (CFD) - vor allem für die so genannten «Kontingentflüchtlinge» Hilfsangebote als so genannte «Integrationsangebote».

In den Anfangsjahren tamilischer Migration waren christliche Gruppierungen in der «Betreuung» tamilischer Geflüchteter aktiv. Bei der Ankunft von tamilischen Geflüchteten in den 1980er Jahren in der Schweiz wurde beispielsweise die Heilsarmee angefragt, bei der Unterbringung der Geflüchteten zu helfen. ${ }^{206}$ Durch Interaktionen mit Mitgliedern dieser Gruppe wurden auch tamilische Migrantinnen und Migranten Mitglieder der Heilsarmee.

Durch diese Kontakte mit christlichen Gruppierungen wurden tamilische Akteure bei ihrer Ankunft in der Schweiz - wie auch die so genannten Indochina-Flüchtlinge, welche im Rahmen der Betreuungskonzepte mit evangelikalen Missionsgruppen in Berührung kamen - teilweise mit christlichen Missionsversuchen oder solchen von neuen religiösen Bewegungen konfrontiert. ${ }^{207}$ Beispielhaft seien hier journalistische Beiträge in einem von evangelikalen Gruppen getragenen Medium aus den 1980er Jahren angeführt, die von der Missionierung tamilischer Asylsuchender berichten. Das idea magazin, eine von der Schweizerischen Evangelischen Allianz (SEA), dem Verband evangelischer Freikirchen und Gemeinschaften (VFG) und dem Verband evangelischer Missionen (AEM) herausgegebene Zeitschrift, berichtet 1987 von ehrenamtlichen, religiös motivierten Unterstützern tamilischer Geflüchteter. Unter der Überschrift «Privater Betreuer lernt tamilische Sprache in Wort und Schrift» heisst es: «Ich besuche meine Freunde etwa dreimal in der Woche, spreche mit ihnen über ihre Probleme und versuche ihnen unaufdringlich, aber deutlich, die Liebe Gottes klar zu

206 Der Dokumentarfilm "My Mother is in Sri Lanka" von Remo Legnazzi aus dem Jahr 1987 zeigt das Leben von tamilischen Geflüchteter in einer von der Heilsarmee geführten Asylunterkunft in Zollikhofen bei Bern.

207 Eine Akteurin des interreligiösen Dialoges, die in den Anfängen tamilischer Migration in die Schweiz Hindus beim Aufbau religiöser Strukturen unterstützend zur Seite stand, berichtet in einem anonymisierten Interview von intensiven Missionierungsversuchen der Scientology-Gruppe und der Zeugen Jehovas in Flüchtlingsunterkünften. 
machen» (idea magazin Nr.3/87, 12.03.1987, 6). Die «Betreuer» reagieren auf die teils prekäre Situation der Geflüchteten, indem sie ihnen christliche Heilskonzepte nahezubringen versuchten. «Lehmann [einer der Betreuer] stellt eine grosse Offenheit für die Hoffnung des Evangeliums fest: «Als Hindus leben die meisten in grosser Hoffnungslosigkeit. Wenn sie erfahren, dass es einen Gott gibt, der ihnen real helfen kann, sind sie sehr daran interessiert, diesen Gott kennenzulernen〉» (idea magazin 1987, 6). Dieses Betreuungskonzept stellte nicht die soziale Unterstützung und Organisation des alltäglichen Lebens in den Vordergrund, sondern die Vermittlung der Lehren der Bibel. Das hier zugrundeliegende Integrationsverständnis geht davon aus, dass eine Eingliederung in ein christliches Land, als welches die Schweiz gesehen wird, angestrebt wird. Daher gehöre es zu einer Beheimatung in diesem Staat dazu, christliche Inhalte zu kennen. «Er helfe ihnen im bescheidenen Rahmen bei Arbeits- und Wohnungssuche; als Hauptaufgabe sehe er aber, die Tamilen in unserem «christlichen〉 Land mit dem Evangelium zu konfrontieren» (idea magazin 1987, 6).

Tamilische Akteurinnen und Akteure berichten, dass in den Anfangsjahren der Migration für evangelikal ausgerichtete Anlässe geworben wurde. Dadurch fand eine Verschiebung im religiösen Feld tamilischer Migrantinnen und Migranten statt. Gerade weil Hindu-Praxis nur in begrenztem Ausmass praktiziert werden konnte, besuchten als Hindus sozialisierte Tamilen auch christliche Anlässe. Eine Folge davon war, dass es im evangelikalen Spektrum zur Gründung von eigenständigen tamilischen Freikirchen kam. Einige Hindus liessen sich nach ihrer Ankunft in der Schweiz christlich taufen und engagierten sich in den neu gegründeten Gemeinden. Tamilische Asylbewerber haben beispielsweise 1989 den Tamil Christian Fellowship (TCF) mit Unterstützung der MEOS Svizzera, einer freikirchlichen Mission für Ausländer in der Schweiz, gegründet. Circa 120 Menschen waren 2011 in der Gruppe organisiert, die aus sechs Gemeinden in der Schweiz bestand (vgl. Eulberg/Niederberger 2011). ${ }^{208}$ Aus dieser Gemeinschaft entstand 1992 die charismatisch geprägte Philadelphia Missionary Church (PMC) mit Hauptsitz in Bern. Der Hauptpastor der Gemeinde wie auch einer der beiden associate reverents waren ursprünglich Hindus und konvertierten erst nach ihrer Migration nach Europa zum christlichen Glauben. Pastor Satkunarajah erklärte 2011 auf der Webpräsenz der Gemeinschaft: «Ich stehe aus einer strenggläubigen Hindu-Familie hervor. Ich wanderte im Jahre 1980 nach Deutschland aus. Von dort aus zog ich im Jahre 1982 in die Schweiz. Durch die Gnade Gottes akzeptierte ich 1988 Jesus

208 Seit 2005 tritt TCF als The Christian Fellowship auf, um auch nicht-tamilische Menschen einzuschliessen. 
Christus als meinen Retter. Im Jahre 1989 wurde ich getauft. Als ich spürte, dass Gott mich für das Amt des Pastors auserwählt hat, entschied ich mich, Ihm zu dienen. Seit 1996 diene ich dem Allmächtigen als Pastor.» ${ }^{209}$

Zusammenfassend kann festgestellt werden, dass die Religionspolitik der christlich geprägten Schweiz tamilischen Hindus ein hohes Mass an Freiheit in der Ausgestaltung des religiösen Lebens zugesteht. Ungleichheiten sind jedoch im Vergleich zu christlichen Organisationen zu nennen, da diese als im nationalen Kontext historisch verankerte Gruppen eine Sonderstellung einnehmen. Je nach der Verfassung des jeweiligen Kantons und den Regularien der Gemeinden werden konkrete Anfragen von religiösen Gruppen bezüglich der Ausgestaltung des religiösen Lebens unterschiedlich gehandhabt. Vor allem für bisher unbekannte Formen religiöser Praktiken, wie sie tamilische Migrierende in die Schweiz mitbrachten, finden sich unterschiedliche Vorgehensweisen. Die Positionierung innerhalb der Religionslandschaft ist geprägt von Kontakten und Auseinandersetzung mit der christlichen Mehrheit des Residenzlandes, was im Folgenden verstärkt aufgegriffen werden soll.

\subsection{Reaktionen der Mehrheitsbevölkerung (Einflussfaktor 5)}

Diskurse der öffentlichen Meinung und das gesellschaftliche Klima stellen weitere Einflussfaktoren dar, welche sich auf die Etablierung von HinduTraditionen tamilischer Migrantinnen und Migranten in der Schweiz auswirkten (vgl. Kap. III 3.3). Die Migrationspolitik des Landes und die öffentlichen Diskurse über Immigranten sind oftmals eng mit jenen über Immigrantenreligionen verbunden, welche zeit- und kontextabhängig unterschiedlichen Dynamiken unterworfen sind. Der Schweizer Soziologe Hans-Joachim Hoffmann-Nowotny konstatierte 2001: «Bisher 〈ferne〉 Religionen [...] sind als 〈Fremdes〉 mit den 〈Fremden〉 in die Schweiz gekommen und stellen strukturelle und kulturelle Selbstverständlichkeiten des Einwanderungslandes in Frage» (Hoffmann-Nowotny 2001, 17).

Wie gezeigt wurde, führten die asylrechtlichen Bestimmungen unter anderem dazu, dass der Schweizer Mehrheitsbevölkerung ein unklares Bild der tamilischen Immigrantengruppe und ihres Flüchtlingsstatus vermittelt wurde (vgl. Kap. III 3.4). Daraus folgte, dass es in den Anfängen tamilischer Migration in die Schweiz sowohl Solidaritätsaktionen mit den Tamilen als auch xenophobe Tendenzen mit rassistisch motivierten Über-

209 www.pmcinternational.ch/copy-of-pastors-of-pmc (01.09.2020). 
griffen gab. ${ }^{210}$ Bereits skizziert wurde, dass die öffentliche Meinung über «die Tamilen» fluide ist und sich seit den 1980er Jahren stark gewandelt hat (vgl. Kap. III 3.3).

Die dargestellten Inkorporationsbedingungen führen in vielen Fällen dazu, dass die Akteure einer zugewanderten Religion Machtstrukturen unterliegen, welche ihnen im nationalen Kontext eine subalterne Position zuweisen. Öffentliche Diskurse über Immigrantenreligionen wurden auch durch die politische Praxis in Fragen von deren Religionsausübung beeinflusst. Während diese bis in die 1990er Jahre durch Offenheit gegenüber den religiösen Anliegen von Migrantinnen und Migranten geprägt war, fand in der ersten Hälfte des 21. Jahrhunderts ein backlash statt. Die öffentliche Meinung wurde durch die Politik der SVP beeinflusst, die sich unter anderem durch eine Politisierung religiöser Differenz auszeichnete (vgl. Pfaff-Czarnecka 2009, 226). Besonders präsent waren die öffentlichen Diskurse im Zuge der Initiative zum Verbot des Baus von Minaretten 2009.

Die Minarettverbots-Initiative und die Volksabstimmung 2009 hatten auch Einfluss auf das öffentliche Auftreten von tamilischen Hindus: Der Präsident des Tempel-Vereins in Trimbach, welcher den ersten repräsentativen Hindu-Tempel in der Schweiz baute, drückte in informellen Gesprächen seine Unsicherheit darüber aus, wie die Schweizer Mehrheitsgesellschaft auf den Bau dieses nicht-christlichen Sakralbaus mit einem 15 Meter hohen Turm reagieren würde, und empfand die nationalen Machtverhältnisse als voreingenommen (vgl. Kap. V 2.1). ${ }^{211}$

Wie im erwähnten Zitat von Hoffmann-Nowotny deutlich wird, spielt der Fremden-Diskurs eine grosse Rolle in der Wahrnehmung der religiösen Praktiken tamilischer Hindus in der Schweiz. Hindu-Akteure der tamilischen Diaspora sind mit Unkenntnis und teilweise Unverständnis eines Grossteils der Mehrheitsbevölkerung gegenüber ihren religiösen Traditionen konfrontiert. Besonders die Praktiken während der Tempelfeste wie Hakenschwingen und Körperpiercings werden als «irritierend» wahrgenommen und müssen von den religiösen Akteuren im Schweizer Kontext verstärkt legitimiert werden (vgl. Kapitel V 3.1). Innerhalb der Schweiz las-

210 Vertovec benennt in seiner Auflistung der kontextuellen Faktoren den Punkt degree of "institutionalized racism", welcher Aspekte eines voreingenommenen öffentlichen Diskurses und mediale Stereotypisierungen mit einschliesst (vgl. Vertovec 2000, 22).

211 Auch das Printmedium Der Beobachter thematisiert die Abgrenzungstendenzen der Verantwortlichen des Tempelbauprojekts zur muslimischen Minderheit und deren Forderungen: «Wann es so weit ist, weiss Vereinspräsident Vasanthavajan Ramalingam noch nicht - überhaupt will er den Hindutempel am liebsten nicht im Zusammenhang mit dem Wangner Minarett erwähnt haben. «Wir wollen nicht mit den Muslimen in einen Topf geworfen werden〉, lässt er ausrichten.» (Müller, Martin, Grosses Bangen in Wangen. In: Der Beobachter, 16.02.2006). 
sen sich Diskurse finden, welche die Praktiken tamilischer Hindus primär als «fremd-religiös» ansehen. ${ }^{212}$ Die Praxis von Hindu-Traditionen kann im Schweizer Exil auf keine gewachsenen Strukturen zurückgreifen, wie dies im Fall christlicher, jüdischer oder mittlerweile auch muslimischer Praktiken der Fall ist. Der einzige Ort, an den eine Anbindung in den Anfängen der Migration stattfinden konnte, war der Krishna-Tempel in Zürich (vgl. Kap. IV 3.3). Aber auch die Praktiken der ISKCON-Anhänger wurden von der Mehrheitsbevölkerung als fremd wahrgenommen und standen am Rande der Gesellschaft. Gerade in den ersten Jahren, als tamilische Geflüchtete in die Schweiz kamen, bestimmte der Sektendiskurs das Bild der sogenannten Hare-Krishna-Bewegung in der Öffentlichkeit (vgl. Kap. IV 3.2).

Die Wahrnehmung des «Hinduismus» als Polytheismus löst vielfach Irritationen innerhalb der christlich geprägten Schweizer Gesellschaft aus. Dies wird immer wieder von unterschiedlichen Diaspora-Akteuren thematisiert. ${ }^{213}$ Eine Informantin der zweiten Generation, Lakhi (20 Jahre), welche seit achtzehn Jahren in der Schweiz lebt, macht dies deutlich. Sie legitimiert das Unverständnis mit Unwissen der Mehrheitsbevölkerung über die Hintergründe der hinduistischen Götterwelt. Ihr Verständnis von «Hinduismus» ist, dass es sich dabei um einen Überbegriff für viele Religionen handelt.

Es ist einfach/eben/Hinduismus hat ja eben viele Götter/und man versteht nicht/wenn man sagt/wir haben viele Götter/weil wir haben auch viele Religionen/also im Hinduismus selber. Und das ist eben/manchmal es ist/für manche ist es einfach unverständlich/wenn man sagt/wir haben viele Götter / fragen sie: <Wieso eigentlich? $>^{214}$

In der Diaspora hinterfragen religiöse Akteure aufgrund der Reaktion der Mehrheitsbevölkerung häufig ihre religiösen Praktiken und Vorstellungen und entwickeln Legitimierungsstrategien, um diese der Mehrheitsbevölkerung zu vermitteln (vgl. Vertovec 1999, 283). Im Umgang damit sind Differenzen zwischen der ersten und der zweiten Generation tamilischer Migrantinnen und Migranten auszumachen.

212 Dieser Diskurs kann durch zahlreiche Medienaussagen belegt werden. Neben anderen war er in den Online-Kommentaren der Schweizer Boulevardzeitung Blick in einem Artikel über das Tempelbauprojekt in Trimbach am 07.11.2010 zu finden. So schrieb der Leser Henry Staeger aus Interlaken: «Dieser Tempel gehört nicht zu unserer Schweiz, sowenig wie ein Minarett. Muss eigentlich die ganze Schweiz verschandelt werden????» (www.blick.ch; 07.11.2010).

213 Tamilische Eltern erzählen mir, dass ihre Kinder in der Schule für die Verehrung des Gottes Gaṇeśa ausgelacht werden, weil gerade die Darstellung des elefantenköpfigen Gottes, der auf einer Maus reitet, bei nicht-hinduistischen Kindern Irritationen auslöse.

214 Interview 2; 12.01.2009. 
Ein Gefühl der Fremdheit bestimmt das Leben eines Gros der ersten Generation von Tamilinnen und Tamilen in der Schweiz. Auch wenn die «Integration» auf dem «Papier» durch die Einbürgerung bescheinigt wurde, bleibt das Fremdheitsgefühl bei vielen tamilischen Schweizern, die nicht in der Schweiz gross wurden, bestehen. Eine 52-jährige Tamilin brachte in Gesprächen mit mir dieses Gefühl wie folgt auf den Punkt: «Ich habe einen Schweizer Pass, aber ich werde in diesem Land immer fremd sein.» Eine in der Schweiz fremde Religion zu praktizieren, fügt sich daher kohärent in das Selbstbild (und auch Fremdbild) vieler Migrantinnen und Migranten als «Fremde» in der Schweiz. Dass Hinduismus in der Schweiz keine Tradition hat, wird vielfach nicht als Dissonanz empfunden. Die religiösen Praktiken hinduistischer Tamilen sind daher keine integrationsfördernden Komponenten (ein «Integrationsplus»), die eine Brücke zur Mehrheitsgesellschaft sein könnte, wie dies der christliche Glaube für christliche Tamilinnen und Tamilen sein kann. Die Hindu-Religion wird ebenso wie die tamilische Kultur von Migrantinnen und Migranten wie auch Akteuren der Mehrheitsgesellschaft als etwas in der Residenzgesellschaft NichtBeheimatetes angesehen und bedeutet somit für die erste Generation im Rückschluss auch ein «Stück portable Heimat».

\section{Zusammenfassung: Der Einfluss der Inkorpora- tionsbedingungen auf tamilische Hindu-Praxis in der Schweiz}

Ziel des vorangegangenen Abschnittes war es, das Bedingungsgefüge der Inkorporationsbedingungen darzustellen, welche die Verortung von tamilischer Hindu-Praxis in der Schweiz beeinflusst haben. Dynamiken und Präsentationsformen von Hindu-Praxis unterliegen diesen inkorporativen Rahmenbedingungen.

Ausgangspunkt der Migrationsbewegungen tamilischer Hindus in die Schweiz war der Bürgerkrieg in Sri Lanka. Die Prägungen durch die politischen wie auch kulturellen Bedingungen in Sri Lanka war eine zentrale Inkorporationsbedingung für tamilische Migrantinnen und Migranten in der Schweiz. Ihr rechtlicher Status als Geflüchtete im Nationalstaat Schweiz, die Integrationspolitik der Schweiz und die öffentlichen Diskurse, die mit den politischen Entscheidungen interferieren, hatten des Weiteren entscheidenden Einfluss auf die Lokalisierungsdynamiken tamilischer Hindus in der Schweiz. 
Die Schweiz als Residenzland für die ersten tamilischen Geflüchteten zeichnete sich dadurch aus, dass es zum einen keine tamilische Kulturszene mit etablierten sozialen Netzwerken wie auch keine hindu-religiösen Strukturen innerhalb der Schweizer Religionslandschaft gab. Folgen davon waren ein Gefühl religiöser Verlassenheit, «spiritual desolation» (McDowell 1996, 244), und ein langsam anlaufender Prozess der religiösen Institutionalisierung innerhalb der (religionspolitischen) Bestimmungen der Schweiz. Die soziale Situation der tamilischen Hindu-Akteure, die eng an die rechtliche Situation gekoppelt ist, beeinflusste das Mass an Ressourcen und die Art und Weise ihrer Ausgestaltung, welche ihnen zum Aufbau religiöser Strukturen zur Verfügung standen und stehen. Die Darstellung des Profils tamilischer Migrantinnen und Migranten zum Untersuchungszeitraum hat gezeigt, dass es sich um eine Gruppe handelte, die sich durch Unterschichtung auszeichnete, aber in welcher mit den in der Schweiz aufgewachsenen Generationen soziale Aufwärtsmobilität zu verzeichnen ist.

Es wurde gezeigt, dass ein umfassendes Geflecht aus «Organisationsformen, Praktiken, Diskursen und politischen Strategien, mit denen ein Residenzstaat Diasporas und Migrantengruppen gegenüber tritt» (Beyeler/Suter Reich 2008, 234), die spezifischen Lokalisierungsdynamiken von Hindu-Praktiken tamilischer Hindus in der Schweiz geformt haben. Der Einfluss der Inkorporationsbedingungen stellt in den folgenden Kapiteln, in welchen konkrete Formen von tamilischer Hindu-Praxis und ihre Lokalisierungsdynamiken dargestellt werden, eine wichtige analytische Perspektive dar. 


\title{
Kapitel IV \\ Soziale Räume des Vollzugs tamilischer Hindu-Praxis in der Schweiz
}

\author{
Places are not inert containers. They are politicized, \\ culturally relative, historically specific, local and \\ multiple constructions. \\ (Rodman 1992, 641)
}

Konkrete Orte tamilischer Hindu-Praxis in der Schweiz sind ein zentraler Fokus für die ethnographische Feldforschung der vorliegenden Studie. Die Etablierung von religiösen Orten, die auch als Identitätsmarker fungieren, ist charakteristisch für viele Gruppen in einer Migrationssituation (vgl. Baumann 2000b, 18 ff.). ${ }^{215}$ Das nun folgende Kapitel stellt sowohl darstellend als auch in seiner Analyse diese Lokalitäten und ihre Dynamiken in den Mittelpunkt. Anschliessend an die vorhergehenden Kapitel zu den Analyseperspektiven Diaspora und Inkorporation fokussiert es auf Formen tamilischer Hindu-Praxis in ihrer räumlichen Gebundenheit. ${ }^{216}$ Wie Margaret C. Rodman in dem Kapitel vorangestellten Zitat konstatiert, sind Orte konstruierte Entitäten, die von ihren Umgebungs- und - wie im vorangegangenen Kapitel gezeigt - Inkorporationsbedingungen beeinflusst sind. Die räumliche Dimension ist dem zugrundeliegenden Konzept Diaspora bereits inhärent: Debatten über die Vertreibung von Menschen aus ihrem Heimatort, das Heimischwerden von Immigrantinnen und Immigranten an zunächst fremden Orten und Rückkehr bzw. der Rückkehrwunsch an die verlassenen Orte sind wichtige Bestandteile von Diaspora-Diskursen (vgl. Kap. II).

215 Des Weiteren thematisieren die Sammelbände Nagel 2013 und Nagel 2015 sehr anschaulich religiöse Praxis von Migrantengruppen in sozialen Räumen und an religiösen Orten.

216 Dabei werden Anleihen an die Religionsgeographie genommen, welche die interferierenden Beziehungsverhältnisse zwischen Religion und Umwelt untersucht (vgl. Rinschede 1999, 19). 
Religiöse Praxis, hier konkret Hindu-Praxis, findet immer an konkreten Orten statt. Ebenso wie migrantische Kulturvereine und Geschäfte, welche von migrierten Menschen geführt und in denen Elemente der «materiellen Kultur» zum Kauf angeboten werden (vgl. Lauser 1997), sind religiöse Orte zumeist von hoher Wichtigkeit für das Leben von zugewanderten Minderheiten (vgl. Baumann/Tunger-Zanetti 2008; Peach/Gale 2003). Solche Räume von Hindu-Praxis werden hier unter Verwendung der Analysekategorie Raum und im weiteren Verlauf der Studie auch unter dem Aspekt der öffentlichen Repräsentation betrachtet (vgl. Kap. V).

Im Folgenden sollen die Orte tamilischer Hindu-Praxis in ihrer Komplexität und wandelbaren Bedeutung beschrieben werden. Es werden Räume (analog zum englischen Begriff space) und konkrete topographische Orte (analog zum englischen Terminus places), an welchen Tamilen in der Schweiz Hindu-Praktiken vollziehen, skizziert und analysiert. In welchen unterschiedlichen sozialen Räumen praktizieren Hindus ihre Traditionen und welche Auswirkungen hat die Diaspora-Situation auf die räumliche Ausgestaltung der Hindu-Praxis?

Es sind zwei zentrale physische Raumkategorien mit unterschiedlichen Zuschreibungen zu finden: Dem Wohnraum wie auch dem Tempel als Sakralraum sind unterschiedliche Handlungen zugeordnet. Ersterer situiert sich im privaten, letzterer im öffentlichen Raum (zur Analysekategorie «öffentlicher Raum» vgl. Abschnitt V.1). Der private Wohnbereich als religiöser Raum ist ein Raum, in welchem an zentraler Stelle die häusliche pücai stattfindet, an dem aber auch lebenszyklische Rituale durchgeführt werden können. Im Tempel dagegen kann die Gegenwart der Göttinnen und Götter durch den Vollzug der Tempel-pücai öffentlich erfahren werden.

In den folgenden Abschnitten des Kapitels werden daher zunächst pūcai-Plätze im privaten Bereich dargestellt (2.). Folgend werden Begegnungsräume und Kontaktzonen, die nicht von tamilischen Akteuren initiiert wurden, aber in denen tamilische Hindu-Praxis in der Schweiz stattfindet, dargestellt (3.). Der Fokus liegt hier auf den Räumen der Krishna Gemeinschaft Schweiz als shared places (3.2) und im Besonderen auf dem Krishna-Tempel der ISKCON in Zürich (3.3). Im anschliessenden Abschnitt werden selbstverwaltete tamilische Tempelräume und ihre Entstehungsdynamiken in den Blick genommen (4.). Zunächst dienten meist angemietete Hallen als religiöse Räume (4.1), was die Frage aufwirft, wann ein Raum als Tempel (tam. $k \bar{o} v i l)^{217}$ bezeichnet werden kann (4.3). Die folgende Darstel-

217 Offiziell werden die meisten Tempel in der Schweiz mit dem Sanskrit-Terminus Alayam für Tempel bezeichnet. Ausnahme bildet der einzige Civan als Hauptgott geweihte Tempel, der sich in der Zürcher Ortschaft Glattbrugg befindet. Er wird mit dem tamilischen Terminus für 
lung und Analyse des Jahresfestes taippoikkal (5.) zeigt exemplarisch diasporische und vor allem auf die räumliche Dimension bezogene Veränderungen in der tamilischen Hindu-Praxis auf. Anhand der Darstellung des Feierns von taipponkal in der Schweiz kann eine Bedeutungsverschiebung des Tempels mit Betonung auf seine Funktion als Vergemeinschaftungsraum in der Diaspora aufgezeigt und der Prozess der Tempelisierung expliziert werden. Neben Verehrungsorten in der Schweiz sind durch transnationale Verbindungen bekannte religiöse Orte innerhalb der tamilischen Diaspora und Wallfahrten nach Indien und ihre Rückbindung an Praktiken in der Schweiz für tamilische Hindus von Bedeutung (6.). Das Kapitel schliesst mit einer zusammenfassenden Darstellung der Orte tamilischer Hindu-Praxis in der Schweiz als sinnlichen Wahrnehmungsräumen und ihrer Lokalisierungsdynamiken (7.).

\section{Orte des Religionshandelns: Raum als Analyse- kategorie}

$\mathrm{Zu}$ den bedeutenden kulturwissenschaftlichen Paradigmenwechseln seit den 1980er Jahren sind der durch eine raumkritische Wende in der Forschung ausgelöste Perspektivenwechsel des spatial turn (vgl. Warf/Arias 2009) wie auch der topographical turn (vgl. Weigel 2002) zu zählen, in welchem Repräsentationsformen von Raum thematisiert wurden. Margaret C. Rodman zeigt auf, dass vor dieser Hinwendung zu räumlichen Kategorien Orten innerhalb ethnographischer Studien wenig Beachtung geschenkt wurde: "[A]nthropologists who take pains to lead students through the minefields of conceptualizing culture often assume that place is unproblematic. It is simply location. It is where people do things" (Rodman 1992, 640). Bereits Anfang der 1990er Jahre machte sie auf die Kategorien «Raum» und «Ort» als neu entdeckte signifikante Kategorien innerhalb der Kulturwissenschaft aufmerksam (Rodman 1992). Dabei bezog sie sich ähnlich wie viele andere Kulturwissenschaftlerinnen und -wissenschaftler, die sich mit Raumkonzepten beschäftigen, auf Michel Foucault, der 1980 in Questions of Geography darauf hinwies, dass eine Beschäftigung mit dieser Kategorie vielfach als implizit ahistorisch angesehen wurde:

Tempel «kōvil» in seinem offiziellen Namen bezeichnet (Civankōvil). Im Sprachgebrauch der Akteure wird nur von kōvil gesprochen. Es gibt unterschiedliche Transkriptionen des Begriffes aus dem Tamilischen. Peter Schalk verwendet in seinen Arbeiten die Schreibweise kōyil. 
If one started to talk in terms of space that meant one was hostile to time. It meant, as the fools say, that one "denied history", that one was a "technocrat". They didn't understand that to trace the forms of implantation, delimitation and demarcation of objects, the modes of tabulation, the organisation of domains meant the throwing into relief of processes - historical ones, needless to say - of power. (Foucault 1980, 70)

Mittlerweile sind «Raum» und «Ort» wichtige Begriffe kulturwissenschaftlicher Analysen geworden (vgl. Csáky/Leitgeb 2009; Döring/Thielmann 2009; Günzel 2007). Dabei geht man meist von der sozialen Konstruiertheit jeglichen Raums aus. Dieser ist nicht einfach gegeben, sondern historisch wandelbar. Während Henri Lefebvre (1974) in La production de l'espace aufzeigt, dass (sozialer) Raum ein (soziales) Produkt ist, verweisen neuere diskursanalytische Ansätze darauf, dass Räume nicht nur sozial, sondern auch diskursiv konstruiert sind. Mit Verweis auf die Sozial-Geographin Doreen Massey wird konstatiert, dass «Räume nicht nur als das Ergebnis einer sozialen Produktion zu verstehen sind, sondern die Konstitution von Räumen integraler Bestandteil der Konstitution des Sozialen ist» (Glasze/Mattissek 2009, 42). Die Räume, in welchen Akteure handeln, verändern sich kontinuierlich und werden permanent ausgehandelt.

Michel de Certeau (1988) nimmt in seinen raumanalytischen Ausführungen eine Unterscheidung zwischen Ort (lieu) und Raum (espace) vor; in dieser Konzeption werden Orte durch Handlungen zu Räumen transformiert: "Space is a practiced place" (Michel de Certeau 1988, 118). ${ }^{218} \mathrm{Kim}$ Knott (2005a, 2005b, 2005c) macht die Implikationen des spatial turn seit mehreren Jahren explizit für die Religionswissenschaft fruchtbar, indem sie dazu anregt, Lefebvres raumbezogene Analysen auch auf religionswissenschaftliche Gegenstände und Themen anzuwenden. Anschliessend an ihre Analysen fand das Wechselverhältnis von «Religion und Spatialität» in religionswissenschaftlichen Analysen immer mehr Beachtung (vgl. Corrigan 2009; Knott 2011; Hermann/Mohn 2015).

Vor dem Hintergrund solcher raumtheoretischen Überlegungen betrachte ich tamilische Hindu-Praxis in der Schweiz als diasporische Praxis im Folgenden nicht als eine entterritorialisierte Form von Praxis, sondern nehme sie in ihrer lokalen Gebundenheit in den Blick- immer im Bewusstsein, dass diese Praxis und ihre spezifischen Lokalisierungen aus global cul-

218 Dieser Unterscheidung folge ich in den folgenden Ausführungen in der Verwendung der Terminologie weitgehend, wenn auch diese dichotome Gegenüberstellung durch de Certeau kritisiert werden kann: «Orte sind statisch und tot, Räume lebendig und werden durch Bewegung erzeugt. De Certeaus Verständnis des Ortes als etwas 〈Totem〉 weist deutliche theologische Spuren auf» (Füssel 2013, 33). 
tural flows (Appadurai 1996) entstanden und die Akteure transnational vernetzt sind. Gegen diejenigen Globalisierungsdiskurse, in denen vor allem das Ende von Nationalstaat und Territorialität proklamiert wird, ${ }^{219}$ will ich hier somit vielmehr der «Macht des Lokalen in einer Welt ohne Grenzen» (Berking 2006, 10) Beachtung schenken. Transnationale Vernetzungen werden so als nur eine Bezugsgrösse von Lokalität in den Blick genommen. Gleichzeitig nimmt die vorliegende Studie immer wieder Bezug auf die vorhandenen Handlungs(spiel)räume von Geflüchteten: Ihre konkreten Lokalitäten beeinflussen auf der einen Seite das Leben der Migrantinnen und Migranten und sagen auf der anderen Seite etwas über die Bedingungen ihrer Inkorporation im Residenzland aus. Die Standorte der von Migrantengruppen genutzten Gebäude können so beispielsweise auf ihre Stellung innerhalb der Mehrheitsgesellschaft hinweisen.

Im Kontext der Themenfelder Inkorporation und Diaspora analysiere ich in Abschnitt IV.3 im Rückgriff auf das von Mary Luise Pratt eingeführte Konzept der contact zone beispielhaft einige derjenigen Orte, an welchen tamilische Hindu-Praxis in der Schweiz in «Kontaktzonen» zur Residenzgesellschaft vollzogen wird.

\title{
2 Der pūcai-Platz im Schrank: Wohnungen als Räume der Ausübung von Hindu-Praxis
}

\author{
As the first and smallest inhabited space, its \\ [home's] boundaries open and close to the wider \\ society. Just as the physical body mirrors the social \\ body in some ways, so too domestic spaces and \\ practices reciprocally interact with culturally \\ constructed images of the society and the cosmos.
}

(Tweed 2006, 105)

219 Vgl. etwa Berking (2006, 10): «Die Unaufmerksamkeit gegenüber der Bedeutung von Orten, Räumen, lokalen Kulturen und Identitätsformen aber gehört zu den öffentlichkeitswirksamsten Effekten einer Globalisierungserzählung, die den Betrachter blind dafür macht, dass die Verschiebung sozialräumlicher Masseinheiten nicht gleichbedeutend mit deren Verschwinden ist. Auch durchlässige Grenzen sind immer noch Grenzen.» 
Ich besuche Familie Suthakaran in Zürich. Ich klingle. Frau Suthakaran antwortet mir über die Sprechanlage und öffnet die Haustür über den Türöffner. Ich gehe in den ersten Stock. Frau Suthakaran steht bei geöffneter Tür auf der Schwelle zur Wohnung. Sie begrüsst mich, indem sie mir die Hand gibt. Sie bittet mich, die Schuhe auszuziehen, bevor ich die Wohnung betrete. Ich stelle meine Schuhe vor die Wohnungstür. Sie führt mich an den Wohnzimmertisch und bittet mich Platz zu nehmen. Mir fällt eine Glasvitrine auf, in welcher zahlreiche metallene Figürchen von Hindu-Gottheiten aufgestellt sind sowie eingerahmte Fotografien von Menschen. [...] Sie erzählt mir, dass die Familie einen «Platz zum Beten» hat. Ich frage, wo dieser ist und ob ich ihn einmal sehen darf. Sie führt mich im Flur Richtung Wohnungstür. Im Gang rechts neben der Tür befindet sich ein Wandschrank aus Holz. Sie öffnet den Schrank. «Das ist unser Platz für die Götter», sagt sie. Im dritten Schrankbrett, ungefähr auf Brusthöhe, sind verschiedene bunte Bilder und kleine Figuren von Hindu-Gottheiten aufgestellt bzw. an die Wand gelehnt. Daneben liegen Bücher in tamilischer Schrift und sind Öllampen aufgestellt (Protokoll vom 03.03.2009).

Die Räumlichkeiten, die tamilischen Hindus als Wohnorte dienen, sind immer auch Räume, in denen die Akteure Hindu-Praktiken vollziehen. Der oben wiedergegebene Auszug aus einem Beobachtungsprotokoll verweist auf verschiedene Aspekte, die den Wohnraum als Austragungsort von Hindu-Praxis in der Diaspora betreffen. Der Wohnbereich ist zugleich zentraler Ort alltäglicher, intimer als auch religiös-kultureller Praktiken von Individuen und auch der sozialen Gruppe «Familie». ${ }^{220}$ Der Wohnbereich konstituiert sich durch Handlungen der in ihm lebenden Akteure. Der Gestalttheoretiker Gert Selle bezeichnet Wohnen als «zentrales Kulturereignis, Inszenierungsform des privaten Alltags schlechthin» (Selle 1993, 9). Dieser Ort wird oftmals als das «zu Hause» beschrieben. ${ }^{221}$

220 Die Bedeutung des Wohnbereichs in Hindu-Traditionen korreliert mit der hohen Bedeutung der Institution Familie. Traditionelle Aufgabe von Frauen und Männern ist es, eine Familie zu gründen und einem Haushalt vorzustehen: "The Hindu home provides a necessary center for all social and religious life. A man has not fulfilled his duties and obligations to his ancestors unless he has been a householder. A woman is considered to be auspicious and blessed while she is married, and incomplete if she is not" (Beck 2005, 2403).

221 Auch Thomas Tweed $(2006,105)$ verwendet in seinen Analysen den Begriff in dieser engen Auslegung: "Home, then, might refer to places of varying scale: a clearing, a hut, a nation, the earth, or the universe. In this wider sense, religious dwelling means finding a place or making a space, however small or large. However, as I am using it here in a more narrow sense, home refers to an intimate controlled space, whether cleared or constructed, that provides for bodily needs - shelter, sleep, sex, healing, and food - and usually, though not always, is inhabited by some members of the family." Mit dem Begriff «zu Hause» rekurrieren viele Geflüchtete auch auf 
In der im Protokollauszug beschriebenen Situation zeigen die Mitglieder der Gastgeberfamilie durch performative Praktiken wie das Ausziehen der Schuhe am Eingang des Wohnbereichs an, dass sie sich in einen Raum begeben, der mit verschiedenen normativen Vorgaben verbunden ist. Das Übertreten der Schwelle, der Gang durch die Wohnungstür lassen den Besucher in einen als privat markierten Bereich eintreten. «Die Haustür ist die entschiedenste Grenze - juristisch, psychologisch, historisch: das behütete Tor zum Hort der privaten Intimität, die als unverletzlich, aber bedroht gilt» (Selle 1993, 39). Normen, welche die Bewohner setzen, regulieren die Handlungen der Akteure innerhalb dieses Raumes.

Wohnraum ist Teil der privaten Sphäre und kann somit als intimer, kontrollierter Raum einen Schutzraum bieten. ${ }^{222}$ Für Immigrantinnen und Immigranten wie die tamilische Minderheit in der Schweiz, welche einen marginalisierten Status in der Residenzgesellschaft einnehmen, kann die Wohnung in besonderer Weise einen geschützten Raum darstellen. Hier können sie in Distanz zu den Regulierungen des öffentlichen Raums der Schweizer Mehrheitsgesellschaft relativ unbefangen eigene kulturelle Praktiken durchführen, ohne von dieser in den Blick genommen zu werden. Der Raum kann, mit Einschränkungen, nach dem Gusto der Mieter gestaltet werden. Individuelle Selbstentwürfe werden in den Wohnungen deutlich, «so dass Wände und Dinge wie Spiegel wirken» (Selle 1993, 85). Zumeist ist tamilischer cultural stuff (vgl. das Fazit der Studie) Bestandteil der Dekorationen der Wohnungen - Bilder von Hindu-Gottheiten sind somit nicht nur am Platz der häuslichen pūcai zu finden (so beispielsweise die im Beobachtungsprotokoll beschriebenen metallenen Figuren, welche in einer Vitrine im Wohnzimmer aufgestellt sind).

Neben seiner Funktion als Rückzugsraum ist der Wohnraum aber immer auch Repräsentationsraum. Wohnen stellt eine «Inszenierungsform» dar. Durch die Gestaltung der Wohnung als Akt der Kommunikation können sich Akteure beispielsweise als besonders auf die Residenzgesellschaft oder die Heimat ausgerichtet präsentieren oder ein spezifisches diasporisches Bewusstsein anzeigen. Durch eine spezifische Raumgestaltung zu sich jährlich wiederholenden Festtagen werden die Kategorien Raum und Zeit ver-

\footnotetext{
ihre Herkunftsregionen in Sri Lanka, was einer im Diaspora-Diskurs gängigen Verwendung des Terminus Heimat/home entspricht.

222 Gert Selle $(1993,10)$ macht diesen Aspekt unter anderem in seiner Analyse des Gegenstandes der Gardine deutlich: «Sie [die Gardinen] dienen weniger dem Lichtschutz, dem Verdecken des üblen Ausblicks oder einer ästhetischen Norm, sondern bilden die unüberschreitbare symbolische Grenze des eigenen Drinnen zum feindlichen Draussen; sie sind der bescheidene Schutz gegen den bösen Blick der Welt.»
} 
bunden: Zum Jahresfest taipponkal (vgl. Abschnitt5) ist es beispielsweise üblich, durch bestimmte Gegenstände und Arrangements - wie beispielsweise durch kumpams ${ }^{223}$, die sichtbar in der Wohnung platziert werden auf den festlichen Charakter des Anlasses zu verweisen bzw. die Wichtigkeit des Festes anzuzeigen. $\mathrm{Zu}$ diesem Anlass sind Besuche von tamilischen Verwandten und Bekannten in ihren Wohnräumen üblich.

\subsection{Lokalisierung und Materialität des pūcai-Platzes}

Anhand des eingangs zitierten Protokolls wird deutlich, dass innerhalb der Wohnung der meisten tamilischen Hindus noch einmal eine räumliche Teilung in nicht-sakralen Wohnbereich und einen Bereich, welcher ausschliesslich auf die Gottheiten ausgerichteten Handlungen vorbehalten ist, erfolgt. Zentral für die Hindu-Praxis zu Hause ist der abgegrenzte Raum, an dem die pūcai im häuslichen Bereich durchgeführt wird. ${ }^{224}$ Dieser ist, wie alle weiteren abgegrenzten Bereiche der Wohnung, mit kultureller Bedeutung aufgeladen: «So dehnt sich jeder begrenzte Raum des Wohnens weit über seine praktische Dreidimensionalität in ein Geflecht imaginärer Beziehungen und Verweise aus. Unter dem Zivilisationsschutt von Einrichtungsnormen und Nutzungsnormen liegen Bilder-Räume des Wohnens wie Fluchten der Vergangenheit, die wir täglich betreten, durch Gebrauch erhalten oder weiter ausgestalten» (Selle 1993, 85). Durch den Gebrauch von in der Schweiz nicht üblichen Gegenständen und visuellen Symbolen wird die in Sri Lanka zurückgelassene Welt in der neuen Umgebung evoziert bzw. eine Verbundenheit zu tamilischen Akteuren der globalen Diaspora hergestellt.

223 Mit kumpams (skr. kumbham oder kalaśa) werden mit Wasser oder anderen Flüssigkeiten oder Reis gefüllte Ritualgefässe bezeichnet, die mit einer Kokosnuss bedeckt sind. Sie sind meist mit Mangoblättern geschmückt (vgl. Luchesi 2003a, 240).

224 Dieser Ort wird in Sanskrit pūjāsālā genannt, was soviel bedeutet wie «abgegrenzter, geheiligter Raum für die pūcai». Die im deutsch- und englischsprachigen gebräuchlichen Begriffe «Schrein» oder «Altar» beschreiben den Ort nur ungenau. Der Terminus «Schrein» (engl. shrine) meint einen Kasten, Behältnis oder einen Schrank. Zentral in diesem Begriff ist also die Komponente, dass der Ort verschlossen werden kann. Die trifft jedoch nicht auf alle Orte der pūcai von Tamilen in der Schweiz zu (vgl. auch Abbildung IV 1). Der Begriff «Altar» meint einen «Aufsatz auf einen Opfertisch», was im beschriebenen Fall nichtzutreffend ist. Im Folgenden verwende ich an erster Stelle den Begriff «pūcai-Platz», welcher die räumliche Dimension am besten ausdrückt und die Handlung, die pūcai, welche hier durchgeführt wird, als zentral setzt. «Schrein» wird nur dann verwendet, wenn der Ort der pūcai kastenförmig ist und verschlossen werden kann. Wenn ein ganzer Raum für die pūcai vorgesehen ist, operiere ich mit dem Begriff «pūcai-Raum». 
Der pūcai-Platz ist integraler Bestandteil des privaten Wohnbereichs tamilischer Hindus in der Schweiz. Die aus dem «Heimatland» mitgebrachten Muster der Gestaltung eines Platzes für die Verehrung der Gottheiten im privaten Bereich prägen die Ausgestaltung der in der Schweiz zumeist angemieteten Wohnungen.

[...] the religious also autocentrically and allocentrically orient themselves by constructing, adorning, and inhabiting domestic space. Religion, in this sense, is housework. It is homemaking. Yet homes vary widely in form, permanence, and scale. Home is not always a permanent dwelling, and it is not always a built structure. (Tweed 2006, 103)

Der Informant Arumugam berichtet, dass «jeder» einen solchen Ort hat: «Zum Beispiel, wenn du gehst zum Beispiel in eine tamilische Familie so/jeder hat irgendwo in eine Ecke/ eine kleine pūcai-Raum». Die meisten tamilischen Hindus verzichten auch in den Residenzländern nicht auf einen Ort der pūcai im Wohnbereich - unabhängig davon, wie die Bedingungen des Wohnraums gestaltet sind. Arumugam führt hier nicht die Religionszugehörigkeit an, an welche der Besitz eines «pūcai-Raums» gebunden ist, sondern die ethnische Herkunft: «jede tamilische Familie hat einen pūcaiRaum (Hervorhebung R.E.)». ${ }^{225}$ Auch ein Grossteil jener Tamilen, welche tendenziell religionskritisch eingestellt sind und sich selbst beispielsweise als sozialistisch bezeichnen, sieht es als obligatorisch an, einen pücai-Platz in ihrem Haushalt zu haben. Für Arumugam beispielsweise, der Vorbehalte gegenüber «Religion» äusserte, ist es selbstverständlich, dass seine Familie in ihrer Wohnung einen Ort hat, an dem die häusliche pūcai vollzogen werden kann. An dieser nimmt er jedoch nicht teil. Es ist seine Frau, welche mit dem Kind morgens vor dessen Schulbesuch vor den Bildern der Gottheiten Handlungen durchführt. Der pūcai-Platz wird wie andere Elemente der materiellen Kultur als für einen tamilischen Haushalt notwendig angesehen. Unter anderem kann der Wohnraum durch die spezifische visuelle Kennzeichnung eines Ortes als Lokalität der häuslichen pūcai als ein tamilisch-hinduistischer Ort ausgezeichnet werden. Die Grenzen zwischen den Zuschreibungen «tamilisch» und «hinduistisch» sind dabei oft fliessend.

Zentral ist, dass im Gegensatz zum Tempel die pūcai zu Hause von jeder instruierten Person durchgeführt werden kann. Gerade angesichts des Priestermangels und des, besonders in den frühen Jahren der Migration, Mangels an Tempelräumen kommt dadurch zum Ausdruck, wie wichtig

225 Damit meint er auch, dass katholisch-tamilische Familien in der Schweiz oft, ähnlich den hinduistischen pūcai-Plätzen, Orte des täglichen Gebets in ihren Wohnungen haben, welche mit Bildern und Figuren aus dem katholischen Spektrum dekoriert sind. 
dieses Ritual für die Migrantengruppe ist, um die religiöse Praxis in fremdreligiöser Umgebung aufrecht zu erhalten.

Im vorgestellten Protokoll-Ausschnitt befindet sich der pücai-Platz in einem Schrank. Ist der Schrank verschlossen, deutet nichts darauf hin, dass sich dahinter ein Arrangement von Bildern mit Gottheiten befindet. So ist der Ort für Besucher, denen er nicht gezeigt werden soll, getarnt und unsichtbar. Durch die Schranktür werden Aussen- und Innenraum verbunden und getrennt (vgl. Selle 1993, 33 ff.). Die Stellung der Schranktür, geöffnet oder geschlossen, kann entweder zur Kennzeichnung als hinduistischer Raum oder zum Verbergen der Hindu-Identität der Bewohner beitragen. Darüber hinaus betont eine Schranktür die Analogie zur pūcai im Tempel, in welcher der Akt des Öffnens des Schreins und das Sichtbarwerden der Gottheit zentrales Element ist.

Bereits die ersten - mehrheitlich männlichen - tamilischen Immigranten in der Schweiz, die in Asylunterkünften lebten, sorgten dafür, dass ein Teil des ihnen zugeteilten sehr begrenzten Raumes für die pūcai abgetrennt wurde (vgl. Kap. III 4.1): «Auch damals / auch damals die Männer / sie haben schon gehabt / eine kleine Ecke. Mindestens eine Schrank oder so / haben sie schon.» Vereinzelt kamen auch ledige tamilische Frauen Ende der 1980er Jahre als Migrantinnen in die Schweiz. Mangai, die 1988 unverheiratet in die Schweiz migrierte, arbeitete nach ihrer Ankunft in einem Krankenhaus. Dort richtete sie sich einen Ort ihrer privaten Hindu-Praxis ein:

[...] ich habe im Personalhaus gewohnt/da habe ich im Schrank/weil ich kann mir nicht vorstellen ohne Gebet / da bin ich so fest gläubig aufgewachsen und habe ich in Schrank so ein Tablar mit Bildern/so geklebt [...]. ${ }^{226}$

Diese Stätten wurden provisorisch eingerichtet. Hier zeigt sich, dass es tamilischen Hindus ein Bedürfnis ist, an jenen Orten, an denen man viel Zeit verbringt, einen Ort für die tägliche pūcai zu haben. Pücai-Orte können also auch an Arbeitsorten oder in tamilischen Geschäften eingerichtet sein.

Der pūcai-Raum ist durch Marker wie die bildliche Darstellung von Gottheiten als «sakral» gekennzeichnet und vom übrigen Wohnraum abgegrenzt. Er ist nur der pūcai vorbehalten, dient ausschliesslich als Ort individueller oder in der Gruppe vollzogener Hindu-Praxis und wird nicht für andere Zwecke genutzt. Diese Lokalität ermöglicht es den Akteuren, täglich, ohne den Wohnraum zu verlassen, mit den Gottheiten zu kommunizieren.

226 Interview 5, 02.12.2008. 
Die ästhetisch vielfältige Ausgestaltung der meisten pūcai-Plätze ist von besonderer Bedeutung: Der/die Betrachtende nimmt in der visuellen Wahrnehmung des Platzes viele verschiedene Reize auf, wie unterschiedliche, meist sehr intensive Farben und unterschiedliche figürliche Arrangements. In der konkreten Ausgestaltung des pūcai-Platzes wie auch in den Handlungen, welche dort vorgenommen werden, spielt die materielle Kultur eine zentrale Rolle.

Zentraler Bestandteil der pūcai-Plätze und Gegenstand der Verehrung sind dabei die zwei- und dreidimensionalen Darstellungen von Gottheiten, Gurus oder anderer wichtiger Figuren aus dem hinduistischen Spektrum. Idealerweise werden sie in Form von Figuren (mürttis), aber auch von Bildern ${ }^{227}$ dargestellt, wobei die Göttinnen und Götter meist so abgebildet sind, dass sie den Blick auf den Betrachtenden richten, um tarisanam (skr. darśana $)^{228}$ zu ermöglichen. Brigitte Luchesi $(2010,203)$ spricht in diesem Kontext von Darśan-Bildern und Götterpostern: «Götterposter sind massenhaft gefertigte zweidimensionale Bildwaren, mithin Druckerzeugnisse, die kostengünstig erhältlich sind, was sie von Einzelwerken bildender Künstler oder Kunstprodukten mit begrenzter Auflage unterscheidet.»

Neben Darstellungen von Gottheiten des hinduistischen Spektrums habe ich an häuslichen pūcai-Plätzen Abbildungen von reform-hinduistischen Guru-Gestalten wie Srithi Sai Baba, Sathya Sai Baba, Mātā Amritanandamayī Devi (vgl. Kap. IV 3.4) oder Lalitha Sripalan (vgl. Kap. IV 6.1) gesehen sowie Bilder von Rāmakṛ̣ṇa, Sarada Devi und Svāmi Vivekānanda. Darüber hinaus finden sich auch Gegenstände aus anderen religiösen Traditionen wie Buddha-Figuren oder christliche Statuetten; sehr verbreitet sind Marienstatuen (wie Plastikstatuen der Maria von Lourdes). Auch symbolische Zeichen - wie beispielsweise das tamilische $\bar{O} m$-Zeichen - sind Abbildungen, welche neben den gegenständlichen Bildern Teile des pūcai-Platzes sind. Ausser diesen Gegenständen der Verehrung sind weitere Elemente der materiellen Kultur notwendig, um die pücai durchzuführen. Gegenstände zur pūcai-Praktizierung sind häufig Glöck-

227 Valentin $(2010,18)$ verweist darauf, dass Sprache und Bilderzeugnis Artikulation dessen sind, was nicht anwesend ist: «Sie [die Bilder] vergegenwärtigen das Abwesende, sei es abwesend als Vergangenes oder zukünftig Erwartetes, ebenso aber als zwar Gegenwärtiges, aber räumlich Distantes oder abwesend als Abstraktes, Spekulatives». Gerade in Diaspora-Situationen kann Bildern eine besondere Bedeutung zukommen, um die Erinnerung an das, was abwesend ist, aufrecht zu erhalten.

228 Der Sanskrit Begriff darśana meint so viel wie «sehen mit Respekt» von jemandem oder etwas, das als heilig angesehen wird und von dem man im Gegenzug Segnungen erhält (vgl. Eck 1998). 
chen aus Metall, Räucherstäbchen und ihre Ständer, ein Gefäss mit Wasser sowie Öl- und Kampferlampen.

Als Beispiel für einen konkreten Ort der häuslichen pūcai wird im Folgenden der von mir fotografierte Ort in der Mietwohnung eines Ehepaars aus Jaffna vorgestellt, welches nun in der Zentralschweiz lebt. Die Reihenhauswohnung befindet sich im ersten Stock und hat vier Zimmer. Eines davon dient als pūcai-Zimmer wie auch als Arbeitszimmer und Ablageort für verschiedene Aktenordner.

Der pūcai-Platz besteht aus Gegenständen, welche auf einer Kommode abgestellt sind, sowie visuellen Darstellungen an der Zimmerwand über der Kommode. Es ist eine vertikale und eine horizontale Ebene auszumachen: Vertikal finden sich die zweidimensionalen Abbildungen der verehrten Gottheiten und Dekorationselemente; horizontal sind zwei- und dreidimensionale Darstellungen von Gottheiten sowie Gegenstände zur Durchführung der pūcai zu finden.

Das Zentrum dieses pūcai-Platzes bilden jene Gottheiten, welche sich in einem grossen Bilderrahmen befinden, um den sich die anderen Darstellungen gruppieren: Im zentral angeordneten Rahmen sind Bilder von Civan und Pārvati, Lakhșmīi, Rāma mit Sita, Laxmanah und Hanuman, Aiyappan, Murukan mit seinen beiden Frauen und Sathya Sai Baba platziert. Die kleineren Bilder rechts im Rahmen zeigen Vināyakar, Turkkai, Srithi Sai Baba, Civan, Murukan und Kannnan. Rechts vom Bilderrahmen sind die Bilder von Kannnan als Baby und Arjuna und Kaṇnan zusammen mit Versen aus der Bhagavadgita aufgehängt. Daneben findet sich ein grosses Poster von Kaṇnan mit Flöte. Daran ist eine Pfauenfeder gehängt, welche auf Murukan, dessen Reittier der Pfau ist, verweist. Links des zentralen Bilderrahmens ist Hanuman sowie eine Postkarte des Perumal Tempels in Jaffna zu sehen. Über diesen Bildern sind zwei künstliche Jasmin-Girlanden aufgehängt. Oberhalb des Bilderrahmens sind drei kupferne yantras angebracht, über denen eine Schnur mit Stroh befestigt ist. Das Arrangement wird mit einer stilisierten Kette aus Mangoblättern, welche verschiedene Gottheiten zeigen, abgeschlossen.

Auch auf der Kommode sind verschiedenste Darstellungen von Gottheiten und religiösen Figuren platziert: Hier finden sich zwei KaṇnanStatuen (eine kleine und eine grosse blaue mit Plastikblumengirlande), eine von einem tamilischen Tempel in Luzern herausgegebene Musik-CD mit religiösen Liedern, welche Turkkai auf dem Cover zeigt, ein Sathya Sai Baba-Bild, eine dicke goldene Buddha-Figur und Vasen mit Plastikblumen. Als Utensilien zur Durchführung der pūcai finden sich ein Muschelhorn, zwei Öllampen (tam. kuttu vilakku), Räucherstäbchen mit Halter und ein Tablett mit vibhūti, Sandelholzpaste und kunkumam. 


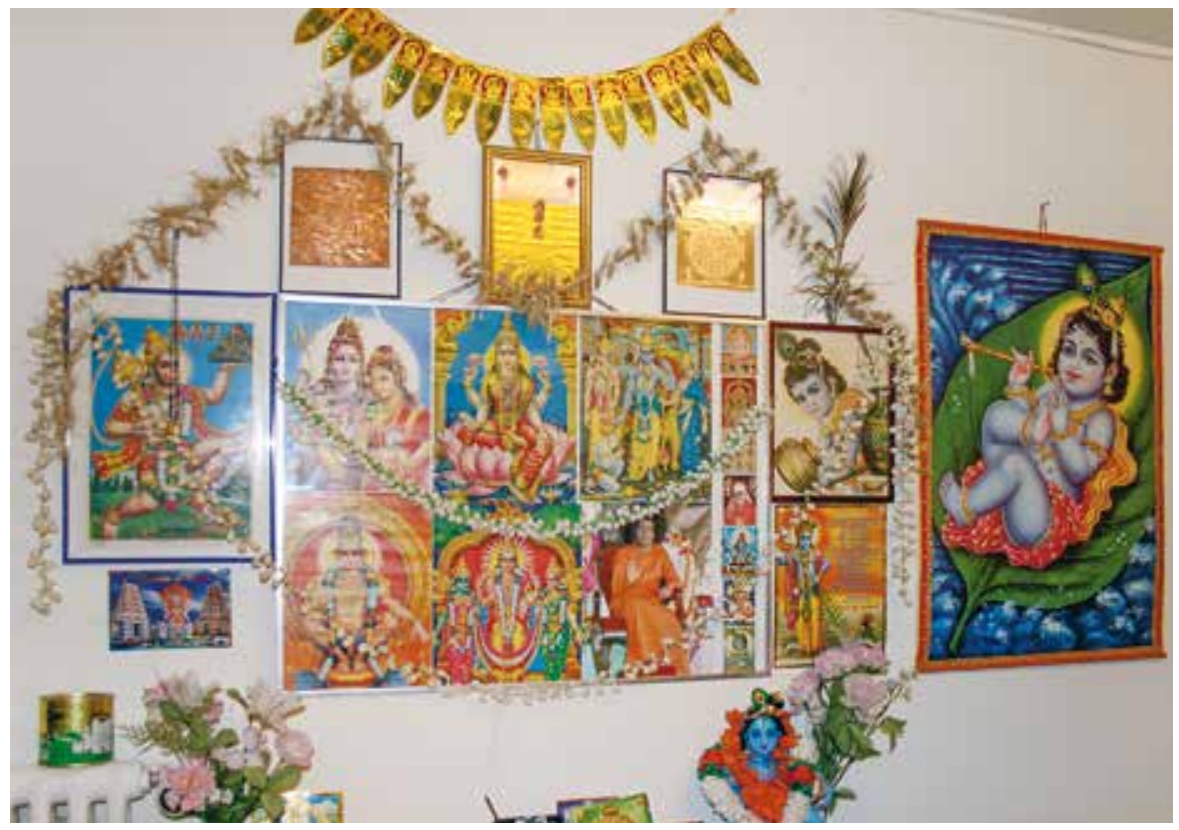

Abb. IV 1: Die materielle Ausgestaltung eines pūcai-Platzes in einer Wohnung (23.11.2007).

Die Abbildungen der Gottheiten aus verschiedenen Hindu-Spektren verweisen auf unterschiedliche Geschichten; diese werden beim Betrachten des pūcai-Platzes mit evoziert. An der individuellen Zusammenstellung lässt sich zumeist auch etwas über die individuellen biographischen Geschichten der Bewohner aussagen.

Das Foto (Abb. IV 1) zeigt die Vielfalt der verehrten Gottheiten. Die Bedeutung von visuellen Darstellungen von Gottheiten als Zentrum des pūcai-Platzes kommt hier klar zum Ausdruck. An der Vielzahl der aufgestellten Gottheiten wird deutlich, dass der pūcai-Platz Ausdruck einer individuell inszenierten Praxis und somit eine individuell gestaltete und wandelbare Kontaktzone der Kommunikation zwischen Akteuren und Göttern ist. Hindu-Akteure stellen ein individuelles Profil zusammen; die Auswahl der Gottheiten unterliegt keinen festgeschriebenen Regeln. So unterscheidet sich das Ensemble der aufgestellten Figuren und Bilder von Haushalt zu Haushalt. Der hier detailliert vorgestellte Ort häuslicher pūcai beinhaltet sowohl Gottheiten, welche der Caiva-Tradition zugehören, als auch Gestalten des Vaishnava-Spektrums. Darüber hinaus sind Figuren von reformhinduistischen Gruppierungen zu finden. 


\subsection{Die häusliche pūcai: performative Hindu-Praxis im Wohnraum}

Die materiellen Elemente werden benutzt, um performativ eine Kommunikationssituation mit den Göttinnen und Göttern und anderen verehrten Gestalten herzustellen. Die Handlungen, welche an diesem abgegrenzten Platz innerhalb des Wohnraums durchgeführt werden, werden zusammenfassend als pūcai bezeichnet.

Im Folgenden zitiere ich aus meinen Beobachtungsprotokollen, in welchen ich eine pūcai in der Wohnung eines Ehepaares in Zürich beschreibe, in der ich zum Essen eingeladen worden war. Die Familie verfügt über einen kleinen eigens für die pūcai eingerichteten Raum:

Herr Chandrasegaram trägt einen weissen dhoti und darüber ein helles Hemd, seine Frau trägt einen Sari. (...) Die Küche sieht für mich sehr aufgeräumt und sauber aus. Vor dem Essen geht das Ehepaar Chandrasegaram zum pūcaiPlatz. Herr Chandrasegaram geht vor, seine Frau folgt ihm. Er trägt aus der Küche ein Tablett aus Edelstahl, auf dem auf einem Bananenblatt zwei Vadais $^{229}$, eine geschälte Banane und Reis und anderes Essbares liegt. Sie folgt ihm und trägt einen Edelstahl-Becher mit Wasser. Ihre Küche geht in die Wohnstube der Familie über. Links vom Übergangsbereich zwischen den beiden Räumen befindet sich ein kleiner Raum, der ungefähr vier Quadratmeter gross ist. Die weisse Tür des Raumes ist offen. Gegenüber der Tür hängen verschiedenste Bilder von Gottheiten und Gurus (in der Mitte Ganeśa, daneben Sai Baba und Krishna und weitere). Über ihnen ist eine brennende Lichterkette aufgespannt. Auf ein Regal oder eine Kommode (ich kann nicht genau erkennen, was es ist) ist ein weisses Tuch gelegt; darauf stehen diverse Gegenstände für die pūcai. Herr Chandrasegaram betritt den Raum und verbeugt sich vor den Bildern der Gottheiten. Er macht zusätzlich zur Lichterkette das Licht im Raum an; es ist sehr hell. Er legt auf die Anrichte das Tablett mit den Gaben. Dann nimmt er eine kleine Glocke und stellt sie auf einen silbernen Untersetzer. Die Glocke klingt dabei. Dann geht er aus dem Raum, und seine Frau kommt von der Schwelle in den Raum hinein. Sie stellt das Wasser ab und öffnet ein tamilisches Buch, welches neben den Gegenständen liegt. Mit diesem stellt sie sich vor die Gottheiten und singt bhajans. (Protokoll vom 04.11.2008)

229 Vadais sind in den tamilischen Gebieten Indiens und Sri Lankas populäre frittierte Teigtaschen, die aus unterschiedlichen Zutaten bestehen können. Meist enthalten sie als Füllung Kartoffeln und Linsen. 
$\mathrm{Zu}$ Beginn macht Herr Chandrasegaram beim Betreten des Raumes ein Zeichen der Ehrehrbietung, indem er sich vor den Bildern der Gottheiten verbeugt. Es folgt eine Vorbereitung des Ortes für die deva-pūcai (auf die Gottheiten ausgerichtete $p \bar{u} c a i)$ : So wird beispielsweise Licht eingeschaltet oder Ollampen werden angezündet. Zentrale Handlung ist das Darbringen von Gaben an die Gottheiten. Diese werden speziell geschmückt auf einem besonderen Tablett vor die Bilder der Gottheiten aufgestellt. Gesten und Handlungen, welche das Darbringen der Gaben umrahmen, sind das Verbeugen und Falten der Hände und das Singen von bhajans oder das Rezitieren von Mantren. Diese werden auswendig oder mit Hilfe eines Buches vorgetragen.

Wie auch die Gestaltung des pūcai-Platzes wird die Performanz der pūcai flexibel gestaltet, der kleinste gemeinsame Nenner sind jedoch Gesten der Ehrehrbietung und das Darbringen von Gaben an die verehrten Gottheiten. Die weitere Ausgestaltung variiert; einige folgen 16 oder 36 vorgegebenen Schritten der Respektserweisung, viele Familien beschränken sich auf ausgewählte Elemente. Akteure, die sich explizit einer spezifischen hinduistischen Strömung zugehörig fühlen - in der Schweiz etwa tamilische Devotees der International Society for Krishna Consciousness (ISKCON), welche in der Swiss Tamil Krishna Society organisiert sind (vgl. Abschnitt 3.2.3) oder die Devotees der Aum Sakthi-Bewegung - folgen einer der häuslichen pūcai vorgegebenen Struktur.

Die Praxis ist fest in den Tages- und/oder Wochenablauf der Akteure eingebunden. Die Informantin Mangai, die sich selbst als sehr religiös bezeichnet, besucht zwei Mal am Tag ihren pūcai-Platz: «Wenn ich aufstehe, dusche ich, dann beten. Dann trinke ich Kaffee und weitere Arbeiten. Und abends gehe ich waschen, dann gehe ich sofort zu kleinen Gebet. Aber morgens mache ich so viertel/ zwanzig Minuten. Lesen / singen ${ }^{230}$. Zentral sind die besonderen Reinheitskonventionen, welche für diesen Ort massgebend sind. Als Vorbereitung für die pūcai ist es vorgesehen, dass man sich vorher wäscht und einige Zeit vorher nichts gegessen hat; Frauen dürfen während ihrer Menstruation keine pūcai vollziehen und meist den pūcai-Raum nicht betreten.

Viele Informanten berichten davon, dass innerhalb der Familien vor allem die Frauen, an erster Stelle die Mutter der Familie, die häusliche pūcai vollziehen. Sie sind die Pujaris, die Hauptakteure der pūcai und geben das Wissen um diese Handlungen an die nächste Generation weiter. Auch die Praktiken, welche an Festtagen zu Hause vollzogen werden, werden vielfach federführend von Frauen durchgeführt.

230 Interview 5; 02.12.2008. 


\section{Und zu Hause?}

$\mathrm{Zu}$ Hause/zum Beispiel die traditionelle Sache so/zum Beispiel/okay/alle das macht meine Frau / zum Beispiel/irgendwo ist 14. April ist unsere Neujahr oder ist 4.Januar ist unsere Thai Pongal/diese/oder. Es gibt auch verschiedene religiöse Tage natürlich. Und dann diese Sache/sie macht einfach eine kleine Teil schon/dann ich mache auch mit. ${ }^{231}$

Viele Informanten bezeichnen den pūcai-Platz als «Platz zum Beten». ${ }^{232}$ Die Durchführung der pūcai und die Ausgestaltung ihrer Plätze entfalten ihre Wirkung durch ihre die unterschiedlichen Sinne ansprechenden Komponenten. Der Akt der pūcai erzeugt einen spezifischen sinnlichen religiösen Wahrnehmungsraum (vgl. Mohn 2010, 2012), der sich vom Wahrnehmungsraum der übrigen Wohnung abgrenzt. Im Rückgriff auf religionsästhetische Überlegungen und die Analyse von religiöser visual culture (vgl. Morgan 2005, 2012) lässt sich die Durchführung hinduistischer pūcais als eine spezifische Blickkultur verstehen. Dabei ist Sehen immer auch soziales Geschehen und Sehgewohnheiten sind als kultur- und kontextabhängig zu betrachten: "Seeing is an interpretative action that relies in memories and experiences of the observer as the world 'out there' is represented in the mind" (Plate 2002, 25). Während der pūcai geht es nicht primär um das kognitive Erfassen von heiligen Texten oder eine rein geistige Konzentration auf die als heilig angesehenen Gestalten. Wie bereits dargestellt wurde, spielt die Visualität im Rahmen der pūcai eine grosse Rolle; tarisanam (skr. darśana), das «Ansichtigwerden einer segensmässigen Grösse» (BeinhauerKöhler 2010, 135) ist zentral.

Jedoch kann nicht nur von einem «Augengottesdienst» (BeinhauerKöhler 2010, 136) gesprochen werden; vielmehr werden alle fünf Sinne aktiviert. Zentral ist es darüber hinaus, nicht nur den Göttinnen und Göttern mit allen körperlichen Sinnen nahe zu sein und die pūcai für alle Sinne erlebbar zu machen, sondern auch alle «Sinne» der Götter zu beschenken. Die angezündeten Räucherstäbchen aktivieren den Geruchssinn, das Erklingen der Glocke und das Singen von bhajans erzeugen Klangerlebnisse und haptisch werden die Götter durch das Berühren ihrer Bildnisse erfahr-

231 Interview 4; 04.12.2008.

232 Viele Akteure operieren in der Kommunikation nach aussen mit dem deutschen Verb «beten». Die Verwendung dieses Begriffs durch tamilische Hindus in der Schweiz kann anzeigen, dass sich diese den Termini der christlich geprägten Umgebung angepasst haben oder ihnen in der erst neu erlernten Fremdsprache keine andere Vokabel zur Verfügung steht, um die Handlungen, welche vollzogen werden, zu benennen. Aus religionswissenschaftlicher Sicht wäre das Verb «verehren» im Kontext einer pūcai wohl die exaktere deutsche Vokabel. 
bar. Die dargebrachten Speisen werden im Anschluss an die pūcai von den Akteuren gegessen. Die pūcai kann also als ästhetische Inszenierung beschrieben werden, die alle fünf Sinne des Verehrers sowie der Gottheit ansprechen soll.

\subsection{Diasporische Veränderungen: vom Gott-Zimmer zum pūcai-Platz im Schrank}

In der räumlichen Ausgestaltung der Hindu-Praxis und der Durchführung der häuslichen pūcai sind diasporische Veränderungen festzustellen. Durch die kommerzielle Massenproduktion der Darśan-Bilder finden sich in vielen Wohnungen identische, kostengünstig erworbene Bilder, die leicht beweglich und abnehmbar sind und den Gegebenheiten des Lebens in der Diaspora-Situation vieler Familien entgegenkommen.

Die räumliche Begrenztheit ist ein zentraler kontextueller Faktor, welcher Veränderungen der tamilischen Hindu-Praxis auslöst (vgl. Abschnitt III.5). In der Schweiz verfügten die meisten tamilischen Migrantenfamilien aufgrund ihrer ökonomischen Situation nur über eingeschränkten Wohnraum. Die Wohnsituation führt oft dazu, dass der Raum, welcher für die pūcai zur Verfügung gestellt werden kann, nicht sehr gross ist. Häufig dient nur ein Brett in einem Schrank, dessen Tür geschlossen werden kann, oder eine Ecke in einem Raum als Ort der häuslichen pūcai. Mangai kontrastiert die räumliche Ausdehnung der pūcai-Plätze in der Schweiz mit deren Grösse in der zurückgelassenen Heimat. Nach ihren Angaben war es dort Standard, dass Familien ein ganzes Zimmer für die Gottheiten im Haus reserviert hatten: «Und das gehört/ in Sri Lanka haben wir eine Zimmer / so Gott-Zimmer eingerichtet.»

Ist der Platz in der Diaspora begrenzt, ist oft auch der Handlungsspielraum für die Durchführung der pūcai eingeschränkt. Mangai berichtet, dass die Positionierung des pūcai-Platzes in ihrem Schrank es verhindert, Feuer anzuzünden:

[...] habe ich in Schrank so ein Tablar mit Bildern/so geklebt/ich darf nicht die Feuer anzünden/oder die Räucherstäbchen/das ist in Schrank/aber so mit Licht habe ich. Weil wenn man einen Raum oder eine Gottbilder hat, soll man solche Kerzen/wir müssen auch Lampen und so. Manchmal ist unmöglich in Schrank / deswegen habe ich so eine Lampe. Aber immer habe ich / jeden Tag gebetet $[\ldots] \cdot{ }^{233}$

233 Interview 5; 02.12.2008. 
Bestimmte räumliche Umstände machen auch in diesem Bereich eine von den Akteuren als authentisch angesehene Ausübung der Praxis schwierig. Mangai berichtet davon, dass sie auf eine Lampe mit elektrischem Licht zurückgreifen musste. Die Lampe fungiert als Imitation einer Kerze und inszeniert Authentizität. Durch Flexibilität und Innovationskraft der Akteure wird die Hindu-Praxis auch unter eingeschränkten Bedingungen aufrechterhalten.

Ein Resultat der beengten Wohnsituation kann sein, dass das Zimmer, in dem sich der pūcai-Platz befindet, auch Ort für andere Handlungen ist, welche nicht dem Spektrum von Hindu-Traditionen zugeordnet werden. Der folgende Auszug aus einem Beobachtungsprotokoll beschreibt einen Raum, der sowohl für religiöse Praxis als auch als Arbeitsplatz genutzt wird:

Ich frage nach dem Ort der häuslichen pūcai. «Ja, ich zeige Ihnen den Platz.» Ich folge Veeran. Wir gehen in ein Zimmer. Das Zimmer scheint in zwei Bereiche aufgeteilt zu sein. Der rechte Teil des Raumes wird durch den pücai-Platz gefüllt. Ein kleiner Tisch steht an der Wand, darauf befinden sich Figuren von Murukan und diverse Gegenstände für die pūcai. Über dem Tisch hängen Bilder von Siva, Ganeśa und Murukan.

Im anderen Teil des Zimmers befindet sich ein Schreibtisch, auf dem ein Computer steht. Auf dem Schreibtisch liegen Block, Bücher und Schreibutensilien. Über dem Schreibtisch, also direkt gegenüber dem pūcai-Platz, sind Plakate der LTTE aufgehängt. Ein Poster zeigt das rote Emblem der LTTE, auf dem in schwarz-gelb ein brüllender Tiger zu sehen ist. Auch ist ein Poster zu sehen, welches den Great Heroes' Day der LTTE ankündet. Pirapāharan [der damalige Anführer der LTTE] ist auf diesem Poster abgebildet (Protokoll, 15.01.2008).

Der hier beschriebene Raum dient als Ort der häuslichen pūcai wie auch als Ort, an dem gearbeitet wird, an dem per Computer mit den Verwandten in der ganzen Welt kommuniziert wird, an dem Nachrichten aus Sri Lanka verfolgt werden ${ }^{234}$ und an dem möglicherweise auch politisch gehandelt wird. Die Aufteilung des Raumes in unterschiedliche Handlungsbereiche wird durch die Darstellungen, die an den Wänden hängen, visuell verdeutlicht. Sie verweist auf multiple Identitäten der Akteure und die parallele Existenz unterschiedlicher Lebensbereiche, welche teilweise interferieren.

Das Zimmer in seiner Gänze kann als Resonanzraum beschrieben werden, in dem die politischen Ereignisse und kulturelle Praktiken in Sri Lanka

234 Neben den Medien der digital tamil diaspora spielen auch tamilische TV-Sender eine grosse Rolle in der Informationsbeschaffung. Im Werbeprospekt des Anbieters cablecom, welcher unterschiedliche Fremdsprachenkanäle anbietet, wurde 2010 mit der Überschrift «Ihr Fenster zur Heimat» ein für 25 Schweizer Franken pro Monat buchbares cablecom tamil, GTV, angeboten. 
widerhallen. Handlungen, welche am Computer ausgeführt werden, wie die Kommunikation mit Menschen in Sri Lanka via E-Mail, Chat oder Skype und das Verfolgen der aktuellen Ereignisse im Herkunftsland, ebenso wie die Durchführung der pūcai beziehen sich auf die zurückgelassenen Regionen in Sri Lanka.

Nur wenn die räumlichen Möglichkeiten vorhanden sind, wird auch in der Schweiz ein ganzes Zimmer für die häusliche pūcai vorgesehen. Familien, welche auch in der Diaspora einen ganzen Raum für die häuslichen Rituale bereitstellen können, stellen eine Ausnahme dar. Mangai schätzt sich daher in Bezug auf ihre Wohnsituation als besonders glücklich ein, da sie nach einigen Jahren in der Schweiz auch hier einen kleinen abgegrenzten Raum als «pūcai-Zimmer» einrichten konnte: «Aber ich habe Glück gehabt. Seit 1996 habe ich so eine kleine Raum [lacht]». «Aber zu Hause in der Wohnung habe ich einen Raum. Jetzt [betont] es ist eine Möglichkeit. Weil es ist eine Reduit/so Putzmittel zu versorgen/eine kleine Raum» ${ }^{235}$. Jedoch ist der Raum im Vergleich zum ideal vorgestellten Raum immer noch begrenzt und nicht als ein solcher konzipiert (sondern als Abstellkammer). Sie bezeichnet ihn als «kleinen Raum» und verwendet nicht die Bezeichnung «Gott-Zimmer», welche sie für die Beschreibung des Raumes in ihrem Zuhause in Sri Lanka benutzt hat.

In der Schweiz können religiöse Vorgaben für die ordnungsgemässe Platzierung des Ortes der pūcai meist nicht eingehalten werden. Denn die Gesamtkonzeption der Wohnung sollte laut den vedischen Schriften auf kosmischen Prinzipien beruhen:

At a symbolic level, the household of a couple serves as a miniature of cosmic principles. Ideally, a home should be laid out as a series of rooms surrounding a single, larger courtyard. This is the same plan that astrologers use to depict the organization and movement of planetary deities and that priests use in laying out a sacred space for ritual purposes. (Beck 2005, 2404)

Entsprechend dieser Grundlage sollte der Platz der pūcai nach astrologischen Vorgaben, den Himmelsrichtungen und Reinheitsvorschriften festgelegt werden. Die Platzierung des pūcai-Platzes ist in der nordöstlichen Ecke des Wohnraums vorgesehen, welche als der Bereich İśänas (eine Form von Civan) angesehen wird. Auch dieser Vorgabe kann in den meisten Fällen aufgrund des knappen Wohnraums und der räumlichen Aufteilung von Mietwohnungen in der Schweiz nicht entsprochen werden.

Die Platzierung des pūcai-Platzes innerhalb der Wohnung unterliegt aber auch aus den Hindu-Traditionen stammenden Reinheitsgeboten. Auf-

235 Interview 5; 02.12.2008. 
grund dieser Vorgaben wird es von orthodoxen Hindus nicht gerne gesehen, wenn der pücai-Platz in der Nähe der Toilette oder im Schlafzimmer platziert ist. Hier sind vor allem die Regeln im Umgang mit der Menstruation von Frauen ausschlaggebend. Viele Familien können wegen des begrenzten Wohnraums oftmals den Ort der häuslichen pücai nicht ordnungsgemäss platzieren. Mangai verweist darauf, dass es in der Schweiz schwierig ist, bestimmte Reinheitsvorschriften einzuhalten:

Aber hier/weil wenn wir Frauen Periode bekommen/wir dürfen nicht beten.

Auch in Zimmer dürfen wir nicht. Aber wenn wir in Schlafzimmer haben/das ist schwierig / meisten hier in der Schweiz sie haben hier im Schlafzimmer. Mit Kochen / wegen der Räume/Schwierigkeiten. ${ }^{236}$

Die Akteure entwickelten verschiedene Strategien, um dieses Dilemma zu lösen. Wenn es keine andere Lösung als die Platzierung im Schlafzimmer der Eltern gibt, dann wird versucht, den Ort der pūcai visuell abzutrennen oder eine möglichst grosse Distanz zwischen pūcai-Ecke und menstruierender Frau herzustellen. ${ }^{237}$

\subsection{Weitere Aspekte häuslicher Hindu-Praxis: zwischen privatem pūcai-Platz und öffentlichen Tempeln}

Die Ausgestaltung des pūcai-Platzes, die Handlungen, die an diesem vollzogen werden, und die Gegenstände, welche benutzt werden, sind eng mit der Tempel-pūcai verknüpft (zu dieser siehe Abschnitt 4 des Kapitels). Der häusliche pūcai-Platz ist auf symbolischer Ebene mit dem öffentlichen Tempelraum verbunden. Mangai spricht davon, dass sie den Ort ihrer pūcai zu Hause «wie einen Tempel» eingerichtet hat:

Aber zu Hause in der Wohnung habe ich einen Raum. [...] Da habe ich so wie einen Tempel eingerichtet. Da habe ich alle Götter habe ich/mehr Ganesha/ viele Ganesha-Bilder. Da kann ich jeden Tag sitzen und beten. ${ }^{238}$

236 Interview 5; 02.12.2008.

237 Vgl. Damaris Lüthi (2005), die solche Lösungsstrategien beschreibt: «Die meisten Leute wohnen jedoch in engen Wohnungen, wo kein separates Zimmer als pūjā-Raum zur Verfügung steht, weshalb sich der Hausschrein oft im Kinderzimmer befindet, solange die Töchter nicht in der Pubertät sind, oder auch im Zimmer einer post-menstruellen Grossmutter». «Andere Schutzmethoden sind ein Vorhang, und einzelne Frauen, bei denen sich der Schrein im Schlafzimmer befindet, wechseln während der Menstruation einfach auf diejenige Seite des Ehebetts, die sich weiter entfernt vom Schrein befindet» (Damaris Lüthi 2005, 28).

238 Interview 5; 02.12.2008. 
Tempel und häuslicher pücai-Platz können daher nicht als voneinander unabhängige Räume angesehen werden. Vielmehr stehen sie in enger Beziehung zu einander:

It would be incorrect to draw any sharp division between Hindu house-hold rites and nondomestic observances. The human body, the domestic living space, and the public temple (...) are ritually similar. Worship relating to one, for a Hindu, is often equivalent to worship at another. (Beck 2005, 2404)

Es besteht eine symbolische Verbindungslinie zwischen dem Tempel als Sakralbau und dem für die pūcai markierten Ort im privaten Wohnraum: "Hindu homes symbolically link family and temple life to ordered energy in the cosmos at large" (Beck 2005, 2404).

Im Folgenden gehe ich in Abschnitt 4.3 auf die Diskurse um die Begriffsdefinition von Tempel - gerade in der Diaspora-Situation - ein. Die Umgebungsbedingungen machen die Abgrenzung zwischen häuslichen Praktiken und Tempelpraktiken teilweise schwierig, wenn beispielsweise die «Tempelrituale» auch in angemieteten Wohnungen durchgeführt werden.

Brenda F.F. Beck (2005) konstatiert, dass Grenzen zwischen einem als privat deklarierten Wohnraum und dem öffentlichen Tempel gegenwärtig in der Durchführung globaler Hindu-Praxis fliessend sind. Dies lässt sich beispielsweise anhand von privat organisierten bhajan-Gruppen beobachten, die sich im Wohnraum einer Person treffen und dort gemeinsam singen:

Public and domestic elements also come together in other Hindu observances.

One tradition, becoming more and more popular at present, is the hymn-singing evening among friends. This event can be held in a public temple, but it is also commonly organized in private. (...) Such gatherings redefine space in a personal home, so that it becomes more like the space of the public temple.

(Beck 2005, 2404f.)

In der Schweiz trafen sich beispielsweise die Devotees von Sathya Sai Baba im Untersuchungszeitraum regelmässig zum gemeinsamen pacanai (skr. bhajan) Singen, entweder in privaten Wohnungen oder zum Beispiel in der Kirche St.Karl in Luzern (vgl. auch Abschnitt3.4). Wenngleich auch diese Formen ritueller Praxis unter raumtheoretischen Aspekten aufschlussreich analysiert werden könnten, kann dies in der vorliegenden Studie nicht geleistet werden.

Zusammenfassend kann gesagt werden, dass das Errichten eines Ortes für performative Hindu-Praxis im Wohnraum für die Akteure von hoher Wichtigkeit war. Die inkorporativen Bedingungen hatten Einfluss auf die räumliche Ausgestaltung der Praxis. Zwar müssen durch die Begrenztheit des Wohnraums Einschränkungen in der Praxis vorgenommen werden, die Akteure nehmen diesen und den pūcai-Platz jedoch als Schutzraum war, in 
dem heimatliche Sphäre durch einen multisensorial erlebbaren Wahrnehmungsraum erschaffen werden kann. Der soziale Raum der privaten pūcai ist gleichzeitig auch Repräsentationsraum, der die individuelle religiöse Praxis der Akteure ausdrückt.

\section{Kontaktzonen: shared places als Räume der Ausübung von Hindu-Praxis}

Nach den Orten der Etablierung häuslicher ritueller Praxis stelle ich im Folgenden jene Orte gemeinschaftlicher Hindu-Praxis dar, die tamilische Gruppen mit anderen Organisationen teilten, wobei die tamilischen Praktizierenden dort oftmals nur Gastrecht hatten. Der Tempel der International Society for Krishna Consciousness (ISKCON) in Zürich und weitere Orte neohinduistischer Gruppierungen waren wichtige erste Anlaufstellen für hindu-tamilische Immigrantinnen und Immigranten, und auch im Untersuchungszeitraum stellen diese «geteilten Orte» wichtige Kontaktzonen dar. Die folgenden Abschnitte beschreiben zunächst solche von tamilischen Hindus genutzte, jedoch nicht von diesen verwaltete Lokalitäten und widmen sich den Dynamiken und Spannungsfeldern der an ihnen stattfindenden Hindu-Praxis. Selbstverwaltete Orte der Ausübung von Hindu-Praxis werden in Abschnitt 4 dargestellt.

Die Träger derjenigen Orte, die hindu-tamilischen Geflüchteten zunächst als Anlaufstellen dienten, waren meist innerhalb der Mehrheitsgesellschaft fester verankert als die tamilische Migrantengruppe. Trägerschaft oder Hoheit über solche Orte lagen vielfach bei nicht-tamilischen Schweizer Bürgern, die entweder neohinduistischen oder christlichen Gruppen angehörten. Trotz Offenheit konnte es infolge asymmetrischer Machtbeziehungen an diesen Orten jedoch auch zu Einschränkungen im Vollzug der Hindu-Praxis der tamilischen Akteure kommen.

Nachdem ich in Kapitel III die Bedingungen der Inkorporation tamilischer Geflüchteter dargestellt habe, kommen hier zunächst Kontaktzonen in den Blick, die durch die Begegnung zwischen neohinduistischen ${ }^{239}$ Grup-

239 Der Begriff Neohinduismus bzw. neohinduistische Bewegung ist im Kontext einer sogenannten Hindu-Renaissance Mitte des 19. Jahrhunderts entstanden und wurde ab den 1950er Jahren in den wissenschaftlichen Diskurs aufgenommen. Als «neohinduistisch» werden gegenwärtig Hindu-Persönlichkeiten und die von ihren gegründeten Organisationen bezeichnet, welche auf Grundlage einer westlich beeinflussten Erziehung oder der Beschäftigung mit westlichem Gedankengut eine Re-Interpretation und Aktualisierung traditioneller indischer 
pierungen und tamilischen Hindus innerhalb der Religionslandschaft der Schweiz entstanden sind. Der Krishna-Tempel in Zürich als bedeutender ISKCON-Ort in der Schweiz wird in Abschnitt 3.3 als wichtige in neohinduistischer Trägerschaft befindliche Kontaktzone exemplarisch beschrieben und analysiert. Die Dynamiken, die innerhalb der Krishna-Gemeinschaft durch die Ankunft tamilischer Hindus entstanden sind, verweisen sowohl auf vielfältige Identitätsdiskurse innerhalb dieser Gruppe als auch auf Prozesse der Etablierung der Immigrantengruppe in der Schweiz.

Die beiden grössten religiösen Gruppen tamilischer Migrantinnen und Migranten - römisch-katholische Tamilen und solche, die sich Hindu-Traditionen zugehörig fühlen - fanden in der Schweiz unterschiedliche Ausgangsbedingungen in der Etablierung ihrer religiösen Traditionen in der neuen Umgebung vor. Die tamilischen Hindus betraten mit der Etablierung von Hindu-Organisationsstrukturen und Hindu-Orten in der Schweiz nahezu Neuland. Im Vergleich zu anderen Diaspora-Ländern wie beispielsweise Grossbritannien oder Kanada, gab es in der Schweiz fast keine gewachsenen religiösen Strukturen von Migrantinnen und Migranten aus Indien, da diese eine der kleinsten Immigrantengruppen im Land darstellen, obwohl seit den 1960er Jahren die Zahl der indischen Staatsbürger in der Schweiz kontinuierlich angestiegen ist. Nach Ursina Wälchli $(2008,34)$ lebten 2008 ca. 13500 Inderinnen und Inder in der Schweiz, wobei über die Zahl an indischen Hindus keine exakten Angaben zu finden sind. Es kann jedoch davon ausgegangen werden, dass 78 Prozent der Gruppe Anhänger von Hindu-Traditionen sind, was eine Zahl von 10500 für das Jahr 2008 ergibt. Nach Wächli $(2008,79)$ wird innerhalb dieser Gruppe in der Diaspora-Situation «Religion» als identitätsstiftender Faktor allerdings abgewertet, während vielmehr regionale Gruppenzugehörigkeiten hervorgehoben werden:

Die Kategorie Hindu wird durchaus identitätsstiftend verstanden, sie wird aber nicht als religiös wahrgenommen. Vielmehr wird sie als die von den Eltern weitergegebenen, lokalen oder regionalen Traditionen verstanden. Die Hindu-Identität ist also regional verankert. (Wälchli 2008, 78f.)

Die seit den 1980er Jahren erfolgte Etablierung sri-lankisch tamilischer Hindu-Orte in der Schweiz ermöglicht es, dass diese auch neu angekommenen indischen Hindus als erste religiöse Anlaufstellen dienen können. Wälchli zitiert einen indischen Informaten wie folgt: "Because there are no Hindu temples I would go to Tamil temples. Because at least Tamil and Indians have

Konzepte vornehmen. Viele betonen dabei den Stellenwert der Bhagavadgita als zentrale Schrift des «Hinduismus». Einige Denker gründeten religiös legitimierte politische Gruppen, die ein nationalistisches Programm vertreten (vgl. Beckerlegge 2006). 
similar culture" (Pradeep, zitiert nach Wälchli 2008, 73). Dieser kontrastiert den Begriff «Hindu-Tempel» mit dem des «tamilischen Tempels» und macht damit deutlich, dass er diesen nicht unter die Kategorie «Hindu» fasst. Nach Wälchli scheint es so zu sein, dass der Kontakt zwischen aus Indien migrierten Menschen und neohinduistischen Bewegungen enger ist als der zwischen den sri-lankisch tamilischen und indischen Hindus. «Tamilische Priester werden von indischen Hindus anscheinend eher weniger engagiert, da diese alle nur im Nebenamt beschäftigt sind und sich nicht sehr um zusätzliche Aufgaben bemühen. Zeremonien von Hare Krishnas oder OmakaranandaAnhängern werden geschätzt» (Wälchli 2008, 70). Teilweise gehen indische Hindus - nach Wälchli - zu tamilischen Tempeln auf Distanz, da sie diese unter anderem als von der LTTE dominiert ansehen, was wiederum die Relevanz der sri-lankischen Bürgerkriegsgeschichte im religiösen Feld aufzeigt. ${ }^{240}$

In der Schweizer Religionslandschaft finden sich darüber hinaus nahezu keine indischen twice migrants (vgl. Vertovec 2000, 15), die Hindu-Traditionen praktizieren; anders als beispielsweise in Grossbritannien lässt sich keine indische Migranten-Gruppe ausmachen, die in einem früheren Einwanderungsland ihre Gruppenidentität ausgebildet hat und diese religiös organisiert praktiziert (vgl. Coward/Hinnells/Williams 2000).

Im Unterschied $\mathrm{zu}$ hindu-tamilischen Migrantinnen und Migranten konnten sich römisch-katholische Tamilen an etablierte Schweizer Kirchgemeinden wenden und in deren Strukturen eingliedern; ausgehend hiervon wurden teilweise eigene tamilische Organisationsformen gebildet. ${ }^{241}$ Durch den Austausch von schweizerischer Bischofskonferenz und sri-lankischer Bischofskonferenz wurde in den 1990er Jahren ein tamilischer Priester in der Schweiz angestellt, welcher römisch-katholische Messen in tamilischer Sprache feierte. ${ }^{242}$ Daraus bildete sich ein tamilisches Zentralkomitee innerhalb der römisch-katholischen Organisationsstrukturen. «Die Organisation

240 Wälchli verweist auf Ajneesh Kumar, den ehemaligen First Secretary der indischen Botschaft aus Bern, der die Gerüchte um Verbindungen der tamilischen Tempel zur LTTE als Hauptgrund für sein Fernbleiben von diesen nennt. Wenn sich diese Tempel explizit von den Tamil Tigers distanzieren würden, würde er diese auch aufsuchen (vgl. Wälchli 2008, 48, 74): «Seiner Meinung nach gehen viele Inder aus politischen Gründen nicht in die Tempel von Hindus aus Sri Lanka» (Wälchli 2008, 74).

241 Eine detaillierte Darstellung der Geschichte und der Organisationsstrukturen römischkatholischer Tamilen in der Schweiz findet sich in Eulberg/Niederberger 2011.

242 Vor der Entsendung eines zuständigen Priesters initiierten die ehemaligen Priesterseminaristen Gabriel Gabrielpillai und Anthony Fernando informelle Zusammenschlüsse unter katholischen Tamilen in der Schweiz. Alle vier Jahre wird ein tamilischer katholischer Priester aus dem Distrikt Mannar/Sri Lanka in die Schweiz entsandt und lebt im Pfarreizentrum ZürichWiedikon (vgl. Eulberg/Niederberger 2011, 4). 
kann in diesem Sinne als Netzwerk bereits bestehender Familienkontakte beschrieben werden, auch wenn sie teils durch die Instanzen der sri-lankischen und schweizerischen Bischofskonferenzen kontrolliert wird» (Eulberg/Niederberger 2011, 4) ${ }^{243}$ Gegenwärtig sind viele tamilisch-katholische Akteure der zweiten Generation sowohl in tamilischen Gottesdiensten und Strukturen engagiert wie auch in Schweizer Gemeinden. Diese Doppelstruktur ist kennzeichnend für die religiöse Praxis vieler «tamilisch-katholischer Schweizer», die sich sowohl in tamilischen Kontexten als auch in den Sphären der Schweizer Mehrheitsgesellschaft bewegen.

Trotz der Differenzen in der Etablierung im neuen Kontext lassen sich auch Ähnlichkeiten zwischen den Gruppen der tamilischen Katholiken und Hindus in der Ausrichtung ihrer religiösen Praxis aufzeigen. Beide betonen in der Diaspora, wie Knut A. Jacobsen (2008a) in Bezug auf Norwegen rekonstruiert hat, in ihrer rituellen Praxis besonders ihre Tamilness (vgl. das Fazit der Studie) und den Rückbezug auf die Herkunftsregionen. Gemeinsam sind den beiden Gruppen auch Herausforderungen in der Etablierung ihrer religiösen Praxis im neuen Kontext - insbesondere im Prozess der Institutionalisierung und der Etablierung eigener religiöser Orte. An erster Stelle ist der Mangel an religiösen Spezialisten und das Arbeitspensum der wenigen tätigen katholisch-tamilischen wie auch der Hindu-Priester zu nennen. ${ }^{244}$ Die Priester beider religiöser Traditionen kommen erst einmal selbst als Fremde in die Schweiz und müssen wie andere migrierte Menschen auch vielfältige Anforderungen bewältigen. Tamilische Katholiken können hier jedoch auf Unterstützungsangebote von Schweizer Gemeinden zurückgreifen. In der Arbeit der Priester, die neben rituellen bzw. liturgischen Aufgaben auch die Betreuung von Gläubigen beinhaltet - sei es durch seelsorgerische Tätigkeiten oder die Begleitung von lebenszyklischen Ritualen im Hindu-Spektrum - spielen migrationsspezifische Problemlagen eine grosse Rolle. Soziale und ökonomische Schwierigkeiten, die in Zusammenhang mit dem Status als «Ausländer» in der Schweiz in Verbindung stehen, oder auch gruppeninterne Probleme wie Generationenkonflikte oder die Verschiebung von Geschlechterrollen, sind hier zu nennen.

Im Folgenden werden die religiösen Kontakte tamilischer Hindus zu sich bereits im Land eingerichteten neohinduistischen Gruppen näher betrachtet. Dabei greife ich auf den von Mary Louise Pratt geprägten Begriff

243 Eine inoffizielle Internetplattform tamilischer Katholiken in der Schweiz stellt die Webadresse www.jesutamil.ch (22.11.2011) dar, auf der unter anderem die Gottesdienstzeiten tamilischsprachiger Messen angegeben sind.

244 Weder die sri-lankische noch die schweizerische Bischofskonferenz stellen finanzielle Ressourcen zur Anstellung weiterer Priester zur Verfügung (vgl. Eulberg/Niederberger 2011, 3). 
der «Kontaktzone» zurück, um Räume dynamischer Interaktion in der Migrationssituation zu beschreiben.

\subsection{Kontaktzonen als Räume dynamischer Interaktion}

Der Begriff der «Kontaktzone» (contact zone) geht auf die US-amerikanische Sprach- und Literaturwissenschaftlerin Mary Louise Pratt zurück. Pratt wendet sich mit Verweis auf Benedict Andersons Idee der imagined communities (vgl. Anderson 1983) gegen die sozio-linguistische Konzeption von «Sprachgemeinschaften», welche als in sich geschlossene, homogene und voneinander abgetrennte Entitäten angesehen werden (vgl. Pratt 1991, 4). Vielmehr plädierte sie für einen Paradigmenwechsel innerhalb der Linguistik, der zentral auf interaktive Prozesse zwischen den Sprachgruppen und ihre Austauschbeziehungen fokussiert (vgl. Pratt 1987). Für die Literaturwissenschaft setzt sie diese Betonung des Aspekts des Kontaktes 1992 in ihrem Buch Imperial Eyes um, in welchem sie lateinamerikanische Reiseliteratur zwischen 1800 und 1980 als Repräsentationsform von Austauschprozessen untersuchte (Pratt 1992). Sie geht davon aus, dass die Prozesse der Neuformierung von Sprache zur Verständigung zwischen unterschiedlichen Sprachgruppen jenen der Neuformierung kultureller Ausdrucksformen als Resultat der Beziehung von Gruppen ähnlich sind. Beide Ergebnisse solcher Begegnungsprozesse (Sprache wie auch kulturelle Formen) werden von Aussenstehenden oftmals als minderwertig angesehen (vgl. Frenz 2004, 24). Jenen Raum, in welchem unterschiedliche Gruppen aufeinandertreffen und Austausch stattfindet, nennt Pratt contact zone. "'Contact zone' is an attempt to invoke the spatial and temporal copresence of subjects previously separated by geographic and historical disjunctures, and whose trajectories now intersect" (Pratt 1992, 7). Sie bezieht sich in der Konzeptualisierung des Begriffs auf Debatten um den Kulturkontakt wie auch auf Diskussionen um den frontier-Begriff, wie sie Frederick Jackson Turner angestossen hat (vgl. Turner 2008 [1893]). Zentral ist im Prattschen Konzept das Spannungspotential der contact zone; der Kontaktbereich ist sowohl von Transfer als auch von Konfrontation geprägt. Hierarchische Differenzen zwischen den Gruppen, welche die Interaktion entscheidend beeinflussen, werden als entscheidende Faktoren für Kontaktprozesse angesehen (vgl. Frenz 2004, 25). Kontaktzonen erscheinen so als "social space where cultures meet, dash, and grapple with each other, often in contexts of highly asymmetrical relations of power [...]" (Pratt 1992, 7). Aus diesem Grund bietet sich das Konzept für eine Untersuchung der Orte des Zusammentreffens von Minderheiten und Mehrheit bzw. von etablierten und neu hinzugekommenen Gruppierungen 
an. Wie Matthias Frenz $(2004,28)$ anmerkt, ist «[d]er Verlauf der Aushandlungsprozesse [...] jedoch nicht allein von der Orientierung der Akteure bestimmt, sondern [...] immer auch von den kontextuellen Bedingungen des sozialen und geographischen Raums abhängig, in denen er stattfindet». In diesem Sinne lässt sich das Konzept der Kontaktzone im Hinblick auf die Untersuchung von Immigrantengruppen sehr gut mit dem in Kapitel III diskutierten Konzept der Inkorporationsbedingungen verbinden.

In den letzten Jahren wird der Begriff der Kontaktzone mit Referenz auf Pratt vermehrt in kulturwissenschaftlichen Arbeiten aufgenommen (vgl. beispielsweise für den englischsprachigen Kontext Clifford 1997 und für den deutschsprachigen Kontext Frenz 2000; Binnenkade 2009). Im Folgenden wird das Konzept der Kontaktzone im Rahmen einer religionswissenschaftlichen Arbeit verwendet und für die Untersuchung der Dynamiken und der Etablierung tamilischer Hindu-Traditionen in der Schweiz herangezogen. Durch die Betonung der interaktiven Prozesse zwischen Gruppen, die in einem asymmetrischen Machtverhältnis zueinanderstehen, bietet es sich für die Untersuchung der Wechselbeziehungen zwischen Immigrantengruppen und der Residenzgesellschaft an. Nicht die Trennlinie zwischen zwei als homogene Einheiten angesehenen Gruppen wird betont, sondern die Aushandlungsprozesse zwischen diesen.

Das von Pratt im Kontext des Kolonialismus und imperialistischen Praktiken wie der Sklaverei verwendete dynamische Modell übertrage ich auf den Schweizer Kontext und gehe von einem Machtgefälle zwischen etablierten Gruppen und der Gruppe der tamilischen Hindus aus. ${ }^{245}$

\section{2 «Am Anfang kamen alle Tamilen zu uns»: Die Krishna Gemeinschaft Schweiz als Anlaufstelle für tamilische Hindus}

Anders als römisch-katholische Tamilen konnten tamilische Hindus, die in die Schweiz kamen, auf keine im Residenzland etablierten Organisationsstrukturen traditioneller Hindu-Praktiken zurückgreifen. In der Schweiz

245 Die Übertragung auf den Schweizer Kontext soll jedoch selbstverständlich keine Gleichsetzung zwischen den Bedingungen für tamilische Hindus in der Schweiz und einem kolonialen Kontext bedeuten.

Auch die Historikerin Alexandra Binnenkade überträgt in ihrer Dissertation zu jüdischchristlichem Alltag im Schweizer Dorf Lengnau das Prattsche Konzept auf ihren Untersuchungskontext und untersucht in ihrer Arbeit Aushandlungsprozesse zwischen christlich geprägter Gesellschaft und einer nicht-christlichen Gruppe (vgl. Binnenkade 2009). 
waren jedoch zum Zeitpunkt der Ankunft der ersten grossen Gruppe tamilischer Geflüchteter neohinduistische Gruppierungen aktiv, deren Mitglieder sich meist aus Schweizer bzw. europäischen «Hindu-Konvertiten» zusammensetzen.

\section{Die Etablierung neohinduistischer Gruppen in der Schweiz}

Die Etablierung neohinduistischer Gruppierungen - von «Hindu-related new religious movements», wie Kim Knott sie nennt ${ }^{246}$ - als Akteure innerhalb der Schweizer Religionslandschaft kann in zwei Phasen eingeteilt werden. Die erste Periode war durch den indischen Reform-Hindu Vivekananda (1863-1902) und seine Bestrebungen, indisches Gedankengut in den Westen zu bringen, geprägt. ${ }^{247}$ Damaliger Hauptakteur innerhalb des neohinduistischen Feldes war der von Vivekananda gegründete Shri Ramakrishna Math. ${ }^{248}$ Mönche des Shri Ramakrishna Math besuchten in den 1930ern regelmässig die Schweiz und versuchten die Lehren Ramakrishnas und Vivekanandas im Westen zu verbreiten (vgl. Gambhirananda 1957). Swami Yatiswarananda (1889-1966) begründete den ersten Ashram der Schweiz. Dieser Ort spiritueller Zusammenkünfte im Engadin bestand jedoch nur fünf Jahre, bis Swami Yatiswarananda wegen des Beginns des Zweiten Weltkriegs Europa gen USA verliess. Nach Kriegsende etablierte sich unter der Federführung von Swami Nityabodhananda (1914-1992) in Genf das Centre Védantique. Auch gegenwärtig ist das Zentrum ein Ort, an dem Hindu-Praxis vollzogen wird. ${ }^{249}$

Die Ankunft der ersten tamilischen Hindus fiel jedoch in die zweite Phase der Etablierung neohinduistischer Gruppen während der 1960er Jahre. Diese prägten neue religiöse Bewegungen mit hinduistischem Hintergrund, welche sich von ihren Heimatorganisationen in Indien abwendeten und sich im Umfeld alternativ-spiritueller Lebensformen etablierten. Es

246 Mit dieser Bezeichnung weist Knott implizit darauf hin, dass sich einige dieser Gruppen selbst nicht als «Hindus» verstehen (vgl. Knott 1987).

247 Vivekananda erlangte auf dem Weltkongress der Religionen 1893 in Chicago weltweit Reputation als einer der zentralen Vertreter «des Hinduismus» (vgl. Koppedrayer 2004). Er gründete in Erinnerung an seinen Lehrer Ramakrishna (1836-1886) die Ramakrishna-Mission. Eines seiner Ziele war es, auch ausserhalb Indiens bestimmte religiöse Ideen wie etwa den KarmaGedanken bekannt zu machen (vgl. Sen 2000; Neubert 2005). Vivekananda selbst besuchte im August 1896 während einer Europareise die Schweiz (vgl. Vivekananda 1970, 368).

248 Die Lehre des Shri Ramakrishna Math zeichnet sich durch eine monistische VedantaAusrichtung aus (vgl. Beckerlegge 2006).

249 Seit 1999 werden hier sonntags pūjās durchgeführt. Daneben bietet das Zentrum Vorträge zur Lehre Ramakrishnas und Vivekanandas sowie Yoga-Stunden an (vgl. www.centrevedantique-ge.org; 01.02.2020). 
entstanden organisatorisch unabhängige Guru-Bewegungen, die öffentlich präsent waren und deren Leiter teilweise im Westen lebten. Gruppierungen wie die Transzendentale Meditation (TM) und die ISKCON waren bestrebt, aktiv neue Mitglieder anzuwerben. Legitimationsgrund der Mitgliederwerbung war in erster Linie die Inspiration durch den lebenden Begründer der Gruppe. Hier wird sich auf das Guru-Konzept in Hindu-Religionen bezogen, in welchem der Guru als Lehrer und inspirierende Autorität angesehen wird. Dieser Aspekt stellt einen zentralen Unterschied zu den von den meisten tamilischen Immigranten praktizierten Traditionen dar.

Ein Nebeneinander von westlichen Akteuren, welche neohinduistischen Gruppen angehören, und asiatischen Migrantinnen und Migranten, welche ihre über Generationen weitergegebene Hindu-Praxis mit in den neuen kulturellen Kontext bringen, ist kennzeichnend für das Hindu-Spektrum in vielen westlichen Ländern. Dabei können Orte neohinduistischer Gruppierungen Kontaktzonen darstellen, welche eine Plattform zum Austausch und zur Aushandlung von Praktiken und Anschauungen bieten. Spannungen zwischen diesen Gruppen mit unterschiedlichem Hintergrund prägen dabei mitunter die Interaktionen. Neohinduistische Orte, welche bereits zur Zeit der Ankunft der ersten grösseren Gruppe sri-lankischer Hindus in der Schweiz existierten, sind beispielsweise der 1973 vom indischen Guru Swami Omkarananda (1930-2000) gegründete Devata-Tempel ${ }^{250}$ des Divine Light Zentrum (DLZ) in Winterthur wie auch der ISKCON-Tempel in Zürich. Die 1966 vom bengalischen Sannyasin A.C. Bhaktivedānta Svāmī Prabhupāda (1896-1977) gegründete ISKCON ist eine der populärsten und bekanntesten neohinduistischen Bewegungen im Westen, welche sich selbst jedoch als eine traditionsreiche Hindu-Vereinigung versteht. Als Weiterentwicklung der Gaudīya Vaishnava Bewegung versucht die ISKCON die Lehre dessen Gründers, des Mystikers Chaitanya (ca. 1486-1533), ausserhalb Indiens zu verbreiten (vgl. Knott 1988; Squarcini/Fizzotti 2004; Neubert 2010a). Während des Booms «neuer religiöser Bewegungen»ab den 1960er Jahren etablierte sich diese sogenannte «Hare Krishna-Bewegung», die besonders in den Anfangsjahren kontrovers wahrgenommen wurde, auch in der Schweiz; der Gründer der Bewegung, Prabhupāda, besuchte das Land 1974. Die ISKCON war eine der ersten Hindu-Gemeinschaften, die sich im öffentlichen Raum der Schweiz präsentierte und sich innerhalb der religiösen Landschaft der Schweiz positionierte. Ihr Tempel

250 Dieser Tempel in Winterthur befindet sich in einem privaten Haus; als zentrales Ritual wird die Feuerzeremonie Akhanda-Devi-Yajna zelebriert (vgl. Eulberg 2008; www.omkarananda. ch/tempel0.php; 01.11.2010). Eine kleine Gruppe tamilischer Hindus besucht auch diesen Ort regelmässig. 
in Zürich zog viele migrierte tamilische Menschen an und ist damit eine wichtige Kontaktzone, die Aufschlüsse über Etablierungsprozesse tamilischer Hindus in der Schweiz gibt.

\section{Kontakte zwischen tamilischen Hindus und der Krishna Gemeinschaft Schweiz in den Anfängen der Immigration}

Im Folgenden wird die Entstehung des ISKCON-Tempels in Zürich als Kontaktzone zwischen westlichen Konvertierten und aus Südasien stammenden Menschen aus einer historischen Perspektive dargestellt. Diese Rekonstruktion basiert vor allem auf Primärquellen und Experteninterviews. Wie kam es zum Kontakt zwischen den Gruppen, wie entstand diese Kontaktzone? Welche Prozesse werden angestossen, wenn tamilische Geflüchtete mit westlichen Neohindus unter ungleichen Machtverhältnissen in einem sozialen Raum aufeinandertreffen? In einem zweiten Schritt wird die Gründung einer eigenen Organisation tamilischer Hindus innerhalb der Kontaktzone als ein Resultat dieser Interaktionen und Aushandlungsprozesse beschrieben. Eine detaillierte Darstellung des ISKCON-Tempels in Zürich als Ort tamilischer Hindu-Praxis in der Schweiz erfolgt dann - vor dem Hintergrund der folgenden Analyse - in Abschnitt3.3.

Wenige Jahre nach der Eröffnung des ISKCON-Tempels in Zürich 1980 besuchten erstmals tamilische Geflüchtete aus Sri Lanka den Tempel. Die Besuche nahmen besonders Anfang der 1990er Jahre stetig zu. Auch in anderen Diaspora-Ländern war oftmals ein öffentlicher Ort der ISKCON der erste Hindu-Tempel, welcher von migrierten Hindus unterschiedlichster Traditionslinien besucht wurde. ${ }^{251}$ Obwohl die ersten Aktivitäten dieser Bewegung in den USA und Europa nicht auf asiatische migrierte Menschen ausgerichtet waren ("ISKCON's founder Bhaktivedanta Swami generally ignored Indian immigrants in the West", Broo 2011, 34), stellen diese heute in vielen ISKCON-Tempeln eine wichtige Besuchergruppe dar. ${ }^{252}$ Durch die Begegnungen und Interaktionen von tamilischen Geflüchteten und westlichen krșna-Devotees entstanden transkulturelle soziale Räume, welche als Kontaktzonen beschrieben werden können. Innerhalb von diesen finden dynamische Aushandlungsprozesse zwischen der Gruppe der tamilischen

251 Dies gilt auch für indische Immigrantinnen und Immigranten, die in den 1960er Jahren in die USA einwanderten (vgl. Williams 1988, 132; Eck 2000, 118; Rochford 2007, 183). T. S. Rukmani beschreibt dies für die kanadische Stadt Montreal, wo seit den 1960er Jahren ein Krishna Tempel zu finden ist, der von der ISKCON betrieben wird (vgl. Rukmani 2005, 55). Für den kanadischen Kontext vgl. des Weiteren Coward 2000, 152 f.; Rochford 2007, 183.

252 Laut Rochford $(2007,182)$ sind achtzig Prozent der Teilnehmer an ISKCON-Sonntagsfesten in Nordamerika aus Asien migrierte Menschen. 
Geflüchteten und den Akteuren der ISKCON statt. Die marginalisierte Position tamilischer Hindus zu jener Zeit, die aus dem unsicheren Flüchtlingsstatus und fehlender religiöser Infrastruktur im Residenzland resultierte, hatte dabei starke Auswirkungen auf ihr Verhältnis zur ISKCON.

Der Kontakt zwischen den Gruppen erfolgte durch Mund-zu-MundPropaganda unter den migrierten tamilischen Menschen wie auch durch gezielte Massnahmen, um die Information über die Existenz eines HinduTempels in der Schweiz unter den tamilischen Geflüchteten zu verbreiten. Tamilische Akteure ergriffen die Initiative, um den Tempel über die gängigen Diaspora-Medien unter ihren Landsleuten bekannt zu machen. So verfasste ein Initiator der Swiss Tamil Krishna Society Anzeigen in tamilischsprachigen Diaspora-Printmedien und entwarf Poster für tamilische Läden in der Schweiz, um auf diesen ISKCON-Ort aufmerksam zu machen. ${ }^{253}$

So I distribute all the Tamils in Switzerland through the newspaper/Tamil newspaper and also through the shops/Lebensmittelshops/advertisement/I put poster everywhere/and I made poster about the puja time and about the temple and Sunday Feast/and after that slowly, slowly the Tamil people they came.

Mandali Bhadra Prabhu, Schweizer ISKCON-Priester und ehemaliger Vizepräsident der Swiss Tamil Krishna Society, fungierte in den Anfängen der tamilischen Immigration in die Schweiz als Kontaktperson und Schnittstelle zwischen westlichen krșna-Devotees und den tamilischen Besuchern. Er erinnert sich wie folgt an die zahlreichen tamilischen Besucher im Zürcher Tempel während der ersten Phase der tamilischen Immigration in die Schweiz: ${ }^{254}$

Die Tamilen sind vor 15/20Jahren gekommen/und die suchten natürlich einen Tempel/und die haben gehört ISKCON und so. Und das war natürlich ein Riesenzulauf, weil wir waren der einzige Tempel. Es gab noch keine tamilischen Tempel. Wir haben hunderttausende von Leuten gehabt. Bei gewissen Festivals hatten wir von hier fast bis zur Bushaltestelle hoch eine Kolonne / so war das damals. Da die Leute Flüchtlinge waren, kamen sie auf uns zu. ${ }^{255}$

253 Das Experten-Interview mit Nirmal Krishna Dasa wurde am 05.12.2010 im KrishnaTempel in Zürich geführt. Die folgenden englischsprachigen Gesprächs-Zitate stammen aus dem Interview mit ihm.

254 Ein Experten-Interview mit Mandali Bhadra Prabhu wurde am 09.03.2008 im KrishnaTempel in Zürich geführt. Die folgenden deutschsprachigen Gesprächs-Zitate stammen aus dem Interview mit ihm.

255 Interview 7; 09.03.2008. 
Mandali Bhadra Prabhu merkt an, dass der Tempel in den Anfängen von allen tamilischen Hindus, unabhängig von ihrer religiösen Ausrichtung, besucht wurde: «Am Anfang kamen alle Tamilen zu uns, egal, ob in KrishnaTradition stehend oder nicht, weil es der einzige Tempel war.» Die religiöse Tradition der ISKCON weicht von der Hauptströmung der Mehrheit der tamilischen Hindus aus Sri Lanka ab. Nur eine Minderheit der tamilischen Hindus folgt der Tradition der Vaiṣnavas; diese wiederum sind meist Anhänger der ISKCON. Die besondere Situation der Diaspora, die auf unterschiedlichsten Ebenen Einschränkungen nach sich zog, nivellierte in den Anfängen die internen religiösen Unterschiede zwischen den tamilischen Hindus. Der von Schweizern geführte Krishna-Tempel wurde auch von Caivas als Ort angenommen, an welchem Hindu-Praxis in der Fremde gemeinschaftlich durchgeführt werden konnte. Er wurde sowohl zur Kontaktzone zwischen Schweizern und Tamilen wie auch zwischen Hindus unterschiedlicher Strömungen. Roger Meier schreibt in der Jubiläumsschrift zum dreissigjährigen Bestehen des Krishna-Tempels in Zürich im Jahr 2010:

Für die gut 200-300 tamilischen Mitglieder, welche sich zur Bhakti-Religion nach Prabhupada bekennen, ist das Züricher Zentrum bis heute ebenso Stätte der Verehrung und «Heimat in der Fremde» wie für diejenigen Tamilen, welche der Verehrung Shivas als Hauptgott treu geblieben sind. (Meier 2010, 22)

In der Schrift «Krishna-Bewusstsein in der Schweiz» zum 25. Jubiläum der Krishna Gemeinschaft Schweiz aus dem Jahr 1996 spricht der damalige Präsident der Schweizerisch-Tamilischen Krishna-Gesellschaft, Nimalkumar, davon, dass der Tempel der ISKCON tamilischen Geflüchteten zur religiösen Heimat in der Fremde wurde:

Wir Tamilen aus Sri Lanka, die als Flüchtlinge in der Schweiz leben, bewundern dieses «Jagannatha Puri des Westens», den Zürcher Krishna-Tempel, aus der Tiefe unseres Herzens, denn dieser Ort ist ein Segen und ein Glück im Unglück für uns. Dank diesem Tempel und den Krishna-Geweihten, die Gott und den Menschen so selbstlos dienen, können wir unsere Kultur auch in der Schweiz ohne Hindernisse leben. (Schweizerische Stiftung für KrishnaBewusstsein 1996, 37)

Indirekt verweist er auf xenophobe Tendenzen, mit welchen tamilische Geflüchtete in der Schweiz konfrontiert werden. Die Mitglieder der ISK$\mathrm{CON}$ weist er gerade als solche Akteure aus, welche eine fremdenfreundliche Haltung gegenüber den ankommenden Geflüchteten zeigten und dieser Minderheit Hilfestellungen anboten:

Wie alle ernsthaften Spiritualisten haben auch die Krishna-Geweihten engstirniges und rassistisches Denken überwunden. Wie sonst könnten sie so 
gütig und grosszügig mit den tamilischen Flüchtlingen umgehen? (Schweizerische Stiftung für Krishna-Bewusstsein 1996, 37)

Die Prozesse der Aufnahme der zugewanderten tamilischen Hindus in die bereits etablierte ISKCON-Tempelgemeinschaft in Zürich waren geprägt von der Bereitschaft der Schweizer Devotees, den Geflüchteten unterstützend zur Seite zu stehen, teilweise aber auch von einer paternalistischen Haltung gegenüber den tamilischen Hindus wie auch von Exklusionstendenzen. Die Diskurse innerhalb der ISKCON wurden von mehrheitsöffentlichen Debatten beeinflusst. Der in Abschnitt III.3 thematisierte FremdenDiskurs zur Zeit der ersten Phase der Einwanderung tamilischer Menschen und der öffentliche Diskurs über «die Tamilen» als Inkorporationsbedingungen spiegelt sich auch in der Aufnahme der tamilischen Hindus durch die ISKCON in Zürich wider. Mitarbeiter von Schweizer Behörden wie auch Schweizer Devotees im ISKCON-Tempel in Zürich, die von der grossen Anzahl an einreisenden Geflüchteten aus Sri Lanka überrascht wurden, reagierten teilweise mit Überforderung auf die Präsenz der tamilischen Migrantinnen und Migranten. Die Tempel-Verantwortlichen diskutierten unterschiedliche Handlungsstrategien, um mit der neuen Situation umzugehen. Eine ambivalente Haltung einiger Schweizer Devotees gegenüber den tamilischen Hindus kam beispielsweise im Vorschlag zum Ausdruck, dass ihnen ein separater Tag gewährt werden sollte, um den Tempel zu besuchen, was eine Segregation der Tamilen zur Folge gehabt hätte. Mandali Bhadra Prabhu spricht xenophob gefärbte Argumente an, die anfänglich auch in der Hare-Krishna-Bewegung gegenüber tamilischen Menschen vorgebracht wurden:

[...] am Anfang da kamen die und da haben die Schweizer hier ein bisschen Angst gehabt. Da kam voll so ein bisschen der Rassist durch, habe ich das Gefühl gehabt. Da haben wir hier grosse Meetings gehabt. Da kam das Thema: $<$ So viele Tamilen, was machen wir?> Und dann hat einer den Vorschlag gemacht/wir sagen/sie kommen nur am Samstag. Und am Sonntag haben wir unser Programm. Und ein anderer hat gesagt: $<$ Wir sollen zurückhaltend sein, weil wenn so viele Schwarze hier sind, dann bekommen wir Probleme mit den Rechtsradikalen. ${ }^{256}$

Mandali Bhadra Prabhu verwies jedoch auf das Potential, welches die tamilischen Hindus mit in die Krishna-Gemeinschaft brachten, und betonte den Gewinn, den sie durch ihre Verbundenheit mit einer an den Tempel gebundenen und über Generationen weitergegebenen Hindu-Praxis für die ISKCON darstellen:

256 Interview 7; 09.03.2008. 
Da habe ich zugehört und gesagt: < Jungs, wacht auf!> Weil ich habe das schon gemerkt: Die Tamilen sind interessiert am Tempel/und die Schweizer auch, aber die haben das nicht so verinnerlicht wie ein Tamile. ${ }^{257}$

Den tamilischen Hindus kam somit nicht nur innerhalb der Mehrheitsgesellschaft durch ihren Immigrantenstatus und fehlende Vertrautheit mit den Gegebenheiten des Residenzlandes eine randständige Position zu; auch die Machtverhältnisse innerhalb der Zürcher Tempelstruktur waren asymmetrisch verteilt. Der ISKCON-Tempel kann in diesem Fall als ein Mikrokosmos der Mehrheitsgesellschaft angesehen werden, in dem ein «Integrationsprozess» von «Tamilen» in eine bereits bestehende, von «Schweizern» geführte gemeinschaftliche Ordnung durchgeführt wurde. Wie der Staat Schweiz als politischer Raum im Hinblick auf die tamilischen Geflüchteten als eine Kontaktzone mit ungleicher Machtverteilung beschrieben werden kann, kann auch der Krishna-Tempel als eine ebensolche Kontaktzone verstanden werden. Die tamilischen Akteure sind sich bewusst, dass die Machtpositionen des Tempels bei den Schweizer Vertretern liegen. Nirmal Krishna Dasa, Mitglied der Swiss Tamil Krishna Society (der Organisation tamilischer ISKCON-Devotees in der Schweiz), bezeichnet den Tempel als «Schweizer Tempel». Die Informantin Lakhi, eine regelmässige Besucherin des Tempels, erklärt: «Der Krishna-Tempel ist von Schweizern geführt. Das Haus gehört auch einem Schweizer.» ${ }^{258}$ Jedoch identifizieren sich viele tamilische Besucher mit dem Tempel und bezeichnen ihn als «unser Tempel». Im folgenden Statement von Nirmal Krishna Dasa kommt der Status dieser Kontaktzone als eines Raums des produktiven Austausches trotz bestehender Hierarchien und der damit einhergehenden Ambivalenz des Ortes prägnant zum Ausdruck:

Working together/because we cannot work alone / because it is Swiss temple. Swiss / they are maintaining the temple/we are only help to them. This is our temple/because we are not living here. We are living outside. But temple is common for us / they give chance. We are using the temple and not feel it is private or something.

Dass der Tempel von ethnischen Schweizern geführt wird und viele Besucher Schweizer sind, führt zu ambivalenten Reaktionen bei tamilischen Besuchern. Auf der einen Seite wird dieses Faktum als eine Form der Bestätigung für Hindu-Praxis im neuen Kontext angesehen. Auf der anderen Seite löst die Besetzung zentraler Funktionen im Tempel durch Schweizer jedoch auch Erstaunen bei den südasiatischen Besuchern aus. Die ethni-

257 Interview 7; 09.03.2008.

258 Interview 2; 12.01.2009. 
sche Zugehörigkeit der religiösen Spezialisten im Tempel im Beziehungsverhältnis zu den südasiatischen «Laien» empfindet Lakhi als eine paradoxe Situation.

Das sind sozusagen die Mönche. Das finde ich noch sehr spannend/weil wir selber als Hindus / wir gehen schon in den Tempel/wir essen kein Fleisch und so / aber wenn du nachher siehst, wie die Schweizer in unsere Religion integrieren/du denkst: <Wo leben die?> Also, die sind ja höher als wir, wenn die so leben. Als wir in der Schweiz/wir wollen uns anpassen. Und sie wollen uns anpassen. $<$ lacht $>$ Da habe ich gedacht: $<$ Nein. $>$ [schüttelt den Kopf] ${ }^{259}$

Lakhi verweist auf die für sie ungewöhnliche Konstellation, dass Schweizer bestrebt sind, sich in die «Hindu-Kultur» integrieren zu wollen, während die Tamilen wiederum bestrebt sind, sich in die «Schweizer Kultur» zu integrieren. Neben den ISKCON-internen Diskussionen um Inklusion und Exklusion der tamilischen Devotees versuchte man nach aussen hin die Präsenz südasiatischer Hindus im ISKCON-Tempel in Zürich als Beleg gegen die Fremdwahrnehmung als «Jugendsekte» (Fuchs 1981) zu nutzen. Der öffentliche Diskurs gegenüber der ISKCON war in den 1980er Jahren durch den Sekten-Diskurs geprägt (vgl. Neubert 2010a, 60). Bei den meisten Konvertiten zur ISKCON setzte ein religiöser Milieuwechsel ein, was in den 1970er Jahren teilweise heftige Reaktionen der Mehrheitsbevölkerung gegenüber der Bewegung hervorrief. Christliche «Weltanschauungsexperten» warnten vor ihr als einer Gruppierung, die zu den «Sekten, Kulten und Jugendreligionen» zu rechnen sei. Die damalige Schweizerische Gesellschaft für Krishna-Bewusstsein (SGKB) versuchte sich durch Kontakte mit sri-lankischen (und auch indischen) Hindus als authentische Hindu-Gemeinschaft zu präsentieren. ${ }^{260}$ Durch die Anwesenheit südasiatischer Devotees in den Tempel erhoffte man sich, die negativ konnotierten Zuschreibungen abzuschwächen und als eine traditionsreiche «Weltreligion» wahrgenommen zu werden, die seit Jahrtausenden in Asien beheimatet ist (vgl. Meier 2010, 21). E. Burke Rochford $(2007,181 \mathrm{ff}$.) bezeichnet diesen Prozess als «Hinduization» der ISKCON.

Durch die zunehmende Teilnahme von tamilischen Devotees an den pūcais im Zürcher Tempel kam es zu strukturellen Veränderungen im Tempel und innerhalb der Organisationsstruktur der ISKCON in der Schweiz. Der Tempel in Zürich erlangte durch den Besucheranstieg von tamilischen Hindus einen Bedeutungszuwachs und wurde 1996 zum offiziellen Haupt-

259 Interview 2; 12.01.2009.

260 Die indischen Hindus, die den Tempel besuchten, wichen meist in ihrem gesellschaftlichen Status und sozialem Profil von dem der tamilischen Besuchenden ab. 
sitz der sich im selben Jahr gründenden Krishna Gemeinschaft Schweiz (KGS). Auch die Sorgen der ISKCON Anfang der 1990er Jahre um ihre Mitgliederzahlen - und damit einhergehende personelle und finanzielle Ressourcen - wurden durch die neu hinzukommenden tamilischen Besuchenden teilweise kompensiert. ${ }^{261}$

\section{Ausdifferenzierungen innerhalb der Kontaktzone: die Gründung der Swiss Tamil Krishna Society}

Die Interaktionen innerhalb der Kontaktzone führten nicht zu einem langfristigen Verschmelzen der beiden Gruppen zu einer neuen einheitlichen Organisation. Vielmehr war eine Konsequenz der Aushandlungsprozesse und Spannungen - aufgrund unterschiedlicher Bedürfnisse und damit einhergehender divergierender Ausrichtungen - eine institutionalisierte Stabilisierung der Gruppendifferenzen innerhalb der ISKCON. Die Ausdifferenzierung der internen Strukturen der ISKCON zeichnet sich durch Innovationen und Wandlungsprozesse aus und birgt Konfliktpotential. Die allgemeine Unterteilung des Schweizer Hindu-Spektrums in Gruppen, die sich aus westlichen konvertierten Menschen zusammensetzen und solchen, die aus asiatischen Migrantinnen und Migranten bestehen, findet sich also auch innerhalb der Organisationsstrukturen der ISKCON wieder. Was Rochford $(2007,190)$ für Nordamerika konstatiert ${ }^{262}$, kann mit Abstrichen auch für die Schweiz bestätigt werden - nur besteht die Gruppe der Südasiaten, welche hier den Tempel besuchen, mehrheitlich aus sri-lankischund nicht indisch-stämmigen Hindus. ${ }^{263}$

261 Für den US-amerikanischen Kontext konstatiert Rochford (2007, 200): “ISKCON’s Indian-Hindu congregation has clearly helped rescue a failing religious organization. In pursuit of needed financial resources in the face of decline, Prabhupada's movement is steadily advancing toward becoming a Western sect of Hinduism."

262 Nur wenige Autoren thematisieren das Verhältnis von westlichen Krishna-Devotees und aus Asien migrierten Devotees ausserhalb Südasiens (vgl. z. B. Williams 1988, 131). E. Burke Rochford Jr. geht in seinem Buch Hare Krishna Transformed auf das Verhältnis der ISKCON zu indisch-stämmigen Menschen in den USA ein (vgl. Rochford 2007, 181 ff.). Die von ihm beschriebenen Dynamiken sind ähnlich wie jene innerhalb der ISKCON-Kontaktzonen in der Schweiz. 2011 hat Måns Broo einen ersten Artikel zum Verhältnis der ISKCON Finnland zu südasiatischen Immigrantinnen und Immigranten veröffentlicht. Darin thematisiert er die Frage, wie Mitglieder der ISKCON, die als «ethnisch finnisch» klassifiziert werden, südasiatische Hindus in ihre Aktivitäten integrieren (Broo 2011).

263 Von parallel communities kann im Hinblick auf den Schweizer Kontext (und vermutlich auch für den nordamerikanischen Kontext) dagegen nicht gesprochen werden. Es finden sich Überlappungen sowie personelle Überschneidungen und auch gemeinsames Feiern von Festen, sodass nicht von einer parallelen Organisationsstruktur gesprochen werden kann. Das hier prä- 
Die ISKCON propagiert trotz der bengalischen Prägung ihrer rituellen Handlungen eine universelle und nicht an einen bestimmten ethnischen Background gebundene Praxis, deren Quintessenz die Verehrung krșnas und seiner Inkarnationen als höchster Gottheit ist. Viele sri-lankisch-tamilische Hindus betonen dagegen, auch aufgrund ihrer Migrationserfahrung, die ethnische Prägung ihrer religiösen Praktiken. Studien zur Hindu-Praxis von migrierten Menschen zeigen, dass es ausserhalb Südasiens eine Tendenz zu einer Ethnisierung der religiösen Praxis gibt. In Ländern, in die unterschiedliche ethnische Hindu-Gruppen einwandern, finden Grenzziehungsprozesse oftmals entlang der regionalen Herkunft und Sprache statt (vgl. Burghart 1987; Williams 1988). ${ }^{264}$

Innerhalb der ISKCON führte das Zusammenkommen von Gruppen mit unterschiedlichen ethnischen Hintergründen in vielen Ländern und so auch in der Schweiz zu Ausdifferenzierungen und zur Entstehung von Sub-Gruppen. Die Eingliederung des Gros der tamilischen Devotees in die bestehenden Strukturen im Zürcher Tempel erfolgt nicht auf individueller, sondern auf kollektiver Basis. Die Fremdwahrnehmung deckte sich mit der Selbstwahrnehmung vieler tamilischer Neuankömmlinge und gründete auf der Annahme, dass sie als distinkte Gruppe mit eigenen (sozialen wie auch religiösen) Bedürfnissen in die Tempelpraxis integriert werden sollten. Innerhalb der ISKCON wurde analog zur bereits etablierten Krishna Gemeinschaft Schweiz 1991 für und von Tamilen eine eigene Gesellschaft die Swiss Tamil Krishna Society (STKS) - als Verein gegründet.

Hier sind Parallelen zur Eingliederung christlicher Migrantinnen und Migranten in bereits bestehende christliche Organisationen im Residenzland festzustellen. Tamilische Christinnen und Christen in der Diaspora organisieren sich vielfach als sogenannte Migrationskirchen bzw. «fremdsprachige Gemeinden» innerhalb der Gemeinden der Residenzgesellschaft. Es finden sich auch buddhistische Gruppierungen in Diaspora-Ländern, die über Sub-Gruppen aus westlichen Praktizierenden wie auch aus buddhistischen Menschen aus Asien verfügen. ${ }^{265}$

ferierte Modell der Kontaktzonen betont daher gerade die Schnittstellen und den Austausch und widerspricht somit dem Gedanken einer strikten Parallelität.

264 In der Schweiz ist die Pluralität unterschiedlicher ethnischer Gruppierungen, die dem Hindu-Spektrum zuzurechnen sind, im Vergleich zu Ländern wie Grossbritannien oder den USA gering.

265 Mit Verweis auf Numrich 1999 weist Rochford auf Parallelen des Verhältnisses von westlichen Konvertierten und asiatischen Immigrantinnen und Immigranten im Feld des Theravada-Buddhismus hin (Rochford 2007, 248). Paul D. Numrich (1999) konstatiert in seiner Studie Old Wisdom in the New World eine doppelte Organisationsstruktur innerhalb theravada-buddhistischer Tempel in den USA, welche er "parallel congregations" nennt. 
Die Swiss Tamil Krishna Society agierte unabhängig von der Stiftung Krishna Gemeinschaft Schweiz (KGS); beide Organisationen sind in die internationale Gesellschaft der ISKCON eingegliedert. Der Tempel wird formell von der KGS geleitet, welche die Tempelräumlichkeiten der STKS zur Verfügung stellen. Laut Nirmal Krishna ist die STKS die einzige regionale Organisation von Tamilen innerhalb der ISKCON. In anderen Ländern fanden sich keine eigenen Societies für tamilische Devotees.

Die STKS wurde nach eigenen Angaben aufgrund unterschiedlicher Bedürfnisse der Gruppen gegründet und verfolgt verschiedene Ziele. Die Verantwortlichen im Zürcher Tempel wie auch die tamilischen Akteure sahen die Notwendigkeit, eigene Organisationsstrukturen für die tamilischen Devotees aufzubauen. Nach Angaben eines der Gründer der Swiss Tamil Krishna Society wurde die Society von Tamilen auf Initiative von Schweizer Devotees ins Leben gerufen. Zwischen KGS und STKS gibt es dabei auch personelle Überschneidungen. Im folgenden Interviewauszug mit Nirmal Krishna kommen paternalistische Strukturen zur Zeit der Gründung der STKS zum Ausdruck:

But they [the Swiss devotees] told me to start the society for the Tamils and go for the Tamils. They also helped me/they also involved/the advisor the society is Swiss too/and the treasurer also/still now is one Swiss devotee/is the treasurer of our Swiss Tamil society. Some like/some not like/this is everywhere.

Ein erklärtes Ziel der STKS ist es, Tamilinnen und Tamilen für die HareKrishna-Bewegung zu gewinnen. Darauf verweist auch der gegenwärtige Präsident der Schweizerischen Tamilischen Krishna Gemeinschaft Sri Caitanya Dev Das (St.Gallen) in der Jubiläumsschrift des Zürcher Tempels 2010:

Ich glaube, dass es irgendwann einmal eine tamilische Gemeinschaft mit voller Hingabe geben wird. Wir versuchen Srila Prabhupadas Botschaft auch an die Tamilen weiter zu geben und unserem Tempel immer zu dienen. (Dev Das 2010, 52)

Die Migrantenorganisation wurde laut Mandali Bhandra Prabhu jedoch nicht nur als Organisation aufgebaut, um die ISKCON durch tamilische Mitglieder zu vergrössern. Ihre Gründung war auch Reaktion auf Vorbehalte einiger Schweizer Devotees gegenüber «den Tamilen». Die Society dient der Stärkung der ethnischen Gruppenidentität und fördert den sozialen Zusammenhalt der tamilischen Besucher. Mandali Bhandra Prabhu sagte dazu im Interview am 09.03.2008 im Krishna-Tempel in Zürich:

Die Zahl der Tamilen, die zu uns kommen, steigt. Weil die Tamilen selber eine Gruppe gebildet haben und so auch die anderen Tamilen inspirieren wollen 
hierher zu kommen. Das ist die Schweizerische Tamilische Krishna Society. Die haben wir gegründet, weil/am Anfang da kamen die und da haben die Schweizer hier ein bisschen Angst gehabt.

Neben der eigenständigen Organisation der tamilischen krṣna-Devotees findet die Zweiteilung der Organisationsstruktur des Krishna-Tempels in Zürich ihren offensichtlichsten Ausdruck in getrennten Sonntagsfesten für tamilische und die mehrheitlich Schweizer (bzw. europäischen) Devotees. Der Einführung zweier Sonntagsfeste ging eine partielle Trennung der beiden Gruppen, tamilischsprachiger und deutschsprachiger Devotees, während des abschliessenden Vortrags des Sonntagsfestes voran. Hier war der ausschlaggebende Grund der Aufteilung die Sprachdifferenz. Nirmal Krishna Dasa berichtet aus dieser Zeit:

That time we together at the Sunday Feast/only one Fest/Sunday Fest/with the Swiss devotees. Three o'clock we start/all together/Tamils also that time/mostly six years or nine years/like this/we together/we do Sunday Feast/three o'clock is bhajan and four o'clock is Vortrag. But for the Tamils we do the separate there/other room. We translate in Tamil/they speak in English and we translate in Tamil. And here is Deutsch/in Tempelraum. Like this we do.

Die STKS führte das getrennte Sonntagsfest für Tamilen somit zunächst als gemeinschaftsbildende Aktivitäten für tamilische Besucher ein.

Zusammenfassend kann festgestellt werden, dass sich die Aufnahmebedingungen für Hindus in den Residenzländern im Hinblick auf die vorfindbare religiöse Infrastruktur durch eine Globalisierung von HinduTraditionen veränderten. In der Schweiz wurde eine neohinduistische Gruppierung, die hauptsächlich von Nicht-Südasiaten geführt wird, zur ersten Anlaufstelle für südasiatische Hindus in fremd-kultureller Umgebung, obwohl die Mehrheit der tamilischen Hindus sich einer anderen Hindu-Strömung zugehörig fühlt, was zeigt, wie wichtig den Akteuren ein religiöser öffentlicher Ort ist.

Der ISKCON-Tempel in Zürich stellte in den Anfängen der Migration eine besondere Kontaktzone dar. Es kam zu einer Umkehr der Machtverhältnisse zwischen südasiatischen und «westlichen» Devotees im religiösen Vollzug. Während der Inder Prabhupada in den Anfängen der ISKCON Menschen aus Europa und den USA in die Durchführung von Hindu-Praxis einführte, waren es nun «Westler», welche die südasiatischen Hindus in den Praktiken der ISKCON unterrichten.

Der Begriff der Kontaktzone nach Pratt zeichnet sich durch asymmetrische Machtverhältnisse aus: das konnte auch am Beispiel des Krishna-Tempels in Zürich gezeigt werden. In den Anfangsjahren waren Exklusions- 
tendenzen und eine paternalistische Haltung gegenüber den tamilischen Geflüchteten festzustellen. Des Weiteren sind Kontaktzonen durch interaktive Prozesse geprägt: Aushandlungsprozesse innerhalb der Organisationsstrukturen des Tempels haben zu strukturellen Veränderungen und der Gründung einer neuen Vereinigung, der Schweizerischen Tamilischen Krishna Gemeinschaft, geführt.

\subsection{Der Krishna-Tempel in Zürich: Gegenwärtige tamilische Hindu-Praxis am Zürichberg}

Die Etablierung der ISKCON in der Schweiz begann etwa zehn Jahre vor der Ankunft der tamilischen Hindus aus Sri Lanka. Als «fremde» religiöse Tradition war diese Bewegung zunächst mit ähnlichen Problemen im Prozess der Etablierung in der Schweiz konfrontiert wie die caivaitischen Hindus aus Sri Lanka. Die Inkorporationsbedingungen der Schweiz führten zu strukturellen Parallelen in der gesellschaftlichen Eingliederung; es lassen sich jedoch auch Unterschiede ausmachen, die in den unterschiedlichen Profilen der Gruppen begründet liegen. Die Suche nach Tempelräumen, welche von den Akteuren als angemessen für die Durchführung ihrer religiösen Praxis angesehen wurden, stellte in beiden Fällen eine Hürde dar. Beide Gruppen mieteten zunächst Räumlichkeiten mit begrenztem Umfang an, um Hindu-Praxis gemeinschaftlich durchzuführen, und sahen sich durch steigende Besucherzahlen mit dem Problem des Platzmangels konfrontiert. Die ISKCON wie auch die tamilischen Tempel-Verantwortlichen suchten daraufhin - auch um mehr Autonomie und einen weiteren Handlungsspielraum zu erlangen - nach grösseren Räumen, die im Idealfall käuflich erworben wurden. Des Weiteren sind in der rechtlichen Inkorporation der beiden Hindu-Gruppierungen ähnliche Tendenzen festzustellen: In beiden Fällen begannen sich die Gruppen als Verein zu organisieren und gingen nach einiger Zeit der Etablierung im Land teilweise zur rechtlichen Form der Stiftung über. ${ }^{266}$

Der erste ISKCON-Tempel wurde 1972 in einem gemieteten Haus in Petit-Lancy bei Genf eröffnet. 1973 schlossen sich krșna-Devotees als «religiöser und kultureller» Verein zusammen (Association internationale pour la conscience de Krishna). Der Tempel zog 1975 aufgrund von Platzmangel ins Château Banquet um; im selben Jahr eröffnete die ISKCON in der Deutschschweiz ein Zentrum. 1977 wurde das Zentrum in der Westschweiz

266 Die Schweizerische Stiftung für Krishna-Bewusstsein wurde 1980 gegründet. Daneben besteht auch der Verein Krishna-Gemeinschaft Schweiz. 
geschlossen und in Düdingen (Kanton Freiburg) wurde eine Bauernhofgemeinschaft eröffnet, welche bis 1983 bestand. Damit fand eine örtliche Verlagerung der Aktivitäten der ISKCON von der Westschweiz in die Deutschschweiz statt. 1980 wurde der bis heute bestehende Tempel in Zürich eröffnet (vgl. Meier 2010).

2010 bestanden neben dem Tempel in Zürich ein 2008 neu eröffneter Tempel in Langenthal und Zentren in Binningen sowie Muttenz bei Basel, Bern, St.Gallen und Locarno. Nach eigenen Angaben hat die ISKCON im Jahr 2008 in der Schweiz 120 Aktivmitglieder, die in den Zentren und Tempeln mithelfen. Daneben ist eine weitaus grössere Zahl an passiven Mitgliedern zu verzeichnen (vgl. Eulberg 2008). 2010 leben rund 250 ISKCONMitglieder in der Schweiz; ihr «Freundeskreis» wird auf mehr als tausend Personen geschätzt (vgl. Meier 2010, 24).

\section{Der Krishna-Tempel in Zürich}

Der Tempel der International Society for Krishna Consciousness (ISKCON) in Zürich ist ein Ort, an dem nicht-südasiatische wie auch südasiatische Anhängerinnen und Anhänger Hindu-Praxis vollziehen. Der Tempel wurde vor der ersten Phase der tamilischen Einwanderung in die Schweiz in einem geräumigen, sich im Besitz der ISKCON befindlichen Haus errichtet; tamilische Hindus fanden darin seit den 1980er Jahren einen permanenten Ort der Verehrung krșnas in der Schweiz. Der Tempel etablierte sich mit den Jahren innerhalb der hinduistischen Tempellandschaft der Schweiz zu einer festen Grösse. In einem historischen Rückblick wurden bereits die Aushandlungsprozesse innerhalb dieser Kontaktzone und die Hintergründe der Entstehung der Swiss Tamil Krishna Society vorgestellt. Im Folgenden wird der Tempel, ausgehend von der Perspektive seiner räumlichen Situierung, als «geteilter Ort» beschrieben, da er von Schweizern geleitet wird, jedoch auch Raum für distinkt «tamilische» Hindu-Praxis bietet.

1979 mieteten Krishna-Devotees eine kleine Wohnung im Zürcher Kreis 4 an, von der aus sie nach einer grösseren Räumlichkeit Ausschau hielten. Bereits 1980 kauften sie ein Haus in der Bergstrasse, welches heute den ISKCON-Tempel beheimatet. ${ }^{267}$ Die Kosten des Kaufes beliefen sich auf knapp eine Million Schweizer Franken, was durch Verkäufe (z.B. von Büchern und Kerzen) und einen Kredit finanziert wurde (vgl. Dasa 2010). Darüber hinaus musste die ISKCON ein grosses Mass an Eigeninitiative aufbringen, um das Gebäude zu renovieren und zu einem, im Sinne der religiösen Regeln der Gemeinschaft, «funktionsfähigen» Tempel umzu-

267 Die Kontaktdaten des Tempels lauten: Bergstrasse 54, 8030 Zürich. 
wandeln. ${ }^{268}$ Damit das Haus schnellstmöglich als Tempel genutzt werden konnte, erfolgte der Umzug der Bildgestalten des Tempels - in Gestalt von Jagannātha ${ }^{269}$ zusammen mit seinem Bruder Baladeva (oder Balarāma) und seiner Schwester Subhadrā - bereits im Jahr des Kaufs (vgl. Meier 2010, 18). Durch Mantren wurde das Gebäude von «unliebsamen 〈feinstofflichen〉 Energien geläutert» (vgl. Dasa 2010, 29). 2002 fand die Einweihung des jetzigen Altars statt. Ähnliche Praktiken zur «Tempelwerdung» eines zu einem anderen Zweck gebauten Gebäudes finden sich auch bei tamilischen Hindu-Tempeln in der Diaspora (vgl. Kap. IV 4).

Differenzen zu tamilischen Hindu-Tempeln in der Schweiz sind vor allem in der sozio-räumlichen Situierung des Tempels und im symbolischen Kapital des Gebäudes auszumachen. Innerhalb des Zürcher Stadtraums ist der Tempel relativ zentral in einer wohlhabenden, ruhigen Wohngegend gelegen und auch das Gebäude des Tempels ist prestigeträchtig. ${ }^{270}$ Die Patriziervilla wurde 1909 von der prominenten Zürcher Bankiersfamilie Julius Bär erbaut und steht unter Heimatschutz. Das von den Krishna-Devotees orange gestrichene Haus ist von alten Bäumen umgeben und an einem Hang gelegen. Aus Sicht vieler Besucher bietet es - obwohl es nicht als hinduistischer Sakralbau errichtet wurde - einen angemessenen Rahmen für den Vollzug von Hindu-Praxis (vgl. Abb. IV 2). Der Eingang wird rechts und links von Säulen umrahmt und ist von Efeu überwachsen. Über dem Eingangsportal ist in Grossbuchstaben «Hare Krishna Tempel» zu lesen. Durch die schriftliche Kennzeichnung als Tempel werden Passanten über den religiösen Charakter des Gebäudes informiert; die Säulen, die den Eingang umrahmen, unterstreichen - obwohl nicht als Element eines Sakralgebäudes errichtet - den sakralen Charakter des Hauses. Symbole aus der Tradition der Vaishnavas (tam. vainavam) an der Aussenseite der Villa zeigen an, dass das Gebäude in dieser Tradition steht: Auf dem Dach des Gebäudes, direkt über der Fassade, ist das aus dem indischen Bundesstaat Orissa importierte Sudarshana-Chakra (Krishnas Feuerrad) angebracht, welches vom 27. bis 29. Mai 2005 durch mehrere Priester feierlich installiert wurde. Wie aus der Webpräsenz der Gemeinschaft hervorgeht, war es ein

268 Im Laufe der Jahre wurde die Aussen- und die Innengestaltung des Gebäudes immer wieder verändert; neben der Erneuerung des Altars 2002 wurde beispielsweise 2006 das Dach des Hauses renoviert. Diese Angaben stammen aus dem am 05.12.2010 im Tempel vom Tempelpräsidenten gehaltenen Dia-Vortrag «30Jahre Krishna Tempel Zürich».

269 Da Jagannātha im indischen Puri (Bundesstaat Orissa) seinen wichtigsten Tempel hat, wird der Tempel in der Bergstrasse intern auch als New Jagannātha Puri Dhama bezeichnet.

270 Auf Wikipedia findet sich ein Eintrag zum Tempel. Dort ist zu lesen, dass seine «Schönheit häufig hervorgehoben wird» (de.wikipedia.org/wiki/Hare-Krishna-Tempel_Zürich; 27.06.2011). 


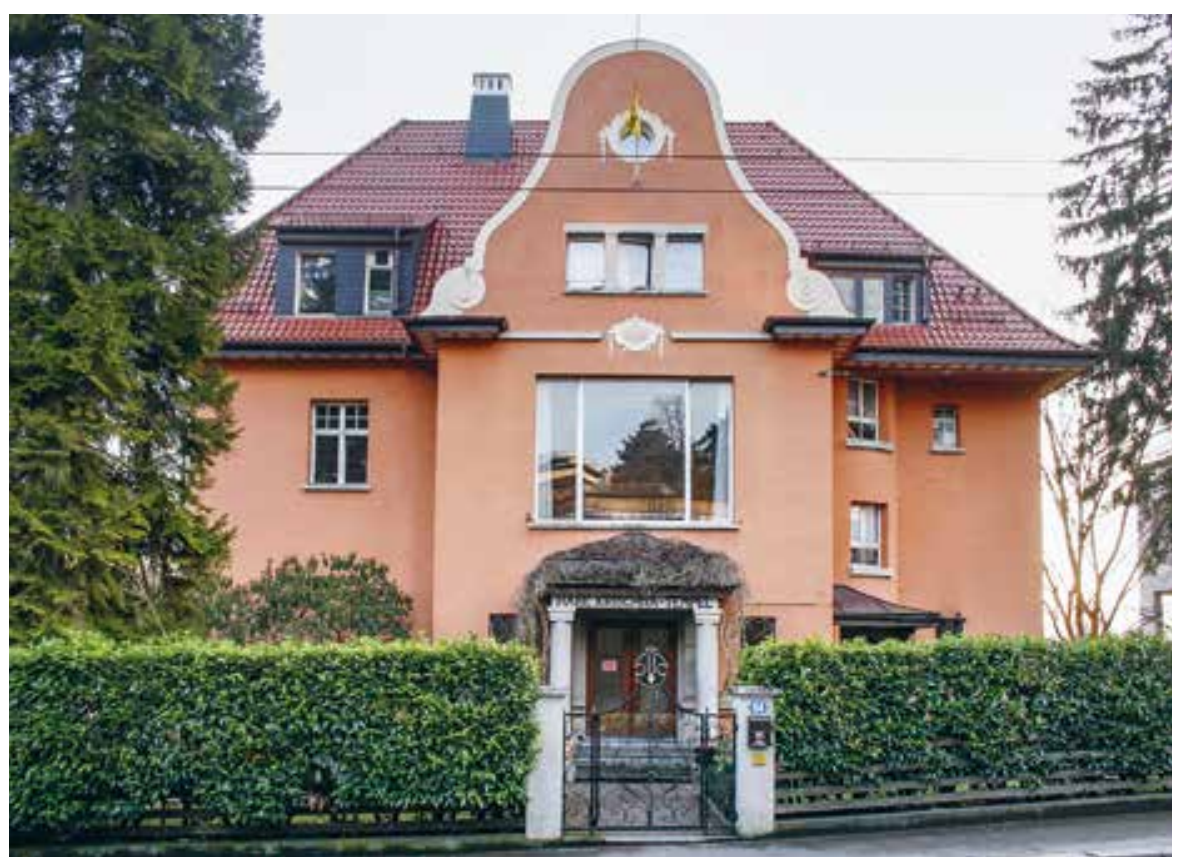

Abb. IV 2: Der Krishna-Tempel der ISKCON in Zürich (09.03.2008).

Ziel der Installation, die öffentliche Sichtbarkeit des Gebäudes als Sakralbau zu erhöhen (auch wenn es den meisten Passanten aufgrund seiner begrenzten Dimension nicht sofort auffällt) und den Besuchern spirituellen Schutz zu bieten.

Das vierstöckige Haus bietet Platz für unterschiedliche Aktivitäten, denen unterschiedliche Räume zugewiesen sind. Dazu zählen die Küche im Untergeschoss, eine Bibliothek, Unterrichtsräume, Mataji- sowie brahmacari-Ashram - die nach Geschlechtern getrennten Wohnbereiche für im Tempel lebende Personen -, ein Zimmer mit Waschraum für wichtige religiöse Spezialisten, die den Tempel besuchen, und der Tempelraum mit den Bildgestalten, der sich im Erdgeschoss der Villa befindet. Ein fliessendes Gewässer befindet sich in unmittelbarer Nähe des Hauses und wird in bestimmte Rituale eingebunden.

Im Gegensatz dazu steht die Situierung der meisten tamilischen Tempel im sozialen Raum der Schweiz. Diese sind in Gegenden mit kostengünstigeren Mietpreisen angesiedelt, die sich in der Regel als wenig prestigefördernd erweisen. Die Beheimatung von Tempeln in Industriehallen und Gewerbequartieren kann als Indikator für eine niedrige Stellung der Migrantenreligion innerhalb der Schweizer Mehrheitsgesellschaft gedeutet 


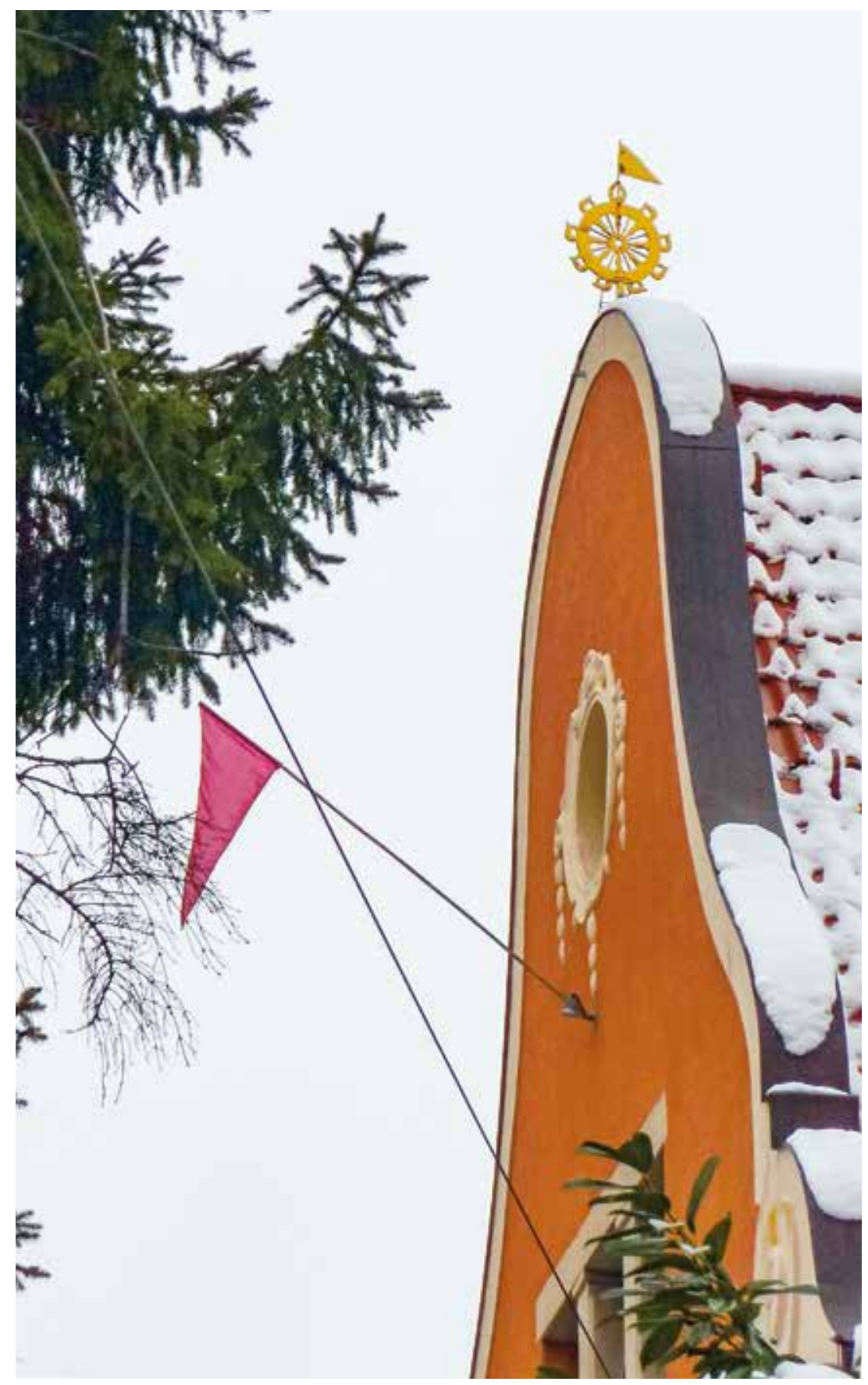

Abb. IV 3: Krishnas Feuerrad (Sudarshana Chakra) auf dem Dach des KrishnaTempels der ISKCON in Zürich (05.12.2010) 
werden, und auch tamilische Besucher äussern ihre Unzufriedenheit mit diesen Lokalitäten (vgl. Kap. IV 4).

Der Grad der Zufriedenheit mit den vorhandenen Räumen kann auch in divergierenden Zuschreibungen und Ansprüchen begründet liegen, welche Akteure beider Gruppen an ihre Sakralbauten herantragen. Während viele tamilische Hindus durch einen prestigeträchtigen Tempel eine «heimatliche» Sphäre rekonstruieren wollen, legen die Schweizer Krishna-Devotees den Schwerpunkt auf die innerliche Haltung der einzelnen Praktizierenden und weniger auf die äusserliche Gestaltung des Ortes der Praxis. ${ }^{271}$ Die Tempel-Verantwortlichen der ISKCON betonen, dass das Äussere des Tempels im Verhältnis zu den im Inneren vollzogenen Handlungen weitaus weniger wichtig sei. Sie zeigen sich mit dem Tempelgebäude zufrieden, da zum einen das Sudarshana Chakra das Gebäude als religiöses ausweist, und sich zum anderen die Gemeinschaft darüber bewusst sei, dass ein TempelNeubau die vorhandenen Ressourcen übersteigen würde. Tamilische Devotees, die dem ISKCON-Tempel verbunden sind, argumentieren ähnlich. Nirmal Krishna Dasa, Gründer der Swiss Tamil Krishna Society, merkt an, dass er sich der Diaspora-Situation bewusst sei und daher andere Massstäbe an einen religiösen Ort als in seinem Herkunftsland Sri Lanka habe. Darüber hinaus verweist er auf religiöse Schriften als Legitimation für die Haltung der ISKCON, welche ihre Tempelbesucher anweisen, die vorhandenen Ressourcen eher für die «spirituelle Vervollkommnung» der einzelnen Devotees als für die Verbesserung der äusserlichen «Hülle» des Tempels zu nutzen. ${ }^{272}$ Hier ein Auszug aus dem Experteninterview, welches am 05.12.2010 im Krishna-Tempel in Zürich mit Nirmal Krishna Dasa geführt wurde: ${ }^{273}$

Here we cannot expect like Indian style / that is normally in other temple also like this / they buy garage / or something / and inside they build/make a / like a temple. To build a temple is not important for us / that is the outside. We have to look in the inside. Shastras say: < Nowadays is waste the time/don't waste your time building a temple / you have to build inside.>

Die Geschichte des Ortes, seine Trägerschaft und die rituelle Praxis, welche im Tempel vollzogen wird, unterscheidet sich vom Gros der selbstverwalte-

271 Die äusserlichen Unterschiede der tamilischen Tempel zum ISKCON-Tempel machen daher in besonderem Masse den Mangel an Ressourcen der in den Tempelvereinen engagierten tamilischen Akteure deutlich.

272 An dieser Stelle sei auf die Tempelgrossbauten der ISKCON in London und anderen Orten in Indien wie auch ausserhalb Südasiens hingewiesen, welche diesem Deutungsmuster entgegenstehen.

273 Die folgenden englischsprachigen Gesprächs-Zitate stammen aus dem Interview mit ihm. 
ten tamilischen Tempel. Diese Differenz wird auch immer wieder von tamilischen Hindus artikuliert. Darüber hinaus wird auch die Atmosphäre im Krishna-Tempel als abweichend von der in tamilischen Tempeln wahrgenommen. Der tamilische Hindu Murari, der tamilisch-traditioneller Tempel-Praxis kritisch gegenübersteht, betont im Interview am 04.12.2008, dass im Krishna-Tempel «so mehr Meditation» sei:

Ich war noch in dem Tempel in Zürich. Weisst du/Hare Rama/Hare Krishna. [...] Dort habe ich gefühlt so ein glie anders als in diesen Tempeln. Anders / so mehr Meditation/in diesem Stil. Für mich ist das schon glie mehr akzeptabel als do hier oder Adliswil oder Root.

Die Beschreibung dieser Demarkationslinie geht oftmals mit einer positiven Bewertung des Zürcher Tempels einher. ${ }^{274}$ Diese Haltung gegenüber dem ISKCON-Tempel durch tamilische Akteure weist Parallelen zur Wahrnehmung von ISKCON-Tempeln in Indien durch südasiatische Besucher auf. Frank Neubert beschreibt dies für den innerhalb der ISKCON bedeutsamen Sri Krishna Balarama Tempel in Vrindavan: «The main reason to visit the temple (in Vrindavan) is to experience a very clean, orderly and wellmanaged temple» (Neubert 2010b, 83).

\section{Getrennte Sonntagsfeste}

Eine Besonderheit innerhalb des ISKCON-Spektrums stellt die Tatsache dar, dass im Zürcher Tempel zwei Sonntagsfeste nacheinander stattfinden. ${ }^{275}$ Zur Praxis aller ISKCON-Tempel gehört das so genannte Sonntagsfest, welches allen Interessierten offensteht. Primäres Ziel ist die «Verbreitung von Krishna-Bewusstsein»; daher kann dieser Anlass auch als Teil der Öffentlichkeitsarbeit der ISKCON angesehen werden (vgl. Neubert 2010a, 92) auf der Webpräsenz des Krishna-Tempels Zürich wurde explizit für diesen Anlass geworben.$^{276}$ Dieses öffentliche Fest, zu dem alle Interessierten eingeladen sind, findet jeden Sonntag um 15 Uhr im Zürcher Tempel statt. Das Fest beginnt mit bhajan-Musik und sankirtan (das öffentliche Chanten der Namen Krishnas) gefolgt von ārati (der Lichtzeremonie) und einem Vortrag, in dem Bhagavadgìtā-Texte interpretiert werden, an den eine Diskussion anschliesst, in welcher die Zuhörer Fragen zum Vortrag stellen kön-

274 Sekar $(2001,179)$ beschreibt ähnliche Tendenzen auch innerhalb der tamilischen community in Kanada.

275 Im ISKCON-Tempel in Dallas/USA wurden ebenfalls separate Feste für «Westler» und aus Asien migrierte Menschen durchgeführt (vgl. Rochford 2007, 198). Mir sind keine weiteren Tempel der ISKCON bekannt, welche dies ebenso handhaben.

276 Vgl. http://krishna.ch/sonntag.html (01.08.2010). 
nen. Das Fest endet mit dem gemeinsamen Essen vom Priester geweihter Speisen, tam. prasādam (skr. prasāda). Anschliessend findet eine vedische Tempelzeremonie und bhajan-Singen statt.

Vor diesem beworbenen Anlass findet im Zürcher Tempel das tamilische Sonntagsfest statt, welches um $12 \mathrm{Uhr}$ mittags beginnt und einem ähnlichen Ablauf wie das «offizielle» Fest folgt. ${ }^{277}$ Die Grenzen zwischen den zwei Besuchergruppen sind fliessend. Sie überlappen sich teilweise, was Austauschprozesse unter den Gruppen fördert. Einige Devotees nehmen an beiden Festen teil: Tamilen besuchen auch das «normale» Sonntagsfest; und auch westliche Devotees und Inder, die tamilisch verstehen, nehmen am tamilischen Anlass teil. ${ }^{278}$

Auf der Diskursebene stellt die Differenzierung in «normales», nicht spezifisch bezeichnetes und «tamilisches» Sonntagsfest gemäss ethnischer und sprachlicher Zugehörigkeit eine Kategorisierung von Krishna-Verehrenden dar. Sie zementiert den Diskurs der Differenz zwischen tamilischen und «westlichen» Besuchern wie auch seine Wirkmacht. Dieser symbolische Akt der Grenzziehung trägt entscheidend zur Herstellung abgetrennter Gruppen bei.

Folgende Ausschnitte meines Besuchsprotokolls vom 05.12.2010 beschreiben einige beim tamilischen Sonntagsfest vollzogene Praktiken:

Im Eingangsraum des Tempels herrscht geschäftiges Treiben; Menschen stellen ihre Schuhe ab, hängen ihre Jacken auf und unterhalten sich. Einige schauen sich die Verkaufsgegenstände an, die im Eingangsbereich hinter einer Theke liegen. Rechts vom Eingangsraum befinden sich in einer Ecke Waschbecken. Mehrere Besucher stehen vor den Spiegeln; ein Junge hält einen Becher mit Sandelholzpaste, in welchen die Umstehenden einen Finger tauchen und sich damit eine senkrechte Linie von der Stirn bis zur Mitte der Nase auftragen. ${ }^{279}$ Die Kinder lachen dabei und die Stimmung wirkt auf mich gelöst. Hinter dem Eingangsbereich betritt man durch eine Holztür den Tempelraum. Im Raum sitzen circa 80 Personen auf dem Boden, meist auf Kissen, mit dem Gesicht zu den Bildgestalten. Mein Blick wandert nach rechts vorne zum Altar. Auf der rechten Seite des geöffneten Tors des Altars mit den Bildgestal-

277 Auf der Webpräsenz des Tempels wurde 2010 nicht auf diesen Anlass verwiesen.

278 «Westliche» Besuchende des tamilischen Festes berichten von einer besonderen Anziehungskraft, welche dieser Anlass auf sie ausübe. Die zusätzlichen rituellen Elemente werden als Differenzmerkmale zum «normalen» Sonntagsfest genannt. Eine mataji erzählte mir am 05.12.2010, dass sie die Buntheit und die zusätzlichen in die Rituale integrierten materiellen Elemente wie Blumen, Obst und Kokosnüsse sehr ansprechend finde.

279 Dabei handelt es sich um das spezifische Tilak der Vaishnavas, welches diese im Tempel in Zürich in unterschiedlicher Form auftragen. 
ten hängt ein Banner, auf dem Krishna und Radha abgebildet sind und ein Text in tamilischen Buchstaben steht; auf der anderen Seite des Torflügels hängt ein Schild mit dem transkribierten lateinischen Text des mahāmantra: Hare Krisna, Hare Krisna, Krisna, Krisna, Hare Hare. Hare Rāma, Rāma Rāma, Hare Hare. Die Statue Prabhupādas auf der anderen Seite des Raumes trägt eine Mütze. Die Gruppe der Sitzenden teilt sich durch einen Durchgang, der von der Statue Prabhupādas in Richtung der Bildgestalten führt. Vom Eingang aus gesehen rechts sitzen Männer; links und in den hinteren Reihen Frauen. Besucher aller Generationen sind anwesend: Kinder laufen im Raum hin und her. Die meisten Besucher, die den Raum betreten, knien vor der Figur Prabhupādas nieder oder strecken ihren Körper vor ihm aus.

Das Sonntagsfest beginnt mit dem Singen des mahämantra, welches von einem westlichen Devotee am Harmonium geleitet wird, der links an der Wand des Raumes sitzt. Alle chanten das Hare Krishna-Mantra, viele klatschen dazu im Rhythmus und benutzen Instrumente - wie Zimbeln, Tamburin, Harmonium und Trommeln. Während des Singens der bhajans verteilt ein Junge Werbekarten, welche auf der Vorderseite den jungen Krishna und auf der Rückseite Informationen in tamilischer Sprache zu krishnayoga.ch geben. Während die Devotees singen, beginnt ein Priester - der, wie mir später ein Devotee erzählt, aus Brasilien stammt, - ārati hinter der Absperrung bei den Bildgestalten durchzuführen. Mir fällt auf, dass sein rechter Oberarm tätowiert ist. Er bläst ein Muschelhorn, zündet Räucherstäbchen und danach Lampen an, die er vor den Bildgestalten schwenkt. Danach übergibt er die Lampe einem tamilischen Mann, der mit dieser durch die Reihen der sitzenden Besucher geht. Diese halten die Hände über das Feuer und führen diese dann zum Gesicht. Danach geht er mit einer Schale Wasser herum und spritzt Wassertropfen auf die Köpfe der Besucher.

Ein Kennzeichen des tamilischen Sonntagsfestes ist, dass nicht-asiatische Devotees mehr rituelle Handlungen ausführen als südasiatische Devotees. Die Priester, welche ārati durchführen, wie auch jene Devotees, welche den anschliessenden Vortrag halten, sind meist keine Tamilen. Differenzen zum offiziellen Sonntagsfest sind in der Sitzrichtung der Devotees auszumachen, welche beim tamilischen Anlass mit Blickrichtung nach vorne zu den Bildgestalten ausfällt, während des zweiten Festes jedoch mit Blick zu den Musikern, also zur Seite. Ausserdem sitzen beim tamilischen Fest Frauen und Männer in Gruppen getrennt, was beim «westlichen» Fest nicht der Fall ist. Diese Aufteilung des Raumes als gendered space stellt eine Parallele $\mathrm{zu}$ «caiva-tamilischer» Tempelpraxis dar. Auffallend ist, dass die Besuchergruppe beim tamilischen Fest generationenübergreifend zusammengesetzt ist, während beim «Schweizer Fest» wenige Kinder oder ältere Menschen anwesend sind. 


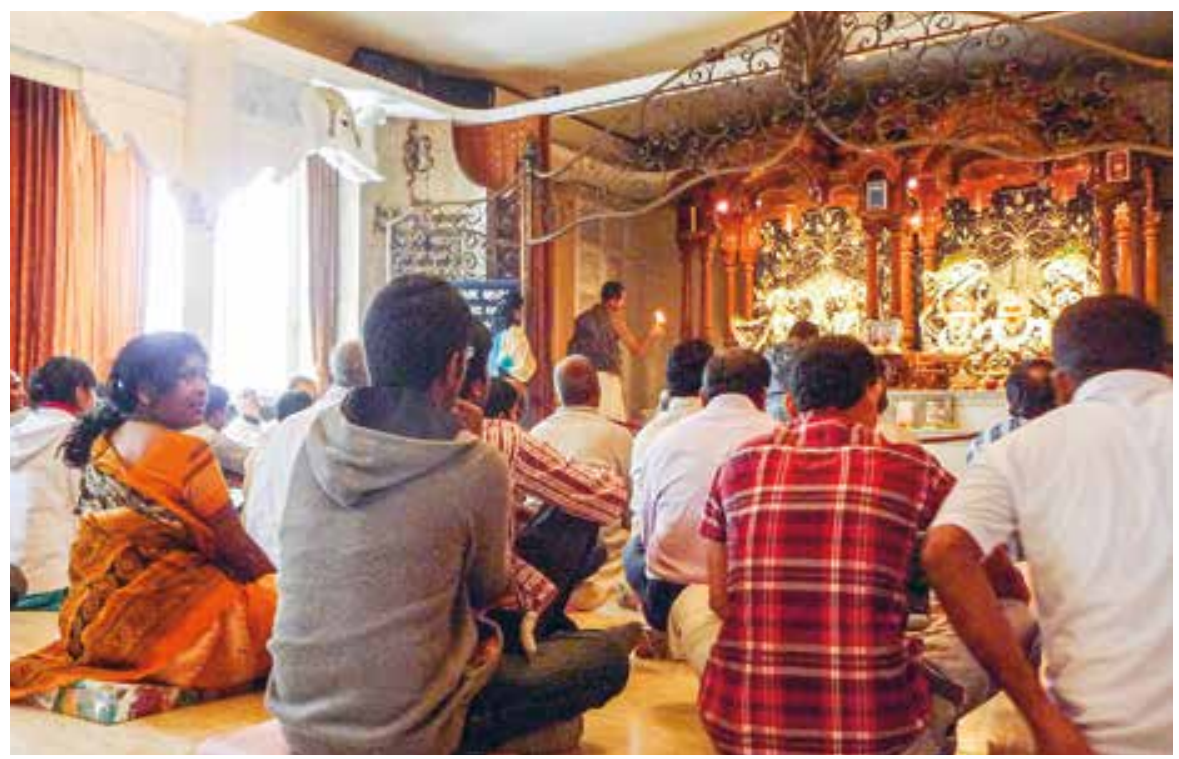

Abb. IV 4: Das tamilische Sonntagsfest im Krishna-Tempel der ISKCON in Zürich (5.12.2010).

Nach dem rituellen Teil folgt der Vortrag. Parallel dazu organisiert die Swiss Tamil Krishna Society (STKS) speziell für tamilische Kinder Religionsunterricht. Da anders als zum «Schweizer» Sonntagsfest unterschiedliche Generationen und auch viele Kinder den Anlass besuchen, ermöglicht dieses Angebot den Eltern, der Lecture in Ruhe zu folgen, ohne auf ihre Kinder aufpassen zu müssen. Die Kinder bekommen auf ihr Alter zugeschnittene Geschichten aus der Bhagavadgìtā in tamilischer Sprache vermittelt, lernen religiöse Lieder und malen religiöse Motive:

Im Bibliotheksraum sitzen sechs tamilische Kinder um einen grossen Tisch, auf dem Stifte und Blätter liegen. In der Mitte liegt eine Ausgabe der Bhagavadgita. Eine Frau betreut die Kinder und begrüsst mich freundlich. Die Kinder zeichnen, indem sie vorgegebene Zahlen der Reihe nach verbinden, ein Sanskrit-Aum, welches sie anschliessend in bunten Farben ausmalen. Unter dem Aum ist zu lesen: "In the holy scriptures can be found, this holy transcendental sound." ${ }^{280}$

Nach dem Vortrag folgt das gemeinsame prasādam. Dieses unterscheidet sich vom prasādam des danach folgenden Sonntagsfestes durch schärfere und speziell tamilische Speisen (wie beispielsweise pājacam, ein in der

280 Auszug aus meinem Besuchsprotokoll des tamilischen Sonntagsfestes am 05.12.2010. 
tamilischen Küche beliebter süsser Reispudding). Das Essen wird auf Edelstahlplatten serviert und gemeinsam auf dem Boden sitzend eingenommen; die Besucher essen mit den Händen. Nach dem Essen bringt jeder den Teller zum Spülen in die Küche ins Untergeschoss. Mandali Bhadra Prabhu, ein Schweizer Devotee, berichtet über diese Neuerung:

Jetzt gibt es tamilisches Essen/es gibt eine tamilische Zeremonie/es gibt einen tamilischen Vortrag/damit man spezifisch auf die Leute eingeht. Das war der Grund. Das Essen wird von Tamilen gekocht/im tamilischen Style. Man muss sich ein bisschen wohl fühlen [...]. ${ }^{281}$

\section{Hintergründe der Einführung eines spezifisch tamilischen Sonntagsfestes}

Die Einführung des tamilischen Sonntagsfestes ist ein Ergebnis von Aushandlungsprozessen Ende der 1990er Jahre. Zentraler Grund dafür, dass das Fest 1997 geteilt wurde, war die zunehmende Besucherzahl und der damit einhergehende Platzmangel. Ausserdem sollte ein Anreiz für die Besucher geschaffen werden, nicht nur zur pūcai, welche mittags stattfindet, zu kommen, sondern auch dem Vortrag des Sonntagsfestes zu folgen. Dieser ist ein wichtiges Element der Weitergabe der Lehre der ISKCON. Nirmal Krishna Dasa berichtet über die Hintergründe:

And after that more Tamil people come/we don't have enough space. This is little and also some people come for 12 o'clock arti. 12 o'clock is more everyday/Sundays / there is puja. There come many people for the 12 o'clock puja and they leave quickly and they don't stay til 3 o'clock. After one of the devotees/he said: <Why we not start/we not do on 12 o'clock? >. And we change this/for everybody more easy. After six years from the start of the society/ 1997 like this.

Mandali Bhadra nennt als weiteren zentralen Grund für die Trennung der Gruppen beim Sonntagsfest die unterschiedlichen Bedürfnisse von tamilischen und «westlichen» Devotees:

Weil die meisten Tamilen sind ja religiös / aber jetzt nicht unbedingt spirituell. Sie kommen in den Tempel, weil sie eine gute Familie wollen/sie kommen in den Tempel, weil sie reich sein wollen, weil sie glücklich/happy sein wollen. Der Schweizer oder Westler kommt hierher, weil er eine spirituelle Erfahrung will. Daraus hat sich etabliert, dass es ein tamilisches Sonntagsfest gibt. Ein Fest für alle würde den Rahmen sprengen und es geht nicht individuell auf die Leute ein.

281 Diese und die folgenden Zitate von Mandali Bhadra Prabhu stammen aus dem Experten-Interview geführt am 09.03.2008 im Krishna-Tempel in Zürich. 
Mandali Bhadra verwendet hier die Topoi «religiös» und «spirituell»als Gegensatzpaar und schreibt tamilischen und nicht-tamilischen Devotees unterschiedliche Bedürfnisse zu: den tamilischen Besuchenden «religiöse» und den als westlich klassifizierten «spirituelle» Beweggründe, welche sie dazu veranlassen, das Sonntagsfest zu besuchen. Tamilen würden eher vor dem Hintergrund materieller und die Familie betreffender Bedürfnisse die Rituale im Tempel besuchen; spirituelle, innerliche Interessen werden primär der Gruppe der «westlichen» Devotees zugeschrieben. Da die ISKCON den hier als «spirituell» bezeichneten Anliegen im Vergleich mit den materiellen Wünschen gemäss der ihr zugrundeliegenden philosophischen Ausrichtung einen höheren Stellenwert zumisst, kann implizit eine Abwertung der hier als «Bedürfnisse der Tamilen» gezeichneten Punkte angenommen werden, die als Ausdruck eines «Verhaftetseins im Weltlichen» gedeutet werden können. Akteure mit spirituellen Bedürfnissen werden als auf einer höheren Stufe stehend eingeordnet als jene, die weltlich orientiert sind. Die Gegenüberstellung der Bedürfnisse der «westlichen» und «tamilischen» Devotees steht im Gegensatz zu Prabhupādas Beschreibung des Verhältnisses des «Westens» zu Indien. Im Anschluss an die vorherrschende Interpretation dieser Beziehung Mitte des 19. Jahrhunderts versteht Prabhupāda den indischen Kulturraum als von «spirituellen Werten» geprägt, während der westliche Kulturraum aus Gesellschaften bestehe, welche den Zugang zur Spiritualität verloren und primär dem Materiellen zugewandt seien (vgl. Neubert 2010b, 79). Es stellt sich die Frage, ob in den Diskursen der ISKCON zur Differenz von westlichen und südasiatischen Devotees ein Wandel stattgefunden hat, oder - und das erscheint aufgrund der speziellen Situation der Migrantinnen und Migranten innerhalb dieser Kontaktzone wahrscheinlicher - Devotees in Indien anders wahrgenommen werden als tamilische Devotees, die als Geflüchtete in fremd-kultureller Umgebung leben.

\section{Krishnaness und Tamilness: Besonderheiten der STKS und ihres Sonntags- festes}

Die Swiss Tamil Krishna Society und das «tamilische» Sonntagsfest als Ausdruck einer spezifisch tamilisch konnotierten Praxis zeichnen sich durch Besonderheiten im Vergleich zur Krishna-Gemeinschaft Schweiz und zum «Schweizer» Sonntagsfest aus. Gemeinsam ist den beiden Organisationen die Bezogenheit auf Krishna, dessen Verehrung zentraler Bestandteil der religiösen Praxis ist. Die STKS betont über die Krishnaness hinaus die Tamilness $^{282}$ der Organisation. Wie auch für andere tamilische Organisationen in der Schweiz spielen für diese distinkt tamilische Gruppe innerhalb

282 Zum Begriff der Tamilness, der Tamilbezogenheit, vgl. das Fazit dieser Studie. 
der Hare-Krishna-Bewegung und ihre Praktiken (A.) die tamilische Sprache, (B.) die Pflege spezifischer tamilischer Traditionselemente wie auch (C.) die transnationale Vernetzung der Diaspora-Tamilen und der Rückbezüge zum Herkunftsland eine wichtige Rolle.

\section{A. Die Bedeutung der tamilischen Sprache}

Damit tamilische Migrantinnen und Migranten Zugang zum Tempelgeschehen der ISKCON finden können, nennt Nirmal Krishna Dasa als zentrale Voraussetzung und als Beweggrund zur Gründung der STKS den Aspekt der Herkunftssprache. Die Sprache nimmt eine Schlüsselrolle in der Vermittlung religiöser Inhalte ein

Why did you start your own society? Because we cannot join/the problem is mainly the language/mainly language. Most of the Tamil people at that time could not speak well Deutsch and most of the Tamils also English not well. And I have the media and the Tamils/you know/they/anyway/they like through the Tamil language/that is why I started that society.

Durch die Formulierung "the Tamils/you know/they/anyway/they like through the Tamil language" spielt er darauf an, dass viele Tamilen die eigene Sprache als eigenständiges Kulturgut besonders wertschätzen. In den Anfängen bewirkte die tamilische Sprache, dass eine Verbindung zwischen tamilischen Hindus und dem ISKCON-Tempel hergestellt werden konnte. Durch die Verwendung der tamilischen Sprache wurden ihnen wichtige Informationen zur Verfügung gestellt und eine heimatliche Atmosphäre geschaffen.

Very less people visited here. The problem is the language that is the problem. And I visit the temple here and I know here is not any details about the temple/about the philosophy/not in Tamil language. And after that I thought myself/I want to translate/in Tamil/from English to Tamil/and distribute the details and all things in Tamil.

In der Tempel-Praxis kommt Übersetzern eine besondere Bedeutung zu, die in engem Kontakt zur Schweizer Tempelleitung stehen und bei religiösen Anlässen ins Tamilische übersetzen. Diese Akteure können mit Ballard als skilled cultural navigators im engeren Sinne bezeichnet werden, die durch sprachliche wie auch soziale Kompetenzen zwischen dem kulturellen Kontext des Herkunfts- und des Residenzlandes vermitteln (vgl. Ballard 1994, 31; Vertovec 2000, 158f.). Die STKS führte dieses Übersetzungsangebot beim tamilischen Sonntagsfest und spezifischen Anlässen im ISKCONTempel in Zürich ein. Die Übersetzer übernehmen hier wichtige Funktionen, indem sie Ansprachen oder den Vortrag des Sonntagsfestes, in welchem «Gottgeweihte» Stellen der Bhagavadgìtā auf den gegenwärtigen 
Kontext hin interpretieren, ins Tamilische übertragen. Zur Verdeutlichung folgt ein Auszug aus meinem Beobachtungsprotokoll vom 05.12.2010:

Die Anwesenden beenden das gemeinsame Musizieren, als ein westlich aussehender Krishna-Devotee an der linken Wand des Raumes auf einem Sitz Platz nimmt. Rechts neben ihn setzt sich ein tamilisch aussehender Mann mit dem Gesicht zu den Besuchern. Der erhöht Sitzende rückt das vor ihm stehende Mikrophon zurecht und begrüsst die Anwesenden auf Englisch mit starkem südasiatischem Akzent. Die Besucher rücken ihre Sitzposition so zurecht, dass sie nun nicht mehr mit Blickrichtung zu den Bildgestalten sitzen, sondern den Vortragenden anschauen. Ein tamilischer Junge und ein Mann gehen durch die Reihen und verteilen tamilische Ausgaben der Bhagavadgitā. Der Sprecher rezitiert auf Sanskrit Kapitel 7 der Bhagavadgitā "Knowledge of the Absolute”. Danach liest er die Stelle auf Englisch vor. Er schaut zu dem neben ihm sitzenden Mann. Ich frage meinen Sitznachbarn, wer dieser ist. Er antwortet mir, dass es der Präsident der Swiss Tamil Krishna Society sei. Dieser übersetzt die Bhagavadgitā-Stelle ins Tamilische. Danach erklärt der westliche Devotee die Stelle. Nach einigen Sätzen stoppt er und der tamilische Devotee übersetzt. Dieses Wechselspiel dauert circa eine Dreiviertelstunde lang.

Neben der mündlichen Übersetzung wird während des Vortrags innerhalb des Sonntagsfestes auch die Bhagavadgìtā in tamilischer Sprache verteilt. Die Bibliothek des Tempels enthält einen Bestand mit tamilischen Büchern, wie eine tamilische Tempelbroschüre, Werke Prabhupādas in tamilischer Sprache und tamilische Kochbücher. Die Bedeutung der tamilischen Sprache hat auch Auswirkungen auf die Tempelökonomie. Verschiedenste ISKCON-Bücher in tamilischer Sprache können im Tempel erworben werden; jeweils an Sonntagen wird links neben dem Eingang ein Verkaufstisch der STKS mit tamilischen Büchern aufgestellt.

\section{B. Pflege spezifischer tamilischer Traditionselemente}

Durch die tamilischen Besuchenden kam es zu Ritualinnovationen im Zürcher Tempel der ISKCON, indem Elemente aus der tamilischen Tradition in die Praxis der Hare Krishna-Bewegung implementiert wurden. Dabei handelt es sich um Ritualtransfer von einer speziellen Hindu-Tradition in eine andere. ${ }^{283}$ Nachdem der Gründer der IKSCON, Prabhupāda, Praktiken der Vaiṣnava-Tradition an die Bedürfnisse seiner «westlichen» Schüler angepasst hatte, wurden die Praktiken im ISKCON-Tempel nun gemäss den Bedürfnissen der südasiatischen Devotees erneut adaptiert. So werden bei-

283 Für den Transfer von ISKCON-Praktiken aus dem Westen zurück nach Südasien vgl. Neubert 2010b. 
spielsweise nur beim tamilischen Sonntagsfest während des ārati Kokosnüsse dargebracht; ansonsten ist diese Praktik innerhalb der ISKCON unbekannt. Dazu aus meinem Besuchsprotokoll vom 05.12.2010:

Ein tamilischer Mann schlägt Kokosnüsse vor dem Altar mit den Bildgestalten in zwei Hälften und lässt das Wasser in einen Eimer laufen. Vereinzelt stehen Frauen auf und bringen Plastik-Körbe mit Bananen, anderen Früchten und Kokosnusshälften nach vorne. Unter dem Korb liegen gelbe Zettel mit Wünschen, welche der Priester entgegennimmt und betrachtet.

Mandali Bhadra nennt als Grund für die Ritualinnovation den Aspekt des «sich zu Hause Fühlens» und verweist damit auf die Diaspora-Situation. Der Tempel soll ihnen Heimat in der Fremde werden; daher gehen die ISKCONDevotees besonders auf die tamilischen Besucher ein und integrieren Elemente aus deren Herkunftstradition. Die neu eingeführten Rituale werden dann im Sinne der ISKCON gedeutet und durch diese Bedeutungszuschreibung in die Tempel-Praxis der Krishna-Bewegung integriert. Zur Einführung des innerhalb tamilischer Tempel wichtigen Rituals arccanai - einem personenbezogenen Ritual, in dem der Gottheit Opfergaben dargebracht werden und dessen Umdeutung durch die ISKCON berichtet Mandali Bhadra:

Und bei den Zeremonien gibt es Kokosnüsse/das macht niemand hier bei den westlichen ISKCON-Leuten. Noch nicht mal/in unserer Bewegung ISKCON gibt es das gar nicht. Aber ich habe das gekannt von Süd-Indien und ich habe gemerkt/die fühlen sich da zu Hause/ und daher machen wir das. Die Kokosnuss / die Schale sind wir und wir wollen das reine Innere Krishna opfern/ das ist das Wasser. Das ist eigentlich eine Gabe, die wir zu Krishna geben. Shiva ist es nicht, denn wir hauen ja nicht Shiva den Kopf ab. Man nennt es arccena/ eine Darbietung. Aber es gibt sie in unserer Tradition nicht in dieser Art und Weise. Für die Tamilen ist die arccena das Wichtigste und bei uns ist es einfach ein Teil vom Ganzen. Sie kommen in den Tempel und dann wird der Name dem deity gesagt/ und das gibt es bei uns auch nicht/dass die einzelnen Familien die Schalen bringen/das gibt es bei uns auch nicht in dieser Art und Weise. ${ }^{284}$

Neben der Einführung von arccanai, dem Darbringen von Kokosnüssen und der Körbe mit Obst und dem beiliegenden Zettel im Rahmen des Sonntagsfestes finden innerhalb des Tempels weitere rituelle Neuerungen durch die tamilischen Besucher statt. Auch die Figuren der innerhalb der CaivamTradition wichtigen Götter Murukañ, Civann und Gaṇeśa, die im an den Tempelraum anschliessenden Zimmer stehen, in welchem u. a. gegessen wird, werden von den tamilischen Besuchern verehrt. Obwohl sie nicht als

284 Interview 7; 09.03.2008. 
mūrttis in die pūja im Tempel eingebunden sind, werden ihnen Gaben dargebracht, wie Blütenblätter und Ketten, die ihnen umgelegt werden.

Spezifisch tamilische Feste, welche innerhalb der ISKCON nicht gefeiert werden, werden von Tamilen im Hare Krishna-Tempel begangen - wie beispielsweise die Samstage für den Gott Sani und auch taipponkkal (vgl. Abschnitt IV 5). Viele tamilische Besucher gaben wichtigen tamilischen Festen den Vorrang vor wichtigen ISKCON-Festen.

Mandali Bhadra weist auf anfängliche kontroverse Diskussionen bezüglich der Ritualinnovationen hin. Er merkt an, dass ein Beweggrund für die Eingliederung «tamilischer» Ritualelemente die schwindende Besucherzahl im Tempel war. Daher war man auf «die Tamilen» angewiesen und versuchte den Tempel für diese attraktiv zu machen. Neben kritischen Stimmen fanden die Tamilen in Mandali Bhadra einen Fürsprecher für ihre Anliegen:

Innerhalb der ISKCON gab es Diskussionen. Es gibt immer so Leute, die sind sehr konservativ. Ich bin da ein bisschen offen/denke, was immer wir Krishna opfern können/sollen wir tun. Ob das nun von unserer bengalischen Tradition her kommt oder nicht/weil ich finde das immer so ein bisschen kleinbürgerlich. Ich war da ein bisschen der Vorreiter / ich habe gesagt, das machen wir, das ist nicht gegen unsere Tradition und da fühlen sie sich zu Hause. Es

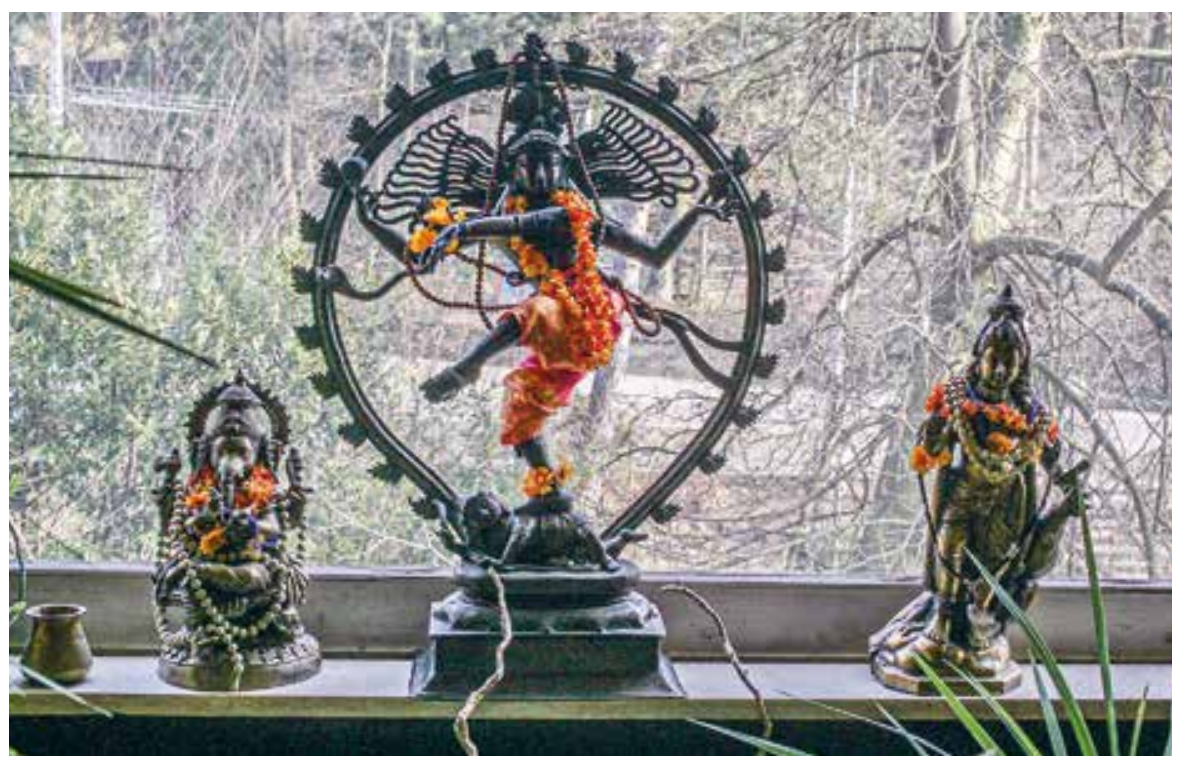

Abb. IV 5: Die Statuen von Murukañ, Civan und Ganeśa im Krishna-Tempel in Zürich (09.03.2008). 
war auch etwas motiviert/das muss ich ganz ehrlich sagen: Weil ich habe gemerkt, dass in der Zeit als ich hier war, da waren 100 Leute hier. Und dann haben sie geheiratet, gingen raus, mussten arbeiten und gingen ihren Weg. Die Tamilen kamen aber trotzdem jeden Sonntag. Und da habe ich gedacht, wir müssen die behalten/die sind wichtig für uns.

\section{Transnationale Vernetzungen und Rückbezüge zum Herkunftsland}

Neben der Bedeutung der tamilischen Sprache und der Einführung neuer ritueller Elemente in die Tempelpraxis zeichnen sich die Aktivitäten der STKS durch transnationale Vernetzungen und Rückbezüge zu Sri Lanka aus. Die im Zürcher Tempel angesiedelte tamilische Gesellschaft initiierte einen transnationalen Zusammenschluss tamilischer Krishna-Devotees und gründete am 05.08.2006 im Pariser ISKCON-Tempel, dem Sri Sri Radha Parisisvara Tempel, die International Tamil Krishna Society. ${ }^{285}$ Somit übernehmen Diaspora-Akteure eine zentrale Rolle in der Vernetzung tamilischer ISKCON-Devotees. Die beteiligten Akteure stammen aus wichtigen Ländern der tamilischen Diaspora. Die Aktivitäten dieser internationalen Gesellschaft reichten auch ins Herkunftsland zurück, indem sie aus der Diaspora heraus Sakralräume der ISKCON in den tamilischen Gebieten Sri Lankas zu etablieren versuchte.

Die Verbundenheit mit der Herkunftsregion wird auch durch soziales Engagement für Not leidende Menschen in Sri Lanka ausgedrückt wie auch durch spezielle Rituale, die sich auf den Krieg in Sri Lanka bezogen. Als beispielsweise der Tsunami 2004 die Insel und viele tamilische Gebiete traf, richtete die STKS ein Spendenkonto ein. Die Gelder wurden über "Food of Life" (FFL) ${ }^{286}$ den tamilischen Gebieten in Sri Lanka zugänglich gemacht. Das soziale Engagement der STKS wird vom Verein Krishna-Gemeinschaft Schweiz unterstützt.

Die Swiss Tamil Krishna Society reagierte auch auf die kriegerischen Auseinandersetzungen, welchen die Bewohner der tamilischen Gebiete Sri Lankas ausgesetzt waren. Wie andere tamilische Tempelvereine in der Schweiz auch, führten sie Rituale aus Anlass des wieder entflammten Bürgerkriegs in Sri Lanka durch. So wurde während des Krieges beim tamili-

285 Vgl. das youtube-Video "Founding the International Tamil Krishna Society" www.youtube.com/ watch?v=64CfFgqHrcY; 01.12.2010. In der Ankündigung des Videos hiess es: "Hare Krishna \& Humble Vanakkams - watch the creation of this new Branch dedicating their service to the Lord and the Tamils worldwide in particular the Eelam Tamils in Sri Lanka".

286 Die zur ISKCON zählende Hilfsorganisation Food for Life organisiert "vegan food relief programs" in Krisen- und Kriegsregionen der Welt. Sie wurde 1974 auf die Initiative Prabhupadas hin gegründet und bietet gegenwärtig in rund 60 Ländern weltweit Ernährungsprojekte an (vgl. www.ffl.org). 
schen Sonntagsfest an jedem letzten Sonntag im Monat ein homa - ein vedisches Feueropfer - für Frieden in Sri Lanka vollzogen. Die Vorträge nach dem àrati gingen in der Interpretation von Bhagavadgìtā-Stellen auch auf den Krieg in Sri Lanka ein. In einem Vortrag bei meinem Besuch dieses Anlasses am 28.01.2008 wurde betont, dass eine Lösung für den Konflikt in der spirituellen Entwicklung der Menschen dort, beispielsweise durch Chanten von Mantren, als Weg zur Überwindung der Körperlichkeit, gesehen wird.

Nach dem offiziellen Kriegsende 2009 wurde das monatlich stattfindende Ritual beendet. Das homa wurde in der Folge einmal im Jahr für Frieden in Sri Lanka und zum Gedenken an die im Krieg verstorbenen Menschen durchgeführt. Der jährliche Anlass findet Ende November statt, in derselben Zeitspanne, in welcher die LTTE am sogenannten Great Heroes' Day jährlich ihrer Toten gedenkt.

\subsection{Weitere Kontaktzonen: Treffpunkte von Sathya Sai Baba-Devotees und die Besuche von Amma}

Über die bisher analysierten Kontaktzonen hinaus finden sich weitere Orte gemeinsam geteilter religiöser Praxis von tamilischen Hindus und religiösen Akteuren der Mehrheitsgesellschaft in der Schweiz, die im Folgenden nur kurz skizziert werden. Vor allem sollen dabei zwei rezente, bedeutende Guru-Gestalten aus dem drawidischen Spektrum und ihre Verehrungsformen in den Blick gerückt werden:

Auch die Treffpunkte der Devotees von Sathya Sai Baba (1926-2011), der sich als Inkarnation von Shirdi Sai Baba (1838-1918) verstand und von seinen Anhängern als Avatar, als «auf Erden herabgestiegene Verkörperung eines Gottes» angesehen wird, stellen religiöse Kontaktzonen für tamilische Hindus in der Schweiz dar. ${ }^{287}$ Diese Bewegung kann dem neohinduistischen Spektrum zugeordnet werden, obgleich sie sich selbst als «Bewegung hinter den Religionen» und damit als universalreligiös versteht (vgl. Klass 1996). Propagiert werden als zentrale Werte Wahrheit, richtiges Handeln, Gewaltlosigkeit, Liebe und Frieden (Sathya, Dharma, Ahimsa, Prema und Shanti, vgl. Sai Baba 1996). 1968 gründete Sathya Sai Baba die Internationale Sathya Sai Organisation.

287 In seinem Geburtsort Puttaparthi (Andhra Pradesh/Indien) hat sich ein grosser Ashram etabliert, der sich karitativ und im Bildungsbereich engagiert und den auch Devotees aus Europa und Sri Lanka besuchen. 
Seit den 1970er Jahren sind Sai Baba-Devotees auch in der Schweiz aktiv und als gemeinnütziger Verein Sathya Sai Koordinations-Komitee Schweiz mit Sitz in Bern organisiert. In der Schweiz waren 2008 ca. 200 Personen im Sathya Sai Koordinations-Komitee organisiert. Die nicht organisierte Anhängerschaft ist jedoch weitaus grösser. ${ }^{288}$ Die Anhänger treffen sich meist wöchentlich am Donnerstag, dem sogenannten Guru-Day zum Singen devotionaler Lieder (skt. bhajans). Eigens wurde für die Devotees vor Ort ein Schweizer Gesangbuch herausgegeben.

Durch Kontakte von tamilischen Migrantinnen und Migranten und Schweizer Sai Baba Anhängern haben sich im Laufe der Zeit eigene Organisationsformen herausgebildet. Ähnlich wie innerhalb der ISKCON bestanden jedoch auch hier unterschiedliche Anlässe innerhalb der Organisation für Schweizer und tamilische Devotees, die über eigene soziale Räume der Verehrung verfügen. ${ }^{289}$

In einem Raum innerhalb der römisch-katholischen Kirche St.Karl in Luzern traf sich im Zeitraum der Feldforschung der Studie monatlich eine tamilische Gruppe zum Singen von pacanais.$^{290}$ Dieser soziale Raum stellt in zweifacher Hinsicht eine besondere Kontaktzone dar: Zum einen wusste die nationale Sai Baba-Organisation lange nichts von der Existenz der tamilischen Gruppe. Erst seit Oktober 2007 besteht ein Zusammenschluss von tamilischen und Schweizer Devotees ausgehend von den tamilischen Praktizierenden. Zum anderen wurde das monatliche bhajan-Singen vom Priester des tamilischen Turkkai Amman Tempels in Luzern geleitet.

Neben der Sai Baba-Bewegung sind auch die Besuche von Mātā Amritanandamayī Devi (genannt Amma) in Winterthur eine Kontaktzone, in welcher sich Schweizer und tamilische Hindus treffen. Amma ist eine weitere von ihren Anhängern als Avatar angesehene spirituelle Lehrerin, die von tamilischen Hindus in der Schweiz verehrt wird. ${ }^{291}$ Auf die Besuche der Hugging Mother, wie sie in weiten Kreisen der Öffentlichkeit genannt wird, wird bei tamilischen Tempelfesten und in tamilischen Läden in der

288 Die Anhänger Sai Babas verstehen sich oftmals auch als Christinnen und Christen. Sie sehen ihre Zugehörigkeit zu einer christlichen Kirche und ihren Status als Sai Baba-Devotee nicht als Widerspruch (vgl. Eulberg 2008).

289 Eyer berichtet 2007, dass es in Zürich, Zollikofen, Langenthal und Burgdorf tamilische Sathya Sai Baba Zentren gibt (vgl. Eyer 2007, 94).

290 Dabei handelt es sich um den Raum, der von 1992 bis 2000 als Turkkai gewidmeter Hindu-Tempelraum für tamilische Hindus diente.

291 Ob Amma sich selbst als Avatar ansieht, ist unklar, da sie dazu nicht klar Stellung bezieht. Tamilische Besucher von Amma verwendeten in Gesprächen mit mir diesen Terminus. Tamilische Informanten sprachen von ihr als «einem Avatar von Aum Shakti». So eine Tamilin aus Küsnacht während des Besuchs Ammas 2007 in Winterthur in einem informellen Gespräch. 
Schweiz durch Poster und Flyer hingewiesen. Zahlreiche Tamilen besuchen die darśanas von Amma während ihrer Aufenthalte in der Schweiz.

Die offizielle Biographie Mātā Amritanandamayī Devis weist klassische Elemente idealtypischer Lebensgeschichten charismatischer, spiritueller Führungsgestalten auf. ${ }^{292} \mathrm{Im}$ Alter von 22 Jahren erlebte Amma ihre ersten Krishna-bhava ${ }^{293}$, welche zwei Jahre später durch Devi-bhavas abgelöst wurden. Dies führte dazu, dass Amma die Aufmerksamkeit der Öffentlichkeit auf sich zog und sich 1981 der Ashram Amritapuri Ashram in Kerala um ihre Person etablierte. Die Organisation Mātā Amritanandamaȳ Math (MAM), die den Ashram leitet, ist heute von der UNO als NGO anerkannt.

Zwar kommt Amma aus der Tradition der Vaishnavas und ihr Weltbild ist auf Advaita-Vedanta aufgebaut, jedoch ist durch die exponierte Stellung der Devi-bhavas der Shaktismus im Laufe ihrer Biographie ins Zentrum ihrer Frömmigkeit gerückt. Die Lehre Ammas wird von dieser ausschliesslich mündlich weitergegeben. Dies wird vielfach als Ausdruck ihres Skeptizismus gegenüber den verschriftlichten, brahmanischen Hindu-Philosophien gedeutet.

Im Zentrum der religiösen Praxis Ammas steht bhakti (skt. Hingabe, Liebe; tam. pakti): ihr Markenzeichen ist das Umarmen ihrer Anhänger während des tarisanam (skr. darśana). Dabei spielen Kasten- und Reinheitsvorschriften keine Rolle, was im hinduistischen Kontext als Ausdruck einer reformatorischen Haltung mit gesellschaftskritischem Impetus angesehen werden kann. ${ }^{294}$

Dabei ist karitatives Tun als spirituelle Praxis ein entscheidender Bestandteil ihrer Lehre. So ist für Amma neben karma-Yoga auch bhakti-

2921953 wurde Amma in Parayakadavu, Kerala, als Sudhamani Idamannel geboren. Sie entstammt einer Fischerfamilie, die der niederen Kaste der Arayan angehört und sich der Krishna-bhakti-Tradition zugehörig fühlt. Aufgrund ihrer Visionen stiess sie früh auf das Unverständnis und die Ablehnung ihrer Familie.

293 Bhava, skt., abgeleitet von der Wurzel bhu (sein, werden) bedeutet wörtlich übersetzt «Werden» oder «Daseinsprozess» und meint im hinduistischen Kontext die «Verkörperung oder Verschmelzung mit einer Gottheit».

294 Darüber hinaus lehren Ammas Schüler in den internationalen Zentren und Satsangs die von ihr entwickelte Integrated Amrita Meditation Technique (IAM). 1989 weihte Amma erstmals einen Brahmasthanam-Tempel ein, wo sie auch Frauen als Tempelpriesterinnen einsetzt, was ihrem Ansatz der Gleichbehandlung der Geschlechter entspricht. Auch ihre Form der Durchführung der pücai lässt sie dem reform-hinduistischen Kontext zuordnen. Allerdings vertritt sie eine traditionelle binäre Geschlechterauffassung, was in ihren Satsang-Ansprachen zum Ausdruck kommt. In diesen spricht sie von unterschiedlichen Geschlechtereigenschaften und unterstreicht die Differenz der Geschlechter. Auch folgt sie insofern traditionellen hinduistischen Auffassungen, als dass sie Frauen während der Menstruation untersagt, eine $p \bar{u} j \bar{a}$ durchzuführen. 


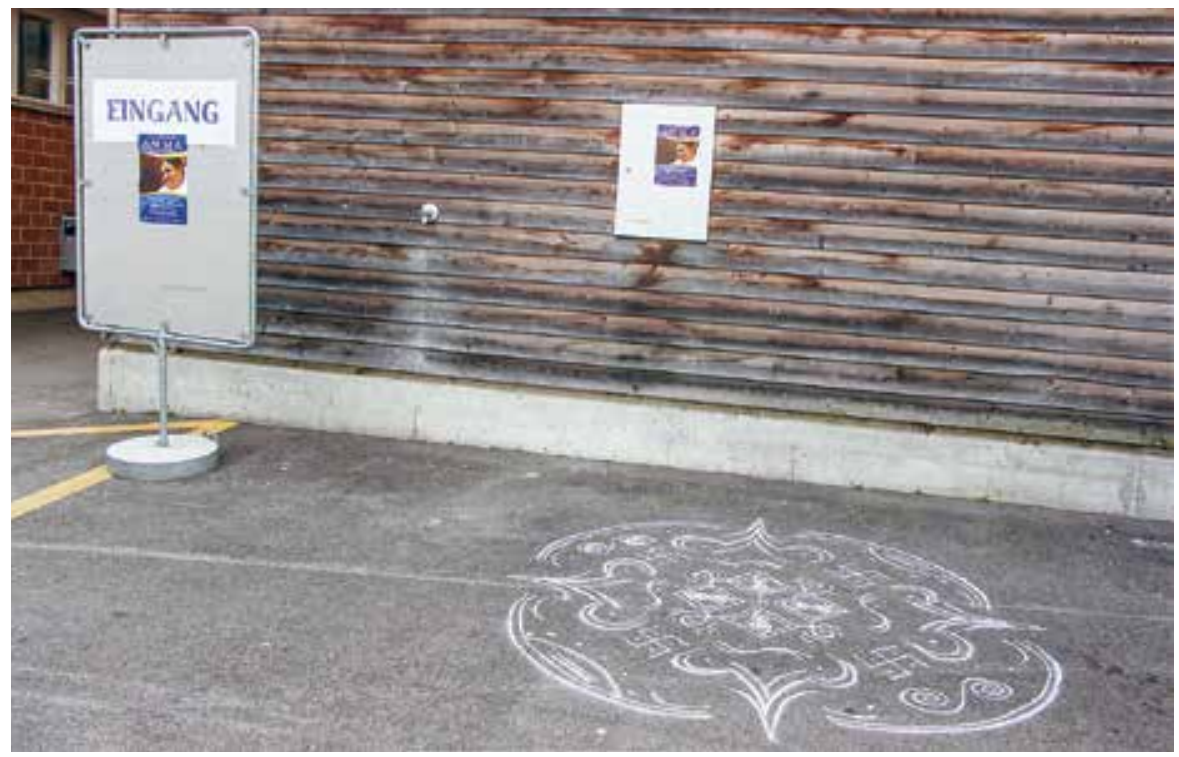

Abb. IV 6: Kōlam vor der Eulachhalle in Winterthur anlässlich des Besuches von Mātā Amritanandamayī Devi (19.10.2007).

Yoga zentral, was in ihrem ausgeprägten sozialen Engagement und der Etablierung zahlreicher karitativer Projekte zum Ausdruck kommt.

Einmal im Jahr reiste Amma nach Europa, um dort darshans zu geben. In die Eulachhallen in Winterthur in der Schweiz kam sie regelmässig jedes Jahr im Herbst. Für viele Tamilinnen und Tamilen stellte der Besuch einer bedeutenden hinduistischen Persönlichkeit in ihrem Exil-Land ein besonders Ereignis dar. Eine Tamilin erzählt: «Alle Tamilen kennen Amma. Sie ist die Mutter. Die Umarmung ist sehr gut. Eine Heilige umarmt uns.» ${ }^{295} \mathrm{Da}$ Amma Malayalam, die Sprache ihrer Heimat Kerala, spricht, sind tamilisch sprechende Menschen nicht auf eine Übersetzung angewiesen, da das zur drawidischen Sprachfamilie gehörige Malayalam von tamilischen Muttersprachlern verstanden wird. Zwar sind tamilische Hindus bei den Besuchen Ammas in der Schweiz im Vergleich zu den europäischen Besuchern in der Minderheit, aber durch ihre Sprachkenntnisse und ihr durch die hinduistische Sozialisation erworbenes Verständnis der rituellen Praxis Ammas kommt ihnen hier eine besondere Stellung zu.

Auch Amma hat sich in den von Naturkatastrophen und vom Bürgerkrieg betroffenen tamilischen Gebieten Sri Lankas karitativ engagiert: nach

295 So ein Tamile aus Schaffhausen während eines Gesprächs 2007 in Winterthur. 


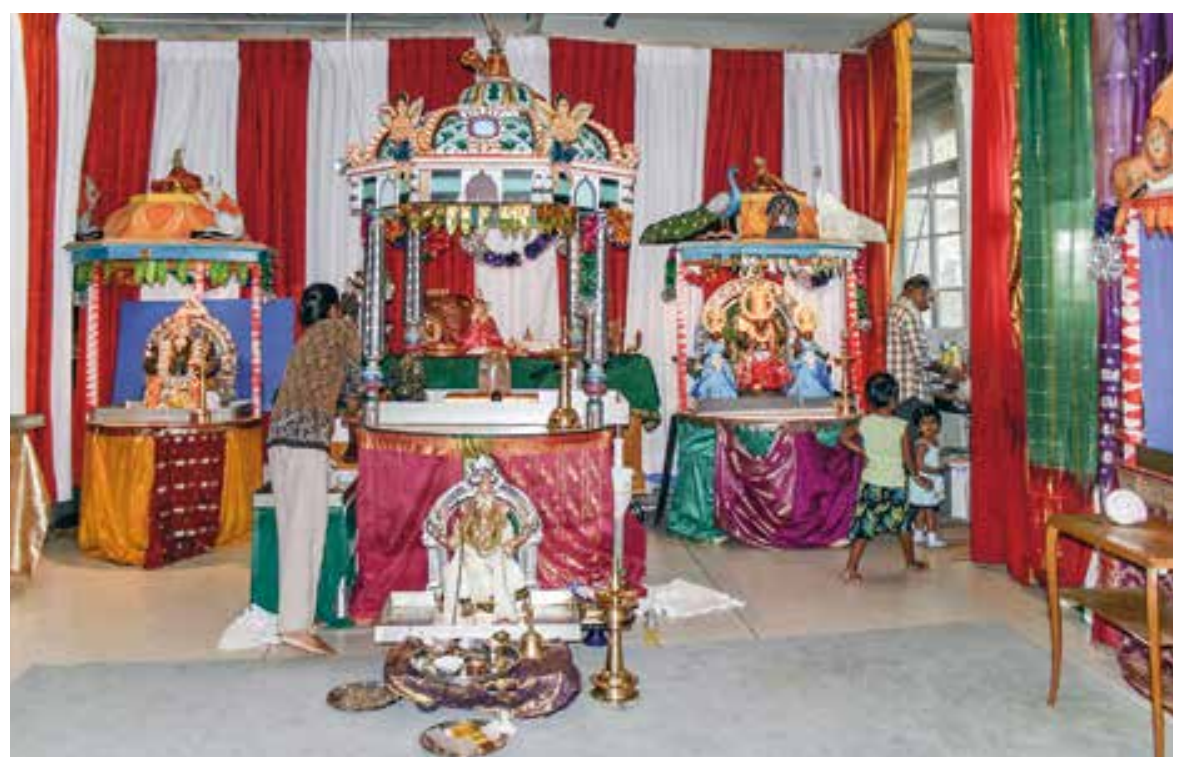

Abb. IV 7: Der Tempelraum von Saivanerikoodam im provisorischen Haus der Religionen an der Schwarztorstrasse 102 in Bern (20.06.2008).

dem Tsunami im Dezember 2004 leistete der MAM vielfältige Notfallhilfe. Amma reiste mehrmals in die betroffenen Gebiete der Insel, wobei sie auch immer führende Politikerinnen und Politiker des Landes traf. Bei ihrem Besuch kurz nach dem Tsunami im Februar 2005 sprach sie mit der damaligen Präsidentin Sri Lankas, Chandrika Kumaratunge, über die politische Situation des Landes. An dem von ihr am 17. Februar $2005 \mathrm{im}$ tamilischen Gebiet Amparai gegebenen darshan nahmen auch 15 LTTE-Vertreter und 20 Mitglieder des tamilischen Sondereinsatzkommandos teil wie auch eine Vertreterin der Regierung. Dies wurde dahingehend gedeutet, dass Amma eine integrative Kraft sei, die Menschen unterschiedlichster Ideologien zusammenbringe.

Eine weitere Kontaktzone war im Untersuchungszeitraum der Raum des reform-hinduistisch ausgerichteten Vereins Saivanerikoodam im Haus der Religionen in Bern. ${ }^{296}$ Dieser befand sich vor der Eröffnung des Projektes Haus der Religionen - Dialog der Kulturen am Europaplatz in Bern in der provisorischen Unterkunft des Hauses der Religionen im «Werkhof» im Berner Quartier Mattenhof. Die religiöse Praxis des Vereins zeichnete sich

296 Der Verein wurde 1993 von fünf Tamilen aus dem Kanton Bern gegründet. Im selben Jahr wurde ein Tempelraum an der Längassstrasse in Bern eingerichtet. 


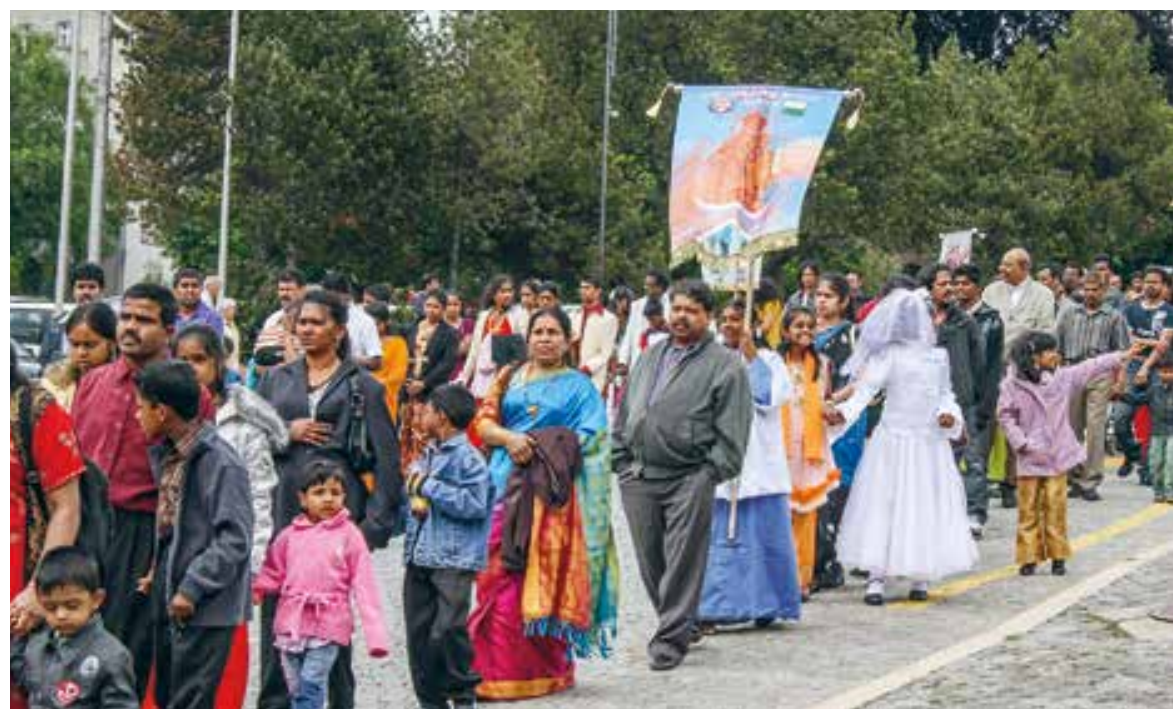

Abb. IV 8: Besuchende der Tamilen-Wallfahrt in Einsiedeln (08.06.2008).

dadurch aus, dass auch Frauen Priesterfunktionen einnehmen können. Im November 2009 waren es nach Angaben eines Mitglieds von Saivanerikoodam beispielsweise sieben Männer und sieben Frauen, die durch den Verein instruiert erlernt hatten, die tägliche pūcai im Tempel und das aratri durchzuführen (vgl. Zimmermann 2014).

Auch christliche Wallfahrtsorte als Treffpunkte von Tamilinnen und Tamilen unterschiedlicher religiöser Ausrichtung stellen Kontaktzonen dar, wie die tamilischen Wallfahrten zum Benediktinerkloster Mariastein im Kanton Solothurn, wo Unserer Lieben Frau von Madhu gedacht wird, und die Tamilen-Wallfahrten zum römisch-katholischen Pilgerort Einsiedeln (vgl. Abb. IV 8). ${ }^{297}$

Zusammenfassend ist festzuhalten, dass eine Analyse von Kontaktzonen instruktiv ist, um Prozesse der dynamischen Interaktion mit im Residenzland beheimaten Gruppen aufzuzeigen. Geteilte soziale Räume können noch einmal differenziert werden in konkrete Räume, die von tamilischen Hindus genutzt, aber nicht von ihnen verwaltet werden, wie der Tempelraum von Saivanerikoodam im Haus der Religionen in Bern und der KrishnaTempel in Zürich, in welchen das tamilische Sonntagsfest und tamilischer

297 An dieser Stelle kann nicht detailliert auf Überlegungen zum sogenannten hindu-christian overlap eingegangen werden; zu sri-lankisch tamilische Christen im deutschsprachigen Raum vgl. u. a. Eulberg/Niederberger 2011. 
Religionsunterricht durchgeführt wird, und solchen Kontaktzonen, die während speziellen Anlässen in sozialen Räumen entstehen. Zu letzterer Kategorie können «Tamilen-Wallfahrten» an christlichen Wallfahrtsorten gezählt werden wie auch die Besuche von Amma in der Schweiz. Bei diesem Anlass ist zwar eine südasiatische Hinduistin Zentrum der Verehrung, organisiert wird die Veranstaltung aber von «Westlern». Tamilische Hindus fühlen sich mit Amma und ihrer Praxis durch ihr Engagement für Frieden in Sri Lanka und ihre Drawidianness verbunden. Letzteres gilt auch für die Verehrung Sathya Sai Babas.

\section{Tempelwerdung in der Diaspora: Angemietete Hallen als Räume der Ausübung von Hindu- Praxis}

Temples are, I argue, about power. (Bastin 2002, 13)

Die pūcai des häuslichen Bereichs findet ihr öffentliches Pendant in der Tempel-pūcai als Form der rituellen Verehrung in der Öffentlichkeit. ${ }^{298}$ Die Tempelpraxis dient dabei der Aufrechterhaltung der kosmischen Ordnung (Good 2001). Jacobsen verweist darauf, dass ein Charakteristikum der srilankisch tamilischen Diaspora gerade die Etablierung von Tempelräumen wie auch öffentliche Performanzen während der Tempelfeste sind:

Establishment of a large number of temples world-wide characterises the Sri Lankan Tamil Hindu diaspora and in many countries the temple festivals of the Sri Lankan Tamils are the largest Hindu festivals of the Hindu diaspora communities. (Jacobsen 2009, 182)

Die öffentlichen Orte von Hindu-Praxis sind für Caivam praktizierende Hindus traditionell die Tempelgebäude. Diese nach aussen hin sichtbaren Sakralstätten sind Marker für die Präsenz des Göttlichen, welche sich in einem im Inneren befindlichen heiligen Raum entfaltet. Sie grenzen die

298 Zur detaillierten Beschreibung der Tempel-Puja in Hindu-Traditionen vgl. Flood 1996; Michaels 1998.

Da die meisten tamilischen Tempel in der Tradition des saiva siddhanta stehen, hat die pūcai als zentrale rituelle Form eine besondere Bedeutung: "Saiva Siddhanta sees ritual as the supreme form of action, whose efficacy derives from Siva” (Good 2001, 240). 
Umgebung von einem als heilig deklarierten Ort ab. Der Tempel (tam. kōvil) wird als potenter Ort angesehen, der ein "field of active power" entfaltet (Kramrisch [1946] 1976, 3). In diesem Sinne kann ein Tempel im Kontext dieser Untersuchung als Kraftort für eine Minderheit angesehen werden.

Die in der Tradition des Caivam stehenden Tempel in der Schweiz sind Orte, welche von den Hindus als Marker für die Gegenwart des Göttlichen auch in der Fremde angesehen werden. Dem Tempel als Austragungsraum von Hindu-Praxis kommt dabei in der Diaspora eine bedeutende Rolle zu. Er dient als Vergemeinschaftungsort der hindu-tamilischen Exilanten in der Schweiz und zeichnet sich durch Multifunktionalität aus. In der Beschreibung des Tempels in St.Gallen wurde in einer Infobroschüre zum Tag der offenen Tür 2008, welche von Mitgliedern der Gruppe Saivanerikoodam verteilt wurde, neben der religiösen Funktion auch der soziale Aspekt betont:

Der Tempel ist längst nicht nur ein wichtiger religiöser Ort für Tamilen im Kanton St. Gallen geworden, sondern auch ein Treffpunkt. Besucher, vor allem Gläubige, kommen jeden Sommer zum einwöchigen Tempelfest nach St. Margrethen. (Seite 12)

Darüber hinaus sind sie als monetäre und spirituelle Investitionen als Schritte zur gesellschaftlichen Eingliederung der tamilischen Migrantinnen und Migranten in fremdkultureller Umgebung zu verstehen.

In der Schweiz befinden sich tamilische Hindu-Tempel immer nur in Gebäuden, nicht in der Natur. Diese Sakralgebäude sind immer auch materielle Kultur (vgl. Corrigan 2009, 168): Zentrale kulturelle Ordnungskategorien und Hierarchisierungen der jeweiligen Tradition nehmen in diesen Gebäuden Gestalt an. Dies lässt sich beispielsweise in der Architektur, Platzordnungen und Dekoration von Hindu-Tempeln ablesen. Tempel lassen sich so als Knotenpunkte verstehen, die soziale Relationen nicht nur abbilden, sondern selbst Teil ihrer Artikulation sind (vgl. Bastin 2002, 8). In Sri Lanka fungierten auch Orte, welche unter einem Baum platziert sind, und Steine als «Tempel», an denen öffentliche pūcai für die Gottheiten vollzogen wird. In der Schweiz finden sich als Orte der pūcai nur markierte Orte innerhalb der privaten Wohnung und innerhalb von geschlossenen Gebäuden, welche als Tempel fungieren. In der Natur findet - nach meinem Kenntnisstand - keine deva-pūcai statt. Mangai verweist im Interview am 02.12.2008 auf Bäume, welche in Sri Lanka den Ort einer öffentlichen pūcai anzeigen: «Wir [gemeint ist, 〈wir〉 in Sri Lanka] haben überall Tempel/ unter die Bäume/und überall/muss man nicht Tempel suchen. Nicht wie in der Schweiz. Überall / alle gehört kleine Tempel».

In der tamilischen Diaspora konnte bis 2013 nur von Sakralstätten und nicht -bauten gesprochen werden, da bis zu diesem Zeitpunkt kein Hindu- 
Tempel als solcher von religiösen Akteuren fertig gebaut und nach rituellen Vorschriften eingeweiht worden war. Die Tempel befinden sich in Räumlichkeiten, die ehemals einem anderen Zweck dienten und umgewidmet wurden.

Im Folgenden soll die Entstehung dieser Räume, die neben tamilischen Kulturvereinen und Lebensmittelläden wichtige Orte der Netzwerkpflege sind, skizziert werden. Diese Ausführungen schliessen immer auch schon den Aspekt der öffentlichen Präsentation von Hindu-Praxis im Gegensatz zur im vorangegangenen Kapitel der Praxis von Hindu-Ritualen im privaten Bereich ein, der in Kap. V. genauer thematisiert wird.

Zunächst stelle ich den Aufbau und die sich daraus ableitbaren Phasen der Etablierung von hindu-tamilischen Organisationsstrukturen in der Schweiz dar (IV 4.1). Auf Kompartmentalisierungsprozesse in den Anfängen der Migration geht spezifisch Kapitel4.2. ein. Daran anschliessend erläutere ich zusammenfassend die Bedingungen, welche erfüllt sein müssen, damit ein Gebäude von den Akteuren als Tempel bezeichnet werden kann (IV 4.3). Kapitel IV 5, in dem exemplarisch am Jahresfest taipongal der Bedeutungswandel des Tempels für die Migrantengruppe dargestellt wird, thematisiert den Prozess der Tempelisierung im Kontext dieser Studie.

\subsection{Von Asylunterkünften zu angemieteten Hallen: Aufbau und Entwicklungsphasen hindu-tamilischer Organisationsstrukturen in der Schweiz}

Neben religiösen Kontakten zu bereits etablierten Gruppierungen in den Anfängen der Migration (vgl. Kap. IV 3.2/3.3) war der Aufbau eigener Institutionalisierungsformen ein zentraler Schritt in der Etablierung tamilischer Hindu-Praktiken in der Schweiz. Die Phasen der Etablierung von tamilischen Hindu-Traditionen in der Schweiz sind dabei eng an die Errichtung von Tempelräumen als zentralen religiösen Orten in der Schweiz gekoppelt. Als die ersten männlichen Migranten in die Schweiz kamen, fanden sie bis auf den Tempel der ISKCON in Zürich (siehe Kap. IV 3.2) - keine Sakralorte vor, welche mit hinduistischen Traditionen verbunden waren. Der Informant Murari, welcher 1983 mit der Gruppe der ersten Bürgerkriegsgeflüchteten aus Sri Lanka in die Schweiz kam, verweist darauf, dass es bei seiner Ankunft kaum hinduistische Orte gab. Die damalige Situation kontrastiert er mit der Situation im Jahr 2008, die ihm Wahlmöglichkeiten beim Besuch von Hindu-Tempeln bot. Ein Wandel der religiösen Landschaft musste jedoch erst von den tamilischen Akteuren in Gang gebracht werden. 
Ich bin auch so lang in der Schweiz hier/auch da 25Jahre schon/24Jahre. Damals ist noch/hat wenige Möglichkeiten in der Schweiz irgendwelche

Tempel gehen/oder Tempel besuchen/oder sogar Tempel/ist irgendwo ein Tempel. Aber jetzt [betont] es gibt mehrere Möglichkeiten.

Die religiöse Funktion der Tempelräume besteht im Bereitstellen von öffentlichem Raum für die Gegenwart göttlicher Macht und für die gemeinschaftliche Durchführung von Ritualen. Durch die im Tempel vollzogenen Rituale findet eine Transformation in einen von den Hindu-Akteuren als «heilig» beschriebenen Ort statt - eine sich in der profanen Sphäre befindliche Lokalität wird in einen Sakralraum umgewandelt: "Not only are the bodies in this space performing an unconscious choreography, but an inner rhythm is created, focusing the attention and transforming secular time and space into a ritual, sacrized locale" (David 2008, 94).

Gemeinschaftlich genutzte Räume können gerade von Migrantinnen und Migranten als stabile und feste Ankerpunkte nach einer Zeit in Bewegung und im Umbruch angesehen werden. "[The buildings] give structure to social networks, persistence to behavior patterns. What we build solidifies society against time and its incessant forces for change" (Gieryn 2002, 35). Auf der anderen Seite lässt sich eine Instabilität in Bezug auf die Lokalisierung feststellen, was sich zum Beispiel in der Umwidmung eines Gebäudes von einer Industriehalle in einen «heiligen Tempel» und wieder zurück in eine Lagerhalle zeigen lässt.

Um einen kurzen historischen Überblick über die Institutionalisierungsprozesse tamilischer Hindu-Traditionen in der Schweiz zu geben, sind diese im Folgenden grob in sieben Phasen eingeteilt. ${ }^{299}$ Dabei sind sowohl Tendenzen zur Ausdifferenzierung, wie beispielsweise die Gründung unterschiedlich religiös ausgerichteter Vereine festzustellen, wie aber auch das Bestreben nach vereinheitlichenden Organisationsstrukturen. ${ }^{300}$

Die einzelnen Phasen können noch einmal genderspezifisch unterteilt werden. Die Institutionalisierung wurde mehrheitlich von männlichen Akteuren getragen, da sie die Mehrzahl der Vorstandsmitglieder in den Tempelvereinen stellen und als Priester Einfluss auf die Etablierung der Hindu-Traditionen haben. Gleichzeitig war die Ankunft von weiblichen

299 Diese Einteilung ist angelehnt an die Darstellung der Phasen der Etablierung von Hindu-Traditionen in England, wie sie von David Bowen (1981) vorgelegt wurde. Bowen skizziert dort die Stufen der Institutionalisierung von Hindus aus Gujarat.

300 Der Verlauf des Institutionalisierungsprozesses in der Schweiz stellt sich ähnlich wie in Deutschland dar (vgl. Back 2007). Auch hier ist die Organisationsform die Vereinsstruktur, und anfänglich wurden in erster Linie bestimmte Gebäude in Gewerbe- und Industriegebieten zu Tempelräumen umgewidmet. 
Migrantinnen allerdings ein entscheidender Motor für die Etablierung von Tempeln in der Schweiz (vgl. Vögeli 2003). Mit der Ankunft von tamilischen Frauen begann die Etablierung einer institutionalisierten religiösen Praxis, welche auf das System Familie abzielte.

\section{Phase: Die Errichtung von pūcai-Ecken durch männliche Migranten}

Die ersten tamilischen Migranten, die in die Schweiz kamen, waren überwiegend junge Männer (siehe Abschnitt III 3). Diese errichteten dort, wo sie untergebracht waren, Plätze, um die häusliche pūcai zu vollziehen. In den meisten kantonalen Durchgangszentren, in denen sie als Asylsuchende lebten, richteten sie gemeinsam einen Schrein ein. ${ }^{301}$ Im Zentrum der religiösen Praxis stand die Beziehung zu und die Verehrungshandlungen für die Göttinnen und Götter.

Die in den Asylunterkünften zur Verfügung gestellten Zimmer stellten somit erste «Tempel»-Räume tamilischer Hindus in der Schweiz dar. ${ }^{302}$ In einer Asylunterkunft in der Nähe von Olten erwirkte im Herbst 1991 eine Gruppe tamilischer Hindus, dass ihnen ein Zimmer zur Verehrung ihrer Götter und Göttinnen zur Verfügung gestellt wurde. ${ }^{303}$ Die Asylsuchenden kauften ein tarisanam [skr. darśana]-Bild, welches als erstes provisorisches Götterbild für die pūcai diente. Das goldumrandete Bild zeigt in der Mitte eine dreidimensional angedeutete Figur der Ampāl, die auf einer Lotusblüte sitzt, und daneben Saraswati, Ganeśa und weitere Gottheiten. Es diente den männlichen Asylbewerbern als visuelle Repräsentation der Gottheiten während der pūcai. Die Initiatoren gründeten bald darauf den Verein zur Förderung der tamilischen Kultur in der Schweiz und eröffneten in einer ehemaligen Lagerhalle am Rande des Ortes Trimbach einen Tempel. In diesem, wie auch in dem 2013 eingeweihten Tempel, der vom Verein gebaut wurde, wurde dieses Kult-Bild - jeweils über dem Eingang zum Tempelinnenraum - aufgehängt. Es verbindet die verschiedenen Orte und Etappen der Hindu-Praxis und erinnert die Akteure an ihre Zeit als Asylsuchende (vgl. Abb. IV 9).

301 Ehemalige Asylsuchende berichteten mir von Durchgangszentren in Basel, Adliswil und Olten, in welchen sie pücai-Plätze errichtet hatten.

302 Im damaligen Durchgangszentrum für Asylsuchende in Langnau kamen bereits 1984 freitags in einem zur Verfügung gestellten Raum tamilische Hindus zusammen, um pūcai zu vollziehen. Aus diesem Engagement ging die Gründung des Vināyakar-Tempels in Langnau hervor (vgl. Eyer 2007, 94).

303 Beteiligt waren unter anderem Vasantharajan Ramalingam (1959-2014), Initiator des Tempelbauprojektes in Trimbach und langjähriger Tempelvereinspräsident, und ein Tamile aus der Brahmanen-Kaste, der später zeitweise Tempelpiester des Sri Mañōnmaṇi Ampāl Tempels in Trimbach war. 


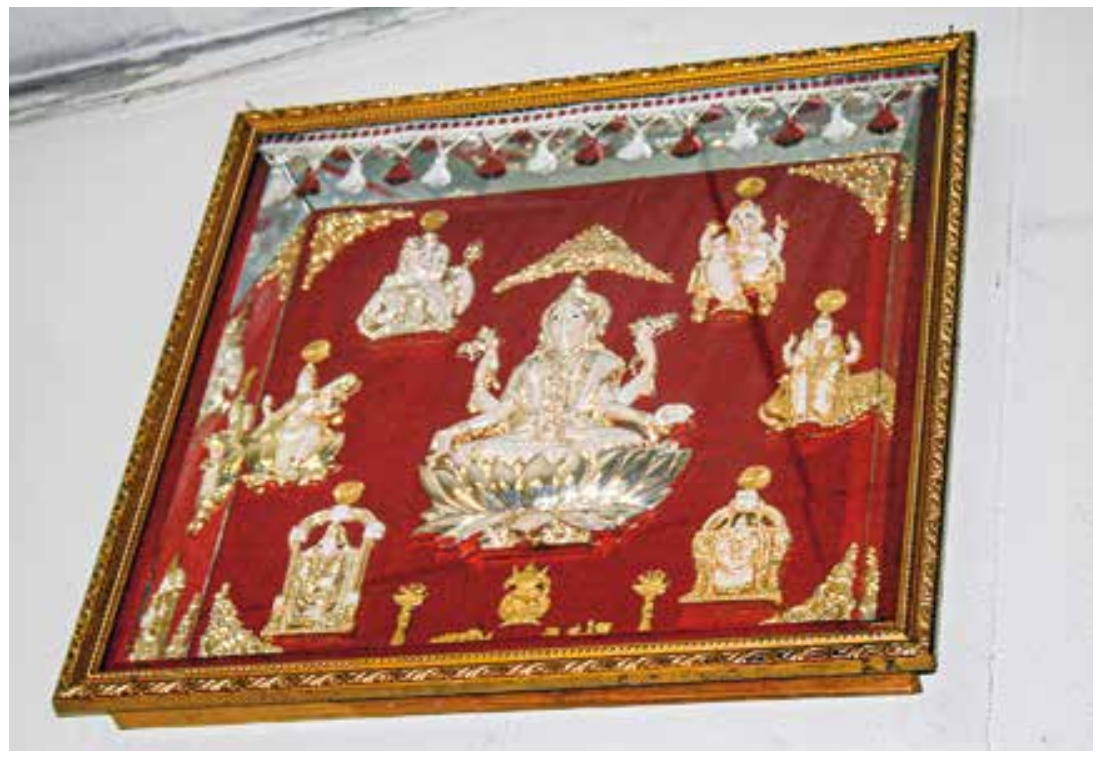

Abb. IV 9: Das tarisañam-Bild, welches u. a. Ampāl zeigt und von Tamilen in den frühen 1990er Jahren in einer Asylunterkunft als Zentrum der pūcai genutzt wurde (11.08.2009).

Auch in privaten Unterkünften wurden Teile der Wohnung als religiöse Orte markiert, wo die Gottheiten verehrt wurden (vgl. Abschnitt IV. 2). Der Priester des Śrī Viṣnu Turkkai Ammañ Tempels in Adliswil berichtete, dass er 1994, nachdem er nicht mehr im Durchgangswohnheim lebte, in seiner privaten Wohnung einen Ort abgrenzte, an dem er die pūcai vollziehen konnte. Da er aus der Brahmanen (tam. pirāmaṇar)-Kaste ${ }^{304}$ stammt $^{305}$ (vgl. Kap. V), kamen immer mehr tamilische Hindus zu ihm nach Hause und baten ihn, wichtige lebenszyklische Rituale (skr. saṃskāra; tam. camskāram) zu vollziehen.

Aber trotzdem sind einem, wenn einem Kind Essen eingeben, sie meinen meine Wohnung auch wie Tempel - also einfach zwei drei Familien kommen, wir kochen etwas, den wir opfern zu Bild, damals keine Figuren nur die Bilder.

304 Das Kastenwesen, tamilisch varna, spielt innerhalb der Strukturierung der tamilischen Gesellschaft in Sri Lanka eine wichtige Rolle. Die LTTE strebte an, das Kastenwesen zu überwinden, wenngleich auch innerhalb ihres sozialen Gefüges Kastenherkunft eine Rolle spielte.

305 Zwar stammt er aus einer Priesterfamilie, hatte jedoch bei seiner Einreise in die Schweiz keine Ausbildung als Priester absolviert. Nach seiner Zeit als Asylsuchender in einem Durchgangswohnheim arbeitete er zunächst als Pflegekraft, während seine Frau und Kinder noch in Sri Lanka waren. 1994 wurde er zum Oberpriester, tamilisch kurukkal, geweiht. 
Zu Bilder opfern/also diese Rituale gemacht/ also andere Format, keine Tem$\mathrm{pel} /$ das ist auch so gewesen. Darum habe ich überlegt, wir müssen unbedingt einen Ort haben/- Tempel.

Der Akteur verweist hier auf das wichtige lebenszyklische Ritual der ersten festen Nahrungsaufnahme des Kindes (skr. annaprāśana), welches durch ein Ritual begleitet wird. Das Beispiel zeigt neben der Wichtigkeit der öffentlichen Lokalisierung der Handlungen die Bedeutung der Priester für die Praxis. Gerade in den Anfängen der Migration war der Priestermangel neben dem Fehlen von öffentlichen Verehrungsorten ein Hindernis für den Vollzug der religiösen Praxis.

Einige Tempelvereine in der Schweiz nennen auch religiöse Persönlichkeiten als Motor für die Gründung von Tempeln in der Schweiz und legitimieren damit ihre religiöse Autorität. So beruft sich der Śrī Civacuppiramaniyar Tempel in Adliswil auf den indisch-tamilischen religiösen Lehrer Kirupanaandha Variyar (1906-1993), bekannt unter dem Namen Variyar Swamigal, der zur Gründung von Tempeln in der Schweiz angeregt habe - ein ihn portraitierendes Gemälde hing im Untersuchungszeitraum im Tempelraum. Seine Religiosität zeichnete sich vor allem durch Murukanpakti (Hingabe an den Gott Murukann) aus. Er reiste zwischen 1944 und 1993 häufig nach Sri Lanka. Auch besuchte er verschiedene tamilische DiasporaLänder, unter anderem die Schweiz. ${ }^{306}$

\section{Phase: Errichtung von Tempelräumen und Gründung von ethno-religiösen Vereinen}

Vielfach unterstützen Schweizer Organisationen wie die römisch-katholische Hilfsorganisation Caritas, der Verein IRAS COTIS ${ }^{307}$ oder für Integration zuständige staatliche Stellen die Bestrebungen tamilischer Hindus Tempelräume zu eröffnen. ${ }^{308}$ Die Caritas war beispielsweise bei der Grün-

306 Laut der nicht mehr existierenden Webseite www.variyarswamigal.com (abgerufen am 02.10.2010) feierte er am 14.01.1990 Pongal in der Schweiz.

307 Der Verein IRAS COTIS, interreligiöse Arbeitsgemeinschaft in der Schweiz, wurde 1992 gegründet und unterstützte in den Anfängen der Migration auch tamilische Hindus im Aufbau religiöser Strukturen (vgl. Kap. V).

308 Bei der Entstehung des Śrī Civacuppiramaṇiyar Tempels in Adliswil stand der Verein IRAS COTIS und die Fachstelle für Integration der Stadt Zürich unterstützend zur Seite. Der Initiator und erste Priester des Tempels berichtet über diese Phase: «Darum also/darum ich bin von die/ich habe Kontakt genommen mit dem IRAS - interreligious Arbeitsgemeinschaft in der Schweiz ehm, / sie haben das mir geholfen zu meinem Raum finden. In Adliswil/einen Raum gefunden und Tempel [2] 1994 - September mit dem Bilder die Tempel angefangen und in 95 wir haben eingerichtet/wie da hier, in einem Tempel, dort auch eingemietet/eine grosse Einweihungsfest gemacht / fünf Tage, vier, fünf Tage lang diese Einweihungsfest». 
dung des Śrī Kalyāna Murukan Tempels in Bern und der Suche nach geeigneten Räumlichkeiten für die Tempel in Langnau und Luzern ${ }^{309}$ beteiligt. Teilweise waren unterstützende Organisationen auch bei der Unterzeichnung des Mietvertrages behilflich, da es Asylbewerbern aufgrund ihres rechtlichen Status nicht möglich war, grössere Lagerhallen zu mieten. ${ }^{310}$

Als Beispiel für die Phase der Errichtung eigener Tempelräume und die Herausforderungen und Lokalisierungsdynamiken, denen diese unterworfen waren, sei hier das Beispiel der Etablierung von Hindu-Tempeln in Basel genannt. ${ }^{311}$ In einer ersten Etappe (1984-1998), die als «Suche nach geeigneten Tempelräumen und Expansion» zusammengefasst werden kann, wurden nacheinander an sechs verschiedenen Orten provisorische Hindu-Tempel errichtet. Grund für die Umzüge war in erster Linie, dass die Grösse des Raumes nicht ausreichte, um mit der wachsenden Anzahl an Tempelbesuchern gemeinschaftlich pūcai durchzuführen.

1984 kam die erste grössere Anzahl von tamilischen Geflüchteten nach Basel. ${ }^{312}$ Motor für die weiteren Entwicklungen hindu-tamilischer Praxis in Basel waren Schweizer Bürgerinnen und Bürger, die im interreligiösen Dialog engagiert waren. Der Basler Religionswissenschaftler und Religionslehrer Christoph Peter Baumann stand in engem Kontakt mit den tamilischen Menschen und bot ihnen an, in seinem Haus eine Räumlichkeit für den Vollzug von pücais zu benutzen, nachdem sie sich aufgrund von christlich-evangelikalen Missionsversuchen in ihrer Asylunterkunft nicht frei fühlten, ihre Hindu-Traditionen zu praktizieren (vgl. Baumann, C.P. 2003, 282).

In den Anfängen der rituellen Praxis dienten Ritualgegenstände, die Baumann von seinen Indienreisen mitgebracht hatte, als Kultgegenstände. Zwischenzeitlich diente auch der Raum eines privaten Kindergartens sonntags als provisorischer Tempelraum (vgl. Baumann, C. P. 2003, 283). Tamilische Männer bauten parallel dazu den Kellerraum von Baumanns Privathaus zu einem Tempelraum um. Am 14. Dezember 1986 wurde der Raum als Sakralstätte Amman geweiht. Die mürttis waren Farbdrucke und kleine

309 In Abschnitt IV 4.2 wird dargestellt, wie die Caritas den Akteuren bei den ersten Schritten der Ausführung gemeinschaftlicher Hindu-Praxis unterstützend zur Seite stand.

310 In Adliswil unterzeichnete beispielsweise das in Basel ansässige Katharina Werk, eine ökumenische Gemeinschaft mit interreligiöser Ausrichtung, den ersten Mietvertrag für den ersten Tempel.

311 Die Darstellung wird rekonstruiert anhand eigener Erhebungen und den Ausführungen des Mitinitiators des Tempels C.P. Baumann; vgl. dazu auch Baumann, C.P. 2003; DuchêneLacroix/Beutter 2011.

312 Als Asylbewerber lebten sie in einem Apartmenthaus in der Burgfelderstrasse 25. Die Männer hatten in ihren Zimmern jeweils einen Hausaltar, wo sie für sich pūcais vollzogen. 
Metallfiguren hinduistischer Gottheiten. Nach Aussagen Baumanns hatte damit «der erste tamilische Hindutempel in der Schweiz eröffnet» (Baumann, C.P. 2003, 283).

Am 14. April 1987 wurde im Erdgeschoss des Baumannschen Hauses das tamilische Neujahrsfest gefeiert. Dieser Raum diente als Meditationsraum ebenso wie als Versammlungsraum des Vereins INFOREL (vgl. Kap. I 3.) und stellte eine Kontaktzone für tamilische Migrantinnen und Migranten in Basel mit Schweizern dar. Am 26. April weihte der Priester auch diesen Raum zu einem hindu-tamilischen Tempel. Die Akteure stellten die Figuren und Abbildungen der Gottheiten aus dem Keller nun in diesem Raum auf. Auf einem Nebenschrein wurde ein Dreizack platziert, der den Gott Vairavan als Tempelwächter darstellte. Jedoch diente der Raum auch Sikhs als Andachtsraum, die jeweils am Sonntagvormittag ihren Gottesdienst feierten. Nachmittags feierten dann die tamilischen Männer ihre pūcai.

Nachdem in einem Schweizer Geschäft eine Figurine von Vināyakar gekauft worden war, wurde der Tempelraum dieser Gottheit geweiht. Nach Angaben von Baumann geschah dies, weil man die Verehrung von Amman als zu anspruchsvoll und zeitintensiv ansah: «Vinayakar hingegen sei gutmütig und verzeihend, so dass der Kult für ihn einfacher einzuhalten gewesen sei» (Baumann, C.P. 2003, 283).

Zentraler Bestandteil der pūcai war die Rezitation des Gayatri Mantras durch den Priester. 1989 kamen laut Baumann in der Regel etwa 30 Personen zu den pücais; an den Festen nahmen 60 bis 70 Personen teil, was die Kapazitäten des Raumes überstieg. Im März 1989 zog der provisorische Tempel in ein angemietetes Zimmer in einem Haus an der Burgfelderstrasse 25, in dem die tamilischen Geflüchteten in den ersten Jahren als Asylbewerber wohnten. Der Tempelraum bekam den offiziellen Namen Sithi Vināyakar-Tempel (vgl. Baumann, C. P. 2003, 284).

Am 19.09.1993 wurde im Rahmen der Vināyakar Caturtti-Prozession unter Anwesenheit von etwa 200 Personen die urcava- mūrtti durch das Viertel getragen und mehrere pūcais in der Öffentlichkeit vollzogen. Diese Prozession ist der erste Ausdruck hindu-tamilischer Praxis in die Schweizer Offentlichkeit. Die Inkorporationsbedingungen gestalteten die konkrete Form der Durchführung mit: Die Prozession war bei der Kantonspolizei angemeldet und bewilligt worden. Gesang wurde jedoch nicht erlaubt - die Anwohner wurden durch Handzettel informiert. Die Zahl der pūcaiBesucherinnen und Besucher stieg in der Folge stetig an, weshalb man sich wieder auf die Suche nach einer grösseren Räumlichkeit machte. ${ }^{313}$

313 Dies ist in erster Linie mit der steigenden Anzahl an tamilischen Geflüchteten in der Schweiz zu erklären. Daher würde ich Baumanns Aussage, dass «das Interesse für die eigene 
Das Beispiel des Entstehungsprozesses des ersten tamilischen HinduTempels in Basel zeigt den Einfluss der vorliegenden Inkorporationsbedingungen auf und macht deutlich, dass die Suche nach passenden Räumlichkeiten, die permanent genutzt werden können, besonders in den Anfängen der Immigration sehr herausfordernd war.

Die Organisationsstrukturen tamilischer Hindus haben sich in der Schweiz den Gegebenheiten des Residenzlandes angeglichen. Die rechtliche Form, in welcher sich tamilische Hindus bzw. Tempel organisieren, hängt ebenfalls von den Inkorporationsbedingungen ab. Religionsgemeinschaften, die nicht öffentlich-rechtlich anerkannt sind, können sich in der Schweiz nur in Form von Vereinen oder Stiftungen organisieren. ${ }^{314}$ Vereinsgründung wird meist bevorzugt, weil es hier wenige Hürden durch staatliche Regulierungen gibt (vgl. Beyeler/Suter 2008, 248). Individuelle Entscheidung ist es, ob sich die Vereine in einem staatlichen Register eintragen lassen. Beyeler und Suter verweisen darauf, dass die Abwesenheit staatlicher Kontrolle auch Ausdruck der fehlenden staatlichen Anerkennung der Existenz der Vereine sei. Durch die Organisation als Verein öffnet man sich auf formeller Ebene basisdemokratischen Prozessen. Dies stellt eine Neuerung gegenüber den Tempelstrukturen in der Herkunftsregion dar. Auch sind die Tempel in der Schweiz formell für alle Kasten offen.

In dieser Phase kam es auch zur Ausdifferenzierung in tamilische Kulturvereine und religiös ausgerichtete Tempelvereine, was in Abschnitt IV. 4.2 anhand des Beispiels des Kulturvereins Tamil Mandram und des Tempelvereins Turkkai Amman in Luzern näher dargestellt wird.

\section{Phase: Etablierung der Tempel-Praxis als Familienaktivität}

Mit dem Familiennachzug und der Entstehung von Familienstrukturen wandelte sich auch das Tempelleben in den provisorisch eingerichteten Räumen. Besuche eines nahegelegenen Tempels wurden als gemeinschaftliche Familienaktivität durchgeführt. Die religiöse Praxis innerhalb der Tempel wurde intensiviert und das Spektrum der Jahresfeste (auch mit öffentlichen Prozessionen), die gefeiert wurden, wurde erweitert.

Durch die Ankunft der Lebenspartnerinnen wurden auch viele ihrem eigenen Selbstverständnis nach nicht religiöse Männer aktiviert, in den

[hindu-tamilische] Religion und Kultur» zunahm, nur bedingt als Erklärung gelten lassen (Baumann, C.P. 2003, 284).

314 Die Organisationsform als Verein gestaltet sich in den meisten Fällen konkret so aus, dass der Vereinsvorstand einen Priester für den Tempel anstellt. Es gibt jedoch auch Ausnahmen: der Śrī Viṣnu Turkkai Ammañ Tempel anfangs in Adliswil und später in Dürnten ist nicht als Verein organisiert, sondern wird alleine vom Priester geführt. 
Tempel zu gehen. Arumugam berichtet beispielsweise, dass er vor der Ankunft seiner zukünftigen Frau in der Schweiz im Residenzland niemals einen Tempel besuchte. Auslöser für seinen ersten Tempelbesuch war, dass seine Verlobte zu ihm in die Schweiz kam und er zusammen mit ihr, als Paar, den Tempel aufsuchte: «Ich bin das erste Mal in den Tempel gegangen als meine Frau da war. Vorher bin ich nicht allein. Eigentlich gehe ich nicht.» ${ }^{315}$

Mit den Jahren etablierte sich der freitagabendliche Tempelbesuch für viele Familien immer mehr als eine gemeinschaftliche Familienaktivität. Mit dem Heranwachsen von Kindern wurde der kulturellen und religiösen Traditionsweitergabe immer grössere Bedeutung zugemessen.

\section{Phase: Ausdifferenzierung der Tempellandschaft und der Tempelvereine}

Mit der steigenden Besucherzahl in den Tempeln kam es auch zu einer Ausdifferenzierung der Tempellandschaft. Zum einen wurde das Spektrum des religiösen Angebots erweitert und es wurden neben den traditionellen Tempeln reformhinduistische Tempelvereine gegründet, wie beispielsweise der Tempel der Aum Sakthi-Bewegung. Bei vielen Akteuren kam es zu einer religiösen Horizonterweiterung, da sie nun auch begannen, diese neu etablierten Orte der Reformgruppen, wie auch christliche Orte, die in tamilischen Kreisen bekannt waren, zu besuchen. Zum anderen spalteten sich aufgrund von internen Differenzen Tempelvereine an einigen Orten ab und es kam zur Gründung unterschiedlicher Tempelvereine und zur Errichtung neuer Tempelräume. Als Beispiel sei die Situation in der Stadt Zürich genannt, die auch Bezüge zur spezifischen Diaspora-Situation aufweist. Im Züricher Stadtteil Affoltern wurde zusätzlich zum Śrī Civacuppiramaṇiyar Tempel, einem der ersten tamilischen Hindu-Tempel der Schweiz, der mit Hilfe von IRAS COTIS und der Stadt Zürich gegründet worden war, ein zweiter Tempel im ersten Stock einer angemieteten Wohnung eröffnet. ${ }^{316}$ In einigen informellen Gesprächen wurde erzählt, dass tamilische Akteure bewusst einen «Gegentempel» zum Tempel in Adliswil gründen wollten, wobei die Neugründung des Civankōvil vor allem auf politische Differenzen und die Positionierung zur LTTE zurückzuführen gewesen sei.

Hinzu kam, dass in unmittelbarer Nähe in Adliswil ein zweiter Tempel gegründet wurde. Der Priester des älteren Śrī Civacuppiramaniyar Tempels verliess diesen und gründete den Śrī Viṣnu Turkkai Ammañ Tempel am selben Ort. Dieser zog 2010 in ein ehemaliges Fabrikgebäude in Dürnten (Kanton Zürich) um, da der Mietvertrag in Adliswil auslief und der Priester sich

315 Interview 3; 09.10.2008.

316 Der Tempel befand sich in der Wehntalerstr. 293 und zog später nach Glattbrugg um. 
ohnehin einen für die Ritualvorschriften geeigneteren Raum wünschte; die Weihungszeremonien fanden am 27.01.2010 statt. ${ }^{317}$

Auch in der Basler Tempellandschaft bestanden zwischen 1998 und 2004 mehrere konkurrierende Tempel: Neben dem bereits 1989 gegründeten Sithi Vināyakar Alayam kamen zwei anderen Gottheiten gewidmete Tempel hinzu, der Sri Raja Rajeswary Ambal-Tempel und der Śrī Civacuppiramaniyar-Tempel.

\section{Phase: Bündelung des religiösen Engagements und Vernetzungen unter den tamilischen Hindus}

Eine gegenläufige Tendenz zu den in Phase 4 beschriebenen Prozessen stellten Bestrebungen dar, die religiösen Aktivitäten zu bündeln und Netzwerkstrukturen unter tamilischen Hindus in der Schweiz aufzubauen.

Die Gründung von Dachverbänden, um die Aktivitäten der tamilischen Hindu-Tempel zu bündeln und gemeinsam in der Schweizer Mehrheitsöffentlichkeit aufzutreten, wurde angedacht. Diese Versuche, einen innerhalb der Schweizer Gesellschaft aktiven Verband zu etablieren, waren im Untersuchungszeitraum noch nicht geglückt. ${ }^{318}$ Allerdings gab es inner-tamilische Netzwerke, die dem Austausch der Tempelvereine dienten.

Man legte Wert auf die Stabilisierung der Tempelvereine zur Gewährleistung der Kontinuität der religiösen Praxis, unter anderem durch Vermittlung religiösen Wissens an die nächste Generation. In Basel wurden 2004 die drei Tempel in einem angemieteten Gebäude in Muttenz zusammengelegt, wo sich der fusionierte Tempel bis 2009 befand. Baumann beschreibt die Motivation, einen fusionierten «Einheitstempel» zu schaffen, der den einfachen Namen Hindu Temple Base ${ }^{\beta 19}$ trägt, wie folgt: «Das [Aufrechterhalten dreier Tempel an einem Ort] führte zu einer Verzettelung der Kräfte. Jüngere Tamilen, die bisher in den drei Tempeln kaum engagiert waren, schafften es, alle Verantwortlichen an einen Tisch zu bringen». ${ }^{320}$

Der neugegründete Tempel war dann den drei Hauptgottheiten der vorangegangenen Tempel geweiht: Vināyakar, Amman und Murukan. Da die

317 Die Verantwortlichen des Tempelvereins bauten die angemietete Lagerhalle in der Edikerstrasse 24 vorab um: der Boden wurde u. a. wärmeisoliert. Vor dem Einzug und der Weihung der Götterstatuen erfolgte am 22.11.2009 die «Grundsteinlegung» des neuen Tempels. Der Gemeindepräsident Dürntens, Hubert R. Rüegg, war bei diesem Ritual anwesend. Der Priester bezog, wie auch schon in Adliswil, eine Wohnung im gleichen Gebäude wie der Tempelraum.

318 Eyer berichtet davon, dass der Verein Saivanerikoodam alle Tempelvereine in einer Dachorganisation zu organisieren versuchte, was jedoch nicht gelang (vgl. Eyer 2007, 96).

$319 \mathrm{Zu}$ beachten ist die englische Schreibweise von «Tempel», was auf die Positionierung innerhalb der transnationalen tamilischen Diaspora verweist.

320 www.inforel.ch/i22e1.html; 30.07.2015 


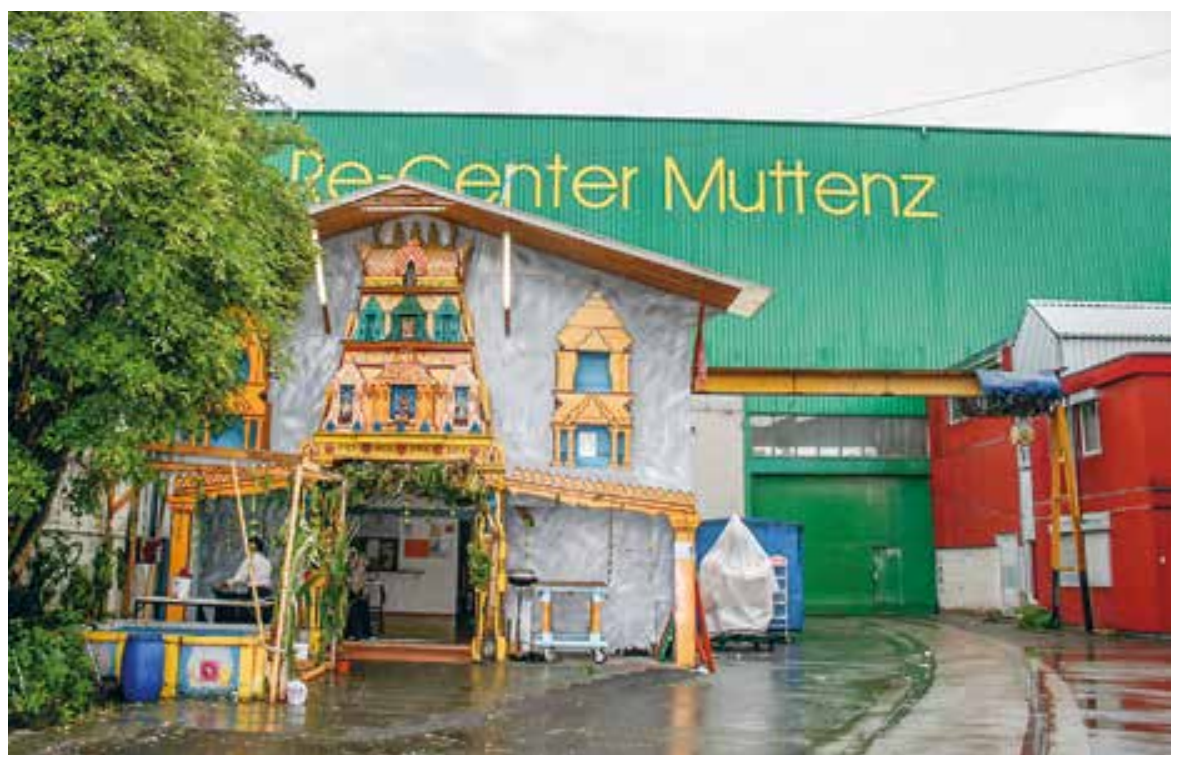

Abb. IV 10: Aussenansicht des tamilischen Hindu-Tempels in Muttenz bei Basel (2004-2009), entstanden aus der Fusion dreier Tempelräume (13.08.2008).

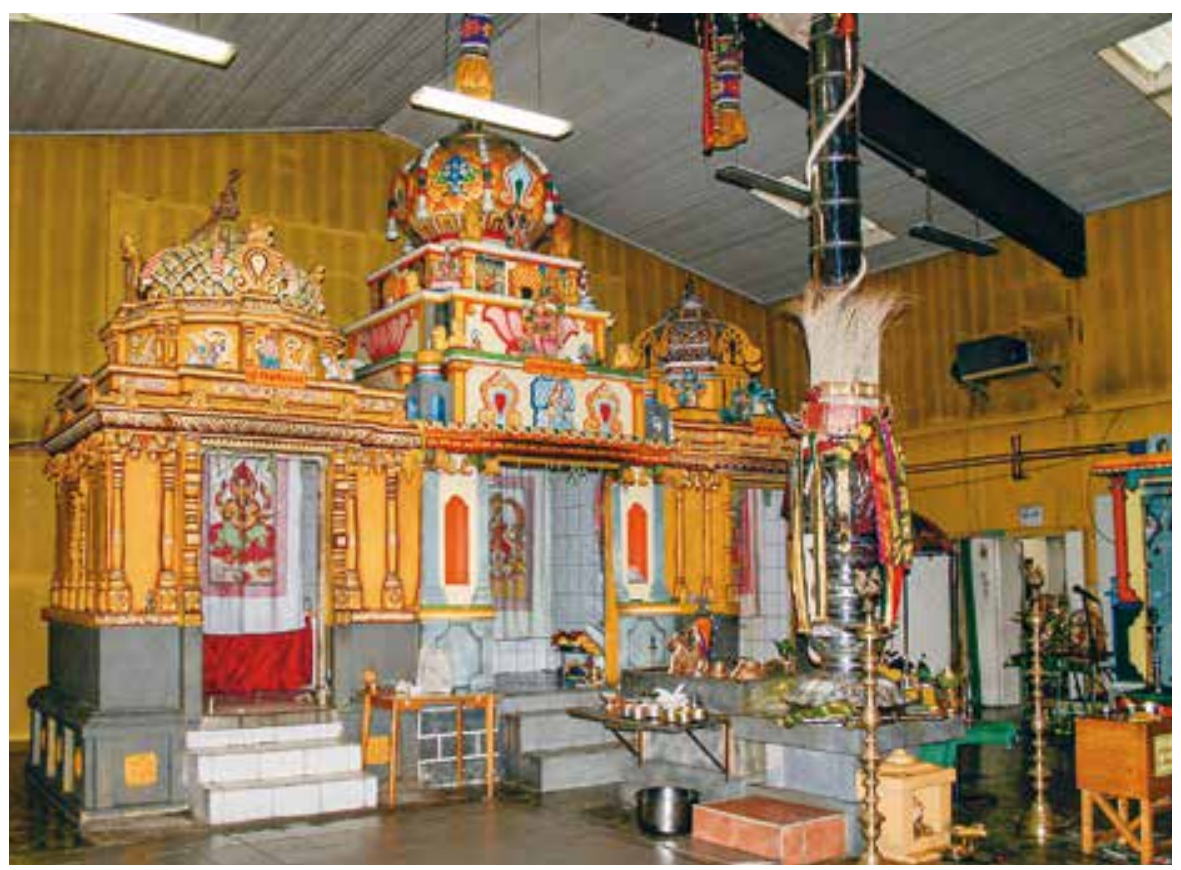

Abb. IV 11: Innenansicht des Tempels in Basel mit den drei Gottheiten Vināyakar, Amman und Murukan geweihten Schreinen (13.08.2008). 
Figur der Amman jedoch in der Mitte des Hauptschreins platziert ist, ihre Söhne zu ihrer rechten und linken, kann sie als Hauptgottheit des Basler Tempels angesehen werden.

In dieser Phase wurde auf die Vermittlung religiösen Wissens an die nächsten Generationen besonderen Wert gelegt. Des Weiteren wurde in die Residenzgesellschaft gerichtetes Engagement, wie beispielsweise solches im interreligiösen Dialog, intensiviert.

\section{Phase: Erwerb von Tempelräumen und Tempelbauprojekte / die Gründung von Stiftungen}

Die letzte Phase des Etablierungs- und Institutionalisierungsprozesses begann mit dem käuflichen Erwerb der Tempelräume und endete mit der Planung von Tempelbauprojekten. Diese Prozesse setzen voraus, dass die Migrantengruppe etabliert war und sich ihre monetäre Situation stabilisiert hatte. Grund für den Kauf von Räumen war, dass diese langfristig und selbstbestimmt nach den eigenen Wünschen eingerichtet werden konnten. In Basel wurde beispielsweise 2009 im Industrieareal Dreispitz ein Gebäude gekauft, in welchen dann der «Einheitstempel» aus den drei vorher nebeneinander bestehenden Tempeln umzog.

Nachdem der Hindu-Tempel Basel sich seit 2004 in Muttenz in einem mühevoll dekorierten Gebäude, inklusive kōpuram-Kulisse, befunden hatte, erhielt der Tempelverein Ende 2008 die Kündigung, weil das Areal verkauft wurde. Daraufhin war der Verein gezwungen, einen neuen Ort zu finden, und entschied sich, ein Gebäude zu kaufen, um nicht noch einmal umziehen zu müssen. 2009 erwarb der Verein in der Mailandstrasse 30 ein Gebäude, in dem provisorisch im ersten Stock ein Tempelraum eingerichtet wurde. ${ }^{321}$

Die Entwicklungen um den Sri Manōnmaṇi Ampāl Ālayam in Trimbach weisen ähnliche Parallelen auf. Hier entschieden sich die Akteure des Tempelvereins jedoch, ein Bauprojekt zu initiieren, und kauften Bauland, um den ersten nach religiösen Vorgaben errichteten Tempel der Schweiz zu bauen. Der Tempel wurde 2013 offiziell eingeweiht.

In dieser Phase gründeten tamilische Hindus als rechtliche Institutionalisierungsform auch Stiftungen. So wurde in Basel beispielsweise im Jahr

321 Der Tempelraum befand sich 2009 noch im ersten Stockwerk des Gebäudes. Es war geplant, zukünftig den Tempelraum ins Erdgeschoss zu verlagern und offiziell einzuweihen. Aufgrund der religiösen Vorgaben ist das Erdgeschoss der präferierte Ort für die Einrichtung eines Tempelraums. 


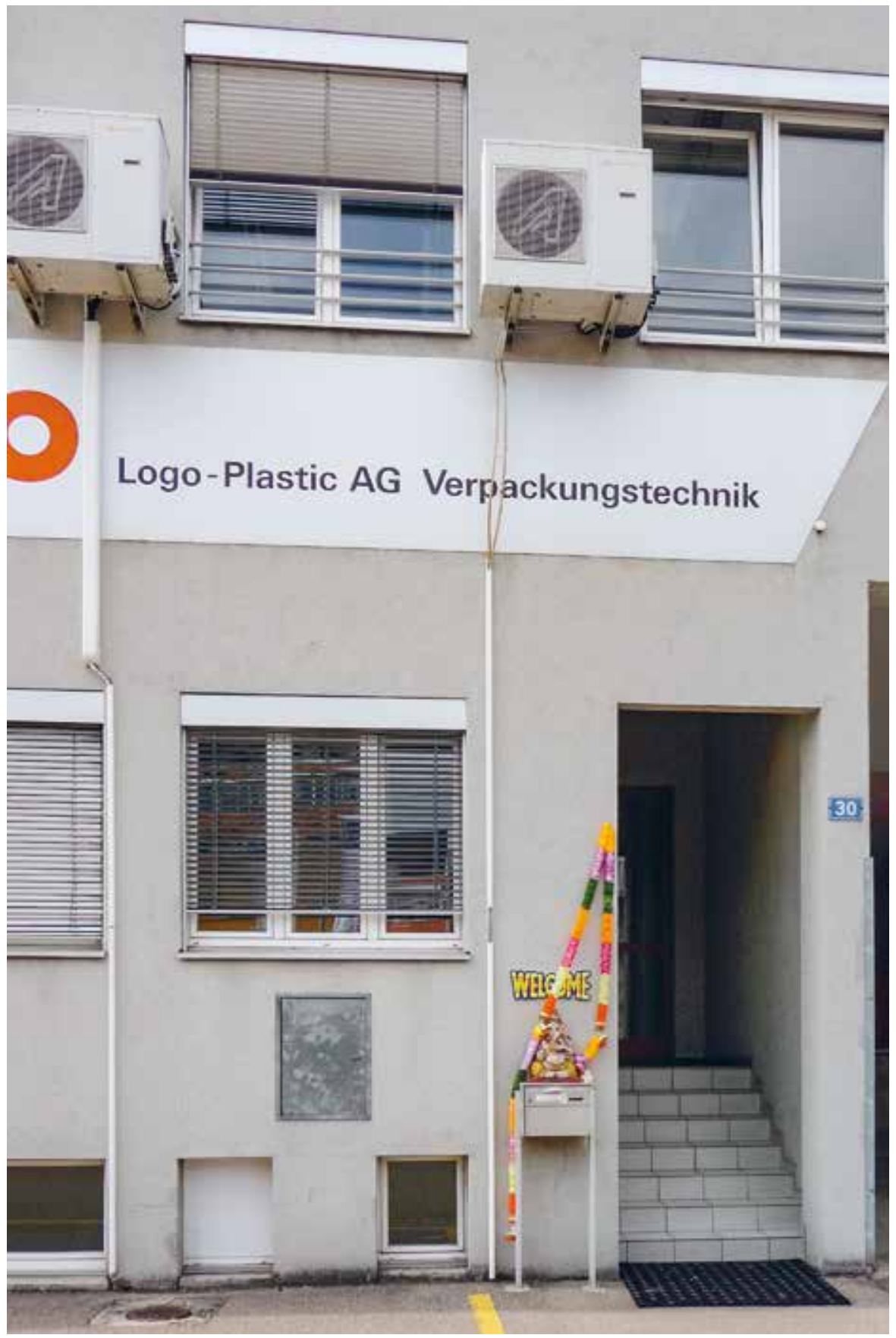

Abb. IV 12: Eingang des Basler Hindu-Tempel im käuflich erworbenen Gebäude im Dreispitzareal (08.04.2009). 


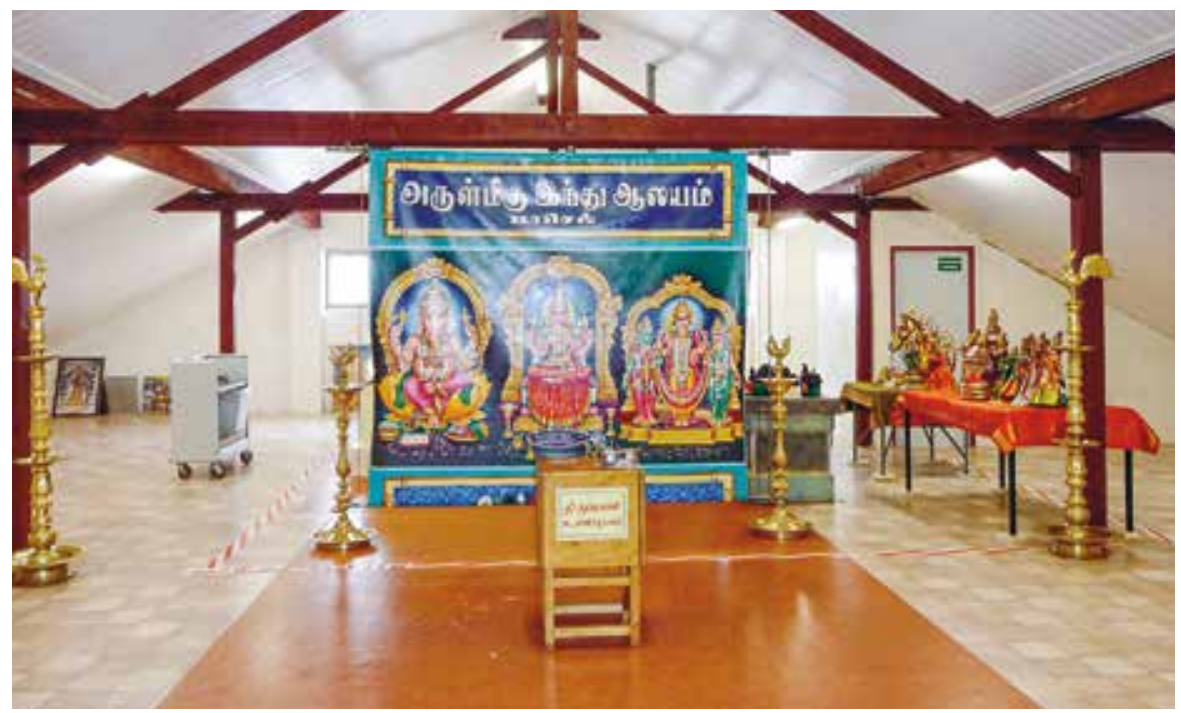

Abb. IV 13: Im Aufbau befindlicher Innenraum des Basler Hindu-Tempels im käuflich erworbenen Gebäude im Dreispitzareal (08.04.2009).

2008 die Stiftung Hindugemeinde mit Sitz in Muttenz ins Leben gerufen, welche den dortigen Tempel unterhielt. ${ }^{322}$

\section{Phase: Realisierung von Tempelbauprojekten und Instandhaltung der Tempelbauten}

Ein letzter Schritt für eine dauerhafte Beheimatung ist der Bau eines HinduTempels nach religiösen Vorgaben. Im Unterschied zu den oftmals durch ihren Mietvertrag zeitlich begrenzten Verehrungsorten wird so ein permanenter Ritualort geschaffen. Die religiöse Praxis kann gemäss Hindu-Vorgaben durchgeführt werden, wobei die Inkorporationsbedingungen auch hier Einfluss haben. Baubestimmungen und andere gesetzliche Vorgaben der Schweiz wirkten sich beispielsweise bei der Errichtung des ersten

322 Die Ziele der Stiftung sind laut Schweizerischem Handelsregister: «Einerseits Bau und Instandhaltung oder Einrichtung eines Hindutempels in der Nordwestschweiz. Andererseits Förderung und Pflege der tamilischen Kultur. Die Stiftung kann insbesondere den Bau und die Instandhaltung oder die Einrichtung eines Hindutempels finanziell unterstützen; weitere religiöse Projekte unterstützen; Projekte zur Förderung der tamilischen Kultur unterstützen; Projekte unterstützen, die dazu dienen, der nicht tamilischen Bevölkerung in der Schweiz die tamilische Kultur näher zu bringen und damit den interkulturellen Austausch zu fördern. Die Stiftung hat gemeinnützigen Charakter und verfolgt keinen Erwerbszweck.» (www.moneyhouse.ch/u/ stiftung_hindugemeinde_CH-280.7.011.706-4.htm, 28.11.2008). 


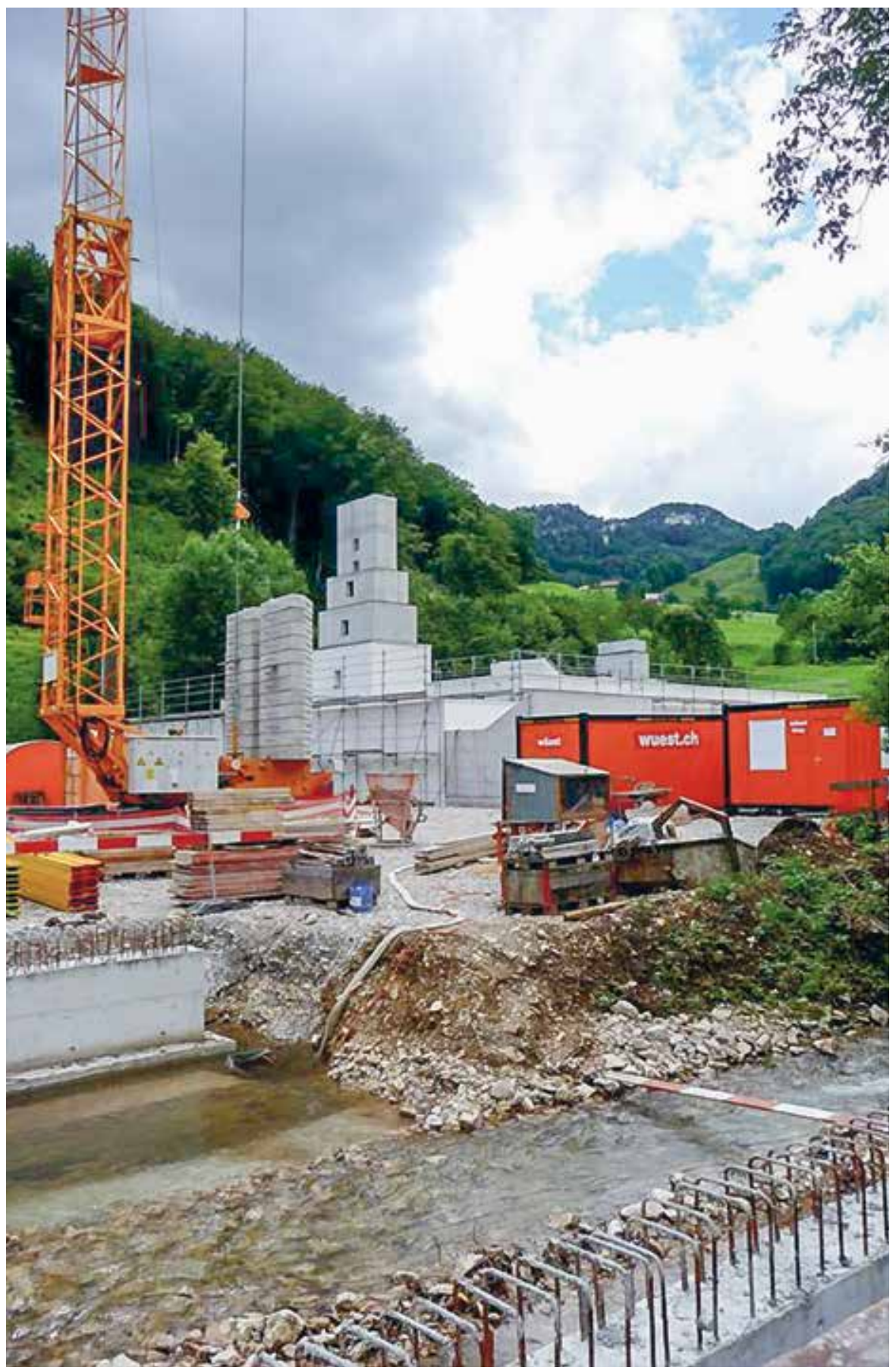

Abb. IV 14: Bauphase des Sri Man̄ōnmaṇi Ampāl Ālayam in Trimbach (04.03.2010). 
Hindu-Tempelbaus in der Schweiz aus. ${ }^{323}$ Nichtsdestotrotz konnten wichtige Bedingungen für als «authentisch» angesehene Praxis erfüllt werden, wie beispielsweise die Nähe zu einem fliessenden Gewässer. Nach der Einweihung der Tempel ist die Instandhaltung und öffentliche Präsentation des Tempels eine grosse Aufgabe der Verantwortlichen. Da die Tempelbauprojekte eine finanzielle Belastung für die Organisatoren waren, sind sie darauf angewiesen, dass der Tempel nun auch Geld erwirtschaftet und im religiösen Feld der tamilischen Diaspora bekannt wird.

\subsection{Tamil Mandram und der Turkkai Amman Tempel in Luzern: Kompartmentalisierungsprozesse in den Anfängen der Migration}

Die in Phase 2 dargestellten Prozesse um die Gründung von ethno-religiösen Vereinen durch tamilische Migrantinnen und Migranten sollen im Folgenden genauer anhand der Phasen der Etablierung des Tempels in Luzern und die dabei erfolgte Unterstützung durch kirchliche Flüchtlingshilfe dargestellt werden. Ausserhalb der privaten Wohnräume tamilischer Migrantinnen und Migranten im Kanton Luzern fand der erste institutionalisierte Vollzug von Hindu-Praxis in den Räumlichkeiten von Tamil Mandram wie auch in einem von der katholischen Kirche zur Verfügung gestellten Raum statt. Der tamilische Verein Tamil Mandram ${ }^{324}$ wurde im Mai 1991 unter Mithilfe der Caritas Luzern, der Caritas Schweiz und dem Kanton Luzern gegründet. Kurz darauf, am 20. Januar 1992, wurde in der römisch-katholischen Kirche St. Karl den Hindus ein Raum zur Verfügung gestellt, wo einmal in der Woche, an jedem Freitag, von einem Priester die pūcai durchgeführt wurde. Die Kirche liegt im sogenannten Basel-Bern-Quartier mit hohem Anteil an Bewohnerinnen und Bewohnern mit Migrationshintergrund. Vorher hatten tamilische Asylsuchende in der von der Caritas geleiteten Asylunterkunft Sonnenhof in Emmenbrücke einen Raum zur Verfügung gestellt bekommen. Auf der Webpräsenz des Turkkai Ammañ Tempels Luzern wurde dieser Raum als Gründungsort des Tempels angegeben. ${ }^{325}$

323 Detailliert dargestellt werden die Etappen der Entstehung des Tempels in der von Martin Baumann und Andreas Tunger-Zanetti herausgegebenen Broschüre «Der Hindutempel in Trimbach. Von der Idee bis zur Einweihung» (Baumann/Tunger-Zanetti 2014).

324 Manram bedeutet so viel wie «Gemeinderat, Rat, Versammlung». Tamil Mandrams gibt es in verschiedensten Residenzländern der tamilischen Diaspora - zum Beispiel den facksonville Tamil Mandram in Florida/USA (vgl. http://jaxtamilmandram.org; 01.10.2010).

325 Das Datum der Gründung wird mit 01.Juli 1991 benannt. «Jeden Freitagabend trafen sich die Gläubigen während 3Stunden zum Gebet» (http://thurkkai.com; 5.1.2021). 
Dem Verein Tamil Mandram ging eine informelle Organisation von Tamilinnen und Tamilen voraus, die das zentrale Ziel hatte, Schulunterricht in tamilischer Sprache für ihre Kinder zu initiieren. Sprachunterricht hatte für die tamilischen Akteure Priorität vor gemeinschaftlichem öffentlichem Vollzug von Hindu-Praxis.

Etwa fünfzehn tamilische Kinder lebten 1990 im Kanton Luzern. ${ }^{326}$ Dass tamilische Geflüchtete trotz der unsicheren Lebensumstände und der Notwendigkeit der Neuorientierung auf unterschiedlichsten Ebenen in fremder Umgebung die sozialen Ressourcen aufbrachten, um bereits 1990 gemeinschaftlichen Tamilisch-Unterricht für ihre Kinder zu organisieren, zeigt die enorme Wichtigkeit der Weitergabe der Sprache für die erste Generation. Gerade der ungesicherte Aufenthaltstatus war Anreiz, den Kindern gute Voraussetzungen einer Eingliederung in Sri Lanka nach einer eventuellen gezwungenen Rückkehr zu bieten oder sie auf eine Rückkehr nach Kriegsende vorzubereiten. Wie an unterschiedlicher Stelle in dieser Studie gezeigt, kommt dem Tamilischen als der Sprache der transnationalen Diaspora eine besondere Bedeutung zu, auch vor dem Hintergrund der die tamilische Sprache marginalisierenden Sprachpolitik innerhalb der Geschichte Sri Lankas (vgl. Abschnitt III 2 und das Fazit der Studie).

Auch das erste Angebot eines organisierten Tamilisch-Unterrichts wurde bereits von der Caritas unterstützt. Am 22. Oktober 1990 startete der Unterricht in einem Raum im Luzerner Bahnhof mit elf Kindern und einem Lehrer. Da immer mehr Eltern für ihre Kinder Interesse am Unterricht zeigten und die Räumlichkeiten beengt waren, zog die Tamil-Schule in das Schulgebäude der öffentlichen Schule Moosmatt (Voltastrasse 35) um. ${ }^{327} 1991$ entstand aus der Tamil-Schule ein Verein, der einen «Treffpunkt für Tamilinnen und Tamilen im Kanton Luzern» betreiben sollte. Die Gründung wurde von einer Begleitgruppe der Caritas unterstützt, die finanzielle Ressourcen bereitstellte. Die Caritas organisierte auch eine 4-Zimmer-Wohnung in einem Altbau im Zentrum der Stadt Luzern als öffentlichen Treffpunkt, der am 1. Februar 1992 eröffnet wurde. Öffentlich wurde der Treffpunkt durch Mund-zu-Mund-Werbung wie auch ein Schreiben der Caritas an alle gemeldeten Tamilen im Kanton Luzern (vgl. Caritas Luzern 1992).

Tamil Mandram war als Verein organisiert; die Organisationsstruktur sah vor, dass der tamilische Vorstand durch eine aus Mitarbeitenden der

326 Die folgenden Angaben sind den im Staatsarchiv Luzern archivierten Berichten der CARITAS des Kantons Luzern, Bereich Flüchtlingshilfe, aus dem Jahr 1992 entnommen.

327 Diese Angaben entstammen der nicht mehr aktiven Homepage: www.lutamilmandram. ch/index.php?option=com_content $\&$ task=view\&id=21\&Itemid=51; 01.10.2010. Aktuell präsentiert sich der Verein virtuell unter http://www.tamilmandram.ch. 
Caritas bestehenden Begleitgruppe unterstützt wurde. Tamil Mandram diente mehreren Bedürfnissen der tamilischen Immigrantinnen und Immigranten. Zentral waren die Vermittlung von Sprachkompetenzen und die Schaffung eines gemeinschaftlichen Ortes im Kanton Luzern. Als Projektziele wurden vom Verein bei seiner Gründung unter anderem folgende Punkte formuliert:

a) Sozialer Treffpunkt: Die Räumlichkeiten von Tamil Mandram dienten in erster Linie als Treffpunkt der etwa 1000 Tamilen, die im Kanton Luzern angesiedelt waren. «Der Treff bietet auch die Möglichkeit, sich in einem geschützten Raum zu treffen, sich zu unterhalten und Informationen auszutauschen» (Caritas Luzern 1992, 2).

b) Ort des Informationsbezugs: Der Treffpunkt war Ort des Informationsbezugs über die Situation im Herkunftsland durch persönlichen Austausch von Neuigkeiten und Zeitungen. Anfang der 1990er Jahre stellten Printmedien noch das zentrale Medium dar, welches die tamilischen Geflüchteten über den Fortgang des Konflikts in Sri Lanka informierte. Nach und nach wurden Printmedien durch das Internet sowie persönliche Nachrichtenvermittlung durch das Telefon ersetzt.

c) Förderung der Fähigkeit der Reintegration bei Rückkehr ins Herkunftsland: Hier wird in erster Linie der Tamilisch-Unterricht für Kinder genannt. Aber auch die Pflege der tamilischen Kultur fällt in diesen Bereich. So wurde etwa eine Bibliothek mit tamilischen Büchern eingerichtet.

d) Stärkung tamilischer Kultur. Als Massnahmen wurden in erster Linie die Bibliothek und Tamilisch-Unterricht für Kinder ausgeführt.

e) Angebote zur Integration durch «Förderung der Fähigkeit der Selbsthilfe»: Zentral waren hier die angebotenen Deutschkurse, die von den Vorstandsmitgliedern organisiert wurden.

Im Laufe der Etablierung der Aktivitäten von Tamil Mandram wurde der Wunsch geäussert, auch religiöse Anlässe, womit im Feld von HinduTraditionen anzusiedelnde Praktiken gemeint waren, mit ins Programm aufzunehmen. Das Initiieren von Hindu-Aktivitäten diente anfänglich in erster Linie der Weitergabe tamilischer Hindu-Traditionen an die nächsten Generationen, was die folgenden Beispiele zeigen.

Die erste institutionalisierte Hindu-Feier im Kanton Luzern, neben der freitäglichen pūcai in St.Karl, war das im Hindu-Monat Ashvin stattfindende Jahresfest Navarāttiri (skr. Navarātri). In den drawidischen Gebieten Südasiens wird dem siebten Tag des Festes, welcher der Göttin des Wissens und Lernens Saraswati gewidmet ist, besondere Bedeutung zugemessen. Im Bericht der Caritas-Begleitgruppe wird es als «tamilisches Fest zum Schulanfang» bezeichnet (vgl. Caritas Luzern 1992, 4), womit es auch ein auf die 
nachfolgende Generation und ihre Bildung gerichteter Anlass ist. Im September 1992 wurde laut dem Zwischenbericht der Caritas-Begleitgruppe in den Räumlichkeiten des Tamil Mandram durch einen Priester an neun Tagen Navarāttiri gefeiert.

Die Etablierung von Hindu-Religionsunterricht war ein zweites wichtiges Anliegen, was sich auch an die in der Schweiz aufwachsenden tamilischen Kinder richtete und der Weitergabe von religiös-kulturellem Wissen diente. Der Religionsunterricht wurde 1993 eingeführt. Er wurde während circa 40 Wochen im Rahmen von drei Wochenstunden angeboten.

Im Laufe der Etablierung von Tamil Mandram wurden religiöse Anlässe immer mehr ausgelagert und die Aktivitäten in übergeordnet tamilische und spezifische Hindu-Handlungen unterteilt. Diese hier zu beobachtenden Prozesse können mit Rückgriff auf den Sozialanthropologen Milton Singer «Kompartmentalisierung» genannt werden. Er entwickelte das Konzept der compartmentalization anhand von Ausdifferenzierungsprozessen unterschiedlicher Lebensbereiche von Hindus im heutigen Chennai (vgl. Singer 1972).

2000 mieteten tamilische Hindus eine Lagerhalle in Gisikon Root bei Luzern, da die Besucherzahl für den Raum im Kirchengebäude zu gross war. Am 07.Juli 2000 wurde der Turkkai Amman Tempel Luzern eröffnet und ein eigener Tempelverein, die Tamilische Hindu Kultur-Gemeinschaft Luzern, gegründet. ${ }^{328}$ Tamil Mandram etablierte sich mit dem Schwerpunkt auf heimatliche Sprache und Kultur-Unterricht (HSK) in der Tribschenstrasse 51 und weiteren Standorten, bevor er in die Luzernerstrasse 127 umzog.

Im Untersuchungszeitraum war Tamil Mandram ein Ort, der sich in erster Linie als Bildungseinrichtung für Tamilen im Kanton Luzern versteht. Auf der Webpräsenz wurde er 2010 als The Home of Tamil Nation Tamilmandram - The home of tamils in Luzern Switzerland bezeichnet, was auf den Anspruch verweist, Treffpunkt aller Tamilen der tamilischen «Nation ${ }^{329}$ und «Heimat» im Kanton Luzern zu sein. Seit 2009 wird kein Religionsunterricht mehr in den Räumlichkeiten von Tamil Mandram in der Tribschenstrasse angeboten; auch werden dort keine Hindu-Feste mehr

328 Im Schweizerischen Handelsregister werden an erster Stelle folgende Aufgaben genannt: «Aufbau, Stärkung und Pflege der tamilischen Kultur, Sprache und Religion sowie der religiösen Seelsorge; Errichtung und Unterhalt unter der Bezeichnung «Amman Hindu Tempel Luzern> in der Zentralschweiz einen für in der Schweiz wohnende Gläubige der tamilischen Hindu-Kultur öffentlich zugänglichen Tempel» (www.moneyhouse.ch/u/tamilische_ hindu_kultur_gemeinschaft_luzern_CH-100.6.794.022-0.htm; 01.08.2015).

329 Die Bezeichnung "The Home of Tamil Nation" weist darauf hin, dass der Verein von einer tamilischen Nation ausgeht, welche sich auf international geltendes Völkerrecht berufen kann. 
gefeiert. Diese finden, als Ergebnis des Kompartmentalisierungsprozesses, nun im Turkkai Amman Tempel statt.

Am Namen und den Aufgaben des Tempelvereins ist jedoch zu erkennen, dass er sich nicht auf das compartement Religion beschränkt, sondern sich als kulturell tamilischer und religiös hinduistischer Verein versteht. Hier interferieren, wie in den meisten tamilischen Tempeln der Schweiz, Tamilness und Hinduness.

Im Kanton Luzern haben sich also, so lässt sich zusammenfassend sagen, zwei zentrale selbstverwaltete Orte von Tamilen etabliert: Tamil Mandram als Ort der Kultur- und vor allem Sprachpflege und der Turkkai Amman Tempel als Ort der Ausführung von tamilischer Hindu-Praxis. Die dargestellten Prozesse betonen die Wichtigkeit eines sozialen Treffpunkts für die Migrantinnen und Migranten in der ersten Zeit nach ihrer Ankunft in der Schweiz, der tamilischen Sprache für diese, der Tamilness der Aktivitäten und Rückbezüge zum Herkunftsland.

\title{
4.3 Doing Temple: Der Prozess der Tempelwerdung eines Gebäudes
}

\author{
Ein Tempel ist ein geweihter, heiliger Ort. Umfang- \\ reiche Rituale haben die göttliche Kraft (Tamilisch: \\ Sakthi) herbeigerufen und in den Statuen, die \\ Götter darstellen, präsent werden lassen. Nach \\ unserem Glauben residieren im Tempel nun die \\ Götter.
}

(Handzettel der Gruppe Saivanerikoodam) ${ }^{330}$

Die Mehrzahl der von tamilischen Hindus in der Schweiz als Tempel definierten Gebäude waren, wie bereits gezeigt wurde, diasporabedingt ursprünglich «profane» Orte ohne religiöse Bedeutung, die durch Umwidmung eine neue Bedeutungszuschreibung zu religiös definierten und bedeutsamen Orten erlangt haben.

Das Gros der Tempel in der Schweiz kann als Innen-Tempel bezeichnet werden: Das materielle Gebäude, welches die äussere Grenze des Tempels darstellt, ist nach aussen hin und zur Mehrheitsgesellschaft gerichtet kaum

330 Handzettel der Gruppe Saivanerikoodam, welcher beim Tag der offenen Tür am 10.06.2008 im Katirvēlāyuta Cuvāmi Tempel in St. Margrethen verteilt wurde. 
als religiöser Ort erkennbar. Meist sind es nur Kennzeichnungen, wie ein tamilisches $\bar{O} m$-Zeichen oder Schilder (vgl. Kap. V 2.1), welche die Gebäude nach aussen hin als Sakralräume sichtbar machen.

Die Gebäude selbst sind nicht von Hindu-Akteuren errichtet worden, sondern dienten zuvor meist als Lager- oder Fabrikhallen. Sie wurden also nicht als Tempel gebaut, sondern mussten erst zu Tempeln werden. Gemäss des in der vorliegenden Studie zugrunde gelegten aktionsorientierten Ansatzes kann hier von doing temple gesprochen werden: Die Gebäude sind nicht per se Tempel, sondern werden von den tamilischen Akteuren erst zu Tempeln gemacht.

Welche Bedingungen müssen erfüllt sein, dass Akteure in der tamilischen Diaspora in der Schweiz einen Raum als Hindu-Tempel bezeichnen? Dieser Frage kommt besonderer Stellenwert zu, da sich in der Schweiz bis zum Abschluss der Feldforschung im Jahr 2013 bis auf eine Ausnahme kein dezidiert als Hindu-Tempel gebautes Gebäude befand. Architektonische Merkmale, welche in konventionellen Definitionen einem Hindu-Tempel zugeschrieben werden, fallen für den Grossteil der Tempel somit weg. Welche Merkmale haben die Lokalitäten gemein, die von den hindu-tamilischen Akteuren im Kontext der tamilischen Diaspora in der Schweiz als Tempel bezeichnet werden?

Religionswissenschaftlich liegen verschiedene Definitionen des Begriffs Tempel vor. Im Kontext tamilischer Hindu-Traditionen in der Schweiz ist eine solche Definition für die hier versuchte Analyse nur dann hilfreich, wenn sie die nicht durch architektonische Merkmale erkennbaren Tempelräume klar von der religiösen Praxis im häuslichen Bereich abgrenzt. Christoph Auffarth $(2006,517)$ benennt als wichtiges Kriterium für einen Tempel «ein grosses dauerhaftes Bild», welches die Präsenz einer Gottheit anzeigt. Dies trifft auf die Hindu-Tempel in der Schweiz zu, aber auch auf Schreine im häuslichen Bereich. Eveline Masilamani-Meyer $(2004,89)$ geht von einer weiten Begriffsbestimmung aus: "A temple is a particular space, a circumscribed piece of land that is distinguished from the rest by being the place of residence of a divine power". Auch im Kontext der tamilischen Diaspora in der Schweiz wird unter Tempel ein abgetrennter Raum verstanden, dem von den Akteuren das Innewohnen göttlicher Kraft zugeschrieben wird. Aber auch diese Definition ist unklar, da sie auch auf die im privaten Bereich vorzufindenden Orte der pūcai zutrifft. Unklar bleibt auch, wie ein bestimmter Raum zu einem Raum der «residence of a divine power» wird.

Im Folgenden soll versucht werden, die Minimalanforderungen, welche einen Raum im Exil in den Augen der Akteurinnen und Akteure zu einem hinduistischen Tempel machen, zu skizzieren. Diese auf dem Selbstverständnis tamilischer Hindus basierende Arbeitsdefinition bezieht sich auf 
hindu-tamilische Tempel in der europäischen Diaspora. Anzumerken ist, dass es religiös konservative Gruppierungen gibt, welche neben diesen Anforderungen - die als Basis anerkannt werden - noch weitere als unabdingbar ansehen.

Die in der folgenden Arbeitsdefinition formulierten Merkmale, welche einen tamilischen Diaspora-Tempel beschreiben, verweisen immer auch auf Grenzbereiche und Konfliktfelder, in welchen religiöse Zugehörigkeiten verhandelt werden. Diese einer genauen Analyse zu unterziehen, ergibt Aufschlüsse über das religiöse Feld.

Als Hindu-Tempel werden in der tamilischen Diaspora in der Schweiz von den Akteuren Räume bezeichnet, in welchen mindestens ein (a) religiöses Bildnis einer (b) dem hinduistischen Spektrum zugeordneten Gottheit (c) rituell installiert wurde, die (d) regelmässig (e) öffentlich zugänglich unter Anleitung eines (f) Priesters (g) verehrt wird (vgl. auch C. P. Baumann 2003, 277f).

\section{a) Religiöses Bildnis}

Unabdingbar für einen als Hindu-Tempel bezeichneten Ort ist mindestens ein dem religiösen Feld zugeordnetes Bildnis, wobei die Anzahl beliebig sein kann. Diese stellen die Gottheit selbst dar, mit welcher Hindus kommunizieren. Als «Präsenzmarker» (Auffarth 2006, 75) können zweidimensionale Darstellungen oder metallene oder steinerne Statuen dienen. Unterschiedliche Meinungen bestehen darüber, was ein adäquates Bild für einen Tempel ist. Akteure kritisieren, dass es sich bei vielen Statuen um keine professionell als mürttis erstellten Statuen handele. Dabei spielt besonders das Material, aus welchem die Figur beschaffen ist, eine wichtige Rolle. Die Diaspora-Situation liess es zu Beginn der tamilischen Migration in die Schweiz nicht zu, dass traditionelle, für die Tempel-Rituale vorgesehene Statuen erworben werden konnten. Dies hatte mehrere Gründe: Zum einen gab es in der Schweiz und im europäischen Umfeld keine Bezugsmöglichkeit und zum anderen liess die ökonomische Situation der Gruppe den Erwerb der zum Teil kostspieligen Statuen nicht zu. Ausserdem war nicht klar, ob sich eine solche Investition überhaupt lohnt, da man nicht wusste, wie lange man im Diaspora-Land bleiben würde.

\section{b) Gottheit, welche als hinduistisch gekennzeichnet wird}

Diese Abbildung wird als eine Gottheit angesehen, welche von den Akteuren dem hinduistischen Spektrum zugerechnet wird. Im Kontext tamilischer Hindu-Traditionen in der Schweiz sind es in der Regel der CaivamTradition zugeordnete Götter und Göttinnen. Zentral ist auch die Namensgebung des Tempels. Dieser wird nach dem/der als Hauptgottheit 
angesehenen Gott/Göttin benannt. Damit kann der Tempel in der Öffentlichkeit namentlich genannt und auf ihn verwiesen werden.

\section{c) Installation der Gottheit}

Diese Darstellung einer Hindu-Gottheit muss durch ein Ritual installiert werden. Es muss einen feierlichen Akt der Installation der Gottheit an diesem Ort geben.

\section{d) Regelmässigkeit der Verehrung}

Die Verehrung der Gottheit muss einem Rhythmus folgen und regelmässig sein. Es muss ein bestimmter Tag in der Woche oder eine bestimmte Uhrzeit am Tag für die Verehrung vorgesehen sein.

\section{e) Öffentlicher Zugang}

Der Ort des Tempels muss innerhalb der community bekannt gemacht werden und öffentlich zugänglich sein. Die meisten Tempel betreiben eine Webpräsenz (vgl. Abschnitt V 2.3) und geben jährlich einen Kalender mit den wichtigsten Festtagen des Tempels heraus.

\section{f) Priester}

Die zentralen rituellen Handlungen werden durch Personen durchgeführt, denen die Rolle als Priester zugeschrieben wird. Es finden Aushandlungsprozesse darüber statt, wer als Priester bezeichnet werden darf und wer nicht.

\section{g) Rituelle Verehrung}

Die Gottheiten müssen nach einem vorgegebenen Ablauf rituell verehrt werden. Hier sind vor allem die Waschungen der Gottheiten (tam. apicēkam, skr. abhișekam) zu nennen, während derer die Götter und Göttinnen mit verschiedenen Materialien wie Milch und Wasser gereinigt werden.

Neben der Bestimmung, dass es sich bei einem Ort um einen «Tempel» handelt, wird in der emischen Perspektive häufig normativ zwischen «nicht richtiger Tempel» und «richtiger/echter Tempel» unterschieden. Diese Differenzierung wurde in den Interviews und Gesprächen immer wieder geäussert. Wird ein Ort als Tempel angesehen, gelten spezifische Bestimmungen, die eingehalten werden sollten, um den Ort nicht zu verunreinigen. In den meisten Tempeln zählt dazu, keine Schuhe zu tragen, am selben Tag vorab keinen Alkohol zu trinken, kein Fleisch zu essen, keine Haustiere mit in den Tempel zu bringen und die Schreine der Gottheiten nicht anzufassen. Die Regulierung, dass Frauen während ihrer Menstruation den Tem- 
pel nicht betreten dürfen, gilt nicht in den Reform-Tempeln der Aum SakthiBewegung.

Über die dargestellte Minimaldefinition hinaus lassen sich zusätzliche Merkmale aufzählen, welche einen Tempel zu einem «richtigen Tempel» machen. Diese Kriterien wurden im Tempelbauprojekt in Trimbach durch die Sakralarchitektur und das Errichten eines kōpurams verwirklicht (vgl. Kap. V 2.2).

\subsection{Weitere Aspekte der Tempellandschaft in der Schweiz: die Etablierung von Reform-Tempeln}

In den dreissig Jahren seit der Ankunft der ersten Tamilen konnte ein weites Netz an tamilischen Hindu-Tempeln in der Schweiz aufgebaut werden. Eine Besonderheit stellte der Melmaruvathur Adiparasakthi Amma Tempel im Industriegebiet in Kirchberg (Kanton Bern) dar, der sich zunächst in Lyss/Suberg befand. ${ }^{331}$ Dieser und weitere kleine Tempelräume ${ }^{332}$ sind Zentren der hinduistischen Reformbewegung Aum Sakthi (tam. Ōm Cakti), die sich durch soziales Engagement auszeichnet (vgl. David 2010). Ihrem im indischen Bundesstaat Tamil Nadu lebenden Guru Sri Bangaru Adigalar (geboren 1941) werden heilende Kräfte zugesprochen, da er als Verkörperung von Amma, der göttlichen Mutter, gilt. Die Bewegung fordert traditionelle patriarchale Standpunkte und Praktiken innerhalb von Hindu-Traditionen heraus. Zentrale Botschaft ist die Gleichheit aller Menschen, zum Ausdruck gebracht durch das Tragen roter Gewänder, welche die Farbe des Blutes aller Menschen symbolisieren soll. Eine Besonderheit der AumShakti-Bewegung ist die Geschlechtergleichheit beim Vollzug der pūcai: Da es die Funktion eines zentralen Brahmanen-Priesters nicht gibt, können Männer wie auch Frauen den pūcai-Dienst ausführen. Die Ambivalenz der Verehrung einer göttlichen weiblichen Kraft verkörpert durch eine männliche Autorität beschreibt Ann David in einer Studie zum Reformtempel im Londoner Stadtteil East Ham wie folgt:

331 Der Tempelverein, der laut Vereinsstatuten Aum Sakthi (Melmaruvathur Adhiparasakthi Kultur-, Gebet- und Sozialverein der Tamilische Volk in der Schweiz) heisst, wurde 2001 gegründet (vgl. Kessler 2013, 275). Bis 2008 war der Melmaruvathur Adiparasakthi Amma Tempel in Lyss in einer angemieteten Lagerhalle lokalisiert, danach zog er nach Kirchberg um. Die Bewegung initiierte in Belp ein Tempelbauprojekt, welches jedoch 2007 scheiterte (vgl. Kap. V 2.2; Kessler 2013).

332 Tempelräume der Reform-Gruppe befanden sich 2008 in Regensdorf (Kanton Zürich) und in La Chaux-de-Fonds (Kanton Neuenburg). 
a Hindu female-managed and negotiated space that takes its authority from a Godly female power manifest through a human male form. It challenges traditional patriarchal views and practices that have historically dominated religion. $(2010,350)$

Die von sri-lankischen Tamilen geführten Reform-Tempel stellen einen globalisierten öffentlichen Raum des Empowerments von Frauen dar, welche auch in den öffentlichen Sphären diasporischer Hindu-Traditionen marginalisiert werden (vgl. Reddy/Zavos 2010, 251).

Die Bedeutungsverschiebung, welche die Institution Tempel erlebte, wird im folgenden Abschnitt exemplarisch anhand der Analyse des Jahresfestes taipponkal dargestellt.

\section{Das Jahresfest taipporikal als Beispiel für den Prozess der Tempelisierung}

Auch die Praxis der hinduistischen Jahresfeste wird in der Diaspora neu organisiert. Die Reinszenierung dieser Anlässe im neuen Umfeld bewirkt, dass es zu Bedeutungsverschiebungen und Veränderungen in der Durchführung kommen kann - abhängig von den Umgebungsfaktoren und den internen Diskursen innerhalb der Diaspora. Eine Auswirkung kann die Verlagerung von Hindu-Praxis vom Wohnraum hin in den öffentlichen Tempel sein.

Der wissenschaftliche Neologismus temple-isation bringt die wachsende Bedeutung von Hindu-Tempeln in der Diaspora zum Ausdruck. Die von der Religionswissenschaftlerin Vasudha Narayanan aufgestellte These besagt, dass die Institution Tempel aufgewertet und die Hindu-Praxis vom häuslichen Bereich in den Bereich des Tempels verschoben wird (vgl. Narayanan 2006; Baumann 2009b). Damit gehen unterschiedliche dynamische Prozesse einher. Narayanan bezieht den in wissenschaftlichen Diskursen oftmals vernachlässigten Aspekt der Gender-Rollen in Diaspora-Situationen mit in ihre Analyse ein: Ihre These impliziert, dass die religiöse Funktion von Frauen in der Diaspora marginalisiert und die Rolle des Priesters aufgewertet werde. Nach Narayanan finde im Exil ein Machtzuwachs des Priesters statt und die patriarchale Organisation der Religionsausübung werde verfestigt.

Im Folgenden stelle ich das Erntefest taipponkkal ${ }^{333}$, welches jährlich Mitte Januar auch in der Schweiz gefeiert wird, als Beispiel für den Transfer

333 Tai bezeichnet den zehnten tamilischen Monat. Das tamilische Verb ponkkal bedeutet «überkochen» und nimmt Bezug auf den Höhepunkt des Festes, das Überkochen von Milch. Taipponkal bedeutet somit Überkochen, ponkkal, im Monat tai. Um die Zusammensetzung der 
eines Jahresfestes, dessen örtliche Durchführung sich in der Diaspora in den öffentlichen Tempelraum verschiebt, genauer dar. Der Śrī Civacuppiramaniyar Tempel in Adliswil beschrieb 2009 auf seiner Homepage die Bedeutung des Festes wie folgt:

Thai Pongal day is an important day for farmers and this is conducted on the 14th of January every year. In the house of every Hindu Family Thai pongal is celebrated in their respective houses. Sweet milk rice is cooked which is called "pongal". ${ }^{334}$

Taipponkkal ist zugleich ein Fest, welches Akteure als einen spezifisch tamilischen Anlass verstehen. Es ist von grosser Bedeutung für viele tamilische Menschen, die sich bemühen, das Fest als Teil des tamilischen Erbes auch in fremd-kultureller Umgebung zu feiern, was als beispielhafter Ausdruck eines tamilischen Diaspora-Bewusstseins gedeutet werden kann (vgl. Abschnitt II 1). Unterschiedliche Bedeutungszuschreibungen des Festes zeigen charakteristische inner-tamilische Diskussionen in Bezug auf das Verhältnis der Sphären Religion und Kultur auf. Darüber hinaus wird anhand der Praxis von taipponkal in der Schweiz deutlich, dass Hindu-Feste in der Diaspora Modifikationen - auch in Bezug auf Zuständigkeiten, die einem bestimmten Geschlecht zugeschrieben sind - unterworfen sind. Im Falle des hier behandelten Festes sind Verschiebungen vor allem im Hinblick auf die räumliche Dimension der Praxis zu beobachten.

Für tamilische Hindus stellt taipponkal eines der wichtigsten Feste im Jahr dar und soll der Familie Wohlstand und Glück bringen (vgl. Jagannathan 2005, 140 f.). Es ist eines jener Jahresfeste, welches von migrierten Tamilinnen und Tamilen in den verschiedensten Regionen der Welt weiterhin begangen wird: "Pongal is a four-days-long harvest festival celebrated by Thamils living all around the world" (Thangavelu 2009). Auf einer eigens taipponkal gewidmeten Internetseite wird auf den verbindenden Charakter des Festes für die tamilische Diaspora hingewiesen:

Tamils living abroad follow their cultural values throughout their significant festival. It is great to note that even the younger generation of Tamils living abroad come forward to contribute to the development of this harvest festival. Through various contributions in celebrating Pongal, the Tamil diaspora maintains and nurtures the cultural distinctiveness. (...) A togetherness is tried to be rooted in the Tamil diaspora by celebrating the Pongal festival at a

beiden tamilischen Wörter deutlich zu machen, transkribiert Schalk den Begriff als tai-p-ponkkal (Schalk 2004a, 172). Das Fest beginnt am letzten Tag des tamilischen Monats mārkali und endet am dritten Tag des Monats tai.

334 www.murugantemple-zh.ch/eng/engindex.php; 14.01.2009. 
single place, where everyone performs the Pongal rituals and share their sweet memories of India. ${ }^{335}$

Charakteristisch für poinkal, wie das Fest verkürzt genannt wird, ist, dass es als spezifisch tamilischer Anlass innerhalb der Hindu-Feste des Jahreszyklus angesehen wird. ${ }^{336}$ Die anderen Feste des Jahreskreises dagegen werden in der Regel als allgemein hinduistisch - unabhängig von der ethnischen Identitätszuschreibung der Praktizierenden - verstanden. Der Präsident der kanadischen Thamil Creative Writers Association, Velupillai Thangavelu, bemerkt: "[Pongal] is the quintessential 'Tamil Festival'. [...] Thamils refer to Pongal as 'Tamizhar Thirunal' (meaning 'the festival of Tamils')". ${ }^{337}$ Die kontinuierliche Begehung des Festes auch im Exil ist demnach nicht nur als Ausdruck der Hinduness der Migrantinnen und Migranten zu verstehen, sondern unterstreicht ausserdem die Bedeutung der Tamilness. Daher kommt diesem Fest innerhalb der tamilischen Diaspora, verstanden als eine ethnische Schicksalsgemeinschaft, eine besondere Bedeutung zu. Taipponkal wird als Ausdruck geteilter tamilischer Identität und als Akt der kulturellen Selbstvergewisserung gefeiert: "Tamils of all shades jointly celebrate Pongkal as a common festival of Tamil identity" ${ }^{338}$

Zur Bedeutung des Festes lassen sich verschiedene inner-tamilische Deutungsmuster identifizieren. Einige tamilische Intellektuelle beschreiben taipponkal als rein kulturellen tamilischen Anlass und beziehen sich dabei auf eine Dichotomie der Sphären «Religion» und «Kultur». Einer Vereinnahmung durch sanskritische Hindu-Traditionen soll entgegengewirkt werden: "Pongal perhaps is the only Tamil cultural insignia that has to a very large extent escaped the intrusion of the interlopers and need to be kept in its pristine non-religious form for the future". ${ }^{339}$ In Sri Lanka gab es

335 www.pongalfestival.org/pongal-around-the-world.html; 22.08.2020 Dieses Zitat ist gefärbt von einer Idealisierung der Praxis des Festes in der Diaspora.

336 Es sei darauf hingewiesen, dass der 14.Januar in den verschiedensten Regionen Südasiens - und nicht nur in den tamilischen Gebieten - als Erntefest gefeiert wird. Dieser astrologisch wichtige Zeitpunkt wird u. a. als Makar Sankranti begangen.

337 Beitrag Thai Pongal, veröffentlicht auf der Webpräsenz tamilnation: www.tamilnation. org/culture/festivals/thaipongal.htm (29.11.2008). Dazu auch der tamilische Aktivist Ramalingam Shanmugalingam auf der gleichen Webpräsenz: "Tamils true cultural day is universal in essence".

338 www.tamilnet.com/art.html?catid=13\&artid=27993; 16.01 .2009 .

339 Vgl. www.tamilnation.org/culture/festivals/thaipongal.htm (10.03.2008). Weiter schreibt hier der im US-amerikanischen Exil lebende tamilische Aktivist Ramalingam Shanmugalingam: "[...] it is a true Tamil festival without the trimmings of foreign religious connotations. Even though Pongal is ascribed to the plough for its significance, it is a Tamil cultural event that embraces and involves many aspects of Tamil life". 
Bestrebungen, das Fest auch unter tamilischen Katholiken als ethnisches Fest für alle Tamilen - unabhängig ihrer Religionszugehörigkeit - einzuführen und es von hinduistischen Konnotationen zu entkoppeln. ${ }^{340}$

Aktivistische tamilische Gruppen schreiben taipponkal eine grosse Bedeutung als genuin tamilisches Fest zu; auf symbolischer Ebene ist es mit der politischen "ponkku tamil"-Rally verbunden, die auch in der Schweiz veranstaltet wurde (vgl. Roberts 2008; Orjuela 2008, 112; Orjuela 2009, 262). Ponku tamil wird mit "tamil uprising" oder "tamil upsurge" ins Englische übersetzt. Damit ist in Analogie zur überkochenden Milch, welche während des Festes aus dem Topf aufsteigt, das Aufbegehren der Tamilen gegen die Unterdrückung durch den singhalesischen Nationalismus gemeint. "Pongu Tamil expressed the Tamil demand for self-determination, while displaying LTTE symbols [...]" (Orjuela 2009, 262). Im Januar 2001 wurde dieser ethnonationalistische Anlass von Studenten der Universität in Jaffna ins Leben gerufen. Daraus entstand die «ponku tamil-Bewegung», welche sich von den tamilischen Gebieten in Sri Lanka auf die tamilische Diaspora ausbreitete. Erstmals wurde dieser Anlass am 5. April 2004 in der Schweiz - vor dem UNO-Gelände in Genf - begangen.

Das Motiv der Milch, welche in einem runden Topf überkocht, wird in der visuellen Repräsentation des Anlasses (auf Postern und in der Dekoration der Bühnen) aufgenommen und teilweise erweitert, indem - anstelle der Milch - der Führer der LTTE, Vēluppillai Pirapākaran (1954-2009), aus dem poinkal-Topf aufsteigt. ${ }^{341}$

Viele tamilische Hindus jedoch verstehen taipponkal als kulturelles wie auch als religiöses Fest und trennen die beiden Sphären nicht. Es wird sowohl als originär tamilischer Anlass wie auch als Hindu-Fest begangen. Der religiöse Charakter wird durch Bezüge des Festes zum Gott Sūrya ${ }^{342}$

340 Der katholische Priester Thevathasan Antony (gestorben 2008) wird als einer der Akteure genannt, der taipponkal auch unter katholischen Tamilen in Sri Lanka etablieren wollte: "He was a reformer in bringing down caste barriers in the Tamil Catholic parishes, and instrumental in making the Christian Tamils adopt celebration of the Thai Pongkal festival as the prime Tamil festival for all Tamils" (www.tamilnet.com/art.html?catid=13\&artid=27779; 11.02.2010).

$341 \mathrm{Zu}$ diesem Anlass wurden Poster aufgehängt, welche Pirapākaran neben einem traditionellen ponkkal-Topf zeigen, aus welchem Reis quillt und in den die Flagge der LTTE gesteckt ist. Im Hintergrund sieht man die Silhouette Tamil Eelams und das Meer (www.tamilnet.com/art. html?catid=13 \&artid=11673; 20.02.2010). Zur «ponku tamil»-Rally 2008 in Bern bestand das Bühnenbild an der rechten Seite aus einem fast menschengrossen ponkkal-Topf, aus welchem Milch überläuft. Daneben, in der Mitte der Bühne, war ein weiterer traditioneller Topf dargestellt, aus welchem Pirapākaran in Militäruniform heraussteigt. Poster zu diesen Anlässen mit den erwähnten Motiven sind in tamilischen Lebensmittelläden zu finden.

342 Der Gott Sūrya stammt allerdings aus der vedischen Sanskrit-Tradition und ist keine Gottheit, welche speziell mit tamilischen Traditionen verbunden ist. 
und die speziellen ponkkal-Anlässe im Tempel unterstrichen. Der Śrī Viṣnu Turkkai Amman Tempel vermerkte 2010 auf seiner Homepage: «Die nach der Regenzeit wiederkehrende Sonne wird verehrt. Hindus beten an dem Tag bei Sonnengott 〈Suriyan〉 um gutes Wetter, Wachstum der Saat und um Gesundheit». ${ }^{343}$ Von tamilischer Seite wird das Fest in der Kommunikation mit der Schweizer Mehrheitsbevölkerung als religiöser Feiertag benannt. ${ }^{344}$

\subsection{Eine Erinnerung an taipporikal in Sri Lanka}

Die Jahresfeste, die in die Schweiz transferiert werden, werden immer auch von Geschichten begleitet, die von der vergangenen Praxis der Feste im Herkunftsland erzählen. Es sind Erinnerungen, welche die Akteure selbst erlebt haben oder welche ihnen von nahestehenden Menschen berichtet wurden. Diese Narrative, die von sowohl zeitlich wie räumlich Entferntem erzählen, dienen den Akteuren oftmals als Vergleichsfolie, um Handlungen in der Schweiz als authentisch oder weniger authentisch zu klassifizieren.

Auch das Feiern von taipponkal in Sri Lanka ist für viele Akteure der ersten Generation ein Teil ihrer Erinnerungen an die zurückgelassene Heimat. Die Geschichten um dieses Fest werden von ihnen an die zweite Generation weitergegeben. In Sri Lanka wird taipponkal in der Regel vier Tage lang begangen, wobei der zweite Tag des Festes staatlicher Feiertag im ganzen Land ist. ${ }^{345}$ Das Fest fällt in die Zeit nach der Monsun-Periode, wenn viele Menschen - besonders in ländlichen Gegenden - ihre Häuser aufgrund der Feuchtigkeit renovieren müssen. Dabei werden Haushaltgegenstände entsorgt und neue erworben. Auf den Feldern können die ersten Ähren geerntet werden (vgl. auch Schalk 2004a, 172).

Eine tamilische Migrantin, Rohini, schildert den Ablauf des Festes in ihrer Heimat vor ihrer Flucht Anfang der 1990er Jahre in einem Gespräch mit mir an taipponkal 2009 wie folgt: ${ }^{346}$

343 www.srithurkkaswiss.ch/2009/Visedam 202009 20_En.pdf, 18.02.2010.

344 Verschiedene Schweizer Kantone haben das Fest in ihren Handreichen zum Umgang mit religiösen Fragen an den Schulen als «hinduistischen Feiertag» vermerkt (vgl. die Handreichung des Erziehungsdepartements des Kantons Basel-Stadt 2007, Umgang mit religiösen Fragen an der Schule, S. 18).

345 Der zweite Tag des Festes, sūrya poìkal, ist jener Tag, an dem das zentrale Ritual des Überkochens stattfindet. Sürya poìkal fällt auf den ersten Tag des tamilischen Monats tai. Im indischen Bundesstaat Tamil Nadu sind zu Anlass von taippoikkal drei Tage Feiertag.

346 Die folgenden Zitate entstammen diesem ausführlichen Interview und ero-epischen Gesprächen am 14.01.2009, welche ich an sūrya poíkal mit Rohini geführt habe. Zu diesem Anlass war ich bei ihrer Familie zum Mittagessen eingeladen und habe bei den Vorbereitungen und 
An diesem Feiertag wurde vor dem Haus ein besonderes kōlam gelegt, ein auf den Boden aufgetragenes Bild aus Reismehl. Vor dem Haus, unter freiem Himmel, wurde, wenn möglich, ein Feuer gemacht, auf dem in einem speziell geformten Tontopf (kuțam) Kuh- oder Kokosnussmilch kochte, bis diese überläuft und auf die Erde fliesst. Bei uns/dete [dort] wir kochen so früher/um 6Uhr,/wenn die Sonne aufgeht/kochen wir. Die Milch muss kochen/richtig überkochen. Die Frauen und die Männer stehen früh auf. Man muss richtig duschen/Haare waschen und richtig duschen. Und was wir kochen, dürfen wir nicht in den Mund nehmen/nicht testen/dete [dort].

Es sei Aufgabe der Männer, sich um das Kochen des Reises zu kümmern, da diese Handlung mit den Aufgaben der Männer in der Landwirtschaft verbunden sei. Dann werden der kochenden Milch Reis und geröstete Linsen beigegeben. Der spezielle poikkal-Reis wurde mit aufgelöstem Palmzucker (jaggary) gesüsst und mit gemahlenem Kardamom gewürzt. Cashewnüsse werden hinzugefügt. Der Topf darf nur einmal benutzt werden - jährlich wird ein neues poìkal-Gefäss benötigt.

Man besucht Freunde und Verwandte und tauscht porkkal-Reis und Festtagswünsche aus. «Aber nur zu Hause machen wir und wir verteilen die andere. Ich koche etwas und die andere kochen etwas. Und sie bringen zu uns und wir. Das ist so.» ${ }^{347}$ Der Reis wird auf einem Bananenblatt mit speziellen Blumen dekoriert serviert. Die Kinder, die den Reis verteilen, bekommen von den Beschenkten Geld. Am nächsten Tag, mättu porkkal, dankt man den Kühen und Büffeln für ihre Dienste. Ihnen werden Ketten mit vatai, Teigtaschen, um den Hals gelegt.

Wir kochen etwas so / weissen Reis und alles / und machen eine vatai. Kennst du vațai? Wir machen vațai auch und wir hängen es an der Kuh seine Hals. Das heisst māttu poíkal. Māttu poìkal machen wir auch am Abend. Das hat eine Bedeutung. Diese Bedeutung weiss ich nicht ganz genau. Aber ich weiss / ich habe schon einmal gewusst. Aber das habe ich jetzt vergessen. Aber hier in der Schweiz macht man es nicht.

Die Erzählung von Rohini ist aus Erinnerungen der Akteurin an das Feiern von taipporkkal in Sri Lanka, welches mehr als zwanzig Jahre zurückliegt, zusammengesetzt. Die Diaspora-Situation bedingt in diesem Fall, dass die Erinnerungen an die Praxis im Herkunftsland mit der Zeit verschwimmen und genaue Detailabläufe der kulturellen Praxis und ihre Bedeutungen partiell vergessen gehen.

dem Kochen des ponkkal-Reises zugeschaut. Unsere Gespräche währenddessen habe ich mit Erlaubnis der Informantin aufgezeichnet. Nicht markierte Zitate stammen von Rohini; Zitate anderer Akteure sind im Folgenden als solche gekennzeichnet.

347 Interview 6; 14.01.2009. 


\subsection{Taipporikal in der Schweiz - diasporische Veränderungen}

Wie Peter Schalk in seiner Studie zu Caivas in Stockholm beobachet hat, ist auch taipponkkal in der Diaspora Veränderungen unterworfen. "It is evident that tai-p-ponkal cannot be celebrated like this in Stockholm where no agricultural surrounding is available. There tai-p-ponkal is limited to the overflowing of a pot of rice in the homes and in the koyil" (Schalk 2004a, 172).

In der Schweiz und anderen Exil-Ländern wird taipponkkal von vier Tagen auf einen Tag verkürzt: Es wird nur am ersten Tag des Monats tai, als sürya ponkkal, gefeiert. Der Tag davor und die beiden Tage danach, māttu ponkkal und kānum ponkkal, werden ausserhalb der tamilischen Gebiete meist nicht mehr gefeiert. Nur der Kern des Festes, das Kochen und Überkochen der Milch, bleibt bestehen.

Rohini berichtet, dass in der Schweiz der darauffolgende dritte Tag des ponkkal-Festes, māttu poíkal, nicht mehr gefeiert wird, da die Landwirtschaft als Lebensgrundlage durch die Migration aufgegeben wurde. «Hier in der Schweiz machen wir das [mättu poinkal] nicht. Wir haben keine Kuh». In der Schweiz fällt auch das Legen von kōlams zu taipponkkal im öffentlichen Raum weg. In Sri Lanka stellen diese einen Ausdruck der öffentlichen Sichtbarkeit des Festes dar und markieren das Haus als Wohnort einer Familie, die taipponkkal feiert. Diese Form der öffentlichen Präsentation ist in der Schweiz in der Regel nicht zu finden, was u.a. auch in der Tatsache begründet liegt, dass die meisten tamilischen Familien in Mietwohnungen leben.

Ein weiteres Hindernis in einer als authentisch klassifizierten Ausübung der Praktiken um taipponkal besteht darin, dass viele Menschen an diesem Tag arbeiten müssen. Die von mir beobachteten taipponkkal-Feste lagen jeweils auf einem Werktag, was von tamilischen Akteuren bedauert wurde. Die Arbeitsverpflichtungen stehen dem Wunsch gegenüber, die HinduPraxis so wie im Herkunftsland zu leben. Besonders der soziale Aspekt, die obligatorischen Besuche zu ponkkal, können hier meist nicht durchgeführt werden. Rohini erklärt: «Heute besuchen sich die Leute hier nicht. Es ist Arbeitstag». Ein Besucher des Tempels in Adliswil am 15.02.2008 bemerkt: «Ponkkal ist für uns wie Weihnachten. In Sri Lanka haben alle frei und wir treffen uns. Hier müssen alle schaffen.» Der Luzerner Priester Sasitharan Sarma nennt im Interview am 19.12.2007 als einen zentralen Wunsch an die Schweizer Behörden, dass an wichtigen Festtagen wie taipponkkal hinduistische Arbeitnehmer arbeitsfrei haben sollen: 
Ich finde hier in der Schweiz meine Religion zu praktizieren ist kein Problem. [...] Es gibt nur zwei Dinge, die für uns manchmal schwierig sind. Eine ist, an unseren Feiertagen können wir nicht immer frei nehmen. Aber die erste Sache, mit den Feiertagen, ist ein Problem. Es gibt drei sehr wichtige Feiertage. Der erste ist das Erntedankfest, ein Dankbarkeitsritual, das wir im Januar machen, das taipponkkal. Und das andere ist das Neujahrsfest im April, und das dritte ist tīpāvali. Wenn drei Tage schwierig sind, dann kann man uns zwei Tage frei geben/die Regierung.

Auch die zentrale Handlung von sūrya porikal, das Kochen des porikalReises (auch pukkai genannt; vgl. McGilvray 1998, 63), unterliegt in der Schweiz verschiedenen Veränderungen: Das Kochen des porkkal-Reises obliegt, nach Angaben der Familie Rohinis, traditionell den Männern der Familie. In der Schweizer Diaspora sind es jedoch meist die Frauen der Familie, die, sofern sie nicht arbeiten, zu Hause den poikkal-Reis vorbereiten. Aufgrund der klimatischen Verhältnisse und der Wohnsituation wird die Milch nicht im Freien und auf Feuer, sondern in den Wohnungen auf der Herdplatte gekocht. ${ }^{348}$

Für die Durchführung von taippoíkal spielt die materielle Kultur eine wichtige Rolle. Man benötigt einen bestimmten Topf und spezifische Zutaten. Der Topf, in dem gekocht wird, sollte neu sein. Rohini erklärt mir, während sie in ihrer Küche den poinkal-Reis zubereitet:

Eigentlich dürfen wir diese Sachen [die Töpfe] nicht benutzen. Warum? Weil jeden Tag ich habe gekocht/Fleisch und Fisch und so. Das muss frische Sache sein. Darum in Sri Lanka wir nehmen eine Holz-Kelle/das ist auch neu. Für den taipponkkal kaufen wir jedes Mal eine neue Topf. ${ }^{349}$

Die Familien, die sich wünschen, dass das Fest möglichst authentisch gefeiert wird, benutzen einen speziell geformten Topf und erwerben jedes Jahr einen neuen. Rohini erzählt:

Einmal / irgendjemand hat mir gezeigt / ich weiss nicht wer. Sie haben drei oder vier solche Pfannen. Jedes Jahr kaufen sie das wieder. Und ich habe gesagt: $<$ Was machst du mit diesem jetzt? Weil das ist Metall, oder?! $>$ [lacht $]$ Ah, es war der Cousin meines Mannes. Er wohnt in Zürich. Er hat drei oder vier Pfannen. Jedes Jahr kauft er/weil bei uns an poikkal man muss neue Pfanne kochen/nicht die alte/darum. Es ist in seinem Kopf/weisst du. Als Kind er hat das gelernt, er kann das nicht wegnehmen. Er traut/oder. Und das ist so.

348 Auch in Sri Lanka sind Modifikationen in der Gestaltung von taipporkal zu beobachten. In den Städten, besonders Colombo, wird der Reis beispielsweise auch im Haus und nicht mehr im Freien gekocht.

349 Interview 6; 14.01.2009. 
Sie verweist auf die Sozialisation des Akteurs, die ihn dazu anhält, auch in der Schweiz die Konventionen des Festes einzuhalten. Viele tamilische Familien in der Schweiz benutzen jedoch zum Kochen des Reises einen Reiskocher und verzichten auf den jedes Jahr neu zu erwerbenden traditionellen Topf. In tamilischen Läden kann man aber auch ein spezielles poíkalSet erwerben, welches aus einem runden Topf zum Kochen und einer Kelle besteht. Dazu liegen in luftdicht verschlossenen Plastikbeuteln alle Zutaten in der richtigen Menge bei (vgl. Abb. IV 15). «Die tamilischen Leute sie können schon/in tamilischen Laden/diese ganze, komplett porkkal/diese Sache / kaufen. Ein Set. Diese Pfanne und alles zusammen.» Diese Variante

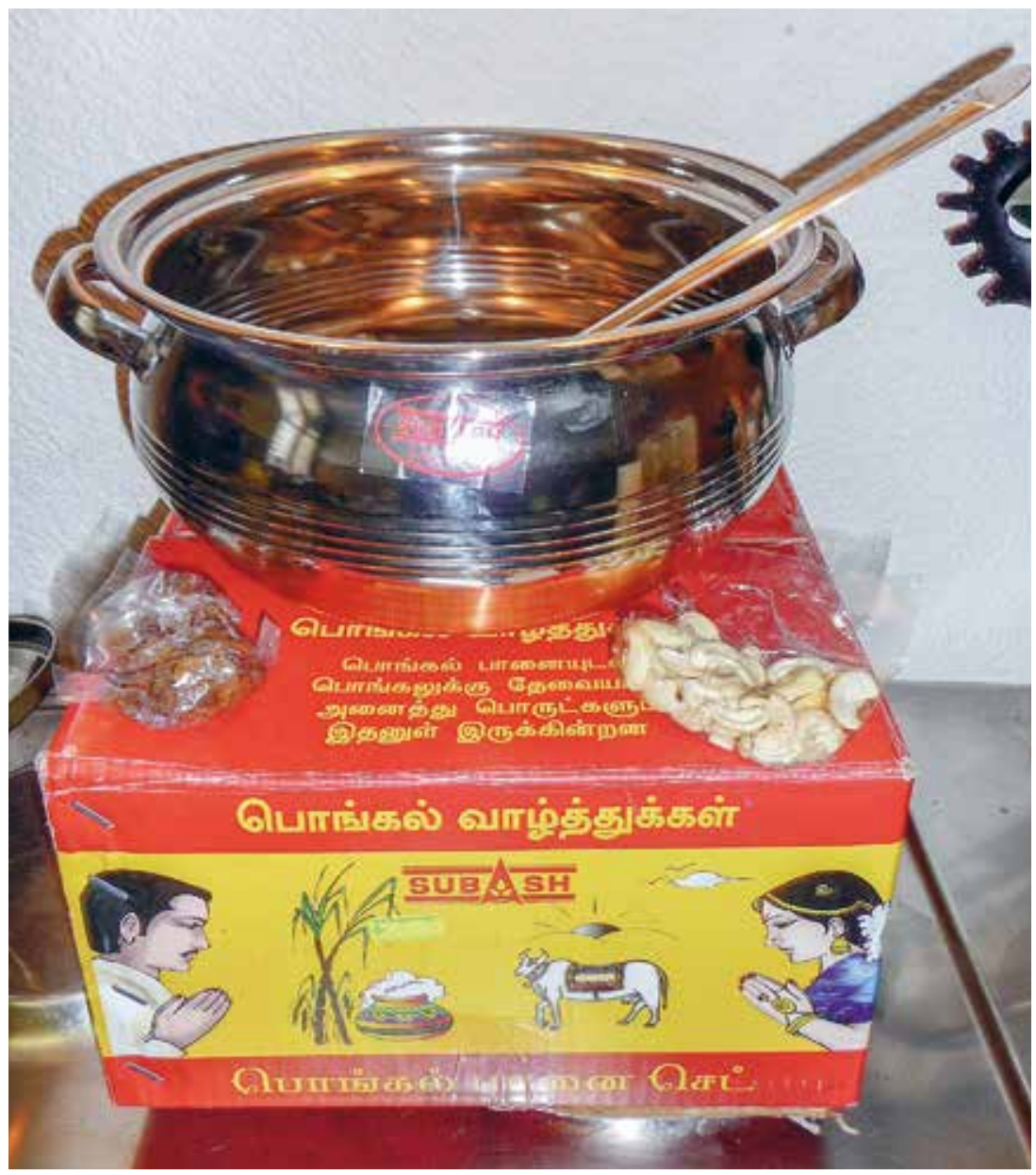

Abb. IV 15: taipponkkal-Set, welches in einem tamilischen Laden in Luzern erworben wurde (10.01.2010). 
weist auf eine Professionalisierung hin, welche es den Akteuren ermöglicht, auch fern der südasiatischen tamilischen Gebiete ohne erhöhten Zeitaufwand und Anstrengungen das Fest nach traditionellen Vorgaben durchzuführen.

Die dargestellte Verpackung zeigt traditionelle Elemente von ponkkal, welche immer wieder in der visuellen Darstellung des Festes verwendet werden, wie den in der Mitte platzierten überkochenden Topf mit Milch, daneben eine Zuckerrohrpalme. Links davon sind eine Kuh (als Verweis auf māttu pońkal) und die Sonne (als Verweis auf den Gott Sūrya) gezeichnet. Ein traditionell gekleideter tamilischer Mann und eine Frau verneigen sich in Richtung der Abbildungen.

Nach der Zubereitung des porkkal-Reises und anderer Gerichte wird ein Teil des Reises vor die Gottheiten des Hausschreins als prasādam gestellt. Traditionell wird der Reis auf einem Bananenblatt platziert (vgl. Abb. IV 16). In der Schweiz ist es schwierig, Bananenblätter zu erwerben: nur in ausgewählten tamilischen Läden oder in bestimmten Supermärkten werden sie verkauft. Rohini merkt an, dass sie vergessen hat, Blumen zu kaufen, um die Gabe zu dekorieren.

Ein zentrales Element der Jahresfeste ist die soziale Komponente. Bestandteile von taipponkkal sind das Überbringen von guten Wünschen und

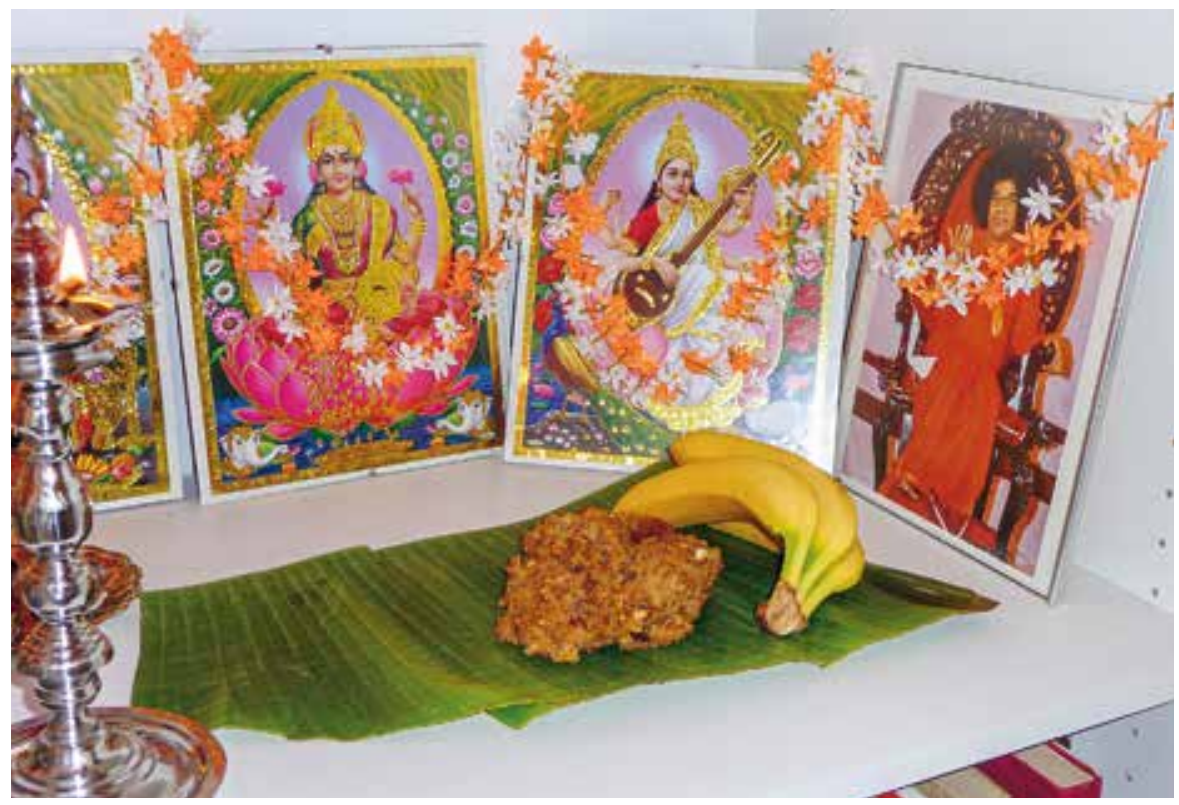

Abb. IV 16: Ponkal-Reis, welcher in einem Hausaltar, der sich in einem Schrank befindet, auf einem Bananenblatt dargebracht wurde. Links brennt die traditionelle Öllampe (14.01.2010). 
die Besuche, bei denen der poinkal-Reis ausgetauscht wird. In der Schweiz ruft man in erster Linie Freunde und Verwandte in Sri Lanka und den verschiedenen Diaspora-Ländern zu poíkal an oder tauscht via digitale Tools ponkkal-Wünsche aus. Dadurch werden die transnationalen Verbindungen unter tamilischen Akteuren gestärkt. Die Bedeutung der privaten poikkalBesuche nimmt in der Diaspora ab, da diese aufgrund der Arbeits- und Wohnsituation meist schwierig durchzuführen sind. Oft ist keine Zeit für Besuche da, weil man arbeiten muss oder die tamilischen Bekannten zu weit verstreut wohnen. Auch kann die Enge einer Mietwohnung ein Hindernis sein, um Besuch in der Art und Weise wie im Herkunftsland zu empfangen.

Die Jahresfeste sind auch immer Anlässe, welche Erinnerungen an die verlassene Heimat aufleben lassen und Migrantinnen und Migranten der ersten Generation bewusstmachen, was sie im Residenzland vermissen; hier spielt insbesondere der soziale Aspekt eine grosse Rolle. Der Anlass führt Rohini vor Augen, dass sie in der «Fremde» lebt und sie es vermisst, solche Feste eingebunden in ein stabiles soziales Netz und zusammen mit ihren erweiterten Familienmitgliedern zu begehen:

\begin{abstract}
Heute ist so/heute ist so ein schöner Tag. Heute da habe ich das wirklich gemerkt / ja. Ich bin wirklich ganz alleine/weisst du. Ganz alleine nicht/ganz alleine nicht. Das kann ich nicht so sagen. Aber meine Mutter, meine Schwester, niemand. Das ist so. Meine damalige Leute nicht. Aber ich habe neue Leute, habe neue Freunde. Es ist schön, es ist wertvoll. Aber ich merke das schon: <Aha>. Ich habe zwei Mal zu meiner Mutter [die in Sri Lanka lebt] telefoniert. [lacht] Und meiner Cousine und mein Onkel und ich habe so überall telefoniert und gute Wünsche [zu taipporikal] gebracht.
\end{abstract}

\title{
5.3 Die räumliche Dimension des Festes - Taipporikal in Schweizer Tempeln
}

In den tamilischen Gebieten Indiens und Sri Lankas wird dieses Erntefest, welches in die Zeit der Reisernte fällt, primär zu Hause gefeiert. Die Durchführung der Rituale im privaten Bereich ist für Hindus obligatorisch. Ein Tempelbesuch, der im Anschluss daran erfolgen kann, wird nur von einer Minderheit durchgeführt. ${ }^{350}$ Rohini berichtet:

350 Es sei darauf hingewiesen, dass es auch in Sri Lanka porkkal-Feiern in Tempeln mit zahlreichen Teilnehmern gibt. In einem Bericht auf TamilNet vom 10.06.2003 heisst es: "Thousands of devotees from different parts of Northeast joined in the pongal celebrations held at Vattapallai Amman Temple, a popular hindu temple in Vanni, Monday. The prevailing climate of peace [...] 
Eigentlich in Sri Lanka ich habe nie in porkal in die Chehl/in Tempel gehen/nur zu Hause. [...] Ob niemand in den Tempel geht, das kann ich nicht versprechen, da müsste man jemanden fragen, der es wirklich weiss. Nur zu Hause machen wir/ und wir verteilen die andere.

Eine entscheidende Verschiebung, die auf die Diaspora-Situation zurückzuführen ist, ist die vermehrte Organisation von ponkal-Feiern in Tempeln. "Although Tamils are well entrenched in these country [sic!] and integrated with the local community, yet they are actively alive to their Hindu religious and Tamil cultural links by organizing Pongal celebration at a single place. Other than that, during Pongal, temples draw a large number of the Tamil diaspora from all European countries, so much so that it becomes the nerve centre of Tamil cultural activism."351 Das Fest wird in der Diaspora sowohl zu Hause als auch im Tempel als gemeinschaftlichem Treffpunkt gefeiert. Eine Besucherin der taipponkkal-Feier im Luzerner Tempel berichtet: «Zu Hause haben wir heute auch ponkal gemacht. Meine Mutter hat das heute Mittag gekocht. Es kochte über auf die Herdplatte: das war der Höhepunkt. Dazu haben wir vatai und anderes gegessen» (Gespräch am 14.01.2010).

Als zentraler Treffpunkt gilt der Tempel, den man vor und/oder nach der Arbeit besucht. Hier wohnt man dem poinkal-Ritual gemeinschaftlich bei und isst noch einmal mit allen zusammen ponkkal-Reis. Rohini erzählt:

Heute treffen sich die Leute hier im Tempel. Darum ist spezialer Tag dete [dort]. Es ist kein Tempeltag heute eigentlich. Sie könnten sonst nicht treffen/es nicht geniessen. Deshalb können sie in den Tempel gehen. Leider ich muss arbeiten um viertel nach fünf heute.

Meist ist es jedoch obligatorisch, dass vorher das Milchüberkochen im kleinen Kreis der Familie zu Hause stattfindet. Versäumt man dies im privaten Bereich, nimmt man an, dass dies Unglück bringe:

Aber die meisten machen noch zu Hause [das Kochen des poìkal-Reises], weil das ist eine Aberglaube. Wenn ich nicht kochen würde, vielleicht ich kann nicht so zwei, drei Jahre nicht kochen. Das heisst: Irgendetwas würde passieren. Zum Beispiel, wenn ich sterben würde/vielleicht. Nachher sie machen das nicht. Darum das ist so irgendwie Aberglaube eigentlich. Aber man hat gern. Heute das muss man machen.

was the reason for such large gathering of devotees at the temple festival, sources said" (www. tamilnet.com/art.html?catid=13\&artid=9171; 25.02.2010). Im Kontext der vorliegenden Arbeit kann nicht geklärt werden, ob diese Zusammenkünfte neuere Entwicklungen in den tamilischen Gebieten Sri Lankas sind und ob diese im Zusammenhang mit aus dem Bürgerkrieg entstandenen Dynamiken stehen.

351 "Pongal in Europe: Britain, France, Germany, Italy, Switzerland, Denmark", www.pongalfestival.org/pongal-europe.html; 22.08.2020. 
Eine verstärkte Verlagerung von taippoinkal in den Tempel liegt vor allem in der sozialen Dimension des Festes begründet. Auch das Feiern von porkkal am Ort «Tempel» unterliegt in der Schweiz diasporischen Veränderungen: aufgrund der klimatischen Verhältnisse wird das Überkochen auch hier nicht im Freien durchgeführt, sondern in das Innere des Tempels verlagert. Während der ponkal-Feiern, die ich in Schweizer Tempeln besucht habe, stand der poinkal-Topf auf einer Gasflamme und nicht wie es traditionell üblich ist auf einem Holzfeuer.

Im Jahr 2008 war der Śrī Civacuppiramaṇiyar Tempel in Adliswil aus Anlass des taipponkal-Festes von 8.30 bis $21 \mathrm{Uhr}$ geöffnet. Die Zeremonie des Milchüberkochens wurde von einem Priester am Abend durchgeführt. Das Feuer wurde durch einen Gaskocher entzündet - die Gasflasche stand frei neben dem Kocher, der in der Mitte des Tempels vor dem Hauptschrein platziert war (vgl. Abb. IV 17). Auf dem Feuer befand sich ein metallener Topf, in dem Milch gekocht wurde. Der Topf war mit Caivam-Markierungen versehen und mit einer Kordel aus Mangoblättern umwickelt. Daneben fand sich ein Behälter mit ungeschältem Reis. Als die Milch überkochte, riefen die Anwesenden «ponkkalo ponkal» und warfen daraufhin Reis in die kochende Milch (vgl. Abb. IV 18-19). Auch im Jahr 2009 war der Tempel zu taippoíkal den ganzen Tag geöffnet. Um $17 \mathrm{Uhr}$ begann die Zeremonie. Die

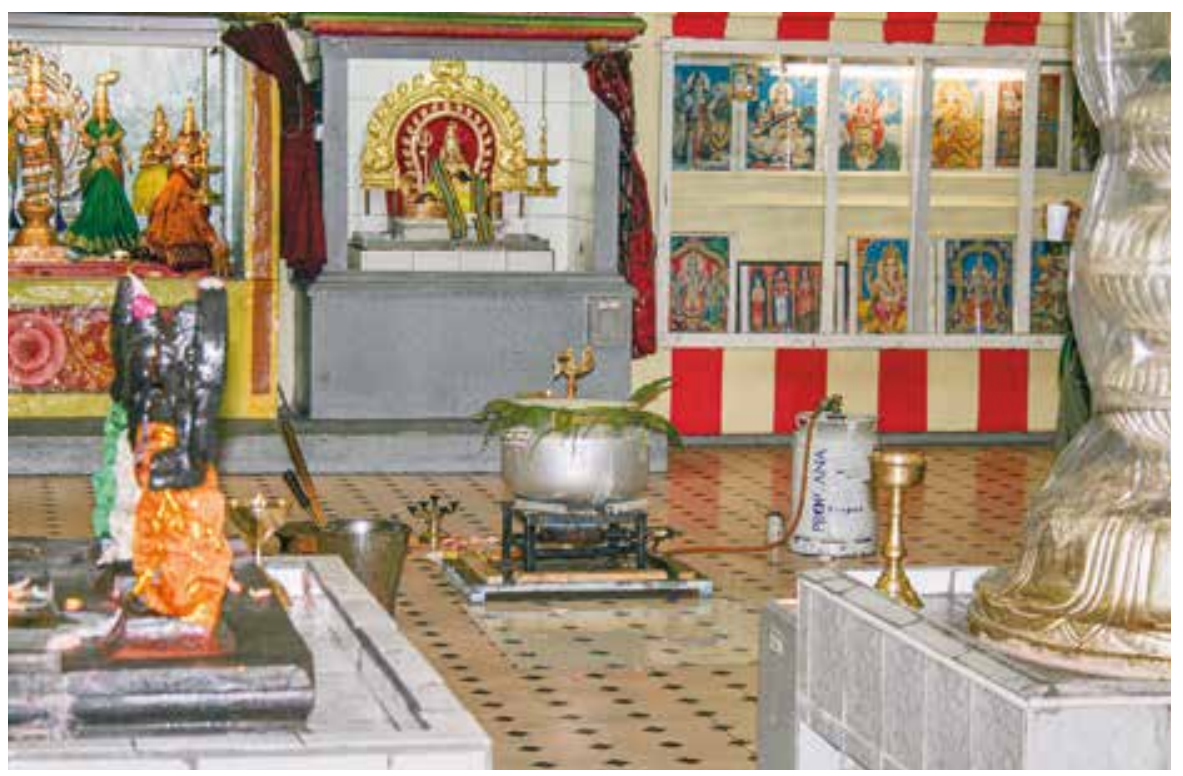

Abb. IV 17: Platzierung des porikal-Topfes auf einem Gaskocher im Tempelinneren des Śrì Civacuppiramaṇiyar Tempels in Adliswil (15.01.2008). 


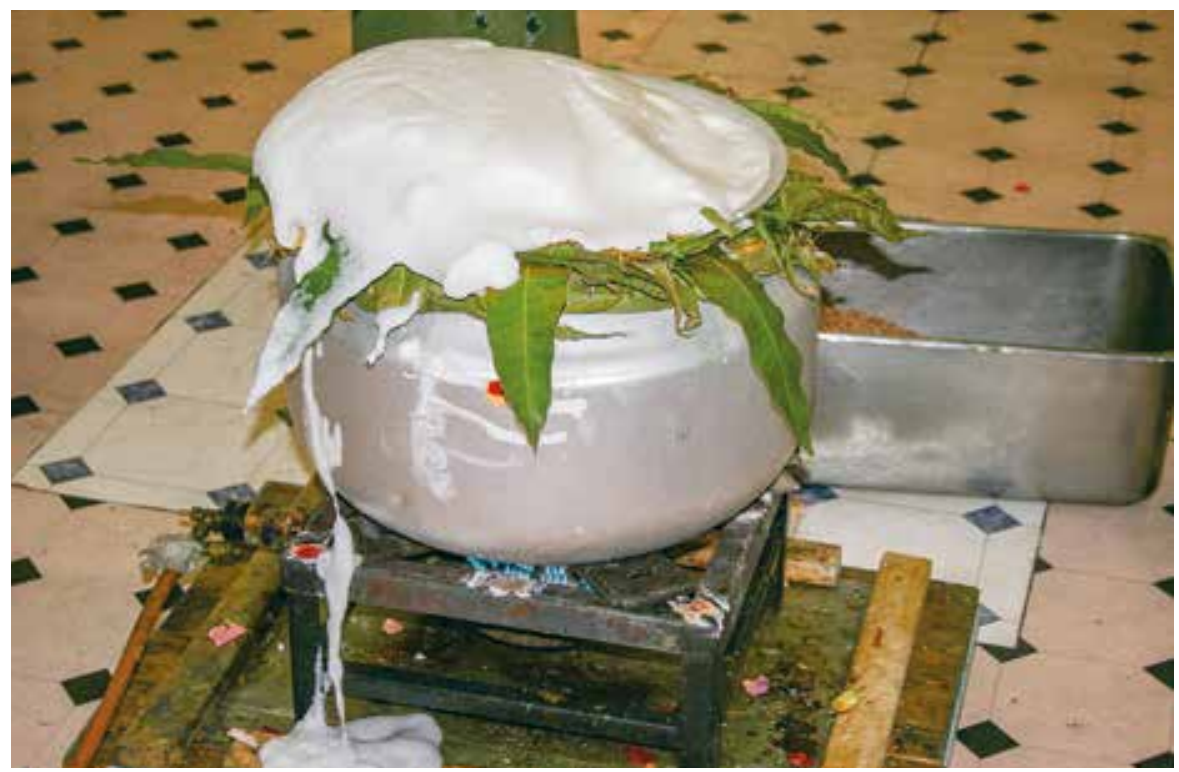

Abb. IV 18: Der Höhepunkt von sūrya poìkal: das Überkochen der Milch (Śrī Civacuppiramaṇiyar Tempel, Adliswil, 15.01.2008).

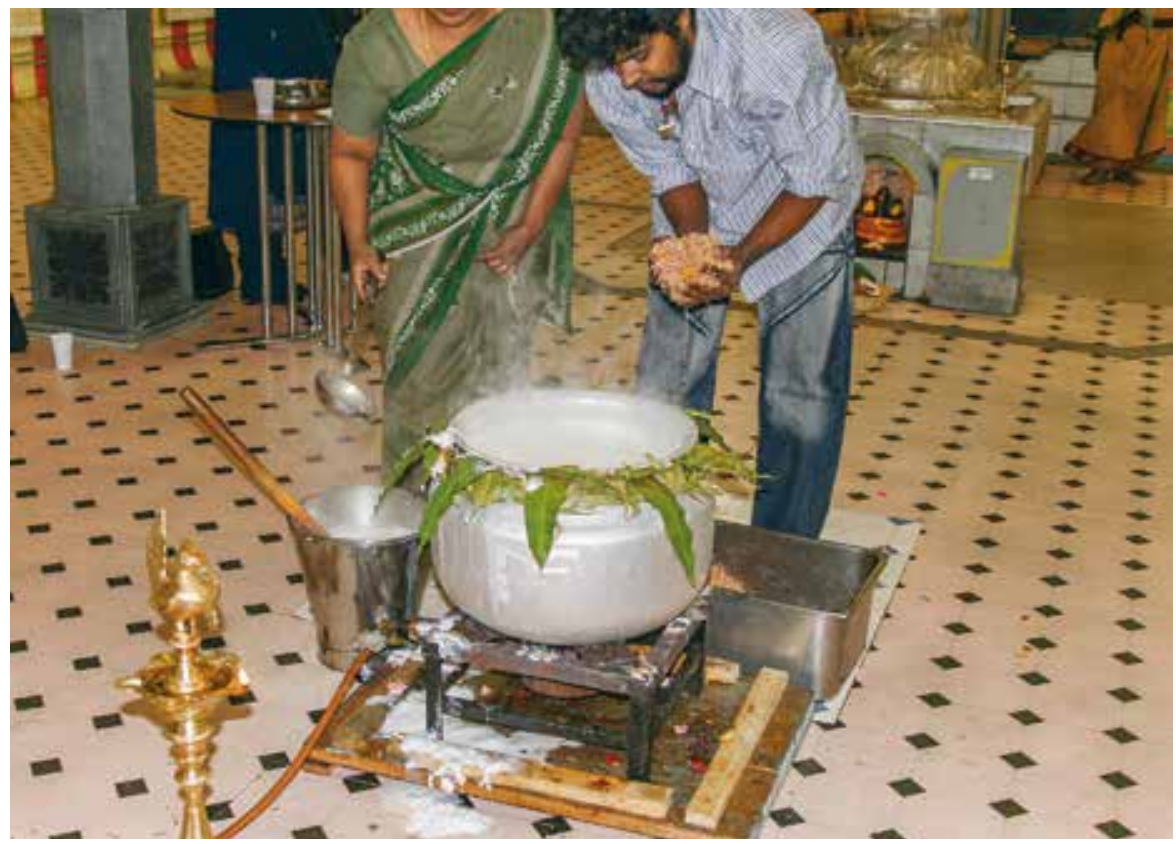

Abb. IV 19: Im Śrī Civacuppiramaniyar Tempel in Adliswil wird der kochenden Milch Reis beigegeben (15.01.2008). 
Homepage des Tempels verwies 2009 auf das doppelte Feiern von poinkal im privaten wie auch im Tempelbereich: "After performing the pooja at home, members of the family sit together to enjoy the pongal. This Thai Pongal ceremony is conducted in the temple too." 352

Im Turkkai Amman Tempel in Luzern fand am 14.01.2009 um 18:30 Uhr am Abend eine pūcai zu taippońkal statt. Dies war eine ausserplanmässige Veranstaltung, da der Tempel ansonsten nur am Dienstag und Freitag geöffnet war. «Um 18:30 haben wir heute im Tempel diese Ding/pücai wegen ponkal. Heute ist Mittwoch. Normalerweise ist Mittwoch kein Tempel». Zum Anlass von taipponkal wurde 2010 der Tempelinnenraum umgestaltet; es wurde ein spezieller Bereich vor dem Hauptschrein als Gebiet markiert, an dem die ponkkal-Rituale stattfinden. ${ }^{353}$ Das Zubereiten des ponkkal-Reises wurde gemeinschaftlich begangen und in Verbindung zur Hauptgottheit des Tempels gesetzt. Parallel zu den Vorbereitungen des ponkal-Reises vor der pūcai fand das Singen von pacanai (skr. bhajan) statt. Ein Auszug aus meinem Besuchsprotokoll am 14.01.2010:

Mitglieder der Familie, welche den Anlass sponsern, stehen um den Topf, in welchem der Reis gekocht wird. Die drei Kinder der Familie und die Mutter schütten gemeinsam Milch aus einem Tetrapack in den Topf: Jeder umschliesst die Milchpackung mit seiner Hand.

Nachdem die Milch kocht, bilden Menschen eine Reihe, um Reis in den Topf zu werfen. Die Akteure schauen zuerst mit Reis in der rechten Hand die Hauptgöttin an und halten einen Moment inne. Danach wird mit der Hand drei Mal im Uhrzeigersinn ein Kreis über den Topf gezogen, bevor der Reis in den Topf geworfen wird. Damit beginnt die Sponsorenfamilie, danach folgt der Priester. Dem Reis und der Milch wird ghee und Honig beigegeben. Dann wird flüssiger Jaggery-Zucker in den Reistopf gegeben. Die Öllampe wird am Gasofen unter dem Reistopf angezündet. Dann ruft eine Gruppe von Männern, die um den Topf stehen, den Priester. Gemeinsam prüfen sie den Reis und diskutieren. Danach geht der Priester in den Hauptschrein und der Reistopf wird alleine gelassen.

Im Vergleich zum gängigen Ablauf von taipporikal in Sri Lanka, in welchem dem Priester keine Funktion bei den Handlungen um sūrya porikal zukommt, wird die Rolle des Priesters in der Schweiz durch die verstärkte Verlagerung in den Tempel aufgewertet.

352 www.murugantemple-zh.ch/eng/engindex.php; 14.01.2009.

353 Ein Teil des Teppichbelags wurde zur Seite geklappt, und dort ein kōlam gezeichnet. In dessen Mitte steht der Reistopf. Der Bereich ist durch eine im oberen Teil an den Säulen gespannte Schnur, an der Mangoblätter hängen, zusätzlich markiert. 
Im Zentrum von taippoikkal im Tempel steht das Kochen des speziellen Reises und das gemeinsame Essen nach der pücai. 2010 wurde im Tempel in Luzern das Überkochen der Milch sogar weggelassen und nur der Reis gekocht. Als Begründung wird angegeben, dass eine Verunreinigung des Bodens vermieden werden soll. Dies deutet auf eine weitere Reduktion bzw. Verschiebung des Charakters des Festes hin.

Oft nehmen Tamilinnen und Tamilen in der Schweizer Diaspora also zweimal am porkal-Ritual teil - einmal im privaten Bereich und dann zusätzlich im Tempel.

\subsection{Der Prozess der Tempelisierung: Das Überkochen der Milch im Tempelraum}

Die Beschäftigung mit dem ponkkal-Fest macht deutlich, dass soziale Bedingungen im Residenzland entscheidend für die dargestellten Verschiebungen religiösen Lebens vom privaten hin in den öffentlichen Bereich sind.

Dynamiken von taipporkkal in der Diaspora können unter dem Begriff der Tempelisierung zusammengefasst werden. Die These der temple-isation als wissenschaftlicher Neologismus verbindet die Theoriefelder «Diaspora», «Gender» und «öffentlicher/privater Raum». Formuliert von Vasudha Narayanan in Bezug auf indische Hindus in den USA (Narayanan 2006) und von Martin Baumann im Hinblick auf Hindus in Europa weiterentwickelt (Baumann 2009b), beinhaltet die These die Verschiebung von religiöser Autorität und Authentizität fort von den Frauen zu Hause hin zum männlichen Ritualspezialisten im Tempel.

Lebenszyklische Riten und religiöse Erziehung werden nun verstärkt von der Institution Tempel übernommen. Feste oder spezifische Rituale, die traditionell in den privaten Räumen der Wohnung unter der Federführung von Frauen begangen wurden, werden in der Diaspora zunehmend in den gemeinschaftlichen, öffentlichen Verehrungsorten unter der Leitung von männlichen Spezialisten gefeiert. Den Platz der traditionellen Instruktoren, Grossmutter bzw. Grosseltern, nehmen in der Diaspora zunehmend die Priester in den Tempeln ein. Häusliche Riten werden nach aussen in den Tempel verlagert (Narayanan 2006).

Mit der These der temple-isation wird die Debatte um öffentliche versus private Religionsausübung aufgegriffen. Sie beschreibt die Auswirkungen der neu entstandenen religiösen Institutionen auf die internen Strukturen der Diasporagruppierungen. Eine gesellschaftliche Etablierung im Residenzland führt dazu, dass religiöse Vergemeinschaftungsorte entstehen, welche dynamische Prozesse innerhalb der community anstossen. Für die 
religiöse Ausübung ist nun auch im Diasporaland ein festgelegter Ort ausserhalb des privaten Wohnbereichs vorhanden. Narayanan weist den öffentlichen Tempelräumen im Vergleich zur Heimat einen erhöhten Stellenwert zu.

Narayanan hat die These für den nordamerikanischen Kontext entwickelt, die ich im Folgenden modifiziert auf die Situation migrierter tamilischer Hindus in der Schweiz übertrage. Vorab sei angemerkt, dass diese These im Hinblick auf die in der Schweiz lebenden indischen Hindus nicht haltbar ist. Die religiöse Praxis der indischen Diaspora ist nicht auf einen Tempel fokussiert und die private Ritualpraxis überwiegt (vgl. Wälchli 2008; vgl. IV 3).

Im Feld tamilischer Hindu-Traditionen in der Schweiz sind Verschiebungen in den Gender-Relationen im religiösen Vollzug auszumachen. Auf der einen Seite bekommen religiöse Reformbewegungen Aufschwung, welche Frauen mehr Rechte im rituellen Vollzug einräumen, so etwa im $\mathrm{Mel}$ maruvathur Adiparasakthi Amma Tempel und weiteren Tempelräumen der Reformbewegung Aum Shakti (Kap. IV 4.4) und bei der Einführung von Priesterinnen in der Reformbewegung Saivanerikoodam (Kap. IV 3.4). Auf der anderen Seite wird jedoch durch die Veränderung der zugeschriebenen Bedeutung des Ortes «Tempel» für die in der Diaspora lebenden Männer und Frauen die Rolle des männlichen Priesters betont.

Der Tempel bietet ein heimatliches Setting und wird zum zentralen Gemeinschaftsort eines Grossteils der Diaspora-Gruppe. Narayanan stellt dies auch für die Tempel in den USA fest:

The models of the temples that have risen here are more like the temples in pre-colonial India than in post-independence India. This means that the temple is like the "village square", in being the focal point of the community. (Mail von Narayanan an mich, 27.04.2008)

In der Diaspora ist der Bedeutungswandel der Institution Tempel im Exil von zentraler Bedeutung und Grund für den Prozess der temple-isation. In den Interviews zeigt sich, dass für viele Tamilen der Tempel auch im Herkunftsland Sri Lanka eine grosse Bedeutung hatte, da sie in den Erzählungen über ihr religiöses Leben vor der Migration immer wieder auf diesen rekurrieren. Festzustellen ist aber, dass das Konzept des Tempels im Herkunftsland und in der Diaspora oft nicht das gleiche ist.

Im Kontext der hindu-tamilischen Diaspora in der Schweiz kommen verstärkende Faktoren hinzu: Eine weitere Modifikation der Bedeutung der Tempel in der Diaspora war auf dem Hintergrund des Konflikts in Sri Lanka und dem Bestreben, Tamilness auch im Exil zu leben, zu sehen. In den Tamilengebieten Sri Lankas dominierten die LTTE den öffentlichen Diskurs. Die 
LTTE als Meinungsführer propagierten eine «religiös neutrale» Ideologie. Bei ihrem Ziel der Verteidigung der tamilischen Bevölkerung und der Aufrechterhaltung tamilischer Kultur ist es nicht zentral, welcher Religion jemand zugehört, zentral ist, wie er/sie sich im Konflikt positioniert. Tamilness kommt hier vor Hinduness.

Im Exil wird der Tempel zum zentralen Ort nicht nur der Hinduness, sondern auch der Tamilness. Er wird zum Hauptaustragungsort tamilischen Lebens in fremd-kultureller Umgebung. Verflechtungen religiöser mit politischen Motiven sind hier offensichtlich. Die Diversität der Diaspora-Akteure verdeutlicht das folgende Beispiel: Eine Tamilin antwortet auf die Fragen nach ihrem religiösen Leben in Sri Lanka mit der Nennung von Tempeln, in denen sie religiös engagiert war. Die Narration enthält viele Erinnerungen, die sich um den Tempel und seine Bedeutung drehen. In der Schweizer Diaspora jedoch spielen die Tempel für sie nur noch eine untergeordnete Rolle. Hier nennt sie privat-religiöse Praktiken als religiöse Ausdrucksformen. Zentral in der Deutung des Interviews ist jedoch die LTTE-kritische Haltung der Interviewten. Der Wandel ihres Verhältnisses zu den Tempeln kann in der von ihr unternommenen unterschiedlichen Bedeutungszuschreibung jener Orte gesehen werden: In der Diaspora wird der Tempel von ihr nicht primär als religiöse Organisation wahrgenommen, sondern als Ort gelebter Tamilness und politischem Aktivismus, dem die Akteurin kritisch gegenübersteht. Daher verhält sie sich in der Diaspora distanziert zu diesen Orten. In Sri Lanka stellen die Tempel für sie jedoch «politikfreie» Räume dar, in denen sie spirituelle Stärkung in harten Zeiten erfahren kann.

In Sri Lanka sind die Entstehungsgeschichte und die Geschichte des Tempels, die Priester und ihr persönlicher Hintergrund sowie das administrative Leitungsgremium meist allgemein bekannt. Der Tempel kann im religiösen Feld klar eingeordnet werden. In der Schweiz bestanden jedoch Unsicherheiten. Einige meiner Informantinnen und Informanten vermieden es, in der Diaspora Tempel zu besuchen, weil sie sich nicht über die politischen Hintergründe der Institution im Klaren oder abgeschreckt durch bestimmte Gerüchte waren, die von Interferenzen politischen und religiösem Engagements in den Tempeln sprachen.

Abschliessend seien die zentralen Aspekte der Praktiken des taipponkkalFestes in der Schweiz zusammengefasst:

a.) Das Feiern von taippońkal markiert und verstärkt Zugehörigkeiten in der Diaspora: Zum einen dient es als Marker tamilischer Hindu-Identität im transnationalen Kontext. Durch die zwischen den Akteuren ausge- 
tauschten Festtagswünsche verstärkt es transnationale Verbindungen. Zum anderen inszeniert es Heimat unabhängig des Ortes. Dabei unterstreichen die Praktiken um taipponkkal die Bedeutung von materieller Kultur für die Diaspora-Akteure.

b.) Es lassen sich verschiedene Zuschreibungen ausmachen, welche das Fest unterschiedlich den postulierten Sphären «Religion», «Kultur» und «Politik» zuordnen. Auch ethno-nationalistische Diskurse haben Einfluss auf die Deutung des Festes. Aktivistinnen und Aktivisten versuchen durch taipponkkal den Aspekt der Tamilness hervorzuheben, indem das Feiern des Festes als integraler Bestandteil der Bewahrung der tamilischen Kultur in fremd-kultureller Umgebung angesehen wird.

c.) Taipponkal unterliegt in der Diasporasituation Anpassungsprozessen an die Gegebenheiten des Residenzlandes. Tamilische Akteure regieren auf die unterschiedlichen Umgebungsfaktoren flexibel und nehmen Innovationen vor. Die Ausübung des Festes wird auf seinen zentralen Kern beschränkt.

d.) Durch die Diasporasituation kommt es zu Verschiebungen der Hauptakteure: Im privaten Bereich findet häufig eine Verlagerung der geschlechtsspezifischen Zuschreibung der Handlungen statt. Im Tempel als zentralem Veranstaltungsort von taippoikkal bleiben es weiterhin traditionell die Männer, welche sich um das Kochen des Reises als zentralen Akt des Festes kümmern. Hier wird die Rolle des Priesters im Kontext des Festes aufgewertet.

e.) Die verstärkte Verlagerung des ursprünglich im privaten Bereich vollzogenen Festes hin zum Tempel unterstreicht die Wichtigkeit der Institution Tempel in der Diaspora. Durch diese Verlagerung soll der soziale Aspekt von taipponkkal bewahrt werden. Der Tempel als multifunktionaler Raum durchlebt einen Bedeutungswandel. Die Prozesse um das Feiern des taipponkkal-Festes sind ein instruktives Beispiel, um die hohe Bedeutung des Tempels als selbstverwalteten Sakralraum für die tamilischen Migrantinnen und Migranten und damit den diasporisch bedingten Prozess der Tempelisierung aufzuzeigen. Tamilness wie auch Hinduness werden durch das Feiern von taipponkal präsentiert; die Pflege spezifischer tamilischer Traditionselemente und der Einsatz materieller Kultur spielt hier eine entscheidende Rolle. 


\title{
6 Transnationale Verbindungen: Orte ausserhalb der Schweiz
}

\author{
Major transnational separatist movements like the \\ Sikhs, the Kurds, and the Sri Lankan Tamils conduct \\ their self-imagining in sites throughout the world, \\ where they have enough members to allow for the \\ emergence of multiple nodes in a larger diasporic \\ public sphere. \\ (Appadurai 1996, 22)
}

Die vorangegangenen Darstellungen von Tempeln als Orten der Verehrung von Hindu-Gottheiten bezogen sich auf Orte innerhalb der Schweiz. Da tamilische Hindus, welche in der Schweiz leben, - wie in Kapitel II 1. gezeigt wurde - aber als Diaspora-Akteure auch Teil eines transnationalen Beziehungsgeflechts sind, beschränkt sich eine individuelle Landkarte des Besuchs von Tempeln der einzelnen Akteure nicht auf das Residenzland, in dem sie leben. Tamilische Hindus, die ihren Wohnsitz in der Schweiz haben, besuchen auch «religiöse Orte» ausserhalb des nationalstaatlichen Raums. Durch die tamilische Sprache als verbindendes Mittel ist der Zugang für tamilische Diaspora-Akteure zu diesen Orten sehr leicht.

Die Inkorporationsbedingungen haben entscheidenden Einfluss darauf, in welchem Mass tamilische Migrantinnen und Migranten Tempel in anderen Diaspora-Ländern besuchen. Die asylrechtlichen Bedingungen der Schweiz, wie in Kapitel III 3.4 dargestellt, schränken die Bewegungsfreiheit von Asylsuchenden teilweise ein. So konnten beispielsweise jene Geflüchteten, die als Asylbewerber in Asylunterkünften untergebracht waren, die nationalstaatlichen Grenzen des Residenzlandes nicht verlassen (vgl. Kap. III 3). Jedoch sind ihnen Hindu-Tempel ausserhalb der Schweiz durch Austausch mit Familienangehörigen und die Präsenz in Medien der tamilischen Diaspora - wie etwa Auflistungen von «tamilischen Tempeln» auf Internetpräsenzen - bekannt (Vgl. Kap. V 2.3). Neue Medien ermöglichen es in besonderer Weise, dass Bezüge zu Orten innerhalb anderen Diaspora-Ländern hergestellt werden, auch wenn diese nicht physisch besucht werden können. Globalisierter Lokalismus kommt zum Beispiel durch Videoaufnahmen, welche Rituale in den Tempeln zeigen und welche von überallher angeschaut werden können, zum Ausdruck. Tamilen in der Schweiz können Feste und Rituale in tamilischen Tempeln in anderen Diaspora-Ländern beispielsweise über Internetplattformen wie 
youtube oder direkte Übertragungen via Videoschaltungen im Internet mitverfolgen. Durch diese technischen Möglichkeiten können auch wichtige Ereignisse - wie lebenszyklische Riten von Familienmitgliedern miterlebt werden, unabhängig vom Ort, an welchem sich die Akteure befinden.

Im Folgenden gehe ich exemplarisch auf Orte innerhalb der globalen tamilischen «Sakrallandkarte» ein. Dabei werden Besuche religiöser Orte an den Wohnorten transnational verstreuter Familienmitglieder wie auch Tempelbesuche bei Reisen ins Herkunftsland thematisiert. Aus religiösen Motiven werden Besuche bei Lalitha Sripalan in Dänemark unternommen (Kap. IV 6.1). Im Besonderen gehe ich auf Wallfahrten tamilischer Akteure nach Indien und ihre Rückbindungen an Praktiken in der Schweiz näher ein. Die Wallfahrt zum Tempel des Gottes Aiyappan kommt besonders in den Blick (IV 6.2). Abschliessend werden christliche Wallfahrtsorte, die von tamilischen Hindus als Orte gelebter Tamilness in der Diaspora besucht werden, kurz thematisiert (IV 6.3).

\subsection{Religiöse Orte einer globalen tamilischen «Sakral- landkarte»}

Die sri-lankisch stämmigen Tamilinnen und Tamilen, die ausserhalb Sri Lankas leben, sind grenzüberschreitend miteinander vernetzt und zeichnen sich durch grosse Mobilität aus. Die Mehrheit der in der Schweiz lebenden Tamilen haben Angehörige, welche in anderen Diasporaländern leben. Somit verfügen viele Akteure über ein breites Wissen zu tamilischen religiösen Orten innerhalb der Diaspora. Jene religiösen Orte an den Wohnorten von Familienmitgliedern, die nicht in der Schweiz leben, werden oftmals nicht primär aufgrund ihrer besonderen religiösen Bedeutung besucht. Vielmehr gehören diese Orte mit zu einem Besuch des Lebensumfeldes der Verwandten oder Bekannten.

Der Śrī Kāmākșì Ampāl Ālayam in Hamm-Uentrop/Deutschland (vgl. Luchesi 2003a; Wilke 2003, 2004) als der erste im traditionell südindischen Stil erbaute Tempel in Kontinentaleuropa ist vielen tamilischen Hindus, die in Mitteleuropa leben, bekannt und jene in der Schweiz lebenden tamilischen Hindus, welche Verwandte in Mittel- oder Norddeutschland haben, haben diesen Tempel meist schon besucht, wie auch tamilische HinduTempel in London, Frankreich, Schweden, den USA oder Kanada. Viele Tempel in den Diaspora-Ländern weisen ähnliche Umgebungsbedingungen und räumliche Situierung auf. Das weltweite Netzwerk von tamilischen Tempeln zeichnet sich durch religiöse Wahrnehmungsräume der 
gleichen «Sinnwelt» aus. Die Anordnungen und ästhetische Gestaltung innerhalb des Tempelinnenraumes folgen oft einem ähnlichen Muster.

Dabei wird oftmals zwischen mainstream-Diaspora-Tempeln und davon abweichenden Bauten, die meist von neohinduistischen Bewegungen errichtet wurden, unterschieden. Beispielhaft ist hier die ästhetische Gestaltung und Wahrnehmung des Tempels der Svāmināāāyana Reformbewegung (vgl. Reifenrath 2009) im Londoner Stadtteil Neasden zu nennen. Dieser Tempel, der sich in einem eigens aus Marmor errichteten Gebäude befindet, wird von einem tamilischen Informanten als besonders schön beschrieben.

Ich war in London. Dann wir haben auch einen Tempel besucht. Das ist auch ein Tempel/das ist von der Swaminarayan-Bewegung. Nur in London einer/ in England. Irgendwie vier/fünf oder sechs in ganzen Welt. Ich finde das ist so schön.

Er weist auf die spezielle Atmosphäre des Tempels hin und beschreibt ihn als Ort der Meditation. Die Handlung, ruhig im Tempel zu sitzen, ordnet er «ausserhalb Religion» zu, welche nicht spezifisch dem Hindu-Spektrum zuzuordnen sei.

Wenn ich in London wäre, dann ich kann schon, wenn ich Zeit habe/wie hier/ich gehe/de Hobby/so oder. Da gehe ich/sitze ich stundelang. Dann komme ich schon/habe ich gemeint, das ist so. Ich sage immer noch/ich bin Hindu. Aber das ist für mich/ausserhalb Religion. Dort ist ein/ähm/irgendwie eine Art von Ruhe/ ein Teil von Meditation. Ich gehe so/ich sitze so. Ich denke nicht etwas anderes. Die Sachen loslassen und komme so. Dort finde ich meine Ruhe/so irgendwie/die Art von Ruhe.

Tamilinnen und Tamilen aus der Schweiz besuchen auch den Sri Apirämi

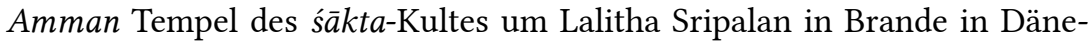
mark (vgl. Fibiger 2003, 2012). Die ursprünglich aus Jaffna stammende Tamilin wird im Tempel als heilendes Medium der Göttin Apirāmi verehrt und übt dort den Tempelpriester(innen)dienst aus. Tamilische Besucherinnen und Besucher verehren durch sie śakti, die weiblich-kosmische Schaffenskraft. Abbildungen von ihr habe ich auch in Schweizer Tempeln wie zum Beispiel am 13.08.2008 im Tempel in Basel (vgl. Abb. IV 20) gesehen. Auch hängen in tamilischen Läden in der Schweiz Ankündigungen von Lalitha Sripalan aus (vgl. Abb. IV 21).

Tamilinnen und Tamilen besuchen bei Reisen nach Sri Lanka die Tempel, welche sie vor der Migration aufgesucht hatten. Der homeland tourism (Cheran 2003, 13) erfuhr nach dem Ende des Bürgerkrieges einen Aufschwung. Auch die Tamilen der zweiten Generation werden so mit den Familientraditionen und dem religiösen Leben im Herkunftsland der Fami- 


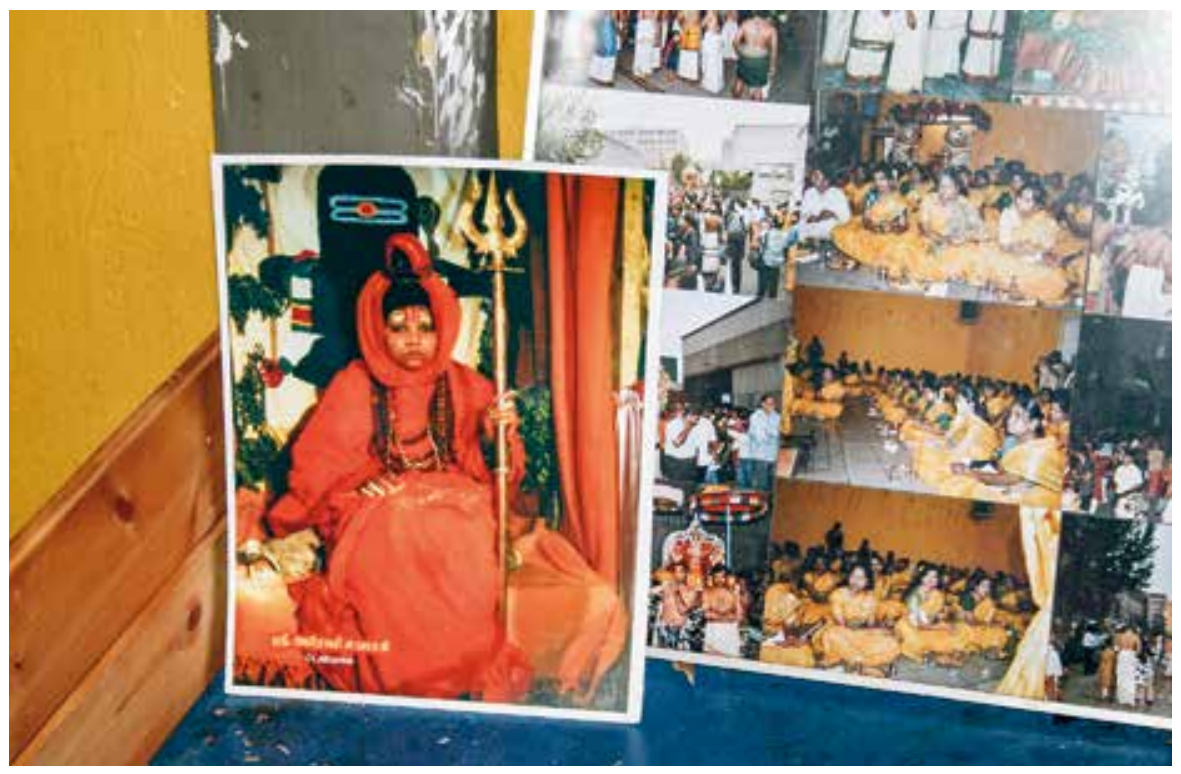

Abb. IV 20: Postkarte der in Dänemark lebenden Lalitha Sripalan im Hindu-Tempel in Muttenz bei Basel (13.08.2008).

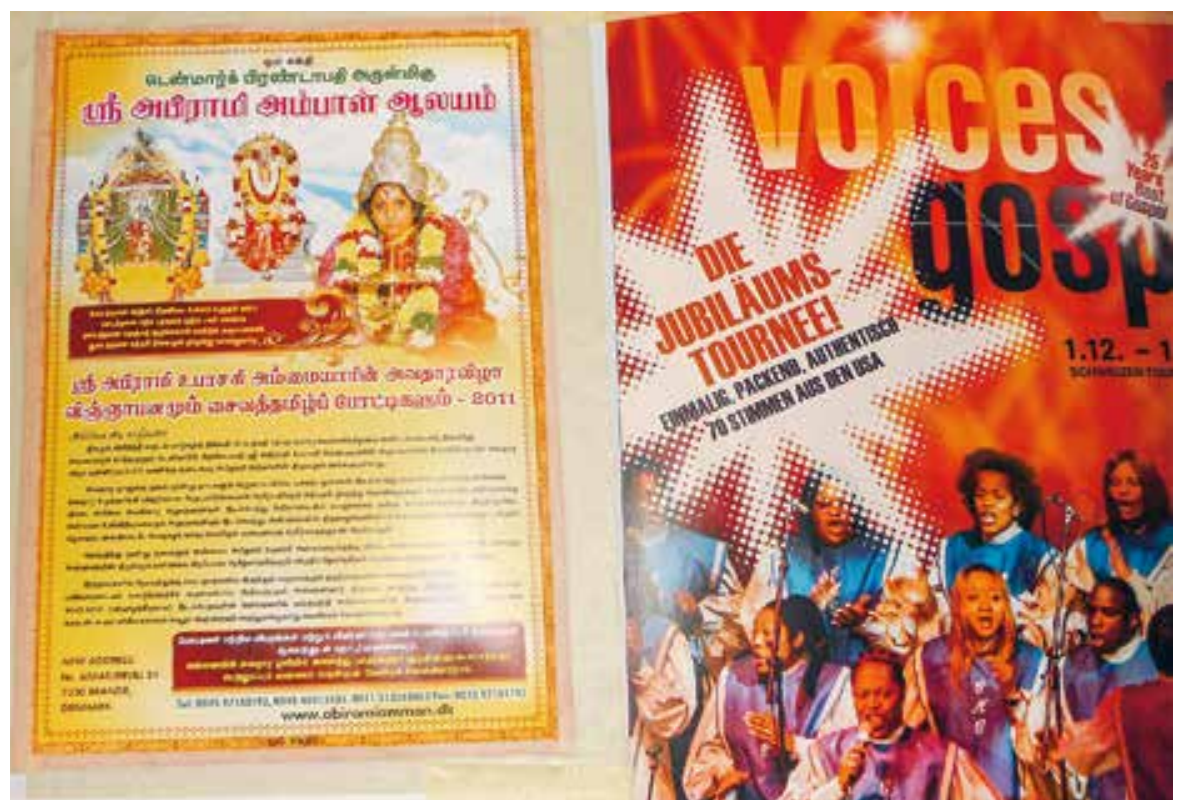

Abb. IV 21: Poster mit Ankündigungen Lalithas und der Bekanntgabe der neuen Adresse des Tempels des śâkta-Kultes, aufgehängt in einem tamilischen Laden in der Luzerner Baselstrasse (14.12.2010). 
lie vertraut gemacht. Wie auch im Residenzland besucht man Tempel in Sri Lanka auch aus sozialen Gründen. Für die Tamilen der ersten Generation stellen die Tempelbesuche Anknüpfungen an ihr Leben in Sri Lanka dar und wecken Erinnerungen:

2004 waren wir in Sri Lanka. Und in der Nähe von uns ist ein grosser Tempel/irgendwie 17 oder 18 Tage/ eine nach dem anderen Tag/immer diese wie sagt man/diese Tempelfest/ist nicht nur ein Tag. Irgendwie 18 Tage oder irgendwie so. Am letzten Tag einfach grosse Fest/und wir waren drei, vier Mal am Abend dort gewesen und am letzte Tag wir waren auch dort gewesen/tausende Leute/wie Ameisen [lacht]. Ich habe gedacht: Ja. Aber diese Tempel waren wir als Kind/wenn wir so in die Schule waren oder so/diese Zeit gehen wir schon mit dem Kollegen/Kollegen zusammen.

Neben den regionalen Tempeln aus den Herkunftsgebieten sind hier unter anderem der wichtige sri-lankische Wallfahrtsort Kataragama (tam. Katirkāmam), der bekannte Perumal-Tempel in Jaffna und der Murukan geweihte Nallūr Kantacuvāmi Kōvil in der Hauptstadt des ehemaligen Königreiches Jaffna, Nallūr, zu nennen.

\title{
6.2 Wallfahrten nach Indien: Sabarimala und die Rück- bindung der Pilgerreisen an Praktiken in der Schweiz
}

\author{
Sabarimala - a South Indian all-male pilgrimage to \\ Aiyappan, a hyper-male deity born from two male \\ gods - plays a role in constructing male identities, \\ at both external (social-structural) and internal \\ (psychological) levels. (Orsella/Orsella 2003, 729)
}

Obwohl Indien von der Mehrheit der sri-lankischen Tamilen nicht als Heimatland angesehen wird, wie anhand der Debatte um den Begriff Hindu-Diaspora bereits gezeigt wurde (vgl. Abschnitt II 2.1), hat bhärat als Mutterland hinduistischer Traditionen für viele sri-lankisch tamilische Hindu-Akteure eine besondere Bedeutung.

Indien ist Handlungsort wichtiger religiöser Geschichten, die vom Wirken der Gottheiten erzählen. Im sri-lankisch-tamilischen Diskurs über Indien wird jedoch noch einmal zwischen der religiösen Bedeutung der Region und dem heutigen Staat Indien und seinen Bewohnern unterschieden. Indien als Sakralregion, vor allem die Orte des drawidischen Indiens, ist für viele sri-lankisch-tamilische Hindus positiv konnotiert, während die 
Republik Indien aufgrund der politischen Ereignisse der letzten Jahrzehnte eher negativ behaftet ist (vgl. Kap. III 2; Kap. IV 6.2). Die Caivam-Traditionen Sri Lankas beziehen sich zentral auf die Traditionslinien Südindiens. Tamilische Hindus, die in der Schweiz leben, reisen nach Südindien, um dort Pilgerreisen zu wichtigen Tempeln zu unternehmen und unterstreichen damit die Verflechtungen der Caivam-Traditionen Sri Lankas mit den tamilischen Traditionslinien in Südindien.

Die Orte in Indien, die tamilische Hindus besuchen, sind Treffpunkte global verstreuter Hindus. Sie ziehen tamilische «Religionstouristen» aus allen Regionen der Welt an - auch solche, die in der Schweiz leben. Kennzeichen von Religionstourismus ist die religiöse Motivation der Reisenden (vgl. Rinschede 1999, 197). Neben der spirituellen Dimension wird das durch das Reisen erzeugte Gemeinschaftsgefühl und das Zusammentreffen mit Tamilinnen und Tamilen, welche in unterschiedlichen Ländern leben, als sehr positiv erlebt.

Einige Familien nutzen die Schweizer Schulferien der Kinder und ihre beruflichen Urlaubstage, um wichtige sakrale Orte in Südindien zu besuchen. Diese Wallfahrten werden im Familienverbund unternommen - Pilgerreisen können individuell in tamilischen Reisebüros zusammengestellt werden - oder durch Tempelvereinsmitglieder für eine Gruppe organisiert. In der Regel werden die religiös motivierten Reisen vor oder nach der Reise mit Praktiken verbunden, die in Bezug zur Wallfahrt stehen. Dies kann durch spezielle pūcais oder das Mitbringen von Andenken als Ausdruck materieller Kultur und durch Geschichten über die religiösen Erlebnisse, die im Schweizer Kontext erzählt werden, geschehen.

Als Beispiel für eine organisierte Gruppenpilgerfahrt wird im Folgenden die Reise einer Gruppe von tamilischen Männern vorgestellt, denen es gemeinsam ist, dass sie regelmässig und in erster Linie den Śrī Viṣnu Turkkai Ammañ Tempel in Adliswil bzw. nach seinem Umzug ab 2010 in Dürnten besuchten. Anfang 2010 flogen sie nach Chennai, die Hauptstadt Tamil Nadus, um in erster Linie zu dem dem Gott Aiyappan geweihten Wallfahrtsort Sabarimala ${ }^{354}$ zu pilgern, aber auch um andere sakrale Orte in den südindischen Bundesstaaten Tamil Nadu, Kerala und Andhra Pradesh zu besuchen. Die Pilger mieteten in Indien ein Auto mit Fahrer und übernachteten an den unterschiedlichen Orten in Gästehäusern.

Als wichtiger Murukan-Pilgerort wurde Palanin (im Bundesstaat Tamil Nadu) besucht. Palanni zählt zu den sechs zentralen Pilgerzentren der

354 Die tamilische Umschrift des Namens des Berges lautet Caparimalai. 
Murukan-Verehrung in Südindien (Clothey 1972, 81). ${ }^{355}$ Palanni wird als der Ort angesehen, an dem eine populäre Geschichte innerhalb des tamilisch hinduistischen Spektrums spielt. Diese wird als sakrales Theater auch in der Schweiz - während des «Mangofestes» (tam. māmpalat tiruvilāa) im Rahmen des jährlichen Tempelfestes (tam. tiruvila ā) - aufgeführt und durch diese Performanz den in der Schweiz lebenden Tamilen vergegenwärtigt und in der Schweiz verortet, was in Kapitel V 3.3 dargestellt wird.

Ein weiterer Pilgerort, welcher von der Wallfahrtsgruppe aus Adliswil besucht wurde, ist die «Stadt der Tempel» Maturai, ebenfalls im Bundesstaat Tamil Nadu. Ein bedeutender Tempel, der von den Pilgern besucht wird, ist der Göttin Minnākși, die als Gefährtin Civañs gilt, geweiht. Die Geschichte von Mīnākșīi ist sehr populär unter Tamilen, auch in der Diaspora.

Tiruccirāppalli (in Tamil Nadu), abgekürzt auch Trichy genannt, ist eine weitere Station der Pilgerreise. Hauptort der Verehrung ist hier der Sri Ranganāthaswamy Tempel, in dem Ranganātha, eine Form von Viṣnu, verehrt wird. Der fünfte Ort, der besucht wurde, ist die Pilgerstadt Tirupati (in Andhra Pradesh), in deren Zentrum der Tirumala Venkkațéśvara Tempel steht. Hier wird der Gott Venkațéśvara verehrt, eine Form von Vișnu.

Höhepunkt der Pilgerreise (tam. yāttirai) war die Wallfahrt der männlichen Hindus aus der Schweiz auf den Berg Sabarimala (im Bundesstaat Kerala) in den Westghats, wo der Gott Aiyappan verehrt wird. Die Wallfahrt - wie auch die Verehrung von Aiyappan im Allgemeinen ${ }^{356}$ - wird von Jahr zu Jahr populärer und zieht immer mehr Hindus an, weshalb im Folgenden näher auf sie eingegangen wird. ${ }^{357}$ Zur jährlichen Wallfahrt reisen auch Hindus aus der Diaspora an - und auch Tamilen aus der Schweiz orga-

355 Tamilen aus der Schweiz reisen aber auch zu den anderen Murukan-Pilgerorten. Arupadaiveedu (tam. «sechs Wohnsitze»), wie die sechs wichtigen Murukan-Tempel genannt werden, befinden sich alle im Bundesstaat Tamil Nadu: Palani, Swamimalai, Tiruthani, Pazhamudircholai, Thiruchendur und Tirupparamkunram.

356 Einige Tempelvereine in der Diaspora ergänzten im Laufe der Zeit die Götterdarstellun-

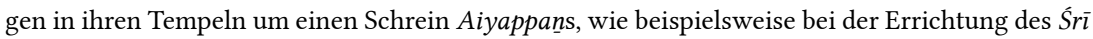
Kāmāksṣi Ampāl Tempels in Hamm 2002 geschehen (Luchesi 2003a, 242). Sein Schrein findet sich in östlicher Himmelsrichtung: Er ist im Hammer Tempel neben Pairavar (skr. Bhairava), rechts neben dem Eingang platziert. 2000 berichtet Diana L. Eck $(2000,231)$ in ihrer Beschreibung des Shiva Vishnu Temple in Washington, D.C. (USA): "Most recently, the temple dedicated an image of Aiyappa who resides on a remote hilltop of Kerala [...]."

3572003 berichteten die Tempel-Administratoren, dass die Zahl der Pilger und die Einnahmen des Tempels steigen (Osella/Osella 2003, 732) und auch meine Informanten geben an, dass die Wallfahrt jedes Jahr mehr Hindus anzieht. Da es sich bei der globalen Popularität Aiyappañs um ein junges Phänomen handelt, wird die Verehrung Aiyappañs nur an wenigen Stellen in der Sekundärliteratur ausführlicher dargestellt. Vgl. auch Joanne Punzo Waghorne (2004, 255), die schreibt: "Sri Ayyappan has rapidly gained devotees in the last decade [...]." 


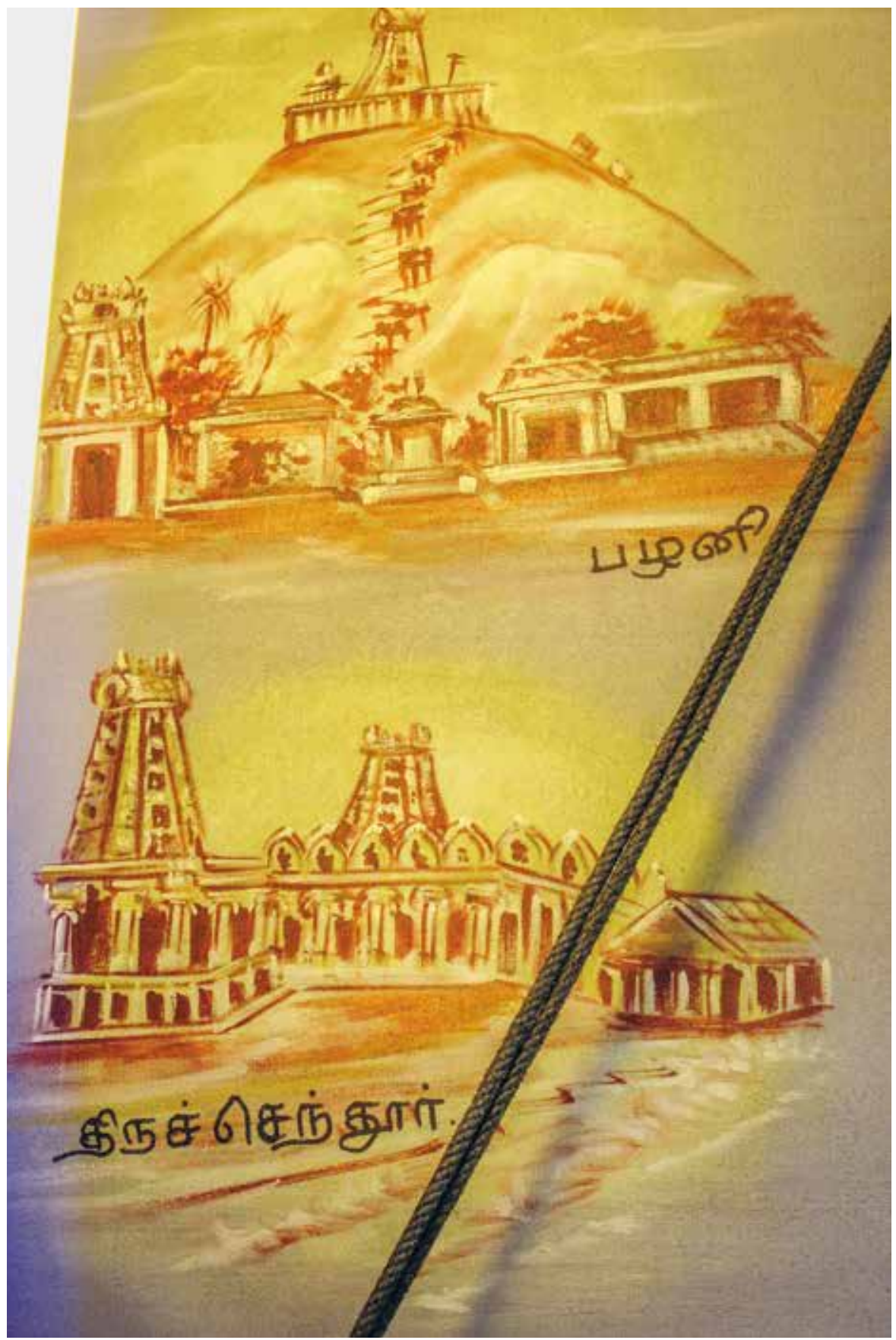

Abb. IV 22: Darstellung des Murukan-Tempels in Palañi (oben) im Śrī Civacuppiramaṇiyar Tempel in Adliswil (18.08.2010). 
nisieren gemeinschaftliche Pilgerreisen, die in der Schweiz rituell vor- und nachbereitet werden. ${ }^{358}$

Die Wallfahrt nach Sabarimala, die geschlechtsspezifischen Regulierungen unterliegt, kann als Reinszenierung der Lebensgeschichte Aiyappans verstanden werden, der als Sohn der männlichen Götter Civan und Viṣnu gilt. ${ }^{359}$ Die Gottheit steht zwischen den Spektren der Caivas und der Vaishnavas und kann als Mittler zwischen den beiden Strömungen fungieren.

In der Entstehungsgeschichte von Aiyappan geht es um das Spiel mit Geschlechterrollen. ${ }^{360}$ Während der Wallfahrt stellen die Pilger einen Teil der Lebensgeschichte Aiyappanns nach. Das dabei erzählte Narrativ beinhaltet folgenden Plot: Der junge Aiyappan sorgte sich um seine schwer kranke Adoptivmutter. Er begab sich in den gefährlichen Wald um Sabarimala, um Tiger-Milch zu holen, welche als einziges Heilmittel für sie galt. Die Adoptivmutter, eine Königin, war jedoch gesund und hatte diese Geschichte erfunden, um Aiyappan in Gefahr zu bringen. Sie hoffte, dass Aiyappan bei dieser Mission getötet werden und ihr eigenes Kind auf den Thron kommen würde. Im Wald begegnete Aiyappan einer wilden Büffelkuh (mit Namen

358 Brigitte Luchesi (2003a, 254f.) berichtet, dass sich die Verehrung Aiyappanss seit den 1950er Jahren auch «unter Tamilen ausbreitete». Ob damit auch Tamilen aus Sri Lanka gemeint sind, wird nicht weiter spezifiziert. Die Gruppe der Pilger, welche ausserhalb des südasiatischen Subkontinents leben, fehlen in der Aufzählung der Teilnehmer bei Corinna und Filippo Osella (2003, 729): "[...] the annual pilgrimage to Sabarimala, the main temple of Ayyappan, visited every year by millions of male devotees from Kerala and from South India as a whole".

359 Aiyappans Reittier ist der Elefant und seine Begleiterinnen - obwohl er als asketisch lebend gezeichnet wird - sind Pūranai und Puṭkalai (vgl. Masilamani-Meyer 2004, 223).

360 Die «Vorgeschichte» Aiyappans findet sich im 8. Buch des Bhāgavata Purāna (vgl. Vanital/Kidwai 2001, 69 ff.). Es existieren verschiedene Lesarten des Narrativs. Caroline und Filippo Osella (2003, 730 f.) erzählen gemäss den Informationen ihrer Feldforschung in Kerala die Geschichte wie folgt: Als Dämonen den Göttern amritha stahlen, suchten die Götter nach Strategien, um dieses wieder zu holen. Vishnu entschied sich für ein mimetisches Theater: Er verkleidete sich als Mohini, die als Sinnbild der verführerischen Frau gilt. Als Frau verkleidet, besuchte er die Dämonen, die am Tisch sassen und auf ihr Essen warteten. Sie konnten nicht mit dem Essen beginnen, weil keine Frau da war, die sie bediente. Vishnu in Frauenkleidern bot den männlichen Dämonen an, sie zu bedienen, wenn sie die Augen schliessen, um die Ehre der «Mohini» zu wahren. Mohini/Vishnu nahm daraufhin das Elixier und flüchtete. Danach erzählte Vishnu Shiva von seinem Trick. Shiva bat Vishnu, ihn als Mohini zu sehen. Vishnu sträubte sich, aber Shiva blieb hartnäckig. In der Gestalt der Mohini war Vishnu so schön, dass Shiva vergass, dass es sich eigentlich um einen Mann handelte, und von Lust überwältigt wurde. Aus der sexuellen Begegnung der beiden entstand Aiyappan, der aus Vishnus Rippe geboren wurde. Vishnu und Shiva schämten sich und legten das Kind in ein Körbchen auf einen Fluss. 
Mahishi), mit der er kämpfte und die er tötete. ${ }^{361}$ Mahishi transformierte sich in die Göttin Ganga, welche durch einen Fluch im Körper des Tieres gefangen war. Als Belohnung bot sie Aiyappan an, sie zu heiraten. Ausserdem klärte sie ihn über seine göttliche Herkunft als Sohn von Vishnu und Shiva auf und über die Falle, die seine Adoptivmutter ihm stellte. Sie sahen es aber als Aiyappans Pflicht an, seine begonnene Aufgabe zu beenden und die Tiger-Milch zu holen. Dies gelang ihm: Auf einem Tiger reitend kehrte er zu seiner Adoptivfamilie zurück. Jedem war nun seine göttliche Natur klargeworden. Nach beendeter Mission kehrte er in den Wald zurück und liess sich auf der Spitze des Berges nieder, wo er seine göttliche Form annahm und die männlichen Pilger empfängt.

Die Imitation der Geschichte mit dem Durchqueren des gefährlichen Waldes (in dem noch heute Tiger leben) und der Besteigung des Berges wird - wie die Informanten in der Schweiz berichten, die eine solche Pilgerfahrt unternommen haben - als sehr anstrengend empfunden, da das Wandern auf den Berg physisch sehr belastend ist. Viele berichten vom Weg der Pilgerreise als Abenteuer und als männliche Heldentat; diese wird besonders von jungen Männern unternommen. Kannicuvāmi ${ }^{362}$ werden die Männer genannt, welche das erste Mal an der Wallfahrt teilnehmen. Sie sind besonders wichtig, da Aiyappan der Göttin erklärte, dass er sie erst heiraten könne, wenn keine kannicuvāmi mehr zu ihm kämen, die ihn verehrten, da er diese nicht vernachlässigen könne. Aufgabe der Erstpilger ist es also, das Zölibat Aiyappans zu bewahren, damit er seine göttliche Kraft behält und weiterhin den Menschen helfen kann.

Höhepunkt der Wallfahrt ist der Anblick des makara jyothi, des Lichtes eines hellen Sternes, welches nach dem Glauben der Pilger an jedem 14. Januar über dem Berg Sabarimala erscheint und Aiyappan verkörpere; auf der Webpräsenz des Śrī Civacuppiramaniyar Tempels in Adliswil hiess es 2009: "At the end of the mandals pooja the devotees start visiting Sabari Malai and full fill their vows and after viewing the Makarajothi the devotees return to their respective houses." ${ }^{363}$ Ein in der Schweiz lebender tamilischer Pilger erzählt mir, dass er «das Licht gesehen» habe und es «echt und keine Imitation» sei.

Die Wallfahrt zeichnet sich durch besondere Gender-Regulierungen aus: Nur Männer und Frauen im nicht-gebärfähigen Alter dürfen an ihr teilneh-

361 Dabei helfen ihm der Muslim Vavarswami und der "tribal man” Karruttaswami (Osella/ Osella 2003, 731). Von einigen Besuchern im Tempel in Adliswil wurde in Gesprächen Aiyappan als eine Gottheit angesehen, die sie mit dem Islam verbinden.

362 Kanni bedeutet auf Tamilisch «Jungfrau».

363 www.murugantemple-zh.ch/eng/engindex.php; 14.01.2009. 
men. Daraus ergibt sich, dass die Pilgerreise so gut wie ein exklusiv männlicher Anlass ist, ein "gendered ritual" (Orsella/Orsella 2003, 730). Caroline und Filippo Osella haben die Hintergründe der Wallfahrt und ihre Funktion bei der Konstruktion von Männlichkeit eingehend untersucht (vgl. Orsella/ Orsella 2003, 729). Der Akt des Pilgerns verbindet das einzelne männliche Individuum zum einen mit dem «hyper-männlichen» Gott und zum anderen mit der Masse der anderen Männer, welche gemeinsam pilgern.

Der Ursprung des Gottes aus zwei männlichen Gottheiten, die homoerotischen Elemente seiner Entstehungsgeschichte und die Beschränkung der Wallfahrt auf fast ausschliesslich männliche Pilger führt dazu, dass Aiyappan von einigen Informanten als Gott angesehen wird, der «Frauen nicht mag».

\section{Rückbindungen der Wallfahrt an Orte in der Schweiz}

Die Wallfahrt ist eingebunden in spezielle Praktiken, die vor und nach der Pilgerreise am Heimatort der Pilger durchgeführt werden, sich jedoch auf das Ereignis und den Ort der Wallfahrt beziehen. Aus meinem Beobachungsprotokoll meines pūcai-Besuches im Śrī Viṣṇu Turkkai Amman Tempel am 15.01.2010:

Ich komme mit einem 22-jährigen Tamilen nach der Tempel-pūcai ins Gespräch. Er erzählt mir, er mache so etwas wie Ramadan. Ich frage ihn, was das genau sei. «Fasten wegen des Gottes Aiyappann», antwortet er mir. Aiyappan sei streng, deshalb trauen sich viele Leute nicht, das Fasten durchzustehen. «Denn jeder Fehler wird bestraft, man muss anständig sein, anständige Gedanken haben und vor allem nichts mit Frauen denken.» Mir fällt auf, dass er eine besondere Kette aus Holzperlen trägt und schwarz gekleidet ist. Er erzählt mir, dass dies äussere Kennzeichen für seine Hinwendung zu Aiyappan seien.

Innerhalb der tamilischen Hindus in der Schweiz stellt die Pilgergruppe eine religiöse männliche Elite dar. Voraussetzung, Teil der Elite zu werden, sind die Zugehörigkeit zum männlichen Geschlecht und die spirituelle Selbstdisziplin des Einzelnen. ${ }^{364}$ Dies macht die Gruppe, trotz der internen

364 Informanten berichten davon, dass während der Wallfahrt «manche Inder rauchen; das darf man nicht». Corinna und Filippo Osella $(2003,734,741)$ berichten von den Unterschieden zwischen Pilgern aus Kerala und aus Tamil Nadu: Die Tamilen befolgen die Regulierungen gewissenhafter und fokussieren mehr auf den religiösen Kern der Wallfahrt. Sie zitieren einen guruswami wie folgt: "Only Tamils are big believers nowadays, more devoted to Aiyappan than Malayalis. They follow vratam properly, go in big groups with a guruswami and cook together [...] they do the pilgrimage as in the old days" (Osella/Osella 2003, 734). Dies bringe ihnen bei der lokalen Bevölkerung den Ruf ein, rückständig und unmodern zu sein. 
Hierarchie, zu einer egalitären devotionalen Gemeinschaft: Es zählt nur der Wille und die Hingabe des Individuums; Kastenregulierungen, Herkunft oder Alter spielen offiziell keine Rolle. Alle Pilger nennen sich untereinander ausnahmslos cuvāmi (skr. svāmi; «heiliger Mann»). Dies macht die Teilnahme für viele Niedrigkastige attraktiv. Äussere Kennzeichen der Pilger sind das Tragen schwarzer oder dunkelblauer Kleidung und eine Kette aus Holzperlen, meist aus indischem Basilikum, Thulasi. Die einheitliche Kleidung unterstreicht den egalitären Charakter unter den Pilgern, was das Gemeinschaftserlebnis fördert.

Wie die anderen in der Schweiz meist von Männern durchgeführten physisch sehr extremen Formen ritueller Praxis wie kāvați oder Hakenschwingen (vgl. Kap. V 3.1), beinhaltet die Wallfahrt nach Sabarimala das Ablegen eines Gelübdes. Als Vorbereitung auf die Wallfahrt nach Sabarimala fasten die Pilger 41 Tage an ihrem jeweiligen Heimatort und vollziehen bestimmte, speziell auf Aiyappan ausgerichtete pūcais in den Tempeln, die einen Schrein für den Gott beherbergen ${ }^{365} 2010$ wurde der Fastenanfang im Śrī Civacuppiramaniyar Tempel in Adliswil am Morgen des 17.11. begonnen und am 27.12.2010 jeweils mit einer speziellen pücai beendet. Diese besondere pücai beinhaltet - ähnlich wie das sakrale Theater zum Anlass des Mangofestes während des Tempelfestes (vgl. V 3.2) - eine ausdrucksstarke mimetische Darstellung der Wallfahrt im Schweizer Tempel. Während der nonverbalen dramatischen Inszenierung, die von den Tempelmusikern begleitet wird, ist ein Junge als Aiyappan verkleidet. Einige männliche Kinder und Erwachsene stellen durch ihre Kostüme Tiger dar; gemeinsam tanzen sie mit den «cuvāmis» im Tempel einen wilden Tanz, in dem sie die gefährliche Wanderung auf den Berg darstellen. Sie halten Pflanzenbüschel und Macheten in der Hand. ${ }^{366}$ Das Licht des makara jyothi wird durch das Hochwerfen bunter Papierfetzen imitiert. Danach folgt ein ekstatischer Tanz der Pilger und «der Tiger» im Tempel.

Über die pūcais während des Fastens hinaus finden in einigen Tempeln während des gesamten Jahres regelmässige pūcais zu Ehren Aiyappañs statt. Auch während der speziellen Aiyappan-pūcai (in der Schweiz) wird der Prozess der Wallfahrt auf den heiligen Berg (in Indien) imitiert. Ein

365 Auf der Homepage des Śrī Civacuppiramaniyar Tempels hiess es 2009: "In the month of November every year the Iyappa Swamy fasting starts with the mandala poojas and mandala pooja will go on for forty-one days. At the end of the mandals pooja the devotees start visiting Sabari Malai and full fill their vows and after viewing the Makarajothi the devotees return to their respective houses", www.murugantemple-zh.ch/eng/engindex.php; 14.01.2009.

366 Vgl. die vom Śrī Civacuppiramaniyar Tempel hochgeladenen Videos des Anlasses auf https://www.youtube.com/watch?v=aCFWsH_dyAI (20.12.2011). 
Tempel, welcher als einer der ersten Aiyappan pūcais und organisierte Wallfahrten nach Sabarimala durchführte, war der Śrī Civacuppiramaṇiyar Tempel in Adliswil. Im Śrī Civacuppiramaṇiyar Tempel wird Aiyappan als Gottheit mit einem eigenen geweihten Schrein verehrt. Darüber hinaus kam 2001 ein eigens für die Aiyappan pūcai angefertigter verschiebbarer Schrein mit vergoldeter Treppe hinzu, die nur für die monatliche Aiyappan $p \bar{u} c a i$ vorgesehen war. Die in Form eines Dreiecks angefertigte Treppe ist circa zwei Meter hoch und besteht aus 18 Stufen. Um portabel zu sein, hat sie Rollen und ist somit problemlos verschiebbar.

An jedem letzten Samstag im Monat fand eine spezielle Aiyappan-pūcai statt. ${ }^{367}$ Die folgenden Ausführungen beziehen sich auf meinen Besuch der Aiyappan pūcai am 31.01.2009:

Der Schrein für Aiyappan befand sich links hinter dem Hauptaltar, in welchem zwei Kultstatuen von Aiyappan platziert waren (Abb. IV 23). ${ }^{368}$ Die pūcai erforderte eine Umplatzierung der Schreine im Tempel. Für den ersten Teil der pūcai wurde die kleinere der beiden Figurinen Aiyappañs in ein Reinigungsbecken vor dem Ganeśa-Schrein gestellt, die grössere auf den portablen Schrein. Die pūcai war in zwei Teile gegliedert: Der erste Teil wurde vor dem Altar Ganeśas vollzogen, der sich rechts vom Schrein Aiyappanns befindet. Dieser war während des ersten Teils der pūcai leer, da sich die kleine mürtti Aiyappans vor dem Ganeśa-Altar befand und die grössere Statue auf dem erhobenen Altar vor dem Murukan-Altar platziert war. Es wurde ein Waschbecken aufgestellt, auf dem eine kleine mūrtti von Swami Aiyappan in einer Schale platziert wurde. An der Seite hatte die Konstruktion eine Öffnung, durch die die Flüssigkeit ablaufen konnte. Diese wurde in einem Plastikeimer aufgefangen. Dahinter befand sich ein

367 Der Kalender des Tempels 2010 führt diesen Anlass als «Ayappaswami puja: Ayyappan Bajan/Spez Gottesdienst» auf. Die Aiyappan pūcai wird auf der Webpräsenz des Tempels wie folgt angekündigt: "Iyappa Swamy poojas are conducted in the Murugan Temple at a very grand scale on the last Saturday, of every month. Lot of people including Iyappa devotees attend this pooja ceremony. Indian as well as Sri Lankan worshippers and devotees attend the Iyappa Swamy pooja festival on the last Saturday of every month". Zur Praxis während des Rituals heisst es weiter: "All the devotees sit together and start reciting Bajanai recitals. The Iyappa Swamy pooja ceremony will start commencing from 5 P.M. and goes on till 9 p.m. Many new faces could be seen praying on the pooja days", www.murugantemple-zh.ch/eng/engindex.php; 14.01.2009.

368 Der Schrein trägt ein Schild, auf dem der Name Sri Aiyappan in tamilischen und lateinischen Buchstaben steht (geschrieben als «Sri Ayyappan»). Im Schrein stehen, wenn keine pūcai für Aiyappan durchgeführt wird, zwei Aiyappan-Statuen. Ursprünglich gab es nur die kleinere der beiden Statuen. Beide Statuen zeigen Aiyappan als jungen Mann, sitzend, die Beine angehoben und mit einem Band (yogapațta) gesichert. Seine rechte Hand zeigt das abhaya mudrā. Auf seiner Stirn befindet sich das vaisnaca nāmam. Beide Statuen tragen eine Kopfbedeckung und sind mit Blumen geschmückt. 


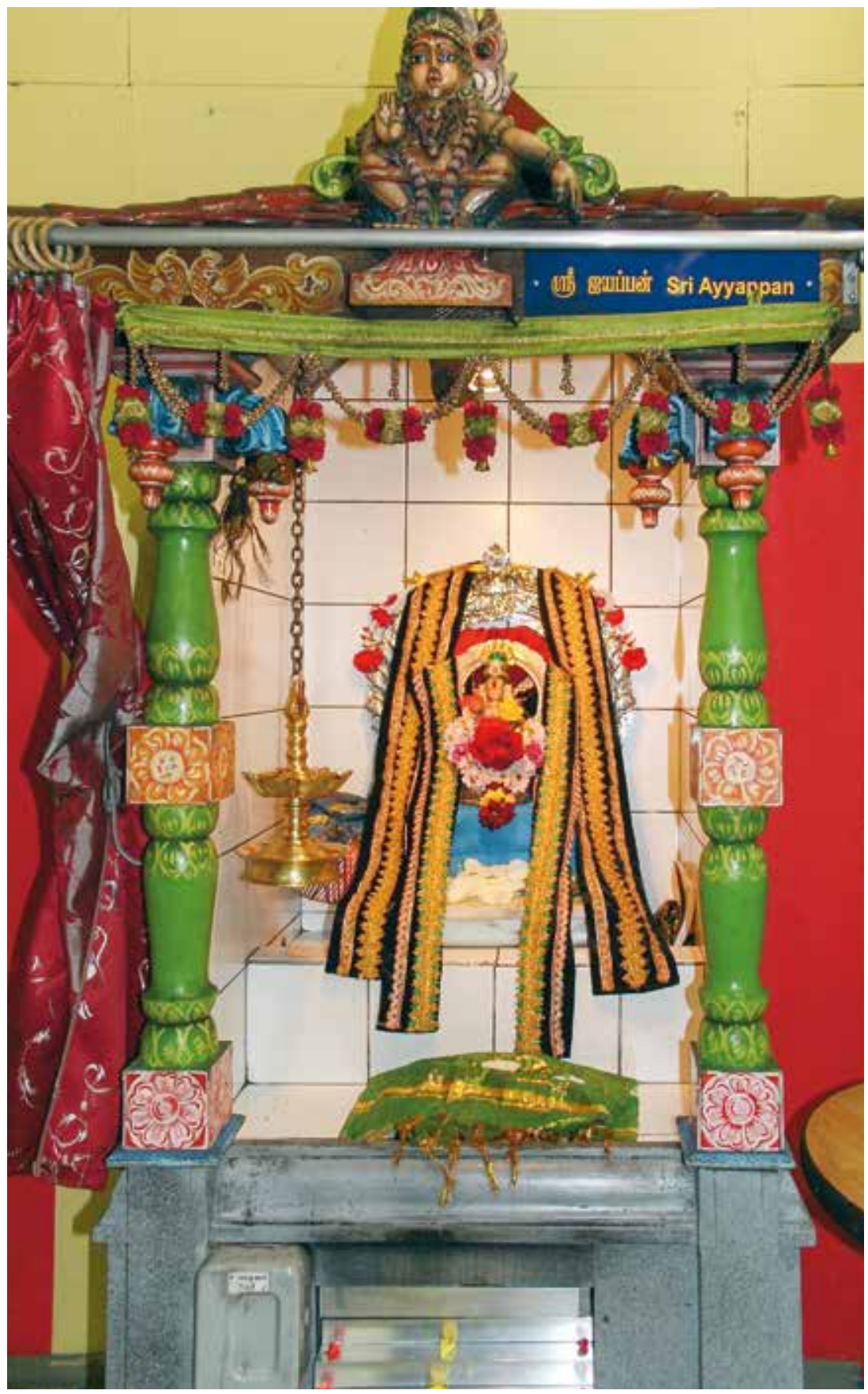

Abb. IV 23: Schrein des Gottes Aiyappan während der Aiyappan pūcai

(Śrī Civacuppiramaṇiyar Tempel in Adliswil; 31.01.2009). 


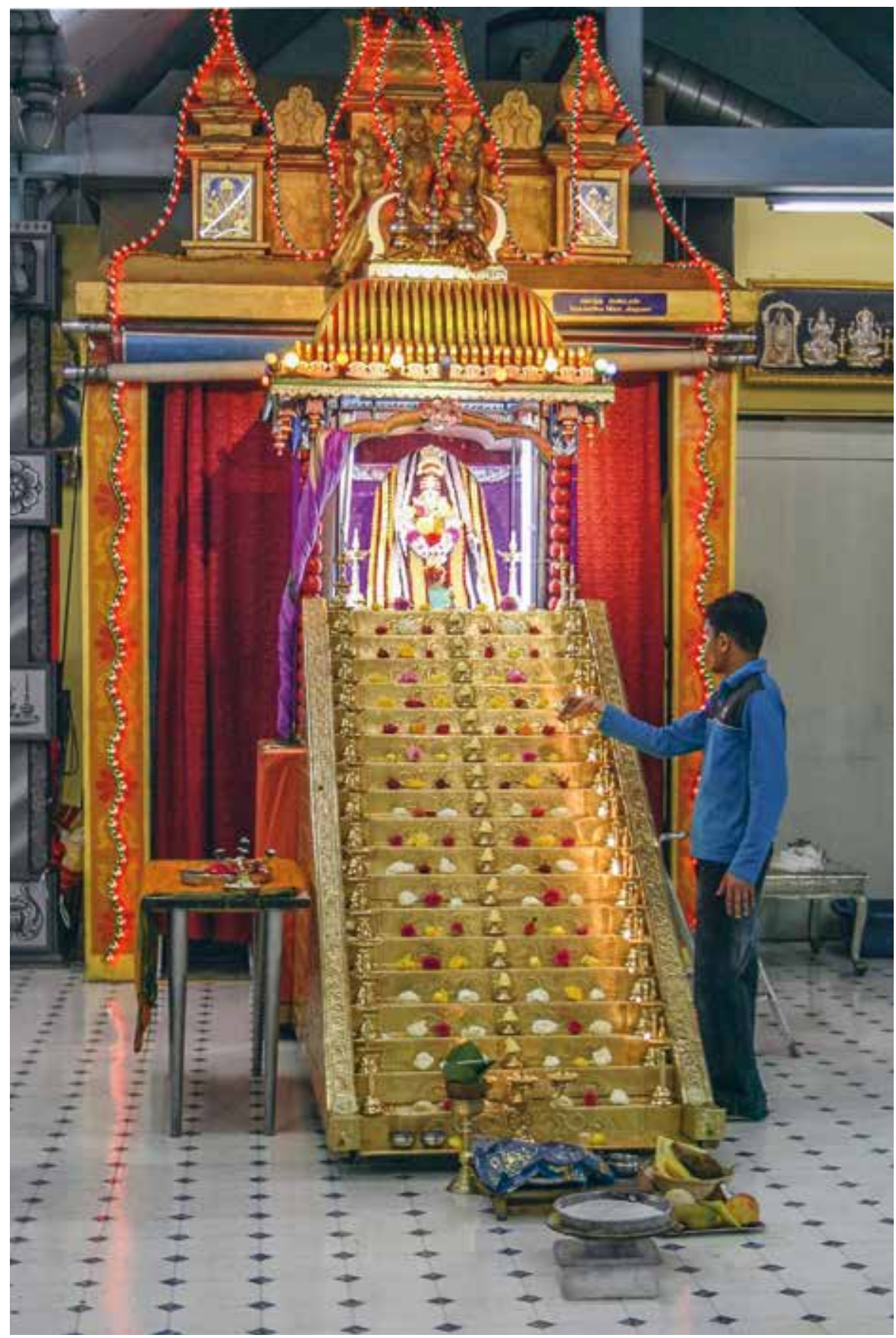

Abb. IV 24: Die 18 vergoldeten Stufen, die wie im südindischen Wallfahrtsort Sabarimala zum Gott Aiyappañ führen (Śrī Civacuppiramaṇiyar Tempel in Adliswil; 31.01.2009). 
runder Tisch, auf dem Lampen und Schalen mit diversen für das Ritual notwenigen Utensilien platziert waren. Darauf folgte die Darstellung der neun Planeten, symbolisiert durch Kokosnüsse. Der Priester sitzt auf dem Boden, vor ihm ein Feuer, und er vollzieht das homa.

Rechts von der Anordnung stehen die am Ritual Teilnehmenden, links die Familie, welche die pūcai gesponsert hat. Der Hilfspriester schüttet nacheinander verschiedene Materialien über die Statue. Danach wird die Statue an jenen Platz gestellt, an dem ansonsten die grössere Statue Aiyappans platziert war.

In der pūcai wird die Wallfahrt nach Sabarimala performativ und durch den Einbezug bestimmter Gegenstände imitiert. Dieser zweite Teil der $p \bar{u} c a i$ wird um die goldene Treppe, die an den portablen Schrein angebracht ist, vollzogen. Der Berg mit 18 Stufen symbolisiert Sabarimala; auf jede Stufe wurden während der pūcai Blumenblätter gelegt und Lichter entzündet. Abschliessend wurde die mūrtti Aiyappans am Ende der pūcai hell durch grelle Glühbirnen in verschiedenen Farben erleuchtet, was das Scheinen des makara jyothi repräsentiert.

Zentrales Element der Schreine für den Gott Aiyappan in den Schweizer Tempeln ist die Treppe, welche den Weg zum Heiligtum Aiyappans auf dem Berg Sabarimala symbolisiert. Abb. IV 25 zeigt bespielhaft den improvisierten Schrein Aiyappans im Śrī Kalyāna Murukañ Tempel in Bern.

Präsent ist die Verehrung Aiyappañs in der Schweiz auch über den Aspekt von materieller Kultur, wie beispielsweise über zum Kauf angebotene CDs mit Liedern zu Ehren Aiyappans, die in tamilischen Lebensmittelläden in der Schweiz angeboten werden.

Zusammenfassend kann gesagt werden, dass Aiyappan eine in Schweizer Tempeln immer populärer werdende Gottheit ist, welche Mittler zwischen den unterschiedlichen Strömungen der Caivas und Vaishnavas sein kann. ${ }^{369}$ Aiyappan stellt eine Identifikationsfigur für Männer dar; von der Wallfahrt geht eine Stärkung der männlichen Gemeinschaft tamilischer Hindus aus. Als Gemeinschaftserlebnis und das Alltagsleben transzendierende Erfahrung stärkt sie auch die Anbindung diasporischer Praktiken an Indien bzw. die drawidischen Herkunftsregionen.

$369 \mathrm{Zu}$ untersuchen wäre, ob und inwiefern die steigende Popularität Aiyappañs unter in der Schweiz lebenden Hindus auch in Verbindung mit der Diaspora-Situation steht, in der die Akteure leben. Die Verehrung Aiyappans sowohl in Südasien als auch in der Diaspora verdient eine genauere Untersuchung. Eine Analyse dieser unter Gesichtspunkten der Gender Studies kann vertiefende Aufschlüsse über das Wechselverhältnis von Religion und Gender geben. Die dargestellten Ausführungen sind als Anregungen zu detaillierteren Untersuchungen der Aiyappan-Verehrung in der Diaspora und der Wallfahrten von Diaspora-Akteuren nach Kerala zu verstehen. 


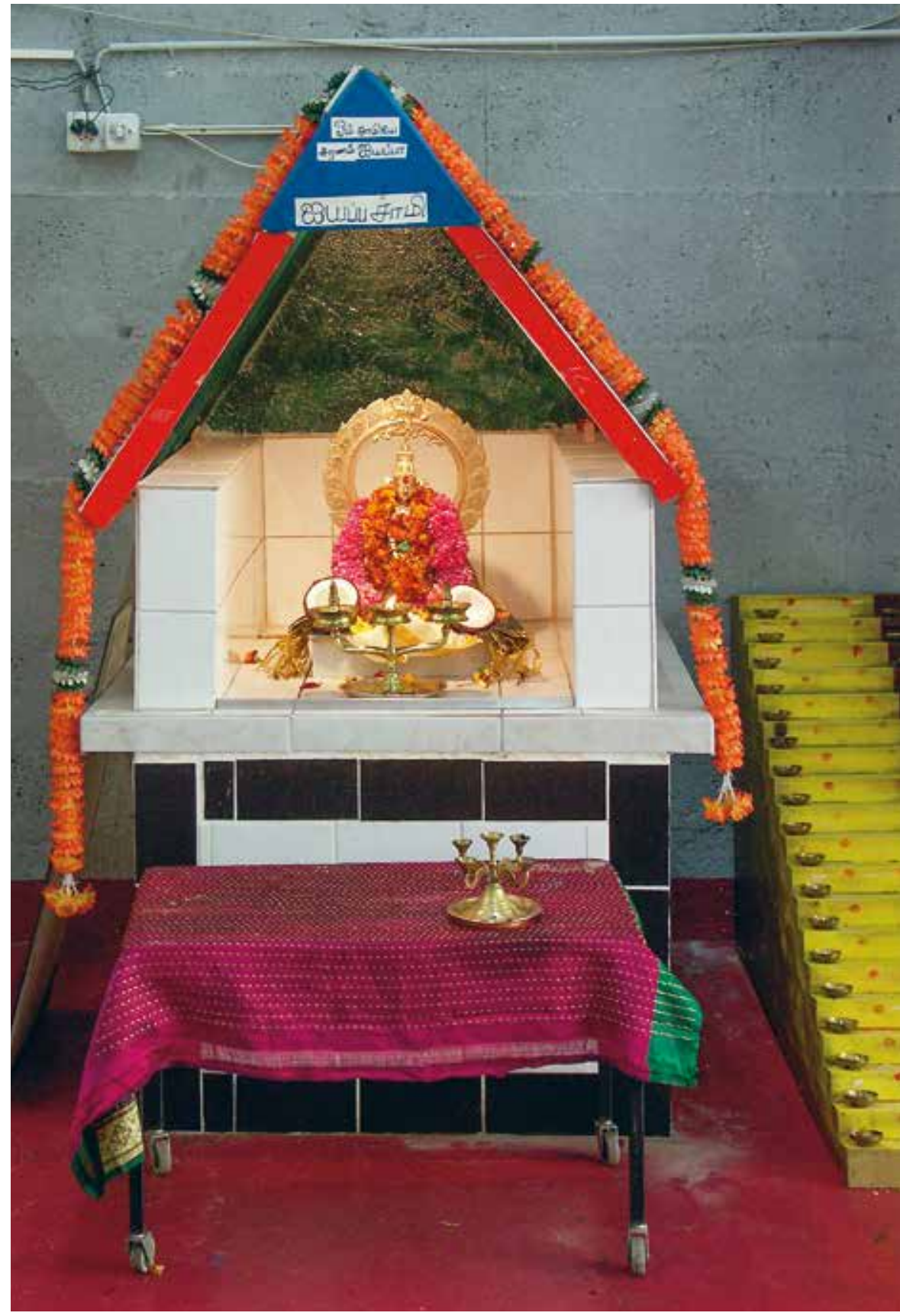

Abb. IV 25: Der improvisierte Schrein zu Ehren Aiyappañs im Śrī Kalyāna Murukan̄ Tempel in Bern, daneben die für die Aiyappan pūcai benötigte Treppe, welche den Weg auf den Berg Sabarimala symbolisiert (13.10.2007). 


\subsection{Weitere Aspekte der transnationalen Vernetzung von religiösen Orten: christliche Wallfahrtsorte}

Neben den oben in Abschnitt IV 3.4 bereits erwähnten christlichen Wallfahrtsorten in der Schweiz stellen auch katholische Pilgerorte in anderen europäischen Ländern wichtige Kontaktzonen und bedeutende Orte einer «tamilischen Sakrallandkarte» dar. Auch hier sind es oft marianisch geprägte Wallfahrtsorte, welche von tamilischen Hindus besucht werden. Wie für viele andere Ort der tamilischen Sakrallandkarte spielt auch hier die tamilische Sprache und der Einbezug tamilischer Traditionselemente, wie sie in Aspekten der materiellen Kultur vorliegen, eine wichtige Rolle.

Im europäischen Kontext sind das südfranzösische Lourdes oder Santiago de Compostela in Spanien wichtige Treffpunkte. Der grösste westeuropäische Wallfahrtsort für Tamilen ist Kevelaer im deutschen Bundesland Nordrhein-Westfalen. Die Tamilen-Wallfahrt wurde 1987 initiiert. Jährlich besuchen circa 15000 Tamilen das Marienfest im August, wovon zwischen 5000 bis 6000 Personen aus dem europäischen Ausland anreisen (vgl. Luchesi in Jacobsen/Raj 2008c, 75 ff.). Zentrum der Prozessionen ist Maria in der Darstellung als Trösterin der Betrübten (Consolatrix Afflictorum) (vgl. Eulberg/Niederberger 2011, 13). Diese Wallfahrtsorte werden entweder gezielt im Rahmen einer Pilgerreise oder während Urlauben oder Besuchen von Familienangehörigen, die nahe der Orte leben, aufgesucht. Teilweise schliessen sich die Besucher auch organisierten Reisegruppen an, welche die Orte besuchen.

Zusammenfassend hat sich gezeigt, dass wichtige religiöse Orte für tamilische Migrantinnen und Migranten nicht nur im Residenzland, sondern auch an unterschiedlichen Orten der tamilischen Diaspora, aber auch in den Herkunftsregionen zu finden sind. Besonders Wallfahrtsorte in Südindien werden von (männlichen) tamilischen Hindus, unabhängig vom Ort, an dem sie leben, besucht. Die Wallfahrtserlebnisse werden auch an Praktiken an den Wohnorten der Pilger angebunden, was anschaulich in der Reinszenierung des Pilgerereignisses nach Sabarimala zum Gott Aiyappan in Schweizer Tempeln gezeigt wurde. Verbindende Elemente innerhalb der transnationalen Netzwerke sind die tamilische Sprache und die Performanz der Tamilness.

Bei den Besuchen von Tempeln an Orten ausserhalb der Schweiz kann zwischen religiös motivierten Reisen, organisierten oder individuellen Wallfahrten und Reisen, die primär den Zweck des Besuches von Familienmitgliedern oder geschäftlich motiviert sind, unterschieden werden. 


\section{Zusammenfassung: Orte tamilischer Hindu- Praxis als sinnliche Wahrnehmungsräume}

Wie in diesem Kapitel gezeigt wurde, erweist sich die Kategorie Raum als geeignetes analytisches Instrument, um die Beheimatung und die Dynamiken tamilischer Hindu-Praxis in der Schweiz zu beschreiben. Wie dargestellt, können die Orte des Vollzugs von Hindu-Praxis unterteilt werden in 1) nicht-öffentliche Orte im häuslichen Bereich, 2) öffentliche Orte, die nicht von Tamilen etabliert wurden, aber auch von diesen zur Ausübung von Hindu-Praxis genutzt werden (shared places), sowie 3) von tamilischen Hindus selbst initiierte Praxisräume. Im Kontext transnationaler Vernetzungen praktizieren tamilische Hindus ihre Religion darüber hinaus nicht nur an Orten im Nationalstaat Schweiz, sondern z. B. ebenfalls im Rahmen von Wallfahrten nach Indien.

Der Wohnraum dient als primärer Ort der Performanz tamilischer Hindu-Praxis, welche fest in das alltägliche Leben der Familien integriert ist (vgl. Abschnitt2). Tamilische Hindus erschaffen dabei einen sinnlich erlebbaren religiösen Wahrnehmungsraum (vgl. Mohn 2012), der zwischen den Devotees und den verehrten Entitäten vermittelt. Der abgegrenzte pūcai-Platz, dessen zentrale Bestandteile die verehrten mūrttis oder DarśanBilder und andere Elemente der materiellen Kultur sind, ist ein individueller Selbstentwurf des jeweiligen Devotees bzw. der Familie. Die zentralen Handlungen zur Verehrung, die zusammenfassend als pūcai bezeichnet werden, stellen durch eine multisensuale ästhetische Inszenierung eine Kommunikationssituation zwischen Devotees und Göttinnen und Göttern bzw. verehrungswürdigen Personen her. Auf symbolischer Ebene ist der pūcai-Platz zu Hause mit dem Tempel und den dort durchgeführten pūcaiHandlungen eng verbunden. Grundlegender Unterschied ist, dass im Tempel nur ein männlicher Priester die pūcai vollziehen kann, während zu Hause die durchführende Person wechseln kann. Sehr häufig vollziehen die Mütter der Familie die Handlungen und geben somit die religiösen Traditionen an die nächste Generation weiter.

Shared places, also Räume, die tamilische Gruppen mit anderen Organisationen teilen, wobei die tamilischen Praktizierenden dort oftmals nur Gastrecht haben, stellten vor allem in den Anfängen der Immigration eine wichtige Kontaktzone dar (vgl. Abschnitt3). Der von Mary Louise Pratt geprägte Begriff der Kontaktzone hat sich als instruktives Instrument erwiesen, um dynamische Interaktionen zwischen Akteuren der schweizerischen Mehrheitsgesellschaft und tamilischen Akteuren aufzuzeigen. Im Laufe der Zeit hat sich so z.B. der Krishna-Tempel in Zürich als wichtiger Ort auch 
der tamilischen Hindu-Praxis etabliert, was sich in der Gründung der Swiss Tamil Krishna Society zeigte. Aber auch andere und zum Teil christliche Orte und Ereignisse können Kontaktzonen zwischen tamilischen und Schweizer Praktizierenden darstellen.

Zentrale Aktivitäten zur Konstruktion dezidiert hindu-tamilischer Wahrnehmungsräume stellten die Etablierung und Selbstverwaltung eigener Tempelräume durch tamilische Hindus dar (vgl. Abschnitt 4).

Die Wichtigkeit von selbstverwalteten Sakralräumen für die Migrantengruppe wurde deutlich. Oftmals galten pūcai-Plätze im privaten Wohnbereich und geteilte Orte als Vorläufer von als Tempelräumen bezeichneten sozialen Räumen. Unter raumtheoretischer Perspektive lassen sich verschiedene Phasen ausmachen, welche das Bestreben zur öffentlichen Sichtbarkeit und zur Professionalisierung der Tempelaktivitäten aufzeigen. Die Lokalisierung der ersten Tempel im sozialen Raum lässt auf einen marginalisierten Status der Migrantengruppe schliessen und steht in Zusammenhang mit den in Kap. III dargestellten Inkorporationsbedingungen. Mit Pierre Bourdieu kann konstatiert werden, dass über die sozio-räumliche Situierung des Tempels Rückschlüsse auf die soziale Stellung tamilischer Migrantinnen und Migranten gezogen werden können: «Der von einem Akteur eingenommene Ort und sein Platz im angeeigneten physischen Raum geben hervorragende Indikatoren für seine Stellung im sozialen Raum ab» (Bourdieu 1991, 26).

Die Fokussierung auf die Kategorie Raum kann in diesem Sinne sowohl Aufschlüsse über die Position der Migrantengruppe innerhalb der Residenzgesellschaft geben wie auch über die Positionierungsstrategien der Gruppe selbst. Die fortschreitende Institutionalisierung ethno-religiöser Vereine tamilischer Menschen in der Schweiz weist auch Tendenzen zur Kompartmentalisierung auf; separate tamilische Kulturvereine und religiöse Tempelvereine wurden gegründet (vgl. Kap. IV 4.2).

Gleichzeitig wird allerdings auch innerhalb religiöser Vereine die Tamilness betont und der tamilischen Sprache, der Aufrechterhaltung spezifischer tamilischer Traditionselemente wie auch der transnationalen Vernetzung der Diaspora-Tamilen und Rückbezüge zu den südasiatischen Herkunftsregionen eine besondere Wichtigkeit zugeschrieben. In allen in diesem Kapitel beschriebenen Raumformen zeigen sich Bezüge zu den tamilischen Heimatregionen: sei es durch das Engagement der Swiss Tamil Krishna Society für die tamilischen Regionen in Sri Lanka oder das Aufstellen von Bildern sich in Jaffna befindlicher Tempel am pūcai-Platz in der Wohnung oder im Tempelraum. Der Materialität kommt in der Ausgestaltung der verschiedenen sozialen Raumformen grosse Bedeutung zu. 
In der privat wie auch öffentlich vollzogenen Hindu-Praxis lassen sich darüber hinaus diasporische Veränderungen ausmachen. So wird die Durchführung der häuslichen pücai oftmals durch den eingeschränkten Wohnraum der meisten tamilischen Migrantenfamilien der ersten Generation in der Schweiz beschränkt. Häufig können auch rituelle Regularien, besonders die Reinheit betreffend, nicht eingehalten werden. Auch ist ein Bedeutungswandel der Institution Tempel festzustellen. Am Beispiel des Jahresfestes taipponkal wurde der Prozess der Tempelisierung verdeutlicht - die räumliche Verschiebung von im häuslichen Bereich vollzogenen Praktiken in den Tempelraum (vgl. Abschnitt5). Somit nimmt die ohnehin hohe Bedeutung der Tempelverehrung als zentrale Form der religiösen Praxis des Caivam in der Diaspora-Situation noch einmal mehr zu.

Durch Mobilität und transnationale Verbindungen wird Hindu-Praxis von in der Schweiz lebenden tamilischen Migrantinnen und Migranten nicht nur im Raum Schweiz vollzogen (vgl. Abschnitt6). Wichtige Bezugsorte stellen etablierte Tempel innerhalb der tamilischen Diaspora, in Sri Lanka oder Tempel an den Wohnorten von Verwandten dar. Auch werden religiös motivierte Reisen in das religiöse Mutterland Indien unternommen, die gleichzeitig ihre Anbindung an Ritualpraktiken an Orte in der Schweiz finden. Durch theatrale Performanzen werden Orte in Südasien im Tempelraum in der Schweiz gegenwärtig - dies zeigt sich in den Performanzen um die Wallfahrt nach Sabarimala - als Reinszenierung der Lebensgeschichte des Gottes Aiyappan - in Schweizer Tempeln. 


\title{
Kapitel V \\ Tempelöffentlichkeiten tamilischer Hindu-Praxis in der Schweiz
}

\author{
["Temple publics" are] notions of group \\ consciousness which are established through \\ the presence of Hindu religious institutions and \\ practices associated with those institutions \\ in different, often globally configured, public \\ spheres. \\ (Reddy/Zavos 2009, 242)
}

Die öffentliche Präsenz von Migrantenreligionen und ihre Forderungen nach Teilhabe am öffentlichen Raum in Europa wurden in den letzten Jahren zu einem wissenschaftlich viel beachteten Thema (vgl. u. a. Baumann 1999, 2007; Lienemann 2009; Catto/Woodhead 2012). Dabei wurden auch die Diskurse, Aushandlungsprozesse und Konflikte, die auftauchen können, wenn Minderheiten in die öffentliche Sphäre der Mehrheitsgesellschaft treten oder innerhalb dieser thematisiert werden, in den Blick genommen. Die Kontroversen um die öffentliche Präsenz islamischer Symbole wurden unter verschiedenen Aspekten analysiert (vgl. Allievi 2003, 2004; Gale 2005; Göle/Ammann 2004; Salvatore 2007). In der Schweiz wurden die Forderungen muslimischer Immigrantinnen und Immigranten nach Teilhabe am öffentlichen Raum medial breit verhandelt und haben zu einem öffentlichen Islam-Diskurs geführt (vgl. Behloul 2005, 2007). Zugespitzt hat sich die Debatte im Volksbegehren zum Verbot von Minaretten (vgl. Lienemann 2009), welches im November 2009 vom Schweizer Stimmvolk angenommen wurde (vgl. Kap. I 2.1). Diskurse um öffentliche Präsentationen von HinduTraditionen finden weitaus weniger statt; auch die Forschungen innerhalb der Diaspora-Studien zur öffentlichen Positionierung von Hindus stehen erst am Anfang (für tamilische Hindus im europäischen Kontext vgl. Jacobsen 2008b; Luchesi 2003b, 2008b). 
Die öffentliche Präsenz tamilischer Hindu-Praxis in der nationalen Schweizer Öffentlichkeit wird durch verschiedene Akteure hergestellt. Als Akteure der Mehrheitsgesellschaft sind an zentraler Stelle die Medien zu nennen, deren Einfluss auf den öffentlichen Diskurs weitreichend ist. Aufgrund der zahlenmässig geringen Anzahl an Hindus in der Schweiz sind diese im Vergleich zu anderen religiösen Traditionen in der öffentlichen Sphäre der Schweiz weniger präsent. Die öffentliche Präsentation von Hindu-Traditionen und die Forderungen von tamilischen Hindus nach Teilhabe am öffentlichen Raum werden von den Schweizer Medien nur marginal wahrgenommen bzw. thematisiert. Printmedien ${ }^{370}$ sowie Fernseh $^{371}$ oder Radioberichte $^{372}$ greifen nur am Rande Hindu-Praxis in der Schweiz auf, wobei meist die Jahresfeste der Tempel in den Blick genommen werden. Öffentliche Aufmerksamkeit wird auch durch den Besuch von Personen, welche prestigeträchtige Ämter innerhalb der Mehrheitsgesellschaft innehaben, erregt. Durch das Auftreten von politischen Verantwortlichen des Residenzlandes in Hindu-Tempeln wird die Mehrheitsöffentlichkeit durch Medienberichterstattung auf diese Institutionen und ihre Akteure aufmerksam. Auch das Ansehen der Tempelvereine im religiösen Feld steigt dadurch. Bürgermeister der jeweiligen Gemeinden besuchten in der Schweiz einige Tempel zum Anlass des Tempelfestes - dies ist z. B. während des Tempelfestes des Śrī Civacuppiramaṇiyar Tempels üblich.

Auch die innerhalb der Mehrheitsgesellschaft angesiedelten akademischen Disziplinen machen Hindu-Praxis öffentlich. Wissenschaftliche Publikationen - wie diese Studie - und mediale Auftritte von Wissenschaftlerinnen und Wissenschaftlern präsentieren tamilische Hindu-Traditionen in der Öffentlichkeit. Durch die Zusammenarbeit von wissenschaftlich

370 In journalistischen Berichten über die tamilische Migrantengruppe und ihre Situation in der Schweiz wurden oftmals Konflikte und die Auswirkungen des Krieges in Sri Lanka auf die Diaspora in der Schweiz thematisiert. Es zeigt sich ein Wandel in der Berichterstattung über tamilische Geflüchtete seit den 1980er Jahren bis heute. Michael Hunziker zeigt, dass sich in der Deutschschweizer Presselandschaft im Zuge des in Kap. III 3.3 dargestellten Imagewandels «der Tamilen» ihr Bild vom «Sündenbock» zum «Vorzeigeausländer» wandelte (vgl. Hunziker 2006).

371 So hat das Schweizer Fernsehen beispielsweise seit 1993 Berichte über das religiöse Leben tamilischer Hindus in der Schweiz in den Sendeformaten 10 vor 10, Tagesschau, Bilder zum Feiertag und Schulfernsehen in unregelmässigen Abständen ausgestrahlt. Viele stellen lebenszyklische Riten oder Hindu-Feste vor.

372 Es finden sich auch Schweizer Radioberichte, welche über Dynamiken in der Etablierung von Hindu-Tempeln in der Schweiz berichten. Radio DRS thematisierte beispielsweise in seiner lokalen Sendung Regionaljournal Basel Baselland die Suche der in Basel lebenden tamilischen Hindus nach einem neuen Tempelgebäude (Hindus brauchen Ersatz für Tempel in Muttenz; 16.5.2008). 
arbeitenden und Hindu-Akteuren entstehen besondere Formen der öffentlichen Präsentation.

Es sind aber auch tamilische Akteure selbst, welche «tamilischen Hinduismus» innerhalb der Mehrheitsöffentlichkeit repräsentieren. Das folgende Kapitel beschränkt sich in erster Linie auf öffentliche Präsentationsformen von Hindu-Praktiken durch Hindu-Akteure. Tempelöffentlichkeiten stellen hier eine zentrale öffentliche Präsentationsform dar. Tamilische Hindus, als Teil einer jungen Migrantengruppe, gehen erste Schritte, um auch in der Schweizer Öffentlichkeit sichtbar zu werden. Diese sind entweder gezielt als solche intendiert oder gehen mit einer Etablierung von Hindu-Tradition im Residenzland Schweiz einher - wie zum Beispiel beim Bau eines traditionellen Tempels. Oftmals sind es die selben tamilischen Hindu-Akteure, welche sich in den Medien präsentieren und als Sprachrohr für die religiöse Gruppe agieren. Der Priester des Śrī Viṣnu Turkkai Amman Tempels in Dürnten, T. Sarahanabavanantha Kurukkal, beispielsweise war im Untersuchungszeitraum eine öffentliche Figur, welche seit den Anfängen der Etablierung von tamilischen Hindu-Institutionen in der Schweizer Öffentlichkeit präsent war (vgl. Kap. IV 4.1): So zeigte das Schweizer Fernsehen bereits am 14.06.1994 einen Bericht über seine Initiation als Oberpriester («Priesterweihe bei den Hindus» im Sendeformat 10 vor 10). Auch in den folgenden Jahren war er in der Schweizer Presse vertreten. ${ }^{373}$ Einen Kinoauftritt hatte er 2010 im Schweizer Spielfilm Madly in Love, welcher die Liebesgeschichte eines hinduistischen Tamilen und einer Deutschen in der Schweiz erzählt. Jene Szenen, die in einem Hindu-Tempel spielten, wurden in «seinem» Tempel in Adliswil gedreht und er agierte bei diesen Aufnahmen als Hindu-Priester. Neben dieser medial oftmals rezipierten Person gibt es tamilische Akteure, die als inoffizielle Ansprechpersonen für die Schweizer Öffentlichkeit dienen. Publikationen, die von Akteuren der Schweizer Mehrheitsgesellschaft herausgegeben werden, dienen Hindus als Plattform, um ihre religiösen Traditionen der Mehrheitsbevölkerung zu präsentieren. Als Beispiele können hier Interviews mit Hindu-Akteuren in Schweizer Zeitungen und das im Fachbuch «Interreligiöser Dialog in der Schweiz» publizierte «Interview mit Sasitharan Ramakrishna Sarma, Hindu Priester im Sri Thurgai Amman Tempel in Root-Gisikon LU» genannt werden (Meili 2008).

Wie auch die Akteure unterschiedlichen Gruppen zugeordnet werden können, finden sich auch unterschiedliche soziale Räume in der Schweiz, an

373 Zum Beispiel wurde gegen Ende des Bürgerkriegs in Sri Lanka ein Interview mit ihm im Tages-Anzeiger veröffentlicht («Zuletzt leiden immer die einfachen Leute». Mit T.S. Kurukkal sprach Daniel Fischer. In: Tages-Anzeiger, 21.02.2009, 66). 
denen tamilische Hindus ihre Hindu-Traditionen der Mehrheitsbevölkerung präsentieren: Es kann unterschieden werden zwischen Kontaktzonen, die durch Akteure der Schweizer Mehrheitsgesellschaft verwaltet werden, selbstverwalteten Orten der tamilischen Minderheit sowie ortsunabhängigen Plattformen wie Internetauftritte. Als Orte der Mehrheitsgesellschaft, an denen Hindu-Akteure ihre religiöse Tradition präsentieren, sind zum einen Räume, welche Schweizer Gemeinden gehören, und zum anderen Räumlichkeiten der Mehrheitsreligion zu nennen. Anlässe, die innerhalb dieser Orte stattfinden, sind oftmals im Rahmen des so genannten interreligiösen Dialogs initiiert worden, der oft auf Initiative christlicher Akteure entstanden ist.

Die folgenden Abschnitte fokussieren nun auf Tempelöffentlichkeiten selbstverwalteter religiöser Orte tamilischer Migrantinnen und Migranten und schliessen damit an die Darstellungen in Kapitel IV zu sozialen Räumen des Vollzugs von Hindu-Praxis tamilischer Migrantinnen und Migranten in der Schweiz an. In Anlehnung an Deepa S. Reddy und John Zavos wird im Folgenden mit dem Begriff der Tempelöffentlichkeiten operiert (vgl. Reddy/Zavos 2010). Der Begriff betont die Bedeutung der Institution Tempel für die öffentliche Präsenz von Hindu-Traditionen und ist bewusst im Plural formuliert. Die Autorin und der Autor verstehen unter temple publics Formen von Gruppenbewusstsein, die durch die Präsenz religiöser Institutionen und Praktiken in unterschiedlichen öffentlichen Sphären konstituiert werden (vgl. Reddy/Zavos 2010, 242). Der Tempel wird als "crucial interface between the public and religion" (Reddy/Zavos 2010, 254) angesehen. Reddy/Zavos machen verschiedene Formen von Tempelöffentlichkeiten aus, die unter anderem in unterschiedlichen kulturellen und historischen Kontexten begründet liegen.

Der Begriff Tempelöffentlichkeiten geht über den öffentlichen Zugang zum Gebäude des Tempels hinaus; ein spezielles Gruppenbewusstsein, das an die Institution Tempel gebunden ist und öffentlich verhandelt wird, wird beispielsweise durch das Verbreiten von Kalendern des Tempels, von den Tempelvereinen herausgegebenen Musik-CDs, vom Tempelverein eigens produzierten Büchern, Flyern und Postern, die auf Veranstaltungen im Tempel hinweisen, erreicht. ${ }^{374}$ In den Bereich der Tempelökonomie fallen

374 Im Schweizer Kontext lassen sich hier zahlreiche Beispiele aus unterschiedlichen Tempeln nennen. So veröffentlichte der Tempelverein des Turkkai Ammañ Tempels in Luzern 2006 ein Liederbuch in tamilischer Sprache, welches im Tempel käuflich erworben werden konnte. Übersetzt lautet der Titel des Buches: «Allgegenwärtig ist die göttliche Kraft. Sammlung gemeinsamer Bittgebete und Fürbittenlieder; Arulmiku Turkkai Amman Alayam; Luzern, Schweiz». 
Stände, welche bei den meisten Tempelfesten in der Schweiz und in einigen Tempeln fest installiert zu finden sind, welche unter anderem Merchandising-Produkte des Tempels verkaufen.

Tempelöffentlichkeit wird auch durch in Hindu-Tempeln stattfindende öffentliche Führungen hergestellt, die der Mehrheitsbevölkerung HinduPraxis nahbringen wollen. Besonders im Rahmen von «Tagen der offenen Tür» oder Veranstaltungen im Rahmen der seit 2007 schweizweit stattfindenden Woche der Religionen (veranstaltet von der IRAS COTIS; vgl. Kap. IV 4.1) finden Begegnungen von Akteuren der Mehrheitsgesellschaft mit tamilischen Akteuren statt.

Im Folgenden wird primär auf verschiedene Formen von Tempelöffentlichkeiten eingegangen. Das Kapitel beginnt mit der Darstellung des Verständnisses der Kategorie Öffentlichkeit in Verbindung mit der analysierten Hindu-Praxis (V 1). In der Darstellung des aktiven Gangs tamilischer Hindus in die öffentliche Sphäre der Schweizer Mehrheitsgesellschaft werden sowohl das Herstellen von Öffentlichkeit durch die Präsentation der Tempel (V 2) als auch performative Hindu-Praxis in der öffentlichen Sphäre (V 3) thematisiert.

Tempelöffentlichkeiten können durch die öffentliche Kennzeichnung der zu einem anderen Zweck gebauten Gebäude als Hindu-Tempel hergestellt werden - wie das Anbringen von Ōm-Zeichen oder das Hissen von Flaggen (V 2.1). Exemplarisch wird die öffentliche Präsentation der Tempel durch ihre Tortürme analysiert. Eine diasporische Innovation aufgrund des Fehlens von Sakralbauten stellt das Anbringen von kōpuram-Kulissen, Kulissen der Tortürme über dem Eingangsbereich des Tempels, dar. Aber auch die Artikulation des Wunsches nach einem durch seine Architektur bereits öffentlich sichtbaren Tempel mit Eingangsturm und der Konstruktionsprozess des ersten tamilischen Hindu-Tempels in traditioneller Architektur in der Schweiz (in Trimbach bei Olten), der auch den Bau eines kōpuram beinhaltete, werden thematisiert (V 2.2). Tempel präsentieren sich jedoch auch im virtuellen öffentlichen Raum des Internets unterschiedlichen Offentlichkeiten (V 2.3).

Ein wichtiger Aspekt von Tempelöffentlichkeit sind die performativen Hindu-Praktiken in öffentlichen Sphären (V 3). Die jährlichen Tempelfeste sind Kristallisationspunkte der öffentlichen Präsentation tamilischer HinduTraditionen in der Schweiz und werden daher eingehend unter dem Aspekt der öffentlichen Repräsentation dargestellt. Besonders der während der Feste vollzogene Tanz mit dem kāvați-Bogen zu Ehren des Gottes Murukan als devotionale Ausdrucksform wird vorgestellt (V 3.1). Sakrales Theater im Tempel als Form der Aktualisierung von Hindu-Mythologie in der Diaspora, welches während des Tempelfestes zum Anlass des «Mango-Festes» 
aufgeführt wird, wird daran anschliessend thematisiert (V 3.2.). Zu den performativen Praktiken zählten im Untersuchungszeitraum auch «interreligiöse Prozessionen» und Friedensgebete mit politischem Hintergrund, welche aufgrund der kriegerischen Ereignisse in Sri Lanka von Tempelvereinen in der Schweiz organisiert wurden (V 3.3). Abschliessend werden zusammenfassend Aushandlungsprozesse auf dem Weg zu einer öffentlichen Hindu-Praxis gebündelt dargestellt (V 4).

\title{
1 Religioning und öffentlicher Raum: Öffentlich- keit als Analysekategorie
}

\author{
In brief, there is no more the public opinion, at the \\ singular, but many, which are more provisional, \\ inconstant and volatile than in the past.
}

(Allievi 2004, 186)

Bereits in Kap. I, der Vorstellung von Öffentlichkeit als Analysekategorie, habe ich deutlich gemacht, dass ich in dieser Untersuchung von einer Pluralität von öffentlichen Sphären ausgehe. Die folgenden Analysen basieren auf der Unterscheidung in Schweizer nationalen Öffentlichkeiten und - in Anlehnung an Appadurais (1996) Konzept der diasporic public spheres - von diasporischen tamilischen Offentlichkeiten.

Jürgen Habermas hat den Begriff der Öffentlichkeit als eigenständige Sphäre in seinem Werk Strukturwandel der Öffentlichkeit analysiert (Habermas 1962) und eine breite wissenschaftliche Diskussion des Begriffes ausgelöst. Der Begriff des Öffentlichen ist nach der Habermasschen historischen Analyse auf verschiedenen Ebenen anzusiedeln: Zum einen ist Offentlichkeit immer nur die eine Seite einer Dichotomie; ein Blick in die Begriffsgeschichte zeigt, dass Öffentlichkeit eng verbunden ist mit der Gegenüberstellung «öffentlich - privat». Die zweite Ebene rekurriert auf den Staat als öffentliche Macht, welcher um das Wohl aller Bürger zu schützen, allgemeinverbindliche Gesetze erlässt. Die dritte Ebene bezieht sich auf Offentlichkeit als Raum, in welchem die öffentliche Meinung artikuliert und debattiert wird. Habermas geht von einer normativen Konzeption von Öffentlichkeit aus und fokussiert auf einen Idealtypus von Öffentlichkeit, den er als bürgerliche Öffentlichkeit bestimmt. Habermas Thesen wurden von verschiedenen Seiten kritisiert; besonders im gegenwärtigen Kontext 
der Globalisierung und damit einhergehender Transformationsprozesse werden einige seiner Postulate als überholt angesehen (vgl. Calhoun 1999). Die Politikwissenschaftlerin Nancy Fraser konstatiert eine Tendenz zur Idealisierung der bürgerlichen Öffentlichkeit in Habermas' Schriften und weist darauf hin, dass marginalisierte Gruppen und ihre Positionierung im öffentlichen Raum zu wenig Beachtung finden. Habermas habe «die Auswirkungen jener strukturellen Ungleichheiten unterschätzt [...], durch die - nominell der Öffentlichkeit angehörende - Menschen der Möglichkeit beraubt werden, als vollwertige Partner, von gleich zu gleich, an der öffentlichen Diskussion teilzunehmen» (Fraser 2009, 151). Besonders die Postulierung der Singularität des öffentlichen Raums wurde für eine Analyse rezenter Entwicklungen in Frage gestellt. "Habermas's account stresses the singularity of the bourgeois conception of the public sphere, its claim to be the public arena, in the singular" (Fraser 1999, 122). Es ist jedoch darauf hinzuweisen, dass Habermas selbst in dem Buch Faktizität und Geltung (1992) sein Öffentlichkeitskonzept überarbeitete und dort von einem Netzwerk von Öffentlichkeiten ausgeht.

Ein weiteres wichtiges Modell zur Konzeption von Öffentlichkeit stellt Hannah Arendts «drei Sphären-Modell» von privatem, öffentlichem und sozialem Raum dar; sie betont dabei im Gegensatz zu Habermas den Aspekt der Räumlichkeit (Arendt 1960 [2006]). Das Modell basiert auf der Annahme, dass es die handelnden Akteure sind, welche einen Raum als privat, sozial oder öffentlich ausweisen. Der öffentliche Raum im Sinne Arendts ist gekennzeichnet durch Artikulation verschiedener Positionen innerhalb von diesem; diese inneren Differenzen können asymmetrisch angelegt sein und zu einem internen Machtgefälle führen (vgl. Geulen 2004). Der soziale Raum, der Bereich der gesellschaftlichen Aktivitäten, welcher zwischen privatem und öffentlichem Raum anzusiedeln ist, zeichnet sich durch Ausschlussmechanismen aus, welche eine Gesellschaft ordnen (vgl. Geulen 2004, 60; vgl. Wicker 1997, 146).

Öffentlichkeit stellt einen dynamischen Prozess dar: «Öffentlich» und «öffentlicher Raum» heisst immer öffentlich für eine bestimmte Gruppe. Öffentlich/privat sind Beobachtungsbegriffe, also Begriffe, die Zuschreibungen von Akteuren ausdrücken. Die Bezeichnung als öffentlich oder privat ist dabei zeit- und kontextabhängig. Im Kontext dieser Studie kann Offentlichkeit also beispielsweise «öffentlich innerhalb der transnationalen sri-lankischen tamilischen Diaspora», «öffentlich innerhalb der tamilischen Diaspora im Nationalstaat Schweiz» oder «öffentlich für die Mehrheitsbevölkerung der Schweiz» heissen.

Reddy und Zavos verweisen auf die Unterscheidung zwischen «im öffentlichen Raum handeln» und «eine Öffentlichkeit herstellen». Ersteres 
bezeichnet lokales Handeln in einem offenen Rahmen, um zu repräsentieren. «Öffentlichkeit formen» bedeutet Gruppeninteressen unabhängig eines lokalen Rahmens auf der Basis einer geteilten Identitätskonstruktion zu artikulieren (vgl. Reddy/Zavos 2010, 244).

Öffentliche Sphären sind wie Kontaktzonen keine wertneutralen Bereiche, sondern geprägt von Machtgefällen, die Minderheiten oftmals einen untergeordneten Stellenwert zuweisen. Minoritäten müssen erst einen bestimmten Status, welcher mit vorhandenen Ressourcen verbunden ist, erlangen, um innerhalb der Mehrheitsöffentlichkeit wahrgenommen zu werden. Allievi konstatiert für Minderheiten in Europa, dass diese erst dann als Teil der öffentlichen nationalen Sphäre anerkannt werden, wenn sie über eine geteilte Gruppenidentität verfügen und die Handlungsmacht besitzen, von ihren politischen Rechten vollumfänglich Gebrauch zu machen:

Muslim communities in Europe - as well as other minority groups - will be recognised as part of the public sphere when they demonstrate that they have a shared culture and when they have enough property and influence to fully exercise their political rights (...). (Allievi 2004, 186)

Daran anschliessend kann man mit Nancy Fraser von Gegen-Öffentlichkeiten sprechen, welche von Minderheiten als Gegenpol zu dominanten Diskursen gebildet werden (vgl. Fraser 1999, 123). ${ }^{375}$ Die Sphäre der diasporisch tamilischen Öffentlichkeit kann als Gegen-Öffentlichkeit beschrieben werden, in der Diaspora-Akteure ihre Identitätskonzepte auf der Grundlage des Bewusstseins einer - im Herkunfts- wie im Residenzland - marginalisierten Gruppe anzugehören, aushandeln.

\section{Minderheitenreligionen und Öffentlichkeit}

Klassische Öffentlichkeitstheorien konstatieren die Verschiebung von Religion in die private Sphäre in der nach-aufklärerischen Moderne und deklariert die öffentliche Sphäre damit als eine säkulare Zone. Auch diese Prämisse kann kritisch hinterfragt werden, da «Religion» auch in säkularen Staaten institutionell in der öffentlichen Sphäre verankert ist. José Casanova hat «Religion» in Verbindung zum modernen Offentlichkeitsbegriff gesetzt und konstatiert, dass Religion untrennbar mit der modernen Dichotomie der Sphären «privat» und «öffentlich» verbunden ist (vgl. Casanova 1994). Casanova geht davon aus, dass Religionen als Ver-

375 Nancy Fraser definiert den Begriff subaltern counterpublic als diskursive Arenen, in denen Mitglieder von marginalisierten Minderheiten vom Diskurs der Dominanzgesellschaft abweichende Interpretationen ihrer Identität und Bedürfnisse formulieren (vgl. Fraser 1999, 123). 
mittlergrösse zwischen der privaten und der öffentlichen Sphäre fungieren und an den permanenten Aushandlungsprozessen zwischen diesen beteiligt sind.

Das Verhältnis von Religion und Öffentlichkeit ist von einem besonderen Spannungsverhältnis geprägt, wenn es sich um Minderheitenreligionen handelt, die gruppeninterne Öffentlichkeit herstellen und sich in gruppenübergreifenden Öffentlichkeiten präsentieren. Öffentliche Sphären sind immer dynamische Machtfelder, welchen eine implizite Normativität inhärent ist. Die Mehrheitsöffentlichkeit stellt einen normierten und zensierten Raum dar, welcher Werte und Normen verteidigt, die für die dominierende Gruppe als identitätsstiftend angesehen werden. Die öffentlichen Sphären unterliegen einer bestimmten Ordnung, der «öffentlichen Ordnung», welche verteidigt wird (vgl. Baumann 1999). Die Bedingungen der Inkorporation wirken auf den Handlungsspielraum der religiösen Gruppierungen ein, und auch religiöse Gruppen beeinflussen durch öffentliches Handeln die gesellschaftlichen Machtverhältnisse.

Ein instruktives Beispiel ist das Streben von Gruppen nach öffentlichrechtlicher Anerkennung als religiöse Gruppe. Anerkannte Religionsgruppen des öffentlichen Rechts können nicht nur bestimmte Privilegien in Anspruch nehmen, wie die Einführung von Religionsunterricht an Schulen, sondern dieser Status ist auch mit einem Zuwachs an Prestige auf der symbolischen Ebene verbunden. Die Anerkennung einer Minderheitenreligion in der Schweiz als Körperschaft des öffentlichen Rechts wurde innerhalb der Presse meist als Anliegen muslimischer Vereine diskutiert. Aber auch der Wunsch tamilischer Hindus nach öffentlich-rechtlicher Anerkennung und dem damit einhergehenden Erwerb von Rechten wurde von Akteuren artikuliert und fand Eingang in Medienmitteilungen (vgl. Kap. III 4.4 zur Religionspolitik der Schweiz als Einflussfaktor der Etablierung tamilischer Hindu-Traditionen).

Im Kontext dieser Studie wird von religioning ausgegangen, welches in unterschiedlichen öffentlichen wie auch privaten Sphären praktiziert wird. Tamilische Hindu-Praxis findet in unterschiedlichen diskursiven Arenen statt: Sie kann sich nur an eine tamilische Öffentlichkeit innerhalb der Schweiz richten oder sich auch bewusst in der Mehrheitsöffentlichkeit präsentieren. Schematisch wird dabei - in Anlehnung an die Postulierung unterschiedlicher transnationaler öffentlicher Sphären - unterschieden in tamilische öffentliche Sphären, die in die transnationale sri-lankische Diaspora eingebunden sind, und in öffentliche Sphären der Schweizer Mehrheitsbevölkerung. Gleichzeitig überlappen diese Bereiche in vielfältiger Weise. 


\section{Präsentationen von Sakralgebäuden als Aspekte von Tempelöffentlichkeiten}

Eine Form der Präsentation tamilischer Hindu-Traditionen in öffentlichen Sphären bezieht sich auf die räumliche Dimension von Gebäuden und ihren Institutionen. Wie repräsentieren Lokalitäten, die von Akteuren der transnationalen tamilischen Diaspora als Verehrungsorte der Hindu-Göttinnen und Götter angesehen werden, tamilische Hindu-Traditionen in öffentlichen Sphären?

Wie bereits dargestellt, sind die Tempelräume tamilischer Hindus in der Schweiz nicht per se Räume, die von der Mehrheitsgesellschaft als öffentliche Sakralgebäude wahrgenommen werden (vgl. Kap. IV 4.). Die «Hinterhof»- oder «Industrie-Tempel» sind meist nur innerhalb der Gruppe tamilischer Hindus in der Schweiz bekannt. Die Zuschreibung dieser Gebäude hängt von der öffentlichen Sphäre ab, in der man sich bewegt: Akteure der Schweizer Mehrheitsöffentlichkeit haben nur selten Kenntnis von der Bedeutung dieser Orte für Hindus. Beim Eintritt in einen tamilischen HinduTempel in der Schweiz wird eine Schwelle überschritten, welche die Sphäre der Schweizer Mehrheitsbevölkerung von einem tamilisch geprägten Raum abgrenzt, in welchem nach Auffassung tamilischer Hindus die Präsenz der Hindu-Gottheiten erlebbar wird. Da die öffentliche Sphäre der Schweiz etwa durch Kirchen, christliche Wegkreuze, Kruzifixe in öffentlichen Gebäuden - christlich geprägt ist, wird der Kontrast zwischen der Sphäre des Tempels und seiner äusseren Umwelt verstärkt.

Im Folgenden werden beispielhaft Formen der öffentlichen Präsentation von Hindu-Tempeln in der Schweiz dargestellt, welche verschiedene Arten von Tempelöffentlichkeiten herstellen. Zum einen werden Kennzeichnungen der Gebäude als Hindu-Tempel analysiert, die den Tempel in unterschiedlichen öffentlichen Sphären präsentieren (V 2.1). Ein besonderes Gewicht wird auf angebrachte Kulissen von Tempeltürmen (kōpuramKulissen) und den Bau der ersten Hindu-Sakraltürme in der Schweiz (V 2.2) gelegt. Des Weiteren wird die Präsentation von Tempeln in virtuellen Öffentlichkeiten dargestellt, da anhand dieses Beispieles verschiedene charakteristische Aspekte öffentlicher diasporischer Präsenation der Tempel aufgezeigt werden können (V 2.3). 


\section{1 Ōm-Zeichen und das Hissen von Flaggen: Öffentliche Kennzeichnung der Gebäude als Hindu-Tempel}

Wie auch im Fall der Gestaltung des Innenraums des Tempels lassen sich durch die Dekoration der äusseren Grenzen der Tempelgebäude Aufschlüsse über die religiöse Ausrichtung und gesellschaftliche Positionierungsstrategien der Tempelvereine ziehen. ${ }^{376}$

Viele Akteure artikulieren, dass es ihnen ein Bedürfnis sei, ihren Tempelraum auch nach aussen hin als einen solchen zu kennzeichnen. Erste Schritte, um die Unsichtbarkeit dieser Tempelgebäude in der öffentlichen Sphäre zu verlassen - "leaving invisibility" wie es Luchesi nennt (Luchesi 2004a, 2008b) - ist die kontinuierliche Erweiterung der Dekoration des Gebäudes nach aussen hin. «Unsichtbar» meint in diesem Zusammenhang unsichtbar für die weitere Schweizer Öffentlichkeit. Bei vielen angemieteten Gebäuden, welche als Tempel dienen, ist zu beobachten, dass sie im Laufe der Zeit von aussen immer mehr dekoriert und durch Schilder oder andere Zeichen als Tempelorte gekennzeichnet werden. Diese Kennzeichnungen verweisen auf eine Etablierung tamilischer Hindu-Traditionen und auf eine Professionalisierung der Tempelvereine. Die Aussendekorationen sind meist permanent angebracht. Es finden sich jedoch auch nur temporär angebrachte äusserlich sichtbare Marker. Die Tempelgebäude werden zum Anlass des Tempelfestes nach aussen hin besonders geschmückt und als sichtbare Tempel dekoriert - wie beispielsweise durch das Anbringen einer kōpuram-Kulisse über dem Tempeleingang, welche aus grosser Dis$\operatorname{tanz}$ wahrgenommen werden kann. Detailliert soll nach einem Überblick über verschiedene Formen der öffentlichen Kennzeichnungen der Gebäude als Tempel auf Tempeltürme als sichtbare Marker eingegangen werden.

Entscheidender Faktor bei der Gestaltung der Aussengrenzen des Gebäudes sind die Inkorporationsbedingungen. Zum einen sind es gesetzliche Regulierungen wie Baubestimmungen und zum anderen ist es die öffentliche Meinung, die Wünsche der Tempelverantwortlichen einschränken können. In einem Bericht aus dem Tages-Anzeiger zur Eröffnung des neuen Tempels in Dürnten wird darauf hingewiesen, dass nur eine minimale öffentliche Kennzeichung des Gebäudes als Sakralraum vorgenommen werde: «Äusserlich ändere sich aber nichts am ehemaligen Fabrikgebäude -

376 Nye beschreibt in seiner Analyse des Baues eines Hindu-Tempels in Edinburgh, dass die Konstruktion des Tempelinnenraums Hand in Hand geht mit der Herstellung von Gruppenidentität und Konstruktionen von religiösen Konzepten (vgl. Nye 1995, 205). 
bis auf einen verschnörkelten Schriftzug. Weitere Verzierungen seien nur im Innern der Liegenschaft gestattet.» ${ }^{377}$

$\mathrm{Zu}$ den im Untersuchungszeitraum vorgenommenen äusserlichen Kennzeichnungen zählen unter anderem das Anbringen von Schriftzügen und visuelle Marker, die darauf hinweisen, dass die Träger des Gebäudes mit Hindu-Traditionen verbunden sind.

Namensschilder sind eine der explizitesten Formen der Kenntlichmachung des Gebäudes als Hindu-Tempel. Besuchende, welche der angeschriebenen Schrift und Sprache mächtig sind, können - ohne angebrachte visuelle Marker deuten zu müssen - direkt ablesen, um welches Gebäude es sich handelt. Auch andere textliche Kennzeichnungen verorten das Gebäude öffentlich sichtbar im Kontext tamilischer Hindu-Traditionen. Die Namensschilder bestehen in der Regel aus einer Kombination aus Schriftzeichen und anderen visuellen Elementen wie leuchtende tamilische $\bar{O} m$-Zeichen oder eine auffallende Farbwahl.

Wie auch in der in Kap. V 2.3 folgenden Analyse der Präsentationen der Tempel im World Wide Web zeigt sich, dass es unterschiedliche Formen der textlichen Gestaltung gibt: Zum einen finden sich öffentliche Kennzeichnungen am Gebäude, welche ausschliesslich in tamilischer Schrift verfasst wurden, und zum anderen solche, die auch in lateinischen Buchstaben geschreiben sind. Im Untersuchungszeitraum fand sich kein von mir besuchtes Tempelgebäude in der Schweiz ohne Kennzeichnung in tamilischer Schrift. Die tamilische Sprache war integraler Bestandteil der Innen- wie auch Aussengestaltung aller besuchten Tempel und verweist damit auf die Verortung der Orte innerhalb der Öffentlichkeit der tamilischen Diaspora (und auf den Stellenwert der tamilischen Sprache und Schrift in dieser).

Der Tempelverein des Śrī Kalyāna Murukañ Tempels in Bern hatte beispielsweise 2007 über dem vorgelagerten Eingang des Gebäudes mittig ein leuchtend gelbes Schild angebracht, auf dem ein grosses Ōm Murukan in tamilischen Buchstaben zu lesen war. ${ }^{378}$ Darunter war ebenfalls in tamilischen Schriftzeichen der Name des Tempels Pērn Śrī Kalyāna Murukan Alayam zu lesen. ${ }^{379}$ Der Tempelname war in weissen Buchstaben geschrieben, welche aus Lampen zusammengesetzt waren, die nachts - wie auch

377 Nina Santner, «Tamilen wollen Tempel in Lagerhalle errichten», in: Tages-Anzeiger; 12.09.2009, S. 65 .

378 Das tamilische $\bar{O}$ war in rot gehalten, während der tamilische Buchstabe $m$ und der Name Murukan in weisser Farbe gestaltet war. Die Farben Weiss und Rot verweisen auch auf die traditionelle Aussengestaltung der Wände traditioneller Caiva-Tempel, die rot-weiss vertikal gestreift sind.

379 Pèrn ist die tamilische Umschrift von Bern und benennt damit den geographischen Ort des Murukan-Tempels. 


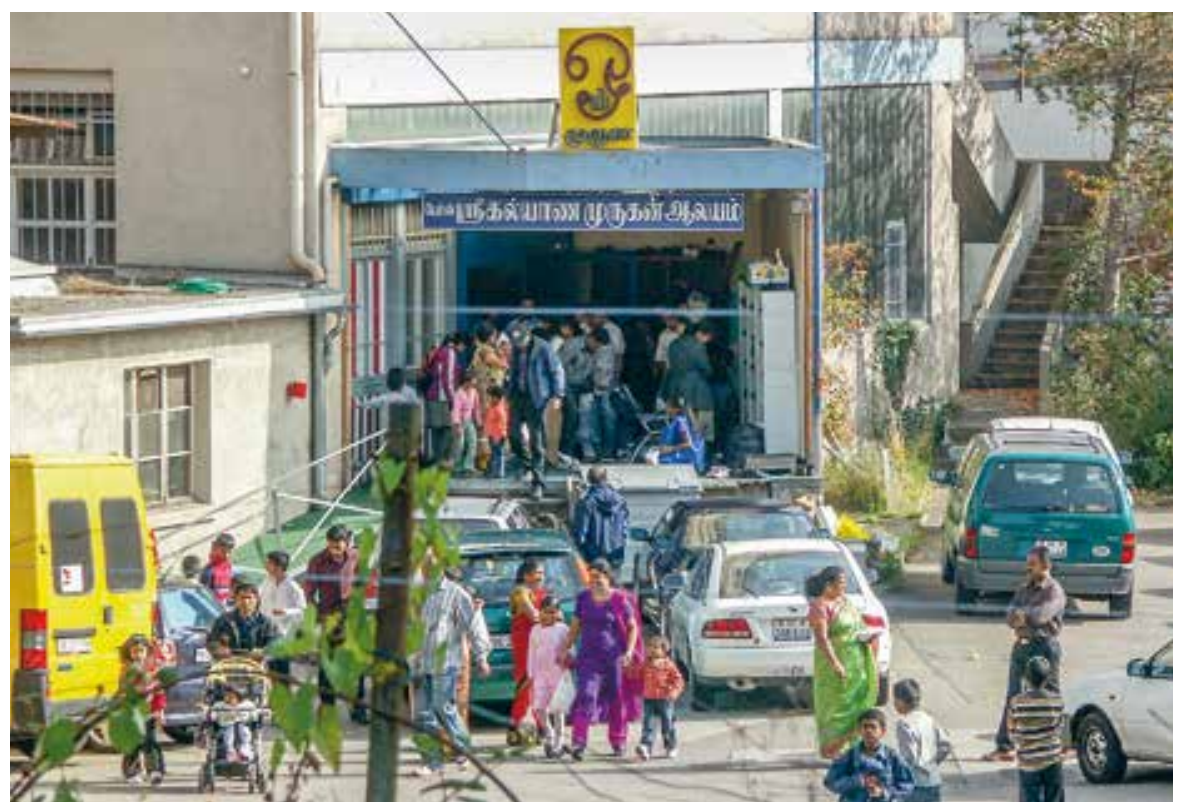

Abb. V 1: Eingang des Śrī Kalyāna Murukañ Tempels in Bern mit tamilischem Ōm-Zeichen und Namensschild in tamilischen Buchstaben (13.10.2007).

die Buchstaben des Ōm Murukan-Schildes (in leuchtendem Rot und Weiss) hell leuchten und als visuelle Signale dienten, um die Verbindung des Gebäudes mit tamilischen Hindu-Traditionen anzuzeigen. Rechts neben den beiden Schriftzügen war ein Strahler angebracht, welcher nachts von weitem auf das Gebäude aufmerksam machte. Durch die Wahl der tamilischen Sprache und Schrift wird an erster Stelle eine tamilische Offentlichkeit angesprochen (vgl. auch Kap. V 2.3). Innerhalb der Schweizer Mehrheitsöffentlichkeit sind diese Zeichen zwar wahrnehmbar, können jedoch nicht gelesen werden - die inhaltliche Botschaft bleibt verborgen. ${ }^{380}$ Akteure der Schweizer Öffentlichkeit schliessen aus den für sie fremden Zeichen, dass in den Räumlichkeiten eine Nicht-Schweizer Gruppe beheimatet ist und es sich um einen für sie exotischen sozialen Raum handelt.

Einige Meter vom Tempelgebäude entfernt, war ein Schild am Strassenrand aufgestellt, welches in lateinischen Buchstaben und einer Kombina-

380 Dies ist ein Unterschied zu den auf tamilische Öffentlichkeiten ausgerichtete TempelHomepages, von denen die Schweizer Mehrheitsgesellschaft nur sehr selten Notiz nimmt, was in der Beschaffenheit des entorteten virtuellen öffentlichen Raumes liegt. In der virtuellen Welt können tamilische Öffentlichkeiten und Schweizer Mehrheitsöffentlichkeiten relativ parallel nebeneinander bestehen. Überlappungen zwischen den verschiedenen Öffentlichkeiten sind in der materiellen, geographisch verorteten Welt häufiger festzustellen. 


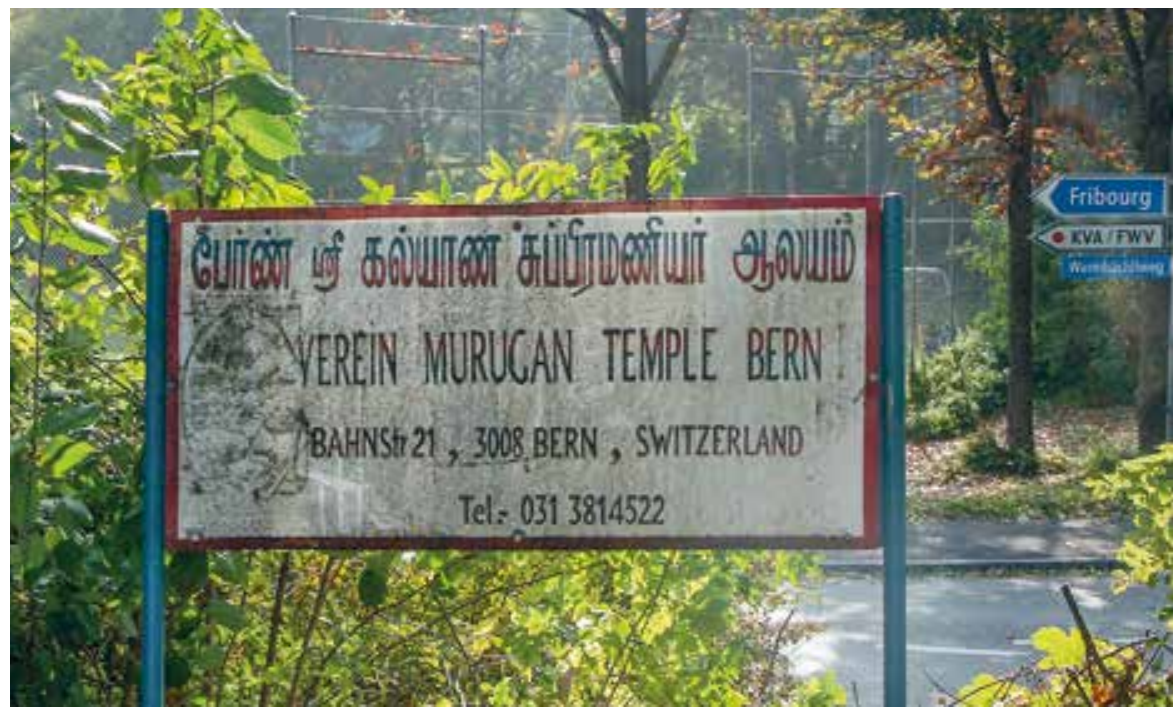

Abb. V 2: Wegschild mit Angaben zum Śrī Kalyāna Murukañ Tempel Bern in verschiedenen Sprachen (13.10.2007).

tion aus deutschen und englischen Begriffen auf den Sitz des «Verein Murugan Temple Bern» hinwies und seine Adresse und Telefonnummer angab (Bahnstr. 21, 3008 Bern, Switzerland). ${ }^{381}$

In der Platzierung dieses Schildes im Gegensatz zur prominenten Platzierung des leuchtenden Namens des Tempels in tamilischer Schrift über seinem Eingang zeigt sich, dass die Benennung des Tempels in tamilischer Schrift grössere Bedeutung für die Akteure hat. Das Wegschild ist auf eine andere Öffentlichkeit ausgerichtet und scheint durch seine Platzierung in der Umgebung in erster Linie nicht-tamilische Vorbeigehende ansprechen zu wollen.

Nahezu «unsichtbar» war der Srī Citti Vināyakar Tempel in Baar, welcher sich im ersten Stock eines Gebäudes im Industriegebiet in Baar befand (Stand: Februar 2008). ${ }^{382}$ Erst im Inneren des Gebäudes wurde im Treppenhaus durch ein Schild in tamilischer Schrift auf den Tempel hingewiesen. Auf dem Namensschild war unter dem Schriftzug ein gemaltes Bild von Vināyakar in einer Lotusblüte sitzend angebracht, neben ihm sein Reittier, die Maus.

381 Interessant ist, dass das Schild, was für Informationsschilder dieser Art eher unüblich ist, bei der Adresse auch das Land (Switzerland) nennt.

382 Die folgenden Ausführungen beziehen sich auf meinen Besuch des Tempels am Freitag, den 15.02.2008 in der Haldenstrasse 5. 


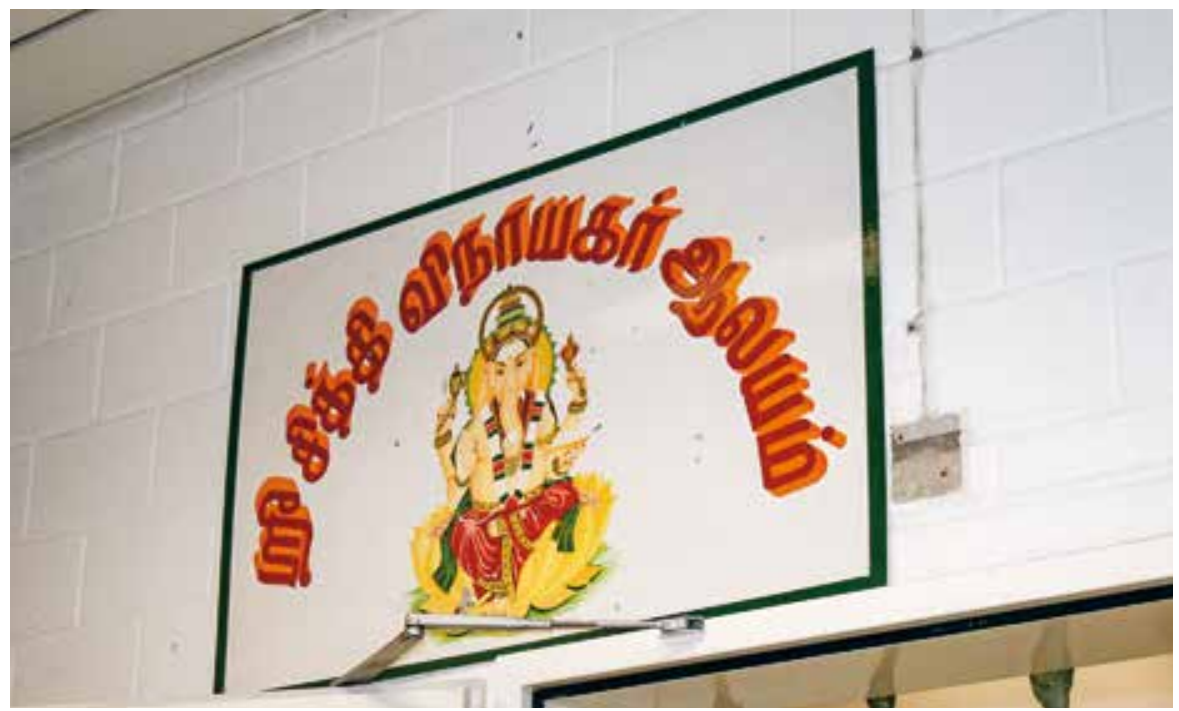

Abb. V 3: Eingangsschild des Srī Citti Vināyakar Tempels in Baar im ersten Stock des Gebäudes (15.02.2008).

Verbreitet ist in der öffentlichen Kennzeichnung der Tempel eine Mischform verschiedener schriftlicher und sprachlicher Codes. Eine Zwischenform nahm das Informationsschild des Śrī Vișnu Turkkai Ammañ Tempels ein: Im ehemaligen Tempel in Adliswil war der Name sowohl in lateinischen als auch in tamilischen Schriftzeichen vermerkt. An erster Stelle wurde in gelber Schrift und lateinischen Buchstaben der Name des Tempels in der zweiten Kommunikationssprache der tamilischen Diaspora, in Englisch, angegeben, welche auch von der Mehrheit der Schweizer und nichttamilischer Hindus verstanden wird. Danach folgte in blauer Schrift der Name des Tempels in tamilischen Buchstaben. Das Schild war farbig gestaltet und enthielt neben dem Namen des Tempels seine Adresse. Daneben war ein gemaltes Bild der Hauptgöttin des Tempels zu sehen. Dieses war auch über dem Eingang des Tempels platziert.

Nach dem Umzug des Tempels 2010 war zur Eröffnung in den neuen Räumlichkeiten in Dürnten das provisorisch neben den Eingang geklebte Plastik-Banner aufwändiger gestaltet als das ehemalige Schild in Adliswil. Neben dem Namen des Tempels - wieder in tamilischer und englischer Sprache - wurde auf das aktuelle Ereignis, das Einweihungsritual, in roter Schrift auf dem Banner hingewiesen. Auffallend war die Abbildung eines sehr grossen und aufwendig gestalteten kōpuram am linken Rand des Plakates (vor der Darstellung der Hauptgöttin in Gelb) sowie eines Tempel- 
turms in der Mitte des Bildes (vgl. die Darstellungen zu kōpuram-Kulissen im Folgenden). ${ }^{383}$

Neben den Schildern, die den Namen der Gebäude nennen und den Raum durch diese schriftliche Kennzeichnung als Tempel auszeichnen, finden sich auch Dekorationselemente, die das Tempelgebäude nach aussen hin als besonderen Raum markieren wie Darstellungen von Göttinnen und Göttern oder Girlanden, die um die Eingangstür gelegt sind.

Der Hindu-Tempel in Basel hatte beispielsweise über dem vorgelagerten Briefkasten seines neuen Gebäudes im Dreispitzareal eine VināyakarFigur aus Holz aufgestellt. Darüber war ein Willkommensschild in Englisch angebracht.

Der Tempel in Trimbach und jene Bauwerke, die gezielt als Tempel geplant wurden, sind bereits durch ihre Architektur darauf ausgerichtet, öffentlich als Tempel sichtbar zu sein. Innerhalb der Caivam-Tradition ist es besonders die Gestaltung der Aussenfassade, die durch das Anbringen von rot-weissen vertikalen Streifen den Tempel als Caiva-Tempel kennzeichnet, sowie die Tempeltürme. Beide Kennzeichnungen werden in den zu anderen Zwecken errichteten Tempeln durch kōpuram-Kulissen und das Streichen von Wänden in rot-weiss aufgenommen.

Weitere Elemente der öffentlichen Präsentation der Hindu-Tempel stellen Flaggen dar, die entweder permanent oder ausschliesslich während des Jahresfestes am Tempel angebracht sind ${ }^{384}$ Flaggen sind bewegliche und weithin sichtbare Symbole, die auf Verbundenheit, Loyalität oder Zugehörigkeit der Akteure verweisen, welche die Flaggen hissen. Besonders im Kontext von Diaspora-Gruppierungen können Flaggen, welche bewusst als öffentliche Symbole präsentiert werden, Aufschluss über formelle Loyalitätsbekenntnisse geben.

Es finden sich jedoch nicht nur Flaggen, welche nationale oder regionale Symbole darstellen, sondern auch solche, welche auf politische oder religiöse Zugehörigkeiten verweisen. Die Sakralgebäude der DiasporaGruppierungen stellen einen besonderen Ort für das Hissen von Flaggen dar. Dies kann Loyalitätsbekenntnisse des Tempels zu einer geographischen oder geo-politischen Region ausdrücken oder Aufschluss über das Bewusstsein von citizenship der Akteure der Tempelvereine geben. Ausserdem können gegebenenfalls Interferenzen der Sphären Religion und Politik angezeigt werden.

383 Einen weiteren Ort der schriftlichen Kenntlichmachung stellen Briefkästen dar. An diesen ist es obligatorisch, dass der Name der Institution in lateinischen Buchstaben angeben wird.

384 Das Hissen von Fahnen im Inneren des Tempels ist integraler Bestandteil des Jahresfestes der Hindu-Tempel. 


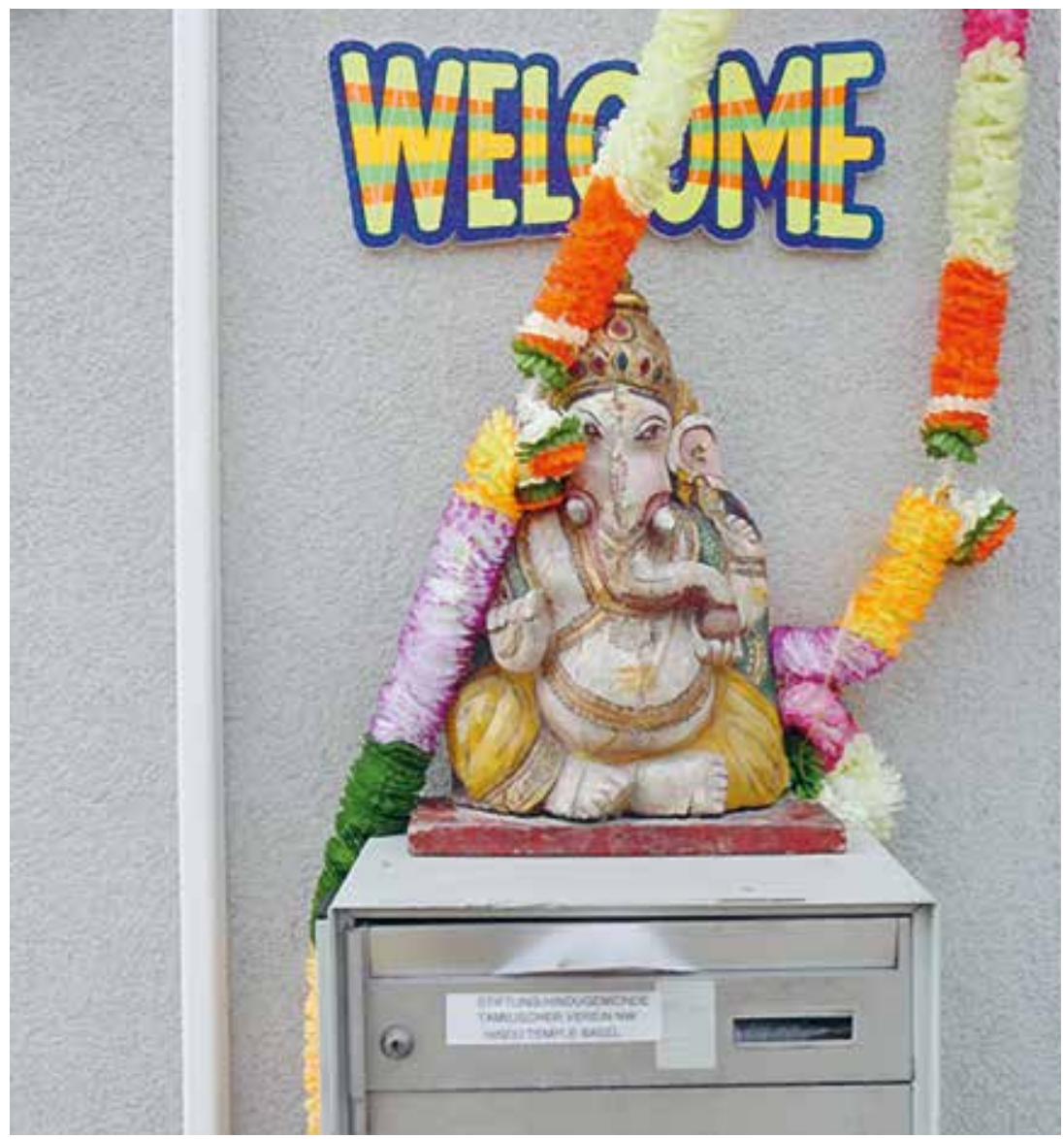

Abb. V 4: Eingang des Hindu-Tempels im vom Tempelverein gekauften Gebäude im Dreispitzareal in Basel (08.04.2009).

Beispielhaft sollen im Folgenden die Flaggen, die während des Tempelfestes des Śrī Civacuppiramaniyar Tempels 2009 weithin sichtbar am Turm wehten, dargestellt und analysiert werden: Rechts und links wehte jeweils eine kleine Flagge des Kantons Zürich und am selben Fahnenmast jene des Königreichs Jaffna (safranfarben mit Abbildung des Bullen Nandī), welches von 1215 bis 1624 im heutigen Sri Lanka existierte. ${ }^{385}$ Darüber war die Nationalflagge der Schweiz angebracht. Am oberen Ende waren zwei Flaggen zu sehen, die auf den Hauptgott des Tempels, Murukan, verwiesen.

385 Die Staatsreligion innerhalb des Königsreiches Jaffna war Caivam. Hauptstadt war die Stadt Nallūr. 
Die gelbe Flagge mit Hahn, die Markierungsfahne von Murukans Armee und eine orangefarbene, welche am Ende gezackt war, zeigte den Speer Murukañs. ${ }^{386}$

Durch das Hissen von Flaggen kann eine Verbundenheit zum Heimatland oder Residenzland oder durch das Hissen beider Flaggen die Bindung an beide Orte ausgedrückt werden. In letztem Fall kann dies ein spezifisches diasporisches Bewusstsein mit multiplen Loyalitäten anzeigen. Das Zeigen der Nationalflagge des Residenzlandes bei performativen Praktiken von Immigranten-Gruppierungen oder an ihren Gebäuden stellt eine besondere Form der Selbstrepräsentation dar. Für den US-amerikanischen Kontext stellt Raymond Brady Williams fest:

For example, the inclusion of an American flag in a parade sponsored by an Asian-Indian Hindu group is a significant element in the rhetoric of self-representation of the group that defines or, in fact, is its ethnicity. (Williams 2004,

Neben den Fahnen, die sich auf den Hauptgott des Tempels beziehen, präsentierten die weiteren Flaggen drei Regionen: den Nationalstaat Schweiz, den Kanton Zürich und das Königreich Jaffna. Die Schweizer Flagge, welche das Kreuz zeigt, verweist auf das christliche Erbe des Landes, die Flagge des Königreiches Jaffna durch die Darstellungen nandīs (Sivas Reittier) auf den hinduistischen Hintergrund. Diese geographischen Räume sind im Tempel symbolisch verbunden: zwischen «hier» (Zürich/Schweiz) und «dort» (Jaffna/Sri Lanka) werden multiple regionale Zugehörigkeiten der tamilischen Immigrantengruppe deutlich. Durch das Hissen der regionalen Flaggen, des jeweiligen Kantons und des Residenzlandes, macht der Tempelverein seine Loyalität zum Residenzland deutlich.

Die Nandī-Flagge (tam. nandī koți) verweist auf die Zugehörigkeit des Tempels zur Caivam-Tradition, aber auch auf Konflikte der verschiedenen Bevölkerungsgruppen in Sri Lanka seit der Unabhängigkeit des Landes 1948 (vgl. Kap. III 2). Diese Konflikte zeigten sich auch in Diskussionen um repräsentative Flaggen für den Staat Sri Lanka. Es wurde diskutiert, welche Flagge als Nationalflagge des unabhängigen Staates dienen sollte. Singhalesische Parlamentarier plädierten für die singhalesische Löwen-Fahne, was von tamilischen Abgeordneten abgelehnt wurde. Es wurde von tamilischer Seite der Vorschlag gemacht, drei Flaggen (für die drei grössten Bevölkerungsgruppen) als Nationalflaggen gelten zu lassen. Zu den beiden genannten sollte eine mit einem Halbmond und Stern versehene Flagge als Symbol für die muslimische Bevölkerung in Sri Lanka treten (Navaratna-Bandara

386 Im Jahr 2010 variierten die Flaggen und ihre Platzierung. 


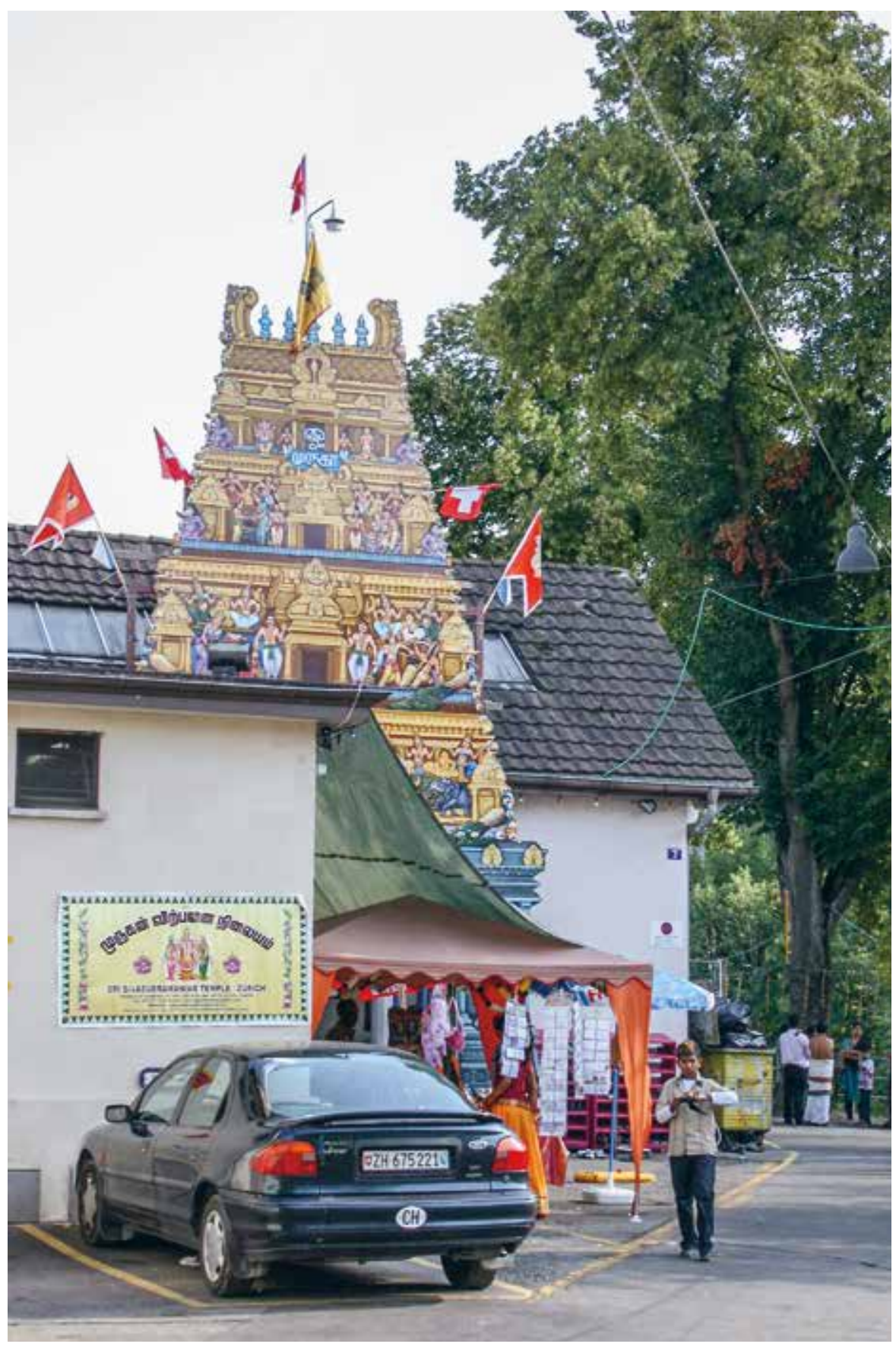

Abb. V 5: Flaggen, die während des Tempelfestes des Śrī Civacuppiramaṇiyar Tempels 2009 gehisst waren (12.08.2009). 
2002, 61) ${ }^{387}$ Dies zeigt die repräsentative Bedeutung der Nandi-Flagge als Zeichen für die tamilische Bevölkerungsgruppe in Sri Lanka.

In den letzten Jahren findet ein hindu-tamilischer Diskurs über das Fehlen einer Flagge als Symbol für eine gemeinsame religiöse Identität innerhalb einer religionspluralistischen Gesellschaft statt. 2008 wurde von Mitgliedern des World Saiva Council ${ }^{88}$ dazu aufgerufen, die Nandi-Flagge konsequent bei Hindu-Anlässen und zu Tempelfesten zu hissen - auch eine Implementierung der Kampagne innerhalb transnationaler tamilischer Netzwerke wurde angestrebt. Die Flagge als repräsentatives Zeichen soll Hindu-Selbstbewusstsein zum Ausdruck bringen. ${ }^{389}$

Zusammenfassend zeigt sich die hohe Bedeutung und der kreative Umgang mit Elementen der materiellen Kultur, um Gebäude, die nicht als Sakralräume gebaut wurden, nach aussen hin als Verehrungsorte für die Göttinnen und Götter zu kennzeichen. Die visuelle Gestaltung steht in $\mathrm{Zu}$ sammenhang mit der Traditionslinie, in welcher die Tempel stehen, aber auch mit den Inkorporationsbedingungen der Residenzgesellschaft. Diese schränken oftmals den Handlungsspielraum der Akteure in der Wahl der Präsentationselemente ein. Es wurde deutlich, dass die tamilische Schrift ein wichtiges Element in der Kennzeichnung der Räume als zu tamilischen Hindu-Traditionen gehörend ist. Durch eine Beschränkung auf tamilische Buchstaben als Repräsentationsform nach aussen werden diese Orte in erster Linie in der diasporisch tamilischen Öffentlichkeit sichtbar. Häufig werden Mischformen verschiedener schriftlicher und sprachlicher Codes verwendet.

Ein instruktives Beispiel der Präsentation der Tempel nach aussen sind Tempeltürme und im Kontext dieser Untersuchung im Besonderen kōpuram-Kulissen als diasporische Innovationen, was im folgenden Abschnitt dargestellt wird.

387 Nachdem 1948 die Löwenflagge als Nationalfahne des Landes proklamiert wurde und es zu Protesten kam, da diese Wahl als Ausdruck des Vormachtsanspruchs der singhalesischen Bevölkerungsgruppe gedeutet wurde, bemühte sich 1950 ein staatliches Komitee um die Aushandlung einer Kompromisslösung. Es wurde ein grüner Streifen für die muslimische Bevölkerungsgruppe und ein safrangelber für die tamilische eingeführt (vgl. Rösel 1996, $324 \mathrm{ff}$.).

388 Diese religiöse NGO mit Sitz in London wurde 1992 mit dem Ziel gegründet, sich für eine Renaissance des Caivam einzusetzen.

389 Der Aufruf wurde beispielsweise durch Zeitungsbeiträge wie den Artikel "Sri Lankan Hindu campaigns for hoisting Nandi flag” in The Indian publik gemacht. Darin verweist einer der Initiatoren der Kampagne, Sinnadurai Dhanapalaa, auf die beiden anderen Religionen der Bevölkerungsgruppen Sri Lankas und ihre sichtbaren Symbole. Er wird wie folgt zitiert: "Muslims raise the Islamic flag, the Buddhists raise theirs, but Hindus do not hoist any though they have the Nandi flag". Artikel von P.K. Balachandran am 20.03.2008 vgl. http://twocircles. net/2008mar19/sri_lankan_hindu_campaigns_hoisting_nandi_flag.html (10.07.2016). 


\subsection{Tempeltortürme als öffentliche Präsentationsform von Hindu-Traditionen in der Diaspora}

Türme von Sakralbauten sind besonders hervorgehobene sichtbare Zeichen der öffentlichen Präsenz der jeweiligen religiösen Traditionen und repräsentieren das Gebäude und damit auch die Trägergruppe selbst in der öffentlichen Sphäre. Ein zentrales architektonisches Element drawidischer Hindu-Tempel sind die Tortürme (tam. kōpuram), die sich in vielen Tempeln in Südindien und Sri Lanka über den Eingängen an allen vier Seiten des Sakralgebäudes befinden; dabei wird der Turm über dem Haupteingang rāja-kōpuram genannt. Traditionell bestehen die kōpurams aus Stein und sind weithin sichtbar. Der spitz zulaufende Turm ist in mehrere Geschosse eingeteilt und hat einen leicht konkaven Umriss (vgl. Michell 1979, 157; Luchesi 2003a, 259 ff.). Die Tortürme haben den Zweck, den Tempel nach aussen hin als solchen zu kennzeichnen und eine Verbindung zwischen dem Wirkraum der Gottheiten im Inneren des Tempels und der Aussenwelt herzustellen. Die Öffnungen in der Mitte der Ebenen dienen als Durchlass für die Emanationen der Gottheiten im Inneren des Tempels (vgl. Luchesi 2003a, 260 f.). Diese wirken dann auch in der öffentlichen Sphäre ausserhalb des Tempels. Die Türme sind in der Regel reichlich mit Figuren verziert, bunt angemalt und schliessen mit einem Tonnendach - ein halbrund, tonnenartig geformtes Dach - ab.

Während der Feldforschungen zu dieser Studie wurde ein dreidimensionaler kōpuram im Zuge des Tempelbauprojekts in Trimbach gebaut. Bei allen anderen Tempeln fehlt ein Torturm, da diese sich in zu anderen Zwecken erbauten Räumlichkeiten befinden. Viele Tempelvereine wünschen sich jedoch einen traditionellen Tempelbau, dessen integraler Bestandteil ein kōpuram ist. Das Fehlen von Sakralarchitektur, welcher in der DiasporaSituation und den eingeschränkten Ressourcen der Migrantengruppe begründet liegt, wird als Mangel empfunden. Da vielen Tempelvereinsmitgliedern jedoch die Handlungsmacht fehlt, um die Situation zu verändern, haben einige Tempelvereine versucht, gangbare Wege einzuschlagen, um dieses Dilemma zu lösen.

Zwei Handlungsstrategien sollen im Folgenden vorgestellt werden: Die erste Aktivität besteht in der temporären oder permanenten Installation von kōpuram-Kulissen, die zweidimensional einen Torturm in der Grösse, die annähernd der Originalgrösse eines kōpuram entspricht, abbilden. Durch die bunte Bemalung und die charakteristische Form wird so ein südindischer kōpuram nachgeahmt. Manche Tempelvereine dachten jedoch auch den Anbau eines kōpurams an, wie jener des Śrī Viṣnu Turkkai Amman Tempels nach seinem Umzug nach Dürnten, oder unternahmen Bestrebun- 


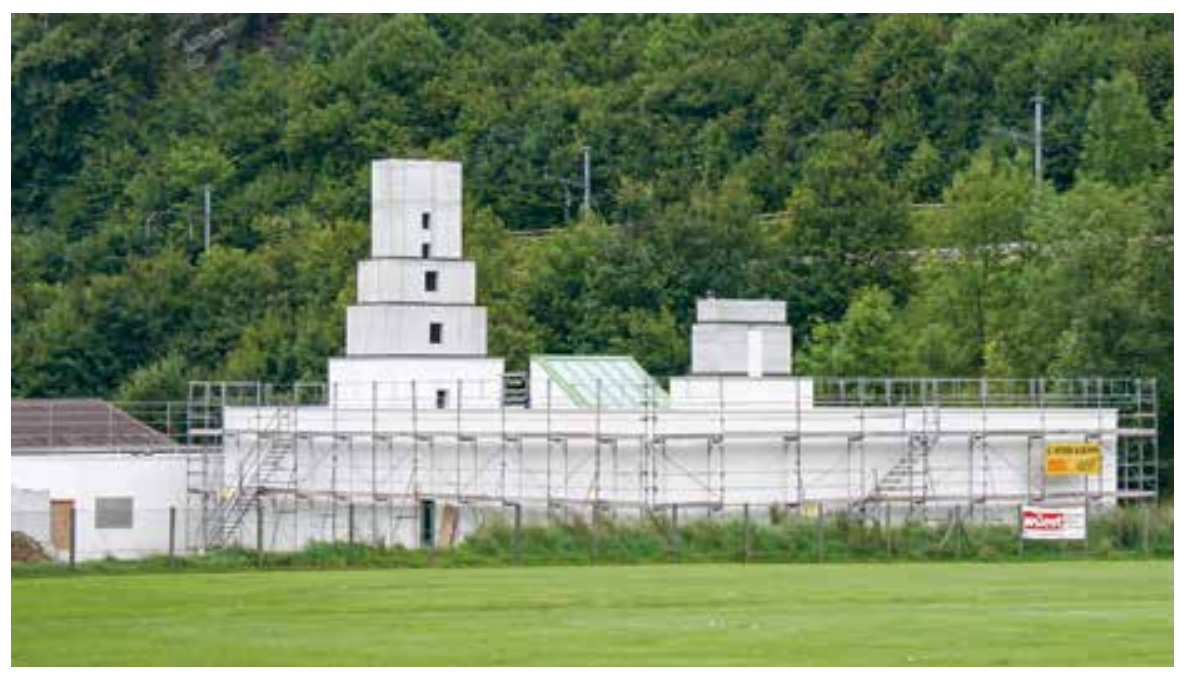

Abb. V 6: Der sich im Bau befindliche Torturm des Sri Man̄ōnmaṇi Ampāl Ālayam in Trimbach (11.08.2009).

gen, um ein Tempelbauprojekt mit dreidimensionalem kōpuram beginnen zu können. In Trimbach wurde der Tempel mit kōpuram im März 2013 feierlich eingeweiht. Jedoch war zu diesem Zeitpunkt der Torturm aus finanziellen Gründen noch nicht dekoriert und gestrichen, was jedoch nachgeholt werden sollte. Der religiöse Zweck des Turmes, der Emanationsdurchlass, war 2013 jedoch bereits gegeben. Der zweite Tempelturm vimānam über dem Hauptschrein des Tempels, dem garbhagrha (tam. karppakkirukam), der für die Einweihungszeremonien eine wichtigere religiöse Bedeutung hatte, war bereits durch indische Handwerker traditionell dekoriert (vgl. Baumann/Tunger-Zanetti 2014).

Kōpuram-Kulissen als Markierungen im öffentlichen Raum

Kōpuram-Kulissen sind Elemente materieller Kultur, welche aufgrund der Diaspora-Situation - als Ersatz für real existierende Tortürme - benutzt werden. Sie sind als eine diasporische Innovation zu bezeichnen, die aus verschiedenen Faktoren entstanden ist: Auf der einen Seite erfordert der Anbau eines traditionellen dreidimensionalen kōpurams enorme finanzielle Mittel, welche die tamilischen Migrantinnen und Migranten als sozio-ökonomisch schwache Gruppe in der Schweiz nicht problemlos aufbringen können. Auf der anderen Seite würde ein aufwändiges Bauverfahren, welches das Einholen rechtlicher Genehmigungen und Aushandlungsprozesse mit der Residenzgesellschaft erfordern würde, vielfach auch die momentanen sozialen Ressourcen der Immigranten-Gruppe übersteigen. 

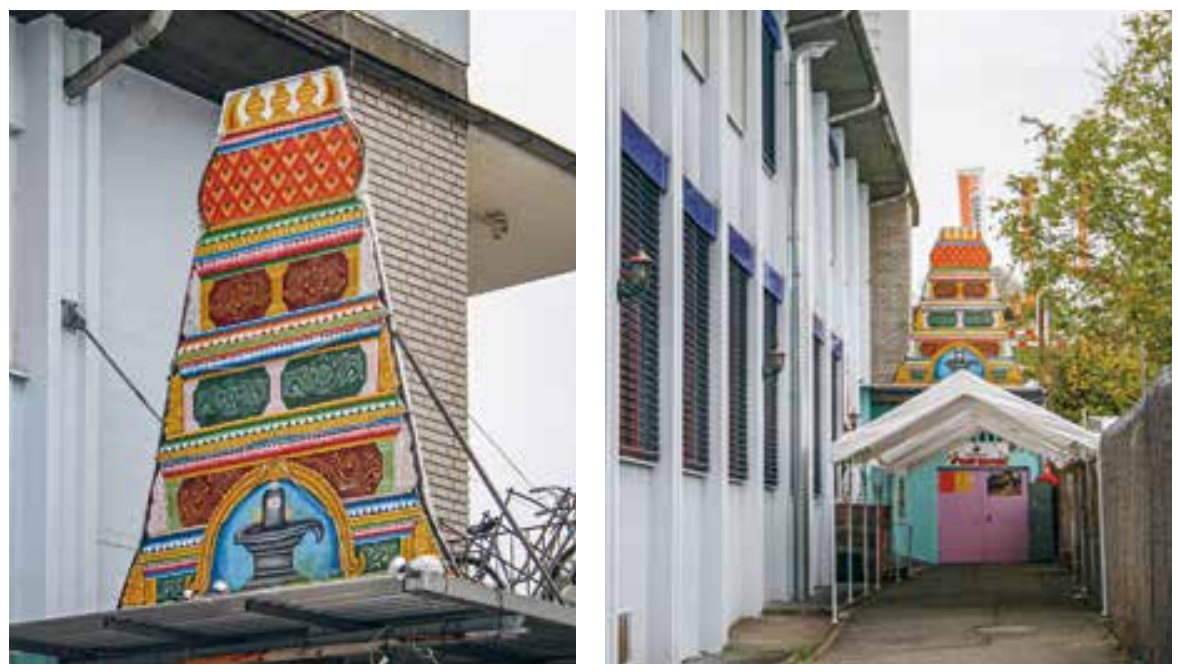

Abb. V 7 / Abb. V 8: Kōpuram-Kulisse des Civannkōvil in Glattbrugg/Zürich (27.10.2008).

Es lassen sich zwei Formen von kōpuram-Kulissen in der Schweiz ausmachen: solche, die permanent über dem Eingangsbereich des Tempels angebracht sind und solche, die nur temporär zum Anlass des Tempelfestes aufgestellt werden. Die Frage, ob eine Kulisse zeitlich begrenzt oder unbegrenzt angebracht wird, steht auch in Zusammenhang mit Fragen der rechtlichen Bewilligung eines solchen Vorbaus. ${ }^{390}$

Der Civankkōvil in Glattbrugg/Zürich hat beispielsweise permanent eine kōpuram-Kulisse über dem Eingang installiert (vgl. Abb. V 7-8). Der stilisierte «Turm» überragt jedoch nicht das Gebäude des Tempels, da sich der Eingang daneben befindet. Die vierstufige Kulisse, die mit der Abbildung eines Tonnendachs abschliesst, zeigt neben Verzierungselementen als einzige gegenständliche Darstellung einen civa-linkam und verweist damit auf den Hauptgott des Tempels, Civan. Auf diesem stilisierten kōpuram fehlen die charakteristischen Skulpturen von Gottheiten und die Abbildungen der Öffnungen. Die Kulisse kann durch Lichtstrahler, die ebenfalls auf dem Wellblech über dem Eingang angebracht sind, beleuchtet werden. Dadurch kann diese Installation zumindest von einer Himmelsrichtung aus auch bei Dunkelheit weithin öffentlich sichtbar sein.

Auch der ehemalige Hindu-Tempel in Muttenz bei Basel (vgl. Kap. IV 4.1) hatte im August 2008 über seinem Eingang eine kōpuram-Kulisse angebracht (vgl. Abb. V 9). Die Kulisse war auf der grau schattierten Gebäudewand ange-

390 Auch spielt hier das Material der Kulisse eine Rolle, welche bei einer permanenten Anbringung den Witterungsverhältnissen in der Schweiz standhalten muss. 


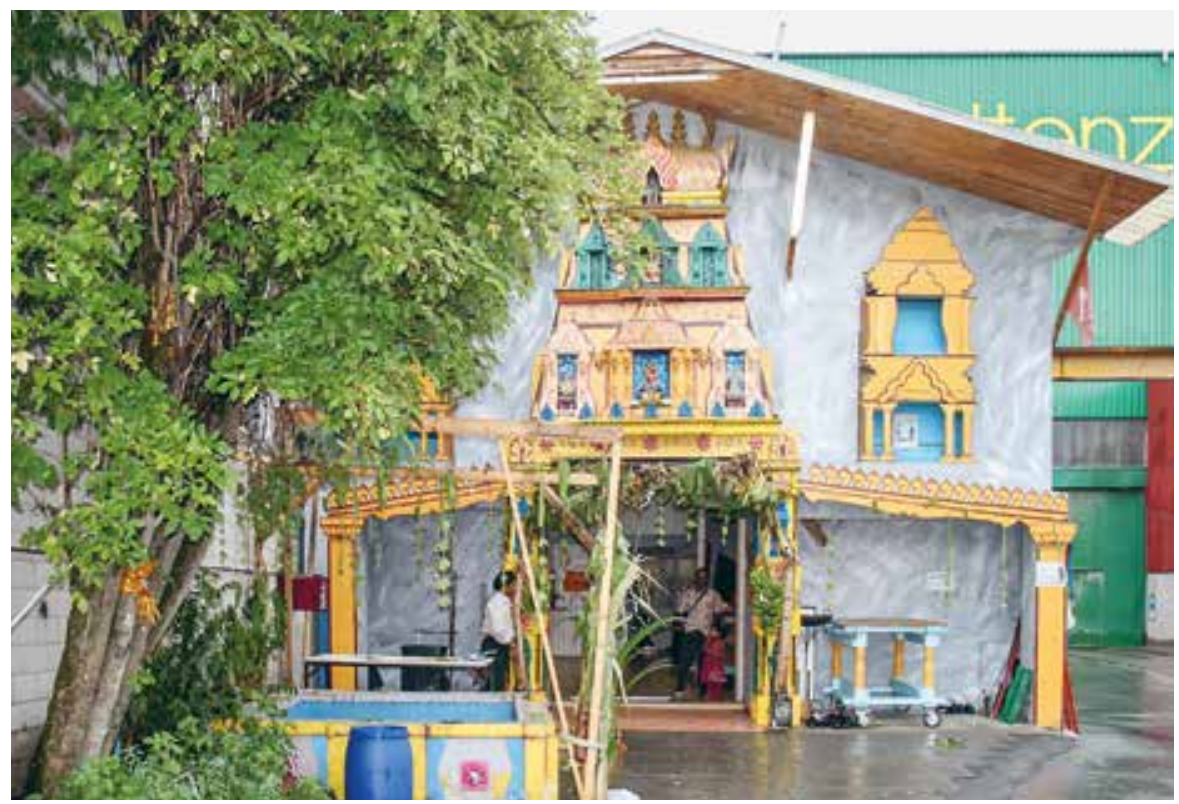

Abb. V 9: Kōpuram-Kulisse des Hindu-Tempels in Muttenz/Basel (11.08.2008).

bracht, welche durch diese Fassade den stilisierten kōpuram besonders betonte. Rechts und links neben dem Torturm waren in der Kulisse zwei kleine Türme zu sehen. Der Hauptturm war in zwei Stufen unterteilt und zeigte als Abschluss ebenfalls die Abbildung eines Tonnendachs. In jeder Ebene waren drei Öffnungen abgebildet. In der ersten Stufe befand sich in jeder Öffnung jeweils eine Gottheit, welche die drei Gottheiten des Tempels abbilden und auf die besondere Geschichte des Tempels verweisen. ${ }^{391}$ In der zweiten Stufe war eine Gottheit in der mittleren Öffnung dargestellt.

Im Inneren des Tempels in Muttenz, nach dem Durchschreiten des Eingangsbereichs, war ausserdem über dem Durchgang zum Hauptbereich des Tempels eine gemalte Abbildung des Tonnendaches eines kōpurams angebracht (vgl. Abb. V 10). Diese zeigte einen civa-linkam, rechts und links von zwei weissen Bullen flankiert, die nandī, das Reittier Civans darstellen, und den Tempel als zum Caivam-Spektrum zugehörig auszeichnen. Dies spricht für einen kreativen Umgang des Tempelvereins mit den räumlichen Gegebenheiten.

Der Tempelverein verfügt jedoch zusätzlich über eine weitere kōpuramKulisse, welche zur Zeit des Tempelfestes aufgestellt wurde (vgl. Abb. V 11).

391 Der Tempel ist aus der Fusion dreier Tempel in Basel, welche Murukañ, Vināyakar und Amman gewidmet waren, im Jahr 2004 entstanden (vgl. Kap. IV 4.1). 


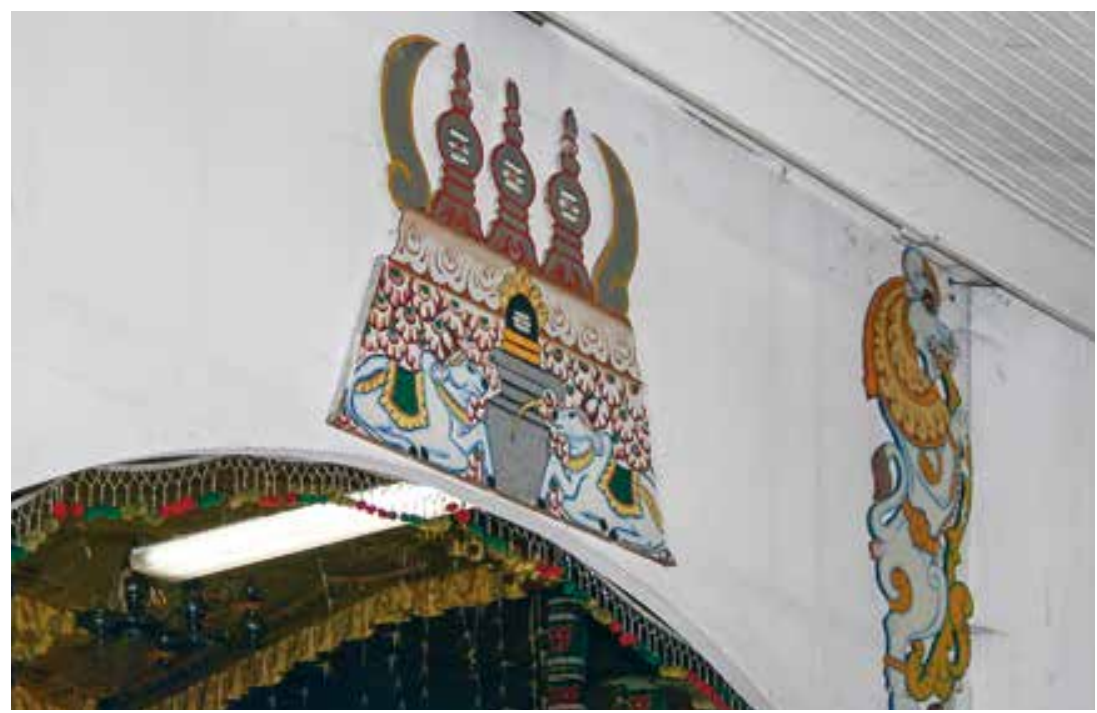

Abb. V 10: Stilisierter kōpuram im Innenbereich des Hindu-Tempels in Muttenz/Basel (11.08.2008).

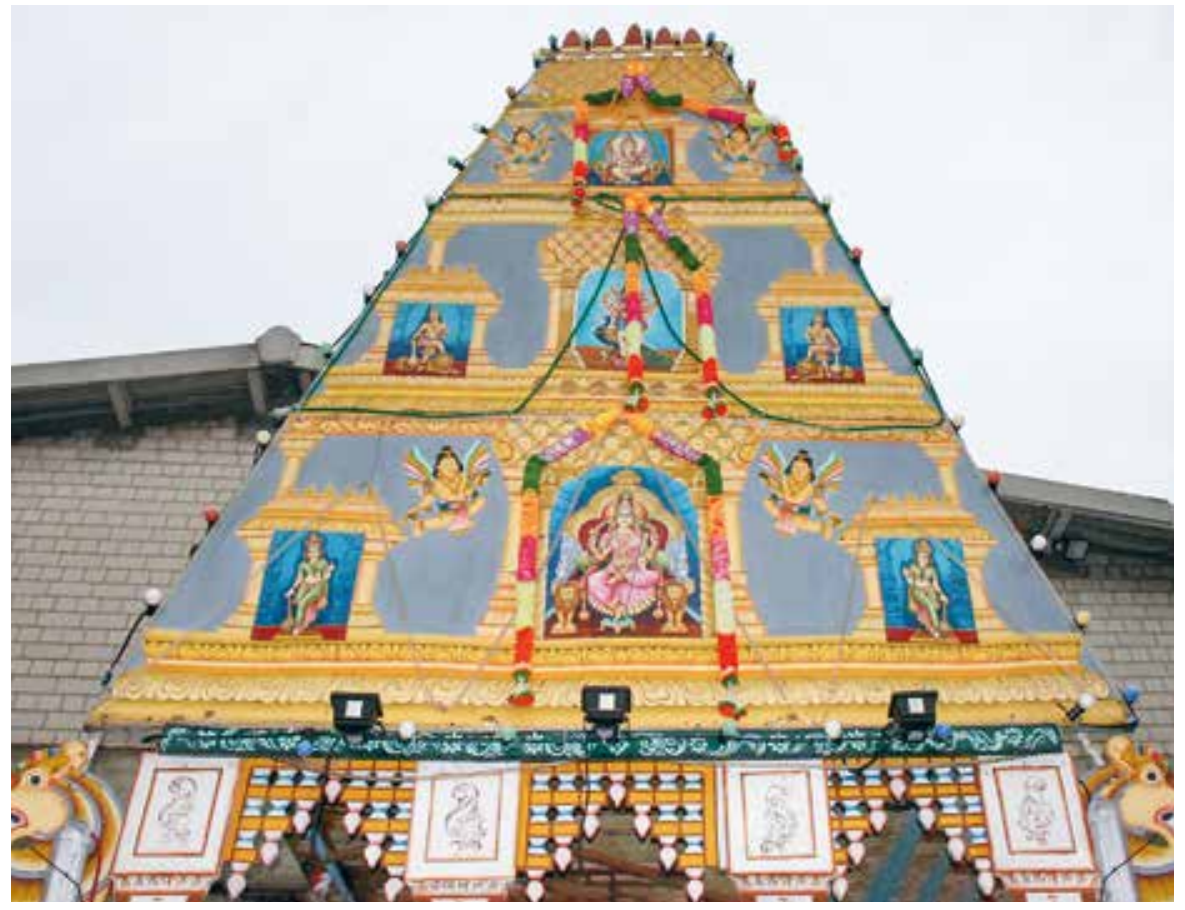

Abb. V 11: Kōpuram-Kulisse zum Anlass des Tempelfestes des Hindu-Tempels in Muttenz/ Basel (11.08.2008). 
Diese war höher als der permanente stilisierte kōpuram und zeigte in den Öffnungen der drei Ebenen an unterster Stelle Turkkai, in der zweiten Ebene Murukan und in der obersten Vināyakar. Neben der Göttin waren rechts und links zwei weibliche Torhüterinnen (skr. dvārśakti; Luchesi 2003a, 269), lächelnd und mit Keule in der Hand, abgebildet. Neben Murukan waren männliche Torhüter (skr. $d v \bar{a} r a p a \bar{l} l a)$, die ebenfalls eine Keule tragen und auf einem Löwen stehen, zu sehen.

Neben diesen Tempeln, die eine kōpuram-Kulisse permanent installiert haben, finden sich in der Schweiz Tempel, an denen nur zum Anlass des jährlichen Tempelfestes eine kōpuram-Kulisse angebracht wird und die den Tempel damit nach aussen hin sichtbar schmücken. Mit dieser Metamorphose des Tempels während der Zeit des Tempelfestes verfolgen die Verantwortlichen den Zweck, den Tempel zu diesem Anlass als in der öffentlichen Sphäre sichtbaren Tempel zu gestalten. Dieser Wandel ist jedoch nur temporär und korreliert mit dem Anlass. Nach Ende des Tempelfestes wird der Tempel für Aussenstehende wieder «unauffälliger» und präsentiert sich primär in tamilischen öffentlichen Sphären.

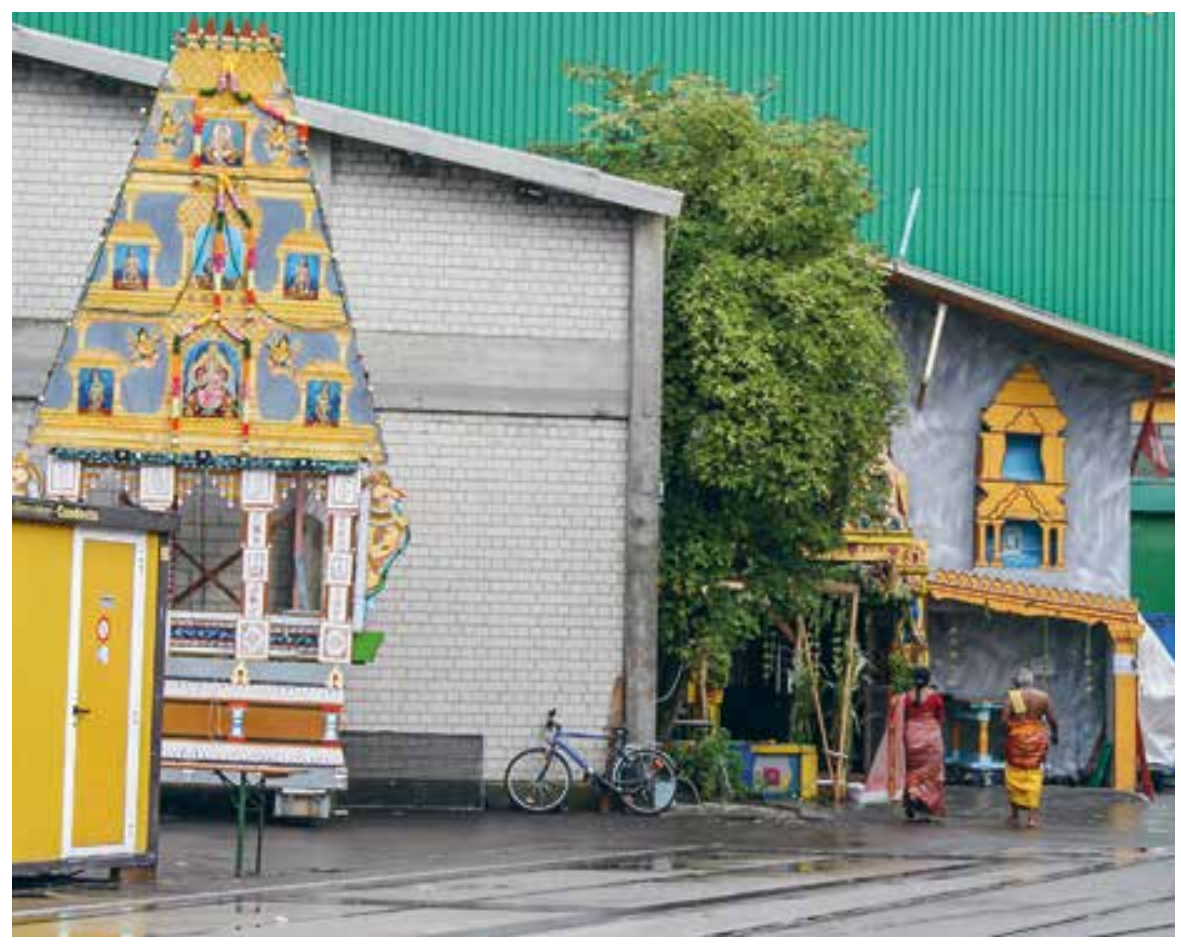

Abb. V 12: Kōpuram-Kulisse zum Anlass des Tempelfestes neben permanenter KōpuramKulisse des Hindu-Tempels in Muttenz/Basel (11.08.2008). 
Als Beispiel für eine temporäre kōpuram-Kulisse sei jene angeführt, welche über dem Tempeleingang des Śrī Civacuppiramaniyar Tempels in Adliswil aus Anlass des Tempelfestes befestigt wurde (vgl. Abb. V.13). ${ }^{392}$ Während zehn Tagen wird der Tempel durch eine dieser Kulissen als «authentischer» südindischer Tempel verkleidet. Die kōpuram-Attrappe in Adliswil, die an einem Holzgestell beim Tempeleingang angebracht war, war visuell sehr auffällig gestaltet und ebenfalls den Dekorationen südindischer kōpuram nachempfunden. Sie besteht aus vier sich nach oben verkürzenden Stockwerken und schliesst mit einer Tonnendach-Kulisse ab. Neben dem Eingangsportal sind rechts und links der Eingangstreppe Abbildungen der Wächtergottheiten dargestellt.

Wie auch bei den traditionellen Eingangsportalen in Südasien bilden die Darstellungen auf dem kōpuram Szenen aus der Mythologie des Hauptgottes des Tempels ab. So verweisen die Abbildungen, die auf der Kulisse des Śrī Civacuppiramaniyar Tempels gemalt sind, auf Murukañ. Unten rechts und links ist ein Pfau, das Reittier Murukans, dargestellt, die weiteren Bilder zeigen in bunten Farben und mit vielen Verzierungen Episoden aus dem Leben Murukañs. Neben den angedeuteten Öffnungen in der Mitte, welche rechts und links von Tempelwächtern bewacht werden, vermitteln insgesamt acht Bilder Narrative aus der Mythologie Murukanns. Auf der zweiten Stufe sind beispielsweise im linken Bild die fünf Kleinkinder, in Lotusblüten liegend, abgebildet, aus denen Murukan (als caravanapavañ) entstanden ist. Dieses Bild verweist auf die Erzählung um Civañs Samenfunken, welche Pārvati zu Murukan, einem Wesen mit sechs Köpfen, zusammengefügt hat. Rechts davon ist eine Szene dargestellt, die Murukan mit seinem Speer im Kampf mit einem Dämon zeigt. Zwischen der dritten und vierten Ebene steht in tamilischen Buchstaben Ōm Murukañ. Das Tonnendach zeigt den vēl, den Speer Murukans. Die Narrative, auf die hier durch malerische Darstellungen Bezug genommen wird, sind vielen Besuchern des Tempelfestes bekannt. ${ }^{393}$ Durch das Erzählen der Geschichten um das Leben Murukans auf dem Eingangsportal des Tempels wird Hindu-Wissen transmedial weitergegeben und öffentlich präsentiert.

Diese kōpuram-Kulisse ist zum einen durch ihre Höhe wie auch durch die vielfarbige Gestaltung und die wehenden Flaggen an ihren Seiten von

392 In den Jahren 2009 und 2010 habe ich diese kōpuram-Kulisse fotografiert. Bilder der gleichen kōpuram-Kulisse waren 2010 auf der Homepage des Tempels aus den Jahren 2009, 2008, 2007, 2006, 2004 und 2003 zu finden (vgl. www.murugantemple-zh.ch; 01.08.2010).

393 Während meiner Teilnahme am Tempelfest haben mich Besucher auf die abgebildeten Geschichten auf dem kōpuram aufmerksam gemacht und mir Geschichten, die um Murukañs Leben kreisen, erzählt. 


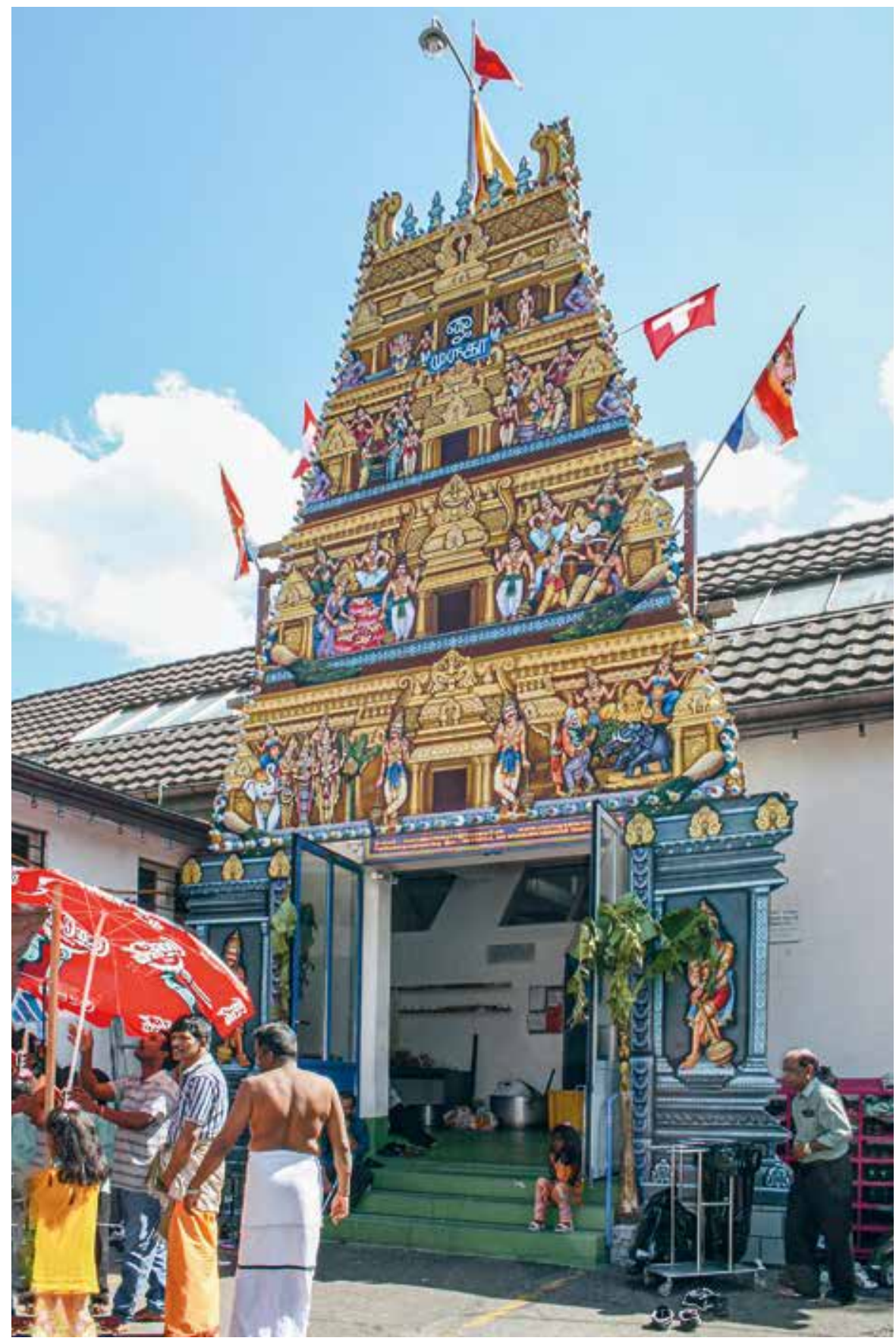

Abb. V 13: Temporäre kōpuram-Kulisse zum Anlass des Tempelfestes des Śrī Civacuppiramaṇiyar Tempels in Adliswil (12.08.2009). 
weitem sichtbar und auffällig (vgl. Kap. V 2.1). Diese öffentliche Sichtbarkeit wird noch einmal durch die Illumination bei Einbruch der Dunkelheit verstärkt. Glühbirnen, abwechselnd in blauer, gelber, grüner und roter Farbe, die an den Rändern angebracht sind, wie auch der Lichtstrahler am oberen Ende, beleuchten die Kulisse am Abend. 2010 wurde zusätzlich ein Strahler angebracht, der von rechts das Eingangsportal anstrahlt.

Die Kulisse dient vor allem dem Zweck, das Gebäude nicht nur im Inneren, sondern auch von aussen für einen begrenzten Zeitraum durch visuelle Markierungen als Tempel zu präsentieren. Der Tempelverein benutzt Darstellungen, die den Tempel während des Tempelfestes mit zweidimensionalem kōpuram zeigen, zu repräsentativen Zwecken. So zeigt eine bhajan$\mathrm{CD}$ des Tempels als zentrales Motiv des Covers den Tempeleingang mit kōpuram-Kulisse und Prozessionswagen davor. Das imitierte Eingangsportal ist auf diesen Fotografien das zentrale Kennzeichnen, welches das Gebäude als Tempel ausweist. Im Kontext der tamilischen Diaspora sind bildliche Darstellungen, die ausgetauscht werden, Elemente, die das Prestige einer religiösen Institution unterstreichen. Gerade für jene Tempel in der Diaspora, welche sich in für andere Zwecke errichteten Räumlichkeiten befinden, sind Dekorationen, die das Gebäude als Tempel markieren, und Abbildungen, welche den Tempel im geschmückten Zustand repräsentieren, von hoher Wichtigkeit, um ihre religiöse Authentizität zu belegen und sich im transnationalen religiösen Feld zu behaupten.

Beide Formen, temporäre wie auch permanente kōpuram-Kulissen, sollen die Gebäude nach aussen hin als Sakralgebäude sichtbar machen und sind zu diesem Zweck südasiatischen «Original»-kōpurams nachempfunden. Die Wirkung dieser Kulissen ist jedoch ambivalent: Auf der einen Seite soll durch dieses Element diasporischer materieller Kultur Authentizität hergestellt werden, auf der anderen Seite aber unterstreicht die Zweidimensionalität die Künstlichkeit der Inszenierung. Es handelt sich also nicht um eine Kopie oder ein Imitat eines kōpurams, welche die Wahrnehmung der Besucher zu täuschen versuchen. Im Falle der skizzierten Beispiele sind der Kulissencharakter der kōpurams und ihre Inszeniertheit unverkennbar. Sie sind für jedermann als Kulisse, als «nicht echter» Tempelturm beschreibbar. Zweck der Kulissen ist es jedoch, im Betrachter die Vorstellung von «echten» dreidimensionalen Türmen zu wecken $;{ }^{394}$ sie erinnern die tamilischen Migrantinnen und Migranten an Hindu-Tempel in Sri Lanka. Die Offensichtlichkeit der Kulisse bewirkt, dass den tamilischen Akteuren deut-

394 Dieser Effekt wird durch perspektivische Darstellungen auf den Kulissen verstärkt: Durch die Abbildung von Säulen und den mittigen Öffnungen wird beispielsweise ein dreidimensionaler Eindruck erweckt. 
lich vor Augen geführt wird, was sie in der Durchführung der Hindu-Praxis in der Schweiz vermissen. Das, was zurückgelassen wurde und nun im Residenzland fehlt, nämlich Sakralarchitektur, in welcher Hindu-Praxis nach traditionellen Vorgaben durchgeführt werden kann, kommt sichtbar zum Ausdruck. Dass die Türme keinen religiös immanenten Zweck erfüllen, zeigt sich besonders deutlich im Element der Öffnungen des Tortürme: Diese sind nur gemalt und stellen keine tatsächliche Verbindung zwischen Tempelinnerem und Torturm dar, durch welche göttliche Emanationen in die Umgebung des Tempels gelangen könnten. Die Abbildungen der Öffnungen weisen lediglich darauf hin, dass es diesen «Emanationsdurchlass» in den Tempeln Sri Lankas gibt, dieser hier in der Schweiz aber nicht möglich ist. Die zweidimensionale Kopie versinnbildlicht somit eindrücklich die Abweichung der Tempelgebäude in der Schweiz von den «echten» Tempeln im Herkunftsland. Sie drückt aus, dass Hindu-Praxis in der Schweiz nur provisorisch durchgeführt werden kann, solange kein «richtiger» Tempel gebaut ist. Darüber hinaus ist sie aber auch Ausdruck der Agency der Hindu-Akteure, die aktiv die Umgebungsbedingungen - im Rahmen ihrer Möglichkeiten - in der Diaspora-Situation in ihrem Sinne gestalten.

\section{Bestrebungen und Hindernisse beim Errichten eines kōpurams}

Das Engagement tamilischer Akteure zur öffentliche Sichtbarmachung der angemieteten Tempelräume ging jedoch über das Errichten von kōpuram-Kulissen hinaus. Der Wunsch und das Bestreben einen in traditioneller südasiatischer Architektur gebauten Tempel zu errichten, was die Konstruktion eines dreidimensionalen kōpuram beinhaltete, wurden von verschiedenen Akteuren der tamilischen Diaspora in der Schweiz formuliert. Studien zur muslimischen Migrantengruppe in der Schweiz haben gezeigt, wie die Regeln und Bedingungen der Schweizer Inkorporationsregime Bauvorhaben von Immigrantenreligionen mitgestalten (vgl. Beyeler/Suter Reich 2009; Suter Reich 2013). Lokale Machtstrukturen und öffentliche Diskurse beeinflussen die öffentliche Präsentation von Minderheiten. Tamilische Hindu-Traditionen sind bisher im Vergleich zur Ausübung muslimischer Praxis seltener in den öffentlichen Fokus geraten und in der öffentlichen Meinung meist positiver konnotiert als «der Islam».

Wie in informellen Gesprächen geäussert wurde, beeinflussten die öffentlichen Diskurse über nicht-christliche Religionen, besonders die politischen Debatte um Moscheen und ihre Minarette in der Schweiz in den Jahren der Untersuchung, die Haltung tamilischer Hindus in Bezug auf die Errichtung von Tempeltürmen. Nach dem Verbot von Minaretten im November 2009 bestanden bei einigen Akteuren Vorbehalte, einen Tempel mit Tempelturm zu errichten. Viele tamilische Verantwortliche waren sich 
nicht klar darüber, wie die Mehrheitsbevölkerung auf ihre Ambitionen reagieren würde und sahen die lokalen Machtstrukturen als tendenziell voreingenommen gegenüber dem öffentlichen Sichtbarwerden «fremder» Religionen an, was zu einer vorsichtigeren Artikulation ihrer Wünsche und Forderungen führte - gerade wenn es sich um Türme von Sakralbauten handelte. In informellen Gesprächen äusserten sowohl der Priester von Dürnten wie auch Vertreter des Tempelvereins in Trimbach ihre Bedenken, dass der Bau eines kōpurams als fremdes architektonisches Element in der Schweiz in Verbindung mit dem Bau von Minaretten gebracht würde. Die Zeitung Der Tages-Anzeiger deutet in einem Artikel zum Umbau einer Halle als Räumlichkeit für den Śrī Viṣnu Turkkai Ammañ Tempel diesen Diskurs wie folgt an: «Denn diese möchten vorerst nur den Innenraum umbauen und an der Eingangspforte zwei Säulen mit traditionellen Verzierungen errichten. Ein Koopuram, ein Tempelturm, ist im Umbau nicht vorgesehen. 〈Wir wollen keine Konflikte schüren〉, sagt der Priester. Derzeit sei wegen der Minarett-Diskussion sowieso nicht der richtige Zeitpunkt dafür. Er wolle auch das Vertrauen der Dürntnerinnen und Dürntner nicht ins Wanken bringen». ${ }^{395}$

Da es den meisten Tempelvereinen aufgrund ihrer Ressourcen nicht möglich war, ein Tempelbauprojekt zu initiieren, wurde von einigen Vereinen, deren Tempel in Gewerbehallen zu finden waren, Überlegungen angestellt, einen kōpuram an das Tempelgebäude zu bauen. So artikulierten die Verantwortlichen des Hindu-Tempels Basel dies für ihr neu erworbenes Gebäude im Basler Dreispitzareal. Konkrete Schritte wurden im Untersuchungszeitraum nicht unternommen. Der Bau eines solchen Vorbaus stand auch nach dem Umzug des Śrī Vișnu Turkkai Ammañ Tempels von Adliswil nach Dürnten im Raum. Abgeschwächt wurden diese Pläne durch die Überlegungen, einen stilisierten kōpuram anzubringen. ${ }^{396}$

Viele Narrative tamilischer Hindus verweisen auf den Wunsch, auch in der Schweiz einen eigenen Tempel zu errichten. Der nach südindischem Vorbild gebaute Tempel soll als «marker of authenticity» (Linda 1999, 389) dienen. Durch das Vorhaben von Immigrantengruppen, religiöse Bauten zu errichten, wird der öffentliche Raum neu ausgehandelt (vgl. Baumann/Tunger-Zanetti 2008). Auch für jene tamilischen Akteure, die sich einen Tempel in traditioneller Architektur wünschen, gehören zu einem solchen Sakralgebäude Tempeltürme als integrale Bestandteile dazu. Dies gilt beispielsweise für den Vināyakar Tempel in Genf, für den langfristig ein Tempelneu-

395 Wilma Hahn, Gemeindepräsident feiert mit Hindus, in: Tages-Anzeiger, 23.11.2009.

396 «Später ist auch eine Kenntlichmachung von aussen durch ein stilisiertes Gopuram (Eingangsportal) geplant». www.religionenschweiz.ch/aktuell.html; 16.09.2010 
bau geplant wird. Der Tempelverein des Geneve Arputha Vinayagar Tempels in Vernier präsentierte 2009 auf seiner Homepage eine eigene Kategorie mit dem Titel "New Temple" in seiner Navigationsleiste. Hier war folgende Passage zu lesen, welche das Bedürfnis nach einem Tempel in traditioneller Architektur klar zum Ausdruck bringt:

It has been the wish of every devotee residing in Geneva to have a Permanent Hindu Temple for the needs of the future/younger generation. The present temple is on a rented apartment and a considerable amount is paid as rent every month. While the daily rituals of the temple are conducted as per the Aagama Rules, it will be good to have the same being done in a temple which is constructed as per the vedic rules which is absent in the present rented apartment. Hence the need for purchasing a piece of land and constructing our own temple has become a necessity. For this purpose, a new bank account has been opened. ${ }^{397}$

Ökonomische Gründe (Mietzahlungen) wie auch religiöse Gründe (die Durchführung der agamischen Rituale in einem nach vedischen Vorgaben gebauten Tempel) werden als Begründung für den geplanten Tempelbau genannt. In chronologischer Abfolge wird die Begründung für die Notwendigkeit einen eigenen Tempel zu errichten, geliefert. Dieses Narrativ liefert die Legitimitätsgrundlage für einen Tempelbau in der Schweiz.

Als zentrale Motivation für den Tempelbau wird die Traditionsvermittlung an die zweite Generation genannt ("for the needs of the future/younger generation"). Auch der Initiator des Bauprojekts und ehemalige Präsident des Tempelvereins Trimbach nannte diesen Grund als wesentlichen Motor für sein Engagement für die Errichtung des ersten Hindu-Tempels in tamilischer Architektur in der Schweiz. ${ }^{398}$

In der oben zitierten Homepage-Passage wird betont, dass der Wunsch nach einem eigens gebauten Tempel ein kollektiver, von allen Hindus getragener Wunsch sei. Weiter enthält sie eine Handlungsaufforderung an «bekennende Hindus», zur Entstehung des Tempels beizutragen: "All Asthikas are hereby requested to take an active role in the construction of the proposed new temple by bringing in their resources from all available quarters" ${ }^{399}$

397 www.vinayagar.com/information_links/Donations.ht; 23.06.2009

398 Auch Rukmani nennt Traditionsvermittlung an die zweite Generation als eine wichtige Motivation für den Bau von Hindu-Tempeln im Residenzland: "[...] when children being born to these immigrant families, their anxiety to preserve some Indian values prompted them to start seriously thinking of building temples where they thought their children could learn the values of the Hindu way of living" (Rukmani 2005, 56).

399 www.vinayagar.com/information_links/Donations.ht; 23.06.2010. 
Neben dem erfolgreich abgeschlossenen Tempelbauprojekt in Trimbach gab es ein weiteres konkret geplantes Projekt, welches jedoch 2007 scheiterte. Die Reformgruppe Aum Sakthi plante in Belp (Kanton Bern) einen Tempel, der auch als soziokulturelles Zentrum gedacht war. Er war vom Architekten Dinesh Zala als Kubusbau mit Kuppel und ohne Tempelturm angedacht worden (vgl. Kessler 2013). Die Initiatoren des Tempelbaus wollten dabei auf die spezifische Tradition zurückgreifen, in welcher der Tempelverein steht (vgl. Kap. IV 4.4): Der Haupttempel dieser Guru-Bewegung, der Adi Parasakthi Tempel im südindischen Mēlmaruvattūr, weicht von den traditionellen südindischen Tempelbauten ab und hat eine Kuppel. Seinem architektonischen Vorbild folgen inzwischen weltweit errichtete Satellitentempel. Der Architekt gab gemäss der Schweizer Zeitung Der Bund an, dass das Gebäude von aussen nicht als Hindu-Tempel erkennbar sein würde: «〈Von aussen sieht man nicht, dass dies ein Tempel ist〉, sagt Zala. Schliesslich habe auch das Bundeshaus eine Kuppel» ${ }^{400}$ Die Kuppel hätte jedoch das Gebäude, ähnlich einem kōpuram, weithin als besonderen Bau sichtbar gemacht. Eine Identifizierung des Gebäudes als sakrales Bauwerk wäre naheliegend gewesen. Das Bauprojekt scheiterte jedoch, da das angedachte Grundstück kurzfristig doch von der Gemeinde Belp selbst erworben worden war.

Der im Laufe des Untersuchungszeitraums erfolgreich abgeschlossene Tempelbau in Trimbach umfasst neben dem vimānam auch einen 14,17 Meter hohen kōpuram, welcher der erste dreidimensionale hinduistische Torturm in der Schweiz ist. Die Höhe des Torturms wurde gemäss den religiösen Vorgaben durch die Bauleitungsfirma Silpakala Nilayam aus Chennai (Tamil Nadu ${ }^{401}$ bestimmt. Diese Vorgabe widersprach jedoch den rechtlichen Vorschriften, die 13,50 Meter als Höchstgrenze in einer Gewerbezone des Kantons vorgeben. Nach einem Aushandlungsprozess wurde die Höhe des Turmes jedoch im Rahmen der Bewilligung des Gestaltungsplanes des Tempels am 04.10.2005 durch die Regierung des Kantons Solothurn gestattet.

Zusammenfassend kann gesagt werden, dass der Umgang mit dem Fehlen von Tempelbauten im Residenzland und im Speziellen eines Eingangstempelturms als Symbol des Sakralgebäudes nach aussen hin zu verschiedenen Handlungsstrategien geführt hat. Zum einen kam es zur diasporischen

400 Manuela Ryter, «Tempel wird verhindert». Der Landkauf der Gemeinde Belp wirft Fragen auf - Tamilen fühlen sich schikaniert, in: Der Bund, 08.09.2007, S.31.

401 Dieses Familienunternehmen, das bereits seit Generationen Tempelbauten betreut, hat zahlreiche tamilische Tempel innerhalb der tamilischen Diaspora gebaut, so auch den Tempel in Hamm/Deutschland. 
«Erfindung» von Kulissen, welche die Türme imitieren, und zum anderen wurden Tempelbauprojekte nach einer Phase der Etablierung der Migrantengruppe im Residenzland initiiert.

Verschiedene Gemeinsamkeiten der sich in der Schweiz befindlichen kōpuram-Kulissen lassen sich ausmachen: Diese sind keine Imitate von südindischen Tortürmen, welche sie möglichst authentisch nachahmen wollen, sondern lediglich zweidimensionale Kulissen, welche bildnerisch durch die charakteristische Form, die Einteilung in verschiedene Ebenen und die Darstellung eines Tonnendaches einen kōpuram symbolisch repräsentieren. ${ }^{402}$ Die vorgestellten kōpuram-Kulissen sind den jeweiligen Hauptgottheiten der Tempel gewidmet und verweisen durch bunte Abbildungen oder Szenen aus der Mythologie der Hauptgottheit auf diese. Die kōpuram-Kulisse dient in erster Linie dazu, das Gebäude in der öffentlichen Sphäre als HinduTempel zu markieren und eine Illusion herzustellen. Durch den Verweis auf ein traditionelles Element südindischer hinduistischer Sakralarchitektur wird angezeigt, dass sich hinter den Mauern ein traditioneller Tempel befindet. Die kōpuram-Kulisse verweist aber gleichzeitig auch auf die Diaspora-Situation, in welcher Hindu-Praxis nicht in gleichem Umfang wie in Südasien gelebt werden kann. Der immanent religiöse Zweck der Tortürme geht durch die Zweidimensionalität verloren und wird auf seine Wirkung als sichtbares Element in der öffentlichen Sphäre reduziert.

Die Planungen zum Bau eines dreidimensionalen koppurams in der Schweiz zeigen die Wichtigkeit des Torturms als symbolischer Ausdruck und auch die Auswirkungen der Inkorporationsbedingungen auf.

\subsection{Tempel-Webpräsenzen: Präsentationen in virtuellen öffentlichen Räumen}

Eine Form von Tempelöffentlichkeit tamilischer Diaspora-Tempel ist ihre Präsentation im virtuellen Raum. Durch Auflistungen der Adressen der Tempel im Internet und den eigenen Webpräsenzen wird die Existenz von Tempeln in der Schweiz einer globalen Öffentlichkeit bekannt gemacht. Die folgenden Darstellungen und Analysen geben einen historischen Rückblick auf die Situation im August 2010 und sind nur als temporäre Momentauf-

402 An dieser Stelle sei auf Parallelen zum Minarett der türkischen Moschee in Wangen/ Schweiz verwiesen: Der Moscheeverein hat dies in seinem Baugesuch ausdrücklich nur als «symbolisches» Minarett bezeichnet. Er versteht es nicht als «richtiges Minarett», das dem Zweck des Rufes des Muezzins dient (vgl. Baumann 2010b, 33). 
nahmen zu verstehen, da sich die Präsentationsformen im virtuellen Raum fortwährend ändern.

Das Internet entkoppelt sozialen Raum von einem konkreten geographischen Ort und ermöglicht - im Vergleich mit anderen Medien - in besonderem Masse soziale Interaktion auch über weite Distanzen hinweg. ${ }^{403}$ Digitale Vernetzung bekommt dadurch in Diaspora-Gemeinschaften einen besonderen Stellenwert, was auch das religiöse Feld miteinschliesst. ${ }^{404}$ Auf der einen Seite wird religiöses Wissen durch das Medium Internet vom konkreten Ort entkoppelt, auf der anderen Seite bringt es Migrantinnen und Migranten religiöse Praktiken im Herkunftsland durch Videoübertragungen usw. nahe (vgl. Krüger 2004, 188).

Eine Systematisierung von Hindu-Tempeln in der Schweiz wird durch Übersichtslisten mit den Adressen von tamilischen Tempeln in der Schweiz erzielt, die auf Webpräsenzen von Akteuren der sri-lankisch tamilischen Diaspora, global agierenden Hindu-Gruppen oder Wissenschaftlerinnen und Wissenschaftlern zu finden sind. Zum einen finden sich dem virtuellen Raum der tamilischen Diaspora zuzuordnende Internetpräsenzen, deren Initierende (neben dem Bereitstellen weiterer Informationen) Listen mit weltweit existierenden tamilischen Hindu-Tempeln präsentieren. ${ }^{405}$ Ferner enthalten religiös ausgerichtete Internetpräsenzen im Kontext eines «globalen Hinduismus» Listen mit Hindu-Tempeln in der Schweiz. Als Beispiel kann die seit 1996 existierende englischsprachige Webpräsenz shaivam.org - an Abode for Hindu God Shiva on the Internet angeführt werden, welche dem Gott Civan und seiner Verehrung gewidmet ist. ${ }^{406}$ Die Ini-

403 Das Medium Internet spielt besonders in der öffentlichen Präsentation politischer Positionen innerhalb der tamilischen Diaspora eine grosse Rolle (zur tamilischen Webpräsenz tamilnet.com vgl. Whitaker 2004, 2006).

404 Für Analysen zum Themenfeld «Hinduismus und Internet» vgl. unter anderem Helland 2010; Scheifinger 2010.

405 Die Tamil Electronic Library, welche ein Sammelsurium aus Internetadressen für tamilischsprachige Personen - in Südasien wie auch der Diaspora - zusammengestellt hat, führte 2010 unter der Rubrik List of Hindu Temples in Europe eine damals nicht mehr aktuelle Liste mit siebzehn Tempeln in der Schweiz auf, welche die Kontaktdaten dieser Institutionen enthielt. Eingeleitet wird die Aufzählung mit einer Aufforderung zur Aktualisierung der Liste: "Here we give a list of Hindu Temples in continental Europe that we are aware of. Please feel free to send in your corrections and additions to the list" (vgl. http://tamilelibrary.org/teli/temple6.html; 01.09.2020).

406 "Shaivam.org is dedicated to worship of Lord Shiva - the God as lovefully addressed by Hindu Shaivities” (www.shaivam.org/about-shaivam; 01.09.2020). Auf diese Internetpräsenz wurde wiederum auch auf Internetseiten von Hindu-Tempeln in der Schweiz hingewiesen. Der Civankōvil in Glattbrugg hatte auf seiner Webpräsenz ein Icon, das zu shaivam.org führt (vgl. www.sivankovil.ch; 13.09.2010). 
tiatoren der Webpräsenz haben sich zum Ziel gesetzt, Caivam und seine Praktiken auch virtuell zu verbreiten. Unter der Rubrik Temples outside India waren 2010 dreizehn Tempel in der Schweiz aufgeführt. ${ }^{407}$ Es findet sich im Internet des Weiteren auch eine Webpräsenz, welche ausschliesslich Murukan-Tempeln in der ganzen Welt gewidmet ist. ${ }^{408}$

Aber nicht nur Akteure der tamilischen Diaspora oder global agierende Hindus haben Listen mit Tempeln in der Schweiz mit Kontaktdaten über das Internet öffentlich zugänglich gemacht: Auch Wissenschaftlerinnen und Wissenschaftler erstellen Überblicke über religiöse Landschaften mit Listen von religiösen Institutionen und Karten, welche die Topographie dieser Orte visuell veranschaulichen. Diese werden auch im virtuellen öffentlichen Raum publiziert: So können Interessierte auf einer vom Religionswissenschaftlichen Seminar der Universität Luzern betriebenen Seite, welche zum Ziel hat, über die wachsende Religionsvielfalt in der Schweiz zu informieren, eine aktuelle Liste mit Kontaktdaten von Tempeln in der Schweiz und eine Übersichtskarte mit tamilischen Hindu-Tempeln entnehmen. ${ }^{409}$

\section{Internetpräsenzen von Tempeln in der Schweiz}

Eine wichtige Form virtueller Tempelöffentlichkeit stellen die Internetpräsenzen der Tempel selbst dar; auch diese haben teilweise Listen mit anderen Hindu-Tempeln in der Schweiz veröffentlicht und verweisen somit aufeinander. Die Seiten dienen als virtuelle Präsentationen der jeweiligen physischen Tempel und sind virtuell zu jeder Zeit und überall abrufbar. Madhavi Mallapragada spricht in diesem Kontext von desktop deity cultures:

(...) a growing trend among prominent temple institutions in India, the US and elsewhere, strategically to deploy the Web for maintaining, extending and, arguably, transforming the presence and relevance of temple cultures in the lives of an increasing mobile, networked, transnational Hindu base. (Mallapragada 2010, $111 \mathrm{f}$.)

407 Hier wurde in Klammern auch eine Überschrift auf Deutsch gewählt: «Hindu kirche [sic!] im der Schweiz» (https://shaivam.org/temples-of-lord-shiva/hindu-temples-of-switzerland; 01.09.2020).

408 Auf der Webpräsenz mit der Überschrift "Lord Muruga ... his most sacred temples, legends and literature” wurden unter anderem fünf Tempel in der Schweiz aufgelistet; vgl. http://s.gokul.tripod.com/arupadaiveedu/html/murugantemplesabroad.html; 01.09.2020

409 Diese Liste war 2020 unter https://www.unilu.ch/fakultaeten/ksf/institute/zentrumreligionsforschung/religionen-schweiz/religionen/hinduismus zu finden.

Eine Liste mit Adressen von Hindu-Tempeln in der Schweiz findet sich auch in Baumann et al. 2003, 448-450 (Stand Ende 2002) und in Eulberg 2008. 
Eine Vielzahl der Tempel in der Schweiz verfügt oder verfügte über eine Webpräsenz, mit welcher sie sich mit ihren Aktivitäten im virtuellen öffentlichen Raum präsentieren. Oliver Krüger unterscheidet drei textuelle Dimensionen einer Webseite. Auf der Ebene der Dimension Pragmatik unterscheidet er zumindest vier zentrale Funktionen einer Internetpräsenz. Die erste von ihm genannte Funktion, Präsentation, trifft auf alle der vorgestellten Tempel-Webpräsenzen zu. Neben der Funktion der Präsentation verfügen einige auch über interaktive Kommunikationsmöglichkeiten (zweite Funktion), indem sie Gästebücher auf ihren Seiten eingerichtet haben. Die dritte und vierte Funktion stellen nach Krüger religiösen Dienstleistungen als neue Entwicklung und kommerziellen Angebote dar (vgl. Krüger 2004, 185). Es fanden sich 2010 auf Internetpräsenzen von Tempeln in der Schweiz zwar keine so genannten cyber-rituals (vgl. Mallapragada 2010); die neuste Entwicklung war jedoch die Einrichtung einer Webpage auf der Internetpräsenz des Śrī Viṣnu Turkkai Ammañ Tempels, auf welcher religiöse Dienstleistungen bestellt werden konnten. ${ }^{410}$ Diese kann als kommerzielle Puja-Webpage bezeichnet werden (vgl. Krüger 2004, 187). Als der Śrī Viṣnu Turkkai Ammañ Tempel Anfang 2010 von Adliswil nach Dürnten umzog, änderte er im Oktober 2010 auch seine Präsentation im Internet und zeigte dadurch einen Wechsel seines Selbstverständnisses an: Aus www.srithurkkaswiss.ch wurde www.srivishnuthurkka.com; der Verweis auf die Existenz des Tempels in der Schweiz wurde durch den vollen Namen der Hauptgottheit ersetzt. Die Wahl des neuen Domainnamens kann auf eine strategische Positionierung im transnationalen Feld tamilischer Hindu-Traditionen als dem Śrī Viṣnu Turkkai Tempel verweisen. Durch die Ergänzung der Webpräsenz durch ein kommerzielles religiöses Dienstleistungsangebot, welches von Akteuren auf jedem beliebigen Kontinent in Anspruch genommen werden kann, ist eine Professionalisierung der Tempelstruktur ablesbar. Dieses Angebot ist angelehnt an neuere Entwicklungen von Tempeln in Indien und auch den USA, welche ihr Dienstleistungsangebot durch die Nutzung des Internets modernisieren.

Dass es sich bei der Präsentation der Tempel im virtuellen öffentlichen Raum um ein dynamisches und schnell veränderndes Feld handelt, zeigt sich daran, dass die Zahl der Webpräsenzen schwankt; neuste Entwicklungen stellen die Präsentation auf social media-Plattformen dar. Einige Webpräsenzen wurden im Laufe der Zeit abgeschaltet und andere kamen neu hinzu. Jene Tempel, die eine Webpräsenz neu einrichten, tun dies im Bewusstsein einer Professionalisierung der Strukturen ihres Tempelvereins. Es gibt auch Tempelvereine, welche ihren Domainnamen und auch den Inhalt ihrer Web-

410 www.srivishnuthurkka.com/poojaireservation.html; 09.10.2010. 
präsenz im Laufe der Jahre geändert haben: Die eingesehenen Internetpräsenzen werden in unterschiedlichen Abständen aktualisiert; einige ändern sich nur einmal im Jahr, indem der aktuelle Kalender mit den Festtagen aufgeschaltet wird, andere Tempelvereine wiederum aktualisieren ihre Internetpräsenzen in sehr regelmässigen und häufigen Abständen.

Im Schweizer Kontext sind die Webpräsenzen der Hindu-Tempel verschieden gestaltet und präsentieren ihre Räumlichkeiten und die hier durchgeführten Rituale in unterschiedlicher Weise.

Visuelle - meist farbvielfältige - Darstellungen, gemalte Bilder der Gottheiten des Tempels oder von Gurus und digitale Fotos spielen auf den Webpräsenzen der Tempelvereine eine besondere Rolle: Bilder göttlicher Figuren, Fotografien von den im Tempel vollzogenen Ritualen (besonders der jährlichen Tempelfeste) sowie von besonderen Ereignissen in der Geschichte des Tempels ${ }^{411}$ werden so der virtuellen Öffentlichkeit präsentiert. Damit wird den Internetnutzenden eine spezifische Perspektive auf vergangene und aktuelle Entwicklungen des Tempels geboten; Bilder werden in Internetpräsentationen zur Positionierung im virtuellen Raum strategisch eingesetzt, um die Institution Tempel prestigeträchtig einer breiten Öffentlichkeit vorzustellen.

Neben visuellen Aspekten setzen viele Tempelvereine auditive Effekte ein: Während beim Starten der Homepage des Tempels der Aum SakthiBewegung das mit verschiedenen visuellen Effekten aufwändig gestaltete Intro erscheint, ist beispielsweise fortwährend das für diese Gruppe wichtigste Mantra - Ōm cakti - zu hören. Die ehemalige Webpräsenz des Śrī Viṣnu Turkkai Ammañ Tempels enthielt als auditives Element das Kāyatrī Mantra.

Die Webpräsenzen der tamilischen Hindu-Tempel in der Schweiz sind zwar im Internet öffentlich zugänglich; sie haben jedoch unterschiedliche Adressaten. Dies kann aus der Sprache und Schrift, in welcher sich die Tempelvereine im Internet präsentieren, geschlossen werden. Es kann unterschieden werden zwischen Webpages, mit denen ausschliesslich eine tamilische Öffentlichkeit angesprochen werden soll und die ausser wenigen Elementen - wie der Adresse des Tempels - nur in tamilischer Sprache und Schrift gestaltet sind, und solchen, die durch die Verwendung deutscher und/oder englischer Sprache auch der nicht-tamilischen Bevölkerung bzw. Tamilinnen und Tamilen der zweiten und dritten Generation in der Diaspora zugänglich sein sollen.

411 Ein solch zentrales Ereignis stellte beispielsweise die Grundsteinlegung des traditionellen Tempelbaus in Trimbach dar, die durch die Präsentation auf der Webseite der virtuellen Öffentlichkeit bekannt gegeben wurde (vgl. www.hindu-tempel.ch/index.php?option=com_ morfeoshow\&task=view \&gallery=1\&Itemid=10; 01.09.2010). 
Im Folgenden werden beispielhaft Internetpräsenzen ausgewählter Tempel in der Schweiz im Hinblick auf ihre Gestaltung und ihr Zielpublikum näher vorgestellt: Die Webpräsenz (http://murugantemple-zh.ch) des Śrī Civacuppiramaniiyar Tempels in Adliswil war Anfang 2010 jene, welche am meisten auch auf nicht-tamilische Besucher zugeschnitten war: Auf der Homepage der im September 2004 eröffneten Domain ${ }^{412}$ wurde dem Besucher angeboten, die Sprache auszuwählen (Deutsch, Tamil, Englisch), in welcher er die Seite sehen will. Somit werden verschiedene Gruppierungen angesprochen: Schweizer Bürger und Personen der zweiten und dritten Generation innerhalb der tamilischen Diaspora in der Schweiz, die kaum oder kein Tamil lesen können (Deutsch), Mitglieder der transnationalen Diaspora, deren Kommunikationssprache Tamil ist, und Personen, die nicht im deutschsprachigen Raum beheimatet sind, wie nicht-tamilische indische Hindus oder Akteure der zweiten Generation der tamilischen Diaspora in anderen Diaspora-Ländern (Englisch). Diesen wurden unterschiedliche Informationen auf den sprachenspezifischen Seiten gegeben. Erklärungen zur Tempelentstehung, der Hauptgottheit Murukan und den Festen, die im Tempel gefeiert werden, fand man zum Beispiel lediglich auf der englischsprachigen Seite, während die tamilische Seite eine Kategorie enthielt, die zur Kumaran Bibliothek des Tempels führte. ${ }^{413}$ Zielpublikum dieser Einrichtung waren tamilsprachige Interessierte, welche hier Bücher zu religiösen Themen in tamilischer Sprache ausleihen konnten. Gemeinsam war allen drei Versionen der Webpräsenz die Angabe der Öffnungszeiten des Tempels, des Jahreskalenders, des Lageplans, einer Fotogalerie, der Kontaktadresse und weiterführender Links.

2020 hat sich das Webinterface der Seite gewandelt und ist primär auf ein tamilisches Publikum ausgerichtet.

Die sehr umfangreiche Internetpräsenz des Civankkōvil in Glattbrugg (www. sivankovil.ch), die in erster Linie ein tamilisches Publikum anspricht, präsentierte jedoch auch Informationen in deutscher Sprache. Auf der Homepage wird der Name des Tempels in tamilischen wie auch lateinischen Buchstaben genannt (Arulmigu Sivan Kovil - Saiva Thamil Sangam) und es findet sich jeweils eine Leiste mit Rubriken der Internetpräsenz in deutscher und in tamilischer Sprache. ${ }^{414}$ Deutschsprachige interne Webpages

412 Nach Angaben des Internetanbieters www.archive.org; 01.09.2010.

413 Vgl. www.murugantemple-zh.ch/kumaran/library.php; 01.04.2010.

414 Die Rubriken in deutscher Sprache, welche horizontal auf der Seite platziert sind, lauten: Home, Über uns, Kontact [sic], Öffnungszeiten, Foto Galerie, Agenda, Links (www.sivankovil.ch; 23.09.2010). Die tamilische Navigationsleiste ist vertikal am linken Rand der Homepage 
enthalten im Vergleich zu den tamilischen weniger Informationen. Die Rubrik Über uns beispielsweise enthielt im Gegensatz zu ihrer tamilischen Variante keinen Text. Die Fotogalerie, welche in der tamilischen wie auch deutschen Navigationsleiste aufgeführt war, zeigte professionell aufgenommene Bilder von Festen, die im Tempel gefeiert wurden (wie beispielsweise des Jahresfestes taipponka ${ }^{415}$ ), sowie Bilderstrecken, welche auf politische Anlässe im Tempel verweisen ${ }^{416}$ und auf rein politische Veranstaltungen ausserhalb des Tempels - wie den Great Heroes' Day der LTTE in Freiburg $2007 .{ }^{417}$

Die Internetpräsenz des Civankōvil in Glattbrugg war technisch aufwändiger als die meisten anderen Tempel-Seiten gestaltet. Eine Leiste am rechten Rand der Homepage verweist auf verschiedene interne wie externe Internetseiten: An erster Stelle wird ein vom Tempelverein betriebenes Web Radio wie auch ein Online-Fernsehkanal des Tempels genannt. Darunter folgt ein Kasten, welcher auf Sivan TV (www.sivantv.com) verweist und zu dem man durch einen Klick auf das Icon, welches einen tanzenden Civan zeigt, gelangt. Sivan TV ist ein vom Tempel betriebener Online-Kanal, welcher über einen Online-Stream tamilische Filme mit religiösen Themen zeigt. Es konnten darüber hinaus auch Video-Clips von im Tempel in Glattbrugg aufgenommene Ereignisse ${ }^{418}$ und tamilische Spielfilme ${ }^{419}$ angeschaut werden. Des Weiteren findet sich neben internen Verweisen - wie auf die Bildergalerie der Seite - ein Icon-Link zur Webpräsenz eines Astrologen in Tamil Nadu ${ }^{420}$ und der Verweis auf ein PDF-Dokument mit dem Jahreskalender des Tempels. ${ }^{421}$

Den meisten Webpräsenzen ist es gemein, dass Hindu-Kalender mit den wichtigsten im Tempel gefeierten Festen zur Verfügung gestellt werden. Damit bietet eine Internetpräsenz den Devotees die Möglichkeit, DetailInformationen zu den Jahresfesten (wie genaues Datum und Uhrzeit des Beginns des Festes) auch im virtuellen Tempel zu erhalten, ohne sich in den physischen Tempel begeben zu müssen.

aufgeführt und enthält zusätzlich Seiten, welche beispielsweise die Anfahrt zum Tempel (www. sivankovil.ch/?pn=path; 23.09.2010) und weitere Caivam-Tempel in der Schweiz (www.sivankovil.ch/?pn=siva_kovil; 23.09.2010) angeben.

415 Vgl. www.sivankovil.ch/Thai_pongal/index.html; 01.09.2010.

416 Vgl. www.sivankovil.ch/mavirar201109/slides/VSR_1341.html; 01.09.2010.

417 Vgl. www.sivankovil.ch/mavirarnal-2007/index.html; 01.09.2020.

$418 \mathrm{Vgl}$. http://sivantv.com/video; 13.09.2010.

419 Vgl. http://sivantv.com/movies; 13.09.2010.

$420 \mathrm{Vgl}$. www.joothidam.com/number.php; 13.09.2010.

421 Vgl. www.sivankovil.ch/sivankovilkalender2010.pdf; 13.09.2010. 
Internetpräsenzen von Tempeln geben auch Aufschluss über die Traditionslinie, in welche sich die Tempelverantwortlichen stellen. Die Seiten zeigen beispielsweise durch die angegebenen Linklisten an, mit welchen Hindu-Tempeln im Herkunfts- bzw. im religiösen Mutterland sich die Tempel in der Schweiz verbunden fühlen. Der Śrī Civacuppiramaṇiyar Tempel in Adliswil verwies unter Links ${ }^{422}$ beispielsweise ausschliesslich auf Murukan-Tempel. Die Schweizerische Internetpräsenz des Aum SakthiTempels war zentral auf die Gestalt ihres Gurus Bangaru Adigalar und seine von Indien ausgehende Aum Sakthi-Bewegung ausgerichtet.

Zusammenfassend lässt sich festhalten, dass das Internet ein wichtiges Medium darstellt, in welchem sich tamilische Hindu-Tempel in der Schweiz einem globalen Publikum öffentlich präsentieren. Durch Auflistungen der Tempel werden die Tempel in der Schweiz in eine Sakraltopographie eingebettet. Die Präsentation von Schweizer Hindu-Tempeln im Internet ist ein Schritt der Tempelvereine, diese öffentlich sichtbarer zu machen und sich in einer bestimmten Art und Weise - durch die visuelle Gestaltung der Seite wie die Auswahl der Bilder, die aufgeschalteten Texte und die gewählte Sprache der Webpräsenz - öffentlich zu positionieren. Da die kommunizierten Informationen, wie bei allen Internetpräsenzen, strategisch ausgewählt sind, kann durch eine spezifische Gestaltung der Tempel-Webpräsenz auf das Selbstverständnis der Tempelvereine geschlossen werden. ${ }^{423}$ Es sind Seiten zu finden, die ausschliesslich in der sri-lankisch tamilischen Diaspora verankert sind und dies in erster Linie durch die Verwendung tamilischer Schrift und Sprache kenntlich machen. Auch kann eine Webpräsenz Aufschluss über die religiöse Ausrichtung der Tempel oder eine politische Tendenz der Tempelverantwortlichen geben. Die Webpräsenzen können aber auch durch Erklärungen zu Festtagen und zur Entstehung des Tempels in englischer oder deutscher Sprache die Öffnung der Tempel zur nichttamilisch sprechenden Öffentlichkeit und zur Schweizer Mehrheitsbevölkerung anzeigen. Festzuhalten ist, dass es sich bei der Repräsentation der Tempel durch eigene Webpräsenzen um gezielte Formen der Öffentlichmachung dieser Institutionen handelt, welche Aufschluss über die offizielle Position des Tempelvereins geben.

422 http://www.murugantemple-zh.ch/german/gerindex.php; 27.09.2010.

423 Es ist jedoch darauf zu verweisen, dass die Gestaltung von Webpräsenzen auch mit der Web- und Medien-Kompetenz der Akteure zusammenhängt. Ist diese gering, dann ist auch das Handlungsvermögen zur Präsentation der gewünschten Inhalte im Internet eingeschränkt. 


\section{Performative Aspekte von Tempelöffentlich- keiten}

Neben der Präsentation von Sakralbauten stellen auch performative Ausdrucksformen Tempelöffentlichkeit her. Die Tempel als konkrete Orte bieten Raum für verschiedenste rituelle Praktiken und öffentliche Performanzen. Einmal sind es die Tempel-basierten Feste, allen voran das jährliche Tempelfest (tam. têrttiruvila - «heiliges Fest des Wagens»), während denen Offentlichkeit performativ hergestellt wird. Aber auch andere jährlich begangene Feste, wie das der Göttin Turkkai gewidmete Fest Navarāttiri (skr. Navarätri), beinhalten in öffentlichen Sphären des Residenzlandes vollzogene Performanzen. Darüber hinaus fanden während des Untersuchungszeitraums öffentliche Ritualkomplexe statt, die sich auf die aktuellen kriegerischen Ereignisse in Sri Lanka bezogen, was in Abschnitt 3.3 gezeigt werden wird.

Performanz wird im Folgenden als kommunikatives Verhalten verstanden, welches in erster Linie durch verkörperte Praktiken hergestellt wird. Während der Performanz sind sowohl die Agierenden wie auch die Zuschauenden Teilnehmende des gerahmten Ereignisses. Die Zuschauenden sind aktiv Wahrnehmende des Geschehens. Die im Folgenden vorgestellten performativen Aspekte von Tempelöffentlichkeiten sind Ausdruck der performative agency (Krüger/Nijhawan/Stavrianopoulou 2005, 4) der Akteure und zeigen die Gestaltungsmacht der tamilischen Hindus auf.

Der Abschnitt beginnt mit während des jährlichen Tempelfestes als Teil von Tempelöffentlichkeit präsentierten Performanzen. Besondere Beachtung finden hier öffentliche Körperpraktiken während der Prozession, die für den «tamilischen» Gott Murukan ausgeführt werden, wie beispielsweise das Tragen des kāvati-Bogens und Speer-Piercing (V 3.1). Knut Jacobsen konstatiert, dass in südasiatischen Diasporen und auch der transnationalen tamilischen Diaspora der performativen Ausdrucksform der Prozession ein immer grösserer Stellenwert zukommt (vgl. Jacobsen 2008b). Daran anschliessend wird sakrales Theater im Tempelraum als Teil des Jahresfestes unter performativen Gesichtspunkten analysiert (V 3.2). Der Abschnitt schliesst mit der Darstellung politisch-religiöser Performanzen wie Gebete in Tempeln und Prozessionen für Frieden und die Verbesserung der Situation der tamilischen Bevölkerung in Sri Lanka (V 3.3). 


\subsection{Tanzen mit dem kāvați-Bogen: Das jährliche Tempelfest als Kristallisationspunkt öffentlicher Präsentation}

Die meisten Schweizer Tempel feiern im Sommer ihr in der Regel zehntägiges jährliches Tempelfest, dessen integraler Bestandteil die Prozession mit den Hauptgottheiten des Tempels ist. Die Tempelfeste stellen zeitlich begrenzte Formate dar, in denen sich tamilische Hindu-Traditionen in unterschiedlichen Formen im öffentlichen Raum präsentieren. Als Gruppenerlebnis sind sie ein verbindendes Element für tamilische Hindus als Minderheitengruppe in der Schweiz. ${ }^{424}$ Die Tempelfeste sind - besonders an den Tagen der Prozession und des Wasserbades der Gottheiten am darauf folgenden Tag - eine der grössten Zusammenkünfte von tamilischen Hindus in der Schweizer Öffentlichkeit.

In der Diaspora-Situation kommt es in der Durchführung des Tempeljahresfestes zu Modifikationen: Luchesi (2008b) weist darauf hin, dass der Zeitpunkt des Festes nicht wie in Sri Lanka nach astrologischen Berechnungen durchgeführt werden kann. Einigen Tempelvereinen in der Schweiz war es aufgrund der Umgebungsbedingungen und der inkorporativen Regularien nicht möglich, die Prozession wie in Südasien um den Tempel herum im Freien durchzuführen. Als diasporische Modifikation haben diese Tempelvereine das Bewegen der Götter im Innenraum des Tempels durchgeführt. Eine Prozession wurde ebenfalls im Inneren des Tempels imitiert. Dies stellt eine Anpassung an die Inkorporationsbedingen dar, um trotz der veränderten Umgebung dennoch das Tempelfest zu feiern. Eine weitere Anpassung stellt die Grösse des Prozessionswagens, têr, dar, welche weitaus kleiner ist als die der meisten Wagen in Sri Lanka. Als Beispiel für eine modifizierte Prozession, die im Inneren des Temples stattfand, sei jene des Turkkai Amman Tempels in Luzern am 11.08.2008 genannt. Der tēr wurde im Inneren des Tempelraums bewegt, wo auch die Prozession stattfand. Die räumliche Situation des angemieteten Tempelraums machte eine Umkreisung des Tempelgebäudes nicht möglich.

Die folgenden Abschnitte beziehen sich auf Prozessionen und ihre performativen Praktiken, die um den Tempel im Freien stattfanden und von den Akteuren damit als «authentischer» wahrgenommen wurden. Die Tempelfeste müssen von den Verantwortlichen aufwändig vorbereitet werden. Das Fest dauert zehn Tage und folgt einem vorgegebenen Ablauf, der

424 Damit setzen sie sich von der Ausrichtung des Festes in Sri Lanka ab, welche nach Schalk zentriert auf eine bestimmte Kaste ist: "In Yālppāṇam, a tiruvilā is normally caste based and run by caste sections, but in Stockholm the tiruvila $\bar{a}$ is caste transcending and based on the help of volunteers" (Schalk 2004a, 179). 


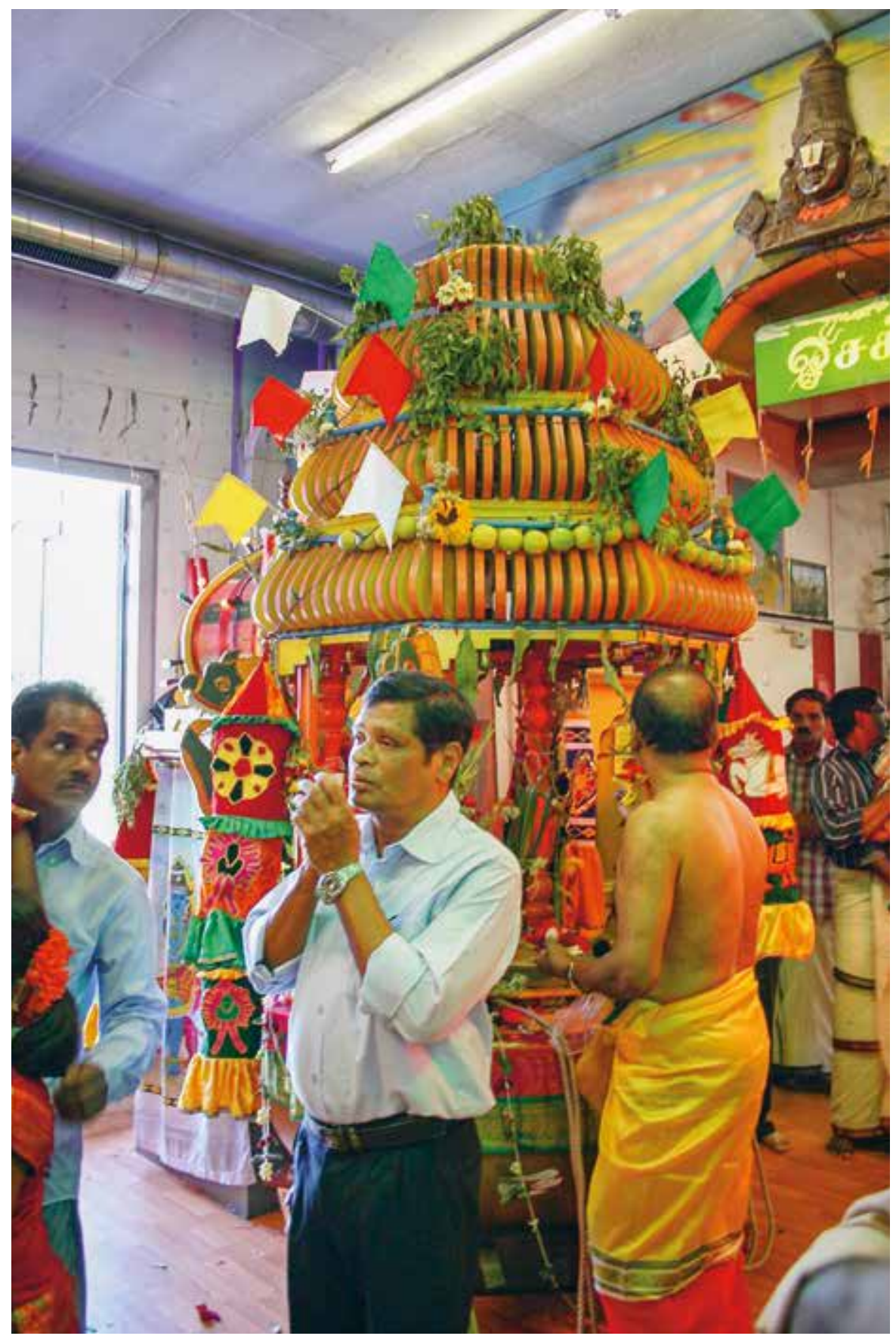

Abb. V 14: Prozessionswagen des Turkkai Ammañ Tempels Luzern im Inneren des Tempelraums (11.08.2008). 
mit dem Hissen der Tempelfahne beginnt. Die folgenden Ausführungen beziehen sich in erster Linie auf die Performanzen an den beiden letzten Tagen des Festes und meine Besuche im Adliswiler Śrī Viṣnnu Turkkai Amman im Jahr 2007 und im Śrī Civacuppiramaṇiyar Tempel Adliswil im Jahr 2008, 2009 und 2010. ${ }^{425}$

Am 15. und 16. August 2009 kamen im Zürcher Vorort Adliswil mehrere Hundert Menschen zusammen, um die beiden letzten Tage des jährlichen Tempelfestes mitzuerleben und zu gestalten. Dieses Fest ist eines der grössten und am häufigsten von der Schweizer Presse rezipierten Feste tamilischer Hindus und verweist auf unterschiedlichste Aspekte ihrer religiösen Praxis und der Etablierung tamilischer Hindu-Traditionen in der Schweiz. Viele südasiatisch gekleidete Fahrgäste sassen an diesen Tagen in der Sihltalbahn, die vom Zürcher Hauptbahnhof kommend in Richtung Adliswil fährt: Frauen in Saris und Punjabis in unterschiedlichen Farben und Männer, welche vereinzelt dhotis - die traditionelle männliche Bekleidung in Südasien - um die Hüften tragen. Von der Haltestelle aus überqueren die Menschen die Sihl, den Fluss, in welchen die Hauptgottheit des Tempels Cuppiramaniyar, der Sohn Civans - am Ende des Festes getaucht werden wird. Während der Tage des Tempelfestes ist über dem Eingang des angemieteten Tempelgebäudes ein Aufsatz angebracht, welcher einen Tempelturm mit bunten hinduistischen Figuren darstellt. Dieser stilisierte kōpuram ragt weit über das Dach des Gebäudes (vgl. Kap. V 2.2). Stände mit asiatischen Lebensmitteln und zum Verkauf angebotenen indischen Filmen sind aufgebaut. Mitglieder des Tempelvereins verkaufen religiöse Bücher in tamilischer Sprache. Über einen Lautsprecher ertönt tamilische Musik, es riecht nach südasiatischem Essen. Im Inneren des Tempels, welcher mit Girlanden festlich geschmückt ist, findet eine pūcai statt: Menschen kommen und gehen. «Es ist wie in Sri Lanka», sagt eine Besucherin. Ein Student aus dem indischen Bundesstaat Andhra Pradesh erzählt, dass dieser Anlass für ihn wie eine Reise in seine Heimat Indien sei. «Ich bin nicht religiös», bemerkt er. Mitglieder des Tempelvereins machen durch Rufe darauf aufmerksam, dass sie für zehn Schweizer Franken «Tickets» verkaufen, auf welche die Gläubigen ihre Bitten und Wünsche an die Gottheiten schreiben können.

Einmal im Jahr wird eine heimatliche Atmosphäre nicht nur in der selbstgestalteten privaten Sphäre multi-sensorial erfahrbar, sondern auch in der öffentlichen Sphäre um den Bereich der Tempelgebäude. Unterschied-

425 Die Performanzen, die am sechsten Tag im Rahmen des so genannten Mangofestes im Śrī Civacuppiramaniyar Tempel durchgeführt wurden, werden ausführlich in Kap. V 3.2 dargestellt. 
liche performative Aspekte machen das Tempelfest zu einem Kristallisationspunkt öffentlicher Präsentation von tamilischen Hindu-Traditionen in der Schweiz. Diasporische Tamilness wird öffentlich durch folgende Aspekte hergestellt: den Einsatz materieller Kultur, die dem tamilischen Spektrum zugeordnet wird (A), die Multi-Sensorialität des Ereignisses (B) und die Auswahl zentraler Akteure als Repräsentanten der Vernetzungen innerhalb der transnationalen tamilischen Diaspora (C).

(A) Der performative Einsatz von materieller Kultur zeigt tamilische Praxis in der Schweizer Offentlichkeit. Das Tragen festlicher traditioneller Kleidung und von Schmuck dient als visuelle Kennzeichnung, welche die Besuchenden von der Mehrheitsbevölkerung unterscheidet und von dieser wahrgenommen werden. ${ }^{426}$ Die Performanz von diasporischer Tamilness geschieht im Wesentlichen durch materielle Elemente - Imitate betonen dabei die Diaspora-Situation. Jasmin-Girlanden aus Plastik beispielsweise, die ins Haar gesteckt werden, da «echte» Jasmin-Blumen nur schwer in der Schweiz erhältlich sind, erinnern an Schmuckpraktiken in Südasien.

Die meisten Zeitungsartikel, die über die Tempelfeste berichten, enthalten auch einen Kommentar über die Bekleidung der tamilischen Besuchenden. Die Farbenvielfalt der traditionellen Kleidung vieler Tamilinnen wird dabei oftmals als ungewohnt «farbenfroh» und «exotisch» beschrieben. Auch im Artikel mit dem aussagekräftigen Titel Exotischer Höhepunkt des Neuen Bülacher Tagblatts zum Tempelfest in Glattbrugg im Jahr 2007 ist folgende Passage zu lesen: «Tamilische Schönheiten in farbenfrohen Saris mit prächtigem Schmuck, beseelte Priester, bunte Altare, auf denen Opfergaben wie Bananen, Orangen oder Kokosnüsse liegen, Blumenblätter und asiatische Musik versetzen einen jäh Tausende von Kilometern nach Osten». ${ }^{427}$

(B) Zentrale performative Elemente des Tempelfestes sind die verkörperten Hindu-Praktiken während der Prozession an den letzten Tagen des Festes. Durch die Multi-Sensorialität der ästhetischen Inszenierung der Prozession werden tamilische Traditionen auf verschiedenen Ebenen auch in der nationalstaatlichen öffentlichen Sphäre der Schweiz sichtbar.

Die Visualität der Performanz spielt eine grosse Rolle durch das Dekorieren des Tempelgebäudes von aussen und das Zeigen der Gottheiten in der Öffentlichkeit. Darüber hinaus wird das multisensorische Erlebnis durch das Kochen und Verzehren von tamilischen Gerichten und die süd-

426 Bekleidungspraktiken als Aspekte materieller Kultur, welche die Akteure an ihrem Körper tragen, können unter verschiedenen Gesichtspunkten analysiert werden (vgl. Küchler/Miller 2005). Auf Aspekte des clothings tamilischer Hindus in der Schweiz kann an dieser Stelle nicht weiter eingegangen werden.

427 Rita Stocker, Exotischer Höhepunkt, in: Neues Bülacher Tagblatt, 25.06.2007. 
asiatische Essenspraktik mit der rechten Hand, Gerüche von brennenden Kampfertöpfen und Räucherstäbchen und die spezielle Musik zu diesem Anlass komplettiert.

(C) Die Zusammensetzung der religiösen Musiker wie auch der Priester, die aus unterschiedlichen Ländern angereist sind, spiegelt die transnationalen Vernetzungen der Diaspora wider. Ein Informant berichtet während des Tempelfestes am 12.08.2009 im Śrī Civacuppiramaṇiyar Tempel in Adliswil ${ }^{428}$ :

Die Musiker sind extra für das Fest gekommen. Sie kommen eigentlich von überall her. Ein paar sind von Kanada/einer ist von Zürich/manchmal kommen sie von Indien, europäischen Ländern. Aber die richtigen Guten muss man von Indien holen/die wohnen auch im Tempel.

Durch die Postulierung einer besonderen Professionalität indischer Musiker wird die Wichtigkeit Indiens im religiösen Kontext für tamilische Hindu-Akteure deutlich.

Der Körper steht im Mittelpunkt der religiösen Selbstinszenierung. ${ }^{429}$ Dabei kommt den jährlichen Prozessionen als rituellen Kommunikationswegen nach innen und aussen eine besondere Bedeutung zu. Einen besonderen Teil der Performanzen während des Tempelfestes stellen Körperpraktiken dar, welche die Akteure spezifisch zu diesem Anlass in der öffentlichen Sphäre durchführen. Geaves weist in seiner Studie zu Caivam in der Diaspora (2007) darauf hin, dass in den verkörperten Ritualen der Körper Austragungsstätte verschiedenster Narrative wird: "The body itself becomes a site of contested narratives where the sociological, the psychological, the political and the religious meet" (Geaves 2007, 194). Erinnerungen, die durch die performenden Körper hervorgerufen werden, spielen eine wichtige Bedeutung in der Popularität der performativen Praktiken in der Diaspora. Durch den Körper der Akteure werden in den Praktiken zwei räumlich-symbolische Kategorien, die Heimat mit der Diaspora, verbunden.

Zentrum der Prozession ist das Heraustragen der Gottheiten aus dem Inneren des Tempels, der Geschlossenheit des Raumes nach aussen, in die öffentliche Sphäre. Das Zielpublikum der Prozessionen ist die breite Öffentlichkeit: Es umfasst nicht nur die Hindu-Devotees, sondern auch alle Mit-

428 Die folgenden Interviewpassagen entstammen diesem Experteninterview. Es wurde mit einem Tempelmitglied des Śrī Civacuppiramaniyar Tempels während des Prozessionstages des Tempelfestes am 12.08.2009 im Büro des Tempels durchgeführt.

429 Besonders im religiösen Vollzug und den religiösen Biografien von tamilischen Frauen spielt die Körperlichkeit eine grosse Rolle: Die Feier der Menarche als zentrales weibliches Übergangsritual und das Fasten als eine wichtige Form hinduistischer Praxis von tamilischen Frauen sind hier u. a. zu nennen. 
glieder der Schweizer Nachbarschaft. Die gesamte Umgebung wird durch die Gegenwart der Götter und Göttinnen, die im Uhrzeigersinn um den Tempel getragen werden, geheiligt. Dies ist eine Möglichkeit, tarisanam (skr. darśana) der geweihten Tempelgötter einmal im Jahr auch ausserhalb des Tempels zu bekommen.

Die Prozessionen umfassen unterschiedliche Praktiken. An erster Stelle steht das Ziehen des Prozessionswagens, des tēr, welcher die Hauptgottheit des Tempels trägt, um das Tempelgebäude. Diese Fahrzeuge der Gottheiten können daher mobile Tempel genannt werden, die in der Schweizer Öffentlichkeit bewegt werden (vgl. Luchesi 2008a). Die meisten Körperpraktiken sind gendered practices und nur einem Geschlecht vorbehalten. Das Ziehen des têr übernehmen Männer, die sich als Respektserweisung vor den Gottheiten, die sie bewegen, besonders kleiden und den Weg barfuss zurücklegen.

Im Folgenden werden zentrale Körperpraktiken als öffentliche Performanzen vorgestellt, die von tamilischen Akteuren an den jährlichen Tempelfesten in der Schweiz durchgeführt werden. Diese wurden vor allem 2007 beim Tempelfest des Śrī Viṣnu Turkkai Amman Tempels in Adliswil und 2009 und 2010 beim Fest des Śrī Civacuppiramaniyar Tempels in Adliswil beobachtet. Die Abfolge der Prozessionsteilnehmenden folgt einem vorgegebenen Schema. Gemeinsam ist vielen dabei vollzogenen Körperpraktiken, dass sie Ausdruck von Gelübden (skr. vrata, tam. nertti) sind (vgl. Baumann 2003b).

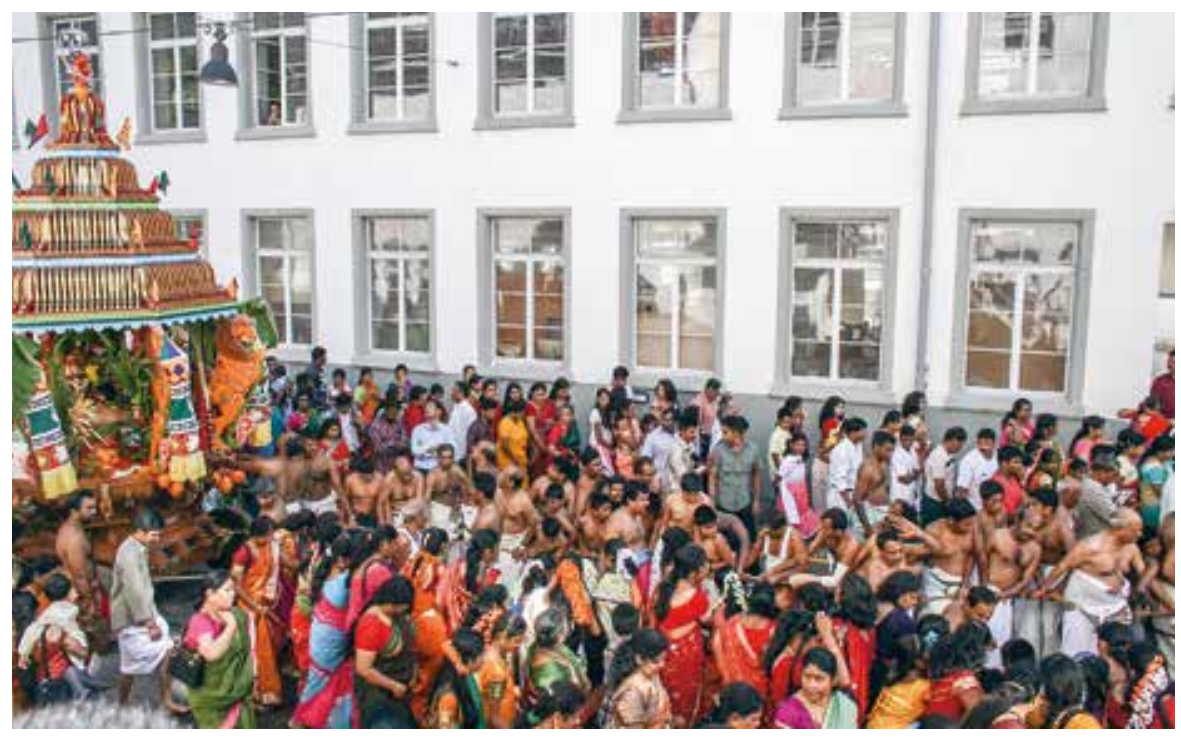

Abb. V 15: Männer, die während des Tempelfestes des Śrī Civacuppiramaṇiyar Tempels in Adliswil am 12.08.2009 den Prozessionswagen ziehen. 


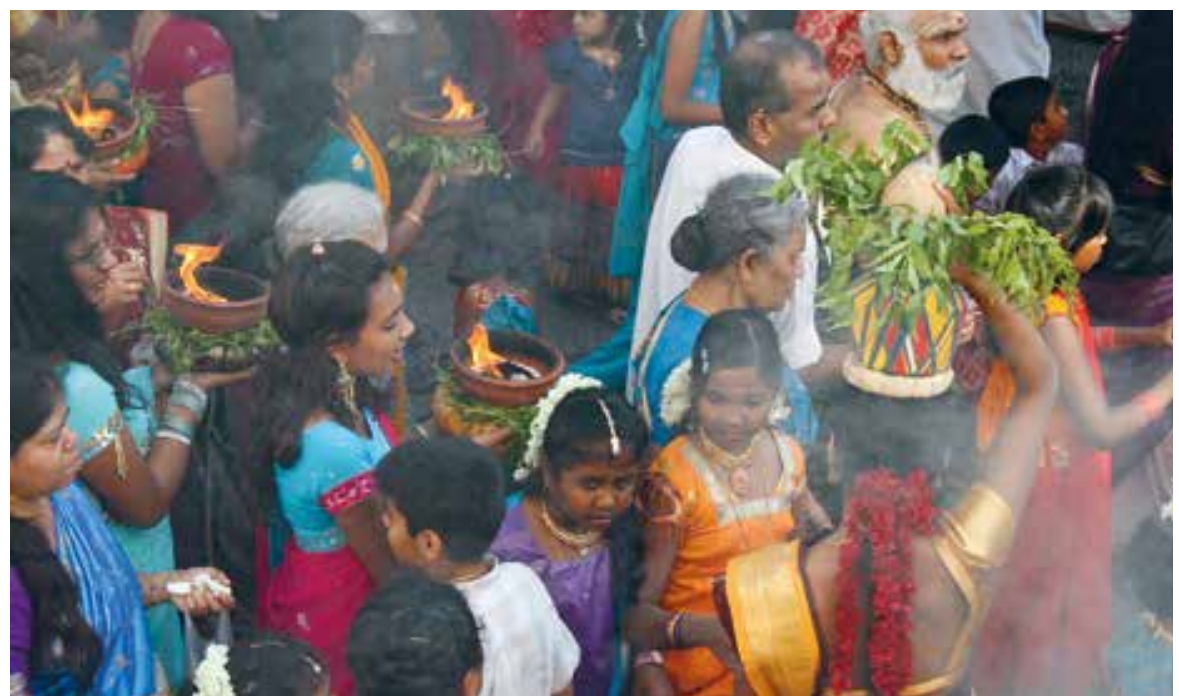

Abb. V 16: Frauen als Prozessionsteilnehmerinnen tragen einen Feuertopf; Tempelfest des Śrī Civacuppiramaṇiyar Tempels am 12.08.2009.

Vor dem Prozessionswagen laufen in der Regel Frauen, die einen Feuertopf mit Kampfer auf dem Kopf tragen. Informanten berichten, dass diese Position so gewählt wurde, damit die Gottheit die Frauen sieht. Ein Teilnehmer des Tempelfestes im Śrì Civacuppiramaṇiyar Tempel in Adliswil am 12.08.2009 berichtet wie folgt über die Motivation der Frauen, diese Handlungen durchzuführen:

Und die Frauen nehmen einen Topf mit dem Feuer/tragen sie auf dem Kopf etwa zwei Stunden lang. Es muss nicht der eigene Wunsch sein. Ich kenne eine Frau, ihr Sohn war krank, und ihr Wunsch war es, dass die Krankheit weggeht. Deshalb hat sie das gemacht.

Eine weitere Form der Gelübdeerfüllung, welche meist von Männern durchgeführt wird, stellt das Zurücklegen des Prozessionswegs auf dem Boden liegend und rollend dar. ${ }^{430}$ «Dann gibt es auch das Rollen/das macht man auch, weil man sich bedankt, weil ein Wunsch in Erfüllung gegangen ist.» Die Durchführenden haben einen weissen dhoti umgewickelt und sind mit «Siva-Asche», so ein Informant, eingerieben. Diese kühle und sei für die Blutzirkulation gut. ${ }^{431}$ Ein weiss gekleideter Mann begleitet die Rollenden

430 Während der Prozession des Tempelfestes des Śrī Civacuppiramaṇiyar Tempels am 12.08.2009 legte auch eine Frau den Prozessionsweg durch Umrollen zurück, was eine Besonderheit darstellte. Die Frau trug einen violetten Sari und rollte zwischen den Männern.

431 Information eines Besuchers des Tempelfestes am 16.08.2009. 
und geht neben ihnen mit einem Eimer mit dieser Asche her. Die Rollenden tragen eine Kokosnuss in der Hand.

Vielfach beziehen sich die extremen körperlichen Praktiken tamilischer Hindus während der Tempelfeste auf die Verehrung des Gottes Murukan und werden von den Akteuren als spezifisch tamilische Ausdrucksformen religiöser Performanz angesehen. Geaves weist daraufhin, dass Murukan schon immer besonders in der öffentlichen Sphäre verehrt wurde und das Territorium seiner Verehrung durch die Handlungen zu «heiligem» öffentlichem Raum wird.

Murugan was always a god of the public spaces worshipped in the fields, valleys, hills and major crossings of the highways. Such communal acts of worship in public spaces are able to partition territory as separate and sacred to the community. (Geaves 2007, 49)

Eine physische Extremform devotionaler Praxis und auffallender Ausdruck tamilisch-hinduistischer Religiosität während der Tempelfeste stellt das Tragen des kāvați-Gestells dar. ${ }^{432}$ Es finden sich verschiedene Formen des so genannten $k \bar{a} v a t ̦ i$, wie diese Form performativer Hindu-Praxis verkürzt genannt wird. Meist wird mit kāvați ein besonderer Trance-Tanz zu Ehren des Gottes Murukan bezeichnet, welcher von Männern bei bestimmten religiösen Festen ${ }^{433}$ vor einem Publikum durchgeführt wird (tam. kāvați ățtam: mit dem kāvați-Bogen tanzen ${ }^{434}$ ).

Da für die Zeit des Tanzes davon ausgegangen wird, dass die Tänzer Murugan verkörpern (vgl. David 2008, 96), wird der kāvați-Tanz besonders in dem Gott Murukan geweihten Tempeln durchgeführt, wie in der Schweiz zum Beispiel im Śrì Civacuppiramaniyar Tempel in Adliswil oder im Śrì Kalyāna Murukan Tempel in Bern. ${ }^{435}$

432 Das tamilische Verb für diese Praxis lautet kāvatiyețttal, was so viel bedeutet wie «einen Mast tragen».

433 Der kāvați-Tanz wurde häufig während der Durchführung des Tai Pūcam-Festes in Malaysia oder Singapur beschrieben (vgl. beispielsweise Clothey 2006).

434 Mit dem tamilischen Begriff ātțam ist eine besondere Form des Tanzes ausgedrückt. Es ist nicht der Tanz aus Vergnügen, sondern der Ausdruck für Bewegungen, die durch die Besessenheit mit einem göttlichen Wesen hervorgerufen werden (vgl. Schalk 2004a, 200). "Let us call it a dance under obsession and vow" (Schalk 2004a, 200).

435 Die folgenden Beschreibungen beziehen sich auf die von mir beobachteten kāvațiTänze im Sri Viṣnu Turkkai Ammañ Tempel in Adliswil(15.09.2007) und im Śrī Civacuppiramaṇiyar Tempel in Adliswil (16.08.2009). Weitere Tempel, die kāvaṭi-Tänze als Bestandteil ihres Tempelfestes während des Untersuchungszeitraums dieser Arbeit durchgeführt haben, waren jene in Bern und in Glattbrugg. Die Tempelfeste in Luzern (9.,10.,11.08.2008) und Trimbach (15.08.2008; 17.08.2009), welche ich besucht habe, beinhalteten keinen kāvați-Tanz. 


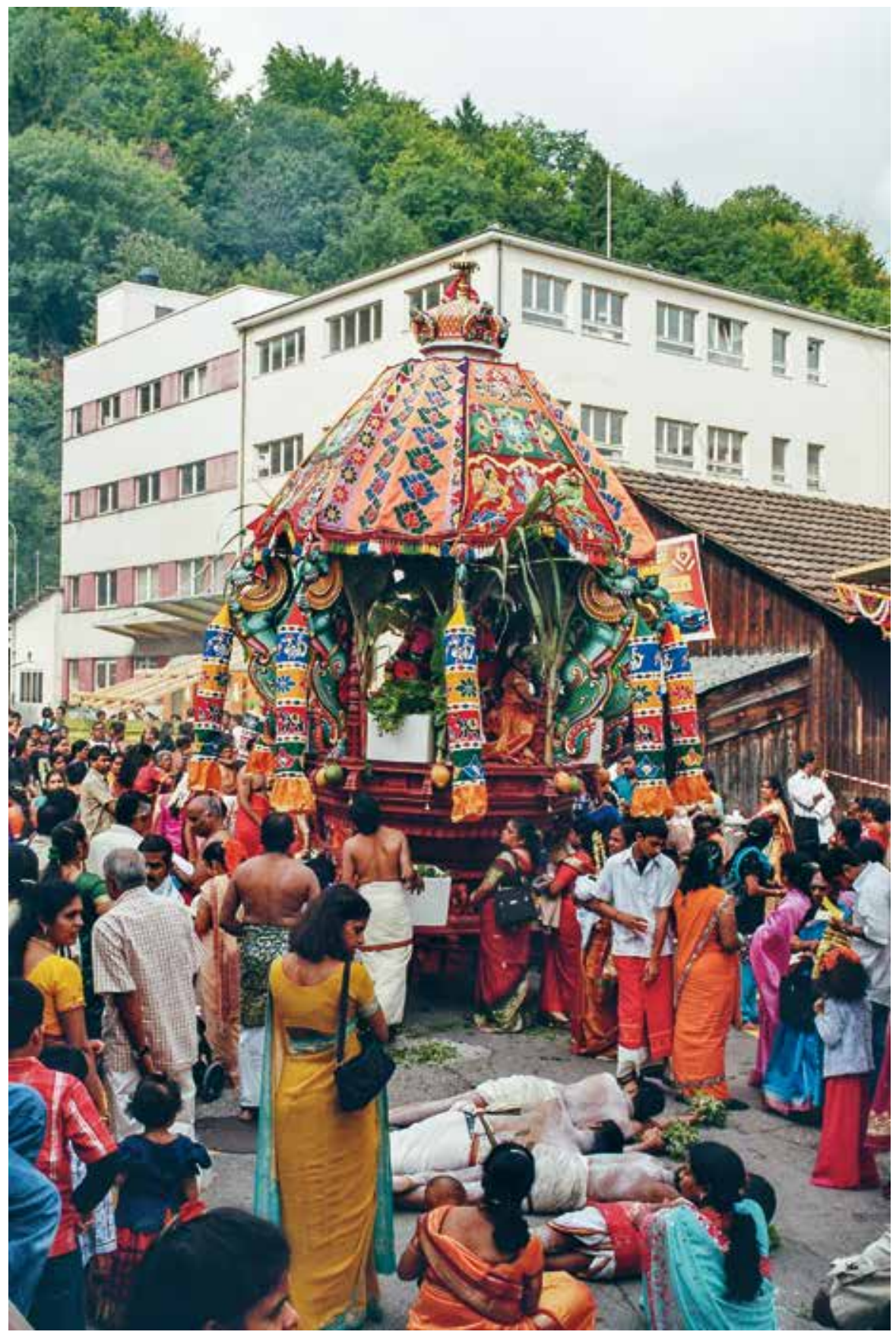

Abb. V 17: Männer, welche am 15.09.2007 den Prozessionsweg während des Tempelfestes des Śrī Viṣnu Turkkai Ammañ Tempels in Adliswil durch Umrollen zurücklegten. 
Kāvați-Tanz ist Ausdruck des Dankes oder der Bitte an die Gottheiten für oder um die Erfüllung eines Wunsches mittels einer rituellen Reinigung durch diese physisch extreme Körperpraktik (vgl. Baumann 2006, 136). Der $k \bar{a} v a t ̦ i$-Tanz verweist also vielfach auf individuelle Sorgen und Bedürfnisse der Akteure.

Der kāvați-Tanz stellt eine komplexe rituelle Performanz dar, zu welcher ein speziell angefertigtes Instrument und eine zweite, assistierende Person benötigt werden. Dem Tanz geht eine intensive Vorbereitungszeit, welche der spirituellen Reinigung dienen soll, voraus. Dazu gehört, dass die Tänzer zehn Tage lang nur eine Mahlzeit pro Tag zu sich nehmen. Während des Tanzes tragen die Akteure ein zweiteiliges geschmücktes Holzgestell, das zu Ehren Murukans auf den Schultern getragen wird. Es besteht aus einem Mast, welcher auf die Schultern gelegt wird und einem Bogen, welcher darüber befestigt wird. Am geschmückten Holzgestell sind rechts und links, vorne und hinten ein Büschel echter Pfauenfedern als Zeichen für Murukañs Reittier, den $\mathrm{Pfau}^{436}$, befestigt.

Während meiner Beobachtungen waren an der Spitze des Bogens mehrere Plastikwedel angebracht, in deren Mitte entweder ein goldener Speer oder ein imitierter grüner Papagei zu sehen war. Der kāvați-Träger kann seine Handlung nicht alleine ausführen, sondern interagiert immer mit einer zweiten Person, die ihm assistiert. Die beiden Personen sind durch eine Schnur verbunden, welche durch Haken im Rücken des Tänzers befestigt ist. Die Anzahl der Haken im Rücken eines Tänzers variiert; üblich ist es, dass zwei oder vier Haken im Rücken festgesteckt werden. Der «Assistent» hält die Schnur in den Händen und dirigiert die andere Person. Luchesi vergleicht die Konstellation mit einem Pfau, der an einer Leine gehalten wird und tanzt. ${ }^{437}$ Der Rhythmus des Tanzes von «Bogenträger und Lenker» ist somit aufeinander abgestimmt. Die Beziehung der beiden Akteure basiert auf einem Vertrauensverhältnis. Die Tänzer fragen, so berichteten Informantinnen und Informanten, eine erfahrene Person an, ob diese bereit sei, den ziehenden Part des Tanzes zu übernehmen. Diese führt diese Handlung nicht wie die Bogenträger als Erfüllung eines Gelübdes an die Gottheiten durch.

Beim Tempelfest des Śrī Viṣnu Turkkai Ammañ Tempels 2007 befand sich unter den tanzenden Männern auch eine Person, welche anstelle des

436 Dieser wird auf Tamilisch mayilvākanañ, der Pfau als Fahrzeug, genannt (vgl. Schalk 2004a, 200).

437 Interpretationen des kāvați-Tanzes können vielfältig ausfallen (vgl. Schalk 2004, 200). Eine Deutung des kāvați-Tanzes besteht darin, dass der Körper des Tänzers zu Murukañs Reittier wird, was durch die Pfauenfedern angezeigt wird. Murukan selbst bewegt sich dann in den Körpern der kāvați tragenden Männer. 


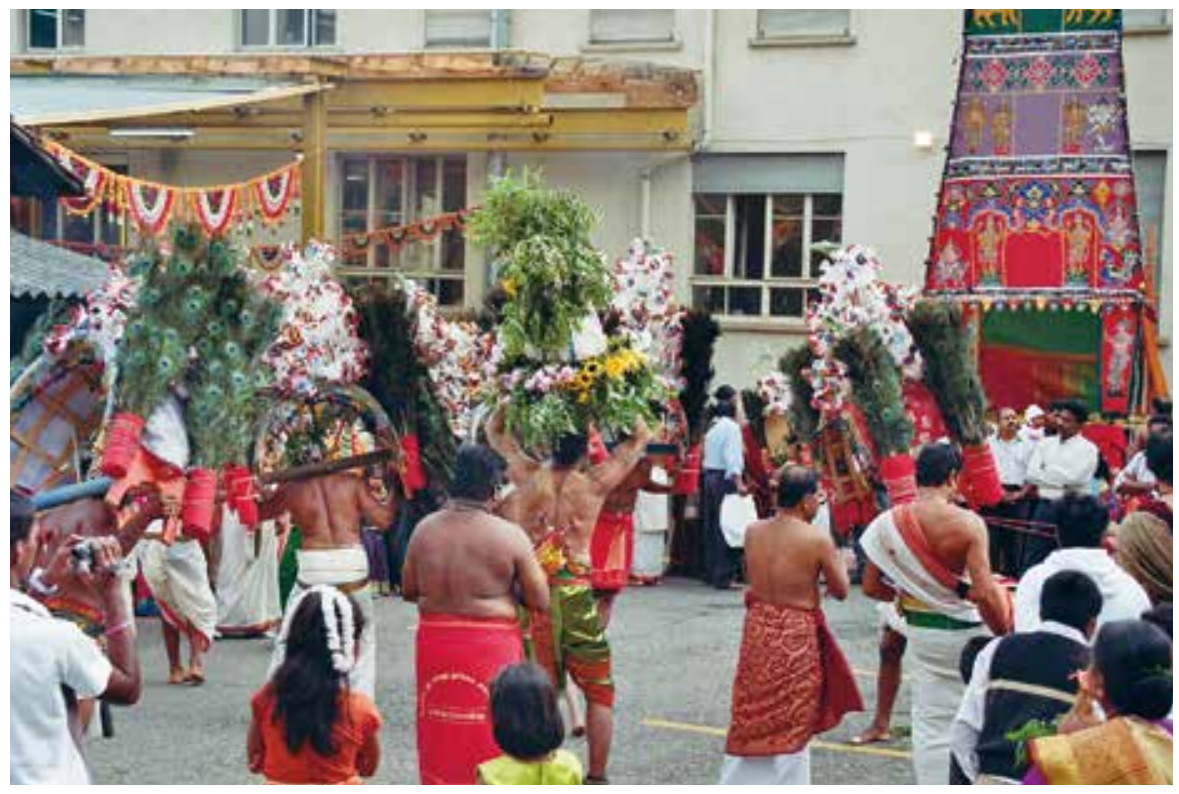

Abb. V 18: Kāvați tanzende Männer während des Tempelfestes des Sri Viṣnu Turkkai Amman Tempels in Adliswil (15.09.2007).

$k a \bar{v} v a t ̦ i$ eine mit Blumen geschmückte Vorrichtung mit konkavem Umriss auf dem Kopf trug und diese mit beiden Händen festhielt. Clothey spricht davon, dass einige Männer kāvați in Form eines Tempelturms tragen (vgl. Clothey 2006, 180). Ihr Körper wird zu einem Tempel, in den Murukan einkehrt. Dies schliesst an die Darstellung zu kōpuram-Kulissen in Kap. V 2.2 an. Der Tempelturm wird hier als mobile Kulisse dargestellt; Tempelraum und Körper der Akteure verschmelzen zu einer Einheit.

Zusätzlich zum Tragen des Bogens und der Haken, die im Rücken der Tanzenden stecken, haben einige Männer auch Zunge und Backen mit einem kleinen Speer durchstochen (tam. vēl kāvați). 2009 stellte es eine Besonderheit auf dem Tempelfest des Śrī Civacuppiramaniyar Tempels dar, dass ein Teilnehmer, der kāvați trug, insgesamt 108, als im Hinduismus bedeutsame Zahl, Haken in seinem Rücken und Armen befestigt hatte, welche als kleine Speere in die Arme des Mannes gesteckt waren. ${ }^{438}$

Die Bewegungen der Akteure sind auf die Musik abgestimmt, welche von Musikern, die neben den Tänzern stehen, gespielt werden. Im tamilischen Spektrum gibt es spezielle kāvati-Lieder, die, wie eine Informantin

438 Die Zahl 108 verweist auf die 108 Namen Murukañs. Dies berichtete mir ein Informant am 16.08.2009 während des Tempelfestes. 


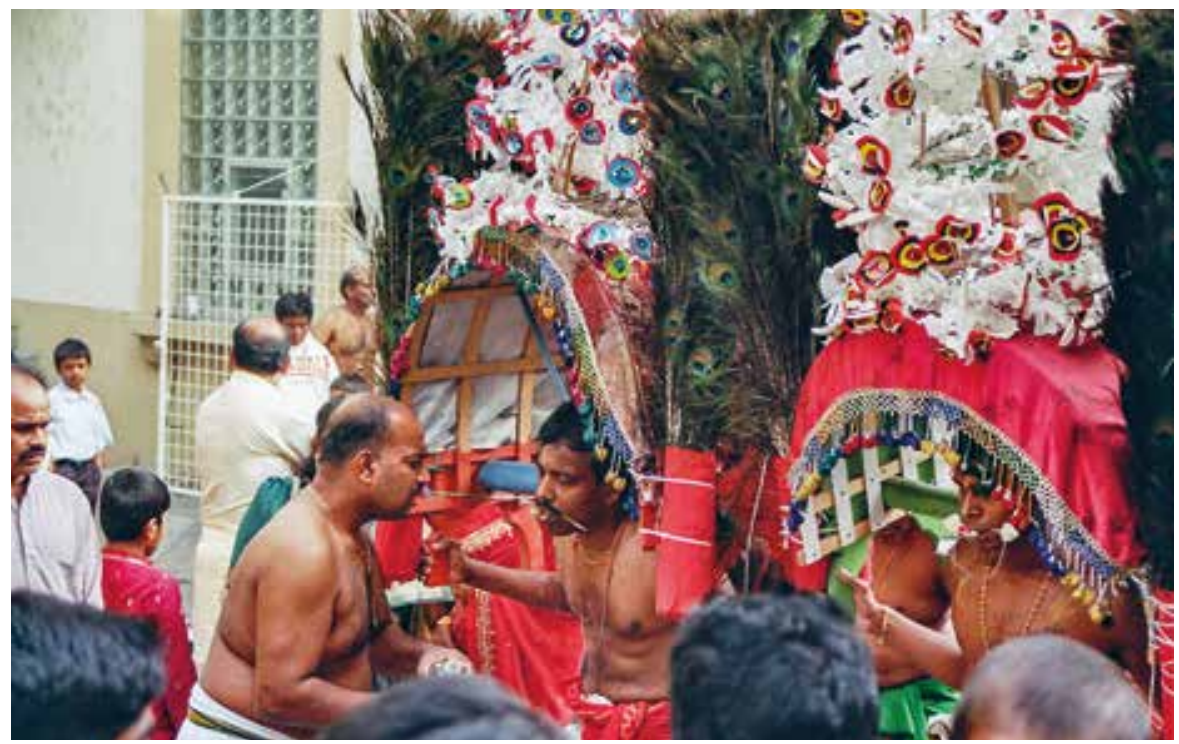

Abb. V 19: Männer, die vēl kāvați praktizieren (Tempelfest des Sri Viṣnu Turkkai Ammann Tempels in Adliswil; 15.09.2007).

berichtet, einen «traurigen Charakter» haben. Eine Person, welche mit Zimbeln in der Hand den Rhythmus angibt, dirigiert die «kāvați-Gruppe». Die Männer, welche kāvațitragen, haben das Gesicht meist in Richtung des Publikums gerichtet. Musiker, Bogenträger und Lenker ergeben, im Gesamtgefüge der Prozessionsbesucher, eine abgegrenzte Gruppe, welche sich rhythmisch im Takt der Musik bewegt. Durch die Musik soll die Gottheit herbeigerufen werden. Fallen die Tänzer in Trance, dann gilt dies als Zeichen, dass die Gottheit den Wunsch des jeweiligen kāvați-Trägers angenommen hat und tatsächlich im Tempel anwesend ist. Martin Baumann nennt die Trance der Tänzer einen Authentizitätsmarker des Tempels: "In a way, the kavadi dancers function as a quality marker of a temple - authenticity and authority is reinforced and acted out physically" (Baumann 2006, 139). Die «kāvați-Gruppe» tanzt vor dem Beginn der Prozession in einem eingegrenzten Bereich, bevor sie sich zusammen mit der Prozessionsgruppe bewegt und den ersten Teil der Prozession bildet, welche vor dem têr hergeht. Durch die Männer, von denen angenommen wird, dass in ihnen während des kāvați-Tanzes Murukan wirkt, wird der Prozessionszug als eine dem sakralen Bereich zugeordnete Parade gekennzeichnet (vgl. Jacobsen 2008b, 5).

Kāvați-Tragen ist eine Praktik, die traditionell ausschliesslich von männlichen Akteuren durchführt wird, was mit meinen Beobachtungen 
übereinstimmt. ${ }^{439}$ Zwar tragen auch Kinder den kāvați-Bogen, jedoch sind auch diese männlichen Geschlechts. ${ }^{440}$

Gelübde (skr. vrata, tam. nertti), die man an die Gottheiten geleistet hat, werden mittels des Tragens von kāvați eingelöst - der Holzbogen wird für Murukan getragen und verweist auf die Hingabe an diesen. Dabei dient der Körper als Mittel der Ergebenheit an die Gottheit. Ein Informant berichtet während des Tempelfestes des Śrī Civacuppiramaṇiyar Tempels in Adliswil 2009: «Am Samstag nehmen viele Kavadi/haben Sie schon gesehen? Man sagt dem Gott/es ist ganz einfach: «Ich habe einen Wunsch, wenn dieser wirklich in Erfüllung geht, dann mache ich für dich das.»» Diese Wünsche können unterschiedlicher Natur sein. Sie können sich um materiellen Wohlstand oder Familienbelange drehen (vgl. Shanmugalingam 2002, 70 ff.). Akteure berichteten häufig vom Wunsch nach Nachwuchs oder Dank für ein Kind, welches geboren wurde. Häufig wird kāvați als Erfüllung für eine Heilung von einer Krankheit des Akteurs selbst oder eines Familienangehörigen getragen. Wie oft diese rituelle Praktik durchgeführt wird, entscheidet der Akteur nach individuellem Ermessen. «Man kann auch sagen, wenn der Wunsch in Erfüllung geht/dann mache ich es für den Rest meines Lebens oder für zwei, drei Jahre» (vgl. auch Clothey 2006, 184).

In der Diaspora-Situation finden sich jedoch auch Anliegen, welche mit dem rechtlichen Status von Tamilinnen und Tamilen als Geflüchtete in Verbindung stehen. So lebte einer der Männer, die im Jahr 2009 während des Tempelfestes des Śrī Civacuppiramaṇiyar Tempels kāvați tanzte, sieben Jahre ohne gültige Papiere in der Schweiz («er lebte 〈illegal〉 hier», wie mir ein Informant berichtete). Sein Wunsch an die Götter war es, in Einklang mit den lokalen Gesetzen in der Schweiz leben zu können. Im Jahr 2008 erhielt er einen legalen Aufenthaltsstatus. Da sein Wunsch erfüllt wurde, tanzte er im darauffolgenden Jahr kāvați, wie er es versprochen hatte. Die-

439 Luchesi und Schalk verweisen jedoch auch auf Frauen, die während einer tamilischen Tempelprozession in Paris kāvați trugen (vgl. Luchesi 2008b, 185; Schalk 2004a, 200).

440 So haben beim Tempelfest des Śrī Viṣnu Turkkai Ammañ Tempels 2007 auch Jungen den Bogen getragen. Im Berner Tempel hing am 09.11.2007 im Eingangsbereich links eine Fotocollage, welche unter anderem ein Foto eines kāvați tragenden Kindes zeigte. Diese gerahmten Bilder präsentieren wichtige Ereignisse im Tempel, rufen diese in Erinnerung und machen sie für alle Tempelbesuchende sichtbar.

Während der Prozession des Tempelfestes des Śrī Civacuppiramaṇiyar Tempels 2009 habe ich zehn Männer gezählt, welche mit kāvaṭi getanzt haben. Kinder trugen zu diesem Anlass keinen kāvați.

Eine Informantin sagte, dass kāvați tragende Kinder pālkāvati genannt würden, da Pāl auf Tamilisch «Milch» bedeutet und damit auf das Stadium der Kindheit der Durchführenden verwiesen würde. Clothey schreibt jedoch, dass pāl kāvati einen Topf mit Milch meint, welcher zu Ehren Murukañs auf dem Kopf getragen wird (vgl. Clothey 2006, 180). 
ses Beispiel zeigt zum einen, dass die religiöse Praxis eng mit den sozialen Lebenswirklichkeiten der Menschen verbunden ist, und zum anderen, dass die spezielle Situation der tamilischen Migrantinnen und Migranten in der Schweiz und die Inkorporationsbedingungen sich in den Formen der Hindu-Praxis widerspiegeln. ${ }^{441}$

Der kāvați-Tanz wird in der Diaspora in ähnlicher Weise wie in Sri Lanka - wie etwa zum Anlass des jährlichen Festes des wichtigen sri-lankischen Wallfahrtsort Kataragama (tam. Katirkāmam; vgl. Younger 2002, $35 \mathrm{ff}$.) und auch als Teil buddhistischer Feste (vgl. Goonasekera 2006, 117) durchgeführt. Geaves verweist auf die sozio-politische Dimension des $k \bar{a} v a t ̦ i$-Tanzes. Er interpretiert diesen für den sri-lankischen Kontext als einen Ausdruck nationaler tamilischer Identität. In der Diaspora-Situation sei die Bedeutung des kāvați-Tanzes vielmehr auf die wirtschaftlichen Ziele der Migrierten und die Bewahrung tamilischer Identität in fremd-kultureller Umgebung gerichtet:

Politically the struggle to carry the kavadi is transformed in diaspora from an act of national identity and struggle for self-determination to one of seeking to achieve economic prosperity whilst simultaneously preserving Tamil identity and ancestral traditions. (Geaves 2007, 194)

Die Durchführung dieser Performanz zeigt, dass die Gemeinschaft im Residenzland etablierter ist, da erst die Möglichkeiten für kāvați-Tanz geschaffen werden mussten. Schalk betont in seiner Beschreibung des Tempels in Stockholm, dass kāvați-Tanz in Stockholm nicht durchgeführt wird, was sich aber in Zukunft durchaus ändern könne, wenn der Tempel sich stärker etabliert haben sollte (vgl. Schalk 2004a, 198). Daher ist es nicht verwunderlich, dass die Zahl der kāvați-Performanzen in der Diaspora ansteigt (Baumann 2006, 140 ff.; Luchesi 2008b, 185).

Neben dem Tragen des kāvați-Bogens ist das Piercen des Gesichtes eine weitere selbstkasteiende Handlung zu Ehren Murukanns. Einige Männer haben einen Speer durch die Backen gestossen, an dessen Ende der vēl als Zeichen Murukans zu sehen ist. In der Regel ist diese Praxis Männern vorbehalten; es finden sich jedoch auch Frauen, die sich zum Anlass des Tempelfestes «piercen» (vgl. Collins 1997). ${ }^{442}$ Im Rahmen der Feldforschung dieser Studie habe ich eine tamilische Prozessionsteilnehmerin des Śri Civacuppiramaniyar Tempelfestes 2009 gesehen, welche sich durch die

441 Ein ähnlicher Wunsch führte auch dazu, dass ein Mann beim Tempelfest des Śrī Kāmākșī Ampāl Tempels 1996 in Hamm kāvați tanzte; vgl. Baumann 2006, 136.

442 Luchesi berichtet davon, dass in den Jahren 2005 und 2006 auch eine gepiercte Frau an der Tempelprozession in Hamm teilnahm (vgl. Luchesi 2008b, 185). 
Backen einen Speer, welcher rechts den vēl und auf der linken Seite einen Dreizack zeigt, gestossen hatte. In der Mitte befand sich eine silberne Vorrichtung, welche die Zunge umschliesst und wie eine Schlange aussah. Der Gegenstand war durch eine silberne Kette, die an ihm hängt, verbunden. Die Frau trug auf dem Kopf einen kumpam mit Neemblättern und Kokosnuss, welchen sie mit der rechten Hand festhielt.

Die Körperpraktiken werden in medialen Berichterstattungen thematisiert, die über diese Grossereignisse berichten. Im Neuen Bülacher Tagblatt hiess es beispielsweise über das Tempelfest in Glattbrugg 2007: «Andere Männer tanzen zu Trommelrhythmen mit einem Kasten auf den Schultern, der schwer anmutet und mit Pfauenfedern geschmückt ist. Durch die Musik geraten die Männer in Trance und bewegen sich ekstatisch mit zum Teil leerem Blick. Plötzlich sinkt einer zu Boden und beginnt zu weinen. Die anderen Männer eilen zu Hilfe, stützen ihn und bespritzen ihn mit Wasser, bis er wieder zu sich kommt». ${ }^{443}$

\section{Eine Extremform des kāvați-Tanzes: «hängender kāvați»}

Eine besondere Form von kāvați-Tanz stellt das so genannte «Hakenschwingen» (tam. cetilattam oder thukku kāvati) dar. Ein Devotee ist durch Haken, die in seiner Haut stecken, und Schnüren an einem mobilen Gestell befestigt und schwingt in der Luft. Eine Informantin nannte diese Form des $k \bar{a} v a t ̦ i$, «hängender kāvați».

Ich habe diese Form der kāvați-Performanz während des Tempelfests des Śrī Viṣnu Turkkai Ammañ Tempels am 15.09.2007 beobachtet. ${ }^{444}$ Der Tempelverein nutzte für diese spezielle Form des kāvați einen eigens konstruierten Aufsatz auf einem Traktor. An einem Anhänger, welcher von einem Traktor gezogen wurde, war ein circa zehn Meter langes Holzgestell befestigt, welches schräg nach oben ragte. In der Mitte der Konstruktion, über der Anhängerkupplung, hing von oben ein Stoffbild der Hauptgöttin des Tempels, Viṣnu Turkkai Ammañ, herab. Der vordere Teil der Wippe und auch der Traktor waren mit Girlanden geschmückt.

Der Rücken des «Tänzers» war über acht Haken an Schnüren an dem hölzernen Aufsatz, der schräg von einem Traktor in die Luft ragte, befestigt, sodass er an der Spitze des Gestells etwa eineinhalb Meter hoch in der Luft hing. An der Spitze war der kāvați befestigt, der mit Pfauenfedern ge-

443 Rita Stocker, Exotischer Höhepunkt, in: Neues Bülacher Tagblatt, 25.06.2007.

444 Die folgenden Ausführungen beziehen sich auf diesen Anlass. In Adliswil wurde die Form des hängenden kāvați seit 2001 praktiziert (vgl. Luchesi 2008b). Baumann berichtet von hook-swinging im Śrī Civacuppiramaṇiyar Tempel in Adliswil im Juni 2003 (vgl. Baumann 2006, 142). 
schmückt war. Hinter dem Bogen stand (oder lag teilweise) ein traditionell gekleideter Mann, welcher wie die Personen auf dem Boden an den Schnüren zog und im Takt der Musik wippte, sodass sich die hängende Person auf und ab bewegte. Ebenso wie die kāvați-Tragenden auf dem Boden wird diesem Devotee zugeschrieben, dass er im Moment der Trance Murukan verkörpere. Dinge oder Menschen, welche er in diesem Zustand berührt, werden als vom Gott Murukan berührt, angesehen.

Der Mann, der am Traktorkran festgebunden ist, wippt im Takt der Musik auf und ab. Um den Hals trägt er eine Blumengirlande. Er hat einen goldenen Dreizack in der Hand und lässt sich immer wieder Neemblätter geben, die er dann einzelnen Personen gibt. Diese verneigen sich dafür vor ihm. Auch lässt er sich hin und wieder Kokosnüsse geben, die er auf den Boden wirft und aufbricht. Dann wird ihm ein Baby übergeben, mit dem er einige Minuten im Arm in der Luft auf und ab wippt. Ein Mann gibt ihm Zeichen, dass er das Kind herunterlassen soll. Er aber winkt ab und bittet um eine Kokosnuss. Erst nachdem er diese auf den Boden geworfen hat, überreicht er das Kind wieder einem Mann, der neben dem Gestell steht. Ab und zu wird er mit Wasser erfrischt. (Auszug aus meinem Protokoll vor der Prozession am 15.09.2007 in Adliswil)

Genau wie die «kāvați-Gruppe», die sich auf dem Boden befindet, ist der $k \bar{a} v a t ̦ i$ vollziehende Devotee Teil der Prozession, die um das Tempelgebäude führt. Der Traktor bewegte sich langsam mit der Prozessionsmenge, wobei ein zweiter «Lenker» am unteren Ende des hölzernen Aufsatzes die Schnüre mit festhält.

Hakenschwingen ist ein performativer Ausdruck, welcher grosse Aufmerksamkeit des Publikums auf sich zieht. Die Besuchenden des Tempelfestes folgten gebannt dem Weg des sich in der Luft befindlichen Devotees. Da der damalige Śrī Viṣnu Turkkai Ammañ Tempel im Adliswiler Industriequartier direkt an einer sehr befahrenen Strasse, dem Soodring, lag, führte die Prozession an dieser Strasse entlang. Teile der Fahrbahn wurden durch eine Absperrung mit Plastikband, welche von tamilischen Ordnern mit orangefarbenen Westen getragen wurden, zum Passieren des Traktors freigehalten. Die Minuten des Vorbeiziehens der Prozessionsgruppe eröffneten den Blick auf den hängenden Mann mit Dreizack in der Hand. Diese Form der Öffentlichkeit führte dazu, dass sich einige Autofahrer im darauffolgenden Jahr bei der Gemeinde darüber beschwerten, dass ihnen der Anblick einer solchen Praktik zugemutet wurde. Ein Mitglied des Tempelvereins des nahe gelegenen Śrī Civacuppiramaniyar Tempels berichtete mir 2009: «Der andere Tempel hier ist in der Nähe von der Autostrasse und dann haben die Autofahrer reklamiert. Sie wollen so etwas nicht sehen». 


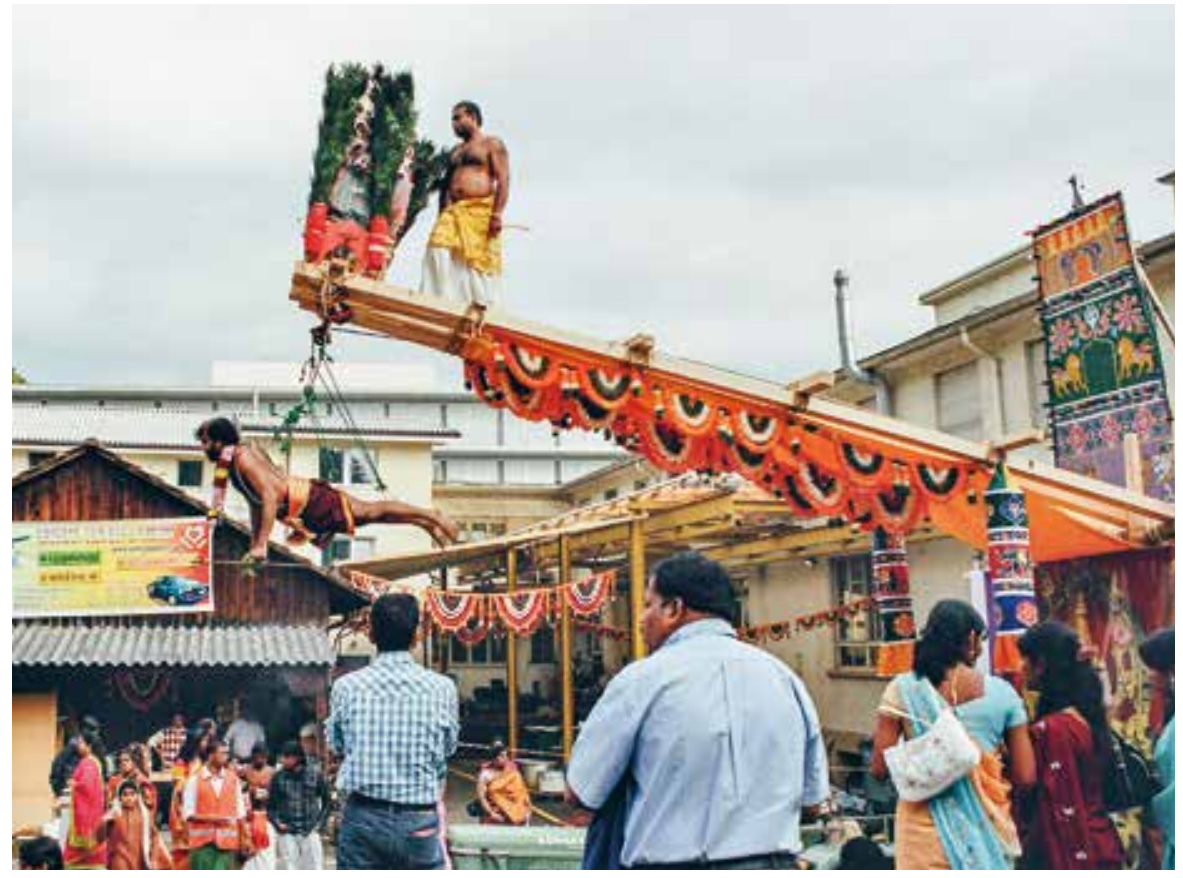

Abb. V 20: Hängender kāvați während des Tempelfestes des Śrī Viṣnu Turkkai Ammañ Tempels am 20.09.2007 in Adliswil.

Die verschiedenen Formen von kāvați sind in verschiedenen öffentlichen Sphären präsent. Sie ziehen sowohl die Aufmerksamkeit des Publikums des Tempelfestes, das Zielpublikum der kāvați-Performanz ist, als auch die Aufmerksamkeit der angrenzenden Anwohnenden und der Mehrheitsbevölkerung auf sich.

Häufig werden sie als fremdartig und tendenziell brutal beschrieben. ${ }^{445}$ Wie in Südasien ist der kāvați-Tanz auch in der Diaspora-Situation eine Praktik, die kontrovers diskutiert wird und die in Indien, nicht aber in Sri Lanka, seit der britischen Kolonialherrschaft verboten ist (vgl. Clothey 2006, 191). Anfang der 2000er Jahre galt die Schweiz unter tamilischen Hindus als Land, welches im Bereich dieser besonderen Form von Hindu-Praxis den Akteuren einen grossen Handlungsspielraum einräumte. Während die Praktik in Deutschland nach einem schweren Unfall durch den Bruch der Konstruktion des hängenden kāvați im Śrī Kāmākș̣i Ampāl Ālayam in

445 Clothey berichtet davon, dass thukku kavadi in London nicht durchgeführt wird, da man befürchtet die Kinder, welche in England sozialisiert wurden, damit abzuschrecken (vgl. Clothey 2006, 190). 
Hamm im Juni 2004 nicht mehr durchgeführt wurde (vgl. Luchsei 2008, 184), wurde sie bis zum Jahr 2008 in der Schweiz praktiziert.

Hier hat man viel, viel dafür investiert. Wir haben von Sri Lanka das Brett speziell angefertigt hierher importiert und das kann gar nicht brechen/darum haben die Leute hier keine Angst. Es sieht extrem aus, aber es kann nicht brechen. In Deutschland ist es gebrochen.

Als Reaktion auf Bedenken wird in der Kommunikation nach aussen immer wieder betont, dass sich die kāvați-Tragenden keinen körperlichen Schaden zufügen, da die Rituale gut vorbereitet und durch professionelle Akteure, die Wissen um diese rituellen Formen haben, begleitet werden. Durch den Konflikt mit Anwohnenden wurde im Untersuchungszeitraum letztmalig 2008 hängender kāvați in der Schweiz durchgeführt.

Im Faltblatt, welches aus Anlass des Tags der offenen Tür des Tempels in St. Margrethen 2008 von Mitgliedern der Gruppe Saivanerikoodam an die Besucher verteilt wurde, wird auf Seite 7 auf potenzielle Kritik am kāvațiTanz reagiert:

Die Segnungen, die der Verehrer durch diese Zeremonie gewinnt, sind millionenfach grösser als der kleine Schmerz, den er sich dabei zufügt. (...) Obwohl dies auf den ersten Blick so aussieht, als wolle man Gottes Unterstützung kaufen, erkennt man bei genauerem Nachdenken jedoch, dass es der Same für höchste Liebe zu Gott ist. Zweifellos wird sich der Wunsch erfüllen, wenn der Verehrer Kavadi ausführt. Aber nach dem Ritual fühlt er sich so von Gott erfüllt, dass seine innerste spirituelle Kammer geöffnet wird.

Diese Interpretation rekurriert darauf, dass sich durch die Durchführung von kāvați erst der formulierte Wunsch erfüllt, nicht aber, dass kāvați als Einlösung des Gelübdes durchgeführt wird. ${ }^{446}$ Kāvați wird als rituelle Praktik eine enorme Macht zugeschrieben, welche zur Wunscherfüllung führe und die Ausführenden näher an die göttliche Sphäre bringe.

Es wurde deutlich, dass es eine Vielzahl von öffentlich praktizierten Körperpraktiken gibt, die elementare Bestandteile der Prozessionen während des Tempelfestes sind und einen öffentlichen Ausdruck von HinduTamilness darstellen. Die perfomativen Ausdrücke während des Tempelfestes machen tamilische Hindu-Traditionen auch in der Schweizer nationalen Öffentlichkeit sichtbar.

446 David skizziert die Hintergründe des kāvați-Tanzes in ähnlicher Weise. Da die Götter über die Reinheit und Hingabe der Tanzenden erfreut sind, erfüllen sie ihnen ihre Wünsche (vgl. David 2008, 96). 


\subsection{Sakrales Theater im Tempel: Aktualisierung von Hindu- Mythologie}

Zu Performanzen anlässlich des jährlichen Tempelfestes (tam. tiruvilāa) gehören in einigen Tempeln auch rituell eingebundene theatrale Aufführungen mit Kindern als Darstellende, die für alle Festbesuchende öffentlich zugänglich sind. Theateraufführungen haben in Hindu-Traditionen traditionell eine pädagogische Funktion und dienen der Weitergabe von HinduMythologie. Sie vermitteln Wissen wie Geschichten über die Gottheiten, die in Hindu-Schriften erzählt werden, und darin übermittelte religiös begründete Werte. Theater wird auch als «fünfter Veda» bezeichnet (vgl. Binder 2010, 526).

Im Rahmen des Mangofestes (tam. māmpalat tiruvilāa), das am sechsten Tag des jährlichen Tempelfestes stattfindet, wurde im Śrì Civacuppiramaniyar Tempel in Adliswil eine in den Purānas verschriftlichte Episode aus dem Leben Murukans, der Hauptgottheit des Tempels (in Gestalt von Cuppiramaṇiyar), aufgeführt. ${ }^{447}$ Hauptpersonen der Geschichte sind die Mitglieder der Kernfamilie Civañs - Civan, seine Frau Pārvati und ihre Söhne Vināyakar, der Erstgeborene, und Murukañ. Der zentrale Handlungsstrang der Geschichte dreht sich darum, dass jener Sohn Civas eine besondere, durch den weisen Seher Nārada überreichte nicht teilbare Mango erhält, der als Erster die Welt umrundet. Der agile Murukan macht sich auf, um mit seinem Reittier, dem Pfau, um die Welt zu fliegen. Der träge, aber schlaue Vināyakar dagegen umkreist seine Eltern mit der Erklärung: «Ihr seid die ganze Welt.» Civan ernennt ihn zum Sieger und überreicht ihm die Frucht. Als Murukan zurückkehrt und erfährt, dass er die Mango nicht gewonnen hat, wird er wütend und zieht sich auf einen nah gelegenen Berg zurück, um als Asket zu leben. Civan sagt daraufhin zu Murukañ: «Du bist die Frucht» (tamilisch «Palam Nì - woher der Name des Ortes abgeleitet ist) und weist mit diesem Ausspruch auf die Überwindung des durch die Mango repräsentierten Materiellen und die Verinnerlichung des Göttlichen als Ziel hin. Der berühmte Murukan-Tempel in der Stadt Palanini, der ein beliebtes Ziel für Pilgerreisen ist, befindet sich auf dem Berg, an dem Murukan in Rage geriet und daraufhin als junger Asket lebte (vgl. Clothey 1972, 82; Collins 1997, 33f.; Younger 2001, 66). ${ }^{448}$

447 Diese Angabe bezieht sich auf die Jahre 2008, 2009 und 2010 des Untersuchungszeitraums.

448 Diese Geschichte wird in verschiedenen Regionen Indiens unterschiedlich erzählt. Ron Geaves erzählt dieses Narrativ in veränderter Form in Saivism in the Diaspora nach. Anstelle 
Durch die szenische Darstellung des Narrativs, welches in mythischer Zeit im indischen Palani (Bundesstaat Tamil Nadu) spielt, wird dieses nach Europa, in die Gegenwart der Schweiz im 21. Jahrhundert geholt. Der Murukan-Pilgerort Palani als Ort der tamilischen Sakrallandkarte wird auf Pilgerfahrten auch von in der Schweiz lebenden tamilischen Hindus besucht (vgl. Kap. IV 6.2). Durch das Schauspiel tamilischer Kinder repräsentiert der Innenraum des Tempels in der Nähe von Zürich für den Moment der Aufführung den südasiatischen Ort Palani.

Das Spiel wurde am 12. August 2009 und am 18. August 2010 um 15 Uhr im Tempelraum des Śrī Civacuppiramaṇiyar Tempels zwischen den Schreinen der Gottheiten aufgeführt. ${ }^{449}$ Der Tempel, dessen Innenraum zu diesem Anlass mit bunten Girlanden geschmückt ist, unterstreicht als Aufführungsort des Stücks, dass diese Performanz Teil einer rituellen Aufführung ist. ${ }^{450}$ In das Theaterstück sind Priester wie auch die bewegbaren Repräsentationsfiguren der Gottheiten (urcava-mürtti) des Tempels integriert, was diese Performanz sowohl als Theaterstück wie auch als Ritual beschreibbar macht. Die Darsteller stehen vor dem mit einem roten Vorhang zugezogenen Schrein (beschriftet als Vasantha Man Dapam) ${ }^{451}$ der Prozessionsbildnisse der Götterfiguren, die auf einem Tisch davor positioniert sind. Die Mitglieder der Kernfamilie um Civan werden also in zweifacher Weise repräsentiert: Einmal in Form der Prozessionsfiguren und einmal in Form von Kindern, welche die Gottheiten darstellen. Es findet sich daher auch eine doppelte Bühnenstruktur: Auf dem Tisch sind die mürttis gemeinsam mit für Rituale wichtigen Gegenständen platziert. Dieses statische Szenario des Spiels ist der rituellen Sphäre zuzuordnen. Die zweite Ebene der Bühne befindet sich auf dem Boden (und nicht etwa auf einer erhöhten Bühne) vor dem Tisch mit den Figuren. Die Kinder repräsentieren die Figuren des Stü-

einer Mango wird in der von ihm geschilderten Variante den Söhnen eine Braut versprochen (vgl. Geaves 2007, 30).

449 Da der sechste Tag des tiruvila à in Schweizer Tempeln immer auf einen Mittwoch fällt, fand das Fest im Śrī Civacuppiramaniyar Tempel jeweils am Mittwoch den 13.08.2008, 12.08.2009 und am 18.08.2010 statt. Ich habe die Aufführung im Tempel 2009 und 2010 besucht.

450 Zur Debatte um die Unterscheidung der Begriffe Ritual, Spiel und Theater in interkulturellen Studien vgl. u. a. Köpping/Rao 2000: «Bereits auf der formalen Ebene teilen Ritual und Theater eine grosse Zahl von Komponenten, die die Behauptung einer mehr als nur analogen Ähnlichkeit dieser zwei Handlungsdomänen des Performativen nahezulegen scheinen. Die meisten Versuche, spezifisch formale Kriterien als Eigenschaften unterschiedlicher performativer Rahmensetzungen aufzulisten, sind sowohl durch ethnographische Beobachtungen als auch durch Schauspieler-Erlebnisberichte aufgelöst worden» (Köpping/Rao 2000, 11).

451 Im Śrī Civacuppiramaṇiyar Tempel wurden zur Erläuterung der Schreine Tafeln angebracht, welche in tamilischen und lateinischen Buchstaben angeben, um welchen Schrein es sich handelt. 
ckes nicht nur, sondern stellen auch die Handlungen der Geschichte performativ dar.

Das Publikum, mehrheitlich Frauen und Kinder, sitzt auf dem Boden oder steht an der Wand, von wo aus es dem Spiel zuschaut. Einige Zuschauende fotografieren oder filmen die szenische Darstellung. Vom Publikum aus gesehen rechts sitzen drei Musiker auf einer Matte und begleiten das Spiel mit ihren Instrumenten. Die Schauspielenden sind tamilische Mädchen und Jungen, welche ihre Texte auswendig gelernt haben und diese mit einstudierter Gestik und Mimik mit Hilfe aufgestellter Mikrophone vortragen. Eine Frau steht mit dem in tamilischer Sprache und Schrift verfassten Skript des Stückes als Souffleuse daneben und liest den Text, den die Kinder auf Tamilisch sprechen, auf dem Papier mit (vgl. Abb. V 21).

Die Kostüme der Kinder sind aufwändig gestaltet und zeichnen die Darstellenden für kundige Zuschauer als eine bestimmte Gottheit oder eine innerhalb der Geschichte wichtige Gestalt aus (vgl. Abb. V 22). Der Darsteller, welcher Nārada spielt, jenen Rishi, der Civan die göttliche Frucht überbrachte, ist in Rot gekleidet und hat eine Laute umgehängt. Jenes Kind, welches Civan spielt, ist mit einem Tigerfell bekleidet und trägt einen Dreizack in der Hand. Eine Schlange sitzt in seinem Haar, es hat eine Brahma-

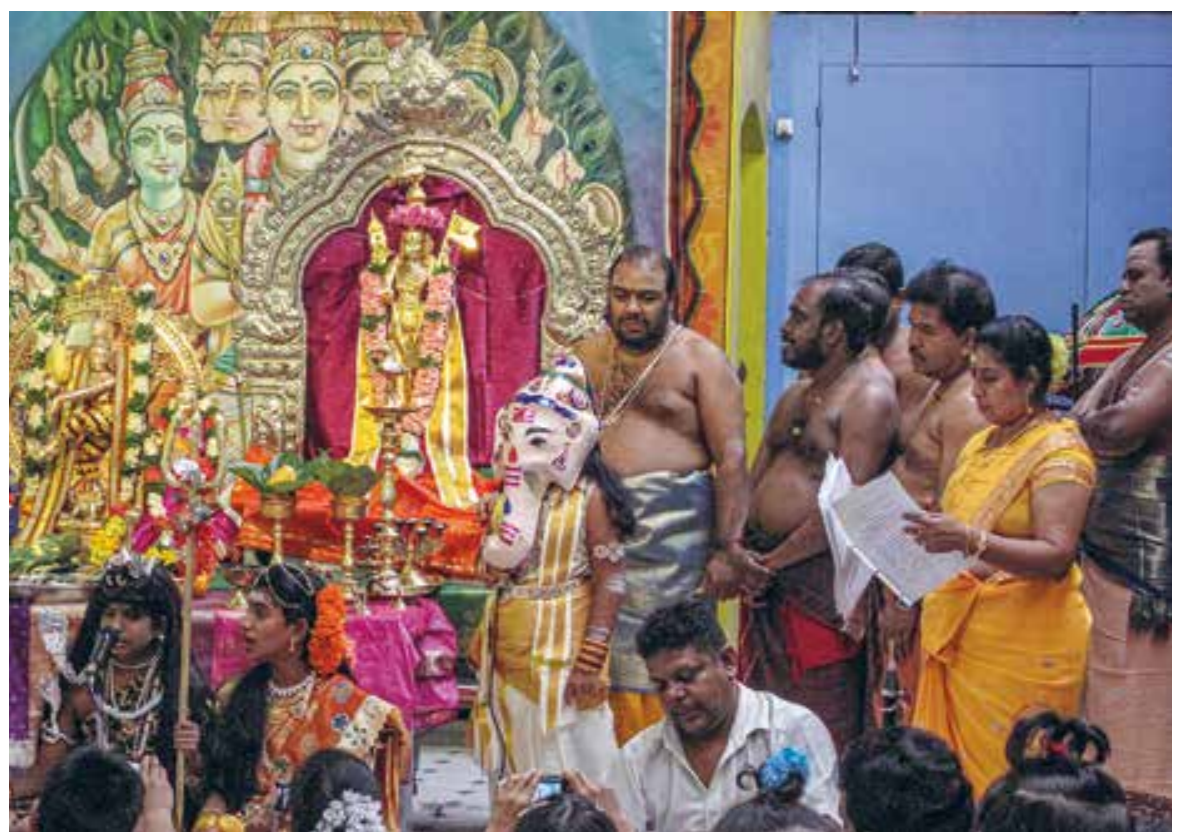

Abb. V 21: Darstellende von Civan, Pārvati und Vināyakar, rechts daneben Priester, Tempelvereinsmitglieder und die Anleiterin des Spiels (12.08.2009). 


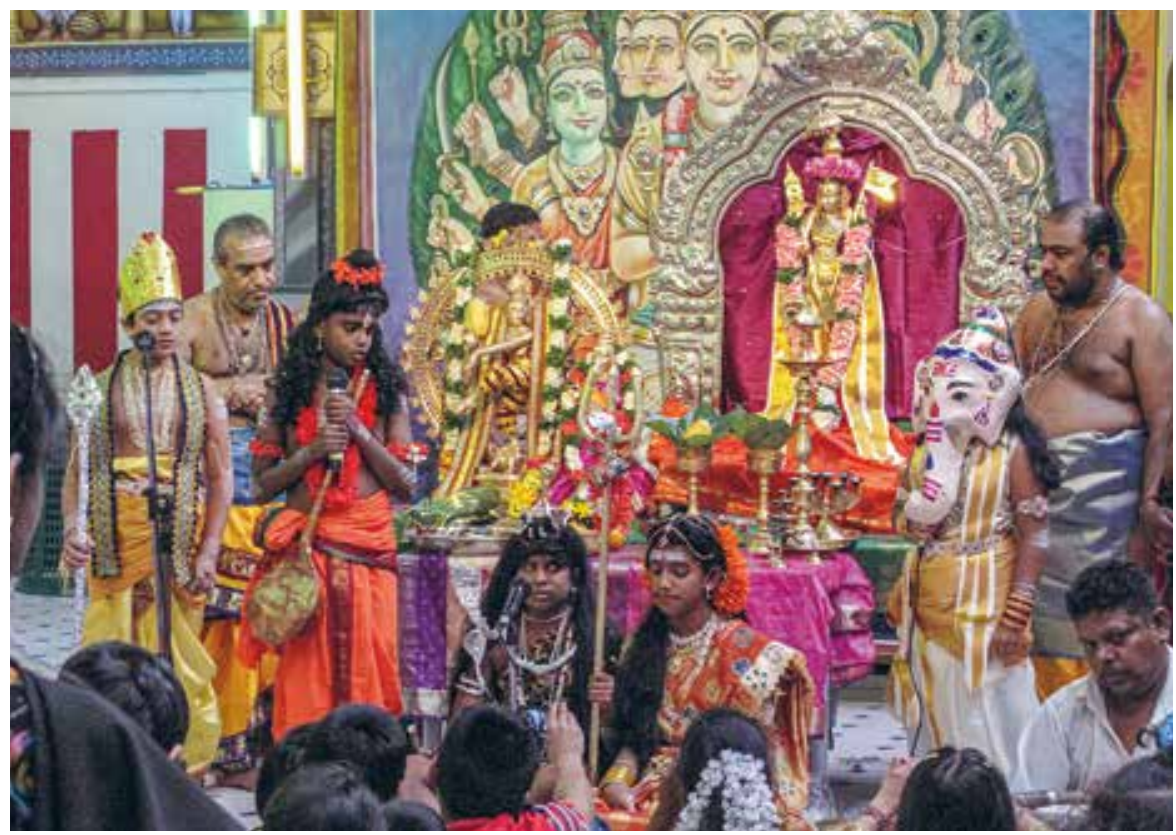

Abb. V 22: Aufführung während des Mangofestes am 18.08.2010 (von links nach rechts: Darsteller Murukañs, der Hauptpriester des Śrī Civacuppiramaniyar Tempels, Darsteller Nāradas, Darsteller Vināyakars. Rechts daneben der zum Tempelfest angereiste Priester, davor sitzen Civan und Pārvati; Zuschauende fotografieren und filmen; 12.08.2009).

nenschnur umgelegt und auf seine Stirn ist die shivaitische Tilaka-Kennzeichnung aufgetragen. Die neben ihm sitzende Pārvati-Darstellerin trägt eine goldene Krone und ist auch mit dem shivaitischen Tilaka versehen. Das Kind, welches Vināyakar darstellt, hat vor dem Gesicht eine Elefantenkopf-Maske aus Pappe, auf welcher auch die drei waagrechten Striche als Kennzeichen für die Zugehörigkeit zur Civan-Familie gemalt sind. Der Murukan Darsteller hält die charakteristische Waffe Murukañs, den Speer (tam. vē $)$, in der Hand. ${ }^{452}$

Ein wichtiges Element des Spiels ist der Wechsel der Repräsentationsfigur, welche Murukan darstellt. Während zu Beginn und gegen Ende des Stückes ein Kind Murukan verkörpert, wird dieser während der Darstellung seiner Reise um die ganze Welt durch die bewegliche kupferne urcavamūrtti Murukañs repräsentiert. Diese ist, mit Blumengirlanden geschmückt und wird, wenn sie die symbolische Bühnenfläche verlässt, von erwachse-

452 Die Geschlechtszugehörigkeit von Darstellenden und den gespielten Figuren stimmt nicht immer überein. So stellen Mädchen nicht nur Pārvati dar, sondern auch andere Figuren des Stückes. 
nen Männern auf einer Sänfte durch den ganzen Tempel getragen. Dabei umkreisen die Teilnehmer den Schrein des Hauptgottes, der ja auch wiederum Murukan ist - der Tempelraum symbolisiert in diesem Moment die ganze Welt. Analog zur zentralen Prozession als Höhepunkt des Tempelfestes findet also vorab eine Prozession im Inneren des Tempels statt. Murukan wird von vier Männern auf einer Sänfte getragen, während ein Mann einen Schirm über ihn hält. Die Musik verändert sich während der dargestellten Reise Murukans zu einem schnelleren Rhythmus und der Hauptpriester klingelt mit einer Schelle. Die Zuschauenden des Stückes folgen jedoch nicht der Murukan-Figur, sondern bleiben an ihrem Platz, ihre Sitzrichtung zur Bühne gerichtet.

In der Fortführung des Theaterstückes übernimmt dann wieder ein Kind die Rolle Murukañs. Durch den Wechsel der Darstellung von Murukan durch einen Menschen hin zu einer geweihten Repräsentationsfigur und wieder in einen menschlichen Körper wird der Zwischenstatus des Spiels zwischen Ritual und Schauspiel zum Ausdruck gebracht. Dieser wird auch dadurch unterstrichen, dass Priester neben den schauspielenden Kindern stehen und als Erzähler während des Spieles fungieren.

Neben den Darstellenden ist ein grosser Behälter mit süssen Honigmangos aufgestellt, welche zum Abschluss vom Priester an die Zuschauer verteilt werden. Zunächst erhalten die Schauspielerinnen und Schauspieler eine Frucht; zusätzlich dazu erhalten sie vom Priester ein Geschenk. Die $\mathrm{Zu}-$ schauenden stellen sich in einer Reihe vor dem Topf an, um eine Mango aus den Händen des Priesters zu erhalten. Dabei sagt dieser zu mir: "God bless you”. Durch die priesterliche Handlung und diese Worte wird noch einmal der rituelle Aspekt des Spiels deutlich. Das Schauspiel wird durch die Einbindung des Publikums am Ende der Vorstellung und die Überreichung der «Murukan-Mango» als «glücksbringendem» Akt auch an die Sphäre ausserhalb des Tempels und die Zeit danach angebunden.

Analog zu den doppelten Repräsentationsfiguren wird eine Mango zuerst in die Arme der mūrtti Civans gelegt und in jenem Moment im Spiel, wenn das Kind, welches Vināyakar spielt, eine Mango erhält (vgl. Abb. V 23), wird auch der dahinterstehenden Vināyakar-Figur eine Mango in die Hand gelegt.

Im Jahr 2010 wurden im Vergleich zu 2009 Elemente der Bühnengestaltung verändert. Der Vorhang vor dem zugezogenen Schrein, welcher den imaginierten Bühnenhintergrund bildete, war 2009 einfarbig; 2010 bildete er Arumukan, die sechsköpfige und zwölfarmige Murukan-Form mit seinen zwei Frauen, ab. Diese Bühnengestaltung verweist von Beginn des Stückes an darauf, dass Murukan die zentrale Figur des Spieles ist. Die Handlung 


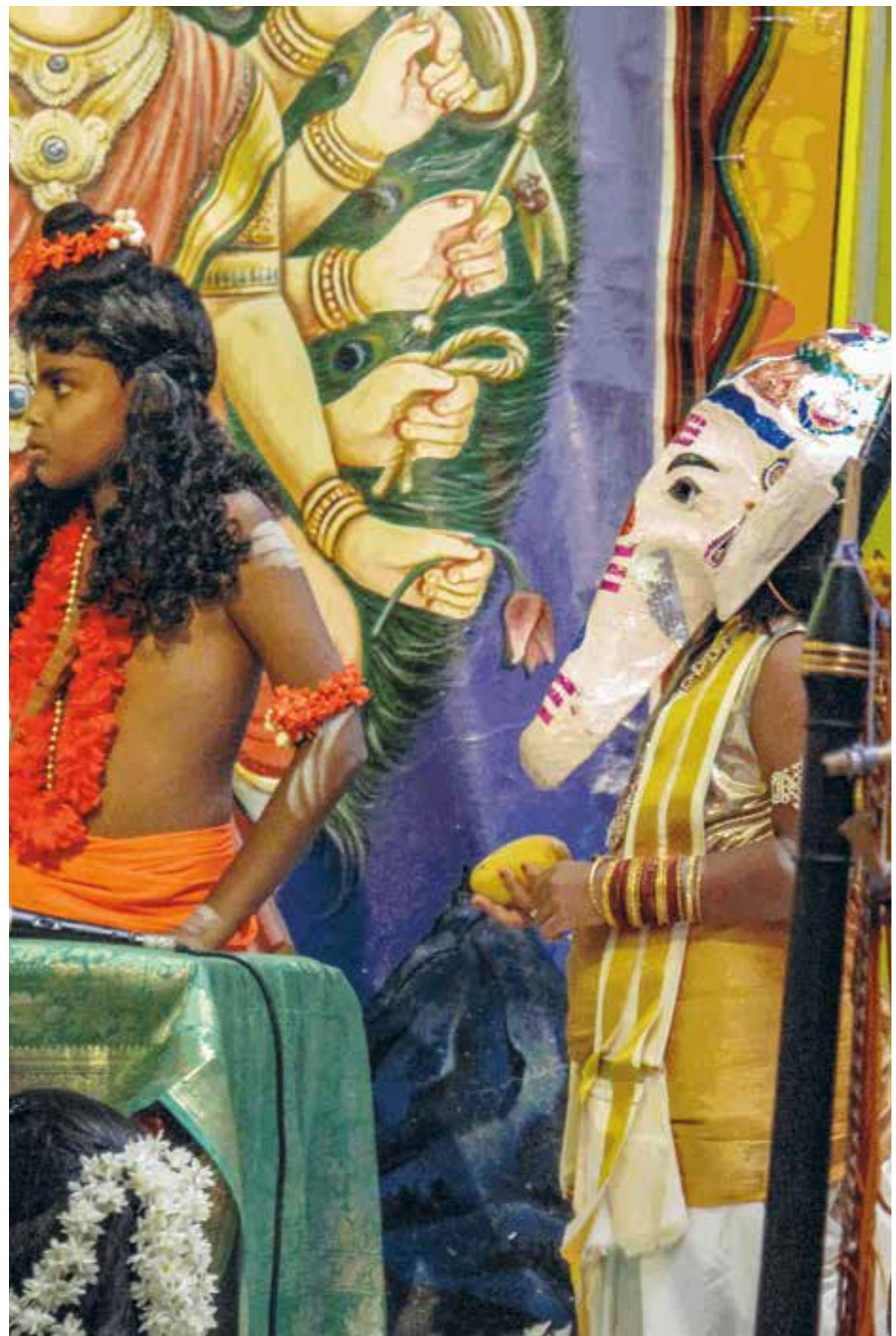

Abb. V 23: Der Vināyakar-Darsteller mit Mango nach dem ersten Teil des Stückes

(12.08.2009). 
in der zweiten Hälfte des Stückes, nach der Weltumrundungs-Prozession Murukañs, kreist um Murukan - obwohl Vināyakar erst einmal von Civan zum Sieger des Wettkampfes gekürt wird.

Interpretationen des Narratives: Eine Botschaft an nachfolgende Generationen Victor Turner, der sich in seinem Werk From Ritual to Theatre: The Human Seriousness of Play unter anderem den Verbindungslinien von "profaner» und «sakraler» Inszenierung gewidmet hat, beschreibt, dass performative Darstellungen Erklärungsformen des Alltags sind, die Verborgenes sichtbar machen können:

In a sense, every type of cultural performance, including ritual, ceremony, carnival, theatre, and poetry, is explanation and explication of life itself, (...). Through the performance process itself, what is normally sealed up, is accessible to everyday observation and reasoning, in the depth of socio-cultural life, is drawn forth. (Turner 1982, 13)

In der beschriebenen Inszenierung im Tempel in Adliswil - wie auch in den beschriebenen Performanzen, die um den Gott Aiyappan kreisen - wird ein Narrativ durch die Performanz von Kindern sichtbar gemacht. Die Kinder selbst verkörpern die Gottheiten (ähnlich den geweihten Götterstatuen im Tempel) und erfahren die Geschichte am eigenen Leib.

Die Performanz beinhaltet den von Turner thematisierten Aspekt des Erklärens (explanation) und der Verdeutlichung (explication). Sie verfolgt pädagogische Ziele, indem sie zum einen den schauspielenden Kindern religiöses Wissen nahebringt und zum anderen eine Botschaft ans Publikum transportiert. Die Geschichte der Aufführung wird mir bei meinem vorausgehenden Anruf im Tempel in Adliswil wie folgt erzählt: «Shiva hat eine Mango bekommen. Shiva hat zwei Söhne: Murugan und Vishnu. Der Vater soll die Mango nun gerecht unter seinen Söhnen aufteilen, aber diese ist nicht zu teilen. Er sagt daher: 〈Wer als erstes drei Mal die Welt umrundet, der bekommt die Mango.> Murugan ist auf seinen Pfau gestiegen und losgeflogen. Vishnu aber hat nur seine Maus und hat seine Eltern drei Mal umrundet. Das ist eine Sage. Sie besagt, dass die Eltern das Allerwichtigste sind.» Diese Variante der Erzählung zeigt die Fluidität des Inhalts der Geschichte an. Der Informant nennt entgegen der gängigen Variante, in welcher Murukan und Vināyakar die Hauptpersonen sind, Vishnu als eine zentrale Figur der Erzählung. ${ }^{453}$ Des Weiteren berichtet der Informant nur vom ersten Teil des Mythos, welcher den Wettstreit Murukañs und

453 Auf meine Nachfrage, ob sich die Geschichte nicht um die beiden Söhne Murukan und Vināyakar drehe, wird mir geantwortet, dass aus Vināyakar Vishnu entstanden sei. 
Vināyakars beinhaltet. Die Auseinandersetzung zwischen Murukan und seinem Vater, die aus diesem Wettbewerb erfolgt, wird nicht erzählt. Das Spiel im Tempel in Adliswil inszeniert auch die Rückkehr Murukans, der zornig über seine Niederlage seine Eltern verliess und sich als Einsiedler auf einen Berg zurückzog. Dieser zweite Teil der Geschichte macht die Bedeutung Murukañs für die Tempelbesucher deutlich. Vināyakar hat zwar durch seine Schläue den Wettbewerb gewonnen; jedoch wird er durch Civans abschliessenden Ausspruch, dass Murukan eigentlich die wahre «Frucht sei» - in Analogie zu Vināyakars Aussage, dass seine Eltern «die ganze Welt seien»-, auf eine niedrigere Stufe als sein Bruder gestellt. Somit ist die Aufführung dieser Geschichte auch Teil von Murukan-bhakti und entspricht der Ausrichtung des Tempels als Murukan-Tempel.

Viele Informanten betonen, dass die dargestellte Geschichte eine Botschaft habe. Diese bestehe darin, dass «die Eltern für die Kinder die ganze Welt sind» und diese daher ihre Eltern zu ehren hätten. In der gegenwärtigen tamilischen Diaspora-Situation, in welcher die Differenz zwischen der ersten Generation, welche noch in Sri Lanka geboren und aufgewachsen ist und den nachfolgenden Generation, die meist in der Schweiz sozialisiert wurde, gross ist, bekommt eine solche take home message der aufgeführten Geschichte noch einmal eine grössere Bedeutung. Zuschauende Tempelbesuchende weisen darauf hin, dass die Inszenierung mit Kindern im Tempel eine diasporische Besonderheit sei. In Sri Lanka werde zum Mangofest das Narrativ innerhalb von rituellen Handlungen mit Hilfe der Götterstatuen nachgeahmt. Dort werden die Figuren während der «Weltumrundung» Murukanns im Freien um das Tempelgebäude getragen. Dass die Performanz in Adliswil nur im Inneren des Tempels stattfindet, ist eine diasporisch bedingte Änderung, welche die Bedeutung der lokalen räumlichen Gegebenheiten für Ritualveränderungen unterstreicht. Motivation für die Einführung des Theaterstücks war die Weitergabe der Geschichte an die nächsten Generationen und kann als Teil von «praktischem Religionsunterricht» angesehen werden.

Der erste Teil der Geschichte beinhaltet auch ein subversives Element. Vināyakar und Murukan werden als ungleiche Brüder gezeichnet, deren Persönlichkeitsmerkmale u.a. dadurch besonders hervorgehoben werden, dass sie unterschiedliche Wege einschlagen: Vināyakar den Weg der Hingabe an seine Eltern und Murukan den Weg des Rückzugs aus der Welt. Murukan wird als entschlossen, sportlich, agil und voller Tatendrang beschrieben, Vināyakar als schlau, aber träge. Durch den Sieg Vināyakars wird seine Lösung als eine besondere Form innovativer Intelligenz betont und dem Publikum als vorbildliche Strategie präsentiert. Jedoch bleibt unbestritten, dass Murukan eigentlich der ist, der das Zentrum der Ge- 
schichte bildet. Der Spannungsbogen des Stücks kreist um seine Figur und seine Entscheidung, als Asket zu leben. Als absolute Autorität erklärt Civan, der Vater, abschliessend, dass Murukan selbst das Ziel (des Wettbewerbs) ist, und die Mango ein Symbol Murukañs sei.

Die Aufführung einer Geschichte aus der Hindu-Mythologie in einem Tempel durch Kinder stellt eine Innovation dar, die in der Diaspora-Situation begründet liegt. Die Theateraufführung mit pädagogischem Auftrag wird mit den traditionellen rituellen Handlungen zum sechsten Tag des jährlichen Tempelfestes in Murukan-Tempeln verbunden und lässt eine Zwischenform zwischen Theateraufführung und Ritual entstehen.

Darüber hinaus vergegenwärtigt die szenische Darstellung einer traditionellen Geschichte aus der Hindu-Mythologie diese in Raum und Zeit. Zum einen wird durch sie der Tempel in der Schweiz mit dem MurukanPilgerort Palani verbunden. Zum anderen wird die aufgeführte HinduErzählung durch die Kinder, welche innerhalb dieser religiösen Performanz die Gottheiten verkörpern, die verwendeten Kostüme wie auch das Setting interpretiert und aktualisiert. Die Theateraufführung spiegelt die Bedeutung der materiellen Kultur für Hindu-Praxis gerade in der Diaspora.

Durch die szenische Darstellung werden aber nicht nur mythologische Geschichten unter Anleitung des Priesters an die nächste Generation weitergegeben. Eine wichtige Funktion der Theateraufführung besteht in der Weitergabe religiösen Wissens und in der Vermittlung von gesellschaftlichen Werten. Respektvolles Verhalten gegenüber den Eltern wird als erstrebenswert vermittelt, wie auch Askese als Teil von Murukan-bhakti als religiöse Praxis betont wird. Der Effekt der Weitergabe wird dadurch verstärkt, dass Akteure der zweiten Generation diese Geschichte performen und die Figuren verkörpern. Die Inszenierung wird von der ersten Generation übernommen, während die theatralen Handlungen im Tempel von der zweiten Generation ausgeführt werden.

\section{3 Öffentliche Präsenz an der Schnittstelle zwischen Religion und Politik: Performanzen für Frieden und Gerechtigkeit}

Von tamilischen Gruppen durchgeführte Performanzen mit religiösen Bezügen in der öffentlichen Sphäre der Schweizer Mehrheitsgesellschaft fanden im Untersuchungszeitraum nicht nur bei Hindu-Tempelfesten und katholischen Wallfahrten statt, sondern auch als einmalige Ereignisse aufgrund aktueller Entwicklungen in Sri Lanka. 
Innerhalb der sri-lankisch tamilischen Diaspora gibt es vielfältige Interferenzen der Sphären Religion und Politik. ${ }^{454}$ Wie in IV 3.3 bereits dargestellt, führte die Swiss Tamil Krishna Society Gebete für den Frieden in Sri Lanka innerhalb ihres tamilischen Sonntagsfestes durch; weitere Formen von «Friedensgebeten» und performative Ausdrücke als Reaktionen auf die Kriegsereignisse, die entweder in Tempeln stattfanden oder von Tempelvereinen mitorganisiert wurden, werden im Folgenden beispielhaft vorgestellt.

Diaspora-Gruppierungen traten nach einer erneuten Eskalation des Bürgerkriegs ab November 2007, als ranghohe Mitglieder der LTTE bei einem Luftschlag der sri-lankischen Armee getötet wurden, und besonders in der Schlussphase des Krieges Ende 2008 bis Mai 2009, verstärkt mit aufs Heimatland ausgerichteten politischen Aktionen in den öffentlichen Raum, um auf die Situation der tamilischen Bevölkerung in Sri Lanka aufmerksam zu machen (vgl. Vimalarajah/Cheran 2010). Besonders die Ereignisse im bis 2009 von der LTTE kontrollierten Distrikt Mullaittīvu mit einem hohen Anteil an tamilischer Bevölkerung im Mai 2009, als Tausende Zivilpersonen in wenigen Tagen ums Leben kamen, waren auch in der Schweiz präsent.

Die Diaspora-Akteure wählten unterschiedliche Formen, um die Schweizer Bevölkerung auf die Ereignisse in Sri Lanka aufmerksam zu machen. ${ }^{455}$ Dieses Engagement kann als bridging bezeichnet werden (Stepick/Ray/Mahler 2009). Neben tamilischen Migrantenorganisationen traten auch HinduAkteure mit politischen Anliegen in der Öffentlichkeit auf. Die DiasporaAkteure führten durch Rückbezüge zum Heimatland Ritualinnovationen in die Hindu-Praxis in der Schweiz ein, die sich durch eine Bandbreite von Ausdrucksformen auszeichneten, wie Prozessionen durch Wohnviertel, interreligiöse Friedensgebete oder die zeitweise Einführung neo-hinduistisch geprägter Meditationsformen in die Tempelpraxis.

Am 25.05.2009 ${ }^{456}$ führte eine von tamilischen Hindus und Christen initiierte und an die religiösen Orte Tempel und Kirche angebundene Prozes-

454 Innerhalb der tamilischen Geschichte finden sich immer wieder Beispiele der Verknüpfung von tamilisch ethno-nationalistischer Politik und Hindu-Religion. Anschaulich kann dies im indischen Bundesstaat Tamil Nadu gezeigt werden, wo ein tamilischer kultureller Nationalismus - mit einer Betonung auf Sprache und Religion - vertreten wurde und wird (vgl. Rösel 1997).

455 So gab eine tamilische Gruppe zwei Mal eine Gratiszeitung, die Aktionszeitung 30Minuten, heraus, welche auf die Ereignisse in Sri Lanka aufmerksam machen sollte. Im April 2009 erschien diese unter der Schlagzeile «Wie wir Tamilen leiden - und warum die Schweiz schweigt». Ausserdem wurde durch drastische Massnahmen wie der Selbstverbrennung eines jungen Tamilen vor dem UNO-Gebäude in Genf am 26.02.2009 und Hungerstreiks versucht, die Aufmerksamkeit der Schweizer Mehrheitsöffentlichkeit auf sich zu ziehen.

456 Die Prozession fiel auf den ersten Tag der Trauerperiode, die von der LTTE aufgrund des Todes ihres Anführers ausgerufen worden war. Der Anlass war jedoch bereits vor Proklama- 
sion durch ein Wohngebiet der Zürcher Orte Glattbrugg und Opfikon, die als Veranstaltung für den Frieden initiiert war, um in einer Zeit schwerer militärischer Gefechte in Sri Lanka für die Menschen dort zu beten und die Schweizer Mehrheitsbevölkerung für die Anliegen der tamilischen Bevölkerung zu sensibilisieren. Diese öffentliche Performanz stellte eine innovative Form des zivilgesellschaftlichen Engagements tamilischer Hindus in der Diaspora dar. Der Begriff der Prozession bezeichnet kollektive Bewegungen, welche religiös und/oder politisch aufgeladen sind. Sie sind «absichtsvoll gestaltete Lokomotionsereignisse» (Gengnagel/Horstmann/ Schwedler 2008, 3). Die Teilnahme an einer Prozession ist per definitionem eine öffentliche Handlung.

Die Prozession war eingebettet in zwei religiöse Zeremonien: Sie begann mit einer pūcai um 17 Uhr im Civan Kōvil in Glattbrugg. Die darauffolgende Prozession startete um 18Uhr am Bahnhof Glattbrugg, führte durch das angrenzende Wohngebiet und endete in der Reformierten Kirche Opfikon mit einem gemeinsamen Friedensgebet, welches von Schweizer Christinnen und Christen geleitet wurde. Organisatoren der Veranstaltung waren die Ökumene Opfikon-Glattbrugg, der Civan Tempel in Glattbrugg und die politisch ausgerichtete Migrantenorganisation Tamilenforum Schweiz. Die Prozession war vorab von der Gemeinde Opfikon bewilligt worden. Bereits im Vorfeld erregte die Prozession mediales Interesse: So berichtete der Tages-Anzeiger vorab über diesen Anlass unter dem Titel «In Opfikon gehen die Tamilen auf die Strasse». ${ }^{457}$ Im Folgenden zitiere ich aus meinem Beobachtungsprotokoll vom 25.05.2009:

Eine Gruppe von circa 40 Tamilen und 10 Schweizern treffen sich am Bahnhof

Glattbrugg. ${ }^{458}$ Frauen wie auch Männer sind teilweise traditionell gekleidet.

tion der Trauerperiode angekündigt worden. Noch in der Zeit vom 17. bis 24. Mai 2009 gingen viele Tamilinnen und Tamilen davon aus, dass Vēluppillai Pirapākarañ lebe und die Verlautbarung seines Todes Propaganda des sri-lankischen Staates sei.

In der Erklärung der LTTE vom 24. Mai 2009 wurde der Tod Pirapāharañ bekannt gegeben und eine Woche der Trauer ausgerufen.

457 Daniel Schurter, In Opfikon gehen die Tamilen auf die Strasse, in: Tages-Anzeiger, 19.05.2010.

458 Die aktuellen Ereignisse in Sri Lanka hatten auch auf die konkrete Ausgestaltung der Prozession Auswirkungen: Im Vorfeld wurde von den Veranstaltern eine grosse Zahl an Teilnehmenden erwartet. «Die Organisatoren des ökumenischen Friedensgebets rechnen mit bis zu 500 Teilnehmern. Es können aber durchaus auch mehr kommen», hiess es im Tages-Anzeiger. Ausserdem wurde befürchtet, dass es eventuell zu gewalttätigen Aktionen einzelner Teilnehmender kommen könnte. Die Atmosphäre war jedoch eher resigniert, still und traurig als aggressiv und laut. Dass weitaus weniger Menschen an der Prozession teilnahmen, lag wahrscheinlich daran, dass am 18.05.2009 die LTTE offiziell besiegt worden war und diese am 24.05., 
Die Stimmung ist gedrückt und eher angespannt. Die Menschen reden kaum. Zwei Männer tragen eine Fackel, die sie nun anzünden. Jeder, der an der Prozession teilnimmt, bekommt ein rotes Grablicht. Journalistinnen und Journalisten befragen die Anwesenden. Die Gruppe beginnt sich zu bewegen; tamilische Ordner - gekleidet mit Verkehrsweste und in weissem Vesti - begleiten die Prozession und schirmen die Menschen von der Seite gegen den Verkehr ab. Ein tamilischer Mann, der am Anfang der Menschenkette geht, schlägt einen circa $20 \mathrm{~cm}$ Durchmesser umfassenden metallenen Gong, der laut hallt. Nach ein paar Minuten kommen zu den Lauten des Gongs die Töne der Kirchenglocken der reformierten Kirche hinzu, die ununterbrochen läuten. Die Prozession führt durch ein Wohngebiet, nicht nur auf dem Fussgängerweg entlang einer befahrenen Strasse, sondern auch durch nichtbefahrene Wege entlang von Gärten; Menschen schauen, durch die Geräuschkulisse aufmerksam geworden, interessiert aus den Fenstern. Eine Passantin fragt mich, was denn los sei. Ein Polizeiauto und Schweizer Ordner folgen der Menschengruppe. Die Prozession kommt auf dem Weg zur Kirche ins Stocken; die Teilnehmenden stehen vor dem Kircheneingang an, um ihre Kerze an einer der beiden Fackeln anzuzünden. Die Menschen begeben sich mit der brennenden roten Grabkerze in der Hand zum Altar und stellen diese auf dem Altar ab; die aufgestellten brennenden Kerzen werden so formiert, dass sie das tamilische $\bar{O} m$-Zeichen ergeben, welches während des Friedensgebets auf dem Altar stehen bleibt.

Die Prozession endete mit einem öffentlichen hindu-christlichen Friedensgebet in der Reformierten Kirche Opfikon. Der Anlass wurde von tamilischen Akteuren, die das Gebet mit dem Blasen des Muschelhorns und einem tamilischen Lied beginnen, und Mitgliedern einer Vorbereitungsgruppe bestehend aus katholischen, reformierten und methodistischen Christinnen und Christen, gestaltet. In der Begrüssung der Teilnehmenden berichtet eine Schweizerin den Anwesenden, dass tamilische Hindus auf sie zukamen mit der Bitte um einen gemeinsamen religiösen Anlass. «Grund war die entsetzliche Lage der Tamilen im Nordosten Sri Lankas.» Der Vertreter des Tempelvereins in Glattbrugg bezeichnete in seiner Ansprache die Situation in Sri Lanka «als noch schlimmer als die Tsunami-Katastrophe». Er erinnert daran, dass viele in der Schweiz lebende Menschen in den letzten Wochen Angehörige in Sri Lanka verloren haben. Es folgten Berichte von Tamilinnen und Tamilen, die von ihrem Leid erzählen. Sowohl hinduistische Elemente wie das Chanten der Silbe $\bar{O} m$ als auch christliche Ele-

also einen Tag vor der Prozession, offiziell durch Selvarasa Pathmanathan den Tod ihres Führers Pirapākaran anerkannten und eine Woche Trauerzeit ausriefen. 


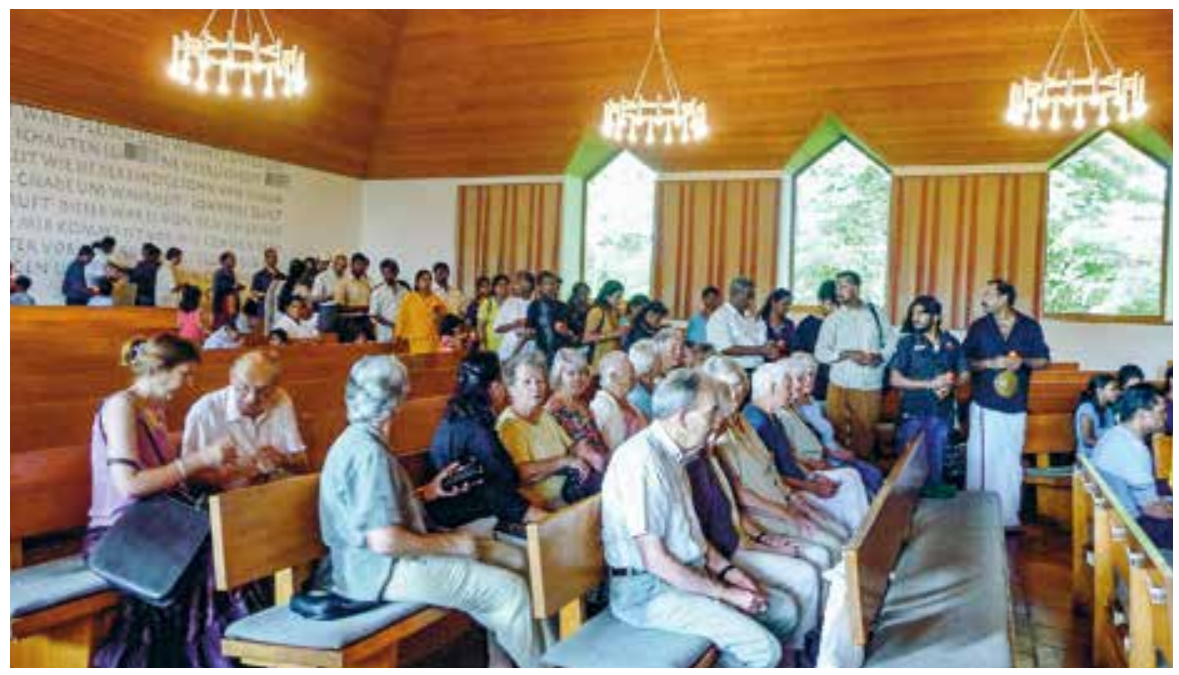

Abb. V 24: Die Prozessionsteilnehmenden kommen in der Reformierten Kirche Opfikon an, um am Friedensgebet teilzunehmen (25.05.2009).

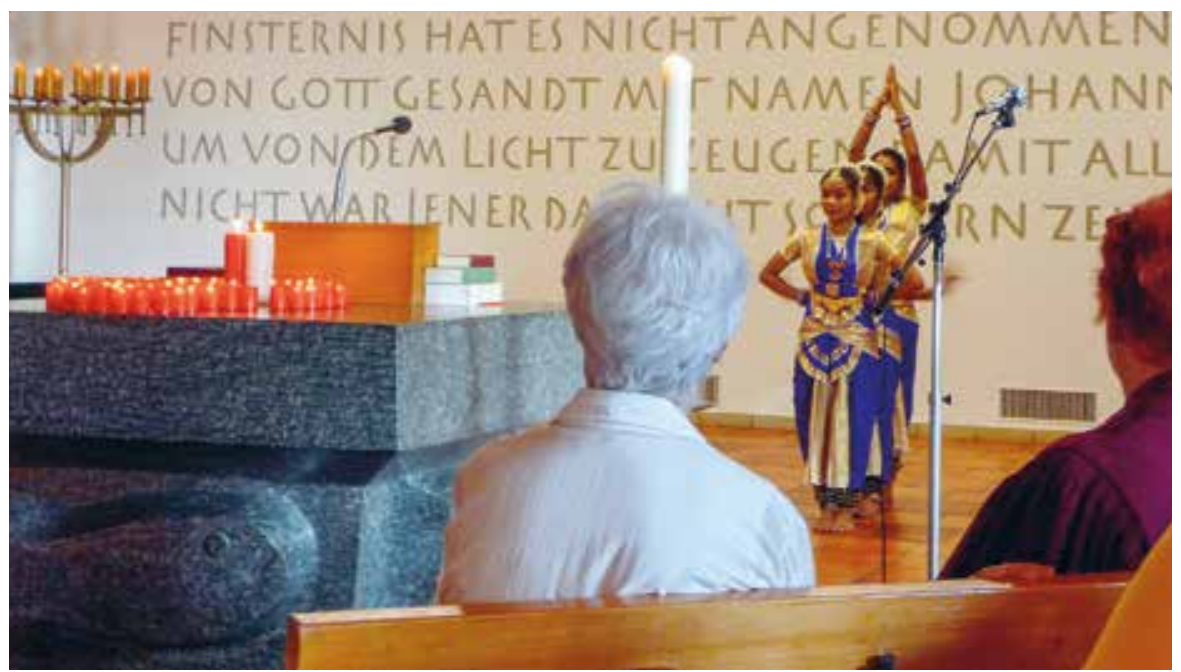

Abb. V 25: bhäratanātyam-Tanz am Ende des Friedensgebets in der Reformierten Kirche Opfikon (25.05.2009).

mente wie das Vortragen von Fürbitten werden in das Gebet eingebaut. Abschluss der Veranstaltung ist eine Tanzvorführung des tamilischen Tanzes bhäratanātyam (tam. paratanātțiyama) und das gemeinsame Sprechen des Vater Unser. 
Im Anschluss an das Friedensgebet fand eine pūcai im Tempel statt, die ich auch besuchte. In meinem Beobachtungsprotokoll vom 25.05.2009 heisst es weiter:

Ich gehe in den Tempel. Es sind nur sehr wenige Menschen anwesend. Rechts an der Wand lehnt Herr X; er trägt einen vesti. Ich finde, er sieht mitgenommen aus. Wir begrüssen uns, indem er mir die Hand gibt. «Wie geht es Ihnen?〉 frage ich. «Nicht gut. Es ist vorbei〉, sagt er.

Die skizzierte öffentliche Demonstration in Glattbrugg Ende Mai 2009 stellt eine besondere Form der öffentlichen Präsentation tamilischer Hindus in der Schweizer Öffentlichkeit dar. Es handelt sich um öffentliches, gemeinsames Auftreten zweier unterschiedlicher religiöser Gruppierungen. Gemeinsam ist christlichen und hinduistischen Prozessionsteilnehmenden ihr Engagement für Frieden und Gerechtigkeit in Sri Lanka. Durch die Kooperation mit in der Mitte der Gesellschaft verankerten Institutionen wie der reformierten Kirchengemeinde wurde Öffentlichkeiten übergreifende Aufmerksamkeit geschaffen. Die Interferenzen zwischen Hindu-Vereinen und politischen Vereinen kommen in den Organisatoren der Veranstaltung, dem Tamilenforums Schweiz und dem Civan-Tempel in Glattbrugg zum Ausdruck. Vertreter politischer/kultureller Gruppierungen wie des Tamilenforum Schweiz und der Tamil Youth Organization nehmen am Anlass teil, sowie religiöse Akteure wie beispielsweise Mitglieder des Tempelvereins Glattbrugg und des reform-hinduistischen Vereins Saivanerikoodam.

Diese Form einer sich in der politischen wie auch religiösen Sphäre anzusiedelnden Prozession stellt eine diasporaspezifische Innovation dar, welche als Reaktion auf die Ereignisse in Sri Lanka entstanden ist. ${ }^{459}$

Als Ritualinnovation kann auch das «Friedensgebet» angesehen werden, das am 01.02.2009 im Śrī Civacuppiramaniyar Tempel in Adliswil durchgeführt wurde. Die von einigen Anwesenden als pücai bezeichnete Performanz wurde initiiert, um auf die eskalierte Situation in Sri Lanka sprituell zu reagieren. Das Ritual wurde nicht vom Priester des Tempels durchgeführt, sondern von einem tamilischen Akteur angeleitet, der neue Formen spiritueller Praxis im Tempel einführte. Bestandteil der Performanz war es unter anderem, dass sich die anwesenden 16 Personen vor dem Schrein Gaṇeśas an den Händen hielten. Im Folgenden wird aus dem Protokoll meiner teilnehmenden Beobachtung vom 01. Februar 2009 zitiert:

459 Neben dem skizzierten Beispiel der Prozession in Glattbrugg und dem hindu-christlichen Friedensgebet etablierten auch andere Tempelvereine 2008 und 2009 spezifische Ritualformen, um auf die Ereignisse in Sri Lanka zu reagieren. 
Der Anleiter des Rituals erklärt den Anwesenden auf Tamilisch etwas. Auf Deutsch erklärt er mir, dass alle das Bild eines Regenbogens über ihrem Kopf visualisieren sollen. Unter jeder Person sei ein Trichter, welcher alles Schlechte nach unten in die Erde ableite. Von unten, von «Mutter Erde», wie er sagte, wird dann wieder frische Energie nach oben geleitet. Nach dieser stehenden Meditation setzen sich die Teilnehmenden im Schneidersitz auf den Boden. Mit beiden Händen soll die Handgeste, das Brahma-Mudra, geformt und so gute Energie zu den Menschen in Sri Lanka gesendet werden. Nicht alle Teilnehmenden formen mit ihren Händen das Brahma-Mudra. Einige haben die Augen geschlossen, andere nicht. Der Ritualleiter liest aus einem Buch vor und flüstert leise. Mit der Hand zeichnet er in der Luft geometrische Figuren. Nach dieser Einheit stehen alle auf und nehmen sich im Kreis an der Hand. Der Ritualleiter beendet das Ritual und bedankt sich. Der Priester erscheint und läutet vor dem Ganesha-Schrein die Glocke. Die Teilnehmenden umkreisen den Schrein und wenden sich dem Hauptschrein zu. Danach stehen die Menschen zusammen und unterhalten sich. Schwarzer Tee mit Zucker wird gereicht.

Nicht nur religiöse, sondern auch politische Vereine bezogen Aspekte aus dem religiösen Feld in ihr Friedensengagement mit ein. So organisierte der Verein Tamilenforum Schweiz ${ }^{460}$ vom 07.02. bis 09.02.2009 «interreligiöse Bettage», ein 48-stündiges Gebet («Gebet von und mit Hindus, Christen, Muslimen, Buddhisten, Juden - die grossen Religionsgemeinschaften») in der Offenen Kirche in St. Gallen. ${ }^{461}$ Eines der Ziele der Veranstaltung war ein informationspolitisches: Die Mehrheitsgesellschaft sollte über die Lage der tamilischen Bevölkerung in Sri Lanka in Kenntnis gesetzt und damit ein Bewusstsein für die leidvolle Situation geweckt werden. «Mit diesen Tagen wollen wir Tamilen auf die humanitäre Tragödie aufmerksam machen, die sich in unserer Heimat im Nordosten von Sri Lanka von der srilankischen Regierung verursacht abspielt» (Schreiben von Ganesh Kumar, Verein Tamilenforum Schweiz, vom 02.02.2009).

Zielrichtung der Veranstaltung war es, für Solidarität mit der tamilischen Betroffenen zu werben und Empathie in der Schweizer Mehrheitsbevölkerung zu wecken. «Mit diesem Schreiben laden wir Sie ein, mit uns zu beten, stille zu sein, zu trauern, zu weinen, uns zu helfen, die schwere Last zu tragen». Im offiziellen Anschreiben an die Schweizer Mehrheitsbevölkerung wird als einzige religiöse Referenz auf eine biblische Quelle ver-

460 Zum Verein Tamilenforum Schweiz vgl. Kap. II 1.4.

461 Das Gebet begann am 07.02.2009 um 17 Uhr und endete zwei Tage später zur gleichen Uhrzeit. Am 09. Februar fand um 14.30 Uhr eine Informationsveranstaltung und Pressekonferenz statt. 


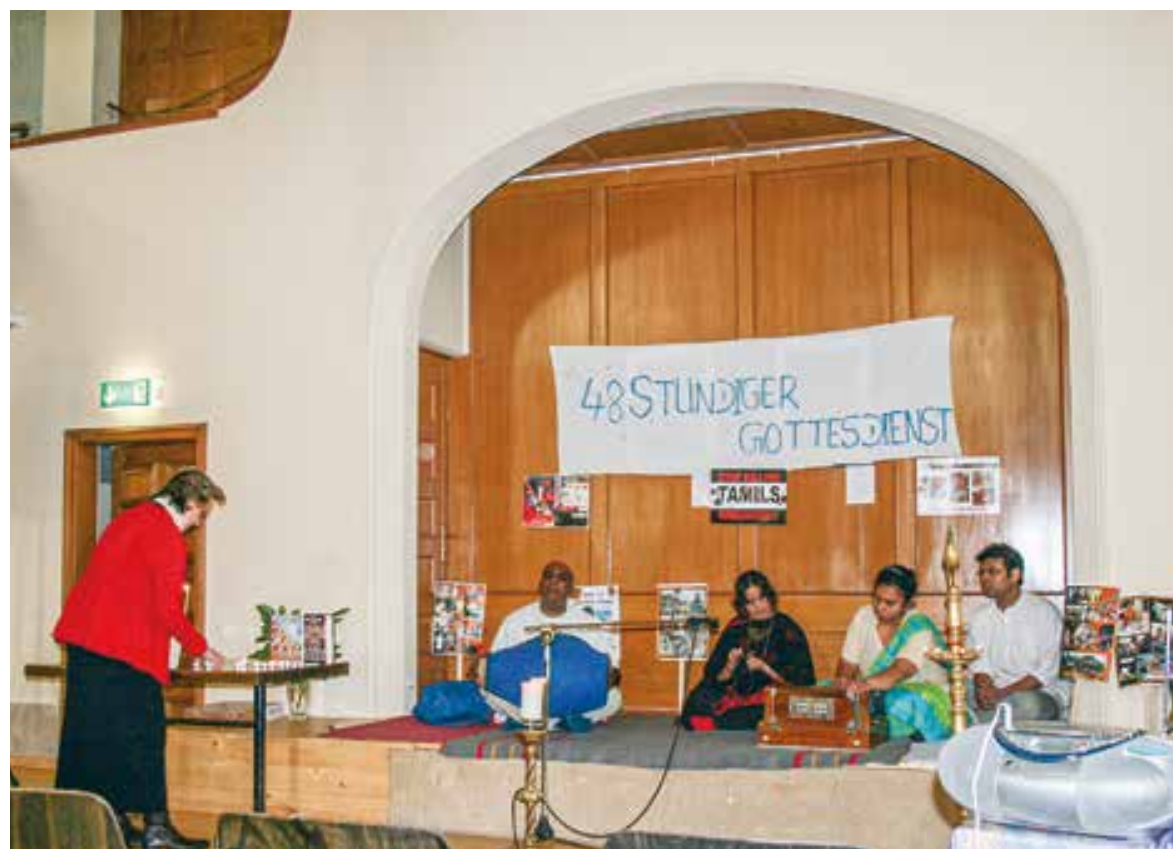

Abb. V 26: Musiker der Vaishnava-Tradition treten während des 48-stündigen Gebets in St. Gallen auf (07.02.2009).

wiesen. Ein Vers aus Psalm 121 wird dem Brief vorangestellt: «Ich hebe meine Augen auf zu den Bergen, woher meine Hilfe kommen wird.» Im Brief wird dann mit diesem Zitat auf die Ausweglosigkeit der Situation der Tamilen in Sri Lanka verwiesen; religiöses Gebet stelle die letzte Hoffnung dar: «In dieser traurigen Situation, können weder die leidenden Menschen in Sri Lanka noch wir mitleidenden Tamilen in der Schweiz mehr tun als unsere Augen auf zu den Bergen zu heben, woher unsere Hilfe kommen wird» (Schreiben von Ganesh Kumar, Verein Tamilenforum Schweiz, vom 02.02.2009).

Die Offene Kirche diente an diesen Tagen darüber hinaus auch als Gemeinschaftsort und safe space für tamilische Besuchende, die zusammenkommen und ihre Sorgen miteinander teilen können: «Ausserdem können wir durch das Gebet wie damals beim Tsunami den betroffenen Tamilen in unserer Umgebung einen Ort bieten, an dem sie ihre Trauer und Betroffenheit, ihre Sorgen und Nöte, mit anderen teilen können» (Schreiben des Tamilenforum Schweiz vom 30.01.2009). 


\section{Zusammenfassung: Tempelbauprojekte und politische Prozessionen als Aushandlungs- prozesse auf dem Weg zu einer öffentlichen Hindu-Praxis}

In der Beschreibung der öffentlichen Präsentation tamilischer Hindu-Praxis in der Schweiz habe ich mich auf die Darstellungen von Tempelöffentlichkeiten beschränkt, die nicht nur die Formen der öffentlichen Präsentation des Tempelgebäudes, sondern auch an die Tempelinstitution gebundene Gruppenpräsentationen mit einschliessen. Zwei Formen sind im Bestreben von Tamilinnen und Tamilen in der Schweiz, ihre Hindu-Praxis auch öffentlich zu praktizieren, unter diesem Aspekt an zentraler Stelle zu nennen:

Zum einen wurde die Präsentation von Sakralgebäuden als Aspekt der Tempelöffentlichkeit dargestellt (V 2). Wie gezeigt wurde, kennzeichnen Elemente der materiellen Kultur wie Ōm-Zeichen, Flaggen (V 2.1) oder kōpuram-Kulissen (V 2.2) die Gebäude in verschiedenen öffentlichen Sphären als Tempel. Tempelbauprojekte nach traditionellen Vorgaben stellen eine der öffentlichkeitswirksamsten Arten der Präsentation von tamilischen Hindu-Traditionen in der Schweiz dar. Das zeigt sich nicht zuletzt im ersten tamilischen Tempelbauprojekt in Trimbach. In Zukunft wird sich zeigen, wie der erste nach religiösen Vorgaben gebaute tamilische Tempel in der Schweiz sich im religiösen Feld und innerhalb der transnationalen tamilischen öffentlichen Sphäre behaupten wird. Über diese konkrete Lokalisierung in der Schweizer nationalen Öffentlichkeit präsentiert die Sichtbarmachung der Tempel in der digitalen Welt diese auch im virtuellen öffentlichen Raum der transnationalen Diaspora (V 2.3). Innerhalb der Tempelöffentlichkeiten finden sich verschiedene Positionierungsstrategien. Oftmals wird innerhalb öffentlicher tamilischer Sphären der Aspekt der Tamilness betont, während innerhalb der Mehrheitsöffentlichkeit die Hinduness hervorgehoben wird.

Zum anderen stellen performative Hindu-Praktiken einen weiteren Ausdruck von Tempelöffentlichkeit dar (V 3), wie das Tanzen mit dem $k \bar{a} v a t i$-Bogen. Sakrales Theater in den Tempeln ist eine weitere Form der öffentlichen Sichtbarmachung und Aktualisierung von Hindu-Traditionen in der Schweiz (V 3.2). In den Tempeln fanden jedoch auch rituelle Performanzen statt, die sich auf die Ereignisse im Herkunftsland bezogen (V 3.3). Der Abschnitt fokussierte auf an Tempel angebundene Handlungen, die auf die Bürgerkriegsgeschehnisse bezogen waren und Ausdruck eines an der Schnittstelle von Religion und Politik angesiedelten Aktivismus waren. 
Die dargestellten Aspekte von tamilischer Hindu-Tempelöffentlichkeit in der Schweiz haben gezeigt, dass lokale Machtstrukturen Einfluss auf die öffentlichen Präsentationsformen haben. Der Prozess des öffentlichen Sichtbarwerdens ist in Zusammenhang mit den Spezifika der tamilischen Diaspora und den Inkorporationsbedingungen der Schweiz zu sehen, wie beispielsweise dem föderalistischen System der Schweiz mit unterschiedlichen Religionspolitiken. Die nationale öffentliche Sphäre ist von unausgewogenen Machtverhältnissen geprägt, da die Präsentation einer Minderheit in der Öffentlichkeit der Dominanzgesellschaft von den Normen der Mehrheit als eine Inkorporationsbedingung beeinflusst wird. Es findet ein anhaltender Aushandlungsprozess um angemessene Formen öffentlicher Sichtbarkeit statt. Tempel und die an diese gebundenen Handlungen und Gruppenidentitäten können innerhalb der Schweizer nationalen Öffentlichkeiten und/oder der diasporischen tamilischen Öffentlichkeiten präsent sein. 


\title{
Fazit: Beheimaten durch diasporische Innovationen
}

\author{
Please always remember, the secret of survival is \\ to embrace change, and to adapt. \\ (Zitat aus dem Roman "A Fine Balance", \\ Mistry [1995] 2006, 231)
}

Ein Bild (Luzern November 2010): Im Fenster des tamilischen Lebensmittelgeschäfts Nanthas Asian Shop Namasivayam im Luzerner Bruchquartier sind verschiedene Gegenstände ausgestellt, die auf unterschiedliche Bezüge tamilischer Hindu-Praxis in der Diaspora verweisen. Bilder von HinduGottheiten, einem Reform-Guru und Jesus hängen neben Werbung für internationale Telefonanbieter und Fotografien aus den letzten Tagen des Bürgerkrieges, die aneinander gereihte tote Menschen zeigen. Diese visuellen Präsentationen und materiellen Kulturelemente stehen für wichtige Teilbereiche der Lebenswelten tamilischer Migrantinnen und Migranten in der Schweiz.

Drei bunte Leuchtbilder zeigen die Hindu-Gottheiten Sarasvati, Lakhṣmī und Gaṇeśa abgebildet, daneben hängt eine Darstellung von Jesus und seinen Jüngern beim letzten Abendmahl und rechts davon ist ein blinkender Murukan, der tamilische Gott (vgl. Kap. II 2.3), auf seinem Pfau zu sehen. Das Nebeneinander verschiedener etablierter Religionstraditionen lässt auf den Stellenwert sowohl von Hindu-Traditionen als auch christlichen Zugehörigkeiten innerhalb der tamilischen Diaspora schliessen. Darüber hängt eine Preisübersicht von Telefonanbietern für Anrufe in die unterschiedlichsten Länder der Welt. Die Fahnen der Länder sind dargestellt, daneben der Slogan $«$ Schweiz $=$ Ausland $=1$ Preis $»$. Die Telefonkarten ermöglichen eine preiswerte Kontaktaufnahme mit Menschen in den unterschiedlichen Kontinenten der sri-lankisch tamilischen Diaspora als weltumspannendes Netzwerk. 
Links davon sieht man eine Werbeanzeige für Sai-Baba-Räucherstäbchen. Hier zeigt sich die Bedeutung materieller Kultur (Räucherstäbchen als Instrumente zur Verehrung der Gottheiten am pūcai-Platz), wie auch der Stellenwert von Akteuren aus dem neohinduistischen Spektrum innerhalb der tamilischen Diaspora. Das Nebeneinander religiöser Motive und politischer Themen wird durch die daneben befestigten Computer-Ausdrucke mit farbigen Fotos von toten Männern, die in eine Reihe nebeneinander aufgebahrt sind, verdeutlicht. Die Seiten sind auf den 07.04.2009 datiert, was Rückschlüsse über den historischen Kontext der Bilder zulässt. Sie wurden in den Tagen der heftigen Gefechte am Ende des Bürgerkriegs in Sri Lanka von einer Webpräsenz mit dem programmatischen Domainnamen TamilWin.com ausgedruckt.

Die Elemente des Schaufensters ergeben ein Bild und zeigen damit die Gleichzeitigkeit und das Nebeneinander sowie die Bezüge unterschiedlicher Bereiche innerhalb der tamilischen Diaspora auf. Religiös konnotierte Praktiken sind immer auch mit anderen Aspekten, welche die tamilische Diaspora konstituieren, verbunden.

Die vorliegende Studie hat Lokalisierungsdynamiken von Hindu-Praxis in der Schweiz im Kontext der sri-lankischen tamilischen Diaspora dargestellt und analysiert. Den Implikationen des spatial turn folgend, hat sie räumliche Kategorien in den Blick gerückt und zum Zentrum der Analyse gemacht.

Vier Analysekategorien - Diaspora, Inkorporation, Raum und Öffentlichkeit - wurden mit ihrem theoretischen Hintergrund vorgestellt (I 1.3). Ihre Relevanz entfalten sie durch ihre vielfältigen Interferenzen innerhalb des analytischen Rahmens in allen Kapiteln der Studie und liefern so wichtige Erkenntnisse zu einer systematisierten Darstellung der Lokalisierungsdynamiken. Es wurde gezeigt, dass auch innerhalb der Feldforschung und der mithilfe der qualitativen empirischen Sozialforschung erhoben Daten die aktuellen Ereignisse sowohl im Herkunfts- wie auch im Residenzland entscheidenden Einfluss hatten (I 2).

Die sri-lankisch tamilische Diaspora (II) stellt einen wichtigen Aspekt der Lokalisierung von Hindu-Praktiken tamilischer Akteure in der Schweiz dar. In der Ausbildung von sozialen Vollzugsräumen von Hindu-Praxis und der Präsentation von tamilischen Hindu-Praktiken in öffentlichen Sphären spielen Bezüge zur sri-lankisch tamilischen Diaspora, Rückbezüge ins Herkunftsland und transnationale Netzwerke eine zentrale Rolle. So sind etwa Pilgerorte in Südasien Bezugsorte für in der Schweiz lebende tamilische Hindus. Dies zeigt das Agieren tamilischer Hindus in einem transnationalen sozialen Raum auf (IV 6). 
Des Weiteren konstituieren die Inkorporationsbedingungen des Residenzlandes Schweiz einen wichtigen Aspekt der Lokalisierungsdynamiken, was in Kapitel III systematisch dargestellt wurde. Die Einflüsse der Inkorporationsbedingungen wurden in den Abschnitten des Kapitels mit Bezug auf die konkrete Lokalisierung der religiösen Praxis verdeutlicht (III 4). Dazu zählen die Prägungen im Herkunftsland (III 4.1), die Flüchtlingspolitik des Aufnahmelandes (III 4.2), die Integrationspolitik der Schweiz und ihre Diskurse (III 4.3), die Religionslandschaft und -politik (III 4.4) und öffentliche Diskurse der Mehrheitsbevölkerung (III 4.5).

Kapitel IV als ein inhaltlicher Schwerpunkt der Studie fokussierte auf verschiedene Formen von sozialen Räumen, in welchen Hindu-Praxis vollzogen wird. Anhand des pūcai-Platzes im Schrank (IV 2), als Sinnbild für diasporische Wandlungsprozesse von Hindu-Praxis im Wohnraum, wurde die Flexibilität von Hindu-Akteuren im Vollzug der Praxis aufgezeigt. Durch das Erschaffen abgegrenzter pūcai-Plätze im privaten Bereich werden multisensual erlebbare religiöse Wahrnehmungsräume hergestellt.

Das Konzept der Kontaktzonen hat sich als sehr fruchtbar erwiesen, um dynamische Interaktionen unter einem räumlichen Aspekt zu betrachten (IV 3). Kontaktzonen spiegeln immer auch Auswirkungen der Inkorporationsbedingungen wider. Über shared places als Sozialräume der Ausübung von Hindu-Praxis wurden Verbindungen zu neo-hinduistischen Gruppen thematisiert. Als besonders instruktiv hat sich die Entstehung und Darstellung eines speziellen tamilischen Sonntagsfestes innerhalb des ISKCONTempels in Zürich erwiesen (IV 3.3/3.4). Hier werden die Spezifika von Hindu-Praxis tamilischer Migrantinnen und Migranten aus Sri Lanka zum Zeitpunkt der Studie deutlich. Es wurde gezeigt, dass der Raum für adäquaten Vollzug für Hindu-Praxis, den der bereits vorhandene Krishna-Tempel darstellte, für die Akteure nicht genügte, um sich am Ort religiös zu beheimaten, da der Aspekt der Tamilness als nicht ausreichend repräsentiert wahrgenommen wurde.

Kapitel IV hat die Wichtigkeit von Sakralräumen für tamilische HinduMigrantinnen und -Migranten als sinnliche Wahrnehmungsräume einer heimatlichen Sphäre und als multifunktionale, selbstverwaltete Räume für eine marginalisierte Migrantengruppe deutlich gemacht. Die Etablierung selbstverwalteter Tempel in angemieteten Hallen und die Errichtung eines tamilischen Tempelnetzwerkes in der Schweiz war ein zentraler Schritt, um sich in der Schweiz zu beheimaten (IV 4.1). Eine Analyse der Diskurse um die Begriffsbestimmung und -abgrenzung des Terminus Tempel als religiösem Wahrnehmungsraum und Vergemeinschaftungsort innerhalb einer Diaspora ohne vorab fest etablierte hindu-religiöse Strukturen konnte konkrete Lokalisierungsdynamiken im Schweizer Kontext aufzeigen (IV 4.3). 
Das Changieren der Lokalisierung von Praktiken zwischen der häuslichen Sphäre und der sri-lankisch tamilischen diasporischen Öffentlichkeit des Tempels zeigt hier spezifische Dynamiken der Diaspora an. Dies wurde exemplarisch anhand des Jahresfestes taippoikkal demonstriert; die Analyse dieses Festes hat den Prozess der so genannten Tempelisierung deutlich gemacht (IV 5).

Die Darstellungen zur öffentlichen Präsentation der hindu-tamilischen Minderheit und im Speziellen zu Dynamiken von Tempelöffentlichkeiten basierte auf der Annahme einer Pluralität öffentlicher Sphären (Kapitel V). Am Beispiel des Aufstellens von kōpuram-Kulissen als öffentlicher Kennzeichnungen der Gebäude als Hindu-Tempel wurde eine diasporisch bedingte Bedeutungsverschiebung der «Türme» deutlich: Der immanent religiöse Zweck von Tortürmen traditioneller Tempel geht durch die Zweidimensionalität verloren und wird auf seine Wirkung als sichtbares Element in der öffentlichen Sphäre reduziert (V 2.1). Zentrale Entwicklung im Forschungsfeld während des Untersuchungszeitraums war der Tempelbau in Trimbach, der als imposanter Ausdruck des Beheimatens von tamilischen Hindu-Traditionen in der Schweiz angesehen werden kann (V 2.2). Als symbolische und soziale Ressource stellt er einen Ort der permanenten Traditionswahrung dar. Eine Analyse der Präsentation der Tempel in der virtuellen Welt war instruktiv, um Positionierungsstrategien in den verschiedenen Sphären der Öffentlichkeiten aufzuzeigen (V 2.3).

Die Analyse zu Performanzen für Frieden und Gerechtigkeit im Kontext des Bürgerkrieges in Sri Lanka (V 3.4) macht erneut die Bedeutung der Rückbezüge ins Herkunftsland und zur transnational agierenden sri-lankisch tamilischen Diaspora deutlich, wie auch die gegenseitigen Beeinflussungen durch die Inkorporationsbedingungen innerhalb der Schweiz. Dieses Themenfeld war besonders im Untersuchungszeitraum der Studie virulent, da dieser mit dem militärischen Ende des Bürgerkriegs in Sri Lanka zusammenfiel.

Der Titel dieses Fazits beinhaltet das Verb beheimaten und zeigt damit den in dieser Untersuchung beschriebenen aktiven Prozess der Akteure an, ihre Hindu-Traditionen in neuen Kontexten zu etablieren. Der Prozess des Beheimatens durch religiöse Performanzen kartiert sozialen Raum und zieht Grenzen zwischen Gruppenidentitäten. Die in der Untersuchung vorgestellten Prozesse des religious homemaking (Tweed 2006, 111), des Erschaffens von Verehrungsorten für die Hindu-Göttinnen und Götter in der Schweiz, werden durch diasporische Innovationen verwirklicht. Diese Agency der Akteure wird jedoch durch die Inkorporationsbedingungen des Residenzlandes eingeschränkt und fordert die Patiency der Akteure. 
Durch alle Kapitel der Studie zieht sich die Darstellung spezifischer Anpassungsprozesse als Resultate von Umgebungsbedingungen, wie sie beispielsweise in der innovativen Form der kōpuram-Kulissen (V 2.2) oder im Prozess der Tempelisierung (IV 5) zum Ausdruck kommen. Durch kreative Anpassungsprozesse entstehen neue Formen religiöser Praktiken. Zusammenfassend kann konstatiert werden, dass die dargestellten Lokalisierungsdynamiken folgende Gemeinsamkeiten aufweisen, die im Folgenden gebündelt systematisiert werden:

(1) die hohe Bedeutung der Tamilness (und Hinduness) als durch Performanzen kommunizierte Repräsentationsform;

(2) vielfältige Rückbezüge auf die Ereignisse im Herkunftsland innerhalb der Performanzen in der Diaspora;

(3) die hohe Bedeutung der Materialität für die Performanz von HinduTamilness;

(4) die Wichtigkeit von selbstverwalteten Sakralräumen für die Migrantengruppe.

\section{Tamilness (und Hinduness) als durch Performanzen kommunizierte Repräsentationsform}

Innerhalb der Lokalisierungsprozesse tamilischer Hindus in der Schweiz spielt, wie an verschiedenen Stellen der Studie gezeigt, die Performanz von Tamilness als Kennzeichnung von Zugehörigkeit in der Diaspora eine bedeutende Rolle. Als zentrales verbindendes Element der Akteure der srilankisch tamilischen Diaspora wurde deutlich, dass die sogenannte Tamilness (Tamilbezogenheit) als Ausdruck von Zugehörigkeit zentral ist.

Dem Begriff der Tamilness liegt kein essentialisierendes Kultur- oder Identitätskonzept zugrunde, sondern er wird als Form von Gruppen-Repräsentation verstanden. Unter Tamilness wird - analog zu anderen Wortbildungen wie Swissness oder Britishness - eine Form der Repräsentation eines als «Kultur» wahrgenommenen kollektiven Selbstverständnisses verstanden. ${ }^{462}$ «Sie [Bilder von Kulturen] sind aber keine <objektiven Gegebenheiten>, die man von individuellen Exemplaren und Angehörigen der Kultur ableiten könnte, sondern Repräsentationen, die aus bestimmten Perspektiven mit spezifischen Interessen entworfen und mit unterschiedlichen Machtansprüchen vertreten werden» (Sökefeld 2004, 23).

Unter Pan-Tamilness kann eine Form der Repräsentation subsumiert werden, deren Akteure auf der Basis eines transnationalen Gruppen-Bewusstseins agieren. Der Terminus Pan-Tamilness beschreibt jene Formen

462 Tamilness wird in unterschiedlichen Kontexten und Zeiten unterschiedlich verhandelt und definiert, wodurch sich die Formen der Repräsentation ändern. 
von Tamilness, die als regionalunabhängig verstanden werden und die Akteure der transnationalen sri-lankisch tamilischen Diaspora verbindet (vgl. Wickramasinghe 2006, 255). Eine Diaspora unterscheidet sich von einer Minderheit durch ihre transnationalen Vernetzungen. Der Bürgerkrieg im ehemaligen Ceylon verstärkte ein transnationales tamilisches Bewusstsein unter den tamilischen Geflüchteten, die weltweit verstreut sind. In den dieser Studie zugrundeliegenden Beobachtungsprotokollen spielen Perfomanzen, die von den Akteuren als in den Bereich der Tamilness fallend bezeichnet wurden, eine wichtige Rolle. Tamilness, die «Tamilbezogenheit», kann als Bindeglied einer heterogenen Gruppe, die gemeinsam die tamilische Diaspora konstituiert, verstanden werden.

Orte wie Bildungseinrichtungen zum Erlernen der tamilischen Sprache, Kulturvereine, in denen tamilische Kultur gepflegt wird, und tamilische Hindu-Tempel stellen Lokalitäten dar, deren gemeinsamer Bezugspunkt die Aufrechterhaltung der Tamilness ist. Auf der dem tamilischen politischen Widerstand nahestehenden Webpräsenz tamilnation.org ${ }^{463}$ war in dem im Jahr 2004 verfassten Online-Artikel The Tamil Diaspora zu lesen, dass die Schweiz ein besonderes Land innerhalb der tamilischen Diaspora in Europa darstelle. Die tamilische «Kulturszene» wird als besonders rege beschrieben, sodass der Autor V. Sivasupramaniam zu dem Fazit gelangt, dass die Schweiz ein Zentrum des tamilischen kulturellen «Aktivismus» sei:

Temples, cultural festivals, international conferences, seminars and meetings draw a large number of the Tamil diaspora from other European countries to the various Swiss cities, so much so that it has become the nerve centre of Tamil cultural activism. (Sivasupramaniam 2004) ${ }^{464}$

Unter kulturellen Aktivitäten subsumiert er hier auch die Institution Tempel, die an erster Stelle genannt wird. Dies unterstreicht, wie auch in der Arbeit gezeigt, dass die Grenzen von Tamilness und Hinduness fliessend sind. Auf der Ebene der religiösen Zugehörigkeit spielt die Hinduness (Bezogenheit auf den Hinduismus) eine zentrale Rolle. In allen in dieser Studie genannten Beispielen lassen sich Interferenzen von Tamilness und Hinduness erkennen. Am Beispiel des Hindu-Jahresfestes taipponkkal konnte dies anschaulich gezeigt werden (vgl. IV 5). Das Fest wird als Ausdruck geteilter tamilischer Identität und als Akt der kulturellen Selbstvergewisserung gefeiert. In der Darstellung des Prozesses der Tempelisierung wurde gezeigt, dass ein tamilischer Hindu-Tempel in der Diaspora verstärkt als Tamilness repräsentierender Ort angesehen wird (vgl. IV 5.4). Sogar innerhalb der

$463 \mathrm{Zu}$ Tamilnation.com vgl. Whitacker 2004.

464 www.tamilnation.org/diaspora/articles/siva.htm (29.11.2008) 
ISKCON-Praxis tamilischer Migrantinnen und Migranten kommt der Tamilness ein hoher Stellenwert zu, was in der Einführung einer eigenen Organisationsstruktur, der Swiss Tamil Krishna Society und eines eigenen Festes, des tamilischen Sonntagsfestes, sichtbar wird (vgl. Kap. IV 3.2/3.3). Hinduness wird oft als ein Aspekt der Performanz von Tamilness verstanden und unter dieser subsumiert.

Folgende Aspekte sind in Bezug auf das Themenfeld besonders hervorzuheben und finden sich in vielen der in dieser Untersuchung genannten Beispiele wieder: (A) die Bedeutung der tamilischen Sprache als Zugehörigkeitsmerkmal und (B) Tamil cultural stuff, die Pflege spezifischer tamilischer Traditionselemente.

\section{(A) Bedeutung der tamilischen Sprache als Zugehörigkeitsmerkmal}

Tamilischer Sprache und Schrift kommen innerhalb der tamilischen Diaspora und auch im Praxiskontext tamilischer Hindu-Traditionen eine wichtige Bedeutung als Zeichen der Zugehörigkeit zu.

Die im ethno-nationalistischen Feld verbreitete Vorstellung der tamilischen Sprache als «Mutter Tamil» (Schalk 2006b, $51 \mathrm{ff}$.) ist vor dem Hintergrund der Sprachpolitik Sri Lankas zu verstehen. In Kapitel II 2.2 wurde dargestellt, dass mit Beginn des Official Language Act 1956, durch welchen die Sprache Sinhala vorübergehend einzige offizielle Sprache des Landes wurde, eine marginalisierende Politik gegenüber der tamilischen Sprache in Sri Lanka praktiziert wurde. Innerhalb der tamilischen Diaspora spielt der Tamil-Sprachunterricht eine wichtige Rolle in der Weitergabe der Tamilness an die nachfolgenden Generationen. ${ }^{465}$ Die Etablierung von Sprachunterricht in tamilischer Sprache wurde am Beispiel von Tamil Mandram in Luzern in dieser Studie exemplarisch dargestellt (vgl. IV 4.2). Dabei wurde in den Anfängen der Migration deutlich, dass die Organisation von Unterricht in tamilischer Sprache für tamilische Kinder prioritär vor der Etablierung öffentlicher Hindu-Praxis war, was auch mit der Hoffnung auf eine baldige Rückkehr nach Sri Lanka in Zusammenhang stand. Bereits 1994 entwickelten Tamilen in der Schweiz einen Lehrplan für TamilischUnterricht. Der Tamil Education Service Switzerland organisierte an zahl-

465 Sivasupramaniam greift 2004 im oben genannten Artikel Tamil-Schulen und Tanz- und Musik-Angebote speziell für den Schweizer Kontext heraus: "Tamil language classes, dance and music classes run by voluntary bodies are fast increasing" (www.tamilnation.org/diaspora/ articles/siva.htm; 29.11.2008). Es sei jedoch auf Wandlungsprozesse verwiesen: vor allem tamilische Eltern der ersten Generation legen grossen Wert auf die Teilnahme ihrer Kinder an organisierten Tamil-Sprachkursen. Unter Schweizer Tamilinnen und Tamilen der zweiten und dritten Generation finden sich vermehrt solche mit einer ambivalenten Haltung gegenüber den Kursen. 
reichen Orten in der Schweiz Unterricht in tamilischer Sprache und einheitliche Prüfungen für die tamilischen Kinder, die einmal im Jahr durchgeführt wurden (vgl. Ganesh/McDowell 2013, 142). ${ }^{466}$

Transnationale Verbindungen werden durch die Kenntnisse der tamilischen Sprache ermöglicht und aufrechterhalten. Kommunikationsmedium an den religiösen Orten der globalen tamilischen «Sakralkarte» ist die tamilische Sprache (vgl. Kap. IV 6.1). So werden, wie Kapitel IV 6.2 gezeigt hat, die Wallfahrten von in der Schweiz lebenden tamilischen Migrantinnen und Migranten nach Indien primär zu Orten in Tamil Nadu unternommen.

Als Performanz von Hinduness und eines verbindenden Elements eines global vernetzten «Hinduismus» kann die Verwendung von Sanskrit als religiöser Sakralsprache in den Tempelritualen verstanden werden. Sanskrit als traditionelle Ritualsprache wird primär von den Priestern rezitiert und von Akteuren während des Singens von Mantren verwendet. Während der Performanzen im Tempel wird es in der Regel von den Akteuren nicht verstanden. Das Spannungsfeld zwischen einer Zugehörigkeit als Hindu und zur tamilischen Diaspora, die auf der ethnischen Identität der Akteure basiert, kommt in diesem Sprachgebrauch innerhalb der Tempel zum Ausdruck.

In devotionalen Liedern (tam. pacanai) im Tempel, Ansprachen durch den Priester und in der schriftlichen Kommunikation (wie Sakralkalender, Flyer, Aushänge) wird in der Regel die tamilische Sprache genutzt. Für die Orientierung im sozialen Raum Tempel ist die Kenntnis des Tamilischen als Kommunikationssprache notwendig. Tamilische Schrift ist integraler Bestandteil der Innen- und Aussenpräsentation der Tempel und kennzeichnet das Gebäude als sakralen Ort (vgl. Kap. V 2.1).

Des Weiteren spielen Medien in tamilischer Sprache, die religiöse Themen behandeln, eine grosse Rolle wie Bücher mit religiösem Inhalt in tamilischer Sprache, die während wichtiger Anlässe, wie den Tempelfesten (vgl. Kap. V 3), verkauft werden. Auch die Veröffentlichung eigener tamilischer Publikationen von Tempelvereinen ist zu nennen, wie das vom Luzerner Tempel 2006 herausgegebene religiöse Liederbuch «Allgegenwärtig ist die

466 Diaspora-Akteure haben transnationale Organisationsstrukturen entwickelt, um innerhalb der tamilischen Diaspora einheitlichen Tamilisch-Unterricht zu institutionalisieren. Das Tamil Education Development Council (TEDC) ist als Beispiel zu nennen, welches den Lehrplan für den Sprachunterricht entwickelt und jährliche vereinheitlichte Prüfungen in unterschiedlichen Diaspora-Ländern durchführt. Im Untersuchungszeitraum war beispielsweise für das Jahr $2008 \mathrm{zu}$ lesen: "13,300 children and students from the Diaspora on Saturday, 3 May 2008 attended annual exams in Tamil language across various countries in Europe and New Zealand" (vgl. Tamil Children in many Lands sit for Worldwide Exams in Tamil Language. In: www.tamilnation. org/diaspora/08tamil_eduation.htm; 26.11.2008). 
göttliche Kraft. Sammlung gemeinsamer Bittgebete- und lieder» in tamilischer Sprache. Im Śrī Civacuppiramaniyar in Adliswil wurde sogar eine Bibliothek (die Kumaran Bibliothek; tam. kumaran nülakam) mit fast ausschliesslich tamilischen Büchern, die religiöse Themen behandeln, aufgebaut (vgl. Baumann 2010, 11). Auch die innerhalb eines rezenten globalen Hinduismus agierenden Organisationen vertreiben tamilische Literatur: diese werden beim Besuch von Amma in der Schweiz (vgl. Kap. IV 3.4) verkauft oder im Krishna-Tempel in Zürich (wie eine Übersetzung der Bhagavadgìta auf Tamilisch; vgl. Kap. IV 3.3).

Die tamilische Sprache nimmt eine Schlüsselrolle in der Vermittlung religiöser Inhalte ein. Dies zeigt anschaulich das Beispiel der Aufführungen von Kindern zum Anlass des Mangofestes im Śrī Civacuppiramaṇiyar Tempel (vgl. Kap. V 3.3). In diesem Theaterstück werden den Zuschauern im Tempelraum religiöse Geschichten in tamilischer Sprache vermittelt. Auch die Einführung eines eigenen tamilischen Sonntagsfestes für die tamilische Sektion der ISKCON in der Schweiz, in welchem die tamilische Sprache verwendet wird, kann hier als Beispiel angeführt werden (vgl. Kap. IV 3.3).

\section{(B) Tamil cultural stuff: Die Pflege spezifischer tamilischer Traditionselemente}

In vielen Beispielen der Studie kommt der Pflege spezifischer tamilischer Traditionselemente eine besondere Bedeutung zu. Tamilness kann beispielsweise durch das obligatorische, nach der pūcai im Tempel verteilte Essen, prasādam, bestehend aus traditionellen tamilischen Gerichten und auch durch tamilische Musik, welche in und um den Tempel zu HinduAnlässen gespielt und gesungen wird, ausgedrückt werden.

Für diese Ausdrucksformen von Tamilness kann der Terminus cultural stuff verwendet werden, welcher neben der Aufgeladenheit von Artefakten mit kulturellen Zuschreibungen auch Aspekte wie Gebräuche und Sprachpraktiken meint. Der Begriff cultural stuff geht auf Fredric Barth zurück, der in Ethnic Groups and Boundaries - angelehnt an Max Weber - mit diesem Terminus ein Konvolut an Elementen wie Sprache, materielle Kultur, Essensgebräuche meint (vgl. Barth 1969, 15). In der Diaspora lebende Tamilinnen und Tamilen transferieren cultural stuff in ihr neues Lebensumfeld. Besonders anschaulich kam die Bedeutung des tamil cultural stuff am Beispiel des tamilischen Sonntagsfestes der Swiss Tamil Krishna Society in Kap. IV 3.3 zum Ausdruck.

Jener cultural stuff, welcher ein Imitat eines in Südasien verbreiteten Aspekts materieller Kultur ist, weckt Erinnerungen an die Herkunftsregion und zeigt anschaulich die Diaspora-Situation auf. Beispiele sind Jasmin-Blumen aus Plastik, die ins Haar gebunden werden, oder künstliche kōpuram-Kulissen. 
Für den Transfer von cultural stuff in einen neuen kulturellen Kontext sind die Orte, an welchen materielle Kultur erworben werden kann, von besonderer Bedeutung. Tamilische Geschäfte haben für die in der Schweiz lebenden Migrantinnen und Migranten einen hohen Stellenwert. Hier können sie Elemente der materiellen Kultur wie traditionelle Kleidung und Accessoires kaufen, welche sonst im Diaspora-Land schwer erhältlich sind. Es finden sich in allen grossen Schweizer Städten tamilische cultural stuffGeschäfte, welche neben Grundnahrungsmitteln eine detailreiche Auswahl an Elementen tamilischer materieller Kultur zum Kauf anbieten. Dazu gehören auch Elemente, welche für Hindu-Praktiken benötigt werden, wie Kampfer, Räucherstäbchen oder Öllampen. Neben diesen Geschäften, welche ein breites Warenangebot anbieten, finden sich spezialisierte Läden, die etwa in erster Linie Goldschmuck oder Textilien vertreiben. Die Geschäfte dienen auch als soziale Treffpunkte der tamilischen Diaspora und sind durch äusserliche Kennzeichnungen, wie Flyer und Poster, als zu dieser gehörig gekennzeichnet. Unterschiedliche Aspekte der tamilischen Diaspora werden hier visuell sichtbar: durch Poster werden beispielsweise politische Diskurse wiedergegeben.

\section{Rückbezüge auf die Ereignisse im Herkunftsland innerhalb der Performanzen in der Diaspora}

Dieses Ergebnis schliesst an und interferiert mit dem in (1) dargestellten Aspekt der Tamilness als Repräsentationsform. Das Bewusstsein der Tamilness wurde durch die Bügerkriegsereignisse in Sri Lanka verstärkt.

Von einigen tamilischen Akteuren wird die sri-lankisch tamilische Diaspora als cultural heritage community verstanden. Sie berufen sich auf ein kulturelles Erbe, welches bewahrt werden soll. Pfaffenberger zeigte bereits 1981 die Wichtigkeit der kulturellen Dimension des tamilischen Separatismus und damit des folgenden Bürgerkriegs in Sri Lanka auf (Pfaffenberger 1981). Einer der zentralen Antriebe bei der Entstehung der tamilischen Widerstandsbewegungen war der Schutz der tamilischen Kultur vor einer drohenden Marginalisierung. Wie gezeigt wurde, zeichnet sich die tamilische Diaspora durch einen starken Rückbezug auf Sri Lanka als Herkunftsregion aus (Kap. II 1). Der Bürgerkrieg beeinflusste das tamilische Leben in der Schweiz, da die Kriegsereignisse unter den Migrantinnen und Migranten sehr präsent waren und diskutiert wurden. Das Leiden der Menschen in Sri Lanka belastete auch tamilische Menschen in der Schweiz und erhöhte ihre vulnerable Lage. Da, besonders nach dem militärischen Sieg über die LTTE 2009, ein Gefühl der Aussichtslosigkeit überwog, fühlten sich tamilische Migrantinnen und Migranten hilflos gegenüber der von ihnen als Unrechtsregime wahrgenommenen Regierung Sri Lankas. 
Eine Leitthese der Studie, dass der Konflikt in Sri Lanka ein entscheidender Einflussfaktor für die Dynamiken der Lokalisierung tamilischer Hindu-Praxis in der Diaspora ist, hat sich gerade im Untersuchungszeitraum bestätigt und konnte an verschiedenen Beispielen aufgezeigt werden. Besonders anschaulich spiegeln sich die Auswirkungen der Ereignisse in der Darstellung der Performanzen für Frieden und Gerechtigkeit von tamilischen Hindu-Akteuren in der Schweiz wider (Kap. V 3.4). Religiöse tamilische Organisationen reagierten auf die Geschehnisse in Sri Lanka. Aber auch in der Praxis des Jahresfestes taipponkal schwingt durch die Parallelen zur politischen ponku tamil-Rally der Topos der Marginalisierung der tamilischen Bevölkerung in Sri Lanka mit (Kap. IV 5).

Es hat sich gezeigt, dass der ethnische Konflikt in Sri Lanka zu einer steigenden Betonung der tamilischen Gruppen-Identität und der Performanz von Tamilness geführt hat. Die Bedeutung interner Unterschiede wie Geschlecht, Kaste und Religion nahm ab. Diese wurden teilweise als NebenDiskurse im Überlebenskampf der tamilischen Kultur verstanden. Knut A. Jacobsen konstatiert Interferenzen der Etablierung tamilischen RitualRaums mit der Stellung der tamilischen Gruppe in Sri Lanka: "The misfortune of the Tamils in the modern nation state of Sri Lanka is an important context for understanding the religious rituals in the Sri Lankan Tamil diaspora" (Jacobsen 2009, 183). Diese Entwicklung muss als besonders zentral innerhalb der aufgezeigten Lokalisierungs-Dynamiken im diasporisch transnationalen Bedingungsgefüge gewertet werden.

\section{Hohe Bedeutung der Materialität für die Performanz von Hindu-Tamilness}

Es wurde gezeigt, dass Artefakten eine zentrale Rolle in der Kennzeichnung der Praktiken als zu tamilischen Hindu-Traditionen gehörig spielen und wesentlich zu ihrem Vollzug dazugehören. Neben dem Terminus cultural stuff hat sich der enger gefasste Begriff der materiellen Kultur etabliert, ${ }^{467}$ welcher mit einer spezifischen kulturellen Bedeutung aufgeladene Artefakte meint (Hahn 2005). Artefakte werden erst von Akteuren mit Bedeutungen aufgeladen, welche - abhängig von den Personen und dem Kontext - variieren können. Dinge können in unterschiedlichen kulturellen Kontexten Unterschiedliches bedeuten. Stuart Hall verweist auf diese Dynamiken der sogenannten Dingbedeutsamkeit:

467 Beide Begrifflichkeiten, materielle Kultur wie auch cultural stuff, sind ungenau gefasst: "Material culture is no better defined than stuff is" (Miller 2010, 1). 
It is participants in a culture who give meaning to people, objects and events. Things in "themselves" rarely if ever have any one single, fixed and unchanging meaning. Even something as obvious as a stone can be a stone, a boundary marker or a piece of sculpture, depending on what it means. [...] It is by our use of things, and what we say, think and feel about them - how we represent them - that we give them a meaning. (Hall 1997, 3)

Als Beispiele wichtiger Aspekte der materiellen Kultur im Untersuchungsfeld sind Gegenstände zu nennen, welche während der pūcai benutzt werden (vgl. IV 2). Durch verschiedene Elemente der materiellen Kultur wie mūrttis oder Darśan-Bilder kann ein individueller Selbstausdruck der eigenen religiösen Praxis der/des Devotee und der Familie zusammengestellt werden. Auch die Utensilien, die zu den Praktiken um das Jahresfest taipponkkal benötigt werden (vgl. IV 5) sind hier beispielhaft aus den in der Untersuchung vorgestellten Dynamiken zu nennen.

Als instruktives Beispiel der Verwendung von materieller Kultur lässt sich das Installieren eines zweidimensionalen kōpuram am Tempeleingang verstehen (Kap. V 2.1). Durch Darstellungen auf diesem und Bilder in den Tempeln wird transmedial Tradition über visuell dargestellte Geschichten vermittelt.

Während des Aufbaus der ersten tamilischen Tempel in der Schweiz und beim Tempelbau war die Verwendung spezifischer materieller Kultur zentral (Kap. IV 4/V 2.2). Aspekte der Materialität und Visualität werden in der Aussenwahrnehmung besonders beachtet und können als Differenzmarker dienen. Schweizer Medien erwähnen in ihrer Berichterstattung über tamilische Hindus materielle Elemente immer wieder an zentraler Stelle. ${ }^{468}$

Die Wendung der Blickrichtung auf die Wechselwirkung von Materialität und religiösen Praktiken und eine Hinwendung zu einer dezidiert religionsästhetischen Analyse (vgl. unter anderem Cancik/Mohr 1988, Laack 2007; Mohn 2010, 2012) kann als sehr fruchtbar für weitere Studien innerhalb des Forschungsfeldes angesehen werden.

468 Am 15. Juli 2008 war beispielsweise in der Zeitung Zürcher Unterländer über das Tempelfest in Glattbrugg folgende Passage zu lesen: «Die ganze Industriestrasse war mit exotischen Früchten und Palmenblättern verziert. Der Duft von Rosenöl und Blütenblättern tauchte die ganze Umgebung in eine südindische Atmosphäre. Kleine Stände mit Schmuck und Zeremonienzubehör untermalten die Szene» (Leo Wyden, Shiva durch das Quartier geführt, in: Zürcher Unterländer, 15.07.2008). 


\section{Wichtigkeit von selbstverwalteten Sakralräumen für die Migrantengruppe}

Für die erst seit wenigen Jahrzehnten bestehende - und damit relativ junge - Diaspora der tamilischen Hindus in der Schweiz ist der Tempel zentraler Ort des Vollzugs hindu-tamilischer Religiosität (vgl. Kap. IV 4). Seit Beginn der Migration tamilischer Hindus in die Schweiz war das Bedürfnis nach eigenen Tempelräumen gross. Das steht im Gegensatz zur indischen Migrantengruppe in der Schweiz, die wenige Bestrebungen unternahm, Sakralräume zu errichten. ${ }^{469}$ Nachdem sich ein Netz von meist nur in tamilisch-öffentlichen Sphären bekannten sakralen Räumen etabliert hat, sind Akteure nun bestrebt, Tempel nach traditionell südindischem Vorbild zu bauen.

Der Tempel dient in der Diaspora als multifunktionaler sozialer Raum und als Ort gelebter Tamilness, was auch politische Diskurse miteinschliessen kann. Erst in zweiter Linie verstehen sich die meisten aus Sri Lanka in die Schweiz gekommenen Hindu-Akteure als Teil eines transnationalen, weltumspannenden «Hinduismus». Schalk konstatiert, dass die TempelPraxis als Ausdruck von «tamilischer Kultur» wie auch «hinduistischer Religion» diese nicht problemlos in den Diskurs eines «transethnischen Hinduismus» eingliedern lässt: "The focus on preserving Tamil culture in exile through the temple creates problems in the desire to connect Tamil Caivam to the global Hindu community" (Schalk 2007, 105).

Es wurde gezeigt, dass der Tempel durch einen Prozess von Tempelisierung einen Bedeutungswandel erlebt (vgl. Kap. IV 5.4). Im Verhältnis zum Tempel spielt der private Raum für die religiöse Praxis in der Regel eine untergeordnete Rolle (vgl. Kap. IV 2). Einige Rituale, die traditionell an die Familie und das Haus gebunden sind, werden in den Tempel ausgelagert. Die tägliche Verehrung der Gottheiten im selbst gestalteten Schrein mit Darśan-Bildern, der offen oder verborgen in der Wohnung zu finden ist, ist oftmals das einzige Ritual, welches im privaten Raum vollzogen wird.

Die spezifische Form der temple-isation hat ihre Ursache in der spezifischen Diaspora-Situation der Tamilen in der Schweiz. Es wurde festgestellt, dass eine Fokussierung auf den Tempel als Anpassung an die Strukturen

469 Ursina Wälchli konstatiert in ihrer Arbeit zur indischen Migrantengruppe in der Schweiz: «Aus den Antworten der Befragten lässt sich feststellen, dass kein Bedürfnis nach einem Tempel vorhanden ist» (Wälchli 2008, 79). Die Gründe dafür liegen in dem meist nur temporären Aufenthalt vieler Inderinnen und Inder zu Ausbildungs- oder befristeten Arbeitszwecken in der Schweiz. Innerhalb der indischen Migrationsgeschichte in die Schweiz überwiegt die Zahl der Kurzaufenthalter die der niedergelassenen Personen (Wälchli 2008, 35). Meist sind es Männer, die für eine bestimmte Zeit alleine in die Schweiz kommen. Ganze Familien, die aus Indien in die Schweiz migrieren, sind die Ausnahme. 
des Residenzlandes anzusehen ist. Zentrale Gründe für die Auslagerung in den öffentlichen Raum sind praktischer Art: Die Ausübung privater Religiosität ist in der Diaspora nicht in gleicher Weise möglich wie im Herkunftsland. Im Folgenden sollen die Gründe für Tempelisierung, wie hier dargestellt, systematisch gebündelt werden:

1. Eingeschränkte private Raumkapazitäten: Aufgrund der wirtschaftlichen Situation vieler tamilischer Familien (vgl. Kap. III 3.5) gab es für die erste Generation tamilischer Hindus kaum die Möglichkeit, in grossen Wohnungen oder Häusern zu leben. Die eingeschränkten Raumkapazitäten grenzten die Ausübung bestimmter Rituale ein. Für bestimmte Feiern ist es in Sri Lanka üblich, diese im Freien zu vollziehen. Vielfach haben die tamilischen Migrantinnen und Migranten in der Schweiz keinen Garten, kein eigenes Land. Der Platzmangel im privaten Bereich motiviert tamilische Hindus, Rituale teilweise in räumlich grosszügigeren öffentlichen Gebäuden zu vollziehen und zu feiern. Der Tempel als bereits etablierte religiöse Institution bietet Platz für grössere Treffen.

2.Leben in Mietshäusern: Auch die Ausstattung der privaten Räumlichkeiten ist ein Hindernis, welches unter Umständen bestimmte Ritualausübungen nicht möglich macht. Besondere Vorsicht lassen viele Akteure bei angemieteten Wohnungen und in Mietshäusern walten, da man Störungen der Nachbarn oder Beschädigungen der Wohnung befürchtet. Als marginalisierte Migrantengruppe spielt auch die Motivation, sich anzupassen und nicht aufzufallen eine Rolle bei der Auslagerung der Rituale aus dem privaten Bereich. Ein in der Schweiz lebender Priester berichtet, warum Hochzeiten lieber im Tempel oder einem Saal und nicht in der Wohnung der Brautleute gefeiert werden: «Und dann andere ist/ das ist: die Nachbarn/ die Nachbarn auch Probleme. Wenn etwas laut. Wenn Samstag, Sonntag eine Hochzeit ist, feiern wird und dann zu Hause ist/dann ist Reklamation. Dann ist Problem.» ${ }^{470}$

3. Soziale Isolation: Da tamilische Hindus als Minderheit meist in nichttamilisch geprägter Nachbarschaft leben, ist oft das Bedürfnis gross, nicht nur an einem räumlich grosszügigen, sondern auch an einem zentral gelegenen Ort zusammenzukommen, um Feste gemeinsam gefeiern zu können. 4. Anpassungen an den Arbeitsrhythmus in der Schweiz: Das Eingebundensein in den konventionellen Arbeitsrhythmus verändert die Ausübung vieler Rituale: Wenn Feste auf einen Werktag fallen, fehlen oftmals die zeitlichen Kapazitäten, um diese im privaten Bereich umfassend vorzubereiten. So wird der Besuch des Tempels präferiert. Viele an den Tempel gebundene

470 Interview mit Sasitharan Ramakrishnasarma am 05.02.2009 in seiner Wohnung in Luzern. 
Rituale werden auf das Wochenende verschoben, damit möglichst viele Menschen an ihnen teilnehmen können; astrologische Berechnungen treten in den Hintergrund.

5.Priestermangel/Mangel an religiösen Autoritäten: Ein Grund, warum Lebenszyklusriten seltener in der privaten Wohnung vollzogen werden, ist der Mangel an Priestern. Diesen ist es aus zeitlichen Gründen oft nicht möglich, die Familien flächendeckend zu lebenszyklischen Riten zu Hause zu besuchen. Viele Familien kommen deshalb in den Tempel. Die demographische Zusammensetzung der tamilischen Diaspora in der Schweiz zeigt einen Mangel an älteren Menschen, welche als religiöse Autoritäten fungieren könnten. In den meisten Fällen wächst die zweite tamilische Generation in der Schweiz ohne ihre Grosseltern auf. Das führt zu einem Autoritätszuwachs der Priester in der hindu-tamilischen Diaspora.

Diese Gründe bedingen, teilweise unterschiedlich gewichtet, eine Auslagerung bestimmter Praktiken in den Tempel. Der Prozess der Tempelisierung kann also als Anpassung an die Gegebenheiten und Strukturen des Residenzlandes verstanden werden.

Für die Praxis tamilischer Hindus in der Schweiz ist das Schaffen von Verehrungsorten für ihre Göttinnen und Götter eine zentrale Handlung im Prozess der religiösen Beheimatung im Aufnahmeland. Die dargestellten Lokalisierungsdynamiken der Hindu-Praxis sind untrennbar mit Geschichte und Ausprägung der sri-lankisch tamilischen Diaspora verknüpft, aber auch die vielfältigen Inkorporationsbedingungen der Schweiz haben Einfluss auf Beheimatungsprozesse.

Die Untersuchung hat einen Überblick über die Ausgangsbedingungen der Etablierung tamilischer Hindu-Traditionen in der Schweiz gegeben und dabei besonders sozialräumliche Aspekte hervorgehoben. Sie dient als Anregung für Detailstudien zum Themenfeld tamilischer Hindu-Praktiken in der Diaspora und kann als Vergleichsstudie im aktuellen Themenfeld «Flucht und Religion» in Europa herangezogen werden. 



\section{Literatur}

Allievi, Stefano. 2003. Konflikte um islamische Symbole in Europa. In: Journal für Konflikt- und Gewaltforschung 5(2): 6-31.

Allievi, Stefano. 2004. Berger Communication and Communities: Public Space, Global Media and Local Umma. In Jamal Malik (Hrsg.), Muslims in Europe: from the Margin to the Centre (S. 185-205). Münster: Lit.

Amarasingam, Amarnath. 2008. Religion and Ethnicity Among Sri Lankan Tamil Youth in Ontario. In: Canadian Ethnic Studies 40(2), 149-69.

Anderson, Benedict R. 1983. Imagined Communities: Reflections on the Origin and Spread of Nationalism. London: Verso.

Anthias, Floya. 1998. Evaluating 'Diaspora': Beyond Ethnicity? In: Sociology 32(2), 557-580.

Appadurai, Arjun. 1996. Modernity at Large: Cultural Dimensions of Globalization. Minneapolis, Minn: University of Minnesota Press.

Apputhurai, Sinnapoo. 2013. Malaysia. In: Peter Reeves (Hrsg.), Encyclopedia of the Sri Lankan Diaspora (S. 78-84). Singapore: Editions Didier Millet.

Arendt, Hannah. 2006. Der Raum des Öffentlichen und der Bereich des Privaten. In: Jörg Dünne, Stephan Günzel (Hrsg.), Raumtheorie. Grundlagentexte aus Philosophie und Kulturwissenschaften (S. 420-433). Suhrkamp: Frankfurt am Main.

Arnold, Christof. 2007. Zum Einfluss der tamilischen Diaspora in der Schweiz auf den Konflikt in Sri Lanka. Unveröffentlichte Lizentiatsarbeit, Universität Bern, Bern.

Atteslander, Peter. 2003. Methoden der empirischen Sozialforschung. Berlin: de Gruyter.

Auffarth, Christoph. 2006. Bild. In: Christoph Auffarth, Hans G. Kippenberg und Axel Michaels (Hrsg.), Wörterbuch der Religionen (S. 75-76). Stuttgart: Kröner.

Aumüller, Jutta. 2009. Assimilation. Kontroversen um ein migrationspolitisches Konzept. Bielefeld: transcript.

Back, Carina. 2007. Hindu-Tempel in Deutschland. Religionen aktuell, Bd.1. Marburg: TectumVerlag.

Ballard, Roger. 1994. Introduction: The Emergence of Desh Pardesh. In: Roger Ballard (Hrsg.), Desh Pardesh: The South Asian Presence in Britain (S. 1-34). London: Hurst and Co.

Ballard, Roger. 2007. South Asian Presence in Britain and its Transnational Connections. In: Ajaya Kumar Sahoo und Brij Maharaj (Hrsg.), Sociology of Diaspora, Vol. 2 (S. 587-617). New Delhi: Rawat Publications.

Bandarage, Asoka. 2008. The Sri Lankan Conflict. Harvard International Review. June 15, 2008, http://hir.harvard.edu/the-sri-lankan-conflict (29.3.2017).

Bandarage, Asoka. 2009. The Separatist Conflict in Sri Lanka. Routledge Contemporary South Asia Series, Vol. 15. Milton Park Abingdon Oxon, New York: Routledge.

Bär, Barbara. 2003. Migration - Risiko oder Chance? Unveröffentlichte Diplomarbeit, Hochschule für soziale Arbeit, Luzern.

Barth, Fredrik. 1969. Ethnic Groups and Boundaries. The Social Organization of Culture Difference. Long Grove, IL.: Waveland Press. 
Bartholomeusz, Tessa J. 2002. In Defense of Dharma: Just-War Ideology in Buddhist Sri Lanka. London: Routledge Curzon.

Bartholomeusz, Tessa J. und Chandra Richard de Silva. 1998. Buddhist Fundamentalism and Identity in Sri Lanka. In Tessa J. Bartholomeusz und Chandra Richard de Silva (Hrsg.), Buddhist Fundamentalism and Minority Identities in Sri Lanka (S.1-35). Albany, NY: State University of New York Press.

Bastin, Rohan. 2002. The Domain of Constant Excess: Plural Worship at the Munnesvaram Temples in Sri Lanka. New York: Berghahn Books.

Bauböck, Rainer. 2001. Integration von Einwanderern - Reflexionen zum Begriff und seine Anwendungsmöglichkeiten. In: Harald Waldrauch (Hrsg.) Die Integration von Einwanderern: Ein Index der rechtlichen Diskriminierung (S. 25-52). Frankfurt a. M.: Campus-Verlag.

Baumann, Christoph-Peter. 2003. Tamilische Hindus und Tempel in der Schweiz. In Martin Baumann, Brigitte Luchesi, Annette Wilke und Peter Schalk (Hrsg.), Tempel und Tamilen in zweiter Heimat. Hindus aus Sri Lanka im deutschsprachigen und skandinavischen Raum (S. 275-294). Religion in der Gesellschaft, Bd. 15, Würzburg: Ergon-Verlag.

Baumann, Gerd. 1999. The Multicultural Riddle. Rethinking Ethnic, National and Religious Identities. New York: Routledge.

Baumann, Martin. 1997. Hindus und Juden in globaler «Zerstreuung». In Hans-Joachim Klimkeit (Hrsg.) Vergleichen und Verstehen in der Religionswissenschaft (S. 185-200). Studies in Oriental Religions, Vol.41, Wiesbaden: Harrassowitz.

Baumann, Martin. 1998. Qualitative Methoden in der Religionswissenschaft. 2., überarb. und erw. Aufl. Marburg: REMID.

Baumann, Martin. 1999. Religion und umstrittener öffentlicher Raum. In: Zeitschrift für Religionswissenschaft 7(2), 187-204.

Baumann, Martin. 2000a. Diaspora: Genealogies of Semantics and Transcultural Comparisons. In: Numen 47(3), 313-337.

Baumann, Martin. 2000b. Migration - Religion - Integration. Buddhistische Vietnamesen und hinduistische Tamilen in Deutschland. Marburg: Diagonal-Verlag.

Baumann, Martin. 2002. Migrant Settlement, Religion, and Phases of Diaspora. In: Migration - A European fournal of International Migration and Ethnic Relations, Vol. 33,34,35, 93-117.

Baumann, Martin. 2003a. Alte Götter in neuer Heimat. Religionswissenschaftliche Analyse zu Diaspora am Beispiel von Hindus auf Trinidad. Religionswissenschaftliche Reihe, Bd. 18. Marburg: Diagonal-Verlag.

Baumann, Martin. 2003b. Selbstkasteiung und Gelübde. Traditionswahrung durch religiöse Praktik. In Martin Baumann, Brigitte Luchesi, Annette Wilke und Peter Schalk (Hrsg.), Tempel und Tamilen in zweiter Heimat. Hindus aus Sri Lanka im deutschsprachigen und skandinavischen Raum (S. 169-188). Würzburg: Ergon-Verlag.

Baumann, Martin. 2003c. Von Sri Lanka in die Bundesrepublik. Flucht, Aufnahme und kulturelle Rekonstruktion. In Martin Baumann, Brigitte Luchesi, Annette Wilke und Peter Schalk (Hrsg.), Tempel und Tamilen in zweiter Heimat. Hindus aus Sri Lanka im deutschsprachigen und skandinavischen Raum (S. 41-73). Würzburg: Ergon-Verlag.

Baumann, Martin. 2006. Performing Vows in Diasporic Contexts: Tamil Hindus, Temples, and Goddesses in Germany. In Selva J. Raj und William P. Harman (Hrsg.), Dealing with Deities: The Ritual Vow in South Asia (S. 129-146). Albany: State University of New York Press.

Baumann, Martin. 2007. Diaspora. In Studienbrief «Religion in der Moderne», Masterstudiengang «Individualisierung und Sozialstruktur». Institut für Soziologie, Fernuniversität Hagen.

Baumann, Martin. 2009a. Migration and Religion. In Peter B. Clarke und Peter Beyer (Hrsg.), The World's Religions. Continuities and Transformation (S. 338-353). London: Routledge. 
Baumann, Martin. 2009b. Templeisation: Continuity and Change of Hindu Traditions in Diaspora. Journal of Religion in Europe 2(2), 149-179.

Baumann, Martin. 2009c. Temples, Cupolas, Minarets: Public Space as Contested Terrain in Contemporary Switzerland. RELIGIO: Revue pro religionistiku 17(2), 141-153.

Baumann, Martin. 2010a. Civic Social Capital and Hindu Tamil Priests and Temples in Switzerland. Finnish fournal of Ethnicity and Migration 5(2), 7-15.

Baumann, Martin. 2010b. Religionswissenschaft, Entzauberung und die neue Öffentlichkeit von Religion(en). In: Bulletin der Vereinigung der Schweizerischen Hochschuldozierenden 36(1), 29-36.

Baumann, Martin, Rafaela Eulberg und Frank André Weigelt. 2011. Zugewanderte Religion, öffentlicher Raum, Wandel von Geschlechterrollen tamilischer Hindus und vietnamesischer Buddhisten. Forschungsprojekt NFP 58. Schlussbericht. Luzern: Universität Luzern.

Baumann, Martin, Brigitte Luchesi, Annette Wilke und Peter Schalk (Hrsg). 2003. Tempel und Tamilen in zweiter Heimat: Hindus aus Sri Lanka im deutschsprachigen und skandinavischen Raum. Religion in der Gesellschaft, Bd. 15. Würzburg: Ergon-Verlag.

Baumann, Martin und Jörg Stolz (Hrsg). 2007a. Eine Schweiz - viele Religionen. Kultur und soziale Praxis. Bielefeld: transcript.

Baumann, Martin und Jörg Stolz. 2007b. Religiöse Vielfalt in der Schweiz. In Martin Baumann und Jörg Stolz (Hrsg.), Eine Schweiz - viele Religionen, Kultur und soziale Praxis (S. 39-66). Bielefeld: transcript.

Baumann, Martin und Andreas Tunger-Zanetti. 2008. Migration und religiöse Bauten: Zur Neuaushandlung des öffentlichen Raums. Kunst und Kirche 4, 32-39.

Baumann, Martin und Andreas Tunger-Zanetti. 2011. Wenn Religionen Häuser bauen. Sakralbauten, Kontroversen und öffentlicher Raum in der Schweizer Demokratie. In Martin Baumann und Frank Neubert (Hrsg.), Religionspolitik - Offentlichkeit - Wissenschaft: Studien zur Neuformierung von Religion in der Gegenwart, (S. 151-188). Zürich: Pano-Verlag.

Baumann, Martin und Andreas Tunger-Zanetti. 2014. Der Hindutempel in Trimbach. Von der Idee bis zur Einweihung. Luzern: Universität Luzern.

Beck, Brenda F.F. 2005. Domestic Observance. In Lindsay Jones (Hrsg.) Encyclopedia of Religion (S. 2403-2406). Vol. 4, Detroit: Macmillan Reference USA.

Beckerlegge, Gwilym. 2006. Swami Vivekananda's Legacy of Service. New Delhi: Oxford University Press.

Behloul, Samuel M. 2007. The Society is watching you! Islam-Diskurs in der Schweiz und die Konstruktion einer öffentlichen Religion. Theologische Berichte 30, 276-317.

Behloul, Samuel M. 2005. Religionspluralismus: europäischer «Normal-» oder «Notfall»? Muslimische Migranten in der Schweiz und die Einbettung in den öffentlichen Raum. In Martin Baumann und Samuel M. Behloul (Hrsg.), Religiöser Pluralismus. Empirische Studien und analytische Perspektiven, Kultur und soziale Praxis (S. 145-169). Bielefeld: transcript.

Beinhauer-Köhler, Bärbel. 2010. «Ein Buddha steht im japanischen Garten in San Francisco»: Blickkulturen und Religionen. In Bärbel Beinhauer-Köhler, Daria Pezzoli-Olgiati und Joachim Valentin (Hrsg.), Religiöse Blicke - Blicke auf das Religiöse: Visualität und Religion (S. 129-148). Zürich: TVZ Theologischer Verlag.

Berking, Helmuth. 2006. Raumtheoretische Paradoxien im Globalisierungsdiskurs. In Helmuth Berking (Hrsg.), Die Macht des Lokalen in einer Welt ohne Grenzen (S. 7-22). Frankfurt a. M.: Campus.

Beutter, Anne und Cédric Duchêne-Lacroix. 2011. Präsenzdynamik und -dimensionen der Kultstätte einer Minderheit: der tamilische Hindutempel in Basel. Tsantsa 16, 129-39. 
Beyeler, Sarah und Virginia Suter Reich. 2008. Inkorporation von zugewanderten Religionsgemeinschaften in der Schweiz am Beispiel der Aleviten und der Ahmadiyya. Schweizerische Zeitschrift für Religions- und Kulturgeschichte 102, 233-259.

Beyeler, Sarah und Virginia Suter Reich. 2009. Sichtbarkeit von Inkorporationsbedingungen am Vergleich muslimischer Bauvorhaben in der Schweiz. Tsantsa 14, 141-146.

Beyer, Peter. 2006. Religions in Global Society. London: Routledge.

Binder, Katrin. 2010. Drama and Theatre. In Knut A. Jacobsen, Helene Basu, Angelika Malinar und Vasudha Narayanan (Hrsg.) Brill's Encyclopedia of Hinduism, (S. 511-528). Leiden, Boston: Brill.

Binnenkade, Alexandra. 2009. KontaktZonen. Füdisch-christlicher Alltag in Lengnau. Bd. 75. Köln: Böhlau Verlag.

Bose, Sumantra. 1994. States, Nations, Sovereignty: Sri Lanka, India, and the Tamil Eelam Movement. New Delhi etc.: Sage Publications.

Bourdieu, Pierre. 1979. Entwurf einer Theorie der Praxis auf der ethnologischen Grundlage der kabylischen Gesellschaft. Frankfurt a. M.: Suhrkamp.

Bourdieu, Pierre. 1991. Physischer, sozialer und angeeigneter physischer Raum. In Martin Wentz (Hrsg.), Stadt-Räume (S.25-34). Frankfurt a. M.: Campus.

Bovay, Claude. 2004. Religionslandschaft in der Schweiz. Statistik der Schweiz, Bd.16, hg.v. Raphä̈l Broquet. Neuchâtel: Bundesamt für Statistik.

Bowen, David G. 1981. The Hindu Community in Bradford. In David G. Bowen (Hrsg.) Hinduism in England (S. 33-60). Bradford: Bradford College.

Bowen, John Richard. 2008. Religions in Practice. An Approach to the Anthropology of Religion. Boston, MA: Pearson.

Braun, Christina und Inge Stephan (Hrsg.). 2006. Gender-Studien: Eine Einführung. 2., aktualisierte Aufl. Stuttgart: Metzler.

Broo, Måns. 2011. ISKCON and South Asian Hindus in Finland: Strategies for Integration. Finnish fournal of Ethnicity and Migration 5(2), 33-38.

Brück, Michael von. 2007. Religionswissenschaft als Kulturwissenschaft: Standortbestimmungen im wissenschaftlichen Feld. In Anne Koch (Hrsg.) Watchtower Religionswissenschaft: Standortbestimmungen im wissenschaftlichen Feld (S. 73-93). Marburg: Diagonal-Verlag.

Brun, Cathrine und Nicholas Van Hear. 2012. Between the Local and the Diasporic: The Shifting Centre of Gravity in War-Torn Sri Lanka's Transnational Politics. Contemporary South Asia 20(1), 61-75.

Brun-Enderlin, Elsbeth. 2000. Tempel für den Gott Vinayagar in Graubünden. Bündner Kirchenbote November 2000, 4 .

Buchli, Victor, Hg. 2002. The Material Culture Reader. Oxford: Berg.

Bullion, Alan J. 1995. India, Sri Lanka and the Tamil Crisis 1976-1994: An International Perspective. London etc.: Pinter.

Bundesamt für Migration BFM (Hrsg.). 2007. Ausländer- und Asylstatistik 2006. Bern.

Bundesamt für Migration BFM (Hrsg.). 2010. Ausländer- und Asylstatistik 2009. Bern.

Bundesamt für Migration BFM (Hrsg.). 2012. Ausländerstatistik 2012. Bern.

Bundesamt für Polizei, EJPD (Hrsg.). 2008. Bericht innere Sicherheit der Schweiz 2007.

Burghart, Richard (Hrsg.). 1987. Hinduism in Great Britain: The Perpetuation of Religion in an Alien Cultural Milieu. London, New York: Tavistock.

Butler, Judith. 1991. Das Unbehagen der Geschlechter. Frankfurt a. M.: Suhrkamp.

Calef, Susan. 2009. Charting New Territory. Religion and "the Gender-Critical Turn". Journal of Religion \& Society 5, 1-5. 
Calhoun, Craig J. (Hrsg.). 1999. Habermas and the Public Sphere. 6. Aufl., Cambridge, Mass.: MIT Press.

Cancik, Hubert und Hubert Mohr. 1988. Religionsästhetik. In Hubert Cancik, Burkhard Gladigow und Matthias Laubscher (Hrsg.), Handbuch religionswissenschaftlicher Grundbegriffe (S. 121-156). Stuttgart: Kohlhammer.

Caritas Luzern, Bereich Flüchtlingshilfe. 1992. Zwischenbericht des 1. Projektjahres 1992 (Januar bis Oktober) der Caritas Begleitgruppe des Vereins Tamil Mandram. Luzern.

Caritas Schweiz, Inlandshilfe. 1984. Betreuergruppen in der Indochina-Aktion, verantwortl. für die Befragung und für die Auswertung René Kleist et al., Luzern.

Casanova, José. 1994. Public Religions in the Modern World. Chicago: University of Chicago Press.

Cattacin, Sandro, Cla Reto Famos, Michael Duttwiler und Hans Mahnig. 2003. Staat und Religion in der Schweiz - Anerkennungskämpfe, Anerkennungsformen. Eine Studie des Schweizerischen Forums für Migrations- und Bevölkerungsstudien (SFM) im Auftrag der Eidgenössischen Kommission gegen Rassismus (EKR), Bern.

Cattacin, Sandro und Bülent Kaya. 2001. Die Politik der Integration von Migrantinnen und Migranten im föderalistischen System der Schweiz. In Lale Akgün und Dietrich Thränhardt (Hrsg.), Integrationspolitik in föderalistischen Systemen. Jahrbuch Migration, Bd. 10 (S.191218). Münster: Lit.

Cheran, R. 2003. Diaspora Circulation and Transnationalism as Agents of Change in the Post Conflict Zones of Sri Lanka. Department of Sociology and Centre for Refugee Studies, York University: Toronto, Canada.

Clifford, James. 1994. Diasporas. Cultural Anthropology 9(3), 302-338.

Clifford, James. 1997. Routes: Travel and Translation in the Late Twentieth Century. Cambridge, Mass.: Harvard University Press.

Clothey, Fred W. 1972. Pilgrimage Centers in the Tamil Cultus of Murukan. fournal of the American Academy of Religion 40(1), 79-95.

Clothey, Fred W. 2005. Tamil Religions. In Lindsay Jones (Hrsg.), Encyclopedia of Religion, Vol. 13 (S. 8973-8979). Farmington, Hills, MI: Macmillan Reference USA.

Clothey, Fred W. 2006. Ritualizing on the Boundaries. Continuity and Innovation in the Tamil Diaspora. Studies in Comparative Religion. Columbia, S.C.: University of South Carolina Press.

Cohen, Phil. 1998. Welcome to the Diasporama. A Cure for the Millennium Blues? New Ethnicities 3, 3-10.

Cohen, Robin. 1997. Global Diasporas: An Introduction. Seattle: University of Washington Press.

Cohen, Robin. 1999. Diasporas and the Nation-State: From Victims to Challengers. In Steven Vertovec und Robin Cohen (Hrsg.), Migration, Diasporas, and Transnationalism (S. 266-279). Cheltenham, UK: Edward Elgar Publishing.

Collins, Elizabeth Fuller. 1997. Pierced by Murugan's Lance. Ritual, Power, and Moral Redemption Among Malaysian Hindus. DeKalb: Northern Illinois University Press.

Corbin, Juliet und Anselm Strauss. 1990. Grounded Theory Research: Procedures, Canons and Evaluative Criteria. Zeitschrift für Soziologie 19(6), 418-427.

Corrigan, John. 2009. Spatiality and Religion. In Barney Warf und Santa Arias (Hrsg.), The Spatial Turn (S. 157-172). London: Routledge.

Coward, Harold G. 2000. Hinduism in Canada. In Harold G. Coward, John R. Hinnells und Raymond Brady Williams (Hrsg.), The South Asian Religious Diaspora in Britain, Canada, and the United States (S. 151-172). Albany, N. Y.: State University of New York Press.

Coward, Harold G., John R. Hinnells, und Raymond Brady Williams (Hrsg.). 2000. The South Asian Religious Diaspora in Britain, Canada, and the United States. Albany, N.Y.: State University of New York Press. 
Csáky, Moritz und Christoph Leitgeb (Hrsg.) 2009. Kommunikation - Gedächtnis - Raum. Kulturwissenschaften nach dem «Spatial Turn». Bielefeld: transcript.

Dahinden, Janine. 2008. Deconstructing Mythological Foundations of Ethnic Identities and Ethnic Group Formation: Albanian-Speaking and New Armenian Immigrants in Switzerland. Journal of Ethnic and Migration Studies 34(1), 55-76.

D’Amato, Gianni. 2001. Vom Ausländer zum Bürger: der Streit um die politische Integration von Einwanderern in Deutschland, Frankreich und der Schweiz. Region, Nation, Europa, Bd.5. Münster: Lit.

D’Amato, Gianni. 2010. Switzerland: A Multicultural Country without Multicultural Policies? In Steven Vertovec und Susanne Wessendorf (Hrsg.), The Multiculturalism Backlash. European Discourses, Policies, and Practices, (S. 130-151). London: Routledge.

D’Amato, Gianni, Brigitta Gerber, und Martina Kamm (Hrsg.). 2005. Menschenschmuggel und irreguläre Migration in der Schweiz. Neuchatel: Swiss Forum for Migration and Population Studies (SFM).

Dasa, Gaura-lila. 2010. Eine Villa am Zürichberg. In Schweizerische Stiftung für KrishnaBewusstsein (Hrsg.), 30 Jahre Krishna-Tempel Zürich (1980-2010) (S. 28-35). Zürich.

David, Ann. 2008. Local Diasporas / Global Trajectories. New Aspects of Religious 'Performance' in British Tamil Hindu Practice. Performance Research 13(3), 89-99.

David, Ann. 2009. Performing for the Gods? Dance and Embodied Ritual in British Hindu Temples. In: South Asian Popular Culture 7(3), 217-231.

David, Ann. 2010. Gendering the Divine. New Forms of Feminine Hindu Worship. International fournal of Hindu Studies 13(3), 337-356.

Deegalle, Mahinda (Hrsg.). 2006. Buddhism, Conflict and Violence in Modern Sri Lanka. Routledge Critical Studies in Buddhism. London, New York: Routledge.

Demmers, Jolle. 2002. Diaspora and Conflict: Locality, Long-Distance Nationalism, and Delocalisation of Conflict Dynamics. Favnost - The Public 9(1), 85-96.

Dev Das, Sri Caitanya. 2010. Die Wurzeln giessen. In Schweizerische Stiftung für KrishnaBewusstsein (Hrsg.), 30 fahre Krishna-Tempel Zürich (1980-2010) (S. 52). Zürich.

DeVotta, Neil. 2004. Blowback: Linguistic Nationalism, Institutional Decay, and Ethnic Conflict in Sri Lanka. Stanford, Calif.: Stanford University Press.

DeVotta, Neil. 2007. Sinhalese Buddhist National Ideology: Implications for Politics and Conflict Resolution in Sri Lanka. Policy Studies, Vol. 40. Washington D. C.: East-West Center Washington.

Diezinger, Angelika (Hrsg.). 1994. Erfahrung mit Methode: Wege sozialwissenschaftlicher Frauenforschung. Forum Frauenforschung, Bd. 8. Freiburg i. Br: Kore.

Doninger O'Flaherty, Wendy. 1973. Siva: The Erotic Ascetic. London, New York: Oxford University Press.

Döring, Jörg und Tristan Thielmann (Hrsg.). 2009. Spatial Turn. Das Raumparadigma in den Kultur- und Sozialwissenschaften. Bielefeld: transcript.

Ebrecht, Jörg und Frank Hillebrandt (Hrsg.). 2002. Bourdieus Theorie der Praxis. Erklärungskraft. Anwendung. Perspektiven. Wiesbaden: Westdeutscher Verlag.

Eck, Diana L. 1998. Darśan: Seeing the Divine Image in India. 3. Aufl. New York: Columbia University Press.

Eck, Diana L. 2000. Negotiating Hindu Identities in America. In Harold G. Coward, John R. Hinnells und Raymond Brady Williams (Hrsg.), The South Asian Religious Diaspora in Britain, Canada, and the United States (S. 219-238). Albany, N.Y.: State University of New York Press.

Engler, Steven. 2005. Two Problems with Constructionism in the Study of Religion. Revista de Estudos da Religião 4, 28-34. 
Eulberg, Rafaela. 2008. Hindu-Traditionen in der Schweiz. In Michael Klöcker und Udo Tworuschka (Hrsg.), Handbuch der Religionen. Kirchen und andere Glaubensgemeinschaften in Deutschland und im deutschsprachigen Raum, 19. Ergänzungslieferung, VIII-24 (S.1-28). München: Olzog Verlag.

Eulberg, Rafaela und Monika Niederberger. 2011. Sri-lankisch tamilische Christen im deutschsprachigen Raum. In Michael Klöcker und Udo Tworuschka (Hrsg.), Handbuch der Religionen. Kirchen und andere Glaubensgemeinschaften in Deutschland und im deutschsprachigen Raum, 29. Ergänzungslieferung, II 6.2.3 (S. 1-21). München: Olzog Verlag.

Eulberg, Rafaela. 2013. Geschichten über das Leben mit den Göttern in der Schweiz. Diasporische Narrative sri-lankisch tamilischer Hindus. In Dirk Johannsen und Gabriela Brahier (Hrsg.), Konstruktionsgeschichten. Narrationsbezogene Ansätze in der Religionsforschung (S. 251-264). Würzburg: Ergon-Verlag.

Eulberg, Rafaela. 2014. Temple publics as interplay of multiple public spheres. Public faces of Sri Lankan Tamil Hindu life in Switzerland. In Ester Gallo (Hrsg.), Migration and Religion in Europe. Comparative Perspectives on South Asian Experiences (S. 111-129). London: Ashgate.

Eulberg, Rafaela, Annika Jacobsen und Petra Tillessen. 2019. The Label of "Religion". Migration and Aspirations of Religious Identities in Contemporary Europe. FIW Working Paper No.11, Bonn.

Eyer, Philippe. 2007. Götter in der Diaspora. Religiöse Rekonstruktionen tamilischer Hindus im Raum Bern im Spannungsfeld zwischen Kontinuität und Wandel. Unveröffentlichte Lizentiatsarbeit, Universität Freiburg i. Ue.

Faist, Thomas. 2007. The Transnational Turn. In Ajaya Kumar Sahoo und Brij Maharaj (Hrsg.) Sociology of Diaspora (S. 227-266). New Delhi: Rawat Publications.

Fibiger, Marianne C. Qvortrup. 2003. Sri Lankan Tamil Hindus in Denmark. Internal and External Cultural and Religious Representations. In Martin Baumann, Brigitte Luchesi, Annette Wilke und Peter Schalk (Hrsg.), Tempel und Tamilen in zweiter Heimat. Hindus aus Sri Lanka im deutschsprachigen und skandinavischen Raum (S.345-362). Würzburg: Ergon-Verlag.

Fibiger, Marianne C. Qvortrup. 2011. Young Tamil Hindus in Denmark and Their Relationship to Tradition and Collective Memory. Finnish fournal of Ethnicity and Migration 5(2), 24-32.

Fibiger, Marianne C. Qvortrup. 2012. When the Hindu-Goddess Moves to Denmark. The Establishment of a Shakta-Tradition. Bulletin for the Study of Religion 41(3), 29-36.

Fitzgerald, Timothy. 2005. Problems with "Religion" as a Category for Understanding Hinduism». In J.E. Llewellyn (Hrsg.), Defining Hinduism: A Reader (S.171-201). London: Equinox.

Flick, Uwe, Ernst von Kardorff und Ines Steinke (Hrsg.). 2000. Qualitative Forschung: ein Handbuch. Reinbek bei Hamburg: Rowohlt.

Flood, Gavin D. 1996. An Introduction to Hinduism. Cambridge: Cambridge University Press.

Flück, Oskar. 2005. Sri Lanka oder: das Ringen der Löwen und Tiger. In Freiplatzaktion Basel (Hrsg.), Und plötzlich standen sie da (S. 54-82). Basel: Eigenverlag.

Foucault, Michel. 1980. Questions on Geography. In Colin Gordon (Hrsg.), Power/Knowledge: Selected Interviews and Other Writings 1972-1977 (S. 63-77). New York: Pantheon.

Franke, Edith und Verena Maske. 2011. Teilnehmende Beobachtung als Verfahren qualitativer Religionsforschung. In Karsten Lehmann und Stefan Kurth (Hrsg.), Religionen erforschen. Kulturwissenschaftliche Methoden in der Religionswissenschaft (S. 105-134). Wiesbaden: VS Verlag für Sozialwissenschaften.

Fraser, Nancy. 1999. Rethinking the Public Sphere. In Craig J. Calhoun (Hrsg.), Habermas and the Public Sphere (S. 109-142). Cambridge, Mass.: MIT Press. 
Fraser, Nancy. 2009. Theorie der Öffentlichkeit: Strukturwandel der Öffentlichkeit (1961). In Hauke Brunkhorst, Cristina Lafont und Regina Kreide (Hrsg.), Habermas- Handbuch (S. 148155). Stuttgart, Weimar: Metzler.

Frenz, Matthias. 2004. Gottes-Mutter-Göttin. Marienverehrung im Spannungsfeld religiöser Traditionen in Südindien. Würzburg: Ergon-Verlag.

Fricke, Dietmar. 2002. Der Tamilen-Singhalesen-Konflikt auf Sri Lanka. Berlin: Verlag Dr. Köster.

Frykenberg, Robert Eric. 1989. The Emergence of Modern "Hinduism" as a Concept and as an Institution. A Reappraisal with Special Reference to South India. In Günther-Dietz Sontheimer und Hermann Kulke (Hrsg.), Hinduism Reconsidered (S. 82-107). New Delhi: Manohar.

Frykenberg, Robert Eric. 1993. Constructions of Hinduism at the Nexus of History and Religion. In: Fournal of Interdisciplinary History 23(3), 523-550.

Fuchs, Eberhard. 1981. fugendsekten. München: Goldmann.

Fuglerud, Øivind. 1999. Life on the Outside: The Tamil Diaspora and Long-distance Nationalism. London: Pluto Press.

Fuglerud, Øivind. 2001. Time and space in the Sri Lanka-Tamil diaspora. Nations and Nationalism 7(2), 195-213.

Fuglerud, Øivind. 2011. Aesthetics of Martyrdom: The Celebration of Violent Death among the Liberation Tigers of Tamil Eelam. In Nerina Weiss und Maria Six-Hohenbalken (Hrsg.), Violence Expressed. An Anthropological Approach, (S. 71-90). London: Routledge.

Füssel, Marian. 2013. Tote Orte und gelebte Räume: zur Raumtheorie von Michel de Certeau S.J. Historical Social Research 38(3), 22-39.

Gajjala, Radhika. 2006. Cyberethnography. Reading South Asian Digital Diasporas. In Kyra Landzelius (Hrsg.), Native on the Net: Indigenous and Diasporic Peoples in the Virtual Age (S. 272-291). London: Routledge.

Gale, Richard. 2005. Representing the City. Mosques and the Planning Process in Birmingham. In: Journal of Ethnic and Migration Studies 31(6), 1161-1179.

Gambhirananda. 1957. History of the Ramakrishna Math and Mission. University of California Advaita Ashrama.

Ganesh, Kamala und Christopher McDowell. 2013. Switzerland. In Peter Reeves (Hrsg.), The Encyclopedia of Sri Lankan Diaspora (S. 137-144). Singapore: Editions Didier Millet.

Geaves, Ron. 2007. Saivism in the Diaspora. Contemporary Forms of Skanda Worship. London: Equinox.

Gebhard, Gunther, Oliver Geisler und Steffen Schröter (Hrsg.) 2007. Heimat: Konturen und Konjunkturen eines umstrittenen Konzepts. Bielefeld: transcript.

Gengnagel, Jörg, Monika Thiel-Horstmann und Gerald Schwedler (Hrsg.). 2008. Prozessionen, Wallfahrten, Aufmärsche: Bewegung zwischen Religion und Politik in Europa und Asien seit dem Mittelalter. Menschen und Kulturen, Bd. 4. Köln: Böhlau.

Geulen, Christian. 2004. Symmetrie und Politik. In Nilüfer Göle und Ludwig Ammann (Hrsg.), Islam in Sicht. Der Auftritt von Muslimen im öffentlichen Raum (S. 45-68). Bielefeld: transcript.

Gilroy, Paul. 1993. The Black Atlantic. Modernity and Double-Consciousness. Cambridge, Mass.: Harvard University Press.

Girtler, Roland. 2001. Methoden der Feldforschung. 4., Aufl. Wien: Böhlau.

Gieryn, Thomas F. 2002. What buildings do. Theory and Society 31(1), 35-74.

Gladigow, Burkhard, Christoph Auffarth und Jörg Rüpke. 2005. Religionswissenschaft als Kulturwissenschaft. Stuttgart: Kohlhammer. 
Glasze, Georg und Annika Mattissek (Hrsg.). 2009. Handbuch Diskurs und Raum. Theorien und Methoden für die Humangeographie sowie die sozial- und kulturwissenschaftliche Raumforschung. Bielefeld: transcript.

Glorius, Birgit. 2007. Transnationale Perspektiven. Eine Studie zur Migration zwischen Polen und Deutschland. Bielefeld: transcript.

Goebel, Dorothea und Ludger Pries. 2003. Transnationale Migration und die Inkorporation von Migranten. Einige konzeptionell theoretische Überlegungen zu einem erweiterten Verständnis gegenwärtiger Inkorporationsprozesse von Migranten. In Frank Swiaczny und Sonja Haug (Hrsg.), Migration - Integration - Minderheiten. Neuere interdisziplinäre Forschungsergebnisse. Materialien zur Bevölkerungswissenschaften des Bundesinstituts für Bevölkerungsforschung, Heft 107, (S.35-48). Wiesbaden.

Göle, Nilüfer und Ludwig Ammann (Hrsg.). 2004. Islam in Sicht. Der Auftritt von Muslimen im öffentlichen Raum. Bielefeld: transcript.

Good, Anthony. 2001. Multiple Meanings in South Indian Temple Worship. Culture and Religion 2(2), 239-260.

Goodhand, Jonathan, Bart Klem und Benedikt Korf. 2009. Religion, Conflict and Boundary Politics in Sri Lanka. European fournal of Development Research 21, 679-698.

Goodhand, Jonathan und Benedikt Korf. 2010. Caught in the Peace Trap? On the Illiberal Consequences of Liberal Peace in Sri Lanka. In Jonathan Goodhand, Benedikt Korf und Jonathan Spencer (Hrsg.), Conflict and Peacebuilding in Sri Lanka: Caught in the Peace Trap? (S. 1-15). London: Routledge.

Goonasekera, Sunil. 2007. Bara: Buddhist Vows of Kataragama. In Selva J. Raj und William P. Harman (Hrsg.), Dealing with Deities: The Ritual Vow in South Asia (S.107-128). Albany: State University of New York Press.

Gordon, Edmund. 1998. Disparate Diasporas: Identity and Politics in an African-Nicaraguan Community. Austin: University of Texas Press.

Gross, Rita, Hg. 1977. Beyond Androcentrism: New Essays on Women and Religion. Missoula, MT: Scholars Press.

Gunn, Janet. 2009. “On Thursdays We Worship the Banana Plant”: Encountering Lived Hinduism in a Canadian Suburb». Method \& Theory in the Study of Religion 21(1), 40-49.

Günzel, Stephan (Hrsg.). 2007. Topologie. Zur Raumbeschreibung in den Kultur- und Medienwissenschaften. Bielefeld: transcript.

Gupta, Akhil und James Ferguson. 2008. Discipline and Practice. In Sanjeev Khagram und Peggy Levitt (Hrsg.), The Transnational Studies Reader, (S. 87-103). New York, NY: Routledge.

Habermas, Jürgen. 1962. Strukturwandel der Öffentlichkeit. Frankfurt a. M.: Suhrkamp.

Hahn, Hans Peter. 2005. Materielle Kultur: Eine Einführung. Ethnologische Paperbacks. Berlin: D. Reimer.

Hall, Stuart, Hg. 1997. Representation. Cultural Representations and Signifying Practices. Culture. London: Sage Publications.

Han, Petrus. 2005. Soziologie der Migration. 2., Aufl. Stuttgart: Lucius \& Lucius.

Hannerz, Ulf. 2003. Transnational Connections: Culture, People, Places. New York: Routledge.

Haraway, Donna. 1995. Situiertes Wissen. Die Wissenschaftsfrage im Feminismus und das

Privileg einer partialen Perspektive. In Donna Haraway, Die Neuerfindung der Natur: Primaten, Cyborgs und Frauen (S. 73-97), Frankfurt/New York: Campus.

Harding, Sandra. 1994. Das Geschlecht des Wissens. Frauen denken die Wissenschaft neu. Frankfurt a. M.: Campus. 
Haug, Werner. 2007. Religion als öffentliche Angelegenheit. Rede von Dr. Werner Haug, Mitglied der Leitungsgruppe Religionsgemeinschaften, Staat und Gesellschaft. Nationales Forschungsprogramm NFP58, am Kick-off-Meeting vom 9. November 2007 in Bern.

Heiler, Friedrich. 1977. Die Frau in den Religionen der Menschheit. Theologische Bibliothek Töpelmann, Bd. 33. Berlin: de Gruyter.

Helland, Christopher. 2010. (Virtually) Been There, (Virtually) Done That. In: online - Heidelberg fournal of Religions on the Internet 4(1), 148-150.

Hellmann-Rajanayagam, Dagmar. 1994. The Tamil Tigers: Armed Struggle for Identity. Beiträge zur Südasienforschung, Bd. 157. Stuttgart: F. Steiner.

Henayaka-Lochbihler, Ranjith und Miriam Lambusta. 2004. The Sri Lankan Diaspora in Italy: An Explorative Mapping. Berghof Research Center for Conflict Management. Berlin.

Hess, Monika und Benedikt Korf. 2014. Tamil Diaspora and the Political Spaces of Second-Generation Activism in Switzerland. Global Networks 14(4), 419-437.

Hettlage, Robert. 1991. Diaspora: Umrisse einer soziologischen Theorie. Österreichische Zeitschrift für Soziologie 16(3), 4-24.

Hettlage, Robert. 2004. Verhandlungskultur, Spannungsausgleich und die Kontrolle ethnischer Konflikte. In Horst Pöttker und Rainer Geißler (Hrsg.), Kritische Empirie (S. 411-429). Wiesbaden: VS Verlag für Sozialwissenschaften.

Hoffmann-Nowotny, Hans-Joachim. 2001. Internationale Migration und das Fremde in der Schweiz. In Hans-Joachim Hoffmann-Nowotny Das Fremde in der Schweiz. Ergebnisse soziologischer Forschungen (S. 11-30). Zürich: Seismo Verlag.

Hondagneu-Sotelo, Pierrette. 2005. Gendering Migration. Not for "Feminists Only" - and not for the Household. In CMD Working Paper. 05-02f. Center for Migration and Development. Princeton, NJ: Princeton University.

Höpflinger, Anna-Katharina, Ann Jeffers und Daria Pezzoli-Olgiati (Hrsg.). 2008. Handbuch Gender und Religion. Göttingen: Vandenhoeck \& Ruprecht.

Hörning, Karl H. und Julia Reuter, Hg. 2004. Doing Culture. Neue Positionen zum Verhältnis von Kultur und sozialer Praxis. Bielefeld: transcript.

Hrdličková, Zuzana. 2008. Cultural Interpretations of Tamil Tigresses and Tamil Women Employed in Non-Traditional Ways: Two New Phenomena in Tamil Sri Lankan Society. Oriental Archive 76, 459-489.

Hudson, Dennis D. 1992. Arumuga Navalar and the Hindu Renaissance Among the Tamils. In Kenneth W. Jones (Hrsg.), Religious Controversy in British India: Dialogues in South Asian Languages (S. 27-51). Albany: State University of New York Press.

Human Rights Watch. 2010. World Report 2010 - Sri Lanka. https://www.hrw.org/worldreport/2010/country-chapters/sri-lanka (08.03.2010).

Hunziker, Michael. 2006. Vom Sündenbock zum Vorzeigeausländer: das Bild der Tamilen in der Deutschschweizer Presse 1982-1994. Unveröffentlichte Lizentiatsarbeit, Universität Freiburg i. Ue.

Jacobsen, Knut A. 2003. Settling in Cold Climate: The Tamil Hindus in Norway. In Martin Baumann, Brigitte Luchesi, Annette Wilke und Peter Schalk (Hrsg.), Tempel und Tamilen in zweiter Heimat. Hindus aus Sri Lanka im deutschsprachigen und skandinavischen Raum (S. 363-377). Würzburg: Ergon-Verlag.

Jacobsen, Knut A. 2004. Establishing Ritual Space in the Hindu Diaspora. In Knut A. Jacobsen (Hrsg.), South Asians in the Diaspora (S. 134-148). Leiden: Brill.

Jacobsen, Knut A. 2006. Hindu Processions, Diaspora and Religious Pluralism. In Penumala Pratap Kumar (Hrsg.), Religious Pluralism in the Diaspora (S. 163-174). Leiden, Boston: Brill. 
Jacobsen, Knut A. 2008a. Processions, Public Space and Sacred Space in the South Asian Diasporas in Norway. In Knut A. Jacobsen (Hrsg.), South Asian Religions on Display. Religious Processions in South Asia and in the Diaspora (S. 191-204). London: Routledge.

Jacobsen, Knut A. (Hrsg.), 2008b. South Asian Religions on Display. Religious Processions in South Asia and in the Diaspora. London: Routledge.

Jacobsen, Knut A. 2009. Establishing Tamil Ritual Space. A Comparative Analysis of the Ritualisation of the Traditions of the Tamil Hindus and the Tamil Roman Catholics in Norway. fournal of Religion in Europe 2(2), 180-198.

Jacobsen, Knut A. und Selva J. Raj (Hrsg.), 2008. South Asian Christian Diaspora. Invisible Diaspora in Europe and North America. Aldershot Hants England, Burlington VT: Ashgate.

Jalal, Ayesha. 2002. Self and Sovereignty: Individual and Community in South Asian Islam Since 1850. London: Routledge.

Jones, Demelza. 2016. Being Tamil, being Hindu: Tamil Migrants' Negotiations of the Absence of Tamil Hindu Spaces in the West Midlands and South West of England. Religion 46(1), 53-74.

Juhasz, Anne und Eva Mey. 2003. Die zweite Generation: Etablierte oder Außenseiter? Biographien von fugendlichen ausländischer Herkunft. Studien zur Sozialwissenschaft. Wiesbaden: Westdeutscher Verlag.

Juschka, Darlene. 1999. The Category of Gender in the Study of Religion. Method and Theory in the Study of Religion 11, 77-105.

Juteau, Danielle. 1999. L'éthnicité et ses frontières. Montréal: Presses de l'Université de Montreal.

Kälin, Walter. 2000. Grundrechte im Kulturkonflikt. Freiheit und Gleichheit in der Einwanderungsgesellschaft. Zürich: NZZ Verlag.

Kessler, Annegret. 2013. Steine des Anstoßes. Diskurse um religiöse Gebäude und Bauvorhaben in der Schweiz. In Dorothea Lüddeckens, Christoph Uehlinger und Rafael Walthert (Hrsg.), Die Sichtbarkeit religiöser Identität: Repräsentation - Differenz - Konflikt (S. 271-312). Zürich: TVZ Theologischer Verlag Zürich.

Khagram, Sanjeev und Peggy Levitt (Hrsg.). 2008. The Transnational Studies Reader. New York, NY: Routledge.

King, Ursula. 2008. Gender-kritische (Ver-)Wandlungen in der Religionswissenschaft. In AnnaKatharina Höpflinger, Ann Jeffers und Daria Pezzoli-Olgiati (Hrsg.) Handbuch Gender und Religion, (S. 29-40). Göttingen: Vandenhoeck \& Ruprecht.

King, Ursula. 2005. Gender and Religion: An Overview. In Lindsay Jones (Hrsg.), Encyclopedia of Religion, Vol. 5 (S. 3296-3310). Detroit: Macmillan.

Kleinert, Corinna. 2004. Fremden Feindlichkeit. Einstellungen junger Deutscher zu Migranten. Wiesbaden: Verlag für Sozialwissenschaften.

Knott, Kim. 1987. Hindu-Related New Religious Movements. In Shap Working Party/Commission for Racial Equality (Hrsg.), Shap Working Party, World Religions in Education: SHAP Handbook (S. 141-143). London.

Knott, Kim. 1988. My Sweet Lord: The Hare Krishna Movement. New Religious Movement Series. San Bernardino, Calif: R. Reginald.

Knott, Kim. 2005a. Space. Revista de Estudos da Religião 4, 108-114.

Knott, Kim. 2005b. Spatial Theory and Method for the Study of Religion. Temenos 41(2), 153-184.

Knott, Kim. 2005c. The Location of Religion. A Spatial Analysis. London: Equinox.

Knott, Kim. 2011. Spatial Methods. In Michael Stausberg und Steven Engler (Hrsg.), The Routledge Handbook of Research Methods in the Study of Religion, (S. 491-501). New York: Routledge.

Knott, Kim und Sean McLoughlin (Hrsg.). 2010. Diasporas. Concepts, Intersections, Identities. London: Zed. 
Knuth, Rebecca. 2006. Burning Books and Leveling Libraries: Extremist Violence and Cultural Destruction. Westport, CT: Praeger.

Koppedrayer, Kay. 2004. Hybrid Constructions: Swami Vivekananda's Presentation of Hinduism at the World's Parliament of Religions, 1893. Religious Studies and Theology 23(1), 7-34.

Köpping, Klaus-Peter und Ursula Rao (Hrsg.). 2000. Im Rausch des Rituals. Gestaltung und Transformation der Wirklichkeit in körperlicher Performanz, Münster: Lit.

Korom, Frank J. 2010. Issues and Themes in the Study of South Asian Diaspora. In Shubha Chaudhuri und Anthony Seeger (Hrsg.), Remembered Rhythms: Essays on Diaspora and the Music of India (S. 17-36). New Delhi: Seagull Press.

Kramrisch, Stella. 1976. The Hindu Temple. New Delhi: Motilal Banarsidass Publishers.

Krüger, Helga. 1999. Geschlecht - eine schwierige Kategorie. In Aylâ Neusel und Angelika Wetterer (Hrsg.), Vielfältige Verschiedenheiten. Geschlechterverhältnisse in Studium, Hochschule und Beruf(S. 35-60). Frankfurt a. M.: Campus.

Krüger, Oliver. 2004. The Internet as Distributor and Mirror of Religious and Ritual Knowledge. Asian fournal of Social Science 32(2), 183-197.

Krüger, Oliver, Michael Nijhawan, und Eftychia Stavrianopoulou. 2005. ,Ritual‘ und ,Agency ‘ Legitimation und Reflexivität ritueller Handlungsmacht. In Forum Ritualdynamik - Diskussionsbeiträge des SFB 619 «Ritualdynamik» der Ruprecht-Karls-Universität Heidelberg (E-fournal).

Küchler, Susanne und Daniel Miller (Hrsg). 2005. Clothing as Material Culture. Oxford, UK: Berg. Laack, Isabel. 2007. Religionsästhetik und Religionsmusikologie. Die Behandlung nonverbaler Quellen in der Religionswissenschaft. In Oliver Krüger (Hrsg.), Nicht alle Wege führen nach Rom. Religionen, Rituale und Religionstheorie jenseits des Mainstreams (S.114-133). Frankfurt a. M.: Lembeck.

Langer, Robert, Dorothea Lüddeckens, Kerstin Radde und Jan Snoek. 2006. Transfer of Ritual. Journal of Ritual Studies 20(1), 1-10.

Lauser, Andrea und Cordula Weiköppel (Hrsg.). 2008. Migration und religiöse Dynamik. Kultur und soziale Praxis. Bielefeld: transcript.

Lefebvre, Henri. 1974. The Production of Space. Malden, Mass.: Blackwell.

Lienemann, Wolfgang. 2009. Religiöse Symbole in der Öffentlichkeit. In Wolfgang W. Müller (Hrsg.), Christentum und Islam. Plädoyer für den Dialog (S.41-64). Zürich: TVZ Theologischer Verlag Zürich.

Limacher, Katharina und Veronica Rückamp. 2016. "Entrance Free - we are Looking Forward to your Visit!": Public Events as Strategies of Legitimisation in Immigrant Religious Organisations. In fournal of Religion in Europe 9(4), 369-401.

Loretan, Adrian. 2007. Der (säkulare) Rechtsstaat und die Religionen. Modelle des Zusammenwirkens in den USA, in Europa und in der Schweiz. In Michael Durst und Hans J. Münk (Hrsg.), Religion und Gesellschaft, Theologische Berichte (S.134-196). Freiburg Schweiz: Paulusverlag.

Luchesi, Brigitte. 2003a. Hinduistische Sakralarchitektur und Tempelgestaltung in Hamm-Uentrop. In Martin Baumann, Brigitte Luchesi, Annette Wilke und Peter Schalk (Hrsg.), Tempel und Tamilen in zweiter Heimat. Hindus aus Sri Lanka im deutschsprachigen und skandinavischen Raum (S. 223-274). Würzburg: Ergon-Verlag.

Luchesi, Brigitte. 2003b. Wege aus der Unsichtbarkeit. Zur Etablierung hindu-tamilischer Religiosität im öffentlichen Raum der Bundesrepublik Deutschland. In Martin Baumann, Brigitte Luchesi, Annette Wilke und Peter Schalk (Hrsg.), Tempel und Tamilen in zweiter Heimat. Hindus aus Sri Lanka im deutschsprachigen und skandinavischen Raum (S. 99-124). Würzburg: Ergon-Verlag. 
Luchesi, Brigitte. 2004a. Leaving Invisibility. The Establishment of Hindu Tamil Religiosity in German Public Sphere. In New Kolam 9\&10.

Luchesi, Brigitte. 2004b. Tamil Hindu Places of Worship in Germany. In Knut A. Jacobsen (Hrsg.), South Asians in the Diaspora. Histories and Religious Traditions (S.116-133). Leiden: Brill.

Luchesi, Brigitte. 2008a. Mobile Tempel. Zur religiösen Festkultur hindu-tamilischer Gemeinschaften in Deutschland. In Volker Gottowik, Holger Jebens und Editha Platte (Hrsg.), Zwischen Aneignung und Verfremdung. Ethnologische Gratwanderungen. Festschrift für KarlHeinz Kohl (S. 353-374). Frankfurt a. M., New York: Campus.

Luchesi, Brigitte. 2008b. Parading Hindu Gods in Public: New Festival Traditions of Tamil Hindus in Germany. In Knut A. Jacobsen (Hrsg.), South Asian Religions on Display. Religious Processions in South Asia and in the Diaspora (S. 178-190). London: Routledge.

Luchesi, Brigitte. 2008c. Seeking the Blessing of the Consolatrix Afflictorum. The Annual Pilgrimage of Sri Lankan Tamils to the Madonna in Kevelaer (Germany). In Knut A. Jacobsen und Selva J. Raj (Hrsg.), South Asian Christian Diaspora. Invisible Diaspora in Europe and North America (S.75-95). Aldershot: Ashgate.

Luchesi, Brigitte. 2010. Darśan-Bilder: hinduistische Verehrungspraxis und populäre Poster in Nordindien. In Bärbel Beinhauer-Köhler, Daria Pezzoli-Olgiati und Joachim Valentin (Hrsg.), Religiöse Blicke - Blicke auf das Religiöse: Visualität und Religion (S.201-226). Zürich: TVZ Theologischer Verlag.

Lüthi, Damaris. 2003. Heimatliche Konventionen im Exil bewahren. Hinduistische und christliche Religiosität tamilischer Flüchtlinge in Bern. In Martin Baumann, Brigitte Luchesi, Annette Wilke und Peter Schalk (Hrsg.), Tempel und Tamilen in zweiter Heimat. Hindus aus Sri Lanka im deutschsprachigen und skandinavischen Raum, (S. 295-322). Würzburg: ErgonVerlag.

Lüthi, Damaris. 2004. Umgang mit Gesundheit und Krankheit bei tamilischen Flüchtlingen im Raum Bern. Bern: Institut für Ethnologie.

Lüthi, Damaris. 2005. Soziale Beziehungen und Werte im Exil bewahren, Arbeitsblätter des Instituts für Ethnologie der Universität Bern, Bd. 30. Bern.

Lüthi, Damaris. 2007. Sri Lanka Tamilen in der Schweiz In Klaus J. Bade, Pieter C. Emmer und Leo Lucassen (Hrsg.), Enzyklopädie Migration in Europa (S.1011-1015). Paderborn: Schöningh/Fink.

Lüthi, Damaris. 2008. Perpetuating Religious and Social Concepts in the Extended Motherland. In Knut A. Jacobsen und Selva J. Raj (Hrsg.), South Asian Christian Diaspora. Invisible Diaspora in Europe and North America (S. 97-116). Aldershot: Ashgate.

Malinar, Angelika. 2009. Hinduismus. Göttingen: Vandenhoeck \& Ruprecht.

Mallapragada, Madhavi. 2010. Desktop Deities: Hindu Temples, Online Cultures and the Politics of Remediation. South Asian Popular Culture 8(2), 109-121.

Manogaran, Chelvadurai und Bryan Pfaffenberger. 1994. The Sri Lankan Tamils. Ethnicity and Identity. Boulder: Westview Press.

Marienstras, Richard. 1989. On the Notion of Diaspora. In Gérard Chaliand und Tony Berrett (Hrsg.), Minority Peoples in the Age of Nation-States (S.119-125). London: Pluto Press.

Markus, Vera. 2005. In der Heimat ihrer Kinder. Tamilen in der Schweiz. Zürich: Offizin.

Masilamani-Meyer, Eveline. 2004. Guardians of Tamilnadu: Folk Deities, Folk Religion, Hindu Themes. Halle: Verlag der Franckeschen Stiftungen.

Mayer, Ruth. 2005. Diaspora. Eine kritische Begriffsbestimmung. Bielefeld: transcript.

McDowell, Christopher. 1996. A Tamil Asylum Diaspora: Sri Lankan Migration, Settlement and Politics in Switzerland. Providence: Berghahn. 
McDowell, Christopher. 1999. The Point of No Return: The Politics of the Swiss Tamil Repatriation Agreement. In Richard Black und Khalid Koser (Hrsg.), The End of the Refugee Cycle. Refugee Repatriation and Reconstruction (S. 126-141). New York [u. a.]: Berghahn Books.

McDowell, Christopher. 2004. Asylum Diaspora: Tamils in Switzerland. In Melvin Ember (Hrsg.), Encyclopedia of Diasporas: Immigrant and Refugee Cultures Around the World (S.534-543). New York, NY: Kluwer Acad./Plenum Publishers.

McGilvray, Dennis B. 1998. Symbolic Heat: Gender, Health \& Worship Among the Tamils of South India and Sri Lanka. Ahmedabad, Middletown NJ, Wappingers' Falls NY: Mapin Publishers in association with University of Colorado Museum Boulder Grantha Corp.

McLoughlin, Sean. 2007. Migration, Diaspora and Transnationalism. In John R. Hinnells (Hrsg.), The Routledge Companion to the Study of Religion (S. 526-549). London: Routledge.

Mehr, Christian. 2001. Asyl in der Schweiz: ein Überblick über den Asyl- und Flüchtlingsbereich. Bern: Bundesamt für Migration.

Meier-Mesquita, Maria Cintia de Perpétua. 1992. Flüchtlinge aus der Dritten Welt: eine Pilotstudie über tamilische Flüchtlinge aus Sri Lanka. Bern.

Meier-Mesquita, Maria Cintia de Perpétua. 1993. Determinanten der Rückkehrwilligkeit der tamilischen Flüchtlinge aus Sri Lanka. In Walter Kälin und Rupert Moser (Hrsg.), Migrationen aus der Dritten Welt: Ursachen - Wirkungen - Handlungsmöglichkeiten, Bern: Haupt.

Meinhold-Bergmann, Mallika Elizabeth. 2006. Interkulturelle Psychosomatik, Ätiologie und Therapie. Srilankische Frauen in Deutschland; ein Vergleich zwischen Tamilinnen und Singhalesinnen. Dissertation, Universität Ulm, Ulm.

Meisig, Konrad. 2001. Tamilischer Hinduismus in Deutschland. Ein Rundgang durch den Vighneśvara-Tempel in Hamm (Westfalen). Mitteilungen für Anthropologie und Religionsgeschichte (MARG) 14, 229-249.

Michaels, Axel. 2006. Ritual and Meaning. In Jens Kreinath, Jan Snoek und Michael Stausberg (Hrsg.), Theorizing Rituals. Issues, Topics, Approaches, Concepts (S. 86-90). Leiden: Brill.

Michell, George. 1979. Der Hindu-Tempel. Bauformen und Bedeutung. Köln: DuMont.

Miller, Daniel. 2010. Stuff. Cambridge: Polity Press.

Mistry, Rohinton. 1995. A Fine Balance. New York: Vintage Books.

Moebius, Stephan. 2010. Kultur. 2. Aufl., Bielefeld: transcript.

Mohn, Jürgen. 2010. Die Konstruktion religiöser Wahrnehmungsräume und der wissenschaftliche Blick: Religionsaisthetische Überlegungen anhand von Gartenanlagen in der europäischen Religionsgeschichte. In Bärbel Beinhauer-Köhler, Daria Pezzoli-Olgiati und Joachim Valentin (Hrsg.), Religiöse Blicke - Blicke auf das Religiöse (S. 59-82). Zürich: TVZ Theologischer Verlag Zürich.

Mohn, Jürgen. 2012. Wahrnehmung der Religion: Aspekte der komparativen Religionswissenschaft in religionsästhetischer Perspektive. Erwägen, Wissen, Ethik 23(2), 241-254.

Moret, Joëlle, Denise Efionayi, und Fabienne Stants. 2007. Die srilankische Diaspora in der Schweiz. Bundespublikationen BBL. Bern: Bundesamt für Migration (BFM).

Morgan, David. 2005. The Sacred Gaze: Religious Visual Culture in Theory and Practice. Berkeley: University of California Press.

Morgan, David. 2012. The Embodied Eye: Religious Visual Culture and the Social Life of Feeling. Berkeley: University of California Press.

Müller, Monika. 2013. Migration und Religion. Junge hinduistische und muslimische Männer in der Schweiz. Wiesbaden: Springer VS.

Müller-Funk, Wolfgang. 2002. Die Kultur und ihre Narrative. Eine Einführung. Wien, New York: Springer. 
Nagel, Alexander-Kenneth (Hrsg.). 2013. Diesseits der Parallelgesellschaft. Neuere Studien zu religiösen Migrantengemeinden in Deutschland. Bielefeld: transcript.

Nagel, Alexander-Kenneth (Hrsg.). 2015. Religiöse Netzwerke. Die zivilgesellschaftlichen Potentiale religiöser Migrantengemeinden. Bielefeld: transcript.

Nagel, Joane. 1994. Constructing Ethnicity. Social Problems 41(1), 152-176.

Narayanan, Vasudha. 2006. Creating Community Spaces in American Hinduism: Authority, Authenticity, and Identity. Unpublished Lecture at the Panel of the Comparative Studies in Hinduism and Judaism Group. Congress of the American Academy of Religion, Washington D. C., 20. November 2006.

Natali, Cristiana. 2008. Building Cemeteries, Constructing Identities. Funerary Practices and Nationalist Discourse among the Tamil Tigers of Sri Lanka. Contemporary South Asia 16(3), 287-301.

Navaratna-Bandara, A.M. 2002. Ethnic Relations and State Crafting in Post-Independence Sri Lanka. In Walter Nubin (Hrsg.), Sri Lanka (S. 57-76). New York: Nova Science Publishers.

Nesbitt, Eleanor. 2006. Locating British Hindus' Sacred Space. Contemporary South Asia 15(2), 195-208.

Neubert, Frank. 2005. Charisma und soziale Dynamik. Religionswissenschaftliche Untersuchungen am Beispiel von Sri Ramakrsna und Svami Vivekananda. Aachen: Shaker.

Neubert, Frank. 2006. Ritualtransfer. In Forum Ritualdynamik - Diskussionsbeiträge des SFB 619 «Ritualdynamik» der Ruprecht-Karls-Universität Heidelberg, 15.

Neubert, Frank. 2010a. Krishnabewusstsein. Die International Society for Krishna Consciousness (ISKCON) - «Hare-Krishna-Bewegung». Marburg: REMID.

Neubert, Frank. 2010b. Transferring and Re-Transferring Religious Practice. ISKCON between "East" and "West". In Ute Hüsken und Christiane Brosius (Hrsg.), Ritual Matters. Dynamic Dimensions in Practice (S. 76-87). London: Routledge India Taylor \& Francis.

Nubin, Walter (Hrsg.). 2002. Sri Lanka: Current Issues and Historical Background. New York: Nova Science Publishers.

Nugteren, Albertina. 2009. Hindu Ritual Dynamics. Case Studies from Contemporary Western Europe: Introduction. Journal of Religion in Europe 2(2), 71-84.

Numrich, Paul David. 1999. Old Wisdom in the New World. Americanization in Two Immigrant Theravada Buddhist Temples. Knoxville: University of Tennessee Press.

Nye, Malory. 1995. A Place for our Gods. The Construction of an Edinburgh Hindu Temple Community. Richmond: Curzon.

Nye, Malory. 2000a. Editorial: Culture and Religion. Culture and Religion 1(1), 5-12.

Nye, Malory. 2000b. Religion, Post-Religionism, and Religioning. Method and Theory in the Study of Religion 12(1), 447-476.

Orjuela, Camilla. 2008. The Identity Politics of Peacebuilding: Civil Society in War-torn Sri Lanka. New Delhi: Sage.

Orjuela, Camilla. 2009. Domesticating Tigers: the LTTE and Peacemaking in Sri Lanka. In Bruce W. Dayton und Louis Kriesberg (Hrsg.), Conflict Transformation and Peacebuilding: Moving from Violence to Sustainable Peace (S. 252-269). London: Routledge.

Orsi, Robert A. 1997. Everyday Miracles: The Study of Lived Religion. In David Hall (Hrsg.), Lived Religion in America: Toward a History of Practice (S. 7-13). Princeton, N.J.: Princeton University Press.

Osella, Filippo und Caroline Osella. 2003. "Ayyappan Saranam": Masculinity and the Sabarimala Pilgrimage in Kerala. Journal of the Royal Anthropological Institute 9(4), 729-754.

Parak, Stephan. 2005. Vom «Sonderfall Tamilen» zum «Normalfall Sri Lanka». In Freiplatzaktion Basel (Hrsg.), Und plötzlich standen sie da (S. 83-103). Basel: Eigenverlag. 
Pathmanathan, S. 2008. Hindus in Sri Lanka. In Denise Cush, Catherine Robinson und Michael York (Hrsg.), Encyclopedia of Hinduism (S. 828-830), London: Routledge.

Peach, Ceri und Richard Gale. 2003. Muslims, Hindus, and Sikhs in the New Religious Landscape of England. Geographical Review 93(4), 469-490.

Pennington, Brian Kemble. 2005. Was Hinduism Invented? Britons, Indians, and the Colonial Construction of Religion. Oxford: Oxford University Press.

Perera, Suvendrini. 2013. "Icons: Mathangi 'Maya' Arulpragasam (M.I.A)". In Peter Reeves (Hrsg.), The Encyclopedia of the Sri Lankan Diaspora (S.59-60). Singapore: Editions Didier Millet.

Pfaff-Czarnecka, Joanna. 2009. Accommodating Religious Diversity in Switzerland. In Paul Bramadat und Matthias Koenig (Hrsg.), International Migration and the Governance of Religious Diversity (S. 225-257). Montreal, Kingston: McGill Queen's University Press.

Pfaffenberger, Bryan. 1981. The Cultural Dimension of Tamil Seperatism in Sri Lanka. In: Asian Survey 21(11), 1145-1157.

Pfaffenberger, Bryan. 1994. The Political Construction of Defensive Nationalism: the 1968 Temple Entry Crisis in Sri Lanka. In Chelvadurai Manogaran und Bryan Pfaffenberger (Hrsg.), The Sri Lankan Tamils: Ethnicity and Identity (S. 143-162). San Francisco, Oxford: Westview Press.

Piguet, Etienne. 2006. Einwanderungsland Schweiz: fünf fahrzehnte halb geöffnete Grenzen. $\mathrm{CH}-$ Wissen/Le savoir suisse. Bern: Haupt.

Plate, S. Brent (Hrsg.). 2002. Religion, Art, and Visual Culture: A Cross-Cultural Reader. New York: Palgrave.

Pratt, Mary Louise. 1987. Linguistic Utopias. In Colin MacCabe, Nigel Fabb, Derek Attridge und Alan Durant (Hrsg.), The Linguistics of Writing: Arguments Between Language and Literature (S. 48-66). Manchester: Manchester University Press.

Pratt, Mary Louise. 1992. Imperial Eyes: Travel Writing and Transculturation. London [u. a.]: Routledge.

Pries, Ludger. 1997. Neue Migration im transnationalen Raum. In Ludger Pries (Hrsg.), Transnationale Migration (S. 15-44). Baden-Baden: Nomos.

Pries, Ludger. 2001. New Transnational Social Spaces. International Migration and Transnational Companies in the Early Twenty-first Century. London: Routledge.

Pries, Ludger. 2003. Transnationalismus, Migration und Inkorporation. Herausforderungen an Raum- und Sozialwissenschaft. geographische revue 5(2), 23-39.

Pries, Ludger. 2005. Arbeitsmigration und Inkorporationsmuster in Europa. In Ludger Pries (Hrsg.), Zwischen den Welten und amtlichen Zuschreibungen. Neue Formen und Herausforderungen der Arbeitsmigration im 21. Jahrhundert (S. 15-41). Essen: Klartext-Verlag.

Pries, Ludger. 2007. Migration und transnationale Inkorporation in Europa. In Magdalena Nowicka (Hrsg.), Von Polen nach Deutschland und zurück. Die Arbeitsmigration und ihre Herausforderungen für Europa (S. 109-132). Bielefeld: transcript.

Projektgruppe «Tamilen». 1984. Auf der Suche nach Zukunft: tamilische Flüchtlinge aus Sri Lanka: Analysen und Handlungsvorschläge. Im Auftrag von Brot für Brüder, Caritas Schweiz, Fastenopfer, HEKS, Helvetas, Swissaid, November 1984.

Reddy, Deepa und John Zavos. 2009. Temple Publics. Religious Institutions and the Construction of Contemporary Hindu Communities. International fournal of Hindu Studies 13(3), 241-260.

Rinschede, Gisbert. 1999. Religionsgeographie. Braunschweig: Westermann.

Roberts, Michael. 2008. Tamil Tigers: Sacrificial Symbolism and 'Dead Body Politics'. Anthropology Today 24(3), 22-23.

Rochford, E. B. 2007. Hare Krishna Transformed. New York [u. a.]: New York University Press. 
Rodman, Margaret C. 1992. Empowering Place: Multilocality and Multivocality. American Anthropologist 94(3), 640-656.

Rodrigues, Hillary P. 2009. Durga. In Knut A. Jacobsen, Helene Basu, Angelika Malinar und Vasudha Narayanan (Hrsg.), Brill's Encyclopedia of Hinduism (S. 535-550). Leiden, Boston: Brill.

Rösel, Jakob. 1996. Die Gestalt und Entstehung des Tamilischen Nationalismus. Berlin: Duncker \& Humblot.

Rösel, Jakob. 1997. Der Bürgerkrieg auf Sri Lanka. Der Tamilenkonflikt: Aufstieg und Niedergang eines singhalesischen Staates. Baden-Baden: Nomos.

Rukmani, T.S. 2005. Women as Cultural Ambassadors in the Montreal Hindu Diaspora. In Nidān $17,53-63$.

Safran, William. 1991. Diasporas in Modern Societies: Myths of Homeland and Return. Diasporas: A fournal of Transnational Studies 1(1), 83-99.

Sahoo, Ajaya Kumar und Brij Maharaj (Hrsg.). 2007. Sociology of Diaspora. New Delhi: Rawat Publications.

Salvatore, Armando. 2007. Säkularisierung, Islam und die Grenzen der Öffentlichkeit in Europa. In Monika Wohlrab-Sahr (Hrsg.), Konfliktfeld Islam in Europa (S.33-49). Baden-Baden: Nomos.

Santos, Boaventura de Sousa. 1995. Toward a New Legal Common Sense: Law, Globalization, and Emancipation. Law in context. London: Butterworths LexisNexis.

Schalk, Peter. 2003a. »Beyond Hindu Festivals»: The Celebration of Great Heroes' Day by the Liberation Tigers of Tamil Eelam (LTTE) in Europe. In Martin Baumann, Brigitte Luchesi, Annette Wilke und Peter Schalk (Hrsg.), Tempel und Tamilen in zweiter Heimat. Hindus aus Sri Lanka im deutschsprachigen und skandinavischen Raum (S.391-420). Würzburg: ErgonVerlag.

Schalk, Peter. 2003b. Tamil Caivas in Stockholm, Sweden. In Martin Baumann, Brigitte Luchesi, Annette Wilke und Peter Schalk (Hrsg.), Tempel und Tamilen in zweiter Heimat. Hindus aus Sri Lanka im deutschsprachigen und skandinavischen Raum (S.379-389). Würzburg: ErgonVerlag.

Schalk, Peter. 2004a. God as a Remover of Obstacles. A Study of Caiva Soteriology Among Ilam Tamil Refugees in Stockholm, Sweden. Uppsala: Uppsala Universitet.

Schalk, Peter. 2004b. ìlam > sihala. An Assessment of an Argument, Acta Universitatis Uppsaliensis. Historia Religionum 23. Uppsala: Uppsala Universitet.

Schalk, Peter 2006a (unter der Mitarbeit von Astrid van Nahl). Cāvilum vālvōm - «Auch im Angesicht des Todes werden wir leben»: Il lamtamile sein im Krieg und in der Fremde. Dortmund: Internationaler Verein Emigrierter Tamilischer Schriftsteller.

Schalk, Peter. 2006b. Tamil: Issues, Topics, Approaches, Concepts. In Jens Kreinath, Jan Snoek und Michael Stausberg (Hrsg.), Theorizing Rituals: Issues, Topics, Approaches, Concepts (S. 91-92). Leiden: Brill.

Schalk, Peter. 2007a. Caivam: A Religion among Tamil Speaking Refugees from Sri Lanka. UNHCR - Refugee Survey Quarterly 26(2), 91-108.

Schalk, Peter (Hrsg.). 2007b. Die Lehre der Befreiungstiger Tamilizlams von der Selbstvernichtung durch göttliche Askese: Vorlage der Quelle «Überlegungen des Anführers». Acta Universitatis Uppsaliensis. Historia Religionum 28. Uppsala: Uppsala Universitet.

Schatzki, Theodore R., K. Knorr-Cetina, und Eike von Savigny (Hrsg.). 2001. The Practice Turn in Contemporary Theory. New York: Routledge.

Scheifinger, Heinz. 2010. Hindu Embodiment and the Internet. online - Heidelberg fournal of Religions on the Internet 4(1), 196-218. 
Schill, Susan. 1991. Tamilische Ehefrauen im Kanton Luzern. Unveröffentlichte Diplomarbeit, Höhere Fachschule für Sozialarbeit, Luzern.

Schnepel, Burkhard. 2005. "In Sleep a King ...”: the Politics of Dreaming in a Cross-Cultural Perspective. Paideuma 51, 209-220.

Schweizerische Stiftung für Krishna-Bewusstsein. 1996. 100 Jahre Prabhupada (1896-1996). 25 Jahre Krishna-Bewusstsein in der Schweiz (1971-1996), Jubiläumsschrift, Zürich.

Sekar, Radhika. 2001. Global Reconstruction of Hinduism: A Case Study of Sri Lankan Tamils in Canada. Ottawa: University of Ottawa.

Selle, Gert. 1993. Die eigenen vier Wände: Zur verborgenen Geschichte des Wohnens. Frankfurt a. M.: Campus.

Sen, Amiya P. 2000. Swami Vivekananda. New Delhi; New York: Oxford University Press.

Shanmugalingam, Nagalingam. 2002. A New Face of Durga. Religion and Social Change in Sri Lanka. Delhi: Kalinga Publications.

Sheffer, Gabriel. 2003. Diaspora Politics: At Home Abroad. Cambridge: Cambridge University Press.

Sheffer, Gabriel. 2007. The Emerge of New Ethno-National Diasporas. In Ajaya Kumar Sahoo und Brij Maharaj (Hrsg.), Sociology of Diaspora, Vol. 1 (S. 43-62). New Delhi: Rawat Publications.

Shukla, Sandhya. 2001. Locations for South Asian Diasporas. Annual Review of Anthropology 30, 551-572.

Singer, Milton. 1972. When a Great Tradition Modernizes: An Anthropological Approach to Indian Civilization. London: Pall Mall Pr.

Sökefeld, Martin. 2004. Das Paradigma kultureller Differenz: Zur Forschung und Diskussion über Einwanderer aus der Türkei in Deutschland. In Martin Sökefeld (Hrsg.), Jenseits des Paradigmas kultureller Differenz. Neue Perspektiven auf Einwanderer aus der Türkei (S. 9-34). Bielefeld: transcript.

Soysal, Yasemin N. 2000. Citizenship and Identity. Ethnic and Racial Studies 23(1), 1-15.

Soysal, Yasemin N. 1994. Limits of Citizenship: Migrants and Postnational Membership in Europa. Chicago u. a.: University of Chicago.

Spencer, Jonathan. 1990. Sri Lanka: History and the Roots of Conflict. London, New York: Routledge.

Spescha, Marc, Antonia Kerland und Peter Bolzli. 2010. Handbuch zum Migrationsrecht. Zürich: Orell Füssli Verlag.

Squarcini, Federico und Eugenio Fizzotti. 2004. Hare Krishna. Salt Lake City: Signature Books.

Sriskandarajah, Dhananjayan. 2004. Tamil Diaspora Politics. In Melvin Ember (Hrsg.), Encyclopedia of Diasporas (S. 493-501). New York, NY: Kluwer Academics/Plenum Publications.

Stausberg, Michael und Steven Engler (Hrsg.). 2011. The Routledge Handbook of Research Methods in the Study of Religion. London, New York: Routledge.

Stepick, Alex, Terry Rey und Sarah J. Mahler (Hrsg.). 2009. Churches and Charity in the Immigrant City: Religion, Immigration, and Civic Engagement in Miami. New Brunswick N. J.: Rutgers University Press.

Stietencron, Heinrich von. 1984. Hinduistische Perspektiven. In Hans Küng, Josef van Ess, Heinrich von Stietencron und Heinz Bechert (Hrsg.), Christentum und Weltreligionen (S. 211-240). München: Piper.

Stolz, Jörg. 2000. Soziologie der Fremdenfeindlichkeit: Theoretische und empirische Analysen. Frankfurt a. M.: Campus.

Stürzinger, Martin. 2002. Mapping der srilankischen Diaspora in der Schweiz. Kurzstudie für Berghof Forschungszentrum für konstruktive Konfliktbearbeitung, Berlin. 
Sugirtharajah, Sharada. 2003. Imagining Hinduism: A Postcolonial Perspective. London: Routledge. Suter, Martin. 2010. Der Koch. Zürich: Diogenes.

Suter Reich, Virginia. 2013. Zwischen Differenz, Solidarität und Ausgrenzung: Inkorporationspfade der alevitischen Bewegung in der Schweiz und im transnationalen Raum. Zürich: Chronos.

Tambiah, Stanley Jeyaraja. 1992. Buddhism Betrayed? Religion, Politics, and Violence in Sri Lanka. Chicago: University of Chicago Press.

Trojanow, Ilija. 2008. Der entfesselte Globus: Reportagen. München: Hanser.

Tsagarousianou, Roza. 2004. Rethinking the Concept of Diaspora. Westminster Papers in Communication and Culture 1(1), 52-66.

Turner, Frederick Jackson. 2008 [1893]. The Significance of the Frontier in American History. London: Penguin.

Turner, Victor. 1982. From Ritual to Theatre. The Human Seriousness of Play. New York: PAJ Publications.

Tweed, Thomas A. 2006. Crossing and Dwelling: A Theory of Religion. Cambridge (Mass.), London: Harvard University Press.

Tyrell, Hartmann. 2008. Soziale und gesellschaftliche Differenzierung. Aufsätze zur soziologischen Theorie. Wiesbaden: VS Verlag für Sozialwissenschaften.

Unnik, Willem Cornelis, van. 1993. Das Selbstverständnis der jüdischen Diaspora in der hellenistisch-römischen Zeit, Arbeiten zur Geschichte des antiken Judentums und des Urchristentums, Bd. 17. Leiden: Brill.

Valentin, Joachim. 2010. Von Bildern sprechen. Hermeneutische Perspektiven auf Visualität und Religion. In Bärbel Beinhauer-Köhler, Daria Pezzoli-Olgiati und Joachim Valentin (Hrsg.), Religiöse Blicke - Blicke auf das Religiöse (S. 17-42). Zürich: TVZ Theologischer Verlag.

Vanita, Ruth und Saleem Kidwai (Hrsg.). 2001. Same-Sex Love in India: Readings in Indian Literature. New York, NY: Palgrave.

van der Veer, Peter und Steven Vertovec. 1991. Brahmanism Abroad: On Caribbean Hinduism as an Ethnic Religion. Ethnology 30(2), 149-166.

Verman, Manish. 2007. Fasts and Festivals of India. New Delhi: Diamond Pocket Books.

Vertovec, Steven (Hrsg.). 1991. Aspects of the South Asian Diaspora. Delhi: Oxford University Press.

Vertovec, Steven. 1999. Three Meanings of 'Diaspora', Exemplified by South Asian Religions. Diaspora 6(3), 277-300.

Vertovec, Steven. 2000. The Hindu Diaspora: Comparative Patterns. London, New York, NY: Routledge.

Vertovec, Steven. 2004. Religion and Diaspora. In Peter Antes, Armin Geertz und Randi Warne (Hrsg.), New Approaches to the Study of Religion. Religion and Reason, Vol.43 (S. 275-304). Berlin: de Gruyter.

Vertovec, Steven. 2009. Transnationalism. London: Routledge.

Vimalarajah, Luxshi und R. Cheran. 2010. Empowering Diasporas: The Dynamics of Post-war Transnational Tamil Politics. In Berghof Occasional Paper No. 31. Berlin: Berghof Peace Support.

Vivekananda, Swami. 1970. The Complete Works of Swami Vivekananda, Vol. 6. University of Virginia Advaita Ashrama.

Vögeli, Johanna. 2003. «,Stärker als ihr denkt‘. Tamilische Frauen in der Schweiz». In Martin Baumann, Brigitte Luchesi, Annette Wilke und Peter Schalk (Hrsg.), Tempel und Tamilen in zweiter Heimat. Hindus aus Sri Lanka im deutschsprachigen und skandinavischen Raum (S. 323-344). Würzburg: Ergon-Verlag. 
Vögeli, Johanna. 2004. Sumangali, die Glückverheissende. Tamilisch-hinduistische Frauen in der Schweiz hg. v. Fachstelle Migration Reformierte Kirchen Bern-Jura-Solothurn.

Vögeli, Johanna. 2005. "Ohne śakti ist śiva nichts»: Tamilische Geschlechterbeziehungen in der Schweiz. Arbeitsblätter des Instituts für Ethnologie der Universität Bern, Bd. 28. Bern.

Waghorne, Joanne Punzo. 2004. Diaspora of the Gods: Modern Hindu Temples in an Urban MiddleClass World. New York: Oxford University Press.

Wahlbeck, Östen. 2002. The Concept of Diaspora as an Analytical Tool in the Study of Refugee Communities. Fournal of Ethnic and Migration Studies 28(2), 221-238.

Wälchli, Ursina. 2008. «Ein Tempel ist wie eine Waschmaschine»: Die religiöse Organisation der Hindus in der Schweiz. Unveröffentlichte Masterarbeit, Universität Bern.

Warf, Barney und Santa Arias (Hrsg.). 2009. The Spatial Turn: Interdisciplinary Perspectives. London: Routledge.

Wayland, Sarah. 2004. Ethnonationalist Networks and Transnational Opportunities: the Sri Lankan Tamil Diaspora. Reviews of International Studies 30(3), 405-426.

Weigel, Sigrid. 2002. Zum ,topographical turn'. Kartographie, Topographie und Raumkonzepte in den Kulturwissenschaften. KulturPoetik 2(2), 151-165.

Werbner, Pnina. 2002. Imagined Diasporas among Manchester Muslims: The Public Performance of Pakistani Transnational Identity Politics. Santa Fe, NM: Currey School of American Research Press.

Werbner, Pnina. 2007. The Place which is Diaspora. In Ajaya Kumar Sahoo und Brij Maharaj (Hrsg.), Sociology of Diaspora, Vol. 2 (S. 643-662). New Delhi: Rawat Publications.

West, Candace und Don H. Zimmerman. 1987. Doing Gender. Gender \& Society 1(2), 125-151.

Whitaker, Mark. 2006. Internet Counter Counter-Insurgency. In Kyra Landzelius (Hrsg.), Native on the Net: Indigenous and Diasporic Peoples in the Virtual Age (S.255-271). London: Routledge.

Whitaker, Mark P. 2004. Tamilnet.com. Anthropological Quarterly 77(3), 469-498.

Wicker, Hans-Rudolf. 1997. Multiculturalism and the Sphere Theories of Hannah Arendt and John Rex. In Hans-Rudolf Wicker (Hrsg.), Rethinking Nationalism and Ethnicity. The Struggle for Meaning and Order in Europe, Nationalism and Internationalism (S.143-162). Oxford: Berg.

Wicker, Hans-Rudolf, Damaris Lüthi, Geert Jan van Dok, Mimi Marbach und Claudia Fischbacher. 1984. Tamilen in der Schweiz. Sozio-kulturelle Hintergründe, Flüchtlingssituation, Perspektiven. Projektgruppe «Tamilen» der Hilfswerke Brot für Brüder, Caritas Schweiz, Fastenopfer, HEKS, Helvetas und Swissaid, Bern.

Wickramasinghe, Nira. 2006. Sri Lanka in the Modern Age: A History of Contested Identities. London: Hurst.

Wilke, Annette. 2003. Die Göttin Kāmākșī und ihr jährlicher śrīcakra-Ritus: Zur neuen Öffentlichkeit einer esoterischen Tradition in Hamm-Uentrop. In Martin Baumann, Brigitte Luchesi, Annette Wilke und Peter Schalk (Hrsg.), Tempel und Tamilen in zweiter Heimat. Hindus aus Sri Lanka im deutschsprachigen und skandinavischen Raum (S. 189-222). Würzburg: Ergon-Verlag.

Wilke, Annette. 2004. The Goddess Kāmākṣi in Hamm-Uentrop (Westphalia, Germany). New Kolam 9\&10, 1-16.

Williams, Raymond Brady. 1988. Religions of Immigrants from India and Pakistan. Cambridge: Cambridge University Press.

Williams, Raymond Brady. 2004. Williams on South Asian Religions and Immigration. Aldershot: Ashgate. 
Wimmer, Andreas und Nina Glick Schiller. 2002. Methodological Nationalism and Beyond. Global Networks 2(4), 301-334.

Winslow, Deborah und Michael D. Woost (Hrsg.). 2004. Economy, Culture, and Civil War in Sri Lanka. Bloomington: Indiana University Press.

Winzeler, Christoph. 2008. Das Verhältnis von Religionen und Staat in rechtlicher Sicht. In Judith Könemann und Georg Vischer (Hrsg.), Interreligiöser Dialog in der Schweiz. Grundlagen Brennpunkte - Praxis (S. 19-45). Zürich: TVZ Theologischer Verlag.

Woodhead, Linda und Rebecca Catto (Hrsg.). 2012. Religion and Change in Modern Britain. London; New York: Routledge.

Younger, Paul. 2002. Playing Host to Deity. Oxford: Oxford University Press.

Younger, Paul und Ramanathapillai, Rajmohan. 2009. Sri Lanka. In Knut A. Jacobsen, Helene Basu, Angelika Malinar und Vasudha Narayanan (Hrsg.), Brill's Encyclopedia of Hinduism (S.321-336). Leiden, Boston: Brill.

Zimmermann, Andrea. 2014. «Die reformierten Hindus von Bern». Unveröffentlichte Masterarbeit, Luzern.

Zulfika, Sithy. 2013. Canada. In Peter Reeves (Hrsg.), The Encyclopedia of the Sri Lankan Diaspora (S. 109-114). Singapore: Editions Didier Millet. 



\section{Diletta Guidi}

\section{L'islam des musées}

\section{La mise en scène de l'islam dans les politiques culturelles françaises}

Volume 10

ISBN 978-2-88351-102-6

\section{L'islam vu par les musées: reflets de notre histoire culturelle, religieuse et politique.}

Paris, Kuala Lumpur, New York, Doha, Berlin, Honolulu, La Chaux-de-Fonds: chacune de ces villes accueille un musée d'art islamique, et bien d'autres encore s'ajoutent à cette liste. Depuis les années 2000, et en particulier au lendemain des attentats du 11 septembre 2001, de plus en plus d'institutions culturelles investissent en effet ce secteur culturel.

Dans ce contexte d'«islamania» muséale internationale, ce livre se penche pour la toute première fois sur le cas de la France, à travers les exemples du Musée du Louvre et de l'Institut du monde arabe. En analysant les mises en scène de l'islam depuis les Expositions coloniales du XIXe siècle à nos jours, cet ouvrage montre qu'il est à la fois utilisé par l'État français pour gérer l'altérité islamique et le reflet de politiques publiques à l'égard de la religion musulmane. Plus largement, le traitement muséal de l'islam permet de réfléchir à la régulation du religieux, et par conséquent à la laïcité. II illustre aussi les tensions politiques et sociales qu'entraînent la présence de l'islam en France et, par extension, la place de l'autre dans les sociétés occidentales désormais multiculturelles et globalisées.

S'intéresser à l'«islam des musées» dépasse ainsi l'observation de l'histoire d'un genre artistique, cela permet de rendre compte d'une partie de notre histoire culturelle, politique, sociale et religieuse. 

Collection CULTUREL

\section{Virginie Fazel}

\section{Religion, guerre et migration: \\ les Syriens au Liban}

Volume 11

ISBN 978-2-88351-109-5

\section{Comment la guerre et la migration affectent- elles la religion? Peut-on parler d'une évolution de la religiosité?}

Que se passe-t-il au niveau de la religiosité lorsque des individus perdent tout suite à la guerre et à la migration forcée? Peut-on observer un renforcement de la religiosité, lorsque leur foi est tout ce qui leur reste? Ou, au contraire, est-ce que ces traumatismes laissent place à une désillusion et à une diminution? La recherche de terrain présentée dans ce livre traite des conséquences de la guerre et de la migration sur la religion et sur l'évolution de la religiosité. Pour répondre à ces questions, l'auteure a conduit une recherche qualitative sur le cas des Syriens réfugiés au Liban, à Beyrouth et dans trois camps de réfugiés à la Bekaa. Il n'existe aujourd'hui que peu de recherches sur les migrations dans les pays limitrophes à ceux en crise. La plupart des travaux sur l'immigration et la religion concernent des pays occidentaux. Pourtant, l'immense majorité d'individus forcés à fuir est déplacée à l'intérieur de leur pays ou dans des pays limitrophes. Ce livre permet donc de développer un aspect encore partiellement étudié en sciences sociales et en sciences des religions. 

Seit den 1980 er Jahren praktizieren tamilische Geflüchtete aus Sri Lanka und ihre Nachkommen Hindu-Traditionen in DiasporaLändern wie der Schweiz. Auf Basis einer ethnographischen Untersuchung analysiert die Autorin Prozesse der Etablierung tamilischer Hindu-Praxis und bietet einen so noch nicht vorhandenen umfangreichen Einblick in die Phasen ihrer Beheimatung. Bei der Ausbildung von Sakralräumen und der Präsentation von tamilischen Hindu-Praktiken in öffentlichen Sphären spielen Rückbezüge ins Herkunftsland und transnationale Netzwerke der sri-lankisch tamilischen Diaspora wie auch die Inkorporationsbedingungen des Residenzlandes Schweiz eine zentrale Rolle.

Die Studie fokussiert insbesondere auf religiöse Orte, ihre Dynamiken und damit verbundene Performanzen. Dabei wird die Wichtigkeit von selbstverwalteten Tempeln als sinnliche, multifunktionale Wahrnehmungsräume für die marginalisierte Gruppe der tamilischen Migrant*innen deutlich. Durch kreative Anpassungsprozesse entstehen neue Formen religiöser Praxis.

Rafaela Eulloerg ist wissenschaftliche Mitarbeiterin in der Abteilung für Religionsforschung am Forum Internationale Wissenschaft der Universität Bonn. Ihre Forschungsschwerpunkte sind u.a. Religion und Migration sowie gendertheoretische Religionswissenschaft. 